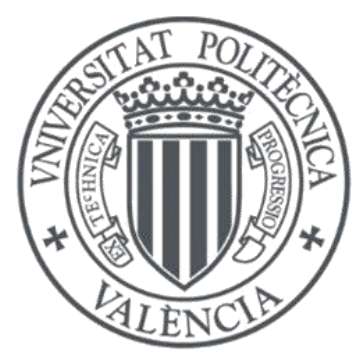

\title{
Dosage optimization and bolted connections for UHPFRC ties
}

\author{
Ph.D. Thesis \\ Esteban Camacho Torregrosa \\ $19 / 12 / 2013$
}

Director: Pedro Serna Ros 



\title{
Dosage optimization and bolted connections for UHPFRC ties
}

\author{
A dissertation submitted to \\ UNIVERSITAT POLITÈCNICA DE VALÈNCIA \\ For the degree of \\ DOCTOR OF SCIENCES UPV \\ Presented by \\ ESTEBAN EFRAÍM CAMACHO TORREGROSA \\ Civil Engineer \\ Born 7.12.1985 \\ Citizen of \\ Valencia, Spain
}

Year 2013

Director: Pedro Serna Ros

Accepted on the recommendation of

Prof. Antonio Aguado

Prof. Jaime Gálvez

Prof. Gonzalo Ruiz

\author{
Composition of Supervisory Committee \\ Prof. Antonio Aguado \\ Prof. Marco Di Prisco \\ Prof. Manuel Fernández Cánovas
}

Instituto de Ciencia y Tecnología del Hormigón (ICITECH)

Departamento de Ingeniería de la Construcción y Proyectos de Ingeniería Civil 


\section{Keywords:}

Ultra High Performance Fiber Reinforced Concrete, dosage optimization, compatibility, precast, bolted connection, joint, applications.

Printed at Valencia

(C) By Esteban Camacho Torregrosa

No part of this volume may be produced, stored in retrieval system or transmitted in any form or by any means, electronic, mechanical, photocopying, recording or otherwise, without the prior written permission of the publishers. 
Los límites son físicos.

Las limitaciones, mentales. 



\section{Summary}

\section{Dosage optimization and bolted connections for UHPFRC ties}

Concrete technology has been in changeful evolution since the Roman Empire time. It is remarkable that the technological progress became of higher magnitude from the second part of the XX Century. Advances in the development of new cements, the appearance of the fibers as a reinforcement for structural applications, and specially the grand progress in the field of the water reducing admixtures enabled the emergence of several types of special concretes. One of the lasts is the Ultra High Performance Fiber Reinforced Concrete (UHPFRC), which incorporates advances of the Self-Compacting Concrete (SCC), Fiber-Reinforced Concrete (FRC) and Ultra High Strength Concrete (UHSC) technology. This exclusive material requires a detailed analysis of the components compatibility and a high control of the materials and processes. Mainly patented products have been used for the few structural elements carried out so far today, but the costs makes doubtful the development of many other potential applications.

In accordance with the previously explained, a simplification of the UHPFRC components and processes is needed. This becomes the first main goal of this Ph.D. thesis, which emphasizes in the use of local available components and simpler mixing processes. Moreover, the singular properties of this material, between ordinary concrete and steel, allow not only the realization of slenderer structures, but also the viability of new concepts unthinkable with ordinary concrete. In this field is focused the second part of the Ph.D. thesis, which develops a bolted connection system between UHPFRC elements.

This research summarizes, first of all, the subfamilies belonging to the HPC-UHPC materials. Afterwards, it is provided a detailed comparison between the dosage and properties of more than a hundred of mixtures proposed by several authors in the last ten years of technology. This becomes a useful tool to recognize correlations between dosages and properties and validate or no preconceived ideas about this material.

Based on this state of art analysis was performed the later development of mixtures, on Chapter 4, which analized the effect of use of simpler components and processes on the UHPFRC. The main idea was use local components available in the Spanish market, identifying the combinations that provide the best rheological and mechanical properties. Steam curing use was avoided since a process simplification is intended. Diferent dosages were developed to be adapted to various levels of performance, and always trying to be as economical as possible. The concretes designed were selfcompacting and mainly combined two fiber types (hybrid), as the flexural performance was of greater relevance. The compressive strength obtained varied in the range between 100 and $170 \mathrm{MPa}$ (cube L=100 mm), and the flexural strength between 15 and $45 \mathrm{MPa}$ (prism $100 \times 100 \times 500 \mathrm{~mm}$ ). Some of the components introduced are very rarely used in UHPFRC, as limestone coarse aggregate or FC3R, a white active residue from the petrol industry. As a result of the research, some simple and practical tips are provided for designers of UHPFRC dosage. At the end of this chapter, five dosages are characterized as examples of useful concretes for different requirement applications. 
In a second part, the idea of a bolted joint connection between UHPFRC elements was proposed. The connection system would be especially useful for struts and ties elements, as truss structures. The possible UHPFRC failure modes were introduced and two different types of tests were designed and performed to evaluate the joint capacity. The geometry of the UHPFRC elements was modified in order to correlate it with the failure mode and maximum load reached. Also a linear finite element analysis was performed to analyze the UHPFRC elements connection. This supported the results of the experimental tests to deduce formulations that predict the maximum load for each failure mode. Finally, a real size truss structure was assembled with bolted joints and tested to verify the good structural behavior of these connections.

To conclude, some applications designed and developed at the Universitat Politècnica de València with the methods and knowledge acquired on UHPFRC are abstracted. In many of them the material was mixed and poured in a traditional precast concrete company, providing adequate rheological and mechanical results. This showed the viability of simpler UHPFRC technology enabling some of the first applications in Spain with this material.

\section{Esteban Camacho, Universitat Politècnica de València,}

December 2013 


\section{Resumen}

\section{Optimización de dosificaciones y conexiones atornilladas para tirantes de UHPFRC}

La tecnología del hormigón ha evolucionado de un modo poco constante desde el Imperio Romano, experimentando un avance tecnológico de mayor magnitud en la segunda mitad del siglo XX. Los adelantos en el desarrollo de nuevos cementos, la aparición de las fibras como un sistema de refuerzo para elementos estructurales, y sobre todo los progresos en el campo de los aditivos reductores de agua han permitido la aparición de varios tipos nuevos de hormigones especiales. Uno de los últimos es el Hormigón de Muy Alto Rendimiento Reforzado con Fibras (UHPFRC), que incorpora adelantos relativos a la tecnología de los Hormigones Autocompactantes (SCC), de los Hormigones Reforzados con Fibras (FRC) y de los hormigones de Muy Alta Resistencia (UHSC). Este producto exclusivo requiere una investigación detallada de la compatibilidad de sus componentes y un elevado nivel de control de los procesos. Los pocos elementos estructurales realizados hasta la fecha se han elaborado sobre todo con dosificaciones patentadas, cuyos costes hacen muy difícil la viabilidad de muchas otras aplicaciones potenciales.

Tal y como se puede intuir por lo explicado previamente, es muy conveniente una simplificación de los componentes y procesos de elaboración del UHPFRC de cara al futuro. Este es uno de los dos objetivos principales de esta Tesis Doctoral, que enfatiza en el uso de componentes locales disponibles y en la simplificación de procesos de fabricación. Además, algunas de las propiedades del material, que se encuentra entre el hormigón convencional y el acero, permiten no solo elaborar estructuras más esbeltas, sino que también hacen viables nuevos conceptos impensables con el hormigón al que estamos acostumbrados. La segunda parte de la Tesis Doctoral se centra en desarrollar una de estas ideas, evaluando la viabilidad de un sistema de conexión atornillada entre elementos de UHPFRC.

Esta investigación comienza introduciendo las subfamilias que pertenecen al entorno de los HPC-UHPC. A continuación se proporciona una comparación de la dosificación y propiedades de un conjunto de más de cien mezclas elaboradas por diferentes autores en los últimos diez años de tecnología del UHPC-UHPFRC. Esto supone una herramienta muy útil para identificar relaciones entre dosificaciones y propiedades, además de permitir validar o no algunas de las ideas preconcebidas que se tienen respecto a este producto.

Basado en el estudio del estado del arte se desarrollaron las posteriores dosificaciones (Capítulo 4), con las que se analizaba el efecto de utilizar componentes y procesos más simples en el UHPFRC. El camino seguido fue utilizar componentes locales disponibles en el mercado español, identificando las combinaciones que proporcionan los mejores resultados reológicos y mecánicos. En ningún caso se utilizó curado al vapor, de acuerdo con la idea de simplificar al máximo los procesos. Se desarrollaron diferentes dosificaciones con varios niveles de exigencia, siempre con el predominio del criterio económico. Los hormigones se diseñaron para ser autocompactantes y la mayoría de ellos combinando dos tipos de fibras (híbridos), dado que se pretendió maximizar la resistencia a flexión. La resistencia a compresión y a flexión equivalente varió entre los 100 y $170 \mathrm{MPa}$ para la primera (en cubo de L=100 mm) y 
los 15 y 45 MPa para la segunda (en probeta prismática 100 x 100 × $500 \mathrm{~mm}$ ). Con algunos de los materiales utilizados prácticamente se carece de experiencia con UHPFRC. Es el caso del árido grueso calizo o el FC3R, un residuo de la industrial del petróleo de color blanco que tiene actividad puzolánica. Las deducciones realizadas se utilizaron finalmente para describir una serie de consejos prácticos para operarios que pretendan utilizar UHPFRC. Finalmente, se caracterizaron cinco dosificaciones como ejemplos de material adecuado para aplicaciones con diferentes niveles de exigencia y condiciones.

En la segunda parte de la tesis se propone la idea de realizar conexiones atornilladas entre elementos de UHPFRC. Este sistema de conexión resulta especialmente útil para conectar las bielas y tirantes de celosías de hormigón. Se introdujeron los posibles modos de fallo del UHPFRC, y para identificarlos y evaluar la capacidad de los elementos se diseñaron dos tipos de ensayos diferentes. La geometría de las piezas de UHPFRC se modificó, obteniendo así su relación con los modos de fallo y la capacidad máxima de cada elemento. Además, la región fue modelada mediante un análisis lineal de elementos finitos, con el objetivo de apoyar los resultados experimentales y poder deducir formulaciones que predigan las cargas máximas y los tipos de fallo de las uniones de UHPFRC. Finalmente, se construyó una celosía a tamaño real con uniones atornilladas para verificar el buen comportamiento estructural de las mismas.

Para concluir, se resumen algunas aplicaciones diseñadas y elaboradas en la Universitat Politècnica de València con los métodos y el conocimiento adquirido con UHPFRC. En muchas de ellas el material fue mezclado y vertido en una empresa de prefabricados convencional, proporcionando resultados reológicos y mecánicos acordes con los objetivos. Esto demostró la viabilidad del UHPFRC desarrollado con tecnología simplificada, dando lugar a algunas de las primeras aplicaciones reales con este material en España.

Esteban Camacho, Universitat Politècnica de València,

Diciembre 2013 


\section{Resum}

\section{Optimització de dosificacions y connexions atornillades per a tirants d'UHPFRC}

La tecnologia del formigó ha evolucionat d'una manera poc constant des dels temps de l'Imperi Romà. Cal destacar que l'avanç tecnològic de la segona meitat del segle XX, ha sigut de major magnitud. Els avanços en el desenvolupament de nous cements, l'aparició de fibres com un sistema de reforç per a elements estructurals i, especialment, progressos en el camp dels additius reductors d'aigua, han permés l'aparició de diversos tipus de formigons especials. Un dels últims es el Formigó de Molt Alt Rendiment Reforçat amb Fibres (UHPFRC), que incorpora avançaments relatius a la tecnologia dels Formigons Autocompactants (SCC), dels formigons reforçats amb fibres (FRC) i dels de Molt Alta Resistència (UHSC). Aquest producte exclusiu, requereix una investigació detallada de la compatibilitat entre components i un elevat nivell de control dels processos. Els escassos elements estructurals el-laborats fins ara s'han fet sobretot amb dosificacions patentades, els costos de les quals, impedeixen la viabilitat d'altres aplicacions potencials.

De tota l'explicació previa es pot deduir que es molt convenient simplificar els components i els processos d'elaboració de l'UHPFRC de cara al futur. Aquest és un dels dos objectius principals de la present Tesi Doctoral, que es centra en l'ús dels components locals disponibles i en la simplificació dels processos de fabricació. A més, algunes de les propietats del material que es troba entre el formigó convencional i l'acer, permiteixen no solament fer estructures més esveltes, sinó també fer viables nous conceptes impensables fins ara amb el formigó al que estem acostumats. La segona part de la Tesi Doctoral desenvolupa una d'eixes idees, evaluant la viabilitat d'un sistema de connexió atornillada entre elements d'UHPFRC.

Aquesta investigació comença amb una breu descripció de les subfamílies que pertanyen a l'entorn dels HPC-UHPC. A continuació, es proporciona una comparació de les dosificacions i propietats d'un conjunt de més de cent mescles, elaborades per diferents autors en l'ultima década, de tecnologia d'UHPC-UHPFRC. Açò suposa una eina molt útil per indentificar les relacions entre dosificacions i propietats $\mathrm{i}$, a més, permet validar o no algunes de les idees preconcebudes que existeixen respecte al producte.

Basat en l'estudi de l'art es van desenvolupar les posteriors dosificacions (Capítol 4), amb les que es va analitzar l'efecte d'utilitzar components i processos més simples en l'UHPFRC. El camí a seguir va ser utilitzar components locals disponibles al mercat espanyol, identificant les combinacions que proporcionen els millors resultats reològics i mecànics. En cap cas es va utilizar guarit al vapor, d'acord amb la idea inicial de simplificar al màxim els processos. És van desenvolupà dosificacions amb diferents nivells d'exigència, sempre seguint el criteri d'economia. Els formigons es van dissenyar per a ser autocompactants, i la majoria d'ells van combinar dos tipus de fibres (híbrids), ja que es va tractar de maximitzar la resistència a flexió. La resistència a compressió i a flexió equivalent, va variar entre els 100 i els 170 MPa per a la primera (en cub de L=100 mm), i entre 15 i $45 \mathrm{MPa}$ per a la segona (en probeta prismàtica de $100 \times 100 \times 500 \mathrm{~mm}$ ). Amb alguns dels materials utilitzats, l'experiència amb UHPFRC és pràcticament nul.la. Es el cas de l'àrid gros o del FC3R, un residu industrial del petroli de color 
blanc que té activitat puzolànica. Les deduccions obtingudes es van utilizar finalment per escriure una sèrie de consells pràctics per a operaris que vullguen emprar UHPFRC. Finalment, es van caracteritzar cinc dosificacions com a examples de material adequat per aplicacions amb diferents nivells d'exigència i condicions.

A la segona part de la tesi es proposa la idea de realitzar connexions atornillades entre elements d'UHPFRC. Aquest sistema resulta especialment útil per conectar les bieles i els tirants de gelosies de formigó. Els possibles modes de trencament van ser explicats, i per identificar-los i avaluar la capacitat dels elements, es van dissenyar dos tipus d'assajos diferents. La geometria de les peces d'UHPFRC es va modificar, obtenint així la seua relació amb el mode de trencament i la capacitat màxima del cada element. A més, la regió fou modelada a través d'un anàlisi lineal d'elements finits, amb l'objectiu de donar suport als resultats experimentals i poder deduir formulacions que prediguen les càrregues màximes i els tipus de trencament de les unions. Finalment, es va construir una gelosia de mida real amb unions atornillades, per verificar el bon comportament estructural d'aquest sistema de connexió.

Per concloure, es resumeixen algunes de les aplicacions dissenyades i el-laborades a la Universitat Politècnica de València amb els mètodes i el coneixement adquirit amb l'UHPFRC. A moltes d'elles, el material fou barrejat i abocat a una empresa de prefabricats convencional, proporcionant resultats reològics i mecànics d'acord amb els objectius. Açò va demostrar la viabilitat de l'UHPFRC desenvolupat amb tecnologia simplificada, donant lloc a algunes de les primeres aplicacions reals d'aquest material a Espanya.

\section{Esteban Camacho, Universitat Politècnica de València,}

Desembre 2013 


\section{Acknowledgements}

This thesis one of the results of the research project FIBAC with reference BIA2009-12722, and given by the Spanish Ministry of Science and Innovation. Support for this project is gratefully acknowledged.

The material development wouldn't be possible without the donation of the components by several companies: Lafarge (cement), Bekaert (steel fibers), SIKA and BASF (PCE admixtures) and Ferroatlántica (silica fume). Also the group GIQUIMA from the UPV donated the FC3R, produced by Omya Clariana. I want to thank all them the support provided. I also want to highlight the help provided by Generalitat Valenciana and the companies Prevalesa S.L., ICOSA Ingeniería Civil S.A. and AIDICO, who even though the difficult economical situation assisted us as much as possible.

With respect to the personal appreciations, my first and widest gratitude is for my supervisor Dr. Pedro Serna Ros, for whom I worked the last 4 years. His positive attitude to live and love for the concrete made much easier the development of this research. I feel very lucky that the topic and supervisor I got resulted not only in gaining knowledge and experience, but also in my personal and professional development.

Secondly I have to highlight the support provided by Juan Ángel López, my job mate in the last 2 years. My work became more efficient thanks to our conversations and his innovative ideas. I am convinced that he is the best possible investment to continue with the UHPFRC research line. The laboratory technicians also deserve my thanks, especially Pascual, Paco and Jürgen for the help provided at laboratory with a positive attitude.

Besides, I have to acknowledge the support provided by my nearest family members whenever I needed it, especially my brother, with whom I share routine due to our parallel career.

At the end, I have to say that the largest support came from some of my friends. Sergio, Cristian, Cals, Pablo and Andreu. This time of Valencia was especially great thanks to the time we spent together. I also want to mention specifically Mireia Llinares, which proximity in the last period became the best motivation; Justina Stukaite, with whom I shared nice experiences around several countries; Tamara Vujacić, always with a nice serbian smile in my mind; Gema Colomer, who still provides me positive energy although she is a bit far away; Milica Vuceljić, always encouraging me with her interest in my improvements, and Anna Soltys, who never forgot me despite the distance.

\section{Esteban Camacho, Universitat Politècnica de València,}

December 2013 



\section{List of symbols and notations}

In the table are shown the abbreviations used in this work, remarking with italic letters, in the case, the most extended units of measure for each one.

\section{Roman letters}

\begin{tabular}{|c|c|}
\hline A\&A & Andreasen and Andersen particle packing model \\
\hline$A \& A_{M O D}$ & Modified Andreasen and Andersen particle packing model \\
\hline $\mathrm{A}_{\mathrm{E}}$ & Area of concrete behind the bolt, parallel to the tensile load $\left(\mathrm{mm}^{2}\right)$ \\
\hline ANOVA & Analysis of Variance \\
\hline $\mathrm{A}_{\mathrm{T}}$ & Area of concrete in the sides of the hole, orthogonal to the tensile load $\left(\mathrm{mm}^{2}\right)$ \\
\hline AVF & Aggregate Volume Fraction (\%) \\
\hline $\mathrm{C}_{3} \mathrm{~A}$ & Tricalcium Aluminate \\
\hline $\mathrm{C} 4 \mathrm{AF}$ & Tetracalcium aluminoferrite \\
\hline CA & Coarse Aggregate \\
\hline $\mathrm{CH}$ & portlandite crystals \\
\hline CMOD & Two Crack Mouth Opening Displacement \\
\hline CPFT & Cumulative Percent Finer Than (\%) \\
\hline $\mathrm{CPM}$ & Compressive Packing Model \\
\hline CRC & Compact Reinforced Concrete \\
\hline CSF & Condensed Silica Fume \\
\hline C-S-H & Calcium silicate hydrate \\
\hline $\mathrm{Ct}$ & Constant \\
\hline $\mathrm{d}_{10}$ & Diameter below which are the $10 \%$ finest particles of a component $(\mu \mathrm{m})$ \\
\hline $\mathrm{d}_{90}$ & Diameter below which are the $90 \%$ finest particles of a component $(\mathrm{mm})$ \\
\hline $\mathrm{d}_{\mathrm{f}}$ & fiber diameter $(\mathrm{mm})$ \\
\hline Dhole & Diameter of the hole $(\mathrm{mm})$ \\
\hline $\mathrm{D}_{\max }\left(=d_{90}\right)$ & Maximum diameter of particle of a component $(\mathrm{mm})$ \\
\hline$D_{\min }\left(=d_{10}\right)$ & Minimum diameter of particle of a component $(\mu \mathrm{m})$ \\
\hline DRI & Degree of Hydration Indexes (\%) \\
\hline $\mathrm{D}_{\text {screw }}$ & Diameter of the screw $(\mathrm{mm})$ \\
\hline DSP & Densified System Particles \\
\hline E & Elastic Modulus, Young's Modulus $\left(\mathrm{N} / \mathrm{mm}^{2}\right)$ \\
\hline $\mathrm{E}_{1}, \mathrm{E}_{2}$ & Fictitious elastic modulus $\left(\mathrm{N} / \mathrm{mm}^{2}\right)$ \\
\hline Ec & Secant Modulus of Elasticity $\left(\mathrm{N} / \mathrm{mm}^{2}\right)$ \\
\hline ECC & Engineered Cementitious Composites \\
\hline EN & European Norm \\
\hline FA & Fly Ash \\
\hline FA & Fine aggregate \\
\hline FC3R & Fluid Catalytic Cracking Catalyst Residue \\
\hline fib & International Federation for Structural Concrete \\
\hline FRC & Fiber-Reinforced Concrete \\
\hline FRUHPC & Fiber Reinforced Ultra High Performance Concrete \\
\hline $\mathrm{f}_{\mathrm{cm}}$ & Average compressive strength of the concrete $\left(\mathrm{N} / \mathrm{mm}^{2}\right)$ \\
\hline $\mathrm{f}_{\mathrm{tj}}$ & Concrete matrix tensile strength $\left(\mathrm{N} / \mathrm{mm}^{2}\right)$ \\
\hline $\mathrm{H}_{0}$ & null hypothesis \\
\hline $\mathrm{H}_{1}$ & alternative hypothesis \\
\hline $\mathrm{HFC}$ & Hybrid Fiber Concrete \\
\hline HMAR & Hormigón de muy alto Rendimiento (Very high Performance Concrete) \\
\hline HPC & High Performance Concrete \\
\hline
\end{tabular}




\begin{tabular}{|c|c|}
\hline HPFRC & High Performance Fiber Reinforced Concrete \\
\hline HPFRCC & High Performance Fiber Reinforced Cement Composites \\
\hline HPHFC & High-Performance Hybrid-Fiber Concrete \\
\hline HRUHPC & Heavy Reinforced Ultra High Performance Concrete \\
\hline HRWRA & High Range Water Reducing Admixtures \\
\hline HSC & High Strength Concrete \\
\hline HY & Hybrid \\
\hline IM & Intensive Mixer \\
\hline IndM & Industrial Mixer \\
\hline ITZ & interfacial transition zone \\
\hline $\mathrm{K}$ & Fiber orientation factor (dimensionless) \\
\hline $\mathrm{kN}$ & KiloNewton $\left(1000 \mathrm{~kg} \cdot \mathrm{m} / \mathrm{s}^{2}\right)$ \\
\hline $\mathrm{l}_{\mathrm{f}}$ & fiber length $(\mathrm{mm})$ \\
\hline LOI & Lost Of Ignition (\%) \\
\hline LVDT & Linear variable differential transformer \\
\hline M & Moment $(k N \cdot m m)$ \\
\hline MMFRC & Multi-Modal Fiber Reinforced Concrete \\
\hline $\mathrm{MPa}$ & MegaPascal $\left(\mathrm{N} / \mathrm{mm}^{2}\right)$ \\
\hline $\mathrm{N}$ & Newton $\left(\mathrm{kg} \cdot \mathrm{m} / \mathrm{s}^{2}\right)$ \\
\hline$n_{i}$ & Division number i of certain element \\
\hline o.b.w. & Over Binder Weight \\
\hline o.c.w. & Over Cement Weight \\
\hline OC & Ordinary Concrete \\
\hline OPC & Ordinary Portland Cement \\
\hline $\mathrm{P}$ & Load applied $(k N)$ \\
\hline PBL & Perfobond Strip \\
\hline PCE & Polycarboxylate ether superplasticizer \\
\hline PVA & Polyvinyl alcohol \\
\hline PVF & Paste Volume Fraction (\%) \\
\hline q & Fuller exponent (dimensionless) \\
\hline QF & Quartz Flour \\
\hline $\mathrm{r}$ & Aspect ratio (dimensionless) \\
\hline $\mathrm{RC}$ & Reinforced Concrete \\
\hline RPC & Reactive Powder Concrete \\
\hline SCC & Self-Compacting Concrete \\
\hline SCFRC & Self-Compacting Fiber Reinforced Concretes \\
\hline SEM & Scanning Electron Microscope \\
\hline SF & Silica Fume \\
\hline SIFCON & Slurry Infiltrated Fiber Concrete \\
\hline SR & sulphate resistant \\
\hline SSF & Sonicated Silica Fume \\
\hline $\mathrm{T}$ & Metric Ton $(1000 \mathrm{~kg})$ \\
\hline$t_{50}$ & Time of the slump flow to reach $50 \mathrm{~cm}$ (seconds) \\
\hline$t_{500}$ & Time of the slump flow to reach $500 \mathrm{~mm}$ (seconds) \\
\hline TM & Tilting Mixer \\
\hline TPD & Ternary Packing Diagram \\
\hline Ts & Stabilization Time (minutes) \\
\hline UFC & Ultra Fiber Concrete \\
\hline UHPC & Ultra High Performance Concrete \\
\hline UHPFC & Ultra High Performance Fiber Concrete \\
\hline UHPFRC & Ultra High Performance Fiber Reinforced Concrete \\
\hline UHSC & Ultra High Strength Concrete \\
\hline
\end{tabular}




\begin{tabular}{|l|l|}
\hline UHSFRC & Ultra High Strength Fiber Reinforced Concrete \\
\hline UNE & Una Norma Española \\
\hline UPV & Universitat Politècnica de València (Polytechnic University of Valencia) \\
\hline USF & Undensified Silica Fume \\
\hline$V_{\mathrm{f}}$ & Fiber Content (\% over total volume) \\
\hline VHPC & Very high Performance Concrete \\
\hline VHPFRC & Very High Performance Fiber Reinforced Concrete \\
\hline VSI & Visual Stability Index (dimensionless) \\
\hline W/B & Water/Binder ratio (dimensionless) \\
\hline W/C & Water/Cement ratio (dimensionless) \\
\hline
\end{tabular}

\section{Greek letters}

\begin{tabular}{|l|l|}
\hline$\dot{\gamma}$ & Shear rate $\left(\mathrm{s}^{-1}\right)$ \\
\hline$\left(\emptyset_{\mathrm{f}}\right)_{\max }$ & Maximum amount of fibers for UHPFRC mortar $(\%)$ \\
\hline$\emptyset$ & Diameter of a steel bar or a steel wire $(\mathrm{mm})$ \\
\hline$\emptyset_{\mathrm{m}}$ & Dense packing fraction of the sand $(\%)$ \\
\hline$\emptyset_{\mathrm{s}}$ & Sand volume fraction $(\%)$ \\
\hline$\delta_{\mathrm{i}}$ & Deflection associated to division i $(\mathrm{mm})$ \\
\hline$\Delta \mathrm{P}$ & Increase of load $(\mathrm{kN})$ \\
\hline$\varepsilon_{\mathrm{i}}$ & Strain associated to a division i (dimensionless) \\
\hline$\varepsilon_{\mathrm{t}, \mathrm{u}}$ & Tensile strain associated to the maximum load $($ dimensionless $)$ \\
\hline$\mu$ & Plastic viscosity $(\mathrm{Pa} \cdot \mathrm{S})$ \\
\hline$\theta_{\mathrm{i}}$ & Angle associated to a division i $($ dimensionless $)$ \\
\hline$\sigma_{\mathrm{bt}}$ & Maximum tensile strength of an FRC $\left(\mathrm{N} / \mathrm{mm}^{2}\right)$ \\
\hline$\sigma_{\mathrm{bt}, \mathrm{k}}$ & Characteristic maximum tensile strength of an FRC $\left(\mathrm{N} / \mathrm{mm}^{2}\right)$ \\
\hline$\sigma_{\mathrm{c}, \text { elast }}$ & Maximum elastic compressive strength $(\mathrm{MPa})$ \\
\hline$\sigma_{\mathrm{c}, \mathrm{u}}$ & Maximum compressive strength $(\mathrm{MPa})$ \\
\hline$\sigma_{\mathrm{t}, \mathrm{u}}$ & Maximum tensile strength $(\mathrm{MPa})$ \\
\hline $\mathrm{T}$ & Shear stress $(\mathrm{Pa})$ \\
\hline$\tau_{0}$ & Yield stress $(\mathrm{Pa})$ \\
\hline $\mathrm{X}$ & Curvature $\left(\mathrm{mm}^{-1}\right)$ \\
\hline$\chi_{\mathrm{f}}$ & Fiber Factor $(\%)$ \\
\hline$\chi_{\mathrm{i}}$ & Curvature in partition i $\left(\mathrm{mm}^{-1}\right)$ \\
\hline
\end{tabular}





\section{Table of contents}

1.1 Preliminary issues 24

1.2 Research Goals 25

1.3 Outline Of THE Ph.D. Thesis 26

2. STATE OF ART ANALYSIS $\quad 29$

2.1 INTRODUCTION 31

2.2 UHPFRC CONCEPTS

2.2.1 WHAT IS UHPC-UHPFRC? 31

2.2.2 BASIC PRINCIPLES 32

2.2.3 UHPFRC TECHNOLOGY NOWADAYS

2.2.4 UHPFRC MANUFACTURERS AND APPLICATIONS 33

2.3 StATE Of ART ANALYSIS 36

2.3.1 HPFRC-UHPFRC TYPES, COMMERCIAL DOSAGES 36

2.3.2 DATABASE OF DOSAGES 40

2.3.3 ANALYSIS OF THE DATABASE DOSAGES DESIGNS

2.3.4 HOW TO DESIGN A UHPFRC DOSAGE?

2.4 Mixing AND CASTING

$\begin{array}{lll}2.4 .1 & \text { MIXERS } & 57\end{array}$

2.4.2 MIXING PROCESS

2.4.3 CASTING $\quad 59$

$\begin{array}{lll}2.4 .4 & \text { CURING SYSTEM } & 60\end{array}$

2.4.5 REASONS TO PRECAST 61

2.5 Properties $\quad 62$

2.5.1 Rhelogical Properties 62

2.5.2 HaRdened State 64

2.6 Design METHODS

2.6.1 RECOMMENDATIONS

2.6.2 FROM BENDING TESTS TO CONSTITUTIVE LAW 74

2.7 CONNECTIONS WHERE UHPFRC TAKES PART

$\begin{array}{lll}2.7 .1 & 75 T R O D U C T I O N & 75\end{array}$

$\begin{array}{lll}2.7 .2 & \text { SHEAR KEYS } & 76\end{array}$

2.7.3 CAST IN PLACE JOINTS

$\begin{array}{lll}2.7 .4 & \text { BOLTED JOINTS } & 80\end{array}$

$\begin{array}{lll}2.7 .5 & \text { SUPPLEMENTARY ELEMENTS } & 82\end{array}$

2.7.6 EPOXY CONNECTIONS

$\begin{array}{lll}2.7 .7 & \text { CONTINUOUS SHEAR CONNECTORS } & 85\end{array}$ 
3.1 INTRODUCTION

3.2 COMPONENTS USED $\quad 89$

$\begin{array}{llr}3.3 & \text { MIXERS } & 94\end{array}$

3.3.1 1 LITER MORTAR MIXER $\quad 94$

3.3.2 30 LITER TILTING DRUM MIXER

3.3.3 50 LITER ROTATING PAN MIXER 96

3.3.4 75 LITER INTENSIVE MIXER 96

3.3.5 110 LITER PLANETARY MIXER 97

$\begin{array}{lll}\text { 3.3.6 } & 1 \mathrm{M}^{3} \text { INDUSTRIAL MIXER } & 98\end{array}$

3.3.7 $2 \mathrm{M}^{3}$ INDUSTRIAL MIXER $\quad 98$

$\begin{array}{ll}3.4 & \text { RHEOLOGICAL TESTS }\end{array}$

3.4.1 MINI-SLUMP CONE TEST $\quad 99$

3.4.2 SLUMP FLOW TEST 100

$\begin{array}{lll}3.4 .3 & \text { RHEOMETER } & 101\end{array}$

3.5 CASTING PROCESS 102

\begin{tabular}{ll}
3.6 & CURING PROCESS \\
\hline & 102
\end{tabular}

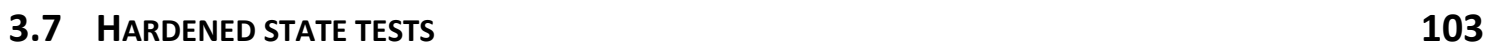

$\begin{array}{lll}3.7 .1 & \text { COMPRESSIVETESTS } & 103\end{array}$

$\begin{array}{lll}3.7 .2 & \text { ELASTIC MODULUS } & 103\end{array}$

$\begin{array}{lll}\text { 3.7.3 } & \text { FLEXURAL TESTS } & 103\end{array}$

$\begin{array}{lll}3.7 .4 \text { MICROSCOPY } & 105\end{array}$

$\begin{array}{lll}3.8 & \text { COMPUTATIONAL PROCESSES } & 105\end{array}$

$\begin{array}{lll}3.8 .1 & \text { BACK ANALYSIS } & 105\end{array}$

4. ON THE INFLUENCE OF SEVERAL VARIABLES IN THE UHPFRC DOSAGE 109

4.1 INTRODUCTION AND MOTIVATIONS

4.2 OBJeCtIVES AND STRUCTURE 112

4.3 UHPC BINDER PROPORTION ANALYSIS

4.3.1 MOtIVATION AND OBJECTIVES 113

$\begin{array}{ll}\text { 4.3.2 EXPERIMENTAL PROGRAM } & 114\end{array}$

$\begin{array}{lll}\text { 4.3.3 RESULTS AND DISCUSSION } & 116\end{array}$

4.3.4 CONCLUSSIONS OF THE UHPC BINDER ANALYSIS 122

4.4 INFLUENCE OF THE W/B RATIO ON THE RHEOLOGY AND HARDENED STATE 123

4.4.1 EFFECT OF W/B ON THE HARDENED STATE: EXPERIMENTAL PROGRAM 123

$\begin{array}{ll}\text { 4.4.2 RESULTS OF THE EFFECT OF W/B ON THE HARDENED STATE } & 124\end{array}$

4.4.3 INFLUENCE ON THE RHEOLOGY: THE CRITICAL SLUMP FLOW 127

4.4.4 CONCLUSSIONS OF THE W/B RATIO EFFECT 129

4.5 ACTIVE ADDITION EFFECT $\quad \mathbf{1 2 9}$

4.5.1 EXPERIMENTAL PROGRAM 130

$\begin{array}{lll}4.5 .2 & \text { RESULTS } & 131\end{array}$ 
$\begin{array}{lll}\text { 4.5.3 CONCLUSSIONS OF THE ACTIVE ADDITION EFFECT } & 137\end{array}$

4.6 Limestone Coarse Aggregate effect 137

$\begin{array}{lll}\text { 4.6.1 EXPERIMENTAL PROGRAM } & 138\end{array}$

$\begin{array}{lll}\text { 4.6.2 } & \text { RESULTS } & 140\end{array}$

4.6.3 CONCLUSSIONS OF THE LIMESTONE COARSE AGgREgATE EFFECT 144

$\begin{array}{lll}\text { 4.7 Particle PaCKING theORY EFFeCt } & \mathbf{1 4 4}\end{array}$

$\begin{array}{lll}\text { 4.7.1 DEFINITION OF THE DOSAGE CRITERIA } & 145\end{array}$

$\begin{array}{lll}\text { 4.7.2 } & \text { EXPERIMENTAL PROGRAM } & 147\end{array}$

$\begin{array}{lll}4.7 .3 & \text { RESULTS } & 147\end{array}$

4.7.4 CONCLUSSIONS OF THE PARTICLE PACKING THEORY EFFECT 150

4.8 MIXER EFFECTS

4.8.1 EXPERIMENTAL PROGRAM 151

4.8.2 RESULTS 153

4.8.3 CONCLUSSIONS OF THE MIXER EFFECT 158

4.9 StATISTICAL ANALYSIS OF THE INFLUENCE OF THE PARAMETERS 158

4.9.1 EXPERIMENTAL PROGRAM 158

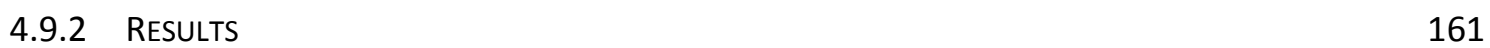

4.10 GENERAL RECOMMENDATIONS FOR VHPFRC-UHPFRC: DOSAGE, MIXING AND POURING 163

4.10.1 DOSAGE COMPONENTS 163

4.10.2 DOSAGE RHEOLOGY 165

4.10.3 MIXING PROCESS 166

4.10.4 POURING OF THE CONCRETE

4.11 IMPLEMENTATION OF THE PREVIOUS CONCEPTS: DOSAGES FOR DIFFERENT REQUIREMENTS $\mathbf{1 6 8}$

4.11.1 OBJECTIVES 168

$\begin{array}{ll}\text { 4.11.2 DEFINITION OF THE DOSAGES } & 169\end{array}$

4.12 SUMMARY AND FINAL REMARKS

5. UHPFRC BOLTED CONNECTIONS

$\begin{array}{lll}5.1 & \text { INTRODUCTION } & 181\end{array}$

5.2 UHPFRC BOLTED JOINTS. FAILURE MODES

5.3 PRELIMINARY TESTS FOR BOLTED CONNECTIONS 186

$\begin{array}{lll}\text { 5.3.1 TEST SET UP } & 186\end{array}$

\begin{tabular}{ll} 
5.3.2 & EXPERIMENTAL PROGRAM \\
\hline
\end{tabular}

$\begin{array}{lll}\text { 5.3.3 ANALYSIS OF THE PRELIMINARY TEST RESULTS } & 190\end{array}$

5.3.4 CONCLUSIONS OF THE PRELIMINARY TESTS 195

5.4 IMPROVED PROPOSAL: SINGLE BOLTED TEST (T) 196

$\begin{array}{lll}5.4 .1 & \text { TEST SET UP } & 196\end{array}$

$\begin{array}{ll}\text { 5.4.2 } & 199\end{array}$

\begin{tabular}{ll}
5.4 .3 & SINGLE BOLTED TEST RESULTS AND ANALYSIS \\
\hline
\end{tabular}

5.4.4 SINGLE BOLTED TEST MODELIZATION 206

$\begin{array}{ll}5.5 & \mathbf{2 1 0}\end{array}$

$\begin{array}{lll}5.5 .1 & \text { INTRODUCTION } & 210\end{array}$ 
5.5.2 DESIGNED ELEMENT

\begin{tabular}{ll}
5.5 .3 & EXPERIMENTAL PROGRAM \\
\hline 5
\end{tabular}

\begin{tabular}{ll}
5.5 .4 & RESULTS \\
\hline
\end{tabular}

$\begin{array}{ll}\text { 5.5.5 CONCLUSIONS OF THE REAL SIZE STRUCTURE TEST } & 227\end{array}$

\begin{tabular}{ll}
5.6 & FORMULATION TO PREDICT FAILURE MODES \\
\hline
\end{tabular}

\begin{tabular}{ll}
5.7 & RECOMMENDATION FOR THE DESIGN OF BOLTED JOINTS \\
\hline
\end{tabular}

6. CONCLUSIONS $\quad 231$

7. POSSIBLE IMPROVEMENTS AND POTENTIAL OF DEVELOPMENT $\quad 235$

8. REFERENCES $\quad 239$

9. ANNEXES 259

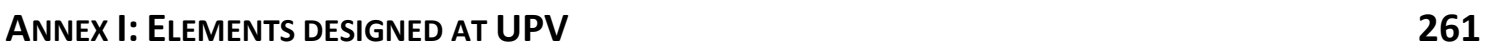

I. INTRODUCTION 261

$\begin{array}{lr}\text { II. StRUCtural APPLICATIONS } & 261\end{array}$

$\pi$ GIRDER FOR UNIDIRECTIONAL LOAD TRANSMISSIONS 261

TRUSSES FOR TEMPORAL STRUCTURES 263

$\begin{array}{lr}\text { PRECAST RETAINING WALL } & 265\end{array}$

$\begin{array}{lr}\text { PRECAST TRUSS FOOTBRIDGE } & 267\end{array}$

$\begin{array}{lr}\text { III. NON-Structural APPLICATIONS } & 269\end{array}$

\begin{tabular}{lr} 
10. OTHERS & 271 \\
\hline
\end{tabular} 
1. INTRODUCTION 


\subsection{Preliminary issues}

Concrete has been in constant development along the centuries, but more especially from the end of the 80' thanks to the development of new cements, the appearance of the fibers as a reinforcement for structural applications, and specially the grand progress in the field of the water reducing admixtures.

One of the lasts successes is the Ultra High Performance Fiber Reinforced Concrete (UHPFRC), which incorporates advances of the Self-Compacting Concrete (SCC), FiberReinforced Concrete (FRC) and Ultra High Strength Concrete (UHSC) technology. This exclusive material requires a detailed analysis of the components compatibility and a high control of the components and processes. There are still some difficulties for the expansion of these materials in a great range of applications:

- UHPC family is wide, and the dosages strongly vary depending on the casting process and the desirable properties. Classification of these products is not clear yet. The lack of information may scare the potential users for daily applications.

- UHPFRC is used particularly in precast industry, casting the elements mainly with patented products and using very exclusive materials and thermal curing. In many cases the price is high compared with other traditional solutions, and the application can only be justified throughout the aesthetics or the longer service life of the structure. Commonly mechanical properties of the material are much higher than the required for the application.

- Reach UHPFRC properties (more than $150 \mathrm{MPa}$ of compressive strength and more than 10 MPa of tensile strength with ductility) require a high control of the materials and processes. That is a reason to have patented premix bags in the market, but in many locations there are not available. Local providers cannot always guarantee constant properties for the materials, so UHPFRC properties might vary. Learn how to control UHPFRC mixtures with this variability is still a challenge.

Obtain the desired properties with simpler technology (without intensive mixers, without steam curing and using simple dosage criteria) requires still deep research. Compatibility between binder and admixture has been shown one of the main key points. Also the majority of dosages optimized up to now have been developed in laboratory. The extrapolation of them to an industrial process is difficult, as the use of standard components, the effect of the mixer size and mixing parameters can strongly affect to the rheological and mechanical properties.

Finally, connections between UHPFRC elements are normally performed with in-situ concretes, a habit adopted from ordinary concrete. However, as material has similarities with the steel, it would be logic that connection methods are also resemblant. Simpler systems should be developed to simplify and fast the construction, promoting then the development of the current potential uses. 


\subsection{RESEARCH GOALS}

The research presented at this Ph.D. covers mainly two aims:

* The study of simplify components and processes in UHPFRC, obtaining different levels of performance. This becames the first experience with UHPFRC technology at Universitat Politècnica de València.

* The development of bolted connection system between UHPFRC precast elements. The design of an adequate testing method is intented. It would provide the correlation between the piece geometries and the failure modes, load carrying capacity and ductility.

Respect to the first part, the main goals are:

- Analyze the UHPC-VHPC dosages with and without fibers designed from the year 2000 up to the present moment by the most significant international researchers.

- Develop dosages with different levels of performance studying the effect of less exclusive materials on the rheological and mechanical properties. These are local active additions, crushed limestone coarse aggregate, normal strength fibers and lower cement content.

- Study the effect of cast the same UHPFRC in mixers with different energy and volume, ranging from 1 to 1000 liters of capacity.

- The analysis of simpler particle packing theories to obtain the adequate sand proportions.

- Based on the experiences, obtain recommendations to design simpler UHPFRC, useful for companies without experience in this field. It should make understand the simplifications that can be accepted in each case depending on the structural requierments.

Respect to the second part, the main goals are:

- Design and development of a testing method for UHPFRC bolted connections. It should provide a low scatter for two similar specimens and suffer the failure in the studied region.

- Study the possible use of the developed material in bolted connections. The failure modes, maximum load, ductility and cracking pattern should be obtained for bolted connections with different geometry. This must be contrasted with a finite linear analysis model. Based on both experiences, formulations to predict the failure modes will be provided.

- Analyze the effect of passive reinforcement in the bolted connections, as a possible solution for exigent structural connections.

- Evaluate the viability and restrictions of a structure with bolted connections with a full scale UHPFRC truss.

The research covers several fields of the UHPFRC use: The evolution of the last years of technology, the development of dosages with simpler materials and processes, the connection of precast elements, and finally, at Annex I, some precast applications as a result of this research. 


\subsection{OUtLine OF THE PH.D. TheSIS}

This Ph.D. thesis consists of seven chapters that are described as follows. An scheme of the connection between them is shown at figure 1.1.

Chapter 1 is a brief introduction that resumes the current problematic, the Ph.D. thesis research goals and its organization.

Chapter 2 is an analysis of the UHPC technology literature. The text is focused in the main subjects related with the subsequent research. Literature from international congresses and journals is abstracted, and 114 dosages from different authors are studied to obtain conclusions of the general practice and corroborate preconceptions and misconceptions.

In Chapter 3 the materials and methodology used are explained. The components used for the UHPFRC dosages are defined. The instruments used as mixers or jacks are introduced. The processes to perform both the mechanical and rheological tests are detailed. Special attention is put in the back analysis process made to deduce the stress-strain tensile law from the bending tests results.

Chapter 4 is a dosage analysis, where the final goal is analyze the effect of several variables that simplify the components and processes to cast UHPFRC. The findings of chapter 2 are taken into account. Some non-exclusive and unusual components are introduced, as limestone coarse aggregates, local silica fume, fluid catalytic cracking residue, or normal strength fibers. Rheological and mechanical properties of the dosages are obtained, studying the suitability of the introduced materials. An univariate ANOVA analysis of these effects provides an overview of the effects of these variables.

Chapter 5 introduces the bolted connections between UHPFRC elements. Two different types of experimental tests are developed to deduce the capacity of the joints, where dimensions and reinforcement steel are modified. An elastic finite element model is also performed to support the experimental tests developed in laboratory. The results helps to understand the cracking evolution up to the maximum load is reached. The last part analyzes the results of a full scale truss made using the bolted joints introduced before.

Chapter 6 shows the conclusions of the Ph.D. thesis. Based in the results of the document, needs and recommendations for a future research are commented.

Chapter 7 abstracts the research lines opened in this Ph.D. that would be interesting to develop in the future.

Finally, in the annexes there is an abstract of several precast elements designed and performed up to this date by the research group, both at laboratory and at precast industry with the dosages from the Ph.D. thesis. Elements vary from prestressed beams or a footbridge to urban furniture. 


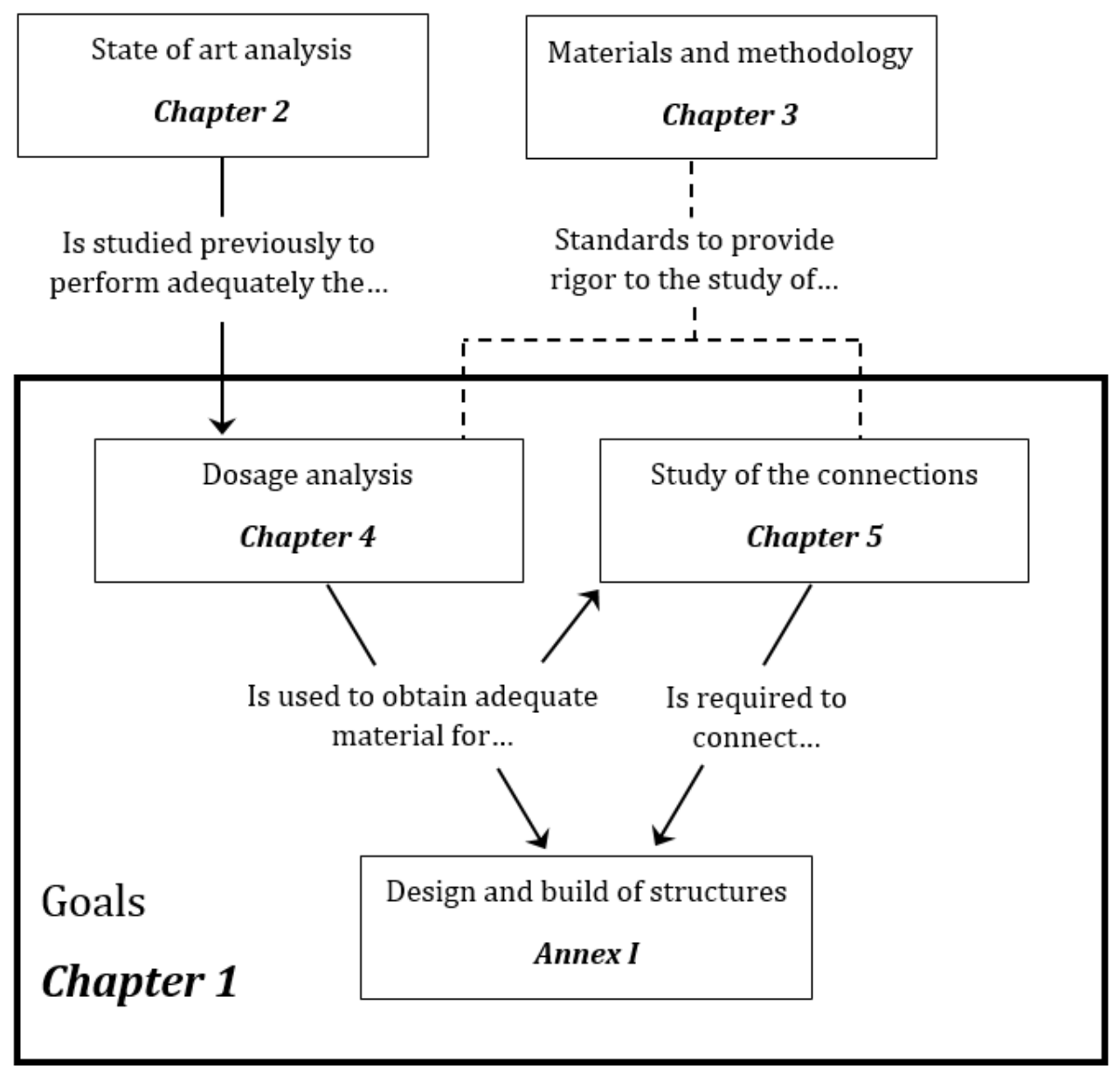

Figure 1.1: Scheme of the connection between the PhD Chapters 


\subsection{INTRODUCTION}

In this chapter, a state of art of UHPC-UHPFRC is provided. The subchapters describe the basic concepts related with the material and level of development nowadays. Information provided is oriented to make understand the problematic treated in this Ph.D. Thesis.

Special attention is put in the different components and processes used to cast UHPFRC, resuming their influence to the rheological and hardened state. A database of 114 dosages from different authors has been created and analyzed to determine the range where UHPFRC dosages vary, corroborating or refuting some of the typical assumptions related with this material. This was a good theoretical beginning to develop the dosages in the subsequent Chapter.

Finally, an abstract of different connection systems applied to UHPFRC elements in real structures is provided.

\subsection{UHPFRC CONCEPTS}

\subsubsection{WHAT IS UHPC-UHPFRC?}

According to its first definition, from the French Interim Recommendations published in 2002 [8], UHPFRC (Ultra High Performance Fiber Reinforced Concrete) are considered the materials with cementitious matrix and characteristic compressive strength after 28 days in excess of $150 \mathrm{MPa}$ (the prism size of the test is no detailed), possibly attaining $250 \mathrm{MPa}$; containing steel fibers in order to achieve ductile behavior under tension and, if possible, to dispense with the need for passive reinforcement. It also contains a high quantity of cement and special aggregate selection. The typical tensile strength of the matrix is over $8 \mathrm{MPa}$ [215] [97]. It has also excellent rheological properties in fresh state, allowing for easy casting of the self-compacting fresh material [26].

From 1997 some innovative applications have been built with this material in the domains of structural, durability and architectural applications [18]; being possible to appreciate an evolutionary progression of the structural forms towards an optimum exploitation. Its properties, always with values placed between steel and concrete, (table 2.1) give to UHPFRC a marked potential development: It is viable design lighter structures, save raw materials, increase the live span and obtain more aesthetic surfaces with shapes that until now were unthinkable with ordinary concrete (OC) [239] [87]. Thanks to this it is possible to end with the long-standing topic that the concrete structures are rude, heavy and ugly [260].

Table 2.1: Properties of different structural materials

\begin{tabular}{|c|c|c|c|c|c|}
\hline Material & $\boldsymbol{\sigma}_{\mathbf{c}, \text { elast }}$ & $\boldsymbol{\sigma}_{\mathbf{c}, \mathbf{u}}$ & $\boldsymbol{\sigma}_{\mathbf{t}, \mathbf{u}}$ & $\boldsymbol{\varepsilon}_{\mathbf{t}, \mathbf{u}}$ & Young Mod. \\
\hline OC & 20 & 40 & 3.5 & $0.1 \% 0$ & $3 * 10^{4}$ \\
\hline Steel S355 & 355 & 470 & 355 & $200 \% 0$ & $2 * 10^{5}$ \\
\hline UHPFRC & 170 & 200 & 9 & $2 \% 0$ & $5 * 10^{4}$ \\
\hline
\end{tabular}




\subsubsection{BASIC PRINCIPLES}

The high strength, durability and ductility of UHPFRC are based in the following principles [215] [261] [192] [262]:

1. Very reduced $\mathrm{W} / \mathrm{B}$ ratio, normally between 0.15 and 0.25 , which minimize the number of capillary pores, almost unconnected between them. Thanks to this, the transport of gases or liquids which attack the concrete is avoided.

2. High packing density, mainly concerning the fine particles, with consequent decrease of the water demanded for the mixing. It should be obtained selecting appropriate size distribution.

3. Use of homogeneous, high strength and reduced diameter aggregates, since micro-cracks that appear in the interphase and limit the strength in a compressive test are proportional to the aggregate size.

4. The use of last generation admixture, in order to provide to the material selfcompactability with low W/B ratio. Then almost all the water added takes part of the hydration reaction of the cementitious materials, being much reduced the capillary pores volume which limits the strength.

5. The use of steel fiber reinforcement to control the evolution of both the micro and the macro crack evolution, increasing then the ductility, tensile, flexural and shear strength.

The most remarkable properties of UHPFRC are the high flexural and compressive strength, its high ductility, durability, toughness, stiffness and thermal resistance. It also provides high quality surface aspects on moldable products [262] [18]. Selfcompactability is also a key point in fresh state, because it allows to control the fiber orientation during the casting process.

In general, UHPFRC structures are able to give immediate saving in terms of primary material consumption, embodied energy, CO2 emissions and global warming potential [253].

UHPFRC cost per cubic meter is much higher than the cost of conventional concrete, but for many applications becomes competitive due to the much smaller volume of material required to perform the structural elements [261]. The decrease of required mass is justified by several reasons: Many covers can be avoided because the absence of conventional passive steel, making possible thinner sections and wider variety of innovative cross-sectional shapes. Besides, the covers of active prestressed steel can be also reduced thanks to the low permeability of the material, and the high tensile-compressive performance implies the need of less concrete volume. This becomes in less mass associated to the self-weight, which is generally the main load of the structures. Then they can be recalculated to reduce even more the volume of material used, dividing in many cases the dead weight respect to ordinary concrete solutions by a factor of three [18].

Examples of several applications where the self-weight of the structure has been reduced between $50 \%$ and $75 \%$ respect to the typical OC solution can be found in [9] [37] [141] [152] [185] [261]. The consumption of materials is strongly minimized and the transport and erection process becomes then simpler. Thanks to this, UHPFRC structures are more efficient and even more beauty and economic, in harmony with the known as "structural art". 


\subsubsection{UHPFRC TECHNOLOGY NOWADAYS}

Throughout history the discovery of a new building material motivated the development of new structural forms associated. These changes, which happened with logic inertia, tended to take profit progressively of the properties of the recently appeared material.

Thought UHPFRC derives from ordinary concrete, it is also a new material due to the marked difference in strength, ductility and durability. For instance, compressive strength is 4 to 8 times higher compared to conventional concrete; however the density of these two materials is almost the same. Therefore, new possibilities for construction in civil engineering are much bigger, but the current conception of concrete structures has to evolve to obtain the best benefit to the material properties [189] [29].

Then, it is necessary define the areas where UHPFRC applications are and can be useful and profitable [239]. Ideally, the structural solutions are more slender and slight than with ordinary concrete, so typical steel structures problems, as vibrations, buckling or local buckling can be more present.

The cubic meter price can be estimated between $\$ 1800$ and $\$ 2200$ ([46], data of 2008), much higher than ordinary concrete, but its use can be justified with the small volume of material used, the simpler transport, the quick assembly and the long service life [262].

Obviously, as every new material, it has an inherent disadvantage to be cast, because the current machinery and building methods require time to be adapted. Cost is also one of the impediments for expansion of the UHPFRC applications: With the actual ordinary concrete typologies the use of UHPFRC doesn't represent improvement enough to justify the costs. Current design codes still detail minimum dimensions and covers for structural elements as columns or beams. This directly closes the door to an efficient design with this norms using UHPFRC.

Up to this moment, the most common way to build UHPFRC structures is by means of precast elements built with one of the few patents existent in the world market (Ductal ${ }^{\circledR}$, CERACEM $\left.{ }^{\circledR}, \mathrm{BCV} ® \ldots\right)$, calculated and designed according to the Interim Design Guidelines for UHPFRC existing in France, Japan or Australia [8] [113] [180] [260]. The great majority of countries where it's being built are Japan, France, USA, Germany, The Netherlands and Denmark [2] [236] [92] [195] [67] [152] [88].

The future of the material largely depends on the appearance of an International Recommendation, which is already under development by the fib Task Group 8.6 [260] (see 2.6.1); and on the expansion of generic UHPFRC dosages using the accessible materials in every region. These dosages should be chosen according to the requirements of each application, reducing then the costs.

\subsubsection{UHPFRC MANUFACTURERS AND APPLICATIONS}

Some precast companies have already more than a decade of experience: Hurks Beton, a Dutch company, uses BSI; and Hi-Con, Danish, works with CRC [3] [92]. However, there is an increasing number of precast companies that are working with UHPC-UHPFRC all over the world. 
Hürks Beton (www.hurks.nl/en), in The Netherland's, is the usual Eiffagge partner for UHPFRC structures, being specialized in the composition of high performance selfcompacting concretes [152] [98]. In Denmark, four different producers are casting CRC, an UHPFRC type (see 2.3.1). 70\% of it pertains to the company Hi-Con (www.crc-tech.com), which introduces small variations in the mix to obtain good quality control [3]. Some UHPFRC are developed with local products in different parts of the world and used for precast structures. They are denoted with a certain name. Some examples are RESCON (developed by the Austrian company SW Umwelttechnik in cooperation of Kassel University), DORSICEM $®$ (from the German company Dorfner [208]), DURA (Malaysia, [255] [256] [257]), or SINNODUR®).

The companies can both develop their own dosages with available materials, optimizing them progressively, or use patented products. An example of the last is the company Sudholt Wasermann (www.sudholt-wasemann.de), which performs the UHPC with the patented compound Nanodur® 5941, from Dyckerhoff. Also the British company OGM (www.ogmgroup.com), specialized in the design and supply of architectural façade elements, uses the patented product TAKTL $®$ (www.taktl-llc.com), which allows the change of bright, texture and colour to provide many different aesthetical options. Also some of the companies that produce the patented products have their own manufacturing plants (VSL-Ductal in Australia [186], BCV Central Béton Rhone-Alpes [51], etc.).

Besides, some concrete manufacturers develop a mixture for certain application. Max Bögl (www.max-boegl.de) is a concrete manufacturer that cast the UHPFRC for the Wild-Brücke in Völkermarkt [102]. ELO Beton is a medium size UHPC manufacturer that produces with its own dosages from 2004 [82]. They produced the elements for the Gärtnerplatz footbridge over the Fulda River.

The most common applications with UHPFRC are civil and structural engineering (footbridges, girders, decks...), structural art (balconies, brise-soleils, elements exposed to aggressive environments (pipes, spillways, etc.), rehabilitation, security buildings susceptible to explosions, and industrial frame construction [253].

The first application of UHPFRC was a truss, the Sherbrooke footbridge, done in 1997 at Canada. Truss constructions take the full advantage of the material strength due to the loading with normal forces. Thus, they are very appropriate with UHPFRC because of the good relation strength compared with the material density. In 2013 a 45 meters length footbridge developed at the UPV was placed at Alicante (Spain) [139].

From then few structures have been built mainly at France, Germany, U.S.A., Japan, South Korea, Australia, Malaysia and Spain. The majority of them are bridges and footbridges, being then unique projects.

However, there is an increasing number of standard elements cast by precast companies, being also offered and sold in the market. Figure 2.1 shows some examples. As can be seen, many of the elements in series produced are those very polyvalent for structural applications. Is in this field where UHPFRC gets more sense, as the high number of elements cast reduces the price of the mold and transport. 


\section{Structural applications}

T shape and U shape bridge girders (DURA®)

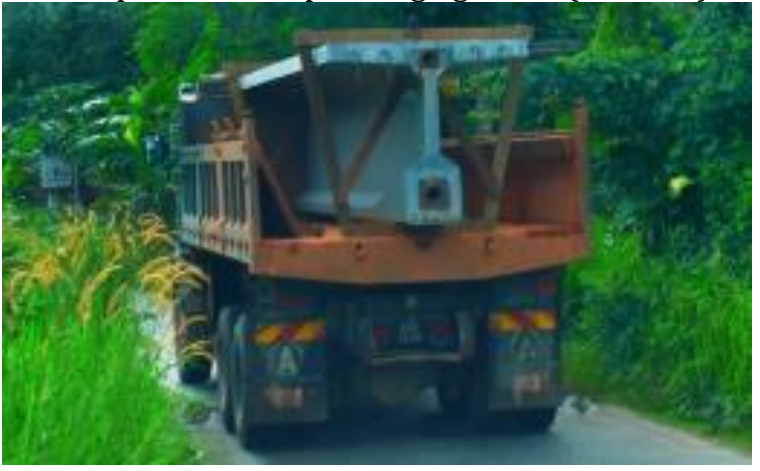

Prestressed and universal beams (DURA®)

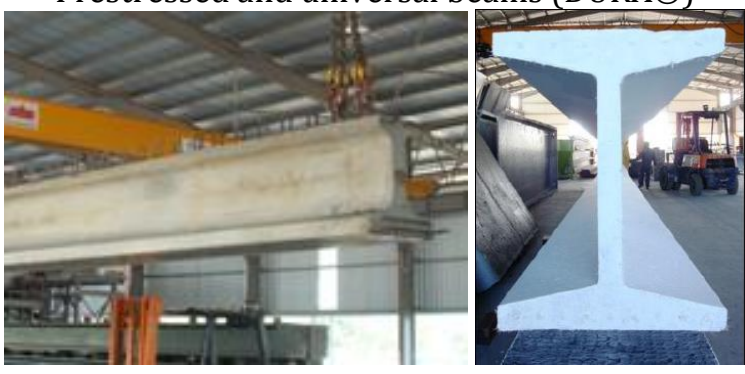

Short Retaining walls (DURA®)

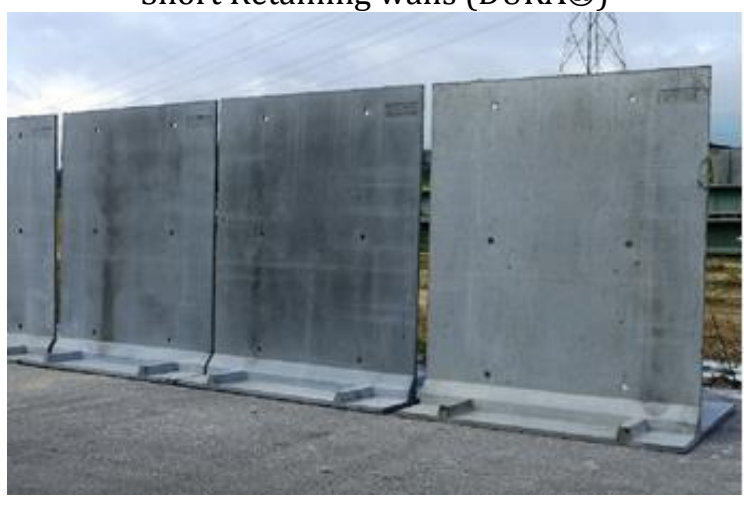

Box girders (Max-Goebl, Graz University)

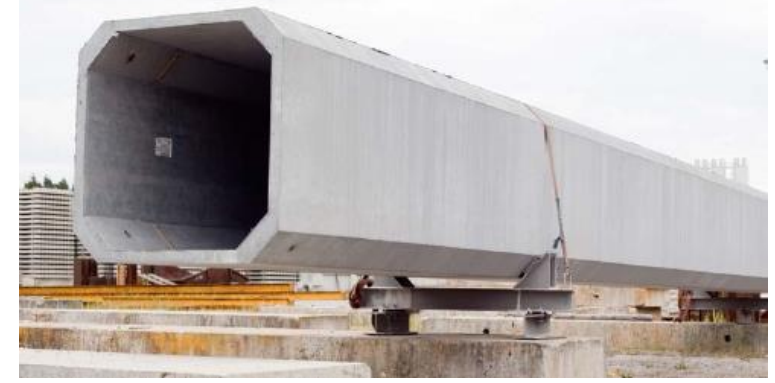

Special applications (ELO Beton $®$ and others)

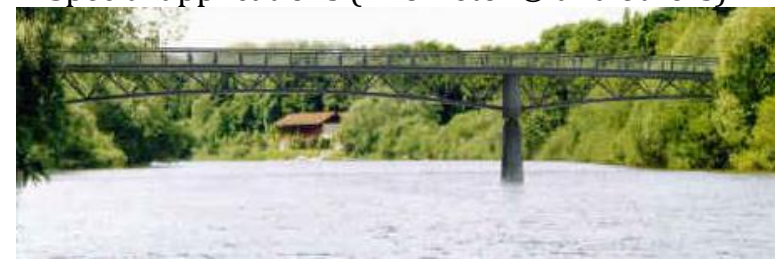

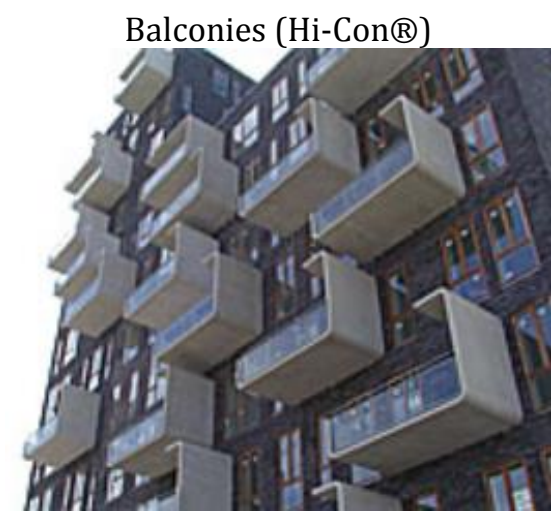

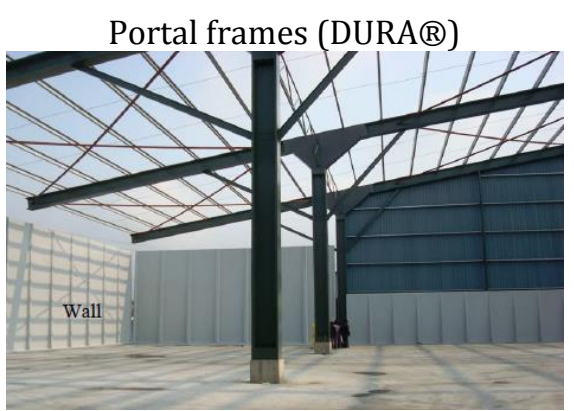

Wall panels (DURA®)

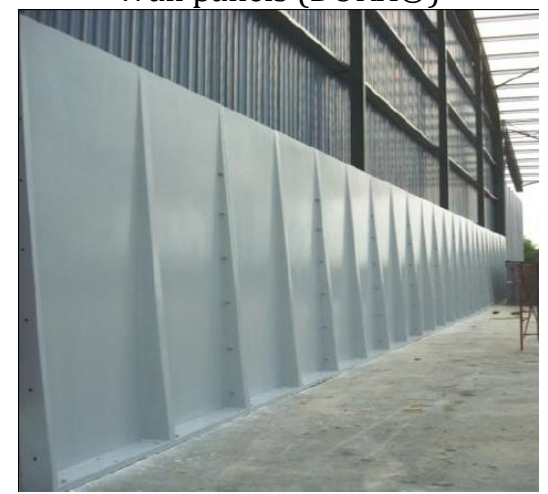

Manholes (Hi-Con $®$, DURA®)

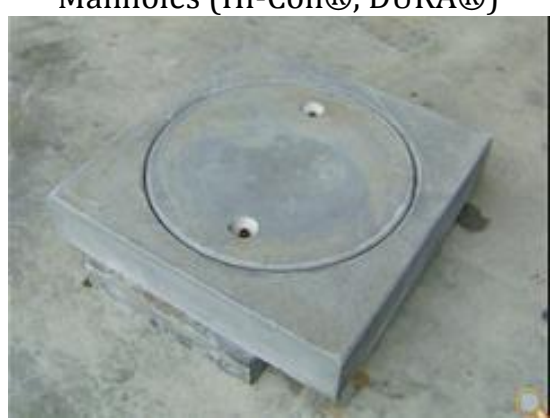

Pedestrian girders (DURA®)

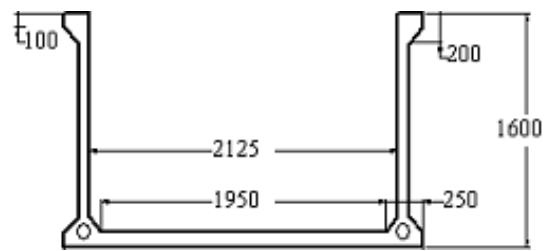




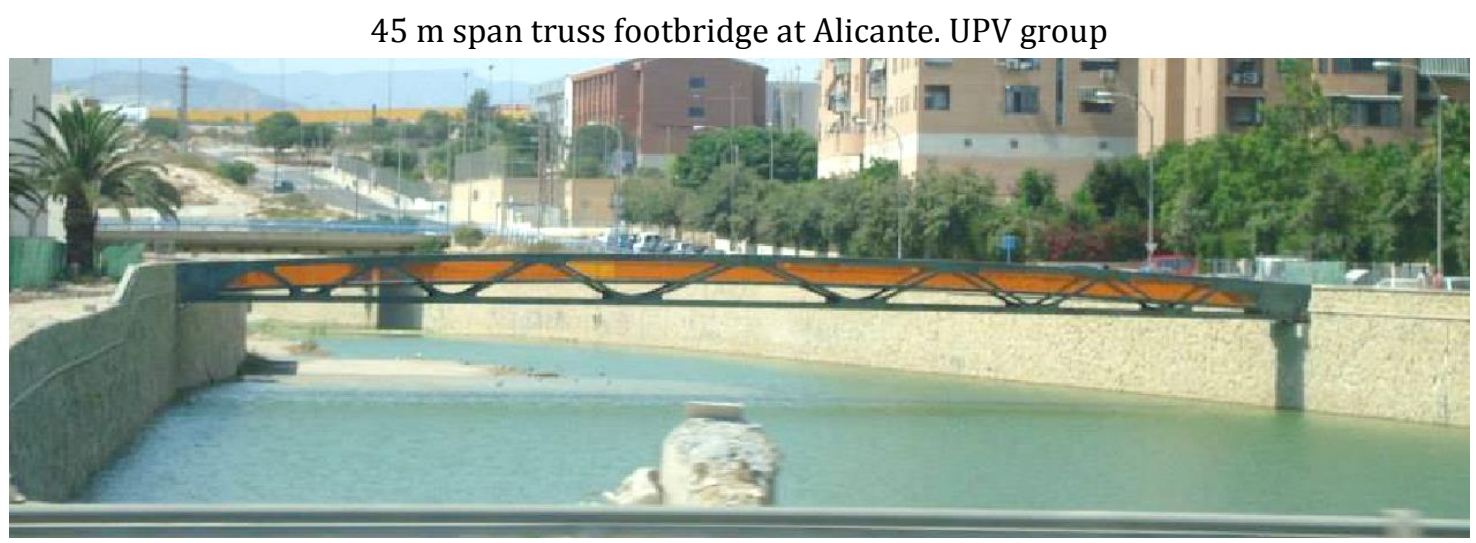

Architectural applications
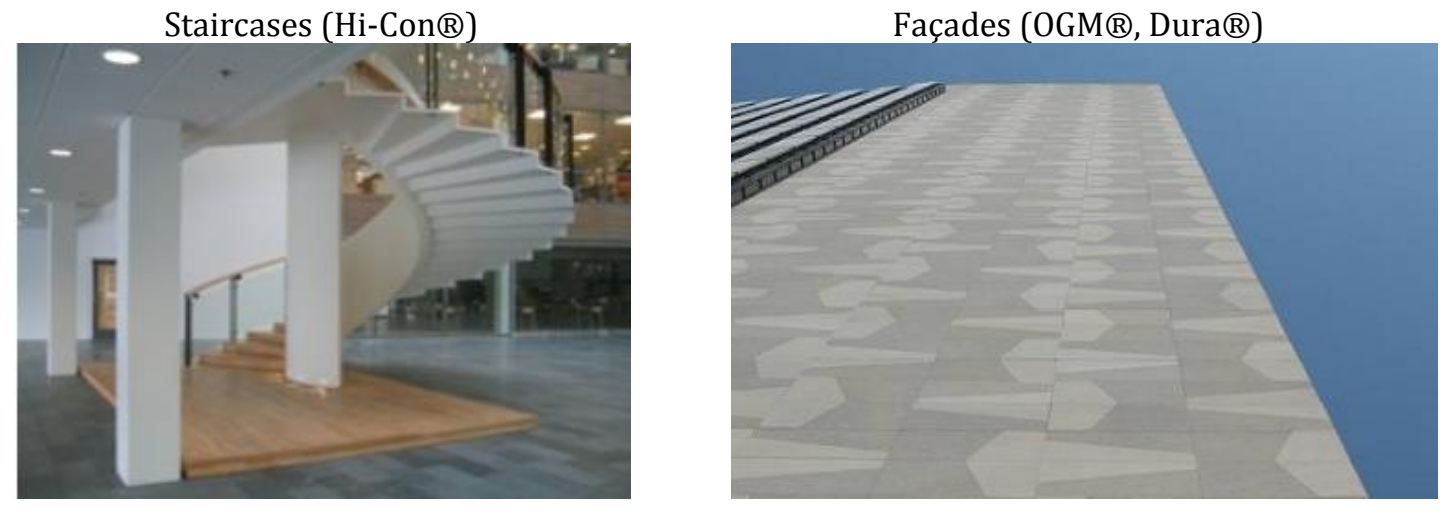

Figure 2.1: Structural and architectural applications with UHPFRC

\subsection{State OF ART ANALYSIS}

\subsubsection{HPFRC-UHPFRC TYPES, COMMERCIAL DOSAGES}

The different UHPC-UHPFRC families are related because all they have properties from combination of three concrete technologies to a greater or lesser extent: Self-compacting concretes (SCC), fiber reinforced concretes (FRC) and high performance concretes (HPC) taken to the extreme. This combination is presented at figure 2.2 .

In the seventies, advances in admixture technologies allowed reach better dispersion of binder particles in the water. This let use effectively active additions with lower size than the cement, filling the holes and reaching then a more compact matrix. This first concept, introduced by Hans Henrik Bache was named DSP (Densified Systems containing homogeneously arranged, ultra-fine Particles). He used ultra-fine cement and lately microsilica, reaching strengths of $128 \mathrm{MPa}$ at $24 \mathrm{~h}$ with specific curing process. From this moment his group worked in the characterization of properties of this type of concrete. The development of DSP, also directed by Bache, towards a less brittle composite resulted in 1986, in the known as CRC (Compact Reinforced Concrete) in the Cement \& Concrete Laboratory of Aalborg Portland, in Denmark [1] [2] [3]. This product is based in a very high strength fiber reinforced matrix and conventional steel reinforcement in high percentage, being named nowadays as HRUHPC (Heavy Reinforced Ultra High Performance Concrete) [29]. It was one of the first examples of a Hybrid FRC. 


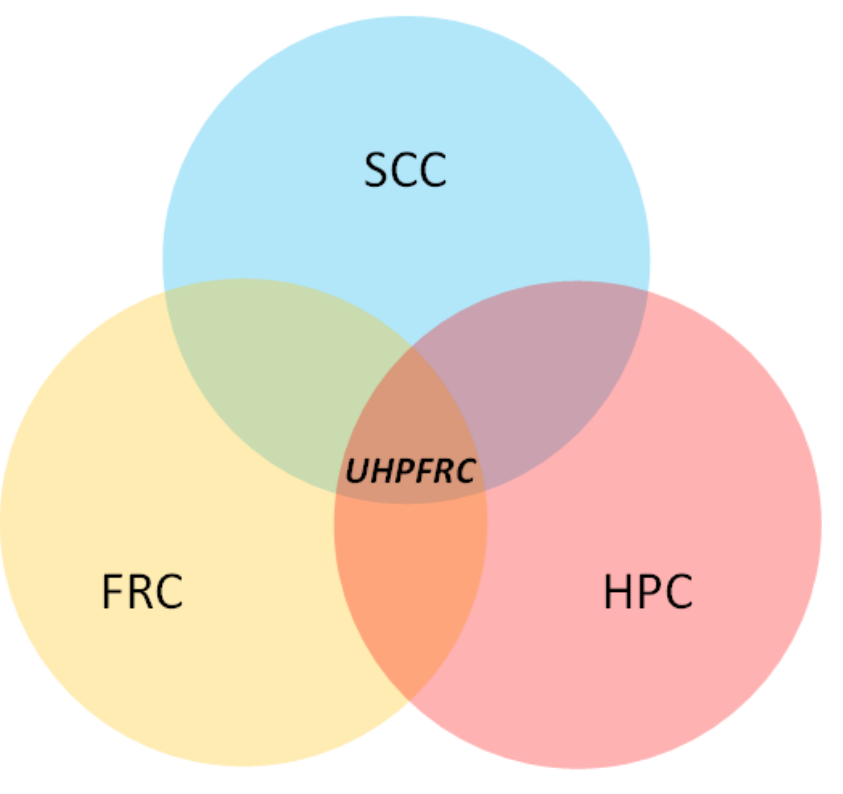

Figure 2.2: Different special concretes

Also at the end of 80' was being developed the SIFCON (Slurry Infiltrated Fiber Concrete, Naaman) technology, based in the idea of pour cementitious fluid slurry with very reduced diameter aggregate over steel fibers, generating then a very compact structure.

Somewhat later, in 1994, De Larrard and Sedran introduced for first time in a research journal the concept of Ultra High Performance Concrete (UHPC). Next year, developing this concept, the name of RPC (Reactive Powder Concrete) was proposed to a patented product with maximum aggregate diameter of $0.6 \mathrm{~mm}$ to reduce the microcracks size and optimize the particle packing density [193]. Still nowadays some UHPFRC without coarse aggregates are named RPC, referring then as UHPC to those with coarse aggregate.

Based in the research of this material, in the 90' emerged its successor, named Ductal ${ }^{\circledR}$ [86] [183], patent born from the research of Laffarge, Bouygues and Rhodia. The next patent appeared in the market was BSI ${ }^{\circ}$, which current evolution is know now as CERACEM $®$, designed by Eiffage and Sika [129] [145] [99]. Few other products have been patented till now, as CEMTEC multiscale $^{\circledR}$ (Rossi, LCPC, 2002) [117] [97] [123] or BCV®, developed by Vicat Group [232]. These patented products, born from common research between companies and universities, are used nowadays in the most developed countries according to the existent recommendations. Some of the typical dosages are shown in table 2.2.

On the same time, Kassel University (Schmidt, 2001) was pioneer and one of the most remarkable in the development of its own UHPFRC [148]. It is the main University coordinating the DFG Priority Program SPP 1182 [78], a program structured for all Germany to optimize and widely study UHPFRC dosages. At this program, concretes with different properties were designed and researched deeply with the name of B1Q, B2Q, B3Q, B4Q, M1Q, M2Q, M3Q, B4B and M2F. Names are according to the binder composition and aggregate type.

On the other hand, there are an increasing number of companies and researchers over the world developing UHPFRC dosages with materials obtained from local suppliers of the region, achieving then good properties with lower prices [96] [257] [157] [219] [74]. The UHPFRC precast elements are usually cast in very technological plants, both with patented or own dosage, with an intensive control of the processes. 
Table 2.2: Dosages and properties of the most used commercial products

\begin{tabular}{|c|c|c|c|c|c|c|c|c|}
\hline & \multicolumn{2}{|c|}{ Ductal@ } & \multicolumn{2}{|c|}{ CERACEM® } & \multicolumn{2}{|c|}{ CEMTEC $_{\text {MULTISCALE }}{ }$} & \multicolumn{2}{|c|}{$\mathrm{BCV} \AA[250][23]$} \\
\hline & Type & $\mathrm{kg} / \mathrm{m}^{3}$ & Type & $\mathrm{kg} / \mathrm{m}^{3}$ & Type & $\mathrm{kg} / \mathrm{m}^{3}$ & Type & $\mathrm{kg} / \mathrm{m}^{3}$ \\
\hline Cement & Portland & 746 & - & 1114 & CEM I 52.5 & 1050 & & $\uparrow$ \\
\hline SF & - & 242 & - & 169 & $12 \mathrm{~m} 2 / \mathrm{g}$ & 275 & & 2115 \\
\hline Quartz fl. & - & 224 & - & - & - & - & & (bag) \\
\hline Sand (mm) & $0,15-0,6$ & 1066 & $0-6$ & 1072 & $<0,5$ & 730 & $2-3$ & $\downarrow$ \\
\hline Water & $\mathrm{W} / \mathrm{C}$ & 0,19 & $\mathrm{~W} / \mathrm{C}$ & 0,19 & $\mathrm{~W} / \mathrm{C}$ & 0,181 & $\mathrm{~W} / \mathrm{C}$ & 0,25 \\
\hline PCE & Chryso & 9 & SIKA & 40 & Chryso Ópt. & 35 & - & 21.5 \\
\hline Fiber (mm) & $13 / 0.2$ & 161 & $20 / 0.3$ & 234 & $10 / 0.2$ & 470 & $20_{2 / 3}+13_{1 / 3}$ & 156 \\
\hline SlumpFlow & $(\mathrm{mm})$ & 700 & $(\mathrm{~mm})$ & 640 & $(\mathrm{~mm})$ & - & $(\mathrm{mm})$ & 750 \\
\hline $\mathbf{f}_{\mathrm{ct}, 28}(\mathrm{MPa})$ & Tens. & 8 & Tens. & 8.8 & - & - & Tens. & 8 \\
\hline $\mathbf{f}_{\mathrm{cm}, 7}$ (Mpa) & $20^{\circ}$ & 101 & $20^{\circ}$ & 165 & $20^{\circ}$ & - & $20^{\circ}$ & 98 \\
\hline $\mathbf{f}_{\mathrm{cm}, 28}$ (Mpa) & $20^{\circ} / 90^{\circ}$ & $124 / 198$ & $20^{\circ}$ & 199 & $20^{\circ}$ & 168 & $20^{\circ} / 90^{\circ}$ & $130-150$ \\
\hline
\end{tabular}

The name provided to the materials of the very high performance concrete family depends on the compressive strength, ductility or fiber content. UHPC (Ultra High Performance Concrete) is the general concept to define materials with characteristic compressive strength higher than $150 \mathrm{MPa}$ after 28 days (prism size not detailed), high cement content and special aggregate selection to provide high compacity. It was formerly named UHSC (Ultra High Strength Concrete [271]), but the current term is more accepted as the material has many other exclusive properties besides compressive strength.

The majority of UHPC contain fibers to provide ductility, being then called UHPFRC (Ultra High Performance Fiber Reinforced Concrete) [8] [85]. This name is the most used in the last years. Other synonyms used are UHPFC (Ultra High Performance Fiber Concrete, [148]), UHSFRC (Ultra High Strength Fiber Reinforced Concrete, [108] [151] [235]), FRUHPC (Fiber Reinforced Ultra High Performance Concrete [169]) or UFC (Ultra Fiber Concrete), used in Japan [236].

Some researchers modified slightly the name for concretes with same features as UHPFRC but with compressive strength between 110 and $150 \mathrm{MPa}$, calling them VHPFRC or HPFRC ([Very] High Performance Fiber Reinforced Concrete) [198] [262]. These concretes, in the region between SCFRC (Self-Compacting Fiber Reinforced Concretes [93]) and UHPFRC offers interesting chances for application. They can have very high flexural performance even though the not ultra high compressive strength.

The UHPFRC-VHPFRC that combine two or more fiber types were initially baptized as High Performance Multimodal Fiber Reinforced Cement Composite (HPMFRCC) by Rossi [202]. A most generalized name in our days is HFC (Hybrid Fiber Concrete), but this concept doesn't include necessarily the high compressive strength. With this fiber cocktail is possible to optimize the tensile-flexural properties [148] [262]. Some of the UHPFRC pertain to the HFC family.

Many of the sub-families described before are schematized in figure 2.3, where different regions show the main special concretes. At figure 2.4 is proposed a temporal line with all the special concretes related with UHPFRC. 


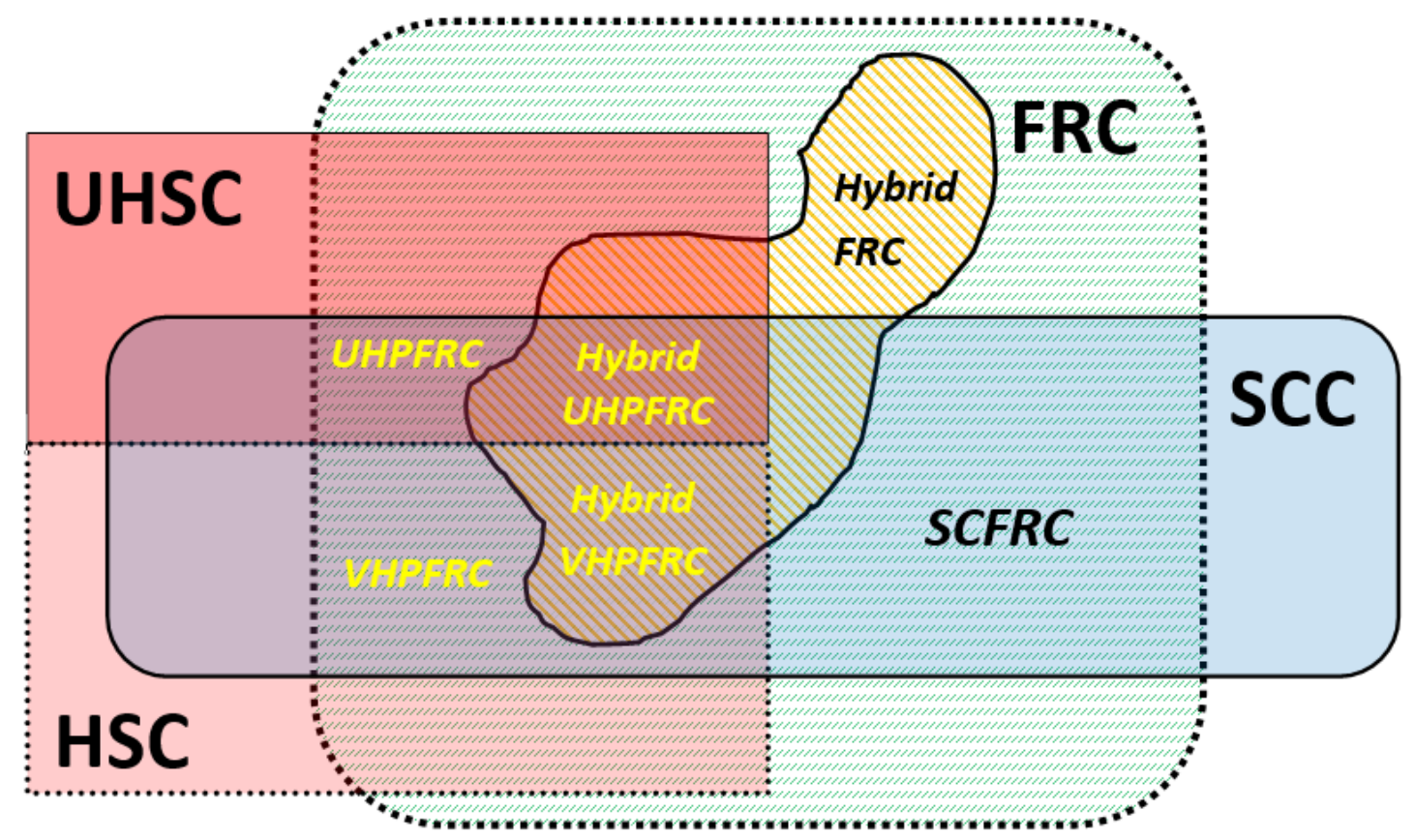

Figure 2.3: Scheme of the special concretes present around UHPFRC

It should be clarified that the translation of UHPC to Spanish is HMAR (Hormigón de Muy Alta Resistencia: Literally, Ultra High Strength Concrete), expressing in the name only one of the remarkable properties of the material. The same initials were used by the UPV Work Group [40] to rename the material as HMAR (Hormigón de muy alto Rendimiento: Ultra High Performance Concrete), defining it more globally as a material that has many other remarkable features: High durability, ductile tensile behavior, selfcompactability... etc.

Attending to an uniaxial tensile behavior classification, fiber reinforced concretes that after the elastic stage develop a single crack and experience a strain softening branch are normally named with the generic term FRC (Fiber Reinforced Concretes), being implicit in this concept that is strain-softening FRC. Those which after the elastic state experience strain hardening response with multi-microcracking are called HPFRCC (High Performance Fiber Reinforced Cement Composites) [160], also named by other authors as SHCC (Strain Hardening Cement Composites) [205]. From March of 2008 this material already count with a specific recommendation in Japan [114]. Some of the commercial UHPFRC pertain to this family due to their high content of steel fibers.

However, many other HPFRCC have a normal or only high compressive strength: ECC (Engineered Cementitious Composites [135]) is a particular type of HPFRCC performed by Li at Michigan University. It develops a very marked strain hardening $\left(3 \%<\varepsilon_{1}<5 \%\right)$ with compressive strengths lower than $90 \mathrm{MPa}$. This is possible reducing the matrix tensile strength and using PVA small size fibers. Another examples are the MMFRC (Multi-Modal Fiber Reinforced Concrete, Rossi, 1987) or HPHFC (High-Performance Hybrid-Fiber Concrete), developed by authors as Marković or Camacho [148] [37] [262], in which strain hardening is developed thanks to the synergy between different steel size fibers, and the compressive strength is in the range of 100-150 MPa. 


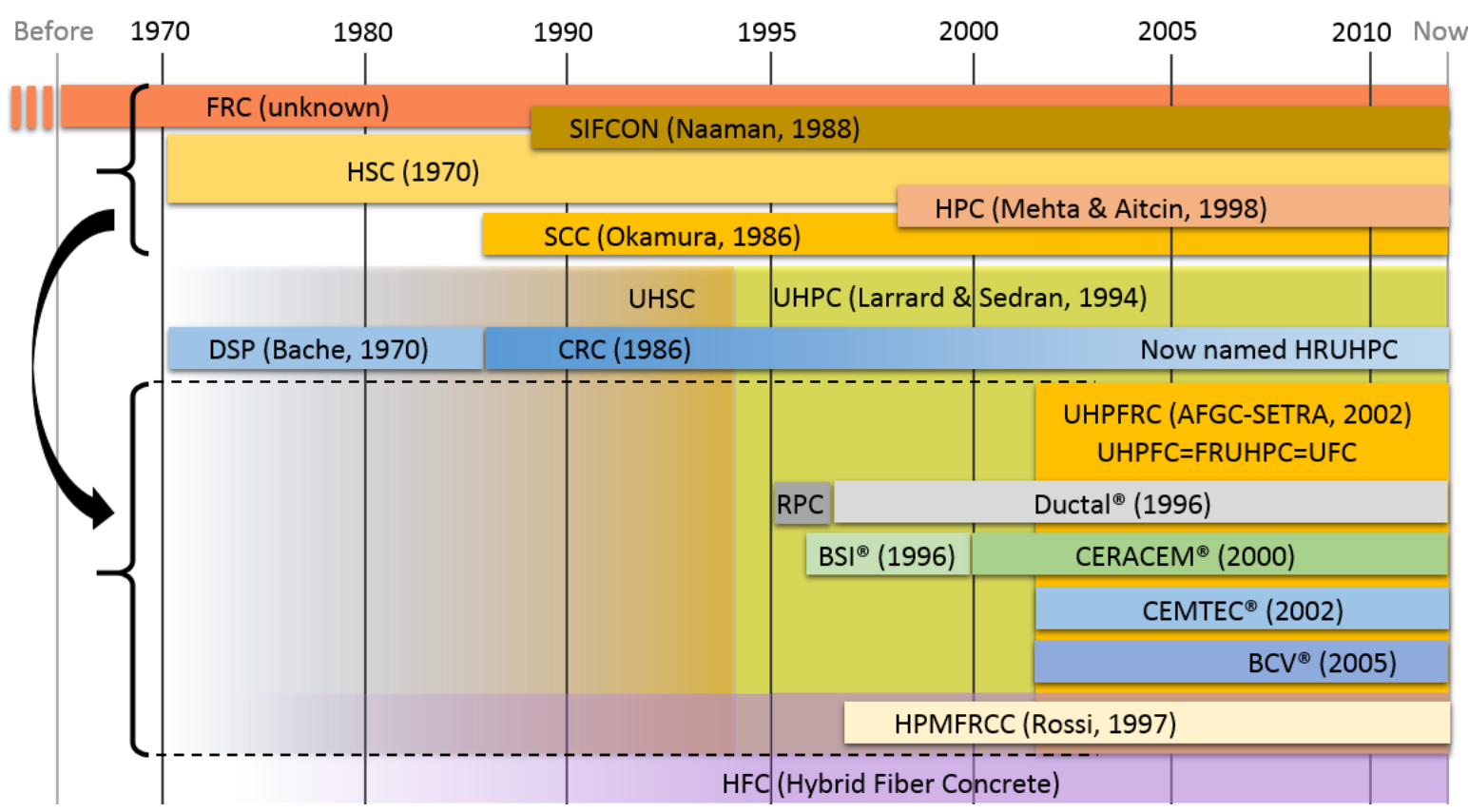

Figure 2.4: Scheme of the different special concretes related with the UHPFRC. The date is the moment when the material name was referenced for first time

\subsubsection{DATABASE OF DOSAGES}

In this subchapter and followings are shown and studied the data of 114 dosages from the three International Symposium on UHPC $(2004,2008,2012$, Kassel), the fib International Workshop on UHPFRC 2009 developed in Marseille, the Congress of High Performance Fiber Reinforced Cement Composites 6 (RILEM, Michigan, 2011), and several documents published in International Journals. The purpose of the database analysis is deduce the most common tendencies in UHPFRC dosification and the most important relations between variables. The properties considered for the study were:

- Complete dosage: Type of components and content.

- Compressive strength at different ages, and for steam curing in the case. The values were transformed to cubic prism of $\mathrm{L}=100 \mathrm{~mm}$ my means of transformation factors [220] [161] [85]. The table 2.3 shows the multiplication transforming factors used:

Table 2.3: Tranforming factors to turn the compressive strengh results to prismatic $L=100 \mathrm{~mm}$

\begin{tabular}{|c|c|c|c|c|c|c|c|}
\hline Type of element tested & Cube & Cube & Cube & Cube & Cyl & Cyl & Cyl \\
\hline Element dimensions $(\mathrm{mm})$ & 100 & 50 & 70 & 70 & $75 \times 150$ & $100 \times 200$ & $150 \times 300$ \\
\hline Factor to turn to $100 \mathrm{~mm}$ prism & 1 & 0.962 & 0.935 & 0.935 & 1.02 & 1.02 & 1.063 \\
\hline
\end{tabular}

- Elastic modulus.

- Rheological Parameters: Slump flow and $t_{500}$.

As logic, not all data is available for every dosage, so in the tables and results showed the number of mixtures analyzed for each parameter is detailed. In the table 2.4 can be seen the number of dosages pertaining to the different subfamilies of VHPC-UHPC introduced at 2.3.1. For the classification has been considered as UHPC-UHPFRC those dosages that reached more than $150 \mathrm{MPa}$ in a $100 \mathrm{~mm}$ cubic prism, whether is steam or air cured. 
In the following subchapters, the explanation of the UHPFRC components and properties will be supported or disproved with correlations established with the database dosages. Logically, the spectrum of dosages analyzed endorse the power of these deductions.

Table 2.4: Families of the studied dosages

\begin{tabular}{|cc|c|}
\hline Type & Number & $\%$ \\
\hline UHPC (no fibers) & 22 & $19 \%$ \\
VHPC (no fibers) & 11 & $10 \%$ \\
Monofiber UHPFRC & 48 & $42 \%$ \\
Monofiber VHPFRC & 19 & $17 \%$ \\
Hybrid-UHPFRC & 4 & $4 \%$ \\
Hybrid-VHPFRC & 10 & $9 \%$ \\
\hline TOTAL & 114 & $100 \%$ \\
\hline
\end{tabular}

\begin{tabular}{|c|c|}
\hline Aggregate and curing & $\%$ \\
\hline Coarse aggregates $(>4 \mathrm{~mm}$ ) & $29,8 \%$ \\
Fine aggregates & $70,2 \%$ \\
\hline $20^{\circ}$ Air Curing & $63.4 \%$ \\
Steam Curing (see 2.4 .4$)$ & $36.6 \%$ \\
\hline
\end{tabular}

\subsubsection{ANALYSIS OF THE DATABASE DOSAGES DESIGNS}

\subsubsection{COMPONENTS}

Generally an UHPFRC dosage contains cement, silica fume, quartz flour (see 2.3.3.4), sand, water, PCE admixture and fibers. The fraction of fines $(<125 \mu \mathrm{m})$ versus UHPC solid constituents amounts much more than $50 \%$ over total weight [229]. Binder becomes a great majority of these fines. This implies an enormous increase of the total surface area; which is dominated by silica fume even though it represents a minor mass fraction of the cement.

In the figure 2.5 can be seen the relative frequency distribution of the binder (as normally it is done, the quartz flour is included as binder, see 2.3.3.4) for 112 dosages of the database studied. Normally dosages with contents smaller than $900 \mathrm{~kg} / \mathrm{m}^{3}$ correspond to coarse aggregate UHPC-VHPC. As can be appreciated, binder weight ranges generally between 1100 and $1300 \mathrm{~kg} / \mathrm{m}^{3}$.

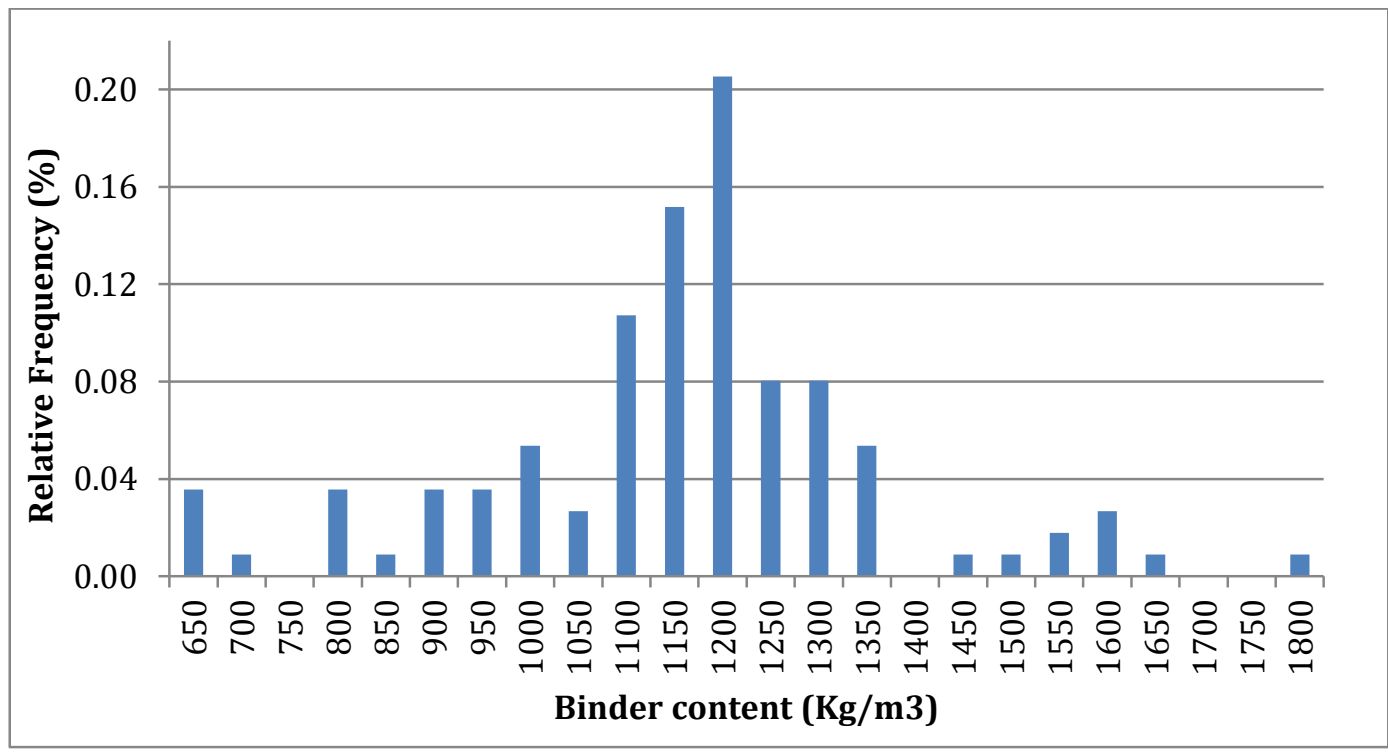

Figure 2.5: Relative Frequency distribution of binder (quartz flour considered) 


\subsubsection{CEMENT}

In UHPC-UHPFRC the cement content used is very high comparing with any other special concrete (between 700 and $1100 \mathrm{~kg} / \mathrm{m}^{3}$ [264]). This implies, with respect to conventional concretes, a noticeable increase of the heat of hydration and autogenous shrinkage. The use of Sulphate Resistant cements can reduce these effects due to the reduced $\mathrm{C}_{3} \mathrm{~A}$ content [108] [208] [264] [96], which causes a better time distribution of the exothermic reaction and leads in smaller autogenous shrinkage [62]. Good rheological and mechanical results have been found with poor $\mathrm{C}_{3} \mathrm{~A}$ cements, as also with the named "oil well cements" [57]. It is proved also that cements with normal $\mathrm{C}_{3} \mathrm{~A}$ content, $\mathrm{SO}_{3}$ and soluble alkali contents affect to the performance of the superplasticizer due to the adsorption inhibition [204].

Figure 2.6 shows the relative frequency diagram of the cement content both for coarse and fine aggregate concretes of the database studied (112 dosages). An average of $200 \mathrm{~kg} / \mathrm{m}^{3}$ less are used for UHPC with coarse aggregates, as logic due to their smaller specific surface.

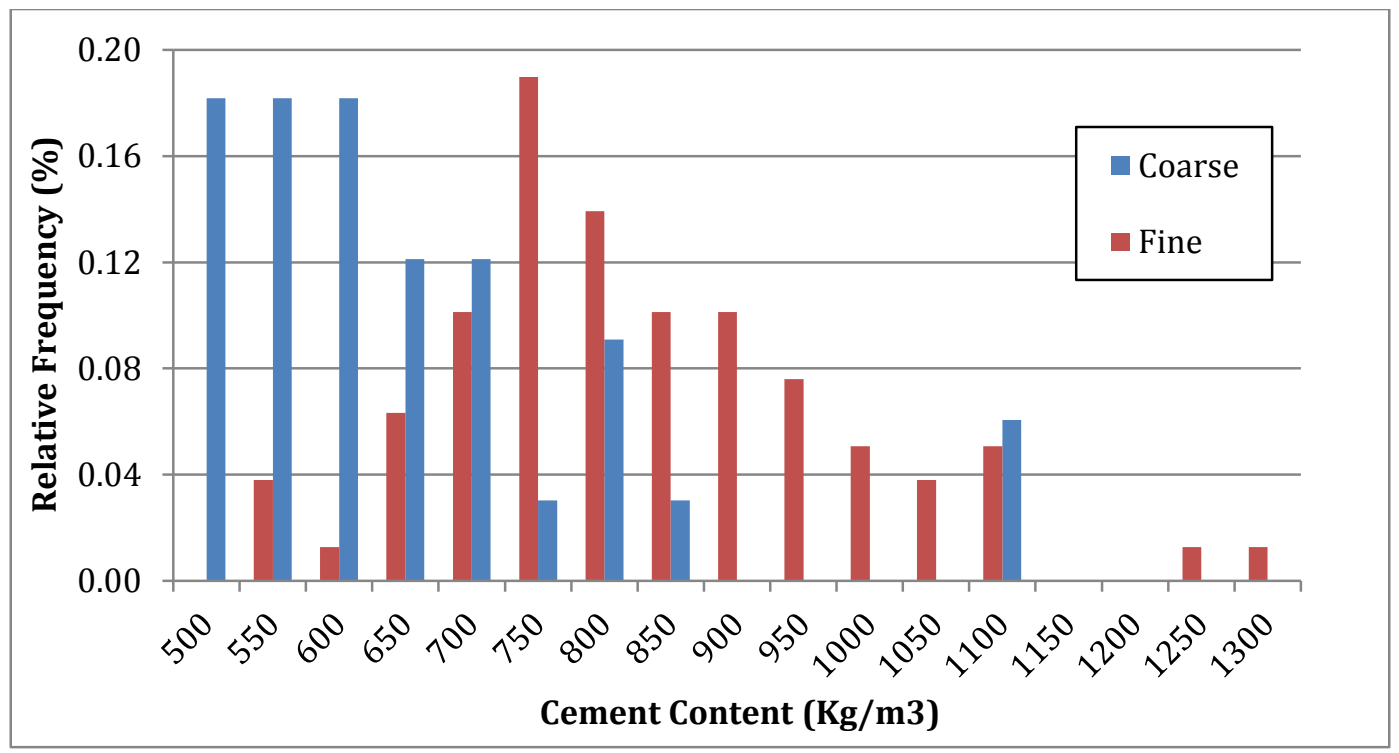

Figure 2.6: Relative Frequency distribution of the cement

It's also common the use of cement type I-42.5 [57] [271] [230] [108], as the specific surface of the particles is smaller than for type I-52.5 cements. The water demand then is more reduced and W/B can be decreased respect to a similar workability mixture with the type I-52.5. This could derive in higher strengths [242] [32] [106].

From the database studied, the percentage of dosages using cement 42.5 and 52.5 is $54 \%$ and $46 \%$ respectively. It was appreciated a slight higher water demand for the dosages with cement 52.5 (average W/B of 0.164 ) than for those with cement 42.5 (average W/B of 0.158 ). Figure 2.7 shows it relating the binder content (including QF) with the total water amount added. Also compressive strength was correlated with the W/B ratio depending on the cement class, but results were very similar for both.

Also, with the data available slump-flow was correlated with the W/B ratio depending on the cement class (figure 2.8), appreciating that higher workability is found with cement 42.5 (average slump flow of $748 \mathrm{~mm}$ ) than for 52.5 (average slump flow of $628 \mathrm{~mm}$ ). 
Besides, Sulphate Resistant (SR) cements are used in 56\% of the dosages, and no Sulphate Resistant cements in 44\%. From the properties of these dosages, the effect of the SR cements utilization over the compressive strength and the slump flow was studied, not finding a significant difference with the no-SR cements. Also the water demand associated to the binder content seemed to be similar for both types of cement. However, as it was said previously, the use of SR cements might be interesting for the better distribution of the hydration heat or the longer setting time.

In any case, the cement type selection depends mainly on the additions and admixtures with it will be combined. The high interaction between these three components [40] [33] recommends previous compatibility tests.

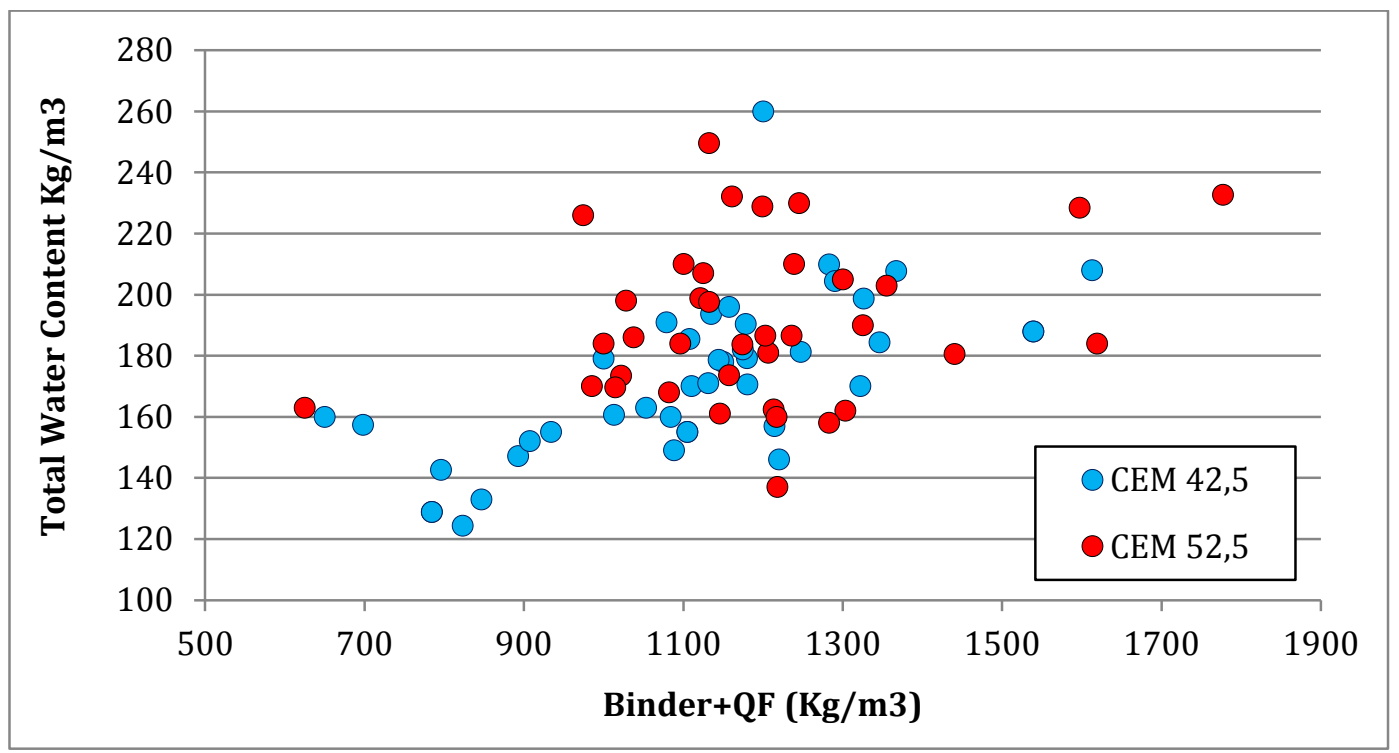

Figure 2.7: Relation between the binder content and the total water content

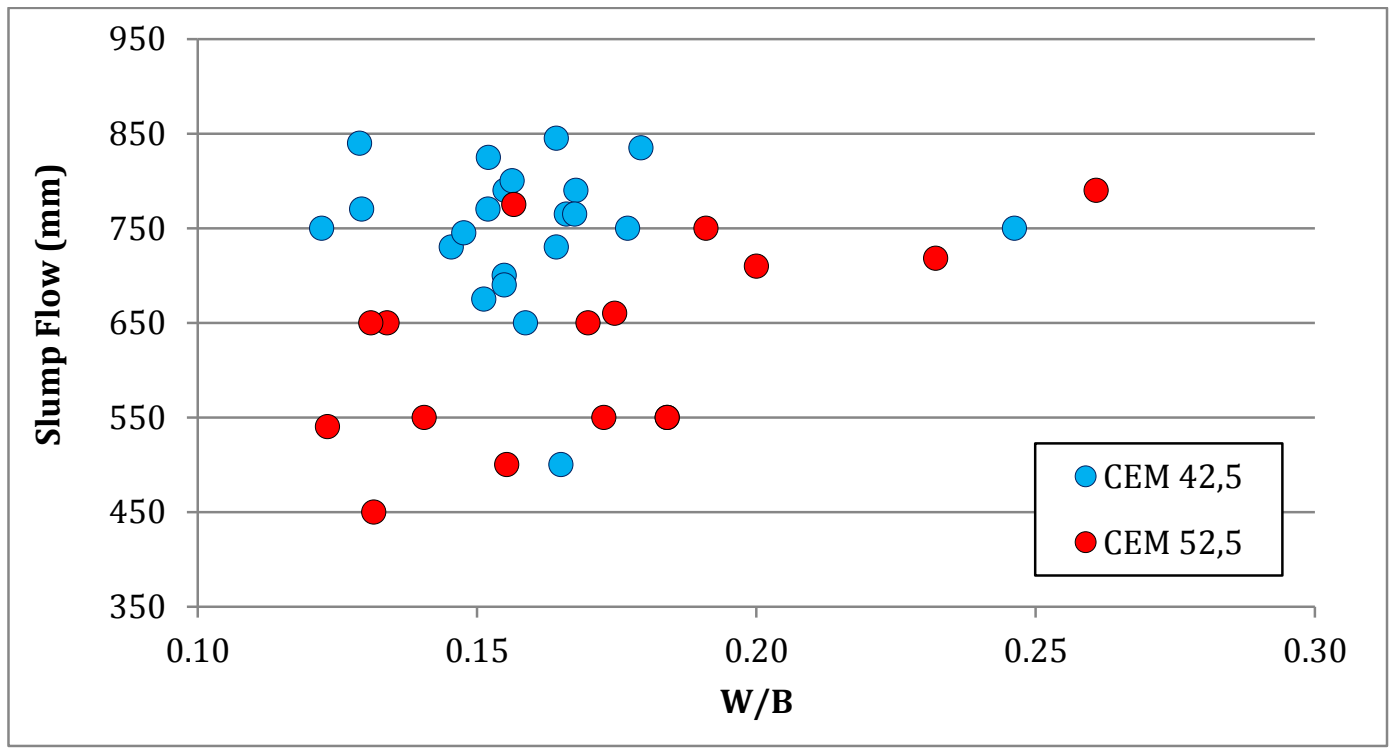

Figure 2.8: Relation between theslump-flow and theW/B ratio

Finally, the cement content in UHPC normally represents between 60 and $80 \%$ of the binder content (including QF). Figure 2.9 shows this ratio for the studied dosages. 


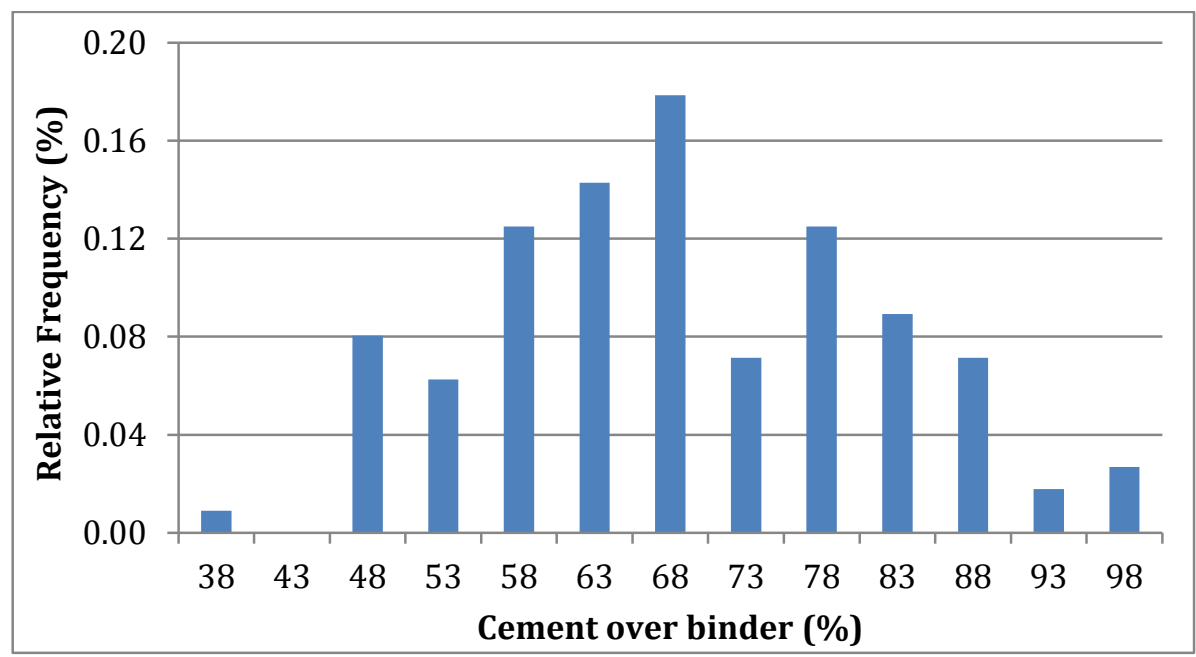

Figure 2.9: Frequency distribution of the ratio Cement/Binder

\subsubsection{ACTIVE ADDITIONS-POZZOLANS}

\subsection{Silica Fume (SF)}

This active addition is a by-product from industrial synthesis of silicon alloys composed of amorphous $\mathrm{SiO}_{2}$. It is considered essential in UHPC-UHPFRC dosages for its positive effect in the hardened state [149] due to its pozzolanic properties. The spherical geometry of the particles, much smaller than the cement ones, is required to reach the highest compacity of the matrix microstructure. The interfacial transition zone (ITZ) between paste and aggregates is also improved [209]. In fresh state the silica fume addition implies a decrease of the workability, a reduction of the stabilization time during the mixing [153] [154] and also higher cohesion/stability due to its high specific surface.

Its optimum content in UHPC-UHPFRC has been found between $20 \%$ and $30 \%$ [206] [173] [234] [198]. In the figure 2.10 can be seen the relative frequency distribution of the silica fume and quartz flour (subsequently introduced) content respect to the cement content of the dosage database studied.

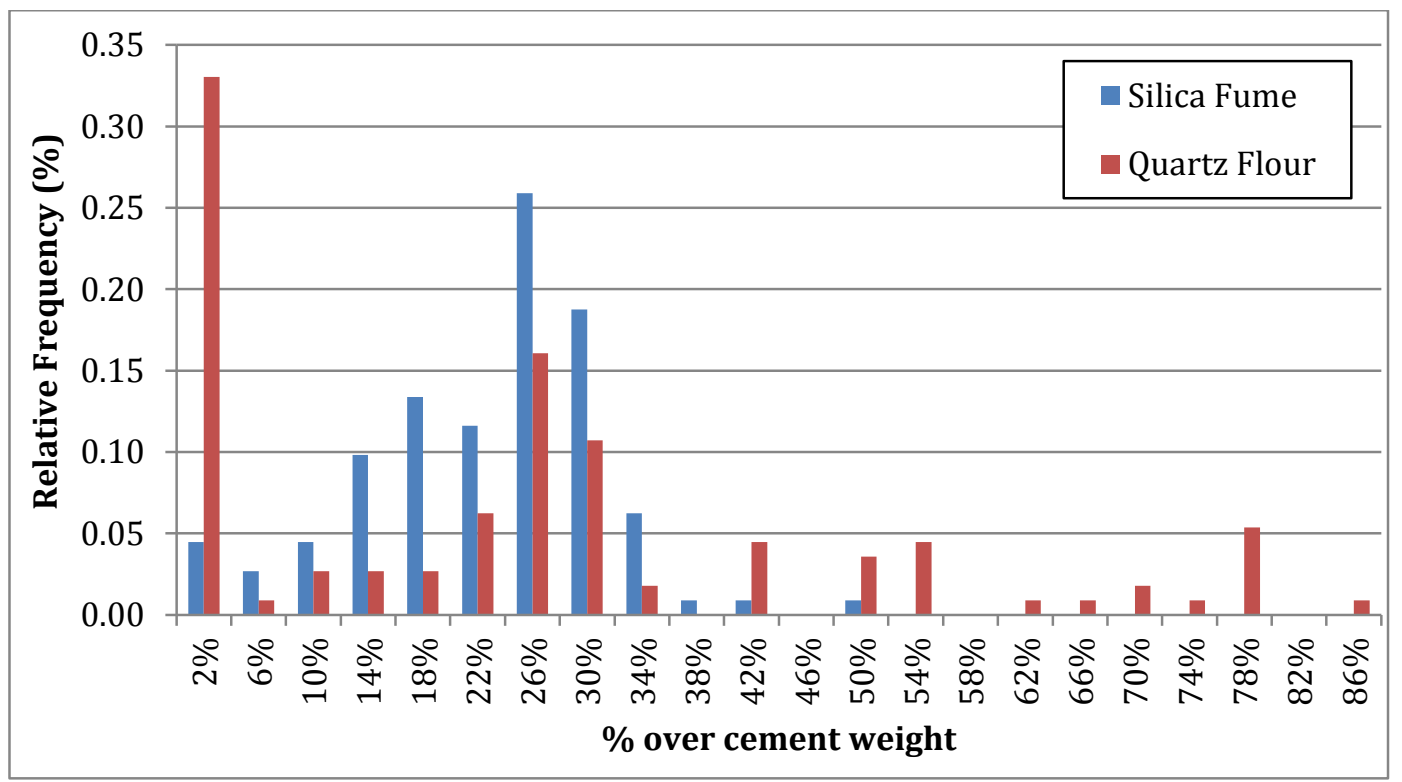

Figure 2.10: Frequency distribution of silica fume and quartz flour ratio over cement weight 
Silica fume can be used in several states: condensed (CSF, named also densified), no condensed (or no densified) and in suspension. The first is the most usual, but its effectiveness depends on the dispersion of the agglomerated silica fume particles, which are better discondensed with an intensive mixing. This implies sometimes better compressive performance when suspension silica fume is used [242]. There are some alternatives to reach an effective dispersion before the mixing, such as the silica fume sonication [197].

Some researchers showed that the effect of the SF over the flexural strength in VHPFRCUHPFRC is not significant ([148] with contents between 4\% and 12\%, Behoul and Sato (1996 and 1999) with contents up to $25 \%$ ). Other researchers deduced that SF improve the interfacial Transition Zone (ITZ) between paste and fibers, so better flexural strength should be obtained [16] [266].

It's important to remark that not every CSF is similar. The main parameters that vary depending on the CSF industrial origin are the colour, the degree of the particles condensation and the content of unburned carbon. This last parameter should be as low as possible due to its high water adsorption capacity [48]. The use in UHPFRC of CSF with a high maximum guaranteed unburned content can decrecrease abruptly the workability and, consequently, reduce the compressive strengths [34] [198].

\subsection{Fly Ash (FA)}

Fly Ash (FA) is a residue from thermoelectric power plants, and its particle morphology is spherical. This provides an enhancement of the workability of the fresh concrete when substitutes cement [95], and also reduces the bleeding risk. The costs are smaller than for the cement and the Activity Index is near to 1 when the W/B ratio is very low, as is the case for UHPC. That's why it is interesting in this case to use it as a second pozzolan, reducing the high cement content.

In some cases its combination of FA with more active additions, as CSF, can develop a very interesting synergy to reach higher mechanical strengths. The key point for FA suitability in a dosage is that its particle size range complements the micro-granulometric curve [57] and also that shows compatibility with the rest of the binder and admixture.

It is a useful pozzolan to cast more economic UHPFRC, being then very suitable to dosages of VHPC-VHPFRC [173] [198]. The main problem to develop the use of FA use in UHPFRC is the difficulty to guarantee a supply with constant properties, what decreases the high level of control required.

The use of FA in UHPC-UHPFRC is not very common (8.1\% of the studied dosages), but when used the cement percentage replaced by the pozzolan is between $10 \%$ and $30 \%$ [193] [40] [225] [198] [110]. It has been shown that fly ash can replace cement in VHPC-UHPC in contents up to $40 \%$ providing similar or even higher long term compressive strengths [271].

\subsubsection{QUARTZ FLOUR}

This crystalline product has same composition than silica sand but smaller diameters, ranging between the cement and the aggregates. As the specific surface is comparable to the cement one [205], sometimes it is considered as binder in the W/B ratio to obtain the required water. Its addition completes the microgranulometrical curve, providing higher compacity to 
the structure, restricting the space available for the growth of the portlandite crystals $(\mathrm{CH})$ [187]. The rheological effect is an increase of the stabilization time, but also better stability of the mixture [153] [154].

It is known that curing the UHPFRC at $20^{\circ}$ the quartz flour is absolutely inert even after long storage times, but it has pozzolanic behavior when the concrete is cured at temperatures over $150^{\circ} \mathrm{C}$ [205] [187]. At figure 2.10 is shown the quartz flour addition respect to the cement content for the database of dosages studied. Almost $70 \%$ of the dosages contain it, being $25 \%$ $30 \%$ the typical addition.

\subsubsection{AGGREGATES}

Generally, the aggregates with higher diameter than $4 \mathrm{~mm}$ are called coarse aggregates, while those with less are named sand. In UHPC-UHPFRC normally two sands are combined to obtain the adequate granulometry. The one with smaller average diameter is called fine sand, while the other is the coarse, not having a specific grain size to define the limit between fine and coarse. When three sands are used, the middle-size one is called medium sand.

Aggregates have main importance in UHPFRC dosages, as the water demand of granular mixes depends strongly on the specific surface and the packing density [137]. Aggregates used in UHPFRC should have very low absorption and high compressive strength, with a maximum diameter generally between 0.5 and $2 \mathrm{~mm}$ [129] [144] [2], because the size of the microcracks that induces the failure is proportional to the aggregate size and also because of the stronger effect of the fibers to the rheology with higher aggregate diameter [148] [150]. Besides, thanks to the high fines content, the compacity theories used to combine adequately the aggregates suggest small maximum diameters.

The packing density of the sands strongly affects to the rheological and hardened state: It's demonstrated that there is a significant correlation between the packing density of the sands and the quantity of plasticizer required to reach a flow mixture [226]. Sand represents the coarser part of the micro-granulometric curve of UHPC, which needs to reach the highest compacity. Many authors reach a great compacity with the combination of two coarse and fine sands, the first in a proportion of 70\% in weight, and the second a 30\% [162] [263] [230] [192] [161].

However, the smaller the aggregates, the larger are the surface to be enveloped with the cementitious paste, leading in a high paste volume required to get a sufficient flowing ability for manufacture [144]. The advantage of coarse aggregates is their low specific surface, which leads in a reduction of the paste volume fraction (PVF) required. This implies a reduction in the cement content, reducing the costs and the autogenous shrinkage. However, the effect over the mechanical strength, fiber orientation and rheology of the mixture will be affected, so its addition has to be studied properly.

Figure 2.11 shows, for the dosage database studied, the decrease of PVF when the maximum diameter increases. For fine aggregate UHPC the PVF ranges between $60 \%$ and $70 \%$. 


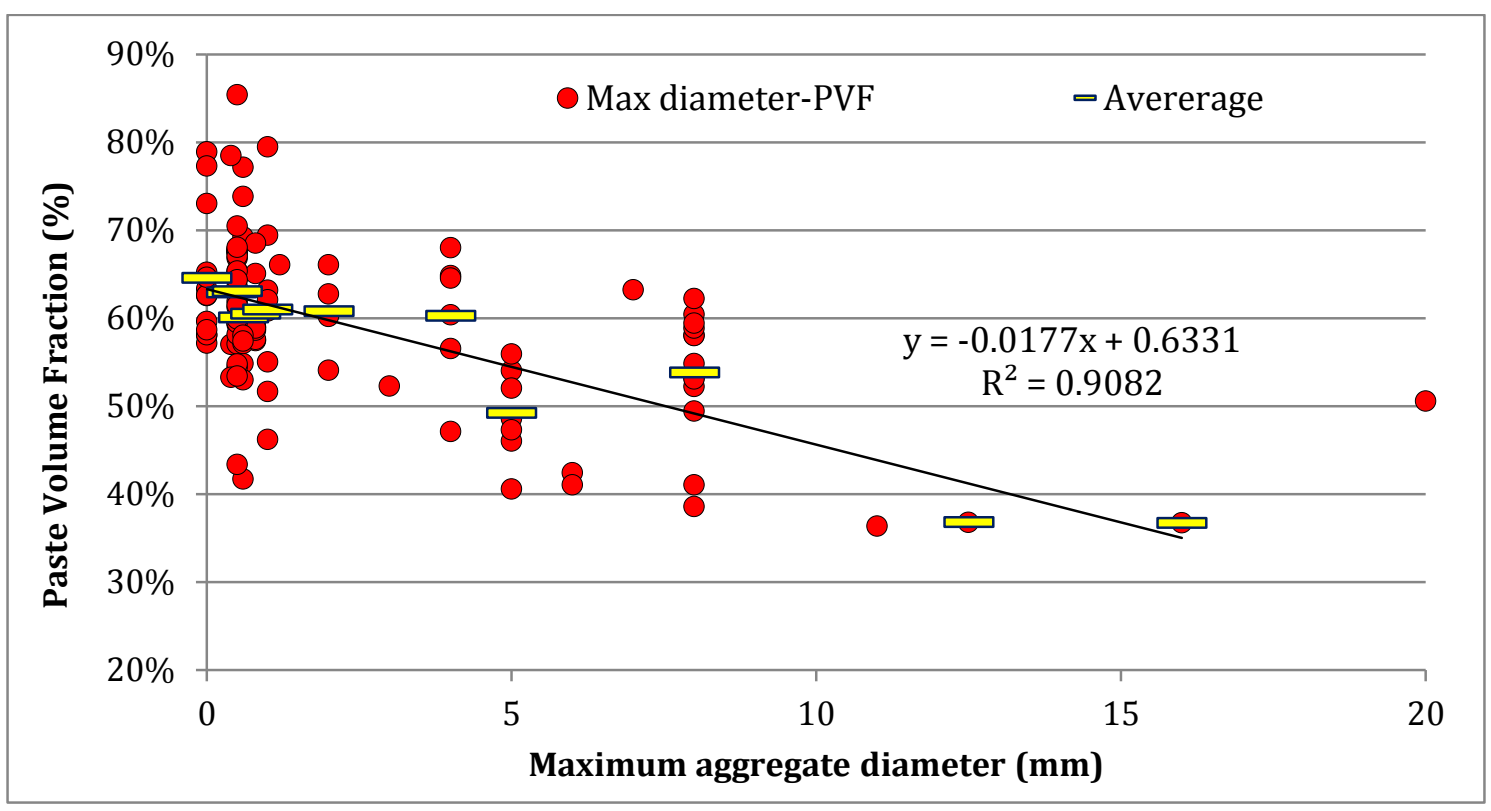

Figure 2.11: Relation between maximum diameter used and the Paste Volume Fraction (PVF)

Some researchers have cast UHPC-UHPFRC using high strength coarse aggregates with maximum diameters up to $8 \mathrm{~mm}$. Schmidt and Mazanec [215] [154] used basalt aggregates, Scheydt [208] used quartz aggregates and Orgass [144] [169] used basalt splits of maximum size $5 \mathrm{~mm}$. Skazlić used crushed diabase with maximum diameters between 1 and $11 \mathrm{~mm}$ to cast VHPFRC [220]. With limestone aggregate, plentiful in an extended region of the Iberian Peninsula, the experience casting UHPC-UHPFRC is almost inexistent.

If the aggregates of the database dosages are studied (figure 2.12), it is seen that for those with maximum diameter smaller than $2 \mathrm{~mm}$, the aggregate used is quartz sand and the typical diameter is $0,5 \mathrm{~mm}$. For concretes with coarse aggregates, the most used is crushed basalt ( $65 \%$ of the cases), and also diabase (17\%). Both rocks have compressive strengths higher than $160 \mathrm{MPa}$. Granite is also used.

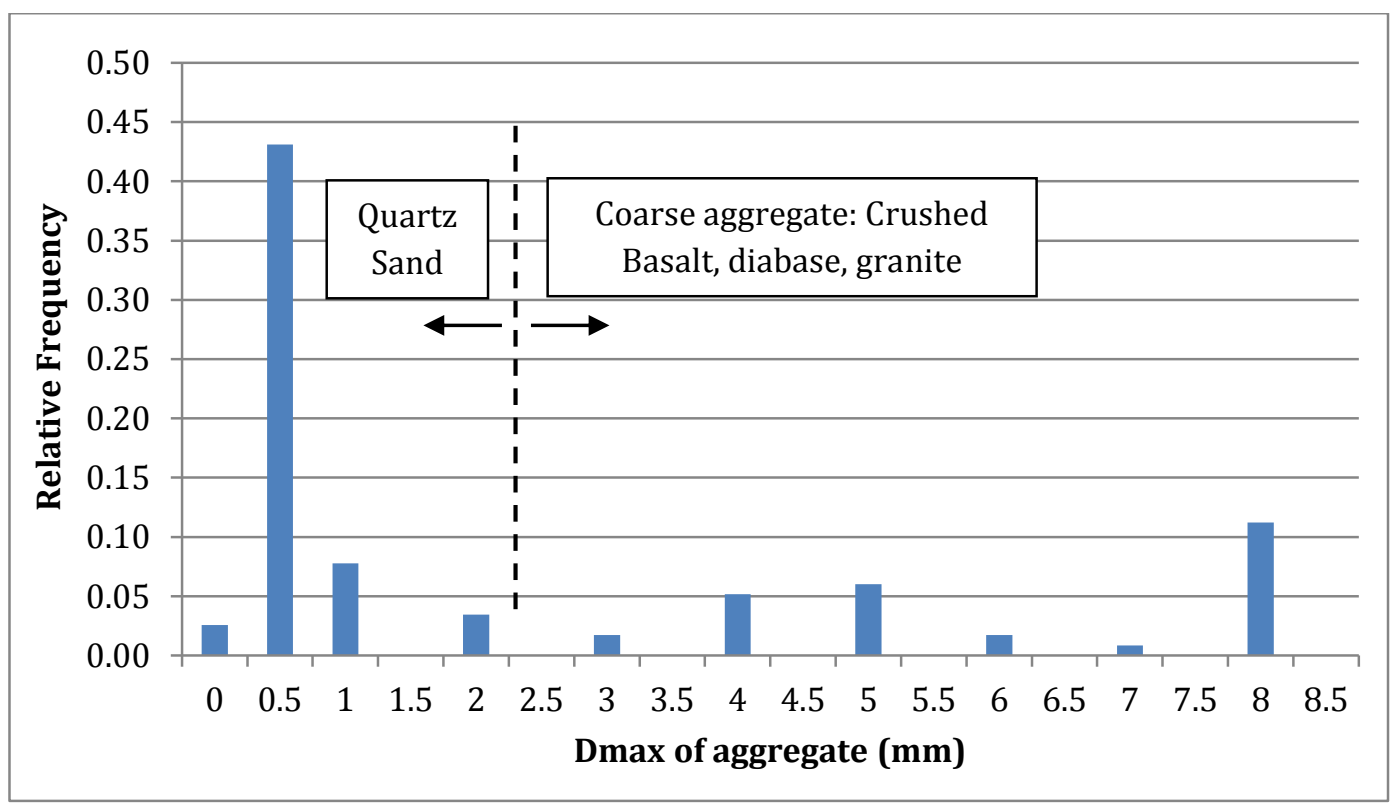

Figure 2.12: Relative frequency of the maximum aggregate diameter 


\subsubsection{SUPERPLASTICIZER}

The admixtures used for casting UHPC-UHPFRC pertain to the so-called $3^{\circ}$ generation, being able to reduce the water content up to a $40 \%$. They are called also polycarboxylate based plasticizers (PCE). Modifying the molecule of the synthetic policarboxilate the main rheological variables can be controlled: Mixing time, setting time and workability. Besides, admixtures which provide a high early strength, interesting to the precast companies, can penalize the strength evolution at medium-long term. All this should be considered when admixture is chosen for an application.

Before use an admixture to cast UHPC-UHPFRC previous tests should be performed. These would show its degree of compatibility with the binder, affecting both to the rheology and mechanical strength evolution [77] [242] [109] [40]. It's also important to find out what is the saturation content, also named critical dosage [242] [208] (the percentage of admixture beyond which there is no significant increase of fluidity), and the mixture dormant period, the time between the end mixing and the hardening of the concrete. Depending on the PCE and cement properties it can be less than $6 \mathrm{~h}$ or even up to $24 \mathrm{~h}$ [97] [96]. It also has to be taken in account that PCE can have different base and depending on the binder components one or other should be chosen. Methacrylate based PCE adsorbs preferentially on cement particles and allyl ether PCE on silica fume [210].

During the UHPFRC mixing, the addition time of the PCE has influence over the rheological properties. A stepwise addition increases the fluidity of the mixture compared with add all at once before; and the higher the cement activity, the more effective is this delayed addition [247]. This phenomenon is related with the formation of the first germs of primary ettringite throughout the mixing. Also the mixing energy and mixer type affect to the time required for a full dispersion of the product.

From the database of dosages studied, $85 \%$ contained a liquid superplasticizer and $15 \%$ dry one. The frequency distribution of figure 2.13 shows that liquid PCE contents over binder weight range normally between 2 and 3.5\%. The average solid content in the liquid PCE is of $31.1 \%$, with a standard deviation of $7.66 \%$.

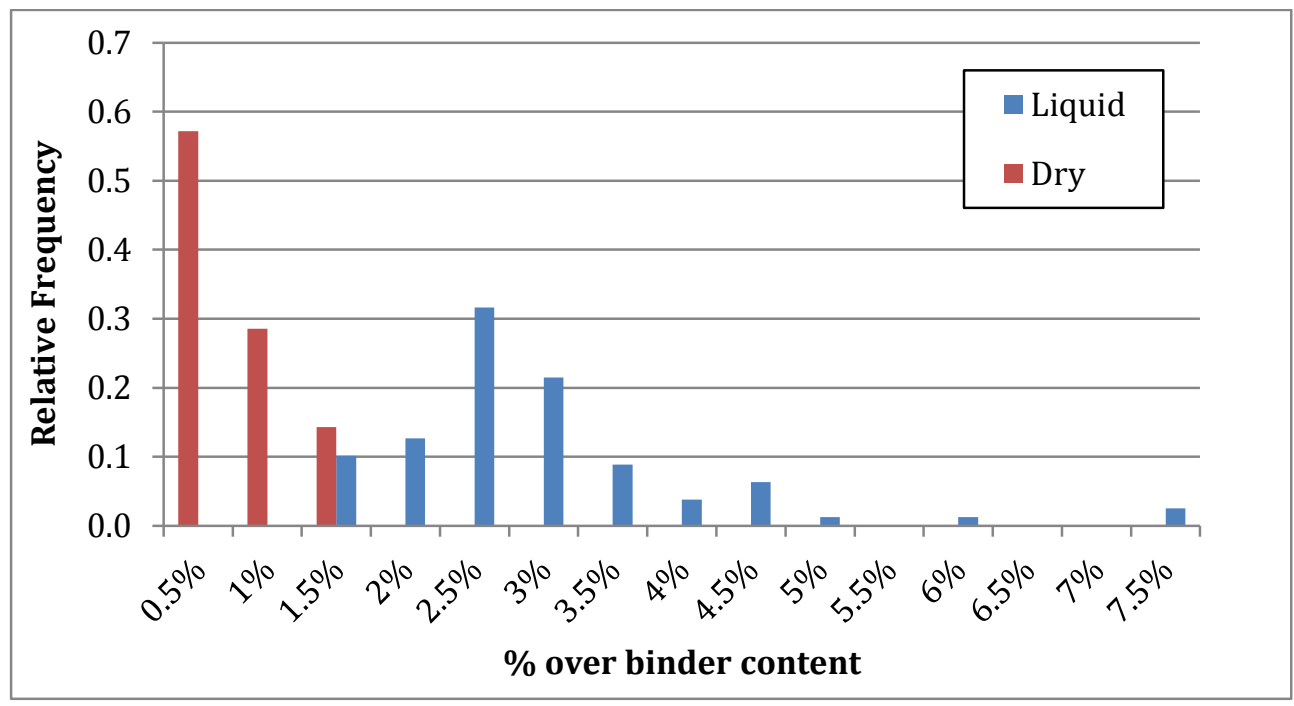

Figure 2.13: Relative frequency of the PCE content over binder weight 


\subsubsection{WATER}

The basic principle to obtain very high compressive strengths is that water not used for the cement hydration has to be as less as possible. Then the capillary porosity (also named active porosity [265]) and their connection will be minimal, increasing strength and durability.

However, it is proved that high workability reduces the content of entrained/entrapped air (also named non-active porosity) [206] [265] and then increases the compressive strength, so the water reduction is limited to obtain a fluidity that allows the air rising. Then, as UHPFRC is selfcompacting, a compromise solution has to be chosen for the water content in order to keep low both the content of capillary and entrapped air. There is another reason to avoid a very fluid composite: The possible steel fibers sedimentation, which density is three times the density of fresh concrete [206]. This happens especially for the case of long fibers, which ratio weight/specific surface is higher than for the shorts.

On the other hand, there is another motivation for not to reduce too much the water content: Not every cement particle is able to contact with water molecules to hydrate. That's the reason why in concretes with W/B lower than 0.42 the percentage of hydrated cement over the total content is less than $100 \%$ [129] [97]. The non-hydrated cement acts as filler, as the quartz flour does when used. This has to be considered in order not to reduce too much the W/B ratio.

The water content that provides the desirable workability in UHPFRC normally corresponds to a W/B ratio ranging between 0.18 and 0.25 [29] [215] [52], depending on the admixture, granulometry and mixing process. Water dosage increases with the binder content, as fine particles have high specific surface. Figure 2.14 shows the correlation between total water content and the binder content (including QF) of the dosages studied from the database. On subchapter 2.5.2 the effect of the $\mathrm{W} / \mathrm{B}$ ratio is studied.

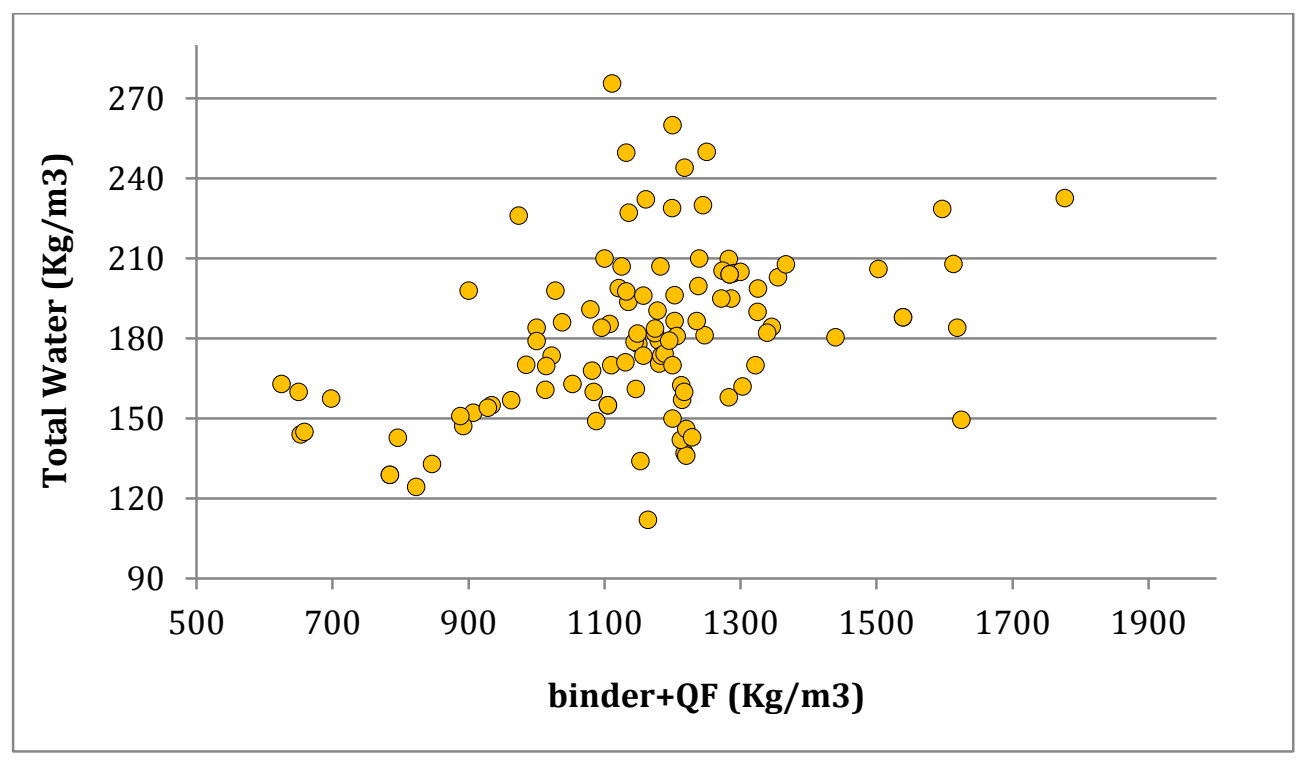

Figure 2.14: Relation between binder (including quartz flour) and total water content

\subsubsection{FIBERS}

Fibers are necessary in UHPFRC to increase the ductility and the post-peak behavior, avoiding brittle failures and also reducing the autogenous shrinkage between 10-15\% [61] [62]. They represent a very substantial part of the total price of the UHPFRC cubic meter. In 
applications with contents between 1.5 and $2.5 \%$ they can represent over $60-80 \%$ of the material costs [261] [141] [123] [120].

Not only price limits the fiber addition. If certain content is exceeded, rheology is affected by the fiber agglomeration. This effect depends on the aspect ratio (length of the fiber divided by its diameter) and the volume fraction, being defined as the fiber volume factor [161]:

$$
\chi_{f}=V_{f} \cdot \frac{l_{f}}{d_{f}}
$$

The spread decreases with an increasing fiber factor, although small values seem to have insignificant influence. Considering the typical fibers used in UHPFRC, authors establish the fiber volume factor to avoid forming clusters in the range of 2-2.5 [148] [161] [263] (value of 2.5 has been chosen for the figure 2.15). The maximum diameter of aggregate in the mixture is also another factor which affects to the fiber orientation, as was studied by several authors (Kelly, 1974; Mc Kee, 1969; Romualdi, 1964; Kobayashi, 1976; Krenchel, 1976 [148]; Serna, 1984).

In the figure 2.15 is shown the fiber volume factor related to the maximum diameter of the mixtures from the database studied. The limit established by some authors for forming clusters is marked with a blue line, and the maximum fiber content that could reach a perfect spacing between the maximum size aggregates is expressed in green with the Krenchel formula (1976). According with this theories, only dosages behind both lines could have a great workability and space orientation.

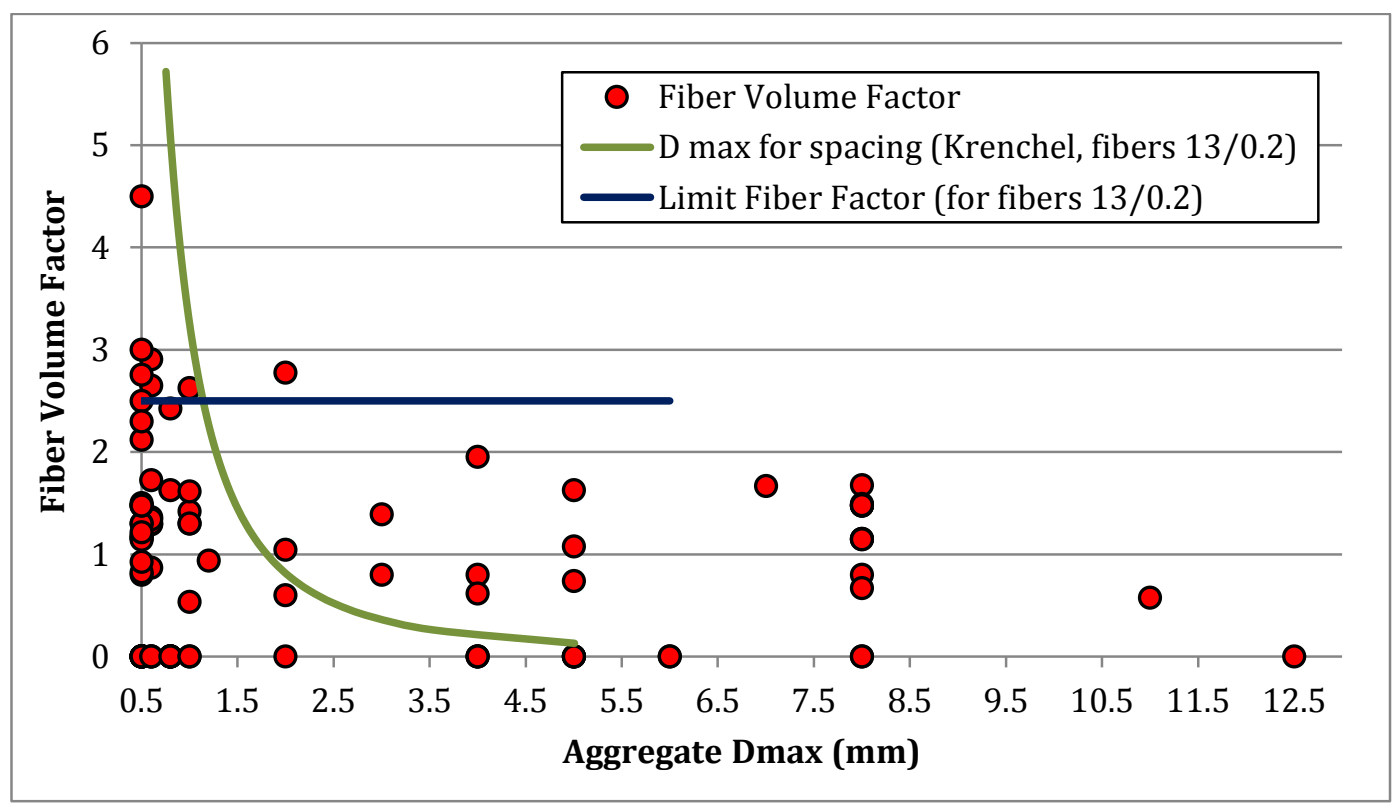

Figure 2.15: Fiber Volume Factor related with the aggregate maximum diameter

In the case of the coarse aggregate UHPC, the aggregate content has to be reduced when fibers are added, according with the interaction already explained. Figure 2.16 shows this effect for the database dosages studied. 


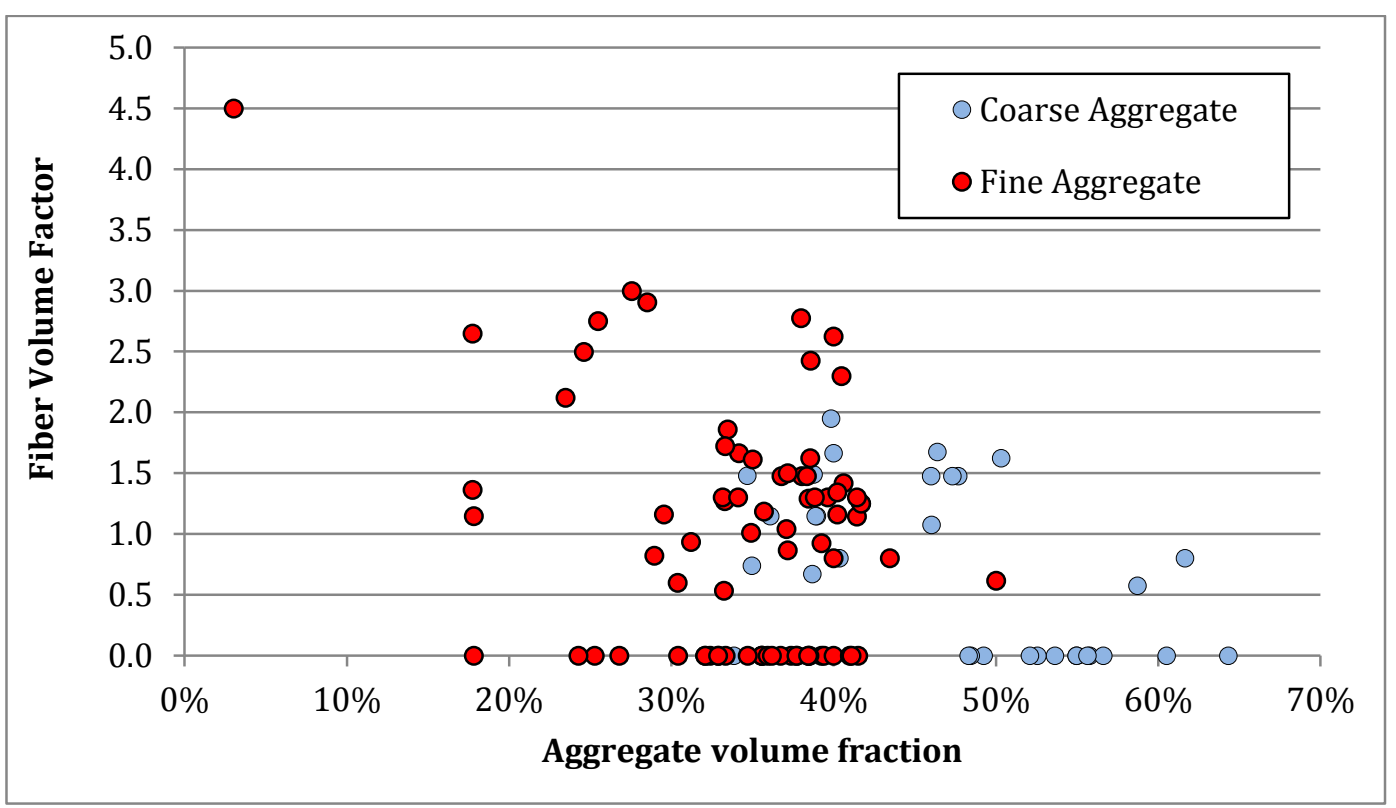

Figure 2.16: Relation between the aggregate volume fraction and the fiber volume factor

On this field, Martinie, Rossi and Roussel [150] proposed a maximum amount of fibers for UHPFRC mortars, according with the formula:

$$
\left(\emptyset_{f}\right)_{\max }=\frac{400}{r} \cdot\left(1-\frac{\emptyset_{S}}{\emptyset_{m}}\right)
$$

Where $r$ is the aspect ratio $\frac{l_{f}}{d_{f}}, \emptyset_{S}$ is the sand volume fraction of the dosage (percentaje of sand in the total volume) and $\emptyset_{m}$ the dense packing fraction of the sand (the fraction of volume that is occupied by the sand when it is randomly placed. It is between 0.5 and 0.7 depending on the sand, and 0.64 for one size spheres. One minus this value is the void fraction).

The most common fibers used in UHPFRC are high tensile strength fibers ( $>2000 \mathrm{MPa}$ ), in a content of $2 \%$ or higher [206]. Normally they are straight, short $(6-20 \mathrm{~mm})$ and with an aspect ratio $\left(\mathrm{l}_{\mathrm{f}} / \mathrm{d}_{\mathrm{f}}\right)$ between 50 and 100 . Their objective is to sew the first microcracks that appear in the concrete, increasing the so-called pseudo-elastic phase.

A second high tensile strength steel fiber type, longer and with anchor, is used generally for the case of hybrid VHPFRC-UHPFRC [148] [37] [262], where the second fiber is the short described before. The flexural performance that they provide is in many cases higher than when only short straight steel fibers are used in similar content. Their purpose is to sew the macrocracks that open and grow during the microcracks evolution. In the hybrid concretes can be noticed the synergistic effect obtained combining both fiber types. This is due to their different type of interaction with the matrix and because the pull-out energy of a single fiber increases when the concrete is fiber reinforced. Also the short fiber orientation is favored in presence of long fibers [148], which provokes higher wall effect and reduces the short fiber random orientation.

According with their micro and macro sewing capacity, short straight fibers normally provide higher flexural strength associated to reduced strains, and medium-long fibers with anchor provide higher ductility. But the election of the fiber type or types used is not only done in base of the flexural performance criteria. In many cases the element cast has reduced 
thickness and difficult pouring, in which case it is convenient avoid the use of medium-long fibers, which would slow down or even block the movement of the fluid mass. On the other side, the wall effect, proportional to the fiber length, may derive in the use of longer fibers in order to reach better alignment.

\subsubsection{HOW TO DESIGN A UHPFRC DOSAGE?}

\subsubsection{WATER AND PCE DOSAGE}

It is well known that the ruling parameter for hardened concrete properties is $\mathrm{W} / \mathrm{B}$ ratio [137], controlling also, together with the admixture, the rheological UHPFRC parameters. It is complicated reach a good flow-ability, with great ability to release the entrapped air, both together with sufficient stability [243] to avoid segregation, and also very reduced W/B ratio to obtain ultra high performance properties. A low water and admixture content will also deal in longer mixing times, implying a waste of time and energy. Also a reduction in excess of water content can decrease the compressive strength due to the lower hydration of the binder [129] [97]. Table 2.5 shows the consequences of add different content of water and PCE admixture.

Table 2.5: Advantages and inconveniences of high and low W/B-PCE addition

\begin{tabular}{|c|c|}
\hline Low W/B - low PCE & High W/B - high PCE \\
\hline Advantages & Advantages \\
\hline $\begin{array}{c}\text { Less capillary pores } \\
\text { No segregation } \\
\text { Smaller costs of the PCE }\end{array}$ & $\begin{array}{c}\text { High workability and small t500 } \\
\text { Less entrapped air } \\
\text { Shorter mixing times } \\
\text { Higher binder hydration }\end{array}$ \\
\hline Inconveniences & Inconveniences \\
\hline $\begin{array}{c}\text { Smaller workability, higher t500 } \\
\text { Longer mixing times and higher wear } \\
\text { Higher entrapped air } \\
\text { Less binder hydration }\end{array}$ & More capillary pores \\
\hline
\end{tabular}

Find a compromise solution for the W/B ratio and PCE content considering the aspects previously explained will simplify the attainment of an optimum UHPFRC both in fresh and hardened state. A mortar flow of free fiber UHPC of $26-28 \mathrm{~cm}$ in the mini-slump test [203] has been proved to provide optimal workability, air removal and stability [206].

Also a primary aspect is the materials compatibility. PCE has to be compatible with the cement and the active addition. Even high quality components cannot from time to time effectively work together. Experimental tests are required to find out the suitability of these three elements acting together [242].

\subsubsection{CEMENT AND SILICA FUME}

It has been proven that a high PVF is necessary to reach de required flowability, and in UHPFRC this means that the fines content should be very high. Cement, silica fume and quartz flour are the most common fine components, where the first is the cheapest, but also implies greater environmental problems (the total $\mathrm{CO} 2$ emission per ton of cement is about 1 tone [146]) and a higher heat hydration reaction. Besides, with very high cement contents an 
increase of the cement quantity does not imply necessarily a strength increase due to the worse compacity.

Therefore, silica fume is added in a percentage over cement content that ranges between $10 \%$ and $30 \%$ (much higher than in ordinary concretes because the portlandite consumption is not a problem). The maximum quantity is limited normally because of its price or decrease of the workability. Quartz flour content over cement weight also ranges between 0 and $30 \%$. The particle size distribution and composition of the available quartz flour might strongly recommend a large addition or obviate it for the dosage.

Consider the paste fines in the granulometric curve analysis is a useful tool to deduce the most adequate component combination. However, the theoretical deductions should be empirically supported, so perform few dosages with different paste proportions is the way to find out the optimum combination.

\subsubsection{PARTICLE PACKING THEORIES}

In 1890, Feret exposed a law that meant that the higher the compacity, the greater the strength. That's why, both with the ITZ optimization and the binder optimization, the physical packing optimization is one of the three fundamental mechanisms to obtain the UHPFRC properties [57]. The packing of cement, filler and aggregates is of great importance, and different models for the granular skeleton optimization have been developed to improve the mixture composition. Particle packing models can be discrete (Binary, Ternary, Multi-modal (De Larrard, Compressive Packing Model)) or continuous (Fuller-Thomson, Andreasen, etc.) [121]. They can also be classified as experimental or numerical [129].

Many theoretical curves have been proposed by researchers for the concrete aggregates granulometric curve: Fuller, Bolomey, Faury, etc. The most used in ordinary concretes are Fuller and Bolomey, which produces a "half $S$ " shape semi-logarithmic grading line.

Fuller proposes a curve for the aggregates, where cement is not included as a fine (see the equation at table 2.5). Figure 2.17 shows the curve for $d_{\max }$ of $2 \mathrm{~mm}$. The formula proposes a sizes range from 250 micrometers to the maximum aggregate diameter. For UHPFRC Fuller formula is not useful, as it is only adequate when the majority of aggregates are bigger than 500 micrometers. If it is used for UHPFRC, the cement content resultant is extremely low.

The Fuller formula used for traditional concretes only considers the sand and coarse aggregate optimization. However, the small size particle distribution becomes essential for UHPFRC and SCC, being the key point to obtain workability with a reduced water content. Then, all the grain size spectrum should be considered in the packing model; which has to achieve that randomly distributed particles, from the smallest to the biggest, provide the highest compacity possible to the matrix.

Bolomey proposes a theoretical curve for macroparticles considering the cement (see table 2.5). Its quantity depends on the desired consistency and the aggregate type. It is a proportional rescale from the Fuller curve to consider the cement. It is not suitable for UHPFRC as it does not provide information of the fines granulometric curve.

In the 30's, Andreasen and Andersen (A\&A) reported a semi-empirical study of the packing of continuous particle size distributions (PSD), a fractal based model [258]. They determined 
the size distribution that provided the highest packing density. Afterwards, Funk and Dinger modified the model to consider the size of the smallest particles, which was assumed zero before. This model is known as the A\& $\mathrm{A}_{\text {modified, }}$ and now is frequently use it as a criteria for determine the UHPFRC granulometry [257] [95] [74] [57]. Both models showed how the higher the packing density of the components, the higher the free water acting as lubricant, providing then greater workability. This implies that PCE and/or water content can be reduced, reaching higher strength. Also contact surface increase so chemical reactions are better transmitted.

Aggregates and binder should be combined properly to generate similar curve to the grading line proposed. A\&A equation suggested a relation between the particle sizes based in the maximum ones, according to the formula shown at table 2.5 [24] [25]:

\begin{tabular}{|c|c|c|c|}
\hline Fuller & Bolomey & A\&A & A\&Amodified \\
\hline$\frac{C P F T}{100 \%}=\sqrt{\frac{D}{D_{\max }}}$ & $\frac{C P F T}{100 \%}=a+(100-a) \sqrt{\frac{D}{D_{\max }}}$ & $\frac{C P F T}{100 \%}=\frac{D^{q}}{D_{\text {Max }}^{q}}$ & $\frac{C P F T}{100 \%}=\frac{D^{q}-D_{\text {Min }}^{q}}{D_{\text {Max }}^{q}-D_{\text {Min }}^{q}}$ \\
\hline \multicolumn{2}{|c|}{ CPFT: Cumulative Percent Finer Than (\%) } \\
\hline
\end{tabular}

Table 2.5: Different theoretical proposes for the granulometric curve

The q value, referred frequently as the Fuller Exponent [226], differs between 0 and 1 . A\&A obtained for their slurries that highest packing happened for $\mathrm{q} \approx 0.37$, and this value has been validated afterwards by computer simulation for spherical particles. Fullers grading line is obtained when $\mathrm{q}=0.5$. Generally, the higher the fines content $(<250 \mu \mathrm{m})$, the lower the q which maximizes the compacity. The $\mathrm{q}$ values used in literature change between 0.25 [95] (recommended by ELKEM ${ }^{\circledast}$ ) and 0.5. The higher the required concrete performance, the smaller the q value recommended, as it implies higher cement content.

Figures 2.17 and 2.18 show the granulometric theoretical curves for Fuller, Bolomey and A\&A. First one is for $D_{\max }=2 \mathrm{~mm}$, and the second is for $D_{\max }=16 \mathrm{~mm}$. Bolomey equation seems to fit very much with the A\&A curve with $q=0.37$, being then an acceptable packing theory for VHPFRC. However, it is recommended that all the grading curve is optimized, and Bolomey method does not consider the smaller sizes.

When $D_{\max }=16 \mathrm{~mm}$ is used, cement content is much more reduced than for $D_{\max }=$ $2 \mathrm{~mm}$, therefore Bolomey might be more accurate as there is less quantity of material not considered for the granular skeleton.

The $A \& A_{\text {modified }}$ formula differs slightly from the $A \& A$, considering the smallest particle size. Formula is shown at table 2.5. Generally silica fume contains the smallest particles of an UHPFRC dosage. In many of these cases $\mathrm{D}_{\min }$ can be assumed $\approx 0.1$ micrometers.

In the figures 2.19 and 2.20 are represented grading lines obtained both with the A\&A and A\&A $A_{\text {modified }}$ formulation with different $q$ values. The maximum and minimum particle diameter used are $2 \mathrm{~mm}$ and $1 \mu \mathrm{m}$ respectively. Figure 2.19 is a semi-logarithmic graph and figure 2.20 a double-logarithmic graph. 


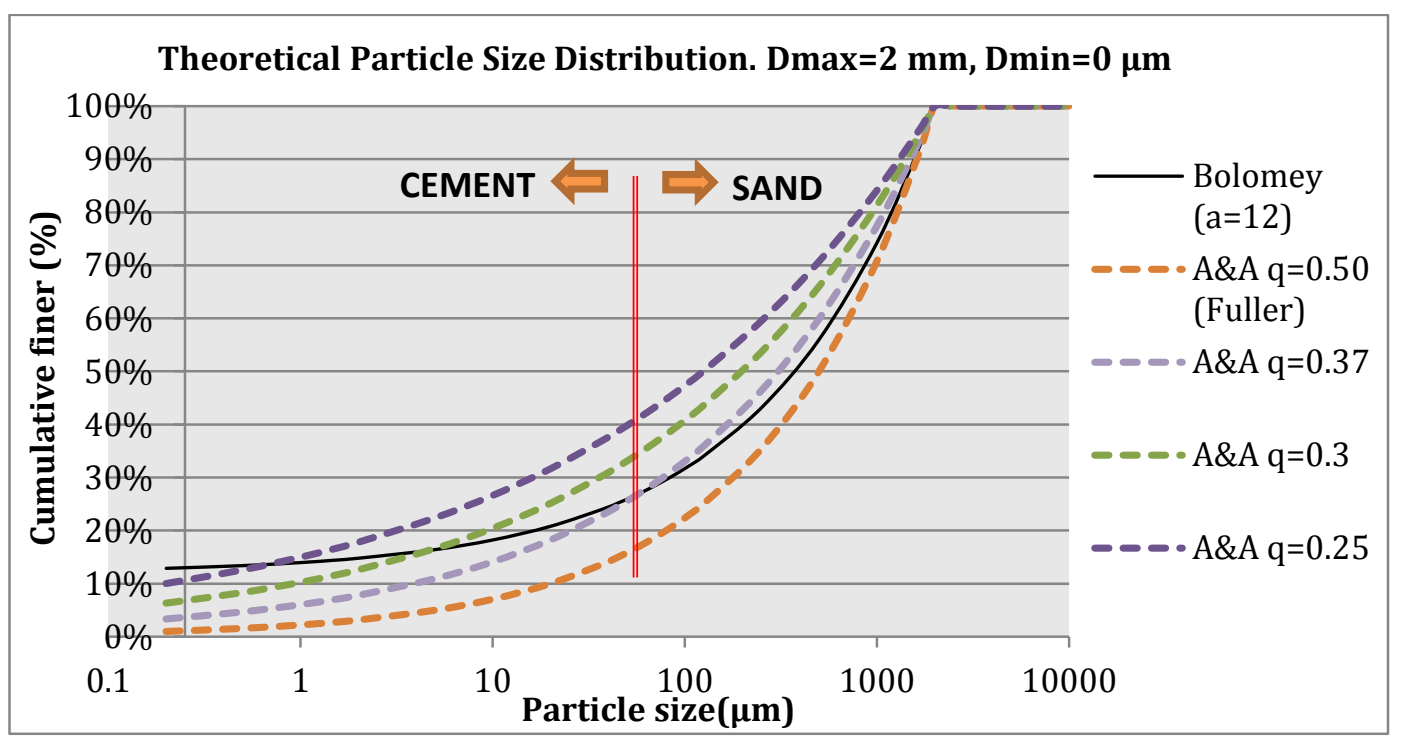

Figure 2.17: Theoretical particle size distribution for Fuller, Bolomey and A\&A method, for D=2 mm

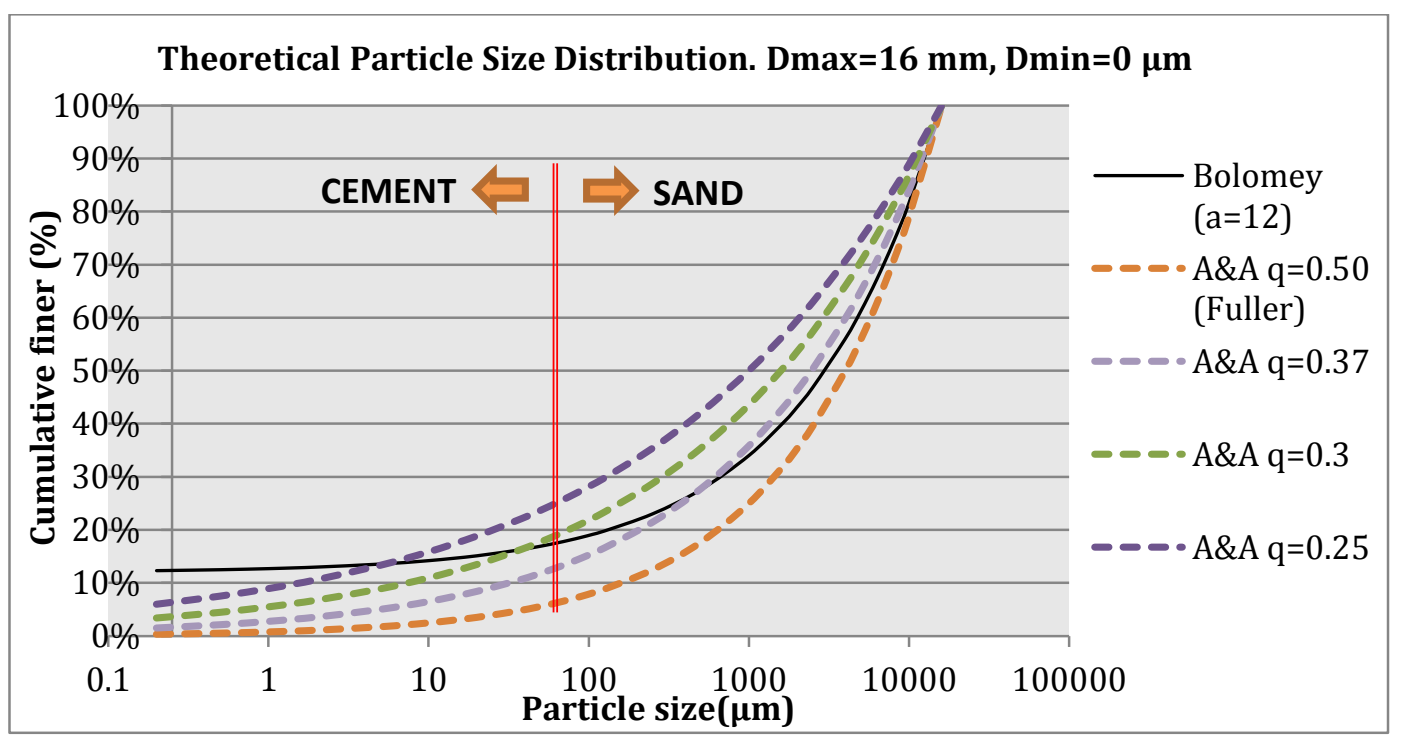

Figure 2.18: Theoretical particle size distribution for Fuller, Bolomey and A\&A method, D=16 mm

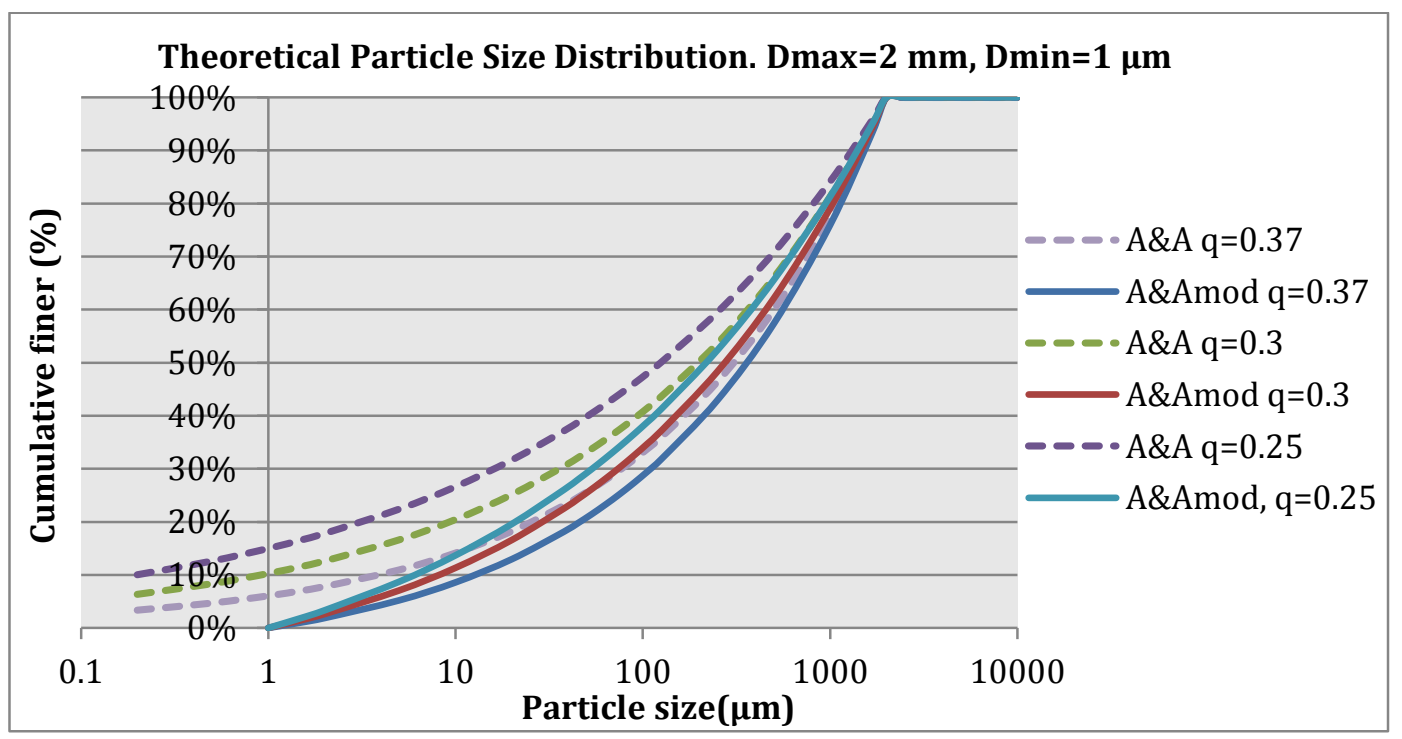

Figure 2.19: Theoretical Particle Size Distribution for the A\&A and the A\&Amodified models. Semilogarithmic plot with Dmax=2 $\mathrm{mm}, \mathrm{Dmin}=1 \mu \mathrm{m}$ 


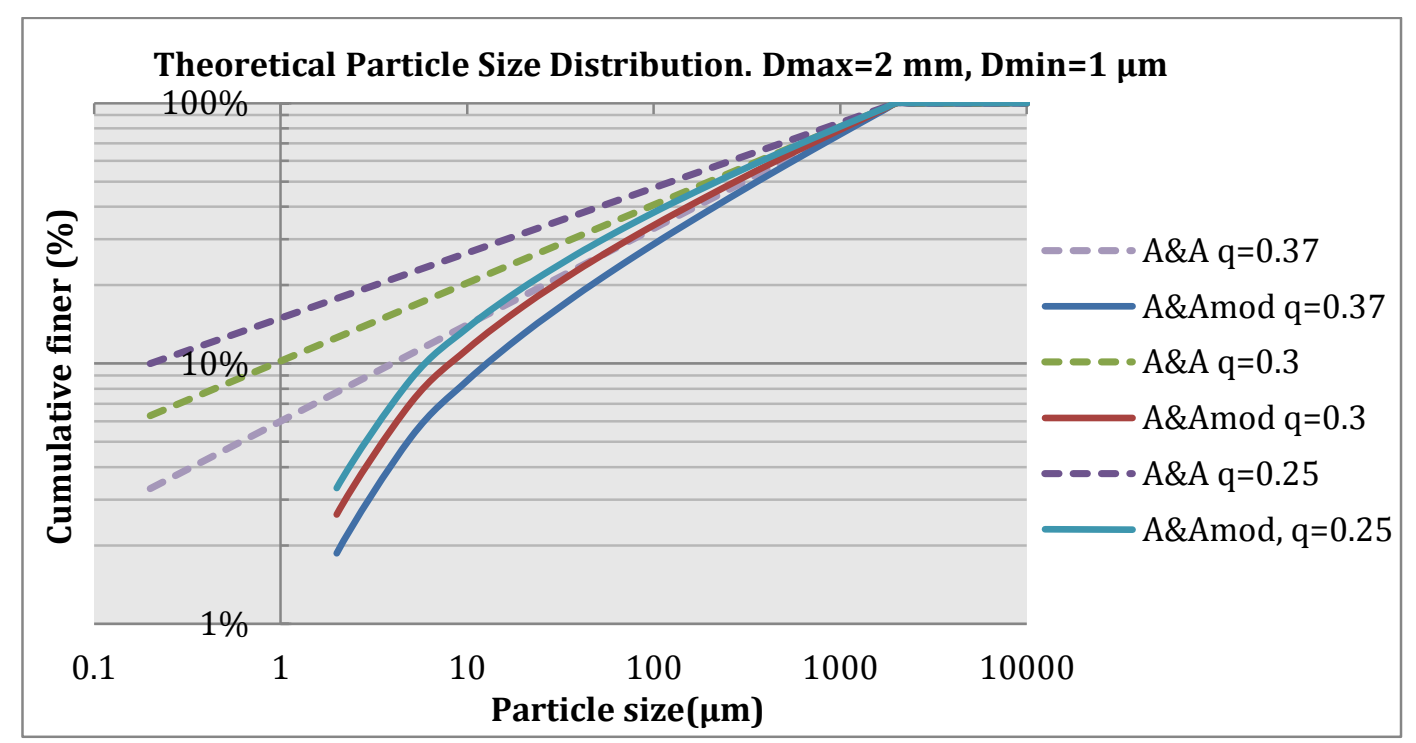

Figure 2.20: Theoretical Particle Size Distribution for the A\&A and the A\&Amodified models. Doublelogarithmic plot with Dmax=2 $\mathrm{mm}, \mathrm{Dmin}=1 \mu \mathrm{m}$

It can be noticed how the A\&A curves in double logarithmic plot become straight, and for the $A \& A_{\text {modified }}$ become a vertical asymptote tending to the minimum particle size. Both models provide much higher fine content than Fuller curve. It has to be remarked that for reduced minimum particle size the grading lines of both equations are very similar, so in the case that silica fume is used and properly dispersed, assume that $\mathrm{D}_{\min }=0$ is an acceptable simplification.

Experimental processes can be also useful to obtain the best aggregates combination. Considering two different sands, Naaman [161] propose a simple way combining both dry in different percentages and analyzing the bulk density. The spread value provided by the minislump to fresh UHPC mixtures made with these sand combinations was higher as higher was the bulk density obtained. As for many other authors, the optimum percentage of fine-coarse sand was obtained for a ratio in the range $30 / 70 \%$. In these cases, the ratio between the maximum diameter of the coarse and fine sand is between 1.6 and 4. Table 2.6 shows how fine sand is never predominant, as better packing density is reached when coarse sand is predominant and fine particles get between the spaces of the bigger ones.

Table 2.6: Proportion of sands used to dosage UHPFRC by different authors. The size ratios indicate firstly the ratio between the $d_{\min }$ of both sands, and also the ratio between the $d_{\max }$ of the sands

\begin{tabular}{|c|c|c|c|c|}
\hline Reference & $\begin{array}{c}\text { Fine sand } \\
\text { (mm) }\end{array}$ & $\begin{array}{c}\text { Coarse sand } \\
\text { (mm) }\end{array}$ & $\begin{array}{c}\text { Size ratios } \\
\text { coarse/fine }\end{array}$ & $\begin{array}{c}\text { Ratio } \\
\text { Dmin/Dmax }\end{array}$ \\
\hline CONAD [65] & 0.15 to 0.3 & 0.425 to 0.6 & $2.8-2$ & $7 / 93$ \\
\hline Lehman et al.[133] & 0 to 0.5 & 0.5 to 2 & Inf-4 & $25 / 75$ \\
\hline CARDIFRC[[230] & 0.2 to 1 & 1 to 2 & $5-2$ & $30 / 70$ \\
\hline Naaman et al. [161] [263] & Dmax=0.2 & Dmax=0.8 & 4 & $30 / 70$ \\
\hline Camacho et al. [33] & 0.1 to 0.6 & 1 to 2 & $10-3.3$ & $30 / 70$ \\
\hline Hong et al. [111] & 0.17 to 0.3 & 0.3 to 0.5 & $1.76-1.7$ & $30 / 70$ \\
\hline Shakhmenko et al. [216] & 0 to 0.5 & 0.3 to 0.8 & inf-1.6 & $30 / 70$ \\
\hline Remy et al. [192] & 0 to 0.5 & 1 to 3 & inf-6 & $32 / 68$ \\
\hline Fidjestol et al. [74] & 0.125 to 0.25 & 0.25 to 1 & $2-4$ & $32 / 68$ \\
\hline Vogt et al. [252] & 0 to 0.25 & 0 to 0.5 & 2 & $50 / 50$ \\
\hline Walraven et al. [259] [261] & 0.125 to 0.5 & 0.5 to 1 & $4-2$ & $50 / 50$ \\
\hline De Larrard [50] & 0.08 to 0.315 & 0.2 to 1 & $2.5-3.17$ & $50 / 50$ \\
\hline Aarup et al. (CRC) [2] & 0 to 2 & 2 to 4 & inf-2 & $50 / 50$ \\
\hline
\end{tabular}


For enhancement of the UHPC robustness a mix design is suggested that secures a surplus of fines for each grain size level. This will not provide the maximum achievable packing density, but will assure that for each grain size level the coarse particles will not become dominant despite of any unfavorable influence. Also a slight deviation from the packing theory is preferable in order to create an instability in the ideal packing, enhancing the flow ability [137] [161]. If fibers are added, this method is also justified because flowability would be less affected if unfavorable conditions increase the coarser particle content or the fiber content.

\subsection{MiXING AND CASTING}

\subsubsection{MIXERS}

The RILEM TC 150-ECM and also the EN 206-1 classifies the efficiency of the mixers as ordinary mixers, performance mixers or high performance mixers, all according to three thresholds of variability of different parameters (quantity of fines, of largest aggregate or of air content). There is not a detailed idea of what means intensive mixing, but it is a widely used concept in the field of the UHPFRC, meaning the use of a powerful mixer, normally with inclined drum, to mix the concrete. In many cases the concept of intensive mixing is associated with an EIRICH mixer, of which the principle was invented in 1924. It consist on a rotating pan transporting the material to be mixed and an eccentrically mounted tool performs the mixing function. This principle gives some advantages compared to planetary mixers. Nold shown that an intensive mixer with rotating pan has the lowest variation coefficient in comparison with the other mixers [55], so they are high performance mixers.

It is generally assumed that UHPFRC requires intensive mixing [206] [153]. Intensive mixers can reach rotor speeds between 1.5 and $20 \mathrm{~m} / \mathrm{s}$ [154]. The kinetic energy applied to the mixture is proportional to the square of the speed. With the mixing is needed to overcome the high particles friction, caused due to the low ratio water/fine particles $(<0.125 \mathrm{~mm})$. It is also required the dispersion of the condensed silica fume agglomerates and distribute the high fiber content properly and without fiber clusters. Finally, the full advantage of the admixture thixotropic properties has to be obtained to surround the maximum particles possible. For all these reasons the mixture rheological and mechanical properties may vary significantly depending on the different mixer parameters (type, volume, power...) [73], which determines the mixer efficiency. Adequate properties can be reached casting the concrete in inclined drum intensive mixers, or in conventional medium energy mixers mixing for longer times [153].

A non-intensive mixing of a UHPFRC product can derive in sticky consistence, which produces a higher air void content in the concrete, and lumps of fresh concrete stuck to the paddles [206]. The efficiency of a mixer has to be checked with the standard deviation of different parameters, measuring then the homogeneity of the mix. These parameters can be the slump-flow, the compressive strength, the air content...etc. [85] [153].

\subsubsection{MIXING PROCESS}

The general mixing process of a UHPFRC mixture is normally divided in the following steps: Binder and aggregate dry mixing, water and admixture addition, and when the fluid state is reached, the fiber addition. The total mixing time is longer than for ordinary concretes, taking between 8 and 15 minutes depending on the fines content and mixer power [206] [64]. 
The water added is, in the first seconds, partly enclosed in agglomerates, which are destroyed progressively with the friction energy. When coarse aggregate is used there is more of this friction, so the time needed to fluidize the concrete is lower, but with a higher power consumption peak [144]. Besides, the finest is the dosage, the longer the mixing time, as there is longer time of friction between particles not in contact with the fluid. Then, increase the aggregate diameter reduces mixing times. In the case of use coarse aggregates, it can be useful add it after the water to avoid the erosion it would suffer during the dry mixing.

The admixture addition is recommended in two parts [206] [225] [210], first one just after the water and the second after agglomerates are already formed, in order not to entrap all the PCE inside in them. This method provides higher workability than one single PCE addition [225]. The first PCE addition increase significantly the mixing power required due to the capillary pressure [154]. If UHPFRC is going to be cast in a precast company, where the same dosage can be often used, is recommendable develop previous tests studding the influence of the time admixture addition in the UHPFRC properties with the industrial mixer [247].

When the binder has considerable content of $\mathrm{C}_{3} \mathrm{~A}$ or $\mathrm{Al}_{2} \mathrm{O}_{3}$, higher power is required from the mixer due to the agglomeration produced by this first step of hydration [206]. This is a second reason for the delayed admixture addition: The rapid formation during the mixing of the first ettringite crystals, between 300 and $500 \mathrm{~nm}$ [210]. The PCE molecules, with sizes 20 or 30 times smaller, are overgrown by these crystals or are chemically incorporated to these new formed hydration products, taking part of their structure and losing their efficiency [247]. The addition of the PCE after the molecules are formed will solve this problem. On the other hand, not all the PCE can be lately added, because a part is necessary to transform from dry to plastic state, destroying the slumps.

While agglomerates are progressively destroyed, the mixing power consumption decreases asymptotically to a stable value, when the mixing process can be concluded. The time required is named Stabilization Time $\left(\mathrm{t}_{\mathrm{s}}\right)$. After it, the fluidity remains maximum and constant during the so-called optimum mixing time, and finally starts a period of excessive mixing, when fines content increase due to the progressive erosion of the coarser particles. This erosion effect is deeper with a higher maximum aggregate diameter and with higher rotation speed tool. Also the beginning of the hydration can start, taking water and then decreasing the fluidity. This may imply a reduction of the compressive strengths [153] [154].

The speed of the mixing rotation tool of intensive mixers can be reduced with the only consequence of longer stabilization times, keeping similar rheological and mechanical properties of the UHPC-UHPFRC than with high rotation speeds. The speed can be varied during the process, being higher in the initial dry mixing to reach a more homogeneous fines and fibers dispersion [153] [154] and after the water addition, when the energy required is the maximum. After the concrete is fluid, high speed mixing should be avoided for not to increase the entrapped air in the final batch [206].

Depending on the dosage the mixing order can be altered. For instance, part of the fibers can be added with the dry materials, applying high speed mixing to the dry mass in order to avoid the fiber clusters in the final product. Another solution is to add slowly the fibers in a controlled manner, via "vibration in", preventing this "balling" [40] [82]. Some authors add part 
of the sand after the fibers addition due to the difficulties of mixing with low W/B ratio and the high fines content [129].

In the table 2.7, some mixing process for UHPC-UHPFRC developed for several authors are shown. Marković [148] cast High Performance Hybrid Concretes with fiber contents between $1 \%$ and $4 \%$. Schachinger et al [206] cast in a 75 l. Zyclos compulsory mixer. Lappa [129] used an intensive pan laboratory mixer EIRICH of 150 liters of capacity. The precast concrete company ELO Beton [82] uses a $1.5 \mathrm{~m}^{3}$ forced pan mixer to cast UHPC. Stähli P. [225] used a Zyclos ZZ 75 HE rotating pan mixer of 75 liters.

Table 2.7: Scheme of mixing processes of UHPFRC dosages performed by different researchers

\begin{tabular}{|c|c|}
\hline Min. & Process [64] \\
\hline $0-4$ & SF+quartz sand are mixed \\
\hline $4-6$ & $\begin{array}{c}\text { Addition of cement and the } \\
\text { quartz flour }\end{array}$ \\
\hline $6-7$ & Addition of water \& PCE \\
\hline $7-12$ & Mixing \\
\hline $12-13$ & Steel fiber addition \\
\hline $13-15$ & Mixing \\
\hline \multicolumn{2}{|c|}{ Mixture (B2Q) finished in 15 min } \\
\hline
\end{tabular}

\begin{tabular}{|c|c|}
\hline \multicolumn{2}{|c|}{ Mixer Ziklos ZZ 75 HE. Speed 2-3 $\mathrm{m} / \mathrm{s}$} \\
\hline Min. & Process [206] \\
\hline $0-1$ & Dry mixing of quartz sand+SF \\
\hline $1-2$ & Addition of water \\
\hline $2-2.7$ & Add of cement \& quartz powder \\
\hline $2.7-3.5$ & $40 \%$ of PCE \\
\hline $3.5-7$ & Break \\
\hline $7-8$ & Addition of $60 \%$ PCE \\
\hline $8-9$ & Steel fiber addition \\
\hline \multicolumn{2}{|c|}{ Mixing finish in 9 min } \\
\hline
\end{tabular}

\begin{tabular}{|c|c|}
\hline \multicolumn{2}{|c|}{ Pan mixer of $1.5 \mathrm{~m}^{3}$} \\
\hline Min. & Process [82] \\
\hline $0-3$ & Dry mixing of aggreg. and binder \\
\hline $3-6.5$ & Addition of water+PCE \\
\hline $6.5-9.5$ & Steel fiber addition \\
\hline \multicolumn{2}{|c|}{ Mix finished in 9-10 min } \\
\hline
\end{tabular}

\begin{tabular}{|c|c|}
\hline \multicolumn{2}{|c|}{ Mixer Ziklos ZZ 75 HE } \\
\hline Min. & Process [225] \\
\hline $0-5$ & Dry mix of cement, FA, SF and sand \\
\hline $0-5$ & Addition of water+part of PCE \\
\hline $5-10$ & Addition of fibers+rest of PCE \\
\hline \multicolumn{2}{|c|}{ Mix finished in 10 min } \\
\hline
\end{tabular}

\begin{tabular}{|c|c|}
\hline \multicolumn{2}{|c|}{ Mixer Ziklos ZZ 100 HE. Whirler 1500 r.p.m. } \\
and EIRICH R-09 W
\end{tabular}

\begin{tabular}{|c|c|}
\hline Min. & Process [148] \\
\hline $0-0.3$ & Aggregate \& cement mixed \\
\hline $0.3-1.3$ & Addition of water and PCE \\
\hline $4.3-7.3$ & Microsilica addition \& mixing \\
\hline $7.3-10.3$ & Steel fiber addition \\
\hline \multicolumn{2}{|c|}{ If homogeneous, finish in 11 min } \\
\hline
\end{tabular}

\subsubsection{CASTING}

The casting process has to be chosen depending on the element performed, being of great importance reach the desired fiber orientation. The most effective way is a fast displacement of the concrete pouring along the linear elements to induce speed to the fibers. Placing the pump in an extreme and let the concrete advance is acceptable when there is enough depth in the element to create great potential energy and give speed to the mass.

After the mixing it can be useful wait some minutes before the pouring for the entrapped air arise. However, UHPFRC has to be poured before the initial set starts, when water loss deteriorates the workability. The exothermic reaction makes that an "elephant skin" arises from drying up of the surface, making more difficult the flow or leading to inhomogeneities [57]. The higher the $\mathrm{C}_{3} \mathrm{~A}$ content, the stronger is this effect. 
Finally, and especially for pieces that users will directly contact, the fibers arising from the surface have to be removed. Different covers textile covers can be placed over the material to favor the aspect homogeneity.

\subsubsection{CURING SYSTEM}

The heat curing process is interesting depending on the properties it can provide respect to the normally cured UHPFRC. In some cases the last are enough to cover the requirements of the application, and then heat curing is avoided due to the energy consuming [111]. However, some precast companies are able to apply a $48 \mathrm{~h}$ and $90^{\circ} \mathrm{C}$ curing process in a steam chamber or wrapping the element in polyethylene (figure 2.21), with a cost smaller than $2 \%$ over the product cost, with a higher benefit gained for the properties.

Some UHPFRC made in precast companies are submitted to air curing at plant temperature. As in ordinary concrete, curing at $30^{\circ} \mathrm{C}$ or $40^{\circ} \mathrm{C}$ provides higher strengths at short term than curing at $20^{\circ} \mathrm{C}$, but the last can develop higher strengths at long term [118]. When heat curing is applied at higher temperatures, the best performance at short term is reached [111], the autogenous shrinkage almost eliminated, the creep coefficient decreases dramatically and porosity is reduced about nearly 50\% [67] [158]. However, some studies have shown that UHPFRC cured at normal temperature show development of higher long term strength [111].

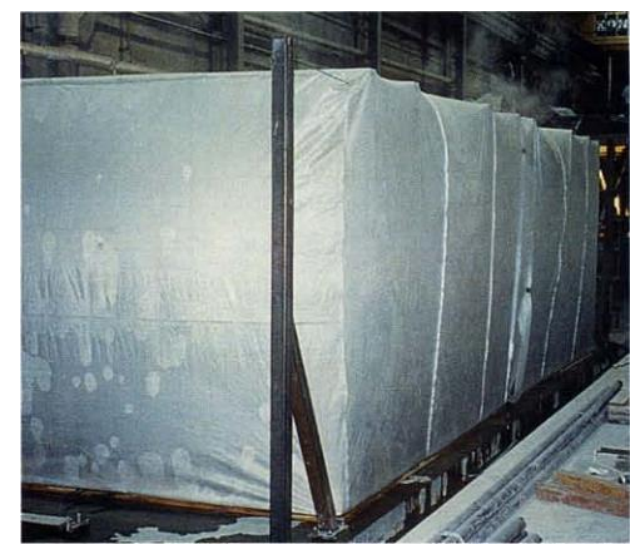

Figure 2.21: Wrapping of an element with polyethylene to apply the steam curing [20]

The Japanese Recommendations [113] suggest develop heat curing during $48 \mathrm{~h}$, at $90^{\circ} \mathrm{C}$ and with $100 \%$ relative humidity. The temperature increase should be $15^{\circ} \mathrm{C} /$ hour until reach the $90^{\circ} \mathrm{C}$. Heat curing is normally applied the second day. Temperature accelerates the pozzolanic reaction of the silica fume with the portlandite. Besides, at this temperature the amorphous C$\mathrm{S}-\mathrm{H}$ phases crystallize to tobermorite and jennite [133]. Some authors have tested other conditions for curing. Camacho [32] experienced that curing at $50^{\circ} \mathrm{C}$ or $80^{\circ} \mathrm{C}$ in air or water environment for 24 hours didn't increase the strength comparing with the 28 days strength in $20^{\circ} \mathrm{C}$ air $100 \%$ relative humidity conditions.

Smaller temperatures are in some cases applied in the first hours at the prefabricated company. For the bridge of Saint Pierre La Cour [195] a $40^{\circ} \mathrm{C}$ heat curing was adopted to get $80 \mathrm{MPa}$ at 18 hours and carry out the prestressing de-tensioning.

The most efficient moment to apply the heat curing is when the cement reaches a high rate of hydration, because the portlandite content is the maximum and then the reactions induced by the temperature are higher. This happens in UHPC over the $4^{\text {th }}$ and $6^{\text {th }}$ day [205]. 
Some of the dosages from the database studied were tested both at 28 days or normal curing and after steam curing. The percentage of strength increase observed for the cured specimens seems to be related with the $\mathrm{W} / \mathrm{C}$ content, as observed in figure 2.22 . The correlation is higher than relating with $\mathrm{W} / \mathrm{B}$ content.

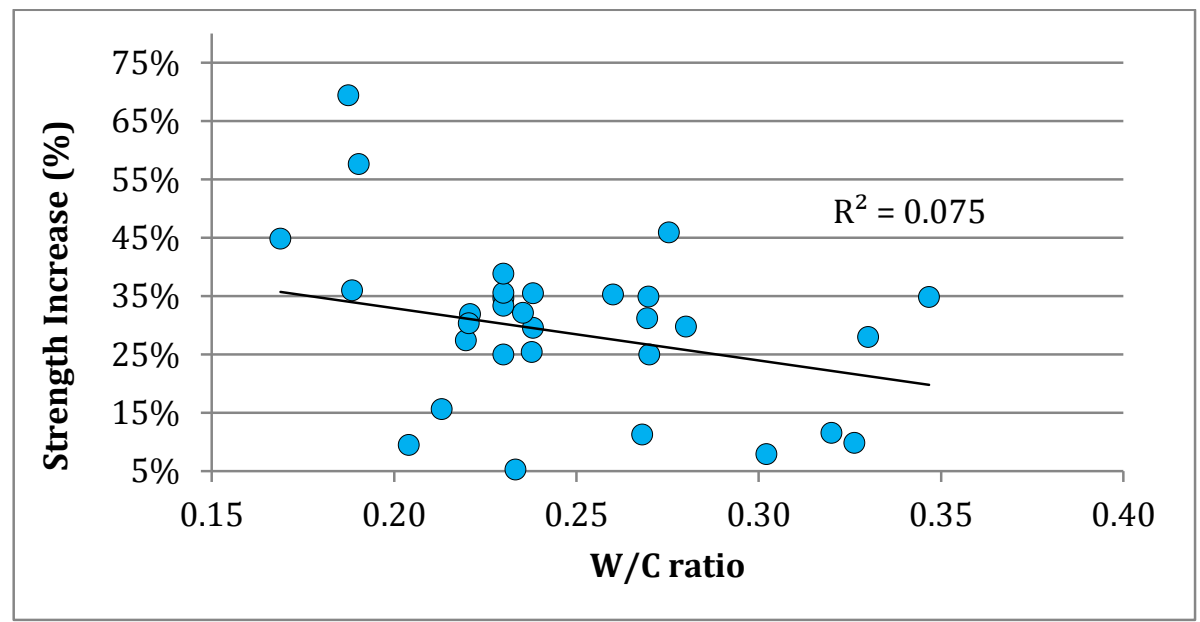

Figure 2.22: Relative compressive strength increase of steam cured elements respect to the $20^{\circ} \mathrm{C}$ air cured elements

\subsubsection{REASONS TO PRECAST}

UHPC-UHPFRC is precast for almost every application. The reason is the high control required for the materials and the mixing and curing processes, which limit the use of UHPFRC to few adapted factories [111]. For practical and economical reasons, in-situ field applications with UHPFRC have to be applied without heat and pressure curing [97].

Many elements are pre-tensioned or post-tensioned in order to exploit the high UHPFRC strength [67]. Elements generally have reduced thickness, which can only be guaranteed in precast conditions. A cover of 10-15 mm can be enough even for very aggressive environments [92] [28], being a too reduced value to be guaranteed with in-situ execution. Also UHPFRC is susceptible to have a low robustness ${ }^{1}$ [137]. This implies that high control is required to the variables, specially the water, and also that the dosage of the optimal mixture designed shouldn`t be strongly affected by slight changes in the proportions.

Besides, in many cases get a certain texture or superficial tonality turns a primary objective, and this is much controllable in precast conditions than casting an in-situ concrete.

The short term compressive strength may be a key point for process efficiency, as it is important that the pieces can be extracted as soon as possible from the prestressing bed. This $24 \mathrm{~h}$ strength depends mainly on the PCE properties, as is in detail explained at section 2.3.3.6. Many commercial products, as Ductal ${ }^{\circledR}$ provide reduced compressive strength at 24 hours [130], being then very adequate apply steam curing for be able to remove the piece soon.

Also the PCE used needs to provide enough opened time to fill the molds with a suitable selfcompacting product. It can be also useful that the cement/PCE combination is not very sensitive to the PCE time addition in the mixing, in order to simplify the casting process [247].

${ }^{1}$ The ability of the concrete mixture to satisfy some requirement despite of any unfavorable influence 
To cast UHPFRC, precast companies should have mixers with energy enough, resistant to the aggregates and fibers abrasion, and dispose a heat curing system (normally used for $48 \mathrm{~h}$ at $90^{\circ} \mathrm{C}$ ) in case that the performance required for the application needs it. Many authors showed the great performance improvement that can be reached with some days of heat treatment or autoclaving. However, this process in many cases becomes non-economically viable for plant production [77]. Another added difficulty to precast companies is the management of the high number UHPFRC components [208]. The quality management of each material, which needs to be stored during some time, requires additional efforts than for ordinary concrete.

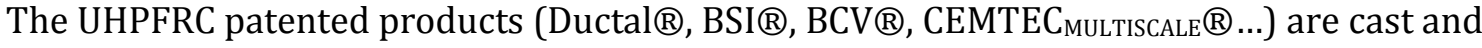
cured in precast conditions, in many cases filling specific molds for create singular geometries ordered for each application.

\subsection{PROperties}

\subsubsection{Rheological Properties}

\subsubsection{RHEOLOGY OF THE UHPFRC}

Rheological behavior of UHPFRC is related with several parameters, mainly the W/B ratio, content of fines, admixture and type/content of fibers. The two first variables can be considered with the concept of Paste Volume Fraction (PVF), which represents the volume of paste (binder, quartz flour, admixture and water) over the total volume. Aggregates are considered floating in the paste medium. With increasing content of them, the viscosity of the paste should be less than for UHPFRC with high PVF, in order to achieve the same target set of fresh state properties than it [72]. Figure 2.23 shows the slump flow depending on the PVF for the database dosages studied. Slump flows obtained for dosages with coarse and fine aggregates are very similar, but the average PVF associated to the first is about $10 \%$ smaller.

Analyzing the frequency distribution of the slump flows of the database dosages (figure 2.24), can be noticed that UHPFRC slump ranges normally between 650 and $800 \mathrm{~mm}$.

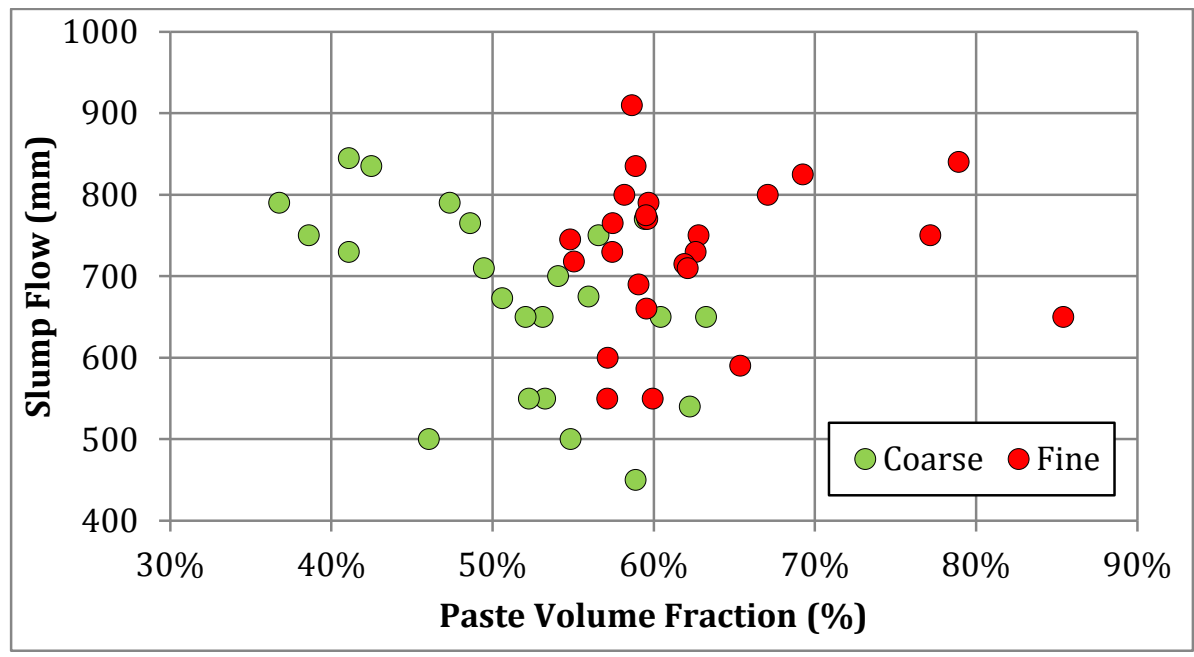

Figure 2.23: Relation between slump-flow and the Paste Volume Fraction (PVF) 


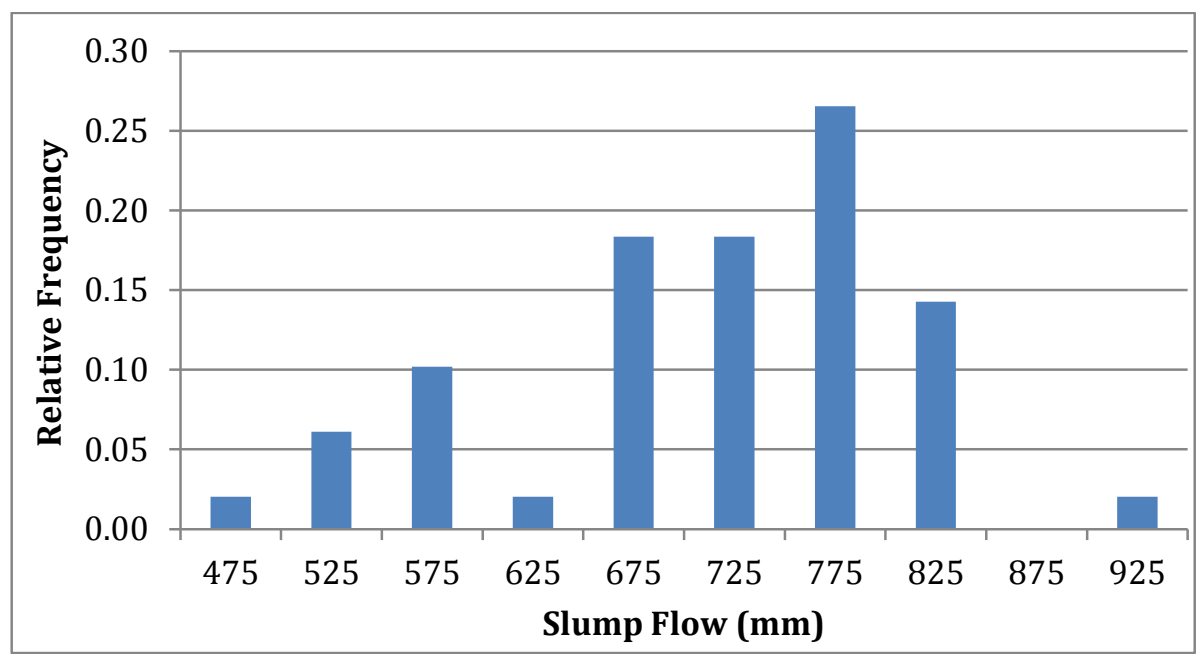

Figure 2.24: Relative frequency of the database slump flows

In a fluid cement paste with low fiber volume fractions, the system can be considered semidiluted, as there is no contact through hydrodynamic effects. Rheology is dominated by the cement paste fluidity. With higher fiber volume fractions there is an existence of a continuous network of fibers in contact, and these contacts dominate the rheological behavior of the system. This effect depends on the value of dense packing fraction. Then, the volume fraction and aspect ratio of the fibers produce a decrease of the workability [93] [201] [150], which can be noticed with the decrease of the slump flow, or, what is the same, with yield stress increase.

A mix design criterion was provided by Martinie \& Rossi [150] to obtain the critical amount of fibers above which fibers form balls and the material is not flowable. The higher the fiber aspect ratio and the higher the sand volume fraction, the lower is the critical fiber content, as was already explained at section 2.3.3.8. This is qualitatively considered by many researchers for the dosage design, since they increase the aggregates fineness when high volume of fibers is required. The typical UHPFRC dosages contain between $1.5 \%$ and $2.5 \%$ of fibers in volume, which is already enough to leads in a reduction of the fluidity of fresh concrete [267].

PCE admixture role in rheology is also important. PCE composition is used to control the opened time and the setting time, so depending on the casting methods and short term compressive strength requirements the PCE will be chosen.

\subsubsection{RHEOLOGICAL PROPERTIES}

Self-compacting concretes, as UHPFRC, can be defined as Bingham fluids. This consist in a relation between the shear strain rate and the shear stress as follows:

$$
\tau=\tau_{0}+\mu \cdot \dot{\gamma}
$$

Being $\tau$ the shear stress, $\tau_{0}$ the yield stress, $\mu$ the plastic viscosity (the slope) and $\dot{\gamma}$ the shear rate. The meaning of this equation is that there is a critical shear stress below which the material behaves as a solid. If the yield stress is exceeded, then the material starts to flow, and the speed of this flow depends on the plastic viscosity value.

These parameters can be determined studying the rheology of the material. Three key points to characterize it are the segregation resistance, filling ability and passing ability. 
The concept of segregation includes every kind of separation in size groups. As the segregation is related with particles with high ratio volume/specific surface [93], UHPC is less susceptible than other concretes to suffer it, since fines are in a high content and also the improved compacity induces higher contact between them [75]. Heavy aggregates sink is also less possible due to the higher density of the paste comparing with the typical of the concrete. Fibers and also coarse aggregates in lesser extent might settle due to the higher density as was explained at 2.3.4.1. This has to be controlled limiting the slump flow, which is related to a yield stress value.

The filling ability is mainly related with the plastic viscosity. It can be estimated with the value of $t_{500}$ of the slump-flow test (EN 12350-5) and mini-cone test [203], which can also be used to determine the workability evolution. The passing ability can be determined with the LBox and J-Ring tests. The absence of coarse aggregates and the presence of very slender fibers make the latter the main parameter that controls the passing ability. For applications with very reduced covers or sharp molds hybrid concretes cannot be placed easily for the difficult filling ability that induces the long fibers.

Selfcompactability conditions the way of filling, the production methods, and influences to the fiber orientation [260]. The best fiber orientation is obtained when all the fibers are in the direction of the efforts, obtaining the $100 \%$ of their efficiency. When fibers are randomly aligned in two dimensions, this efficiency becomes $2 / \pi(63.7 \%)$, and when the fibers are $3 \mathrm{D}$ randomly distributed the efficiency is 50\% [43]. However, other authors have shown in pullout tests that fibers inclined between $15^{\circ}$ and $30^{\circ}$ give about a $20 \%$ better pull-out response than the perfectly aligned ones [148].

Fiber orientation is controlled mainly by three parameters: The gravity, the wall effect and the direction vector of the flow (1.4. of [8]). This becomes a great reason to design high flowable dosages, as in them fiber orientation can be controlled with the UHPFRC flow. After the pouring, the French Recommendations suggest some tests to verify the fiber orientation in the hardened real size structural elements, extracting a part of them in different directions to perform later flexural or tensile tests [8] [152].

\subsubsection{HARDENED STATE}

\subsubsection{COMPRESSIVE STRENGTH}

Compressive strength in UHPFRC is affected mainly by the binder content, the W/B ratio, the matrix compacity and the compatibility of PCE and binder. In UHPFRC the first stage of the stress-strain relation, the linear elastic stage, is more pronounced than in ordinary concretes [129], especially at long term (see figure 2.25). The post-peak behavior depends mainly on the fiber content and type.

Several researchers ensure that steel fibers addition doesn't increase significantly the compressive strength. UHPC without fibers has been cast in laboratory reaching compressive strengths between 150 and $200 \mathrm{MPa}$ [144] [242]. However, failure is extremely brittle and explosive, requiring at least a $2 \%$ of fibers to provide enough ductility. Some researchers assert that a $2 \%$ fiber addition may increase the compressive strength about $10 \%$ [170]. 


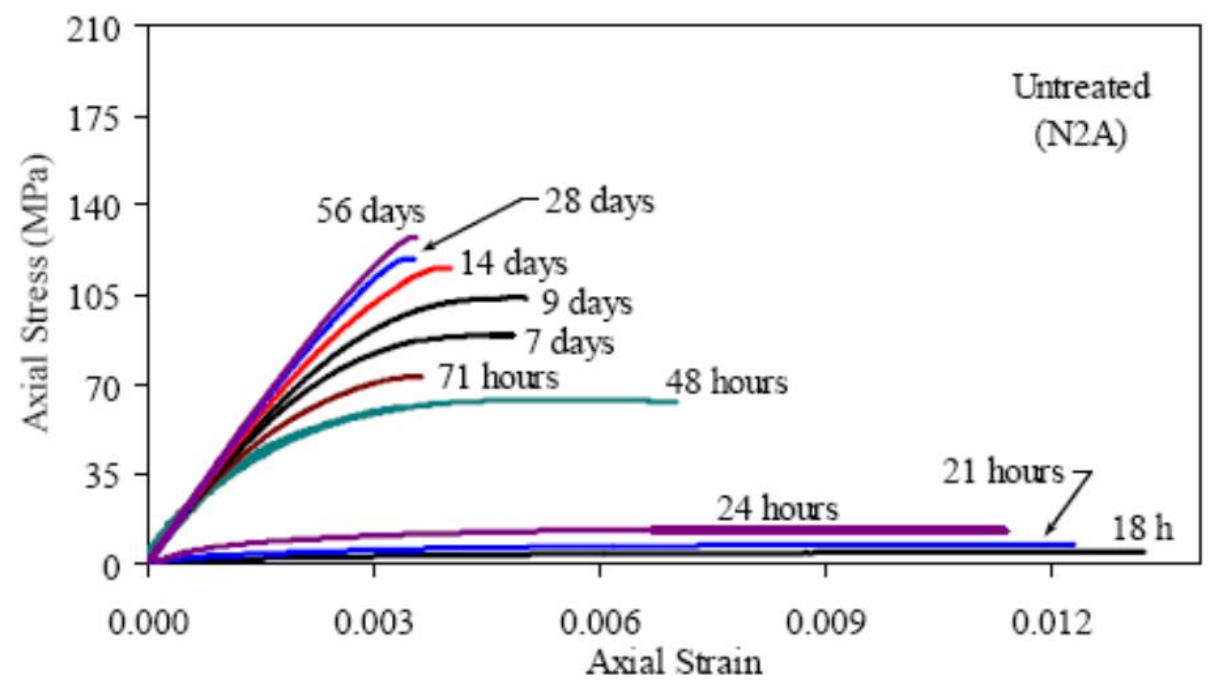

Figure 2.25: Graph of stress-strain response of untreated Ductal ${ }^{\circ}$. Compressive test made to a cylinder 76 × 152 mm according with the norm ASTM C39 [89]

Figure 2.26 shows the compressive strength (transformed when required to a cube of length $100 \mathrm{~mm}$ ) related with the binder content for the database studied. It is split in coarse or fine aggregates, and steam or air curing. Both coarse and fine aggregates range in similar compressive strength values. For similar binder contents, high compressive strength differences between dosages can be found. This is related mainly to the adequate or inadequate compatibility between cement, active addition and PCE admixture.

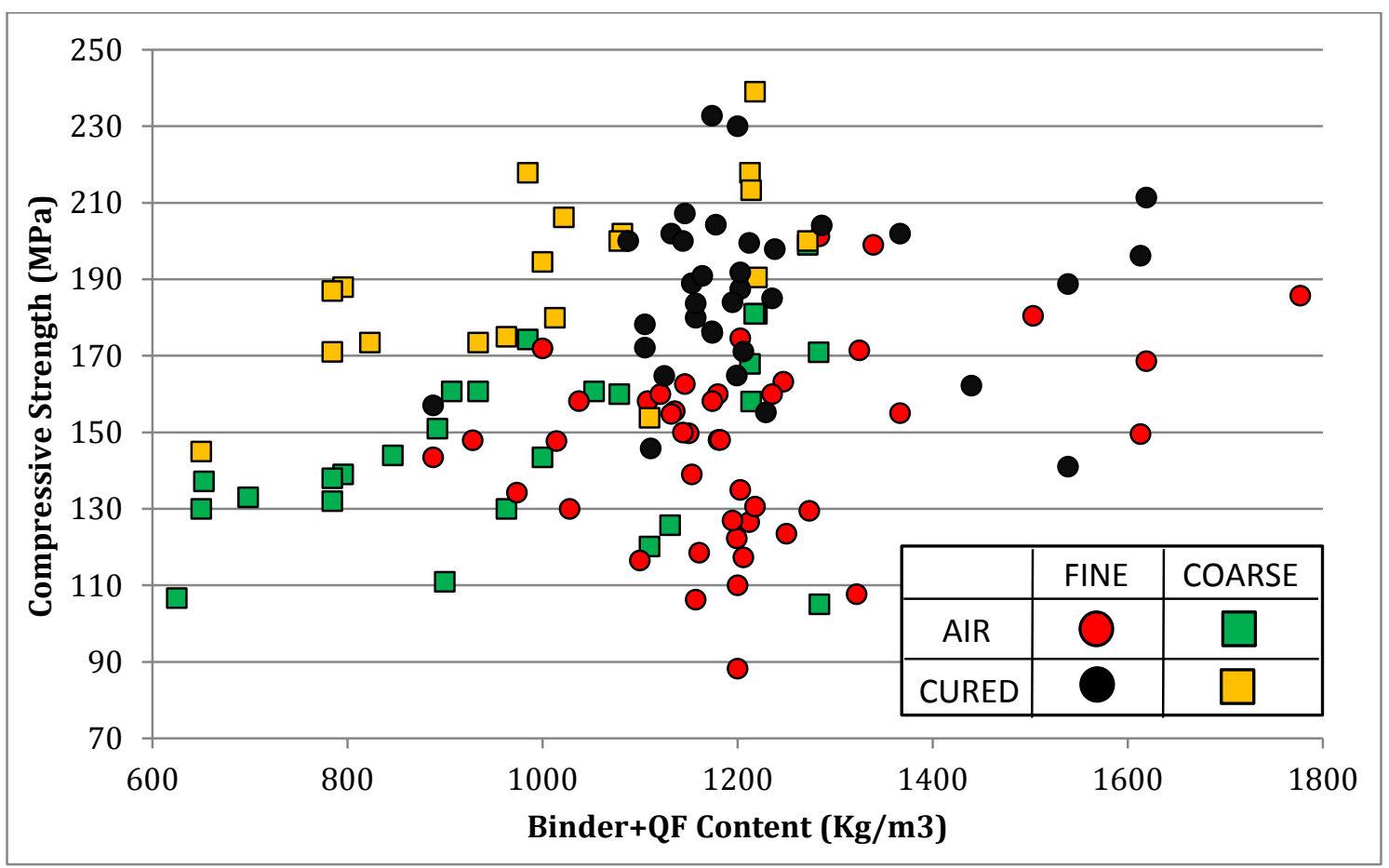

Figure 2.26: Compressive strength related with the binder content

Very fine inert particles might also affect to the compressive strength as they provide better packing. In the figures 2.27 and 2.28 is appreciated the compressive strength (obtained in 100 $\mathrm{mm}$ length cubes) depending on the $\mathrm{W} / \mathrm{B}$ ratio with and without considering the quartz flour (see 2.3.3.4) as binder. If it is not included, less than a $5 \%$ of the compressive strength variability is explained by $\mathrm{W} / \mathrm{B}$ ratio, while including it this value is between $12.7 \%$ and $23.3 \%$, depending if the concrete is steam cured or not. 
A regression contrast proved that there is significant negative linear correlation between the $\mathrm{W} /(\mathrm{B}+\mathrm{QF})$ and the compressive strength. It's interesting to highlight that the correlation is higher for air cured specimens, even though some authors remarked the possible reactivity of the quartz flour only when steam curing processes are carried out.

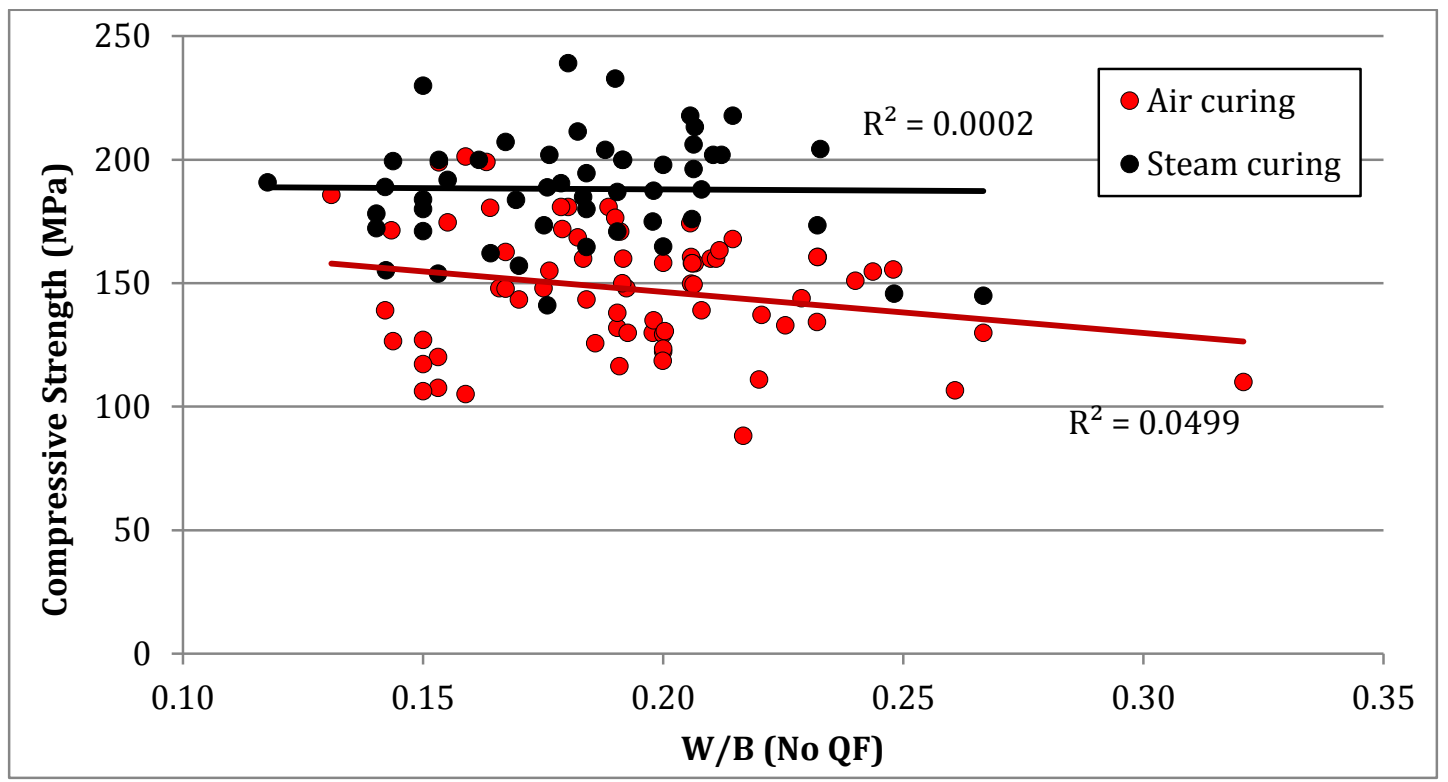

Figure 2.27: Compressive strenth related with $W / B$ ratio (quartz flour is not considered as a binder)

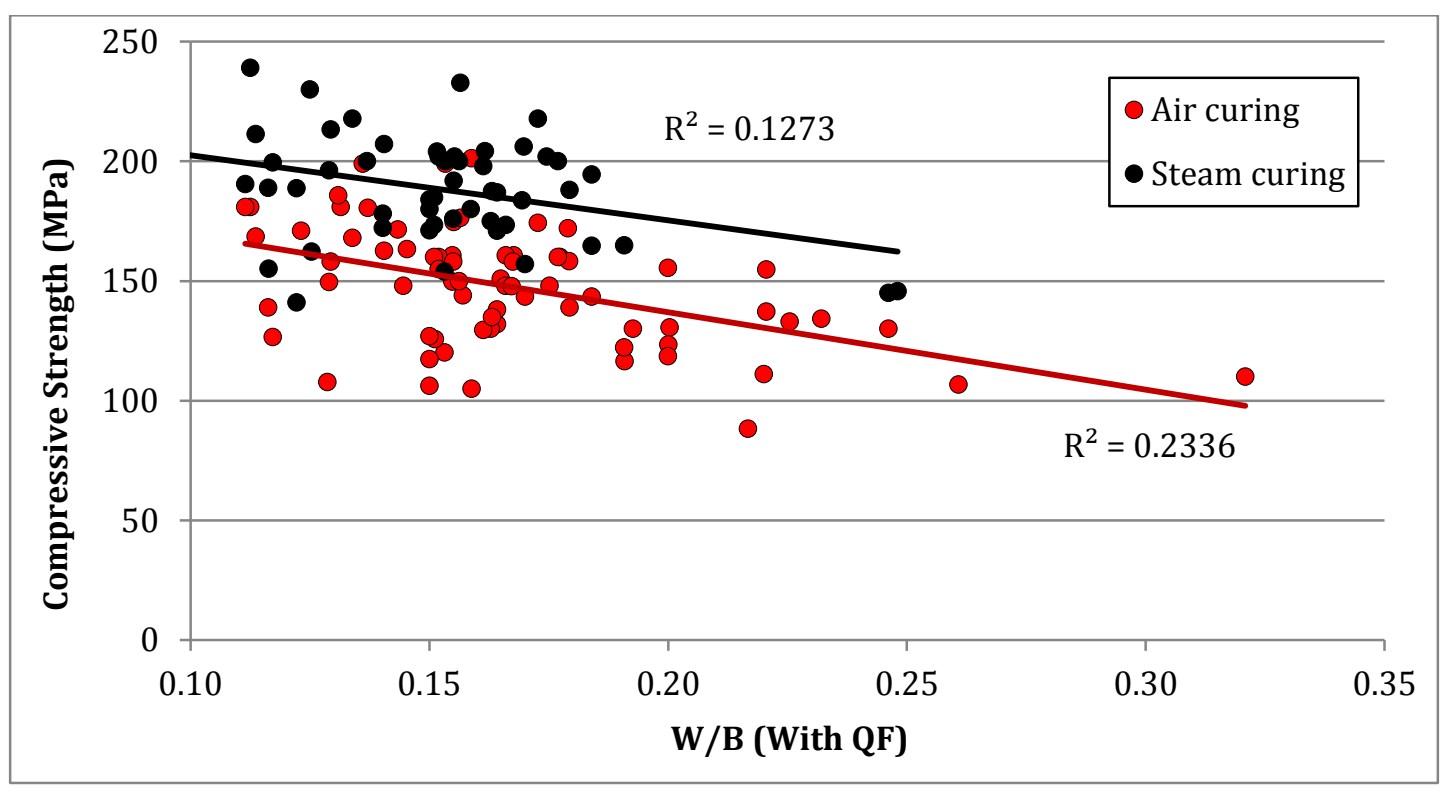

Figure 2.28: Compressive strenth related with the $W / B$ ratio ( $Q F$ considered in the binder)

It is accepted that, considering two specimens from the same dosage, for the same hydration degree both have similar properties [212]. Then, the compressive strength development is a function of the degree of hydration indexes (DRI), and can be modeled by hyperbolic or exponential equations [97] [111]. However, there is not a clear idea of how evolves the compressive strength at very long term, as UHPFRC is a relatively new material. Some researchers ensure that, unlike ordinary concrete in which strength increases during decades, UHPFRC reaches its final strength at over 90 days [97]. On the other side, some authors extracted cylinders from the first UHPFRC structures after years of being built and showed that the safety factor increased due to the unexpected higher compressive strength [205]. 
Compressive strength of concrete is the basic and most important material parameter for design concrete structures [220], as it is related with many other variables like durability or compacity. That's why it can be a useful and easy way parameter to develop a dosage optimization. The characterization of the compressive strength should be carried out in samples that represent the size section of the element designed, as testing with different geometries provide different results [170] [85]. Normally the higher the slenderness, the smaller is the compressive strength.

\subsubsection{Young ModuluS}

The young modulus of UHPFRC is higher than for conventional concretes. Its magnitude depends mainly on the type of aggregate used, the curing process and the paste volume fraction. Generally, the coarser the aggregate, the higher the value of young modulus. Besides, the rate of development of the elastic modulus for no-heat treated UHPC is higher than that for the tensile strengths but comparable to that of the compressive strength [249].

On the figures 2.29 and 2.30 are presented the relations between the compressive strength (cube of length $100 \mathrm{~mm}$ ) and the known elastic modulus of the database dosages. At figure 2.29 are presented also the formulations proposed by different norms (Model Code 90, Eurocode 2, ACI-318, and EHE 2008) for ordinary concretes. The proposed by the Spanish norm ( $E=$ $8500 \cdot \sqrt[3]{f_{c m}}$ ) seems adequate to estimate the value for the fine aggregate air cured UHPC. Eurocode 2 equation $\left(E=9500 \cdot \sqrt[3]{f_{c m}}\right)$ seems to fit better with coarse aggregate UHPC. Figure 2.30 compares with some correlations proposed for UHPC materials [249]. Equations proposed by Ma et Al. $\left(E=16364 \cdot \ln \left(f_{c m}\right)-34828\right)$ and Graybeal $\left(2007, E=3840 \cdot \sqrt{f_{c m}}\right)$ predict adequately the relation between compressive strength and young modulus for the untreated fine aggregate dosages. Steam cured specimens are not well predicted with any formula, and the one proposed by Sritharan (2003) seems to be more accurate with the coarse aggregate untreated dosages. In this case, the dispersion of the data is high since the young modulus depends largely on the type of coarse aggregate used.

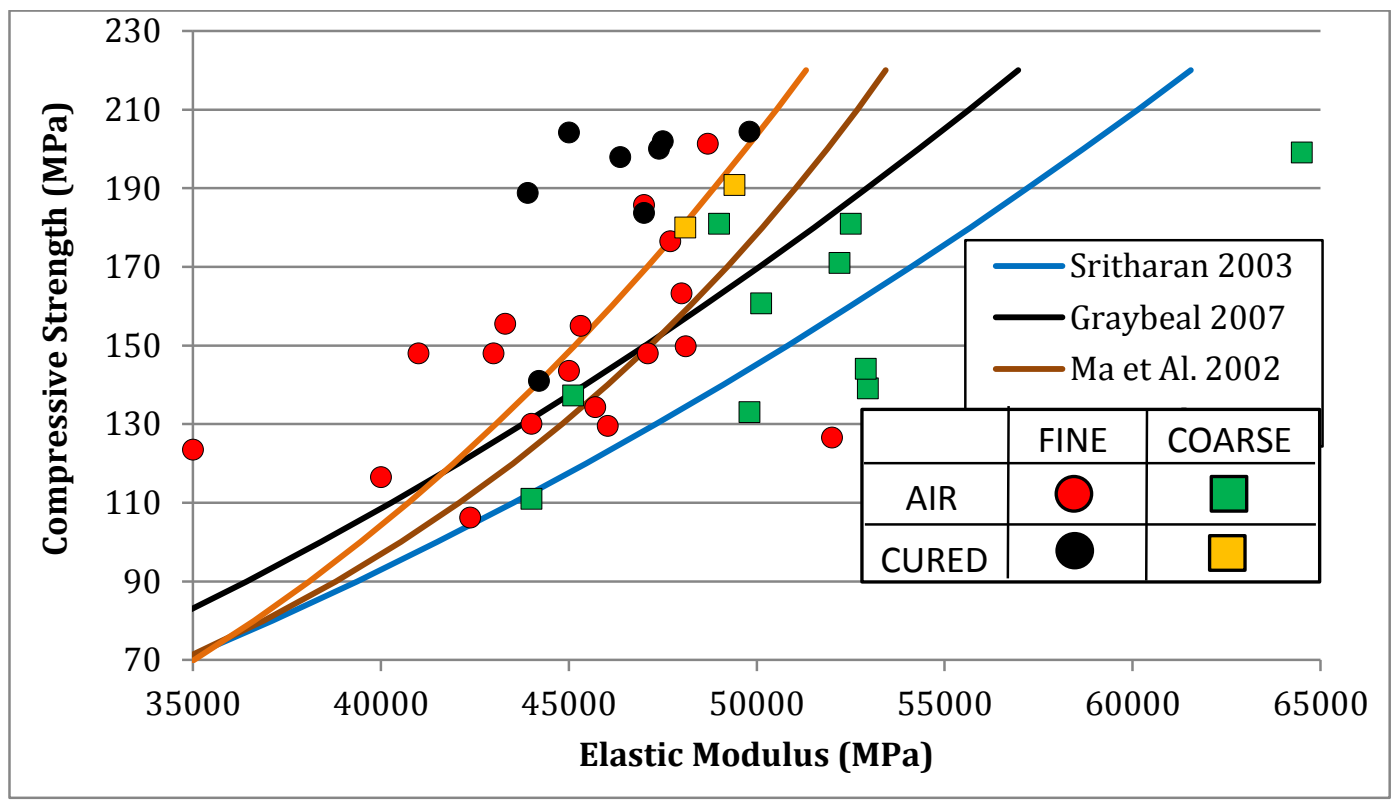

Figure 2.29: Elastic Modulus related with the compressive strength, and curves proposed by different norms codes for ordinary concrete 


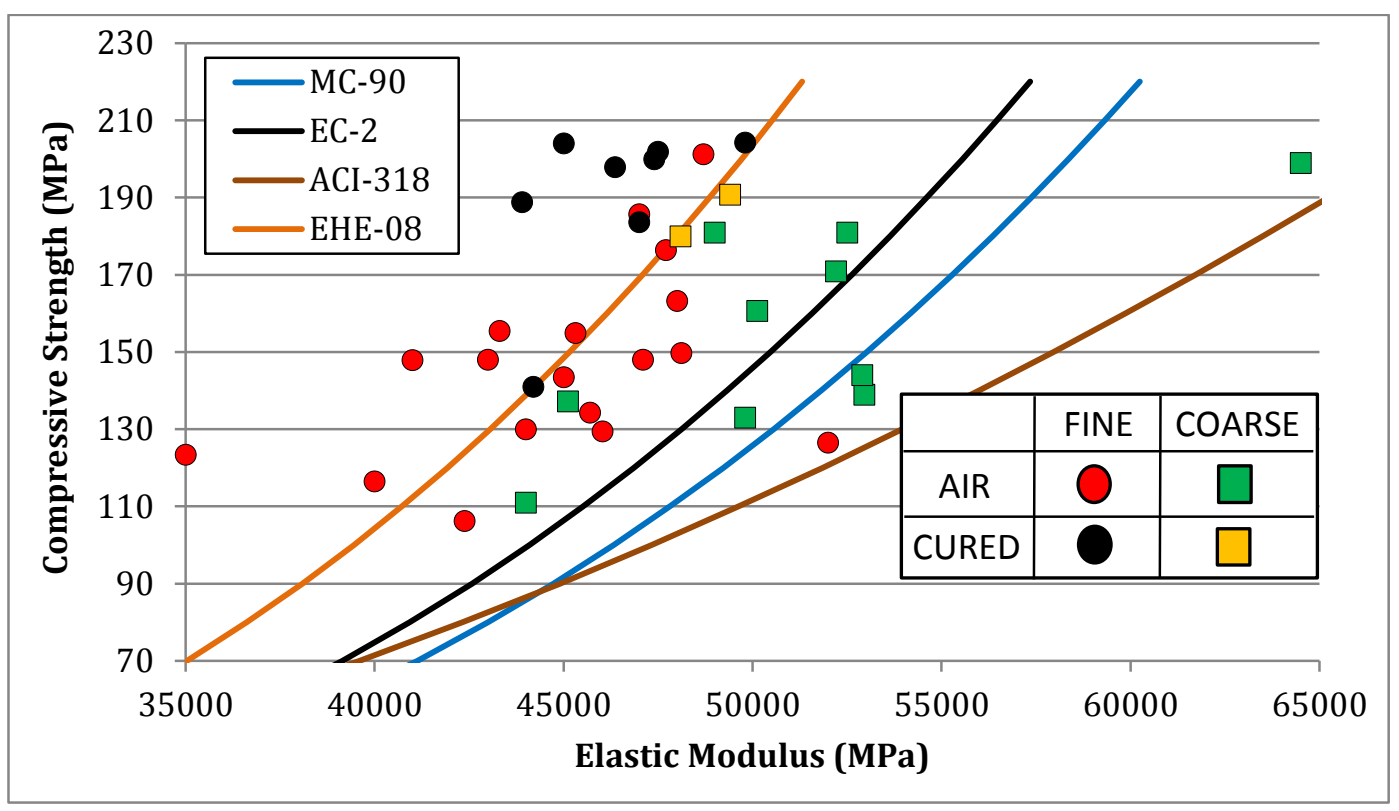

Figure 2.30: Elastic Modulus related with the compressive strength, and curves proposed by different researchers for UHPC

\subsubsection{TENSILE AND FLEXURAL BEHAVIOR}

Normally UHPFRC differs from FRC in the flexural and tensile behavior. In the case of a general FRC submitted to tensile efforts, it reaches the maximum tensile strength immediately before the single crack appears. Depending on the concrete-fiber adherence and the fiber tensile strength, load decreases abruptly (fiber brittle failure) or decreases progressively during the so-called strain softening (ductile failure due to the fiber pull-out). For the bending efforts it is called deflection softening.

The high strength of the fibers used in UHPFRC is enough to the carry the load when the first crack opens, and the matrix-fiber frictional stresses is so high that fiber doesn't slip initially. Then, load can be increased after first crack appears, and the good fiber-matrix bond allow the appearance of second, third, and $n$ microcracks that don't develop, being then invisible to the human eye. Water spray onto the surface of the element is a way to detect them [257]. This micro-cracking process while load is increasing is named strain hardening (deflection hardening in the case of bending). The "hardening" part of the diagram can be considered as a proof of the well-designed UHPFRC [262]. Once load reaches a top value, fibers pull-out in the weakest section and one of the microcracks develops, becoming a macrocrack, and decreasing the load during the strain softening process.

Figure 2.31 show the typical flexural strength/central span displacement of a UHPFRC with deflection hardening response [37]. The prism size is $100 \times 100 \times 400 \mathrm{~mm}$ (figure 2.32).

Thanks to the deflection hardening, a beam can reach a high tensile strain in the lower part without visible cracks, even with the active or passive reinforcement exceeded the yield value. This means that the crack width Serviceability Limit State will not restrict the capacity of the designed elements, as macro-cracks only appear when structure is near to the collapse.

In a direct tensile test to a strain hardening UHPFRC, several micro-cracks appear progressively. They can be assumed together as an "equivalent strain". With high values of equivalent strain, for which active or passive reinforcement is plasticized, the UHPFRC tensile 
capacity is still remarkable. This implies that structural capacity of both elements can be added, because both reach their maximum strength associated to the similar strains, taking the full advantage of the material properties.
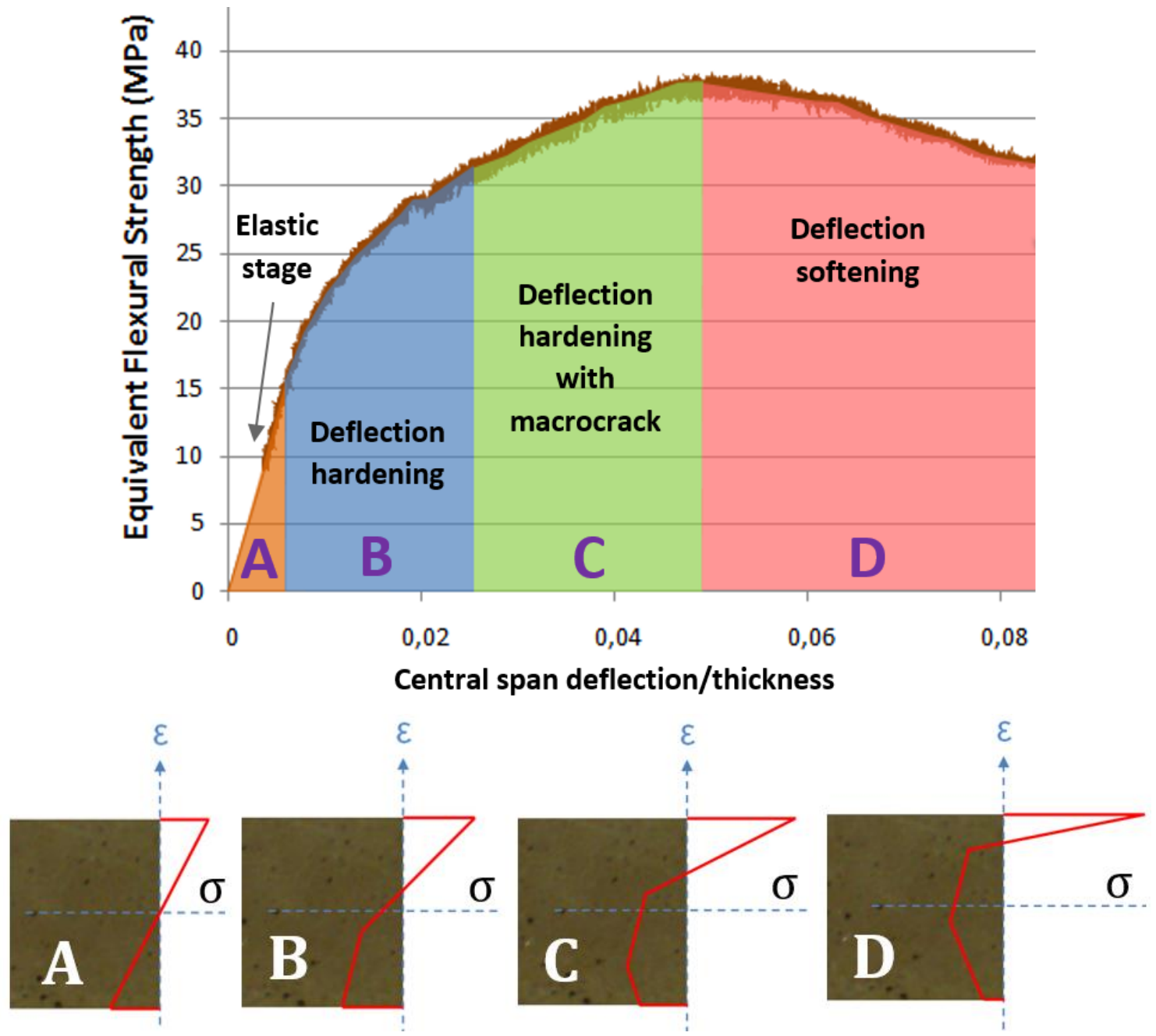

Figure 2.31: Four main stages of the UHPFRC flexural behaviour

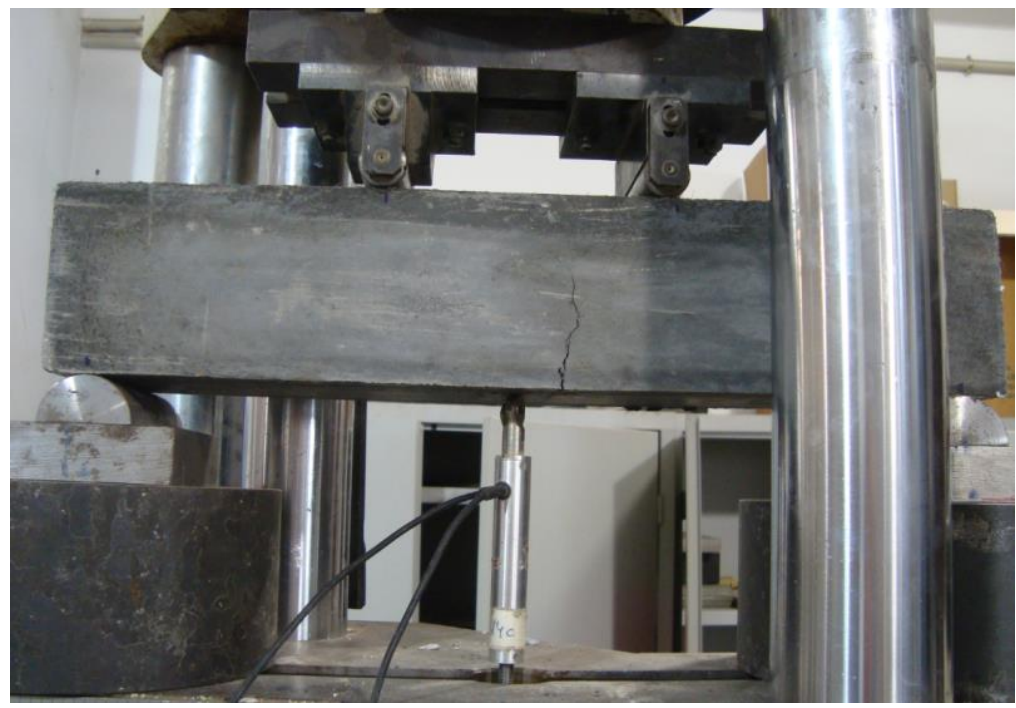

Figure 2.32: Flexural four point bending test 
The first initial cracking stress depends mainly on the tensile toughness of the composite (as long as the cracking appears due to the tensile strain), and the ultimate tensile strength depends on the bridging effect of the steel fibers, which is due to the fiber-matrix bond as well as the tensile strength of the fiber [235]. Several authors demonstrated that matrix strength and tensile strength are both higher with steel fibers [116] [43].

HPFRC-UHPFRC fibers are smaller than in FRC, so they are already activated when microcracks occur in concrete. Hence, in tensile test the concrete appears to stay longer in the elastic phase. If longer fibers are combined with the short ones (composing the named Hybrid UHPFRC), they are activated in the strain hardening phase, avoiding the development of a macrocrack up to considerable strains [262]. The specific goal of each fiber size may create a synergy, improving the post-cracking behavior and/or the maximum flexural and tensile strength [170] [148] [147].

Both direct tensile strength and flexural strengths depends mainly on the fiber properties and increase with the volume dosed. The most typical UHPFRC dosages contain $1.5 \%-2.5 \%$ of fibers over total volume. With this contents of short straight or anchored fibers, direct tensile strength ranges between 9 and $15 \mathrm{MPa}$ [116] [73] [43] [86], observing generally strain hardening behavior with fiber contents higher than $2.5 \%$. Flexural strength, thought is strongly related with tensile strength, depends much more on the test type performed (span, points of loading, possible notch) and the geometry of the prism tested. 28 days flexural strength for unnotched beams normally ranges between 15 and $50 \mathrm{MPa}$ [170] [73].

There is not agreement about the rate of development of the mechanical properties. Hong et al. [111] affirm that time evolution of the tensile strength seems to be very similar to the elastic modulus evolution, reaching the final tensile and flexural strength earlier than the compressive strength. However, Habel et al. showed in 2006 [249] that tensile strength reaches its maximum value more slow than compressive strength and elastic modulus, which evolves very similar (figure 2.33 ).

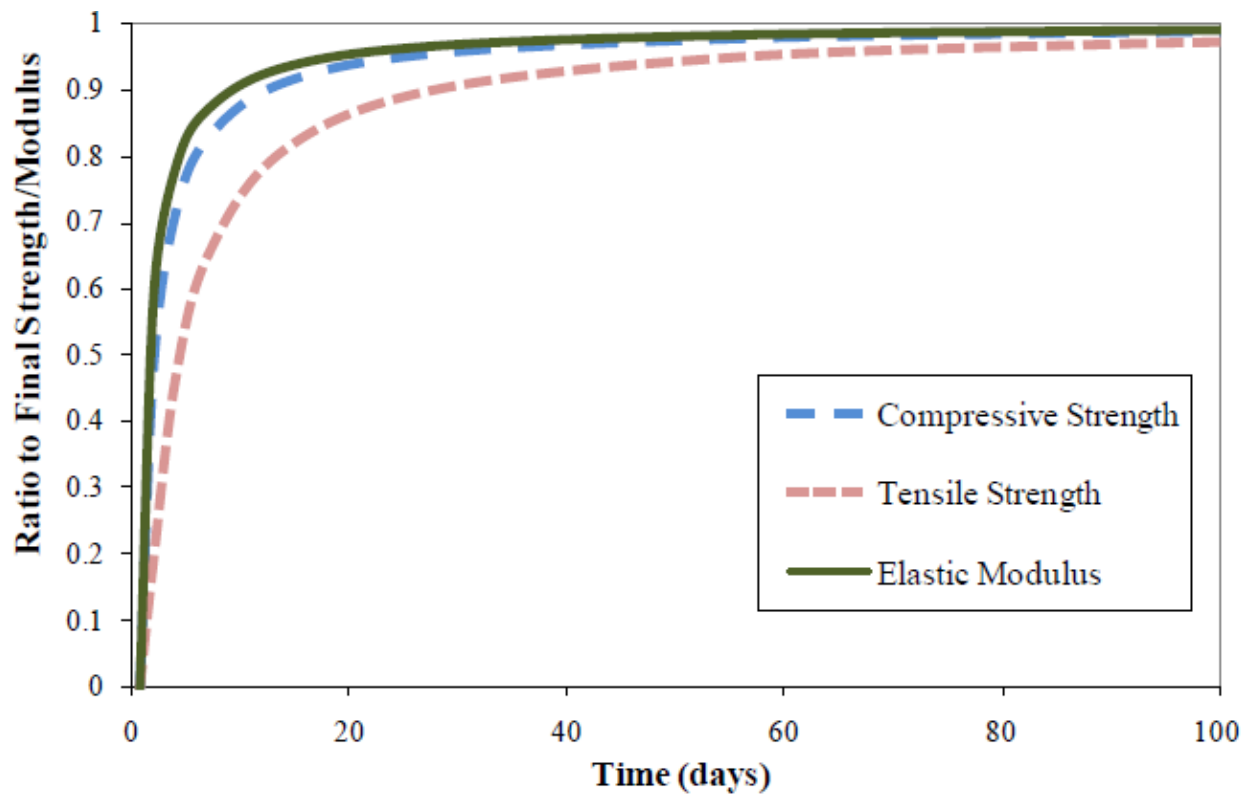

Figure 2.33: Rate of development of elastic modulus, compressive and tensile strength for untreated Ductal® 
Flexural and tensile failures must be ductile. It is said that the design of the material is optimal if fibers are working at $80-90 \%$ of their tensile strength when submitted to maximum tensile load. Fiber aspect ratio and tensile strength have to be chosen according to that. In some cases too high performance of the matrix is not recommendable. High fiber bond strength (adhesive, frictional and mechanical) can lead in the tensile failure of the fibers during the fiber pull-out process [123]. Also a very high tensile strength of the matrix implies lower number of micro-cracks during the strain hardening process. Figure 2.34 is showing results of four point bending tests ( $100 \times 100 \times 400 \mathrm{~mm}$ in un-notched prism) done to different type of special concretes [31].

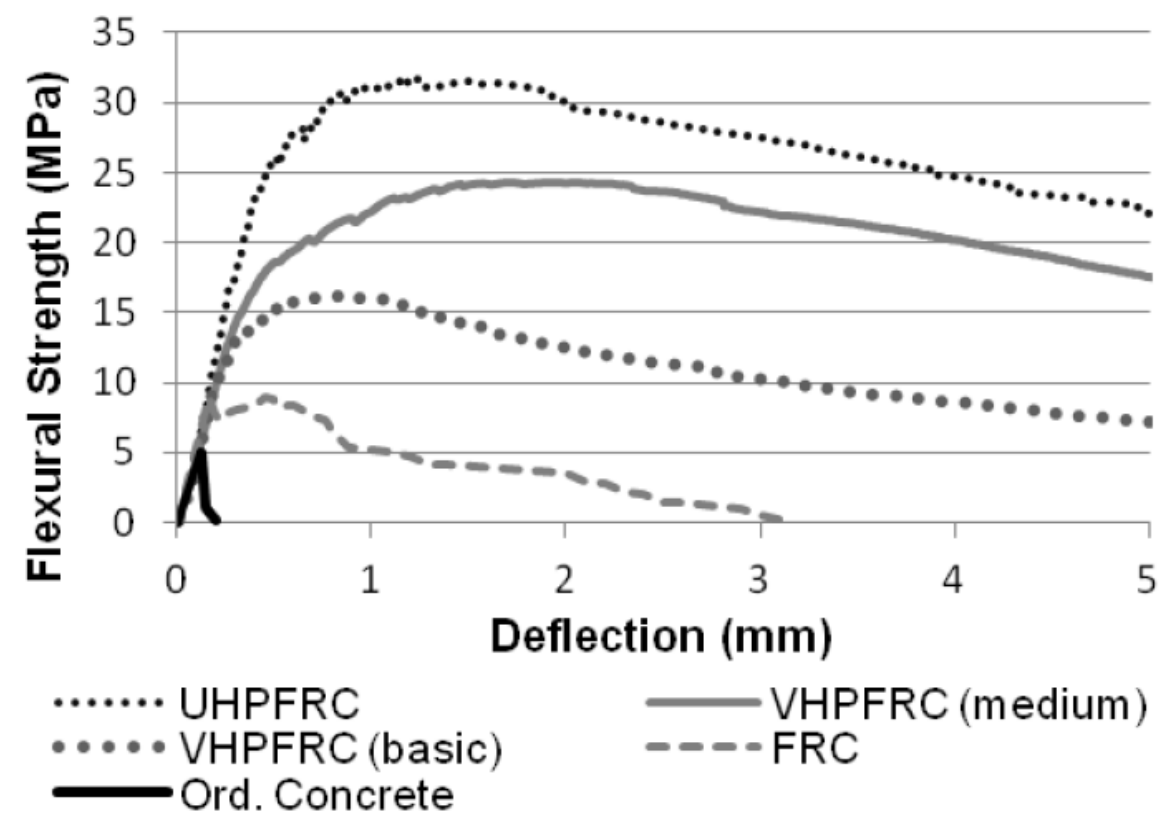

Figure 2.34: Flexural strength-deflection of tests made to different performance concretes [31]

Figure 2.35 shows the result of several direct tensile strength tests done to a dogbone specimen. As tensile tests are very tricky to perform [43], especially the un-notched ones, the tensile properties are in many cases obtained indirectly by an inverse analysis applied to the results deduced from flexural tests.
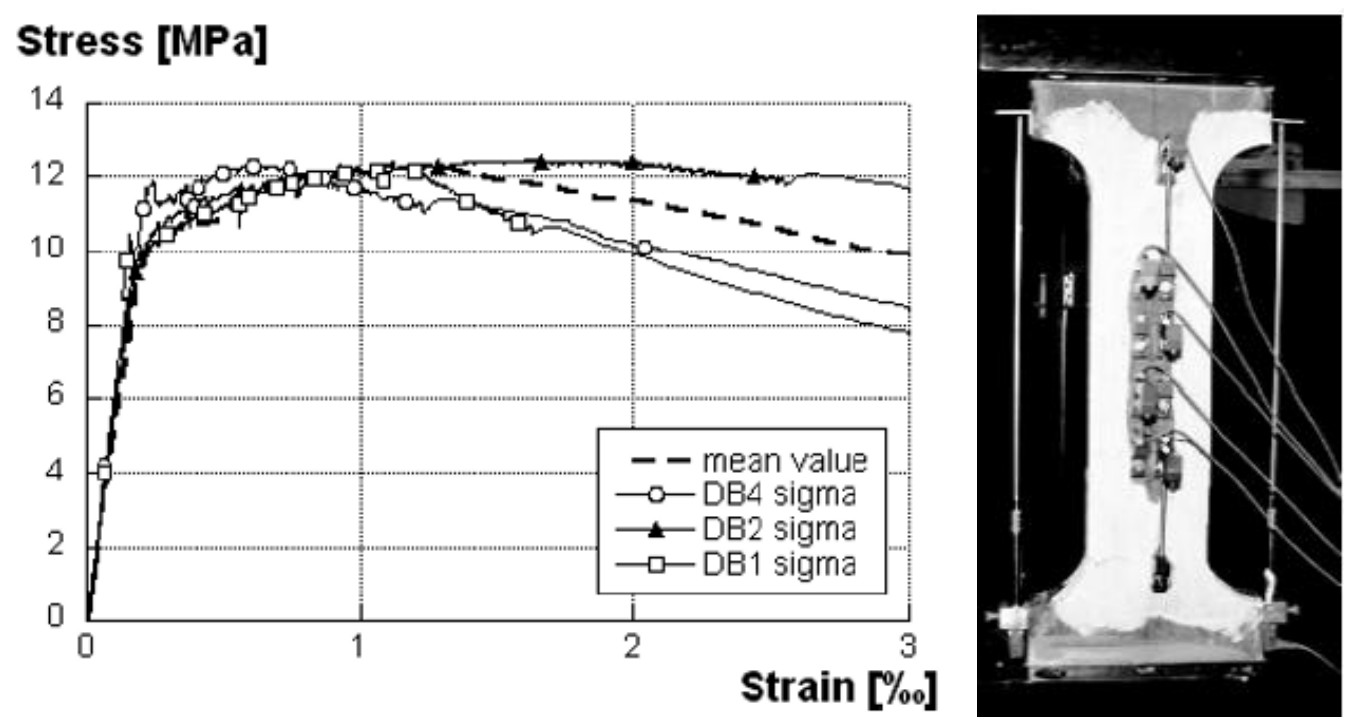

Figure 2.35: Tensile testing of a dogbone specimen of dimensions $50 \times 20 \times 2.8 \mathrm{~cm}$ [166] 


\subsection{DESIGN METHODS}

\subsubsection{RECOMMENDATIONS}

The European Standard Norm EN-206-1 [63] about specification, performance, production and conformity of concrete, defines several special concretes. Relating to high strength, it only defines HSC as the one with a strength class higher than $50 \mathrm{MPa}$ in $150 \times 300 \mathrm{~mm}$ cylinder, or $60 \mathrm{MPa}$ in $100 \mathrm{~mm}$ cube. There is not any reference to UHPC or UHPFRC.

Meanwhile, the Model Code 2010 classifies concrete according with the 28 days characteristic compressive strength $\mathrm{f}_{\text {ck. }}$. It defines Ultra High Strength Concrete (UHSC) as the one with a cylinder $\mathrm{f}_{\text {ck }}$ higher than 110-120 MPa, or 130-140 MPa in $\mathrm{L}=100 \mathrm{~mm}$ cubes. There is not any reference to UHPC or UHPFRC. As for other concretes, the modulus of elasticity, Poisson's ratio and fracture properties are defined for C120 concrete class, but conceiving it as a material without fibers.

The fib Task Group 8.6 (Ultra High Performance Fibre Reinforced Concrete. Chairman: Joost Walraven) is working with the aim to generate a first international set of design rules for UHPFRC [260], which will open the material to a much wider understanding. As UHPFRC is a quickly developing material, it is tried to take the profit of the existing experience and combine it with the recent research programs.

However, there are already few national recommendations for the Design and Construction with UHPFRC. The first and most comprehensive are the French, from AFGC-Setra (2002). In them are treated aspects related with the mechanical properties, design rules and durability. Also the Japanese Recommendations, published at 2004 by the JSCE have been used widely since the experience building footbridges in Japan is considerable.

The French Recommendation makes a distinction between three types of structural elements: Thin slabs (if thickness is less than 3 times the fiber length), thick slabs and beams. The proposal from the FIB task group is reduce this to only two: Thin slabs and massive elements [13]. As the majority of building codes, AFGC proposes a constitutive law for concrete with a stress-strain relation for the structural design.

In the compressive behavior, fibers are not explicitly taken in account, so the stress strain curve is similar to the curves of normal concrete. In ULS, Compressive branch is characterized by an elastoplastic diagram with maximum value of $0.85 \cdot f_{c k} / \gamma_{b}$, with an ultimate strain of $\varepsilon_{u}=0.35 \%$.

The fibers are considered for the tensile behavior, which has a multilineal stress-strain law divided by segments (see figure 2.36), where two different effects can be distinguished:

- An elastic phase, limited by the tensile strength of the cementitious composite $f_{t j} / \gamma_{b f}$.

- A post-cracking behavior with strain hardening behavior. This consist in the increasing tensile carrying capacity of the fibers after the cement composite cracking. 


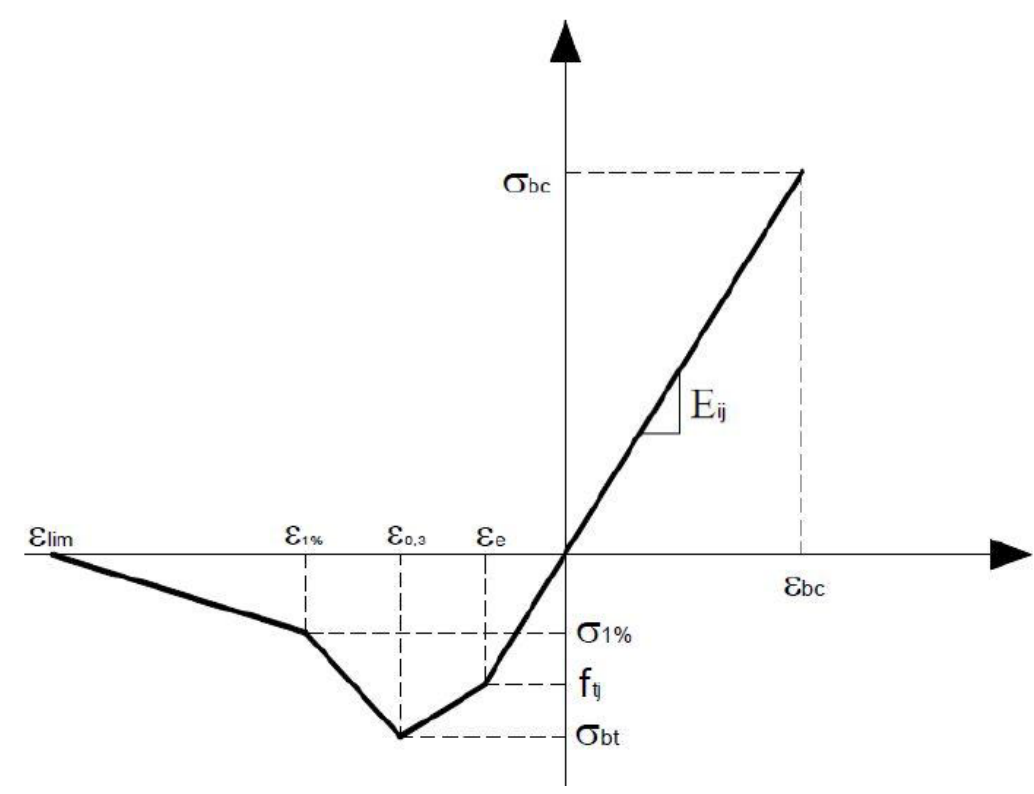

Figure 2.36: Stress-Strain law suggested by the French Reccommendation for UHPFRC

The maximum tensile capacity is associated with an equivalent strain equivalent to a crack width of $0.3 \mathrm{~mm}$. This strain is obtained with the following equation:

$$
\varepsilon_{u 0.3}=\frac{f_{t j}}{\gamma_{b f} \cdot E_{i j}}+\frac{0.3}{l_{c}}
$$

Where $l_{c}=0.66 * \mathrm{H}$ (being $\mathrm{H}$ the section high, the formula is for no reinforced elements) is characteristic length, used to transform the stress-crack width law in to a constitutive stressstrain law. After the maximum strength, the strain softening is produced up to an equivalent strain of $1 \%$, which is obtained with the following equation:

$$
\varepsilon_{u 0.3}=\frac{f_{t j}}{\gamma_{b f} \cdot E_{i j}}+\frac{w_{1 \%}}{l_{c}}
$$

Where $w_{1 \%}=0.01 \cdot H$, being $\mathrm{H}$ the section high of the element tested. From this strain value, the tension is reduced to 0 , value associated to the following strain:

$$
\varepsilon_{\lim }=\frac{l_{f}}{4 \cdot l_{c}}
$$

Being $l_{f}$ the fiber length.

The values of tensile strength associated to $\varepsilon_{u 0.3}$ and $\varepsilon_{u 1 \%}$ should be calculated with the inverse analysis performed to elements that reproduce adequately the behavior of the real piece. Other option is test different elements but reduce the tension with a K factor (from 1.25 to 1.75). The $\mathrm{K}$ factor considers the effect of the different fiber orientation between the real element and the element tested. AFGC does not explain a structured procedure to develop an inverse analysis, but it considers the effect of the fiber orientation. For ULS a safety factor $\gamma_{b f}$ is used, being iqual to 1.05 or 1.3 in the case of accidental or fundamental load combinations. Moreover, the Japanese Recommendations [113] also uses the concept of equivalent length. However, the strain hardening is simulated with a plastic plateau. 


\subsubsection{FROM BENDING TESTS TO CONSTITUTIVE LAW}

It is well known that direct tensile test methods are limited due to their complexity, time consuming and advanced equipment required. Therefore, it is not suitable for quality control purpose [205] [21] [171]. Thus, the flexural tests are much more extended as represent an easy alternative. The first procedures applied to FRC (Kooiman, 2000) were based on three point bending tests, assuming that only one crack was present. In general, bending tests should be performed to four point bending tests to unnotched specimens, otherwise the multiple cracking is not properly activated and there is not a region with constant curvature. The two most known models to obtain the constitutive law for strain hardening materials are the inverse analysis and the hinge model [32]:

\section{Inverse analysis:}

To obtain the tensile stress-strain relation from this tests an inverse analysis needs to be developed. Many authors have performed inverse analysis processes with some success. Some of them are:

- AFGC-SETRA (2002): This recommendations suggest how to obtain the tensile stress-crack width law by back analysis to the law bending moment - crack width obtained from flexural tests on notched prisms. The goal is obtain the tensile stress distribution in the cracked section of the element tested. Two formulas proposing the mechanical equilibrium of the section are provided (moment and tensile force). The crack width is related with the curvature of the uncracked section using a kinematic formula. An iterative process needs to be applied to obtain the two unknown variables: The crack depth and the stress.

- The Japan Concrete Institute (JCI) method and University of Michigan method (Ostergaard 1995, Kanakubo 2006 and Qian-Li 2007) are both based on a simplified elastic-plastic tensile model and can predict tensile properties from a four point bending test via sectional analysis similar to the developed by Maalej and li in 1994 [205].

The UM method may be more appealing to the users compared with the JCI as there is no need of LVDTs. However, originally it predicted only tensile strain capacity and not tensile strength, but Qian and Li [205] incorporated in 2008 a simple method to predict also the tensile strength. It uses the flexural stress-deflection curve to obtain a prediction of the bilinear tensile behavior (elastic and strain hardening behavior).

- Baby, Graybeal et al. (2012) [15]: They proposed two methods to obtain tensile stressstrain law from four point bending tests. The goal of both was avoid many assumptions to do the analysis. The comparison of both methods with the direct tensile tests showed a slight higher strength and strain of the firsts due to the better fiber orientation of the tensile face in the bending tests. The methods consisted in:

- Method 1: Measure the midspan strain on the tensile face. The experimental curve bending moment-middle span strain is converted in a tensile stress-strain curve using an inverse analysis, which consist in the equilibrium of moment and forces for each value of strain and its bending moment associated. The strain along the section is considered linear.

- Method 2: Measure the midspan deflection of the four point bending test, so the experimental curve obtained is a bending moment-middle span deflection law. By an elastic equation is possible to deduce the bending moment-middle span curvature. This curve is 
later converted into a tensile stress-strain curve using inverse analysis from the elastic loading until the maximum bending moment.

- Bretschneider et al. presented in 2013 [21] an inverse analysis method for strain hardening cement composites based on measure experimentally the beam curvature in the constant moment region of a four point bending test with LVDTs. The advantage of this method is that it requires less assumptions than the measurement of the force and the central span deflection. With the curve, an evolutionary algorithm finds the multilinear strain hardening curve which better reproduces the experimental curve. Direct tensile tests showed that there is a slight overestimation of the strength, probably due to the better orientation of the fibers in the bending test.

Hinge model:

- Østergaard et al. (DTU) [171], researchers from the Technical University of Denmark (DTU), developed an inverse method using the hinge model, which included both the strain hardening and tension softening effect. The model assumes that the element tested generates a structural localization mechanism after the crack. The associated moment and deflection depends on the hinge equations proposed. It was used along least square to obtain the tensile behavior from the bending tests. The model predicts an experimental load-deflection curve and the tensile properties deduced agree well with FEM analysis.

\subsection{CONNECTIONS WHERE UHPFRC TAKES PART}

\subsubsection{INTRODUCTION}

A new material as UHPFRC needs to adapt new methods and processes, as mixing, casting, pouring, or connection between elements. The last is one of the less studied subjects up to the moment concerning to this material.

UHPFRC use increases the efficiency of the structure, since the load carrying capacity of the material is higher. This also leads in higher stresses on the composite joint [105], so different connection methods than those used for ordinary concrete can be required. UHPFRC structures can be built economically and in short construction periods, so the adoption of an efficient joint technology becomes a key point to obtain the maximum profit of this concrete [237].

The jointing of precast system has been always a source of potential maintenance [178]. The use of UHPFRC is a low maintenance solution. Its high ductility and strength makes it suitable to be used for the connection of ordinary concrete elements. It is worth to connect UHPFRC elements to each other or to other ordinary concrete elements. Also other materials, as steel or epoxy resins can be used to connect precast UHPFRC pieces. Also post-tension of the concrete and shear keys are a simple way to connect single precast pieces to each other, and in many real cases both have been used together.

Present practical experience tends to favor corrugated wet joints, the keying material being either epoxy-glue or a small layer of UHPFRC, with post-tensioning ensuring a minimum compression even under infrequent service loads. Whatever the technique, geometrical control of the segments given their whole casting, setting, hardening and pre-loading process, 
appears of critical importance [245]. Some examples of real applications, separated by types, are attached in the following lines.

\subsubsection{SHEAR KEYS}

Shear keys are a very used solution to connect precast elements with ordinary concrete, being in many cases combined with other methods as concrete post-tensioning or epoxy-resin. Also in UHPFRC it is used.

\subsubsection{SHEET PILES}

As a first example, Grünewald et al. [249] developed UHPFRC sheet piles conceiving them as the typical steel sheet piles (figures 2.37 and 2.38). The connection between each other consisted in continuous shear keys without any ordinary reinforcement. During the pouring process, the longitudinal flow of the selfcompacting product caused a fiber orientation that increased the flexural strength, but didn't benefit the ductility of the shear keys. However, with an ordinary sheet pile installation process, the shear keys suffered only minor damage.

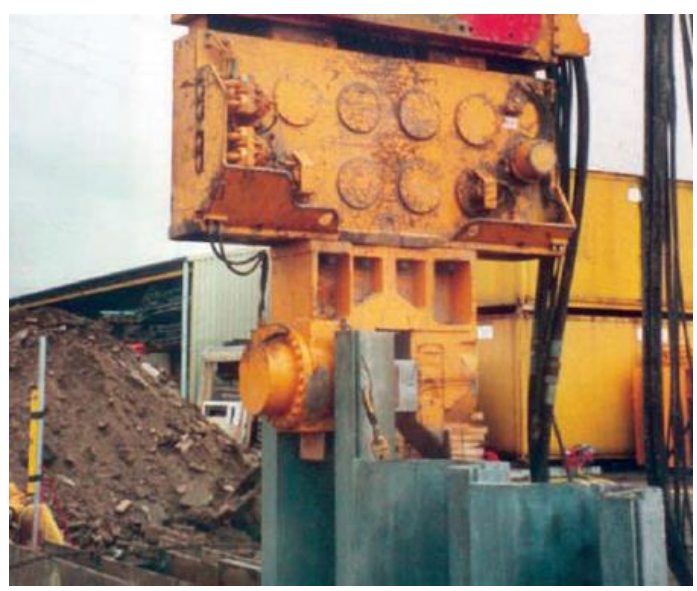

Figure 2.37: UHPFRC sheet piles being hammered

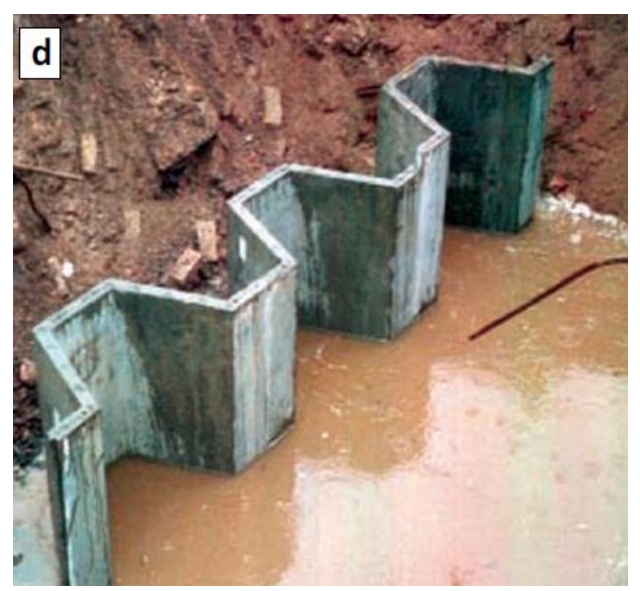

Figure 3.38: Sheet piles already placed

\subsubsection{FOOTBRIDGES}

In the Sherbrooke footbridge, the first RPC structure built, the connection between the six bridge precast segments that compose the full element was done thanks to the match cast design, and also with internal tendons that provided continuity (figure 2.39).

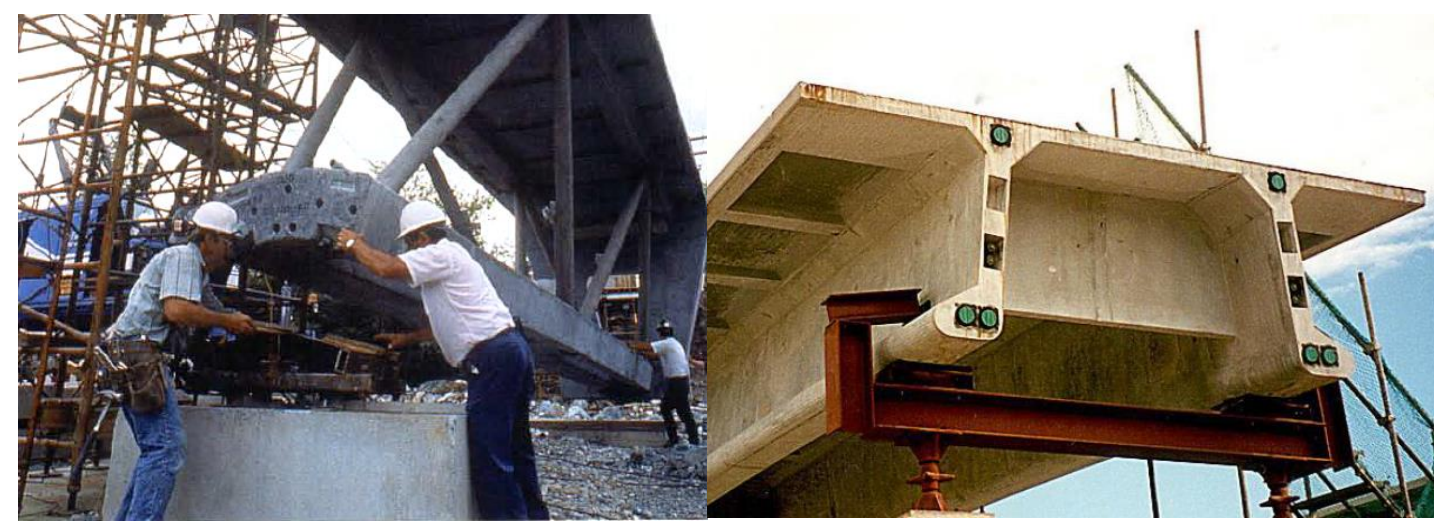

Figure 3.39: Construction procedure of the Sherbrooke footbridge
Figure 2.40: Sakata Mirai footbridge in the construction process 
The same procedure was used at the Sakata Mirai footbridge, where a temporary support allowed to place an internal longitudinal prestressing that joined the prefabricated elements, which also had shear keys (figure 2.40).

\subsubsection{CAST IN PLACE JOINTS}

The use of Post-Tensioning (P/T) across the joints of precast deck panels has been used as a method to ensure the deck effectively remains structurally monolithic while performing under the constant pounding of truck wheel loads and seasonal conditions and that the joint does not deteriorate or leak. However, post-tensioning is expensive, requires specific expertise and equipment for installation. In-situ UHPFRC provides opportunities for bridge engineers to design shorter joint widths for precast deck systems without the use of post-tensioning, guaranteeing lot of years of low maintenance usage.

The high control and mixing requirements of the UHPFRC normally difficult the achievement of a successful in-situ UHPFRC. Also, the material continuity may be difficultly achieved when precast components are made of heat-treated UHPFRC, while cast-in-place joints will generally not be heat-treated [245]. However, an in-situ UHPFRC have some advantages: The self-leveling of the material, the superior freeze/thaw resistance, low porosity, reduced joint size and complexity, improved durability, speed of construction, elimination of post-tensioning and extended usage life [178]. Also there is higher capacity to carry the efforts of the truck loadings across the joints. Minimizing the joint size also reduces the quantity of jointing material to be cast on-site and simplified the precast panel manufacturing [178]. Then, in some cases if it is possible UHPFRC is cast in-situ to connect two elements, made of UHPFRC or OC.

\subsubsection{DUCTAL@ IN-SITU APPLICATIONS IN BRIDGES}

One of the examples is the use of UHPFRC to create a continuous deck with two isostatic spans, as it is done with ordinary concrete. It was used at the first road UHPFRC bridge made (Bourg Les Valence, 2000-2001) [25] [22], where $\pi$-shaped precast prestressed UHPFRC beams from the different spans (two of 20 meters long each one, see figure 2.41) were connected using in-situ UHPFRC, using also reinforcement steel bars.

Ductal ${ }^{\circledR}$ has been also used by Lafarge North America to solve the problem with deteriorating bridges, also in the joints. It provides strength, durability, highly moldable products, high quality surface aspect and a short bond development length. One of their first uses was at the CN Ride Overhead Bridge (placed at Rany Lake, year 2006 [22] [178]), where UHPFRC was used in-situ to connect reinforced high strength concrete deck panels (see figure 2.42). It was shown that UHPFRC, used as a jointing material in conjunction with reinforced HPC panels provides a synergistic, new approach for reconstruction of bridge superstructures. Since this application, the Ministry of Transportation of Ontario (MTO) used a similar type of solution for 14 bridge deck projects, from which many are completed and others in various phases of design or construction [179].

Later, in 2008, the New York State Department of Transportation (NYSDOT) decided to investigate the use of UHPC joint fill with full-depth precast deck panels for replacement of deteriorating highway bridge decks. It enabled the simplification of the precast panel fabrication and installation processes. The NYSDOT development a four phase program in 
order to investigate, prototype and test UHPFRC this application for the NY state highway system. Material was assumed to provide sufficient bond development to allow full continuity of the rebar, as if it were continuous through the joint. Previous tests showed that the bond development length of a $13 \mathrm{~mm}$ bar in UHPC is less than $75 \mathrm{~mm}$. They used for first time in-situ UHPFRC joints at a $25.9 \mathrm{~m}$ single span Deck Bulb-Tee girder-bridge in the Village of Lyons, NY.

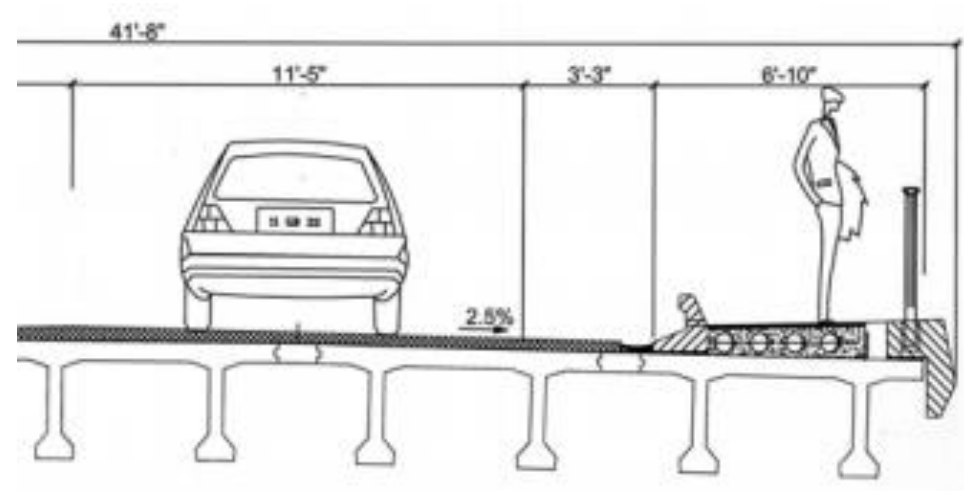

Figure 2.41: Half typical cross section of Bourg les Valences bridge

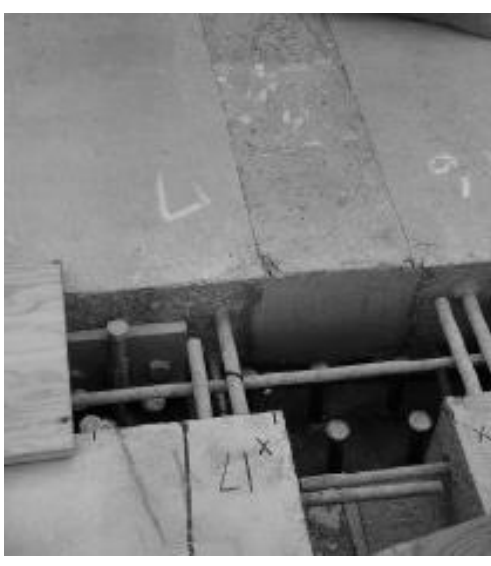

Figure 2.42: One of the joints of the CN Ride Overhead Bridge

The second demonstration project selected for UHPFRC joint fill was a $39 \mathrm{~m}$ single span, 2lane, full-depth precast deck panel bridge on steel beams near Oneonta, NY, in Otsego County. NYSDOT validated in this project the field casting process for UHPC joint fill in full-depth precast deck panels. The goal was built on the experience gained from Village of Lyons project.

The Oneonta project consisted of 22 precast deck panels set on five $38.8 \mathrm{~m}$ long steel girders. The $6.4 \mathrm{~m} \times 3.39 \mathrm{~m}$ panels had a thickness of $200 \mathrm{~mm}$ (the depth also of the joints), being reinforced with $16 \mathrm{~mm}$ galvanized rebar each-way top and bottom (see figure 2.43), with hairpin bars in the joints. Typical UHPFRC joints were $152 \mathrm{~mm}$ wide, utilizing $11.5 \mathrm{~m}^{3}$ joint-fill material (figures 2.44 and 2.45, which show their distribution in both directions). The bridge received a $50 \mathrm{~mm}$ bonded concrete over-lay with an integral non-skid surface texture.

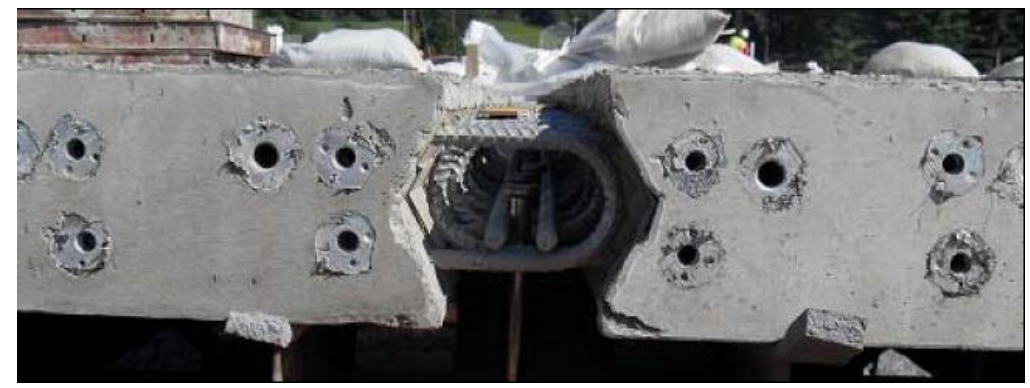

Figure 2.43: Detail of the connection between two panels

The in-situ concrete was mixed at two portable mixers IMER Mortarman 750, capable of batching $0.15 \mathrm{~m}^{3}$ per 20 minute. Every batch is checked for plastic properties and also compressive strength was later validated. The UHPFRC joint material was transported to the joints by power buggy or wheel barrow then dumped directly into the joints without any vibration (Figure 2.45). The joints were covered to avoid surface dehydration of the joint fill, and then allowed to cure until reaching $100 \mathrm{MPa}$ before opening to traffic. At ambient temperatures $\left(20^{\circ} \mathrm{C}\right)$ without any accelerators, the time to reach this $100 \mathrm{MPa}$ would be approximately 3 days, being possible to reduce it with accelerator or heat. 


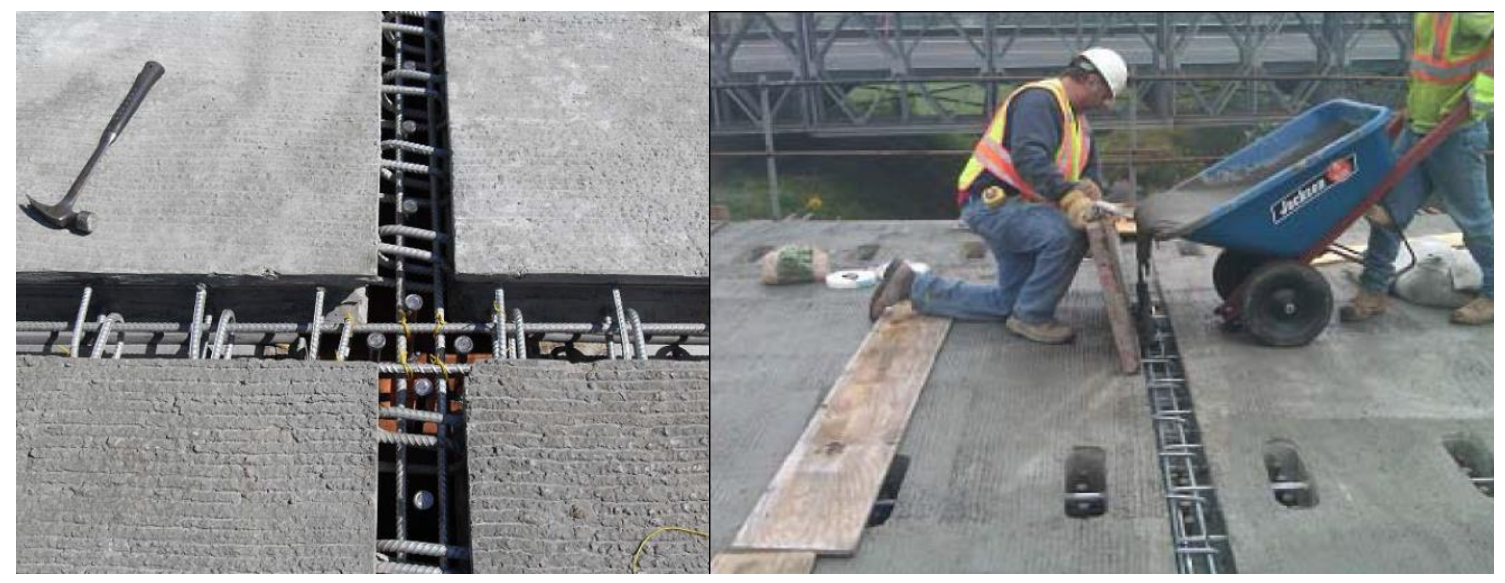

Figure 2.44:Intersection of the center line joint and transverse joint prior to filling

Figure 2.45: Filling the joints with UHPFRC

\subsubsection{BRIDGES WITH OTHER UHPFRC}

Other in-situ UHPFRC joint was used at the $25 \mathrm{~m}$ long Kampung Ulu Geroh Bridge. Two UHPFRC T-precast beams were used to save a span of $25.5 \mathrm{~m}$, where the width required was $3.5 \mathrm{~m}$. The transversal connection between the beams was done with conventional reinforcement and in-situ UHPFRC. The last was poured at the jointing area without any external compacting tools. Figures 2.47 and 2.48 are showing the process. After 1 day, the formwork was removed and the in-situ UHPFRC attained an average cube compressive strength of $70 \mathrm{MPa}$. After 14 days, the cube sample of the in-situ stitch where tested to have an average cube compressive strength of $145 \mathrm{MPa}$ [253].

Some commercial UHPFRCs are also used for these applications: The so-called Compact Reinforced Concrete (CRC, a type of UHPFRC) has been used from years ago as an in-situ cast joint between precast conventional concrete elements (figure 2.49) or between other CRC elements (figure 2.50). It is suitable for have high strength, ductility and exceptional bond properties. The full anchorage can be achieved after 3 days with an embedment length of 5 to 8 diameters of ordinary steel bar. After this time, surely the failure cannot be suffered in the joints. The figure 2.50 shows the system used in many cases [14]. Similar type of joints have been used with UHPC at the bridge of the Canandagua Outlet in New York, in order to make smaller and more durable joint and in shorter construction time.

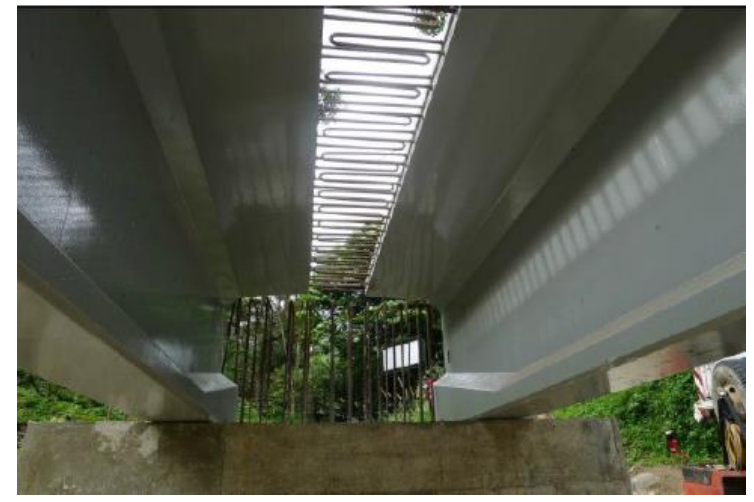

Figure 2.47: Transversal conection between the T beams

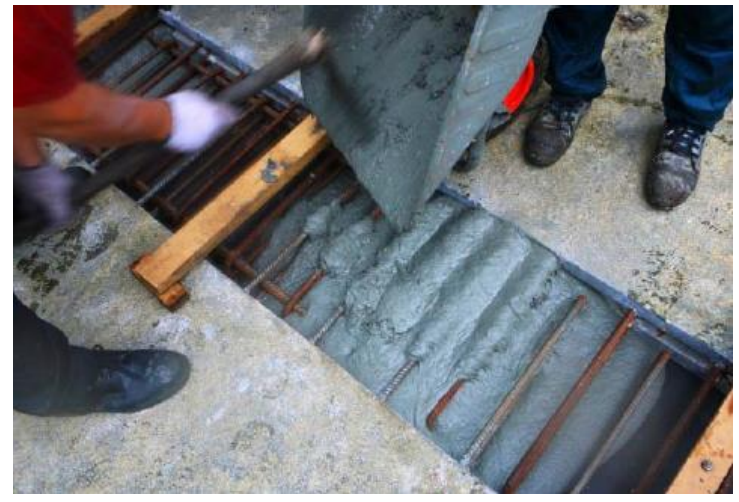

Figure 2.48: In-situ concrete being poured 


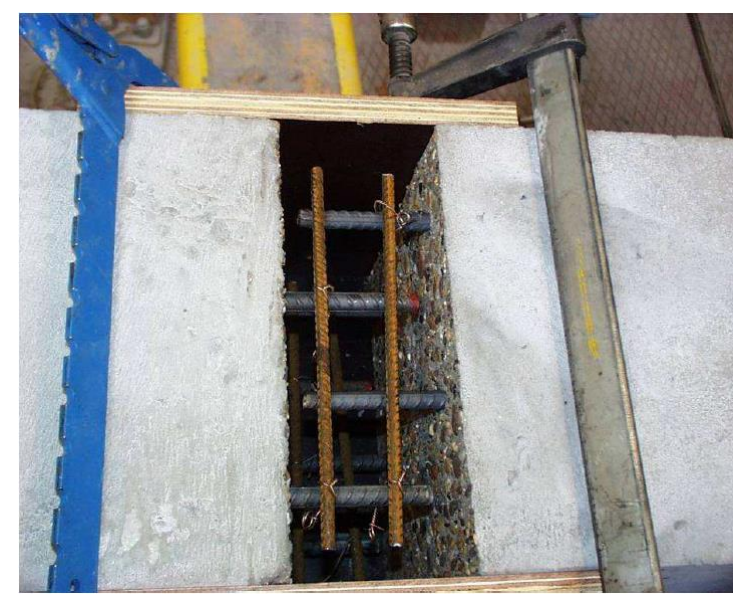

Figure 2.49: CRC joint made between OC elements

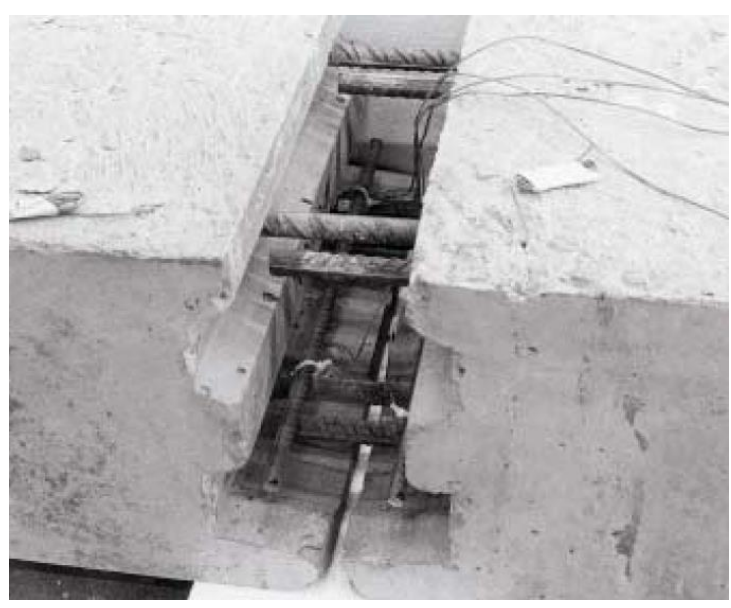

Figure 2.50: Connection between CRC elements

\subsubsection{FOOTBRIDGES}

The Sakata Mirai footbridge [57] [238] (already shown at figure 2.40), made with Ductal ${ }^{\circledR}$ and already referenced before because of the shear keys, also used an in-situ transversal and longitudinal joint to connect the six precast segments that compose the full structure to each other. The in-situ concrete was RPC, like the material used for cast the elements. The joints were heat-cured using electrical heaters and insulation.

\subsubsection{COLUMNS}

Also in UHPFRC column-slab connections an in-situ concrete might be required. UHPFRC columns are more slender than conventional concrete ones. Thus, the connection with an ordinary concrete slab cannot be designed as it is traditionally done with conventional columns. Due to the difference of concrete strength it is not possible to achieve sufficient bearing capacity with a simple connection. Then, Schenck and Küchler [207] proposed several methods to connect UHPFRC filled tubes with ordinary concrete slabs. The one shown in the figure 2.51, requires rebars in the joint area and a steel mounting element cast with in-situ ordinary concrete. This example shows how traditional connection methods require a new design if some of the materials is UHPFRC.

\subsubsection{BOLTED JOINTS}

\subsubsection{CANNOPIES}

One of the first uses of bolts was at the Shawnessy Station, on Canada. The design required three canopies to be connected to each other with a series of bolts along the ribs of the canopies. The individual precast elements were joined together with a bolted seam at the apex of the curve and a beam tension tie across the opening at the base. After the assembly, the unit was structurally stable [54]. An assembly jig was used to locate accurately the individual halves and allow them to be rolled together.

The struts were connected to the canopies and the columns with stainless steel connections through pinning and welding. The strut to mid-column connection was done also with a stainless steel connection bolts, where the interfacing sections were "buttered" with epoxy (figure 2.52). 


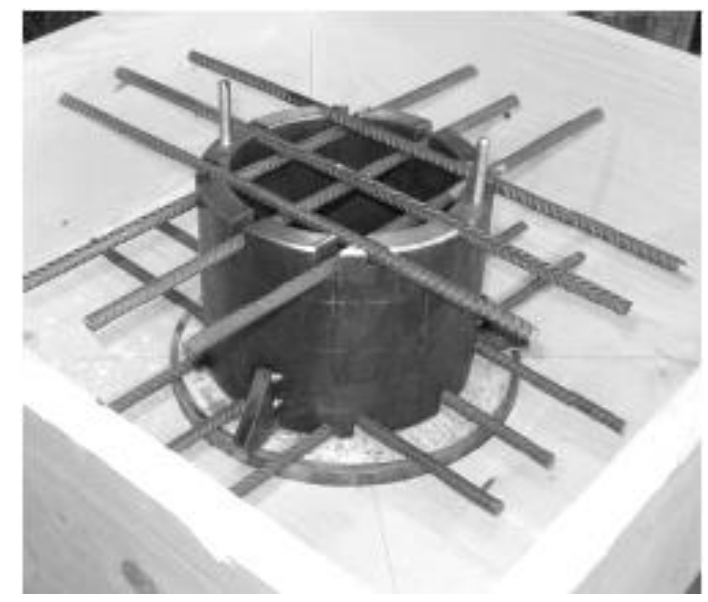

Figure 2.51: Special mounting element

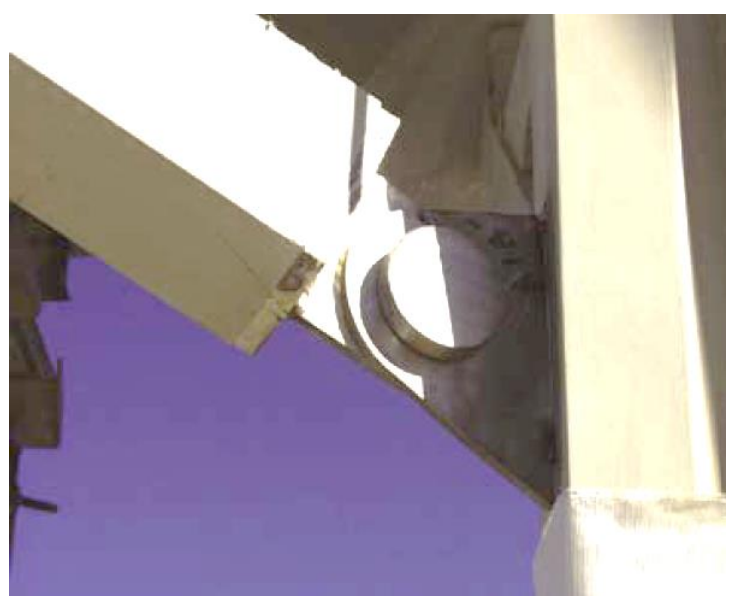

Figure 2.52: Detail of the steel bolted connection

\subsubsection{RETAINING WALLS AND WALL PANNELS}

Voo et al. [253] proposed thin and light-weight wall panels without any conventional steel reinforcements. Each wall panel had a height of $7 \mathrm{~m}$ and a width of $2 \mathrm{~m}$, thickness of $30 \mathrm{~mm}$ and comes with a self-weight of $2400 \mathrm{~kg}$ per piece, and two ribbed beams as wide as $75 \mathrm{~mm}$ and a base pad of $100 \mathrm{~mm}$ in thickness (figure 2.53). The solution to connect the wall was easy to install as pre-positioned bolts. Nuts were used to connect the wall panel to the floors, requiring also some grout to uneven floor base. No cast in-situ work was required. The same connection type can be used for the cantilever retaining walls (figure 2.54) suggested also by the same working group. Both precast elements are actually sold in the market.

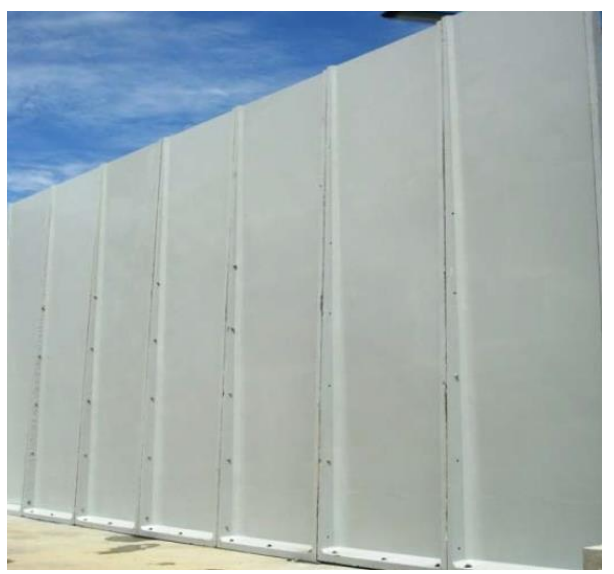

Figure 2.53: DURA® Light Wall pannels

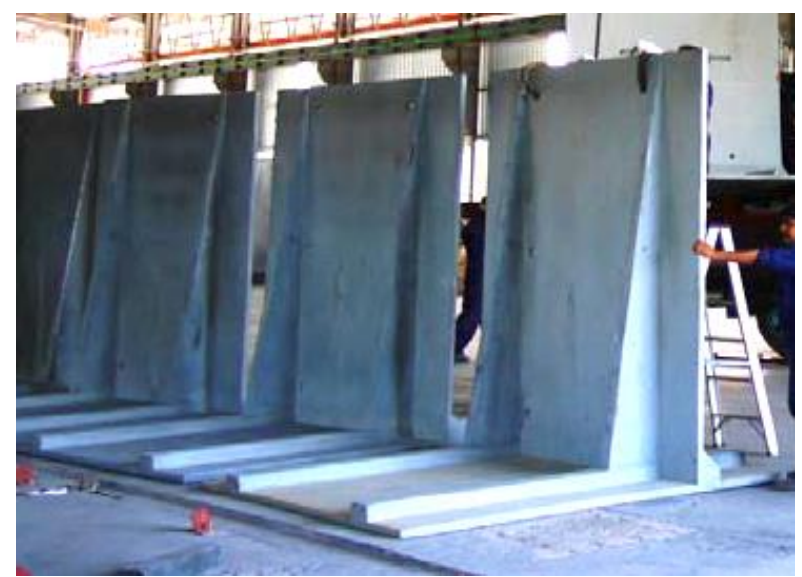

Figure 2.54: Retaining walls made with DURA®

\subsubsection{PORTAL Frames}

The world first portal frame using UHPFRC (The Wilson Hall) was built at Malaysia, and designed by Voo and Poon at 2008. The commercial material was Dura Technology Sdn. Bhd. (Perak, Malaysia). Each portal frame is spaced $12 \mathrm{~m}$ and the hall consists of eight pieces of DURA® UHPC prestressed columns, internal rafters, cantilevers and haunch connections as shown in figure 2.55. Columns and beams are connected to the joining piece using steel bars and bolted joints that allowed a monolithic connection. The installation of the portal frame was completed in 6 days with a simple process: The bars of the rafters were placed to match in the 
haunch connection holes, and then the nuts were screwed in. Figures 2.55 and 2.56 are showing half of the symmetrical portal and the massive end of a rafter with the bolt holes.

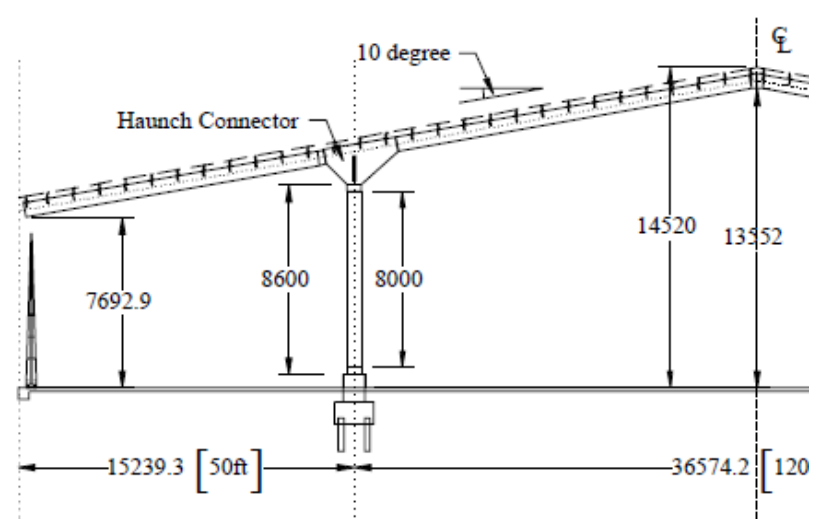

Figure 2.55: Design of the portal frame

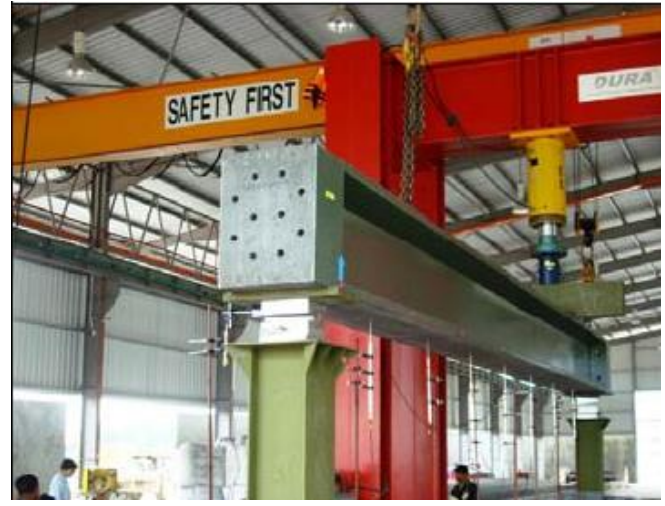

Figure 2.56: Shear test of a rafter beam, where the massive end can be seen

\subsubsection{BRIDGES}

The bridge over the Jackway Park consists of three $\pi$ girders. To connect the girders and act as diagrams, the span includes tubular steel diaphragms attached between the bottoms of the bulbs of the girders at the third points of the span (figure 2.57). The connection is made with bolted joints.

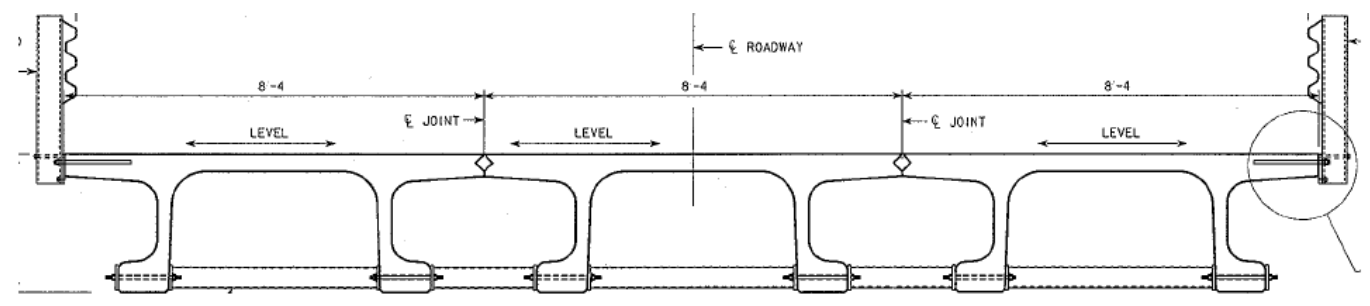

Fig 2.57: Jackway Park Bridge cross section with three UHPFRC beams and the diaphrams

\subsubsection{SUPPLEMENTARY ELEMENTS}

Many attempts have been done to connect UHPFRC truss systems. Although joint elements and prestressing tendons are required as additional elements, some authors affirm that it is possible to reduce the production costs and construction time [165].

\subsubsection{MODULAR TRUSS}

Professor Viet Tue et al. [88] proposed a modular UHPC truss construction where the elements are braced with each other by means of UHPC joint elements (figure 2.58, left) and prestressing tendons, being possible to assemble at the prefabricated company or at the construction site. The system consists of separate chords, braces, posts and connecting tension elements. The chords are prestessed with tendons. The main advantage is the high flexibility for transport and erection, as the assembly can be carried out on the building site.

The truss elements can be prefabricated in different lengths, being cut by saw. The connecting elements proposed transmit compressive, tension and shear forces between the connected truss elements, being reinforced to avoid their failure (figure 2.58, right). 
Compressive strength transmission is carried via contact, the tension via prestressed tendons, and the shear forces via friction forces activated with the prestressing.
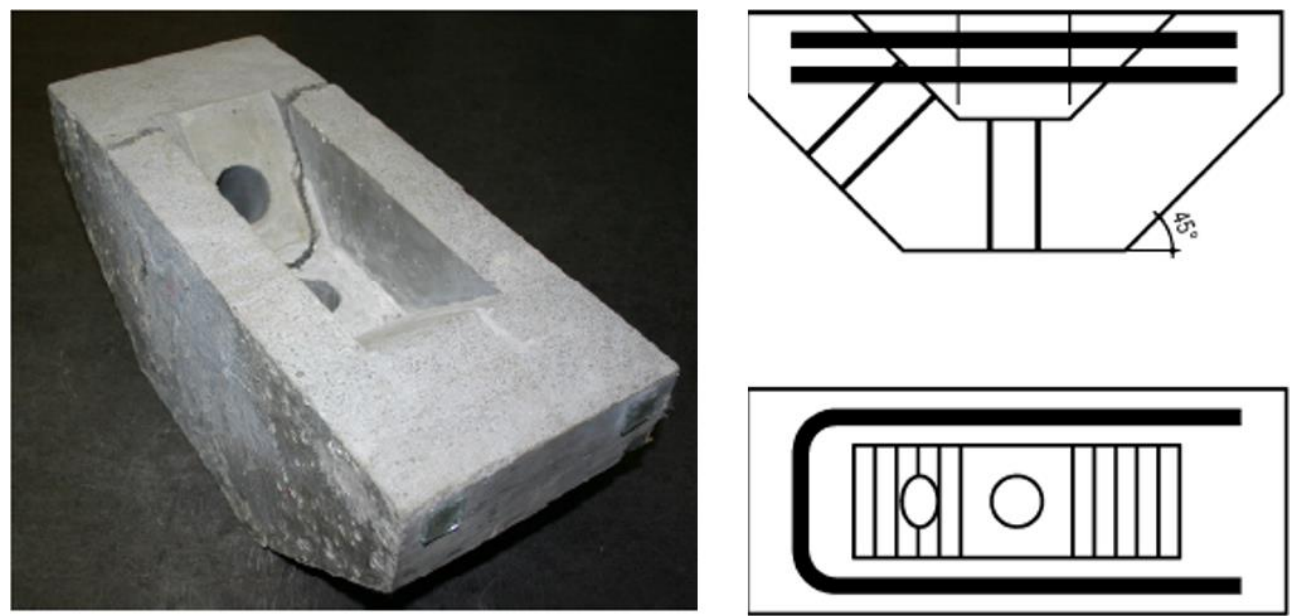

Figure 2.58: Connecting element without reinforcement after test and design of the element with ordinary reinforcement

\subsubsection{ARCH STRUCTURE FOR BRIDGE}

WILD Road Bridge (Völkermart, Austria): For this bridge, knee special FRC elements were designed as connectors to build an arch structure with UHPFRC box girders [188], where external tendons running inside the arches helped to made possible the assemble. An additional wrapping with Carbon Fibre Reinforced Polymer sheet were used to cover the connection and avoid brittle failure in this region. Figure 2.59 shows a scheme of the concept.

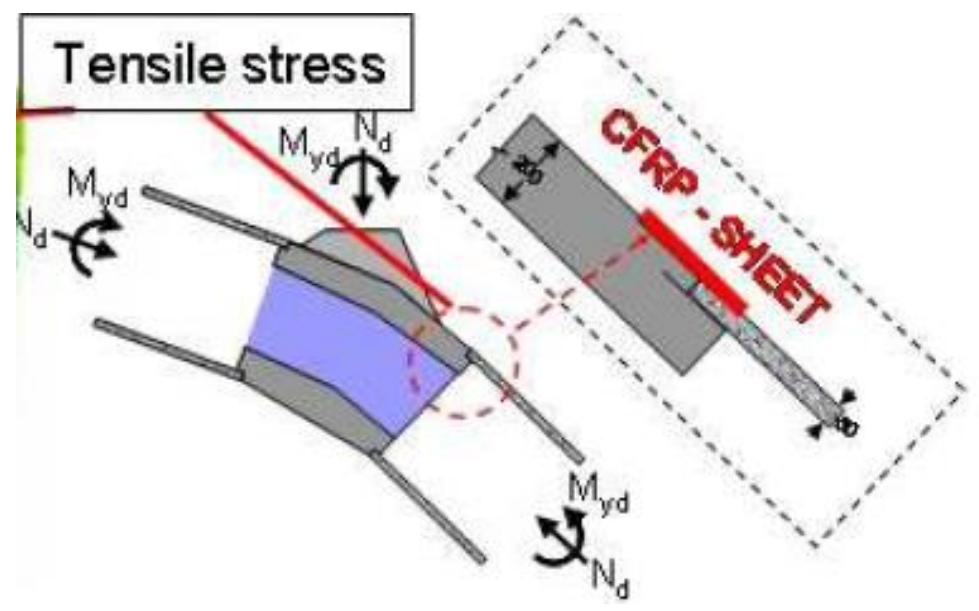

Figure 2.59: Detail of a knee of the arch structure

\subsubsection{EPOXY CONNECTIONS}

Due to the relatively high tensile strength (around 10-12 MPa) and the dense structure, UHPC is very well suited for gluing. This holds true for the application of UHPC elements amongst each other [68], becoming a durable high strength adhesive. This bonding sometimes can be the only joining method to connect precast elements each other or with steel. Epoxy resins can also be combined with shear keys, inducing larger failure loads than some types of cast-in-place joints [132]. 


\subsubsection{GÄRTNERPLATZ BRIDGE}

One of the first footbridges built was the Gärtnerplatz Bridge, over the river Fulda, in Kassel, a multispan solution with a total length of $132 \mathrm{~m}$ [67]. The structural concept consists on a hybrid steel-UHPC truss structure, where the fist is used for the truss diagonals and the bottom chord and the second for the deck and upper chord. The bridge has two type of UHPC connections:

- For transfer the shear forces from the diagonals to the upper chord prestressed bolted friction connections are used.

- A glued one (with epoxyresines) between the UHPFRC deck plates ( 2 x $5 \mathrm{~m}$, being the last deck width) and the UHPFRC upper chords, also made of UHPFRC. Gluing was selected for the difficulty develop a bolted connection. The construction process required that the plates were lift one by one and glued to the upper chord and to the previous plate, reducing then additional stresses. The epoxy glue, from SIKA®, shown a tensile and shear strength practically identical with the UHPC itself. The measured friction coefficient between the UHPC and the sand blasted steel amounted to $\mu>0.80$. For the durability, additional test were done to the glued connection with thermal/hygral loading. It showed that the sandblasted UHPC surfaces provides a durable strength.

\subsubsection{COMPOSITE BEAMS AND REHABILITATION}

Also mixed connections between two concrete types are possible. Elmadhy developed a structural system creating a beam section that consisted on a Glass Fiber Reinforced Polymer with external reinforcement, and a thin layer of UHPC cast on the top, to carry the compressive stresses. The composite action between both materials was ensured through shear stud connectors and moisture insensitive epoxy adhesive applied on the top flange of the GFRP section before casting the UHPC. The tests shown that wet bonding of UHPC to the GFRP box section using moisture insensitive epoxy can provide excellent bond, as a linear strain distribution was measured experimentally along the mid-span section. On the figure 2.60 can be seen the compressive failure mode.

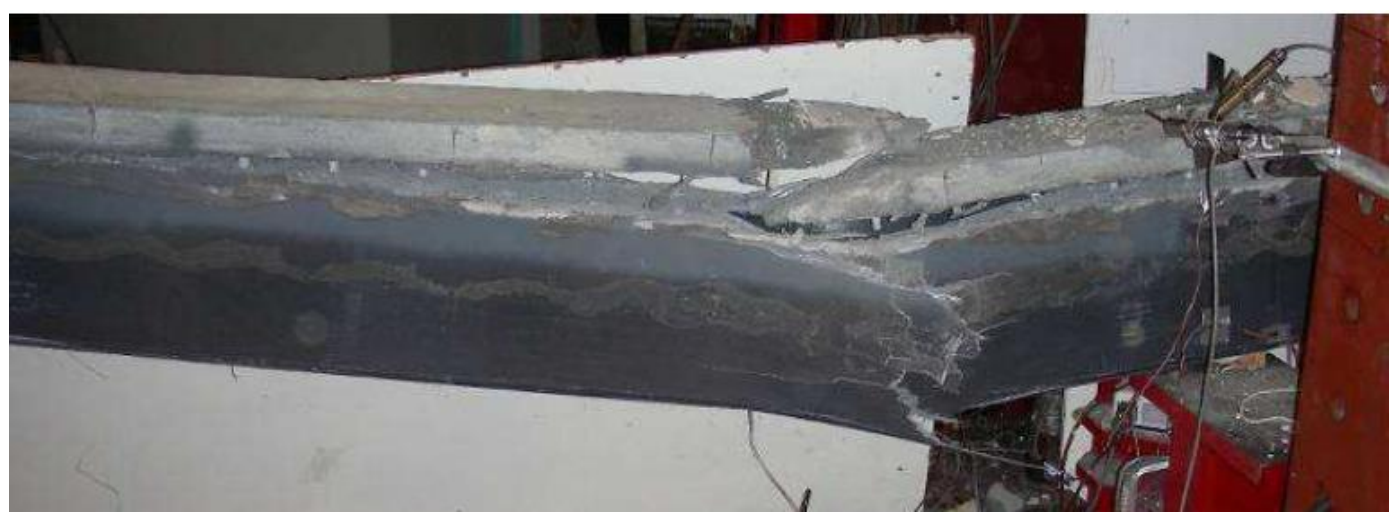

Figure 2.60: Failure of the tested beam

For orthotropic decks epoxy-resin has been also used: Over the steel, a $2 \mathrm{~mm}$ layer of epoxy resins is applied, on which fine broken aggregate is sprayed in order to obtain an interface layer with sufficient bonding capacity [179]. 
Also, the UHPFRC known as CARDIFRC $囚$ is designed to be used as bonded strips in the tension chord for rehabilitation and improvement of existing beams, incorporating also reinforcement bars. The material is normally bonded to the concrete member with epoxy adhesive. The composite beams have been proved with four point flexural tests and exhibited monolithic behavior, so the joint shows great performance [53].

Finally, epoxy-resin connection was used in the in the Toll Station of the Millau Bridge (2004) [181]. Applications with steel connectors glued to the UHPFRC for shear connections in composite structures are also satisfactorily reported [104].

\subsubsection{CONTINUOUS SHEAR CONNECTORS}

\subsubsection{PERFOBOND STRIP}

One of the most used systems for connect UHPFRC pieces is the Perfobond Strip (PBL), developed by Leonhardt. It has been used for girders [235] and slab-girder connections for bridges mainly in Japan [167] [236] [237]. These shear connectors consists in a steel piece with two holes that connects both materials for shear transmission. Some tests have compared stud shear connectors with the PBL joints, indicating much larger shear resistance capacity and shear rigidity for the lasts. The high initial shear transfer of the PBL joints plays an important role for it [237]. Figures 2.61 and 2.62 show the use of PBL joints in a Japan bridge. The system has been used at the Akakura Onsen Yukemuri Bridge (year 2004), Horikoshi C-Ramp Bridge year 2005), Mikaneike Footbridge (year 2007), Akasaka Yagenzaka Footbridge (year 2009).

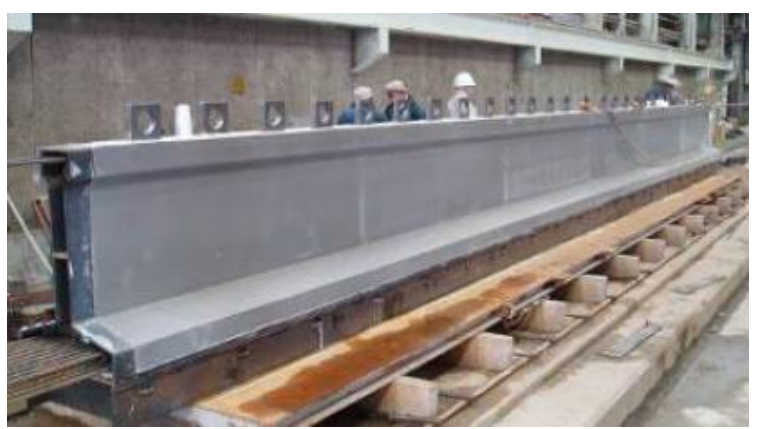

Figure 2.61: Perfobond system (PBL)

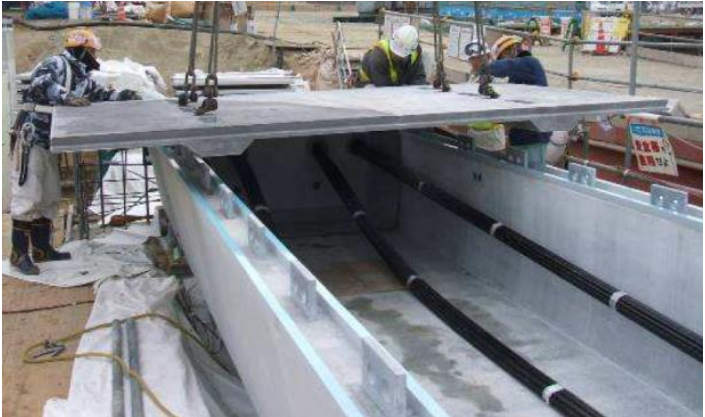

Figure 2.62: Connection between pieces

\subsubsection{COMPOSITE STEEL-UHPFRC BEAMS}

Continuous shear connectors can also be used in composite steel-concrete beam. In them, normally the steel carries the tensile forces and the concrete is arranged in the compression zone. Traditionally a composite beam of steel and concrete has the shear connection accomplished by headed studs. However, the higher the strength concrete, the more limited is this solution. Due to their high load carrying capacity and high initial stiffness continuous shear connectors, as the puzzle strips proposed by Hegger and Rauscher [105] in the DFG priority program SPP 1182. They are shown at the picture and are very appropriate. In order to analyze the ductility some push out tests were performed.

The shape has the advantage that with the cut of the web I-steel section two beams can be produced because of the symmetry. 
Additional transverse steel reinforcement is required, as seen at figure 2.63 [105] [104] [265]. Different failure modes have been found at laboratory tests depending on the thickness of the connector (see figure 2.64). After optimize the dimensions of the shear connector thickness and of the reinforcement, a composite beam with this connection type was tested in bending and the failure mode suffered was at the compression zone, showing the suitability of this continuous joint (figure 2.65).

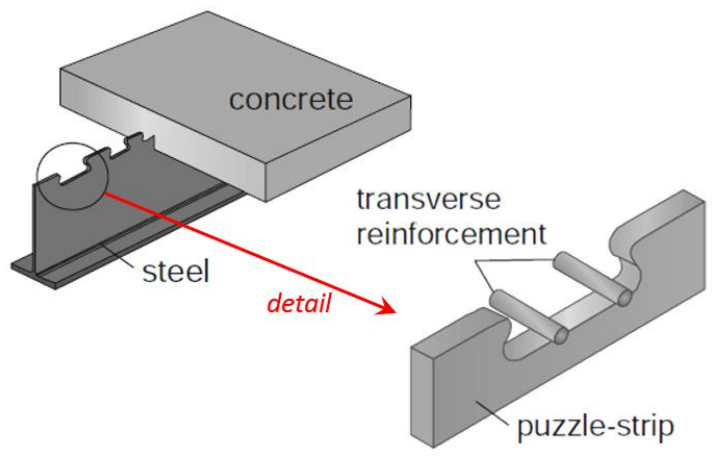

Figure 2.63: Connection system between UHPC and steel

\section{contact pressure concrete shearing}

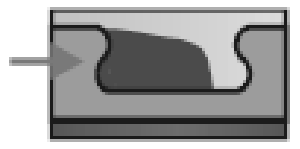

concrete pry-out

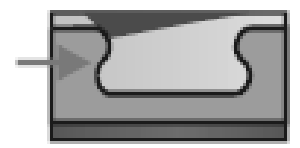

Figure 2.64: Possible failure modes of the steel-UHPFRC connection
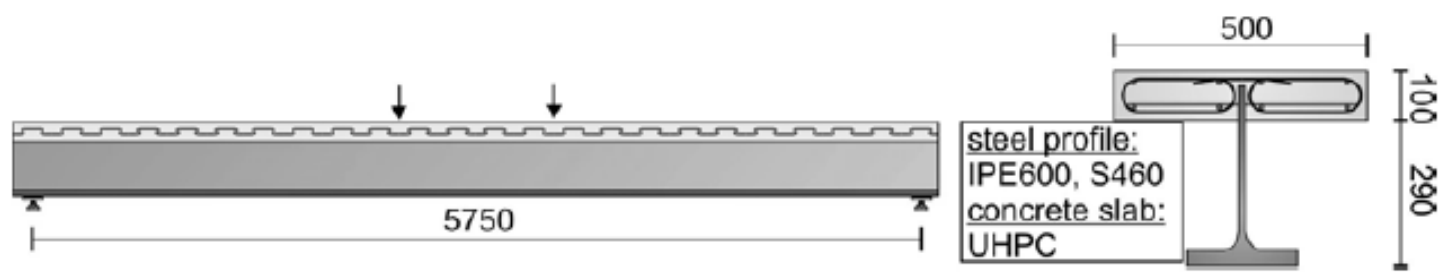

Figure 2.65: Beam test under positive bending

\subsubsection{COMPOSITE BRIDGE UHPFRC-ORDINARY CONCRETE}

Voo et al. [253] built a 50 m length composite bridge (Kampung Linsum Bridge), where the solution is a single U-Girder made of UHPFRC with topped with a cast in-situ reinforced concrete deck. The connection between the UHPFRC girder and the in-situ slab was done with shear reinforcement at the top flanges (figure 2.66), and the precast $U$ segments were joined together with shear keys and with the pos-tension of the strands.

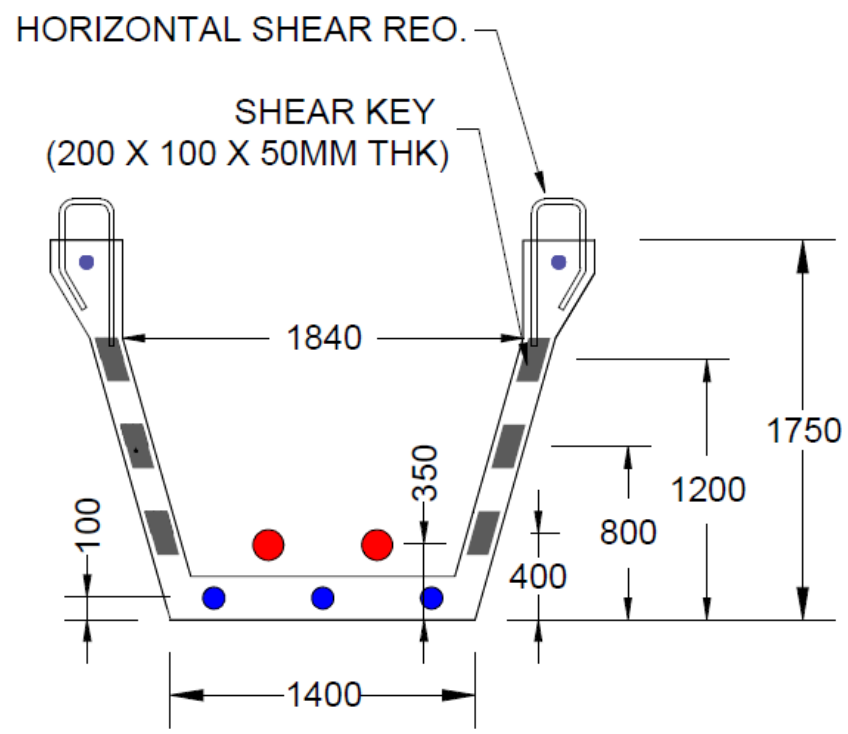

Figure 2.66: UHPFRC U-Girder with the shear reinforcement, shear keys and post-tension system 
Materials AND Methodology

\section{MATERIALS AND METHODOLOGY}




\subsection{INTRODUCTION}

This chapter explains the components, instruments and processes used along the Ph.D. thesis. The order chosen is similar to the steps followed to cast concrete: Materials, mixers, rheological tests, curing process, hardened state tests and analysis of the results. It is important to highlight that the mixing steps described for each mixer are the result of a considerable number of batches cast in previous researches. Basically by trial and error process the most adequate steps and times were found for each machine. The same happens with components, being the most suitable after try many others available in the market in previous researches.

The six concrete mixers, used at laboratory or at the precast industry, are introduced with the mixing sequence used to cast the material. Later the tests performed in chapter 4 to determine UHPC-UHPFRC properties are also detailed. There is a wide explanation of the connection tests carried out in Chapter 5 , since both types have been specially set for this Ph.D.

Finally, there is an explanation of the back analysis performed to deduce the tensile stressstrain law from the bending tests results, and also of the computational process performed to analyze the cracking patterns of the connection element tested.

\subsection{COMPONENTS USED}

All the materials along this entire chapter are described at tables 3.1 and 3.2., having at figures 3.1 to 3.6 the granulometry of the binders and aggregates. At figures 3.7, 3.8 and 3.9 is shown the aspect of some of the dry components. They were chosen to have great quality, high attainability and low variability in the properties.

Besides, one of the used pozzolanic additions is explained here, as it was not introduce in the State of Art because of the absence of international experience using it.

\section{Fluid Catalytic Cracking Catalyst Residue (FC3R)}

Fluid Catalytic Cracking Catalyst Residue (FC3R) [175], is a pozzolanic residue from petrol refinery processes. This product is a zeolite type inorganic silica-alumina compound with particle size ranging between 0.1 and $30 \mu \mathrm{m}$. Particles have a high degree of roughness with irregular shapes due to the previous process of grinding. Its special geometry implies a decrease in the workability of the mixtures if it substitutes Ordinary Portland Cement, but this effect is less marked than with some CSF [176] [34]. The non-spherical geometry of the particles could be a disadvantage to play the same role as silica fume to increase the compacity.

FC3R has an Activity Index in the same range as CSF and it is commercialized in a not condensed state, what means that no intensive energy mixing is required to develop the potential efficiency of the addition. As CSF, FC3R could also produce a significant reduction of the thickness of the Interfacial Transition Zone (ITZ), improving the mechanical strength and durability [176] [209]. Besides, its white color can provide additional aesthetic possibilities.

The FC3R has not been used in concrete for structural applications. Only research has been developed adding it to ordinary concrete in laboratory conditions with successful results. The 
worldwide volume of FC3R residue produced is much smaller as for SF, so normalization of its use could be more difficult.

Table 3.1: Properties of the binders, the aggregates and the admixtures used

\begin{tabular}{|c|c|c|c|c|}
\hline \multicolumn{5}{|c|}{ CEMENTS } \\
\hline Type & \multicolumn{4}{|c|}{ I 52.5 R/SR, Lafarge Cementos S.A.U., Villaluenga de la Sagra factory. } \\
\hline Setting time & \multicolumn{4}{|c|}{ Initial setting: $138 \mathrm{~min}$, Final Setting: $187 \mathrm{~min}$. } \\
\hline Strength [6] & \multicolumn{4}{|c|}{2 days: $38.5 \mathrm{MPa}, 28$ days: $61.8 \mathrm{MPa}$. } \\
\hline Composition & \multicolumn{4}{|c|}{$\mathrm{C}_{3} \mathrm{~A}=4.0 \%, \mathrm{C}_{3} \mathrm{~A}+\mathrm{C}_{4} \mathrm{AF}=14.2 \%$. Clinker $97.5 \%$} \\
\hline Type & \multicolumn{4}{|c|}{ I 42.5 R/SR, Lafarge Cementos S.A.U., Sagunto factory. } \\
\hline Setting time & \multicolumn{4}{|c|}{ Initial setting: $209 \mathrm{~min}$, Final Setting: $291 \mathrm{~min}$. } \\
\hline Strength [6] & \multicolumn{4}{|c|}{2 days: $29.9 \mathrm{MPa}, 28$ days: $57.2 \mathrm{MPa}$. } \\
\hline Composition & \multicolumn{4}{|c|}{$\mathrm{C}_{3} \mathrm{~A}=3.3 \%, \mathrm{C}_{3} \mathrm{~A}+\mathrm{C}_{4} \mathrm{AF}=15.8 \%$. Clinker $96 \%$} \\
\hline \multicolumn{5}{|c|}{ SILICA FUME } \\
\hline Silica Fume & \multicolumn{4}{|c|}{ Ferroatlántica S.A. Condensed (25 kg bag) } \\
\hline Composition & \multicolumn{4}{|c|}{$\mathrm{SiO}_{2}>85 \%, \mathrm{CaO}<1 \%, \mathrm{Al}_{2} \mathrm{O}_{3}<1 \%$, Carbon $<4 \%$} \\
\hline Silica Fume & \multicolumn{4}{|c|}{ ELKEM A.S., 940-Densified (25 kg bag) } \\
\hline Composition & \multicolumn{4}{|c|}{$\mathrm{SiO}_{2}>90 \%$, average $\mathrm{SiO}_{2}=94.8 \%$, Lost of ignition $<3.0 \%$} \\
\hline Silica Fume & \multicolumn{4}{|c|}{ ELKEM A.S., 940 -Undensified (25 kg/bag) } \\
\hline Composition & \multicolumn{4}{|c|}{$\mathrm{SiO}_{2}>90 \%$, average $\mathrm{SiO}_{2}=94.8 \%$, Lost of ignition $<3.0 \%$} \\
\hline \multicolumn{5}{|c|}{ OTHER ADDITIONS } \\
\hline FC3R & \multicolumn{4}{|c|}{ Omya Clariana S.A. (25 kg bag) } \\
\hline Composition & \multicolumn{4}{|c|}{$\mathrm{SiO}_{2}=48.2 \%, \mathrm{CaO}<0.01 \%, \mathrm{Al}_{2} \mathrm{O}_{3}=46 \%$, Carbon $=0 \%, \mathrm{LOI}=1.5 \%$} \\
\hline Fly Ash & \multicolumn{4}{|c|}{ Andorra Thermal Station (Teruel) } \\
\hline Composition & \multicolumn{4}{|c|}{$\mathrm{SiO}_{2}>40.9 \%, \mathrm{CaO}=9.8 \%, \mathrm{Al}_{2} \mathrm{O}_{3}=24.7 \%, \mathrm{Fe}_{2} \mathrm{O}_{3}=13.6 \%, \mathrm{Na}_{2} \mathrm{O}+\mathrm{K}_{2} \mathrm{O}=1.7 \%$} \\
\hline \multicolumn{5}{|c|}{ QUARTZ FLOUR } \\
\hline Type & \multicolumn{4}{|c|}{ U-S500, Sikron, Sibelco Ispania } \\
\hline Composition & \multicolumn{4}{|c|}{$\mathrm{SiO}_{2}=95.5 \%, \mathrm{Al}_{2} \mathrm{O}_{3}=2.5 \%, \mathrm{Fe}_{2} \mathrm{O}_{3}=0.1 \%, \mathrm{CaO}+\mathrm{MgO}<0.11 \%, \mathrm{LOI}=1.5 \%$} \\
\hline Sizes & \multicolumn{4}{|c|}{ Average particle size $=6.5 \mu \mathrm{m}, \mathrm{d}_{10}<3 \mu \mathrm{m}, \mathrm{d}_{90}<18 \mu \mathrm{m}$} \\
\hline \multicolumn{5}{|c|}{ QUARTZ SANDS } \\
\hline Type & \multicolumn{4}{|c|}{ 0-0.6 mm (AFA-60) and 0-2 mm (AFA-45) from Caolines Lapiedra S.A., } \\
\hline Composition & \multicolumn{4}{|c|}{$\mathrm{SiO}_{2}=98.6 \%, \mathrm{Al}_{2} \mathrm{O}_{3}=0.53 \%, \mathrm{~K}_{2} \mathrm{O}=0.45 \%$, porosity $=0 \%, \mathrm{LOI}=0.15 \%$} \\
\hline \multicolumn{5}{|c|}{ LIMESTONE COARSE AGGREGATE } \\
\hline Type & $4-7 \mathrm{~mm}$ & hed limestone ag & gate, from $S$ & NVAL S.L. \\
\hline Properties & Porosity & & & \\
\hline & & PCE ADM & URES & \\
\hline Bran & & Solid cont. (\%) & Density & Dosage recommended \\
\hline Sika Viscocre & e® $20 \mathrm{HE}$ & $40 \%$ & $1.08 \mathrm{~kg} / \mathrm{l}$ & $0.2-1 \%$ over binder weight \\
\hline BASF GLENIUI & ® SKY575 & $30 \%$ & $1.04 \mathrm{~kg} / \mathrm{l}$ & $0.5-2.5 \%$ over cement weight \\
\hline BASF GLENIU & I@ ACE32 & $17.5 \%$ & $1.04 \mathrm{~kg} / \mathrm{l}$ & $0.5-2.5 \%$ over cement weight \\
\hline
\end{tabular}




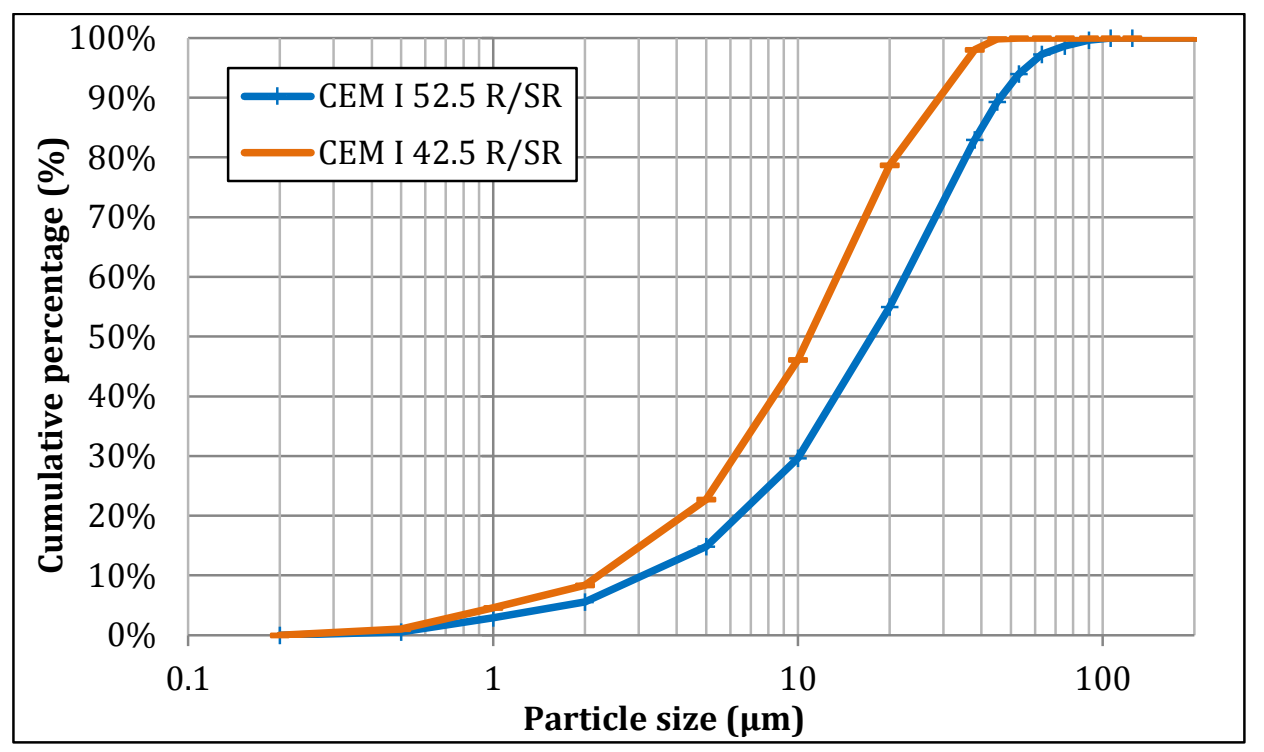

Figure 3.1: Granulometry of the cements

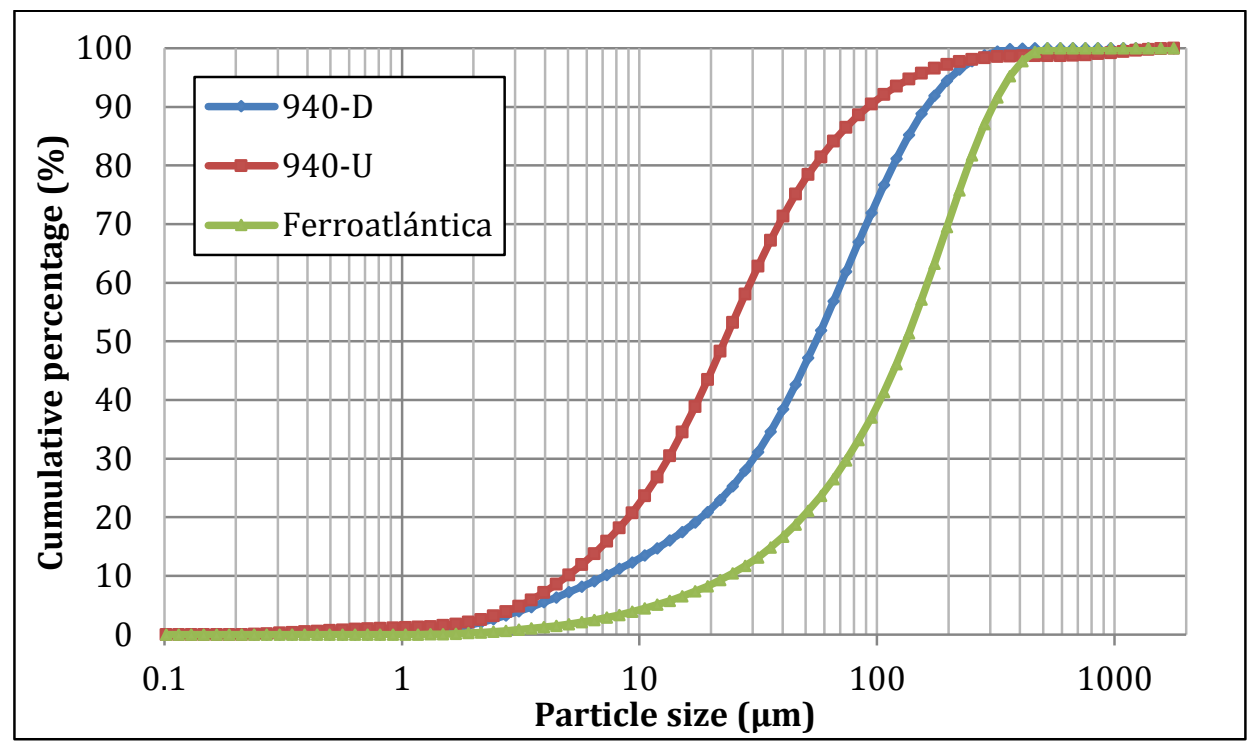

Figure 3.2: Granulometry of the silica fumes (before dispersion)

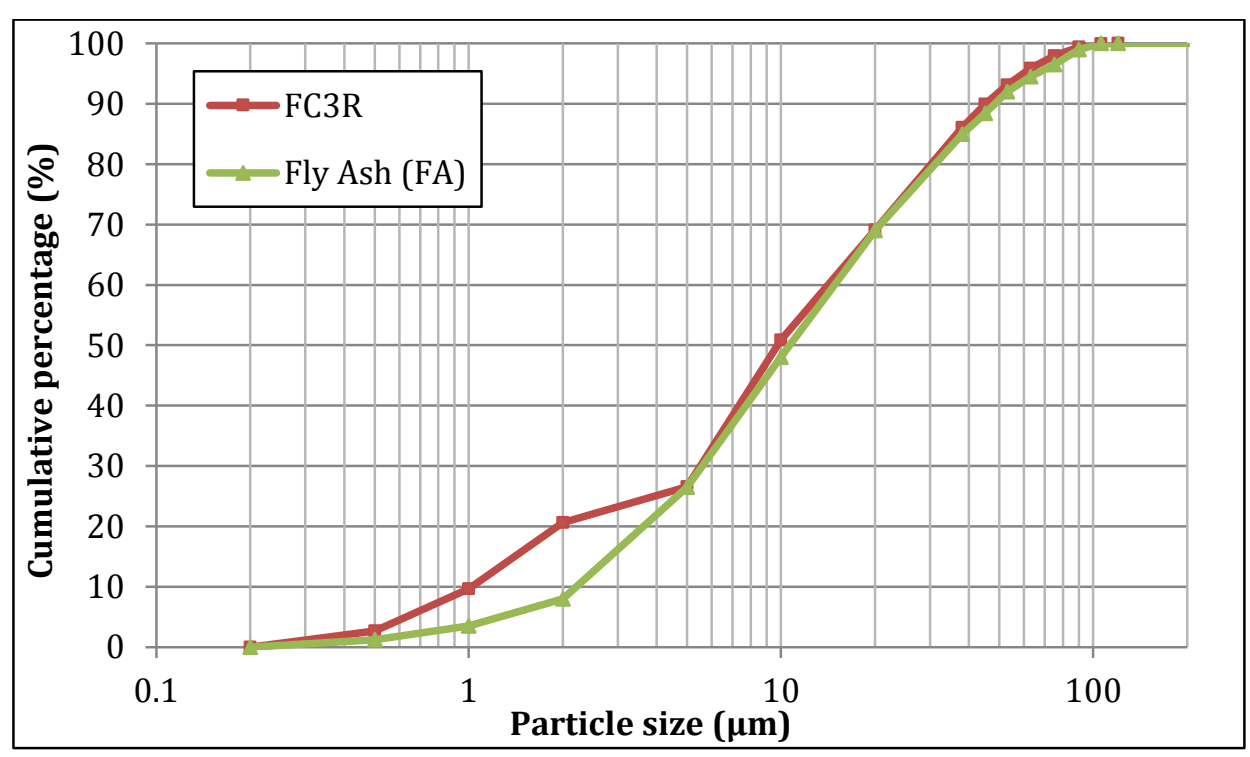

Figure 3.3: Granulometry of FC3R and fly ash 


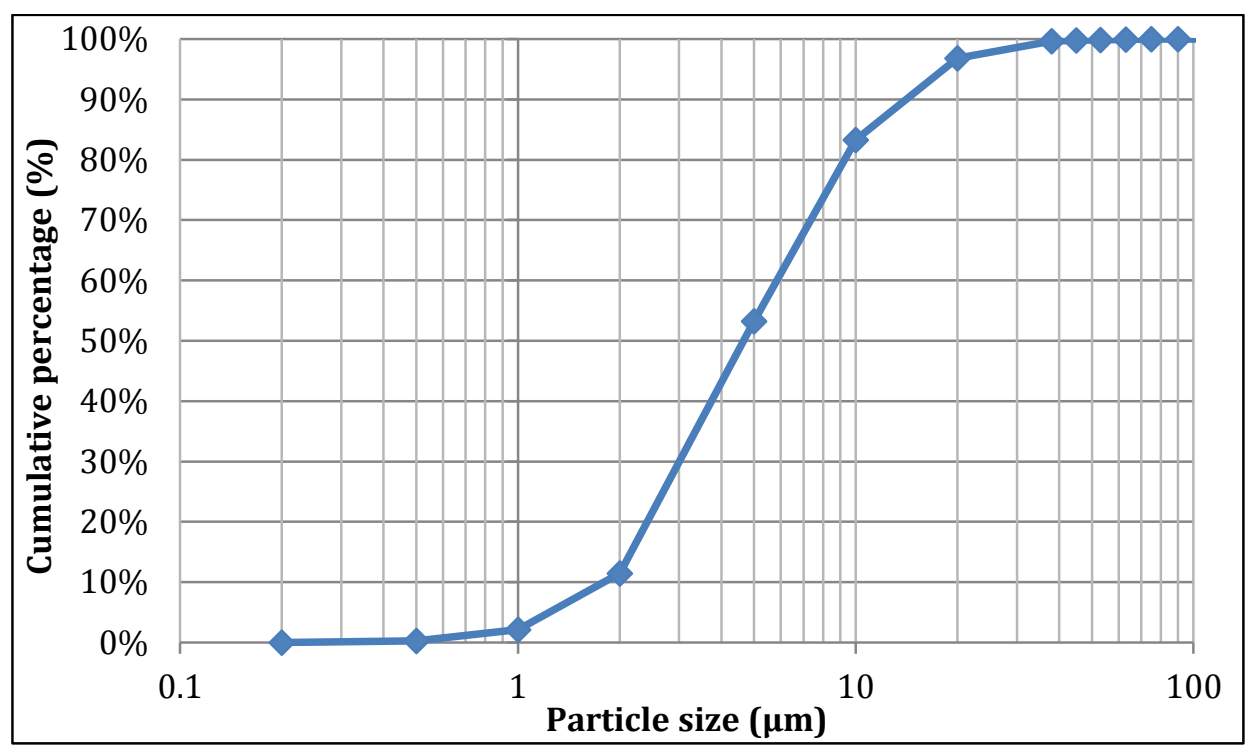

Figure 3.4: Granulometry of the quartz flour

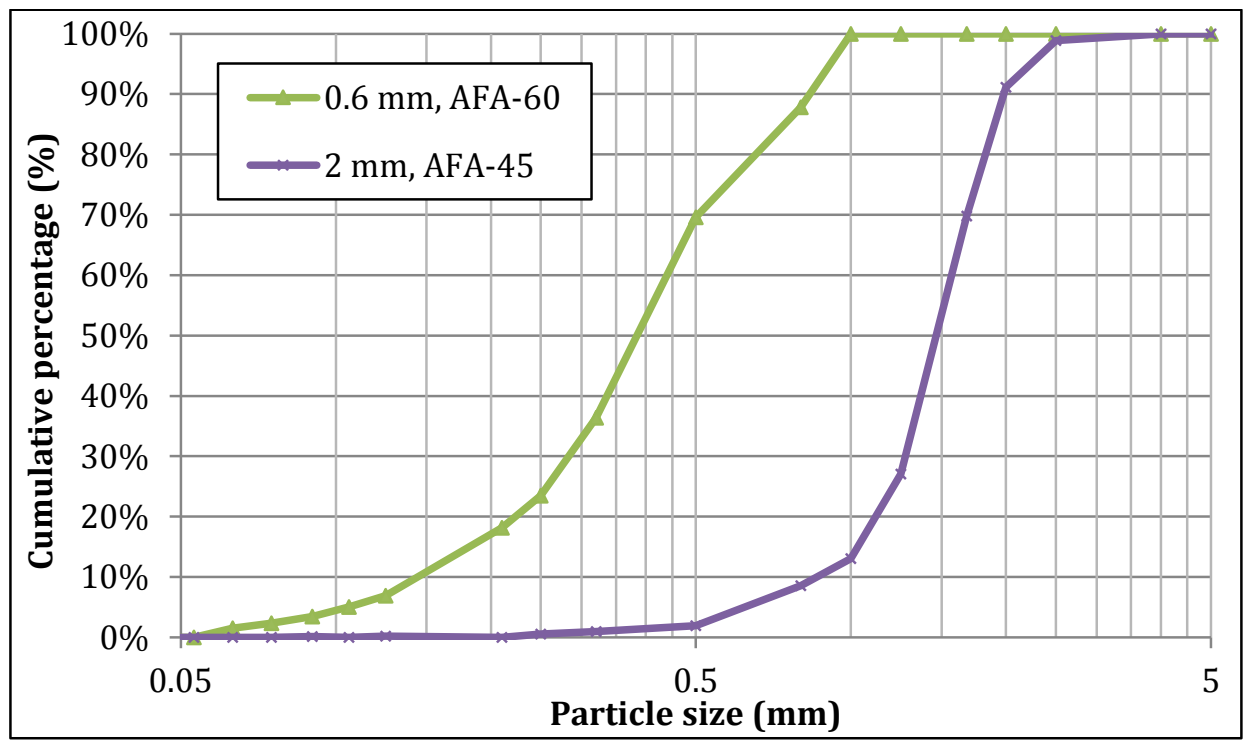

Figure 3.5: Granulometry of the quartz sands

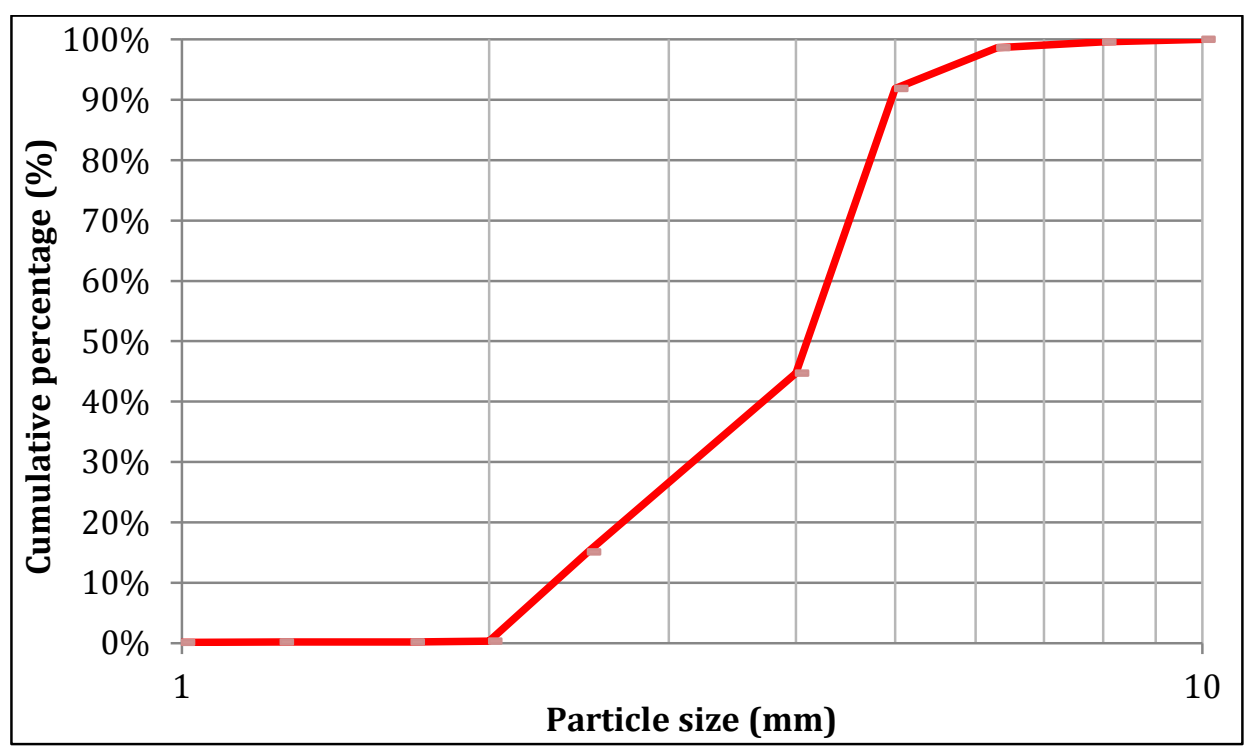

Figure 3.6: Granulometry of limestone coarse aggregate 


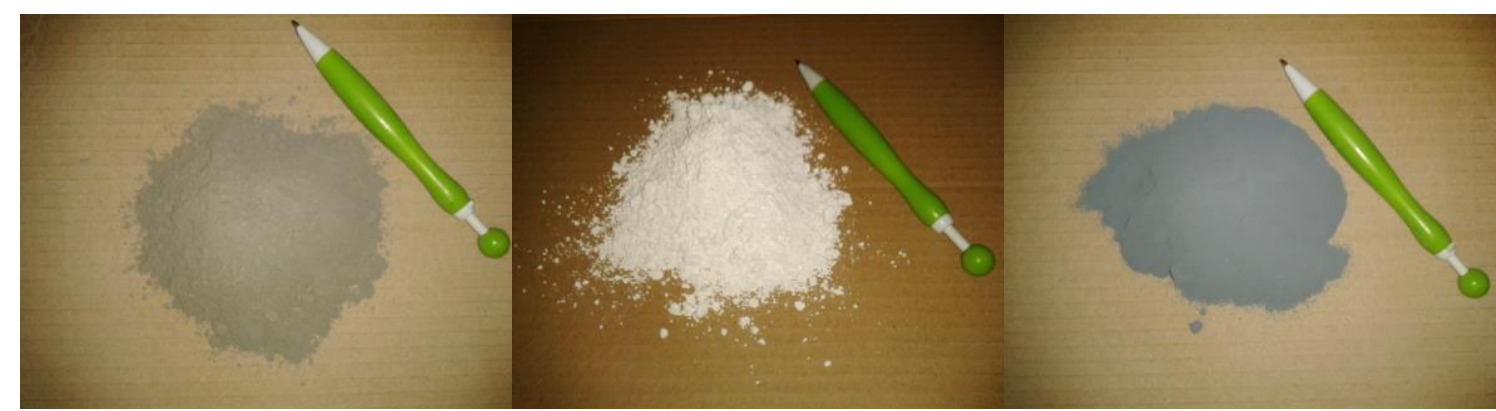

Cement $52.5 R / S R$

Quartz flour

Condensed Silica Fume (CSF)

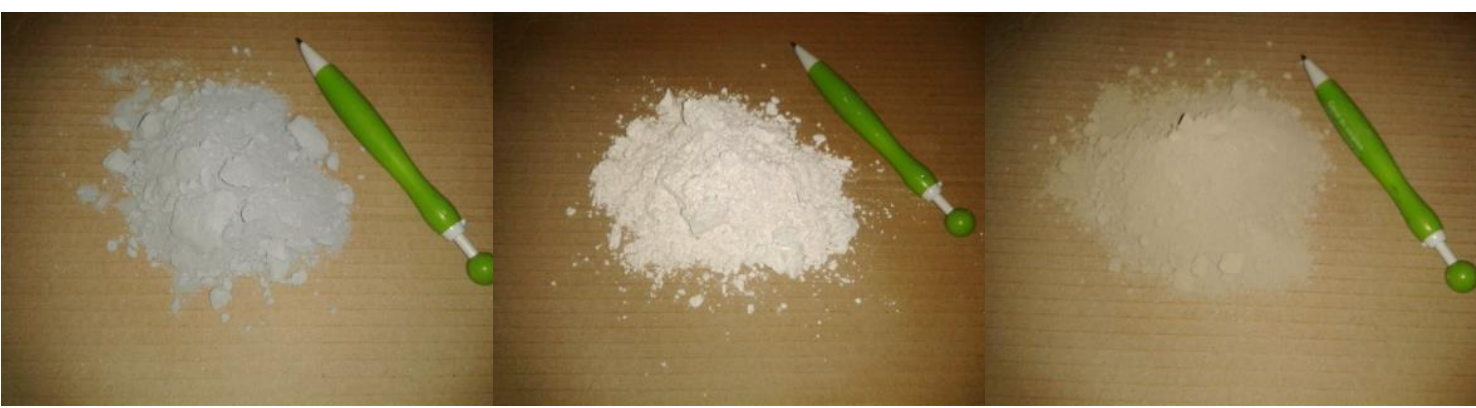

Uncond. Silica Fume (USF)

FC3R

Fly Ash (FA)

Figure 3.7: Photos of the binders used

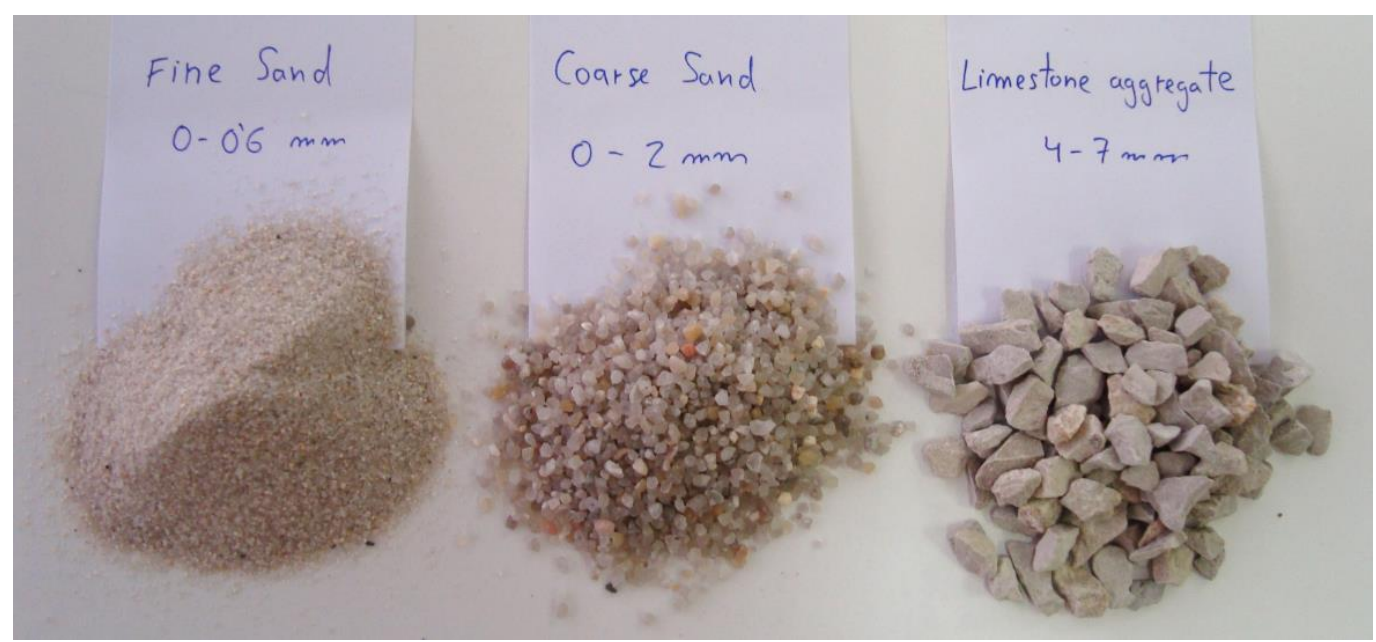

Figure 3.8: Photos of the quartz sand and limestone coarse aggregate

Table 3.2: Properties of the fibers used

\begin{tabular}{|c|c|}
\hline \multicolumn{2}{|r|}{ FIBERS } \\
\hline $\begin{array}{c}\text { Type } \\
\text { Properties } \\
\text { Number of fibers }\end{array}$ & $\begin{array}{l}\text { OL-13/0.16, Bekaert Dramix } ® \\
\text { Length=13 mm, } d=160 \mu \mathrm{m} \text {, Tensile strength }>2000 \mathrm{MPa} \text {, without anchors } \\
490.000 \text { fibers per kilogram }\end{array}$ \\
\hline $\begin{array}{c}\text { Type } \\
\text { Properties } \\
\text { Number of fibers }\end{array}$ & $\begin{array}{l}\text { RC- } 80 / 30-B P, \text { Bekaert Dramix }{ }^{\circledR} \\
\text { Length }=30 \mathrm{~mm}, \mathrm{~d}=375 \mu \mathrm{m} \text {, Tensile strength }>2300 \mathrm{MPa} \text {, with anchors } \\
38.600 \text { fibers per kilogram }\end{array}$ \\
\hline $\begin{array}{c}\text { Type } \\
\text { Properties } \\
\text { Number of fibers }\end{array}$ & $\begin{array}{l}\text { RC-65/35-BN, Bekaert Dramix® } \\
\text { Length=35 mm, d=540 } \mu \mathrm{m} \text {, Tensile strength }>1200 \mathrm{MPa} \text {, with anchors } \\
16.100 \text { fibers per kilogram }\end{array}$ \\
\hline $\begin{array}{c}\text { Type } \\
\text { Properties } \\
\text { Number of fibers }\end{array}$ & $\begin{array}{l}\text { RC-80/35-BN, Bekaert Dramix® } \\
\text { Length }=35 \mathrm{~mm}, \mathrm{~d}=440 \mathrm{~m} \text {, Tensile strength }>1200 \mathrm{MPa} \text {, with anchors } \\
24.300 \text { fibers per kilogram }\end{array}$ \\
\hline
\end{tabular}




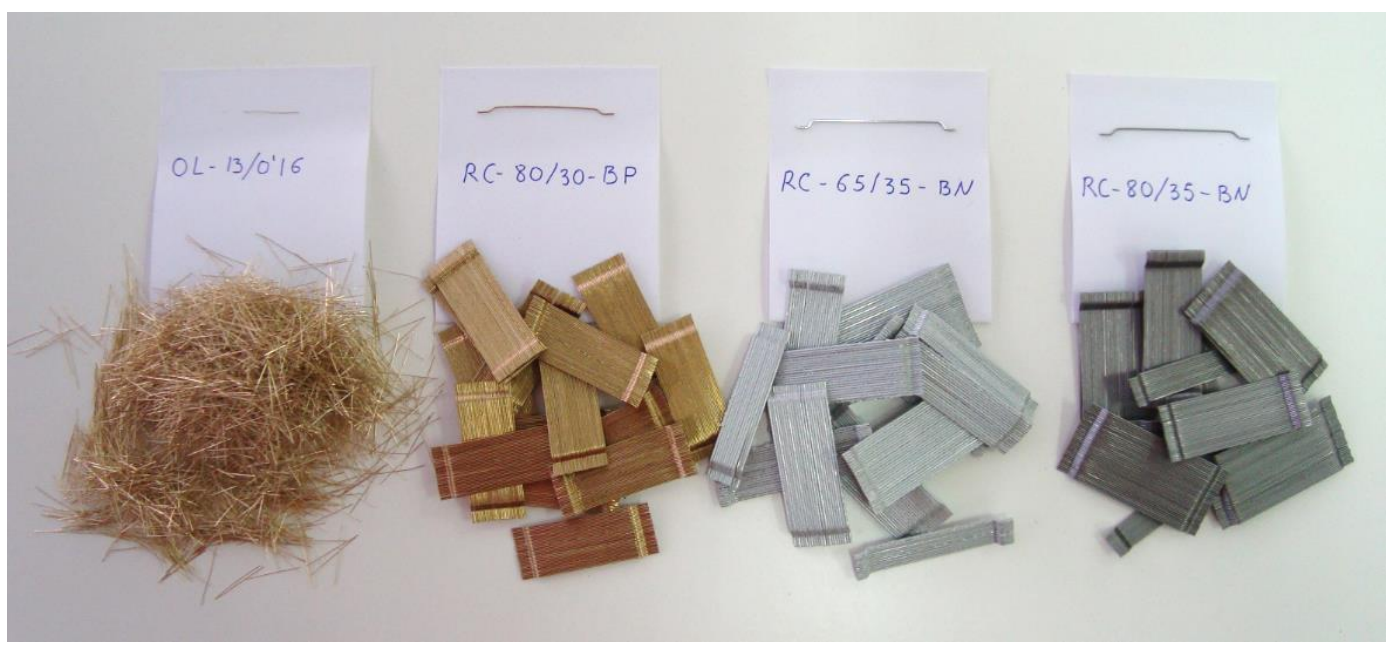

Figure 3.9: Photo of the different fibers used

\subsection{MIXERS}

Several mixers were used to cast UHPFRC in this Ph.D. thesis, and with all them the rheological and mechanical features of the material were adequate in greater or lesser extent. They are classified in the following lines according to the RILEM TC 150-ECM, and also described from minor to higher drum volume, and the mixing process used for each one is detailed.

\subsubsection{LITER MORTAR MIXER}

This planetary mortar mixer (model AMPL from the brand Mecanizados MEF S.L., figures 3.10 and 3.11) has a pan volume of four liters and can cast a maximum of 1 liter of UHPCUHPFRC. The material is removed with the displacement and removal of the bowl. The power is $0.37 \mathrm{~kW}$ and, according with the experiments performed, it can mix adequately mixtures with maximum aggregate diameter of $3 \mathrm{~mm}$ and maximum fiber content of $2.5 \%$. Higher sizes or fiber contents can lead in the blockade of the paddle with the stainless bowl. Segregation risks in this mixer with UHPFRC are reduced.

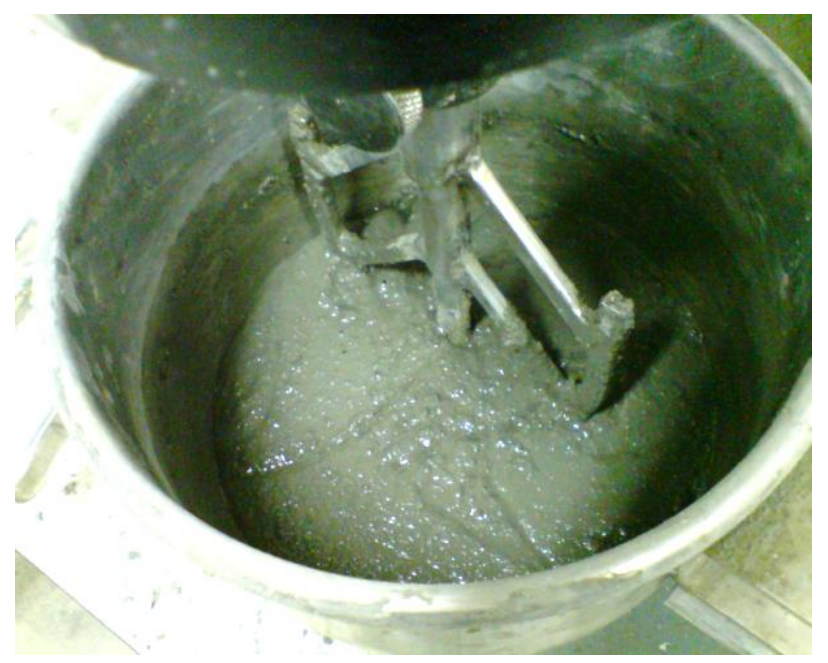

Figure 3.10: Mortar mixer with UHPC

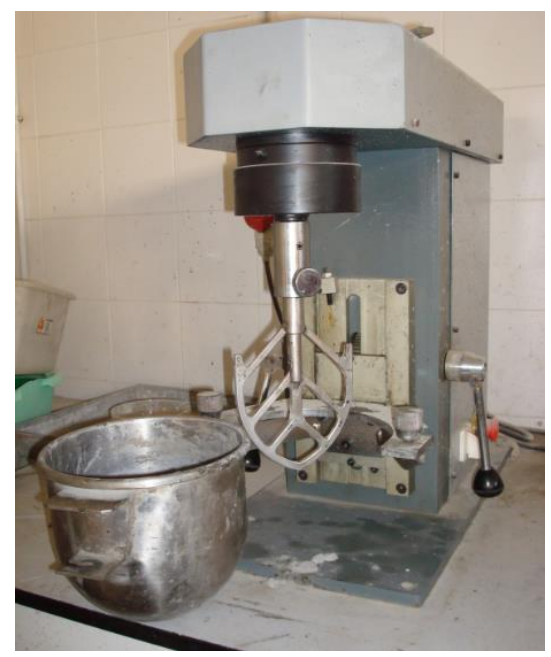

Figure 3.11: View of the mortar mixer 
It has two rotational speeds: 60 and 120 r.p.m. The mixing process generally applied to the UHPFRC mixed in this Ph.D. is shown in the table 3.3, and it was found to be the optimum in previous researches of the author [41]. The consistency of the material changes between minutes 5 and 7, mainly depending on the PCE admixture and the active addition of the dosage.

Table 3.3: Mixing process adopted in this Ph.D for the mortar mixer

\begin{tabular}{|c|c|c|c|}
\hline Min. & Process & Speed & Aspect \\
\hline 0-1.5 & Aggregates and binder are mixed & 60 r.p.m. & Dry \\
\hline $\mathbf{1 . 5 - 2 . 5}$ & Addition of water and 50\% of the PCE & 60 r.p.m. & Dry \\
\hline $\mathbf{2 . 5 - 3 . 5}$ & Stop the mixer & 0 r.p.m. & Dry \\
\hline $\mathbf{3 . 5 - 7}$ & Addition of the remaining PCE and mixing & 60 r.p.m. & Dry-Plastic-Fluid \\
\hline $\mathbf{7 - 9}$ & High speed mixing & 120 r.p.m. & Fluid \\
\hline $\mathbf{9 - 1 3}$ & Addition of short/long fibers and mixing & 60 r.p.m. & Fluid \\
\hline \multicolumn{2}{|r|}{ If homogeneous mixture, finish in 13 min } & & \\
\hline
\end{tabular}

\subsubsection{LITER TILTING DRUM MIXER}

The tilting drum inclined mixer (model M.Z.-100-NB, from IMER S.A.) is non-forced and has discontinuous paddles (figures 3.12 and 3.13). There is no relative movement between paddles and drum, drum mixing takes place by lifting part of the material and then letting it fall. The drum's rotatory speed is 25 r.p.m., and the power of the engine is $0.243 \mathrm{~kW}$. The maximum concrete volume that can be cast is 30 liters, but in the case of UHPFRC the adequate volume was found between 15 and 20 liters. Segregation risks with UHPFRC in this mixer are much higher comparing with others, as W/B ratio has to be increased to reach high workability.

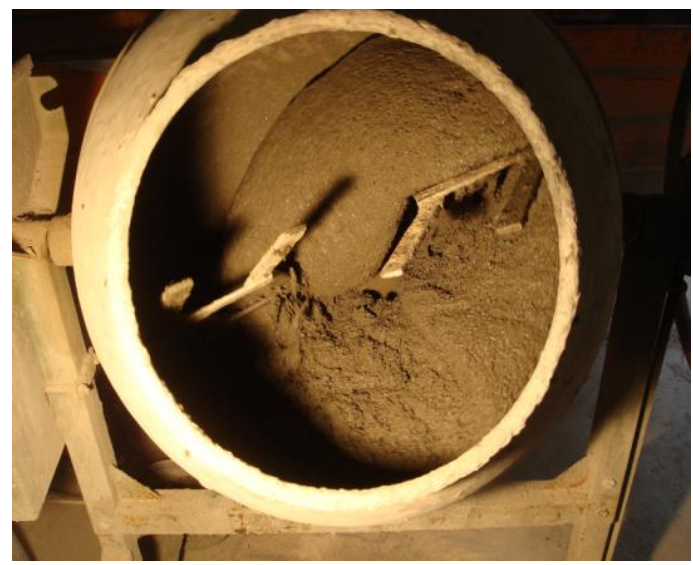

Figure 3.12: Drum mixer mixing UHPFRC

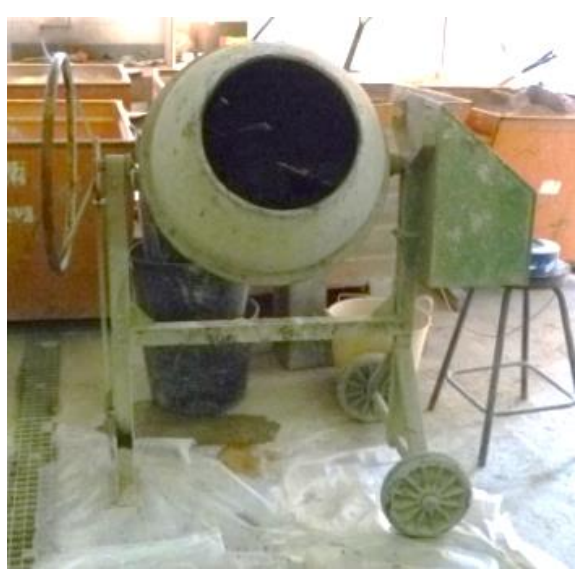

Figure 3.13: General view of the drum mixer

Mixing time is very long as the non-forced mixing requires that particles disperse rubbing each other. Fibers bundles also require longer mixing time to separate. The mixing process is summarized in table 3.4, and it was optimized at previous researches [40] [31].

Table 3.4: Mixing process adopted in this Ph.D for the tilting drum mixer

\begin{tabular}{|c|c|c|c|}
\hline Min. & Process & Speed & Aspect \\
\hline $\mathbf{0 - 2}$ & Aggregates and binder are mixed & Constant & Dry \\
\hline $\mathbf{2 - 6}$ & Addition of water and 50\% of the PCE & Constant & Dry-Slumps \\
\hline $\mathbf{6 - 2 0}$ & Addition of the remaining PCE and mixing & Constant & Slumps-Plastic-Fluid \\
\hline $\mathbf{2 0 - 2 6}$ & Addition of short/long fibers and mixing & Constant & Fluid \\
\hline \multicolumn{2}{|c|}{ If homogeneous mixture, finish in 26 min } & & \\
\hline
\end{tabular}




\subsubsection{LITER ROTATING PAN MIXER}

This pan mixer (PEMAT Zyclos ZK-50-HE, figures 3.14 and 3.15) has both a rotating pan and star, joining with both $2.25 \mathrm{~kW}$ of power. The rotational speed of the whirler for this case was of 200 r.p.m. The UHPFRC volume that can be cast ranges between 15 and 30 liters. The mixing process applied is described at table 3.5, being found adequate after mix two checkup batches.

Table 3.5: Mixing process adopted in this Ph.D for the planetary mixer

\begin{tabular}{|c|c|c|c|}
\hline Min. & Process & Speed & Aspect \\
\hline $\mathbf{0 - 2}$ & Aggregates and binder are mixed & Constant & Dry \\
\hline $\mathbf{2 - 4}$ & Addition of water and 50\% of the PCE & Constant & Dry \\
\hline $\mathbf{4 - 6}$ & Stop the mixer & 0 r.p.m. & Dry \\
\hline $\mathbf{6 - 1 0}$ & Addition of the remaining PCE and mixing & Constant & Dry-plastic-fluid \\
\hline $\mathbf{1 0 - 1 5}$ & Addition of the fibers and mixing & Constant & Fluid \\
\hline \multicolumn{2}{|c|}{ If homogeneous mixture, finish in 15 min } & & \\
\hline
\end{tabular}

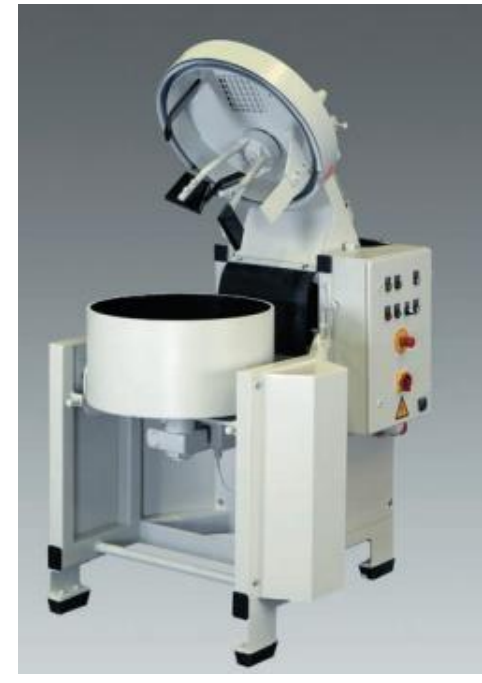

Figure 3.14: Zyclos rotating pan mixer

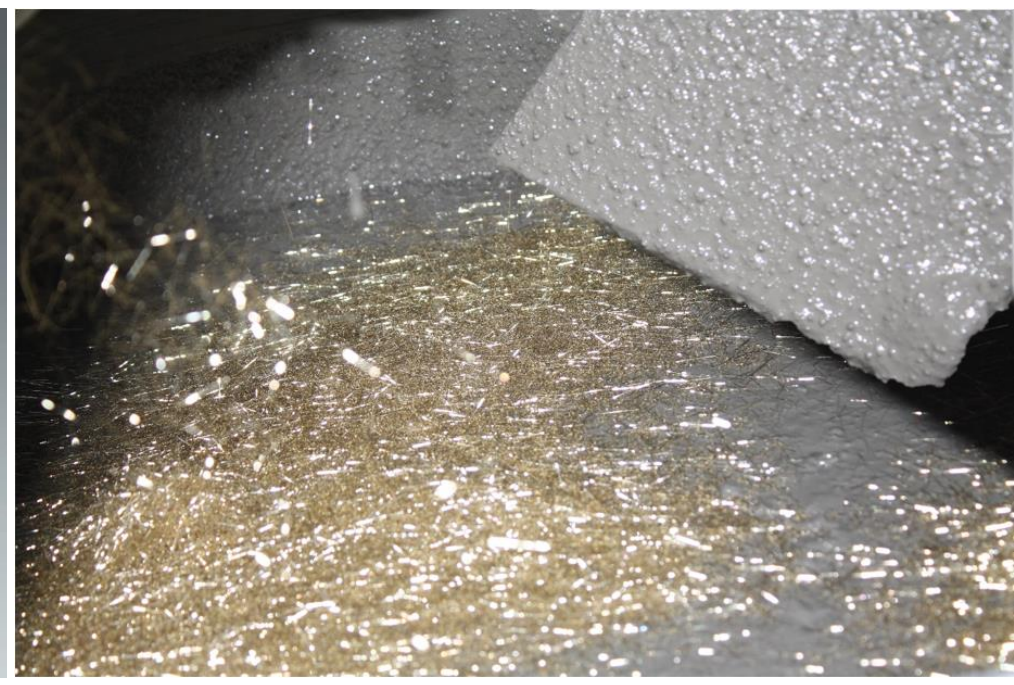

Figure 3.15: Pan after the fiber addition during the mixing

\subsubsection{LITER INTENSIVE MIXER}

This laboratory Intensive pan mixer (EIRICH R-08W, figure 3.16) is one of the most recommended to cast UHPFRC. Many authors have used it with different mixing processes [144] [56] [42] [154] [211]. The power of the agitator is $11 \mathrm{~kW}$, and adding the pan and discharge system is $13.9 \mathrm{~kW}$. The concrete volume that can be cast with the standard tool ranges between 15 and 50 liters.

It has an inclined rotating mixing pan (both directions) and a single rotating mixing tool, which rotational speed can vary between 50 and 700 r.p.m. All the mixing process is controlled from a high efficiency control system (figure 3.17). There is no limitation indicated from the manufacturer for the fiber content and the maximum aggregate size. The tendency to segregation is reduced. To find out the best mixing process, initially the steps of other researchers with the same mixer were adopted. The mixing of more than 50 batches in previous works [40] [33] let reach an optimum process, which consists in the steps expressed in table 3.6. 


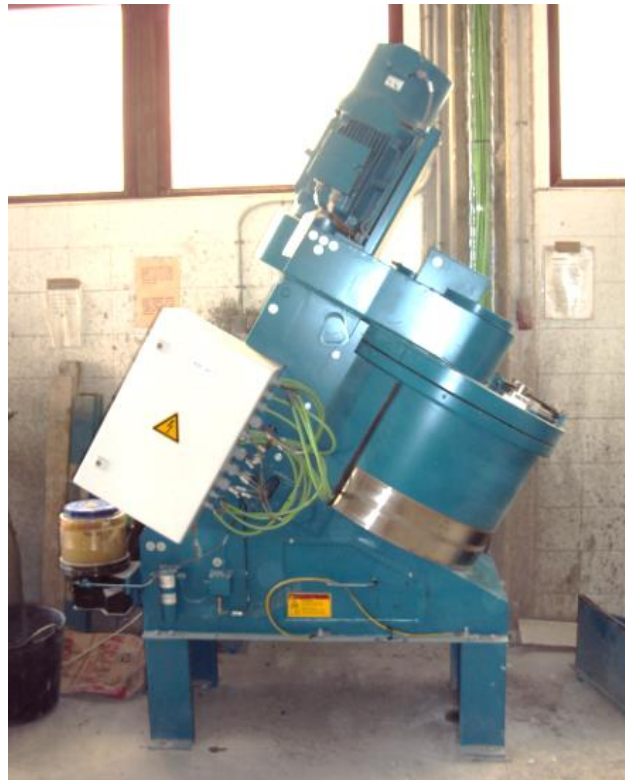

Figure 3.16: Intensive mixer

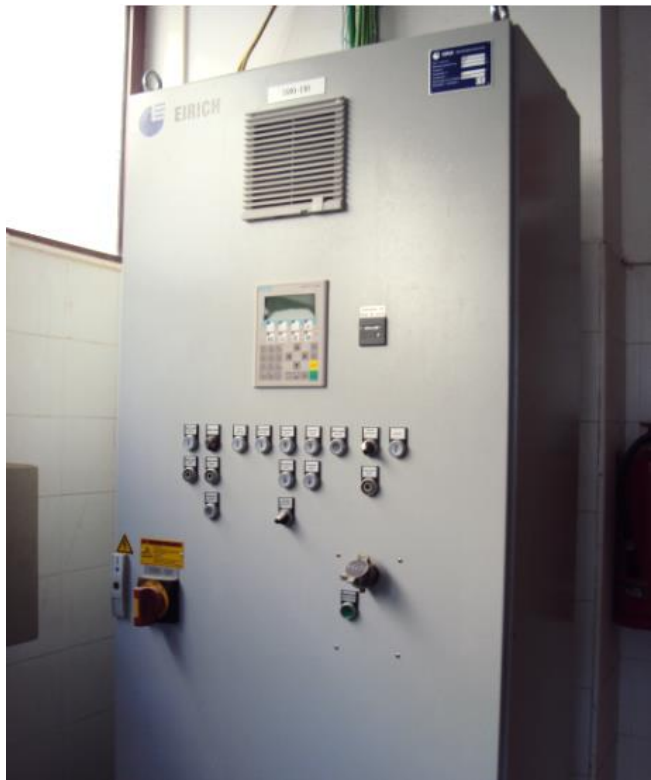

Figure 3.17: High efficiency control

Table 3.6: Mixing process adopted in this Ph.D for the intensive mixer

\begin{tabular}{|c|c|c|c|}
\hline Min. & Process & Speed & Aspect \\
\hline $\mathbf{0 - 2}$ & Aggregates, short fibers and binder are mixed & 300 r.p.m. & Dry \\
\hline $\mathbf{2 - 3}$ & Addition of water and 50\% of the PCE & 120 r.p.m. & Dry \\
\hline $\mathbf{3 - 6}$ & Mixing & 300 r.p.m & Dry-Plastic \\
\hline $\mathbf{6 - 8}$ & Addition of the remaining PCE and mixing & 300 r.p.m & Plastic-Fluid \\
\hline $\mathbf{8 - 1 1}$ & Addition of the long fibers and mixing & 120 r.p.m. & Fluid \\
\hline \multicolumn{2}{|c|}{ If homogeneous mixture, finish in 11 min } & & \\
\hline
\end{tabular}

\subsubsection{LITER PLANETARY MIXER}

This pan mixer (BETONMASS ST $150 \mathrm{CD}$, figures 3.18 and 3.19) has a drum of 150 liters and 110 liters of conventional concrete can be cast. It was used to cast 100 liters of UHPFRC (for perform $\pi$ girders at laboratory), and the power is $4.05 \mathrm{~kW}$. The mixing consists in four concentric rotating solid paddles (according with classification of RILEM TC-150 ECM). There is no limitation for the fiber content or the maximum aggregate diameter. There is only one rotation speed and direction. The possibility of UHPFRC segregation is low-medium.

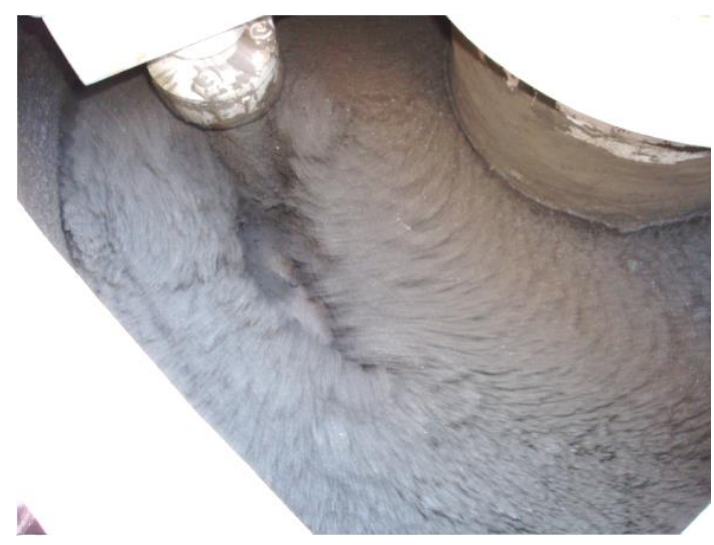

Figure 3.18: Planetary mixer with UHPC

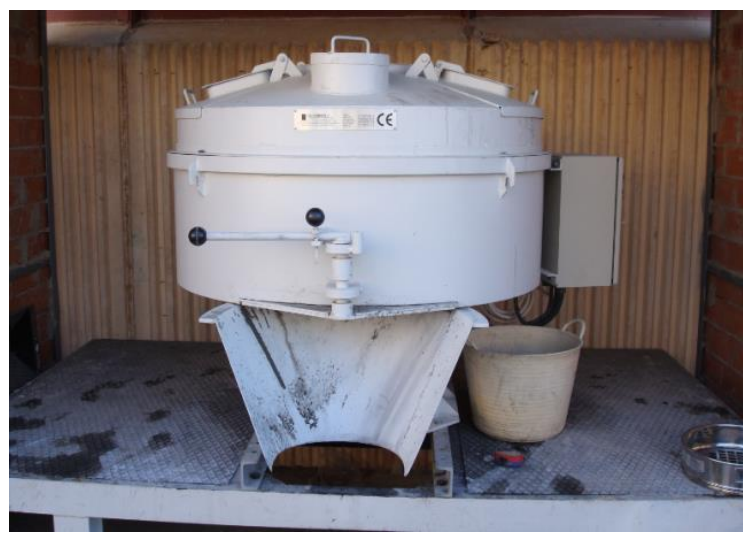

Figure 3.19: General view of the planetary mixer 
The mixing process followed when used to cast UHPFRC was the same that the described at 3.3.3 for the 50 liter Zyclos rotating pan mixer (table 3.5). More information about it can be found at [41].

\subsection{6 $1 \mathrm{M}^{3}$ INDUSTRIAL MIXER}

An industrial pan mixer (Fejmert FP-1-RM, figures 3.20 and 3.21) with seven concentric mixing paddles was used to cast big volumes of UHPFRC at the precast company (PREVALESA). The maximum volume of ordinary concrete that can be mixed is $1 \mathrm{~m}^{3}$, but for the UHPFRC volumes between 290 and 500 liters were cast. The mixer power is $37 \mathrm{~kW}$. The mixing process is schematized in the table 3.7. This sequence was found to be the optimum along the batches that were cast on a previous research [142] [139]. As the volume is smaller than the cast generally, the margin of error of the automatic water and PCE addition becames high. Then the water is added in two parts, and the quantity of the second one can depend on the decision after a visual checking during the mixing.

Table 3.7: Mixing process adopted in this Ph.D for the $1 \mathrm{~m}^{3}$ industrial mixer

\begin{tabular}{|c|c|c|c|}
\hline Min. & Process & Speed & Aspect \\
\hline $\mathbf{0 - 3}$ & Aggregates, short fiber and binder are mixed & Constant & Dry \\
\hline $\mathbf{3 - 5}$ & Addition of 70\% of water and 50\% of the PCE & Constant & Dry \\
\hline $\mathbf{5 - 8}$ & Addition of the remaining water & Constant & Dry-Plastic \\
\hline $\mathbf{8 - 1 2}$ & Addition of the remaining PCE and mixing & Constant & Plastic-fluid \\
\hline $\mathbf{1 2 - 1 5}$ & Addition of the long fibers and mixing & Constant & Fluid \\
\hline \multicolumn{2}{|c|}{ If homogeneous mixture, finish in 15 min } & & \\
\hline
\end{tabular}

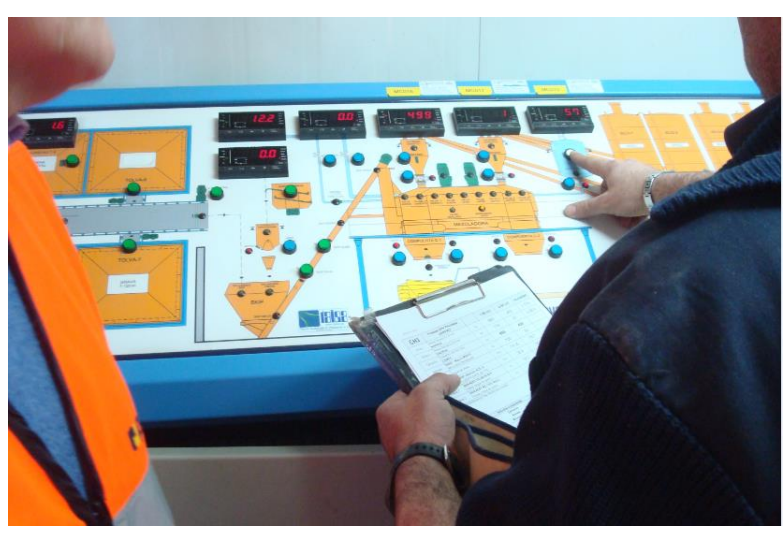

Figure 3.20: Control panel of the industrial mixer

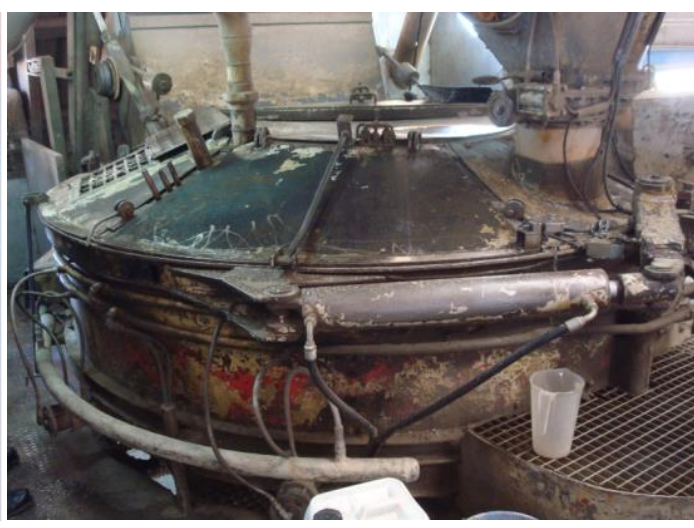

Figure 3.21: General view of the mixer

\subsection{7 $2 \mathrm{M}^{3}$ INDUSTRIAL MIXER}

A largest industrial pan mixer (Skako Apollo 3000, a Dannish brand, figures 3.22 and 3.23) with two stars and four shovels, was used at the precast company PREVALESA to cast UHPFRC for the applications that required the biggest batches. The maximum volume of ordinary concrete that can be mixed is $2 \mathrm{~m}^{3}$, and for the case of UHPFRC volumes between 0.9 and 1.7 $\mathrm{m}^{3}$ were mixed successfully (normally $1.3 \mathrm{~m}^{3}$ ). The motor size consists in two engines of 37 $\mathrm{kW}$ each one. 
The mixing sequence (table 3.8) was modified respect to previous experiences on the $1 \mathrm{~m}^{3}$ industrial mixer, and optimized along the batches mixed for the $43 \mathrm{~m}$ length footbridge over the Ovejas ravine [140][138][139].

As the volume is smaller than the cast generally, the margin of error of the automatic water and PCE addition becames high. Then the water is added in two parts, and the quantity of the second one can depend on the decision after a visual checking during the mixing.

Sometimes, when real applications were cast, the mixing time was increased for the neccessity of maintain the mixture in dinamic state until finish the casting of the previous batch. Then, the last step increased up to 35 minutes without a significant effect to the rheology or compressive strength.

Table 3.8: Mixing process adopted in this Ph.D for the $2 \mathrm{~m}^{3}$ industrial mixer

\begin{tabular}{|c|c|c|c|}
\hline Min. & Process & Speed & Aspect \\
\hline $\mathbf{0 - 3}$ & Aggregates and silica fume are mixed & Constant & Dry \\
\hline $\mathbf{3 - 5}$ & Addition of 70\% of the water & Constant & Dry \\
\hline $\mathbf{5 - 7}$ & Addition of the cement & Constant & Dry \\
\hline $\mathbf{7 - 9}$ & Addition of remaining water and 60\% of the PCE & Constant & Dry-Plastic \\
\hline $\mathbf{9 - 1 3}$ & Addition of the remaining PCE and mixing & Constant & Plastic-fluid \\
\hline $\mathbf{1 3 - 1 8}$ & Addition of the long fibers and mixing & Constant & Fluid \\
\hline \multicolumn{2}{|c|}{ If homogeneous mixture, finish in $\mathbf{1 8} \mathbf{~ m i n}$} & & \\
\hline
\end{tabular}

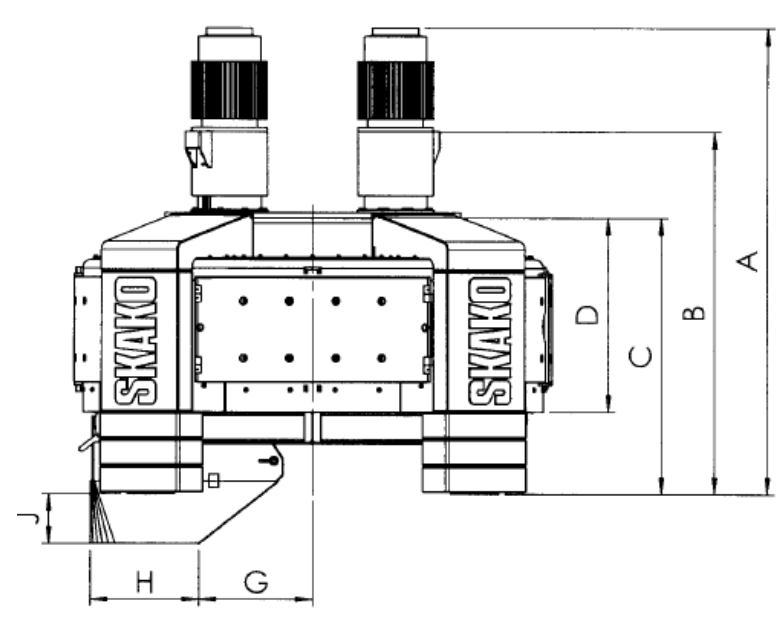

Figure 3.22: Scheme of the industrial mixer

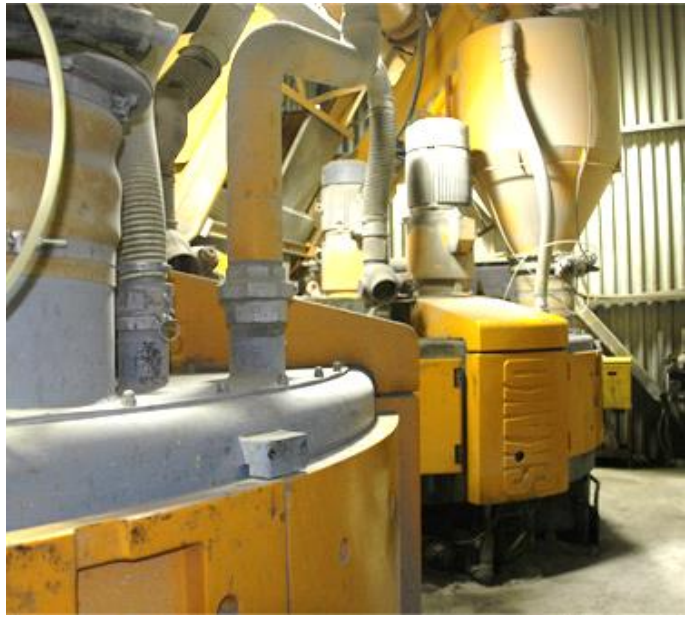

Figure 3.23: General view of the mixer

\subsection{RHEOLOGICAL TESTS}

\subsubsection{MINI-SLUMP CONE TEST}

This method is suitable to measure the filling ability of a mixture when the volume of concrete is reduced. It was designed by Kantro [119]. It is based in the same tronco-conical mould that is used in the test UNE-1015-3 (minor and major radios of 35 and $50 \mathrm{~mm}$ ). As a small version of the slump flow, becomes especially useful when the volume of material cast is 
reduced. Several authors used this test to determine the rheology of UHPC-UHPFRC mixtures [42] [77] [252] [137] [58] [243] [151] [111] [48] [133] [270].

The test consist in fill the element with the fresh UHPC-UHPFRC without applying compaction and rise after the cone. The slump size evolves and after a minute the two orthogonal diameters are measured. The result of the test is the average of both values. The measure obtained ranges between 15 and $35 \mathrm{~cm}$. As for the normal slump flow, these data should be related with the yield stress, though the correlation found by some researchers between both values was poor [73]. Figure 3.24 shows the cone filled over a mirror with a fresh UHPC mixture developed in this Ph.D.
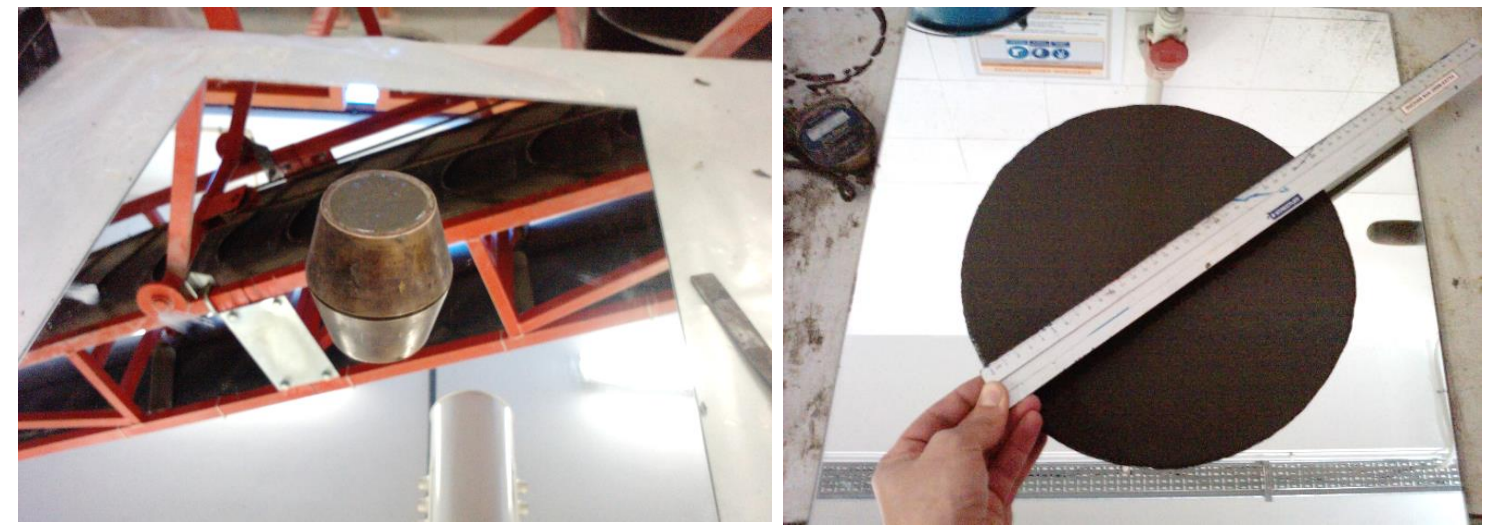

Figure 3.24: Mini-slump cone of one of the mixtures performed in this Ph.D. thesis

\subsubsection{SLUMP FLOW TEST}

Slump flow test is the simplest and most widely used test method for measure the flowability of self-compacting concrete. Self-compacting UHPC-UHPFRC requires a slump diameter higher than $500 \mathrm{~mm}$. In general, mixtures are considered also self-leveling if the slump flow is higher than $650 \mathrm{~mm}$ [225]. The procedure to apply it is developed in the norm EN-12350-8 (Testing fresh concrete-Part 8. Self-compacting concrete-Slump flow test), and according with it was performed in this Ph.D.

Also with the slump flow test can be measured the time required for the slump to reach a diameter of $500 \mathrm{~mm}\left(\mathrm{t}_{500}\right)$. A higher $\mathrm{t}_{500}$ indicates higher viscosity and then, better stability [84]. The value of the $t_{500}$ can be determined recording the test and studying the frames, as was done at this study.

Finally, the level of segregation and bleeding of the concrete can be appreciated with a visual analysis. There is a qualitative scale to designate this, proposed in the ASTM C1611 and named Visual Stability Index (VSI). It ranks the stability of the concrete with the numbers 0, 1, 2 and 3 , being 0 a high stability and 3 a concrete with all the segregation signs [84].

Figures 3.25 and 3.26 show the procedure developed in the laboratory. A homogeneous plastic sheet was extended in the base before test in order to proceed always in similar conditions and clean fast. 


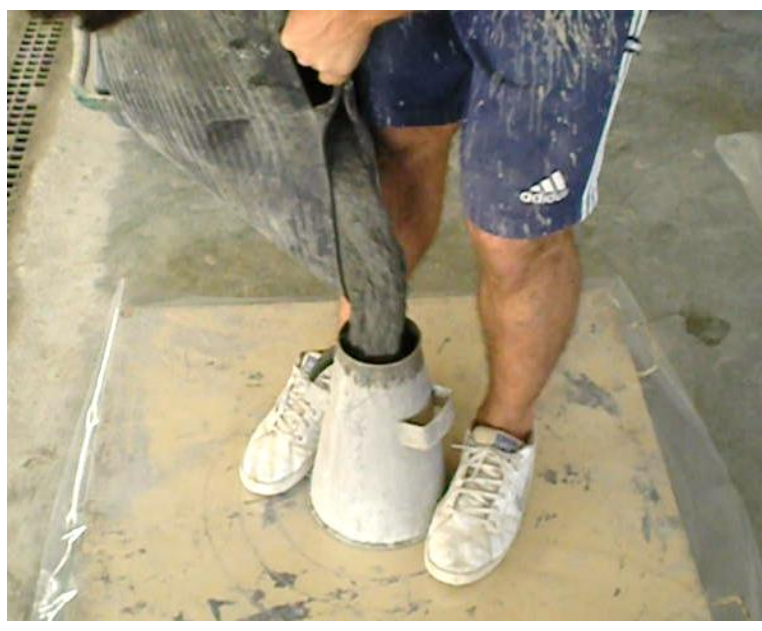

Figure 3.25: Filling of the cone with UHPFRC

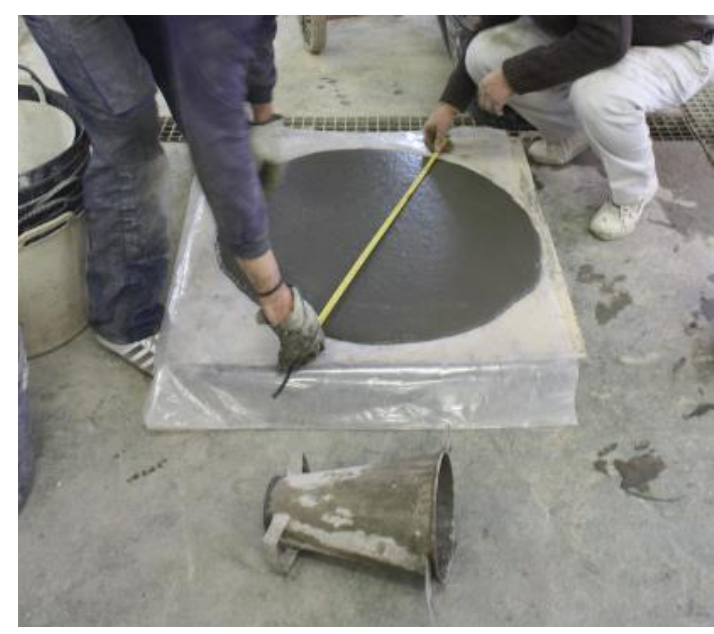

Figure 3.26: Slump flow measurement

\subsubsection{RHEOMETER}

The rheometer is a useful tool to determine the self-compacting properties of concrete. In this case the model used was a 4-C Rheometer developed from the Danish Technological Institute.

The system is a PC automated slump flow test where the flow curve (spread vs. time) is determined using digital image analysis. The tool has a camera that records the evolution of the diameter on the $70 \mathrm{~s}$ after rise the cone, obtaining the flow curve (figure 3.27). It is subsequently compared to a database of finite elements simulated flow curves to give the yield stress and plastic viscosity [49]. Analyzing this data the yield stress and the plastic viscosity are deduced. Besides, it provides the value of $t_{500}$ and the slump cone diameter depending on the time. Figure 3.28 shows the instrument after a test with a UHPFRC mixture of this Ph.D.

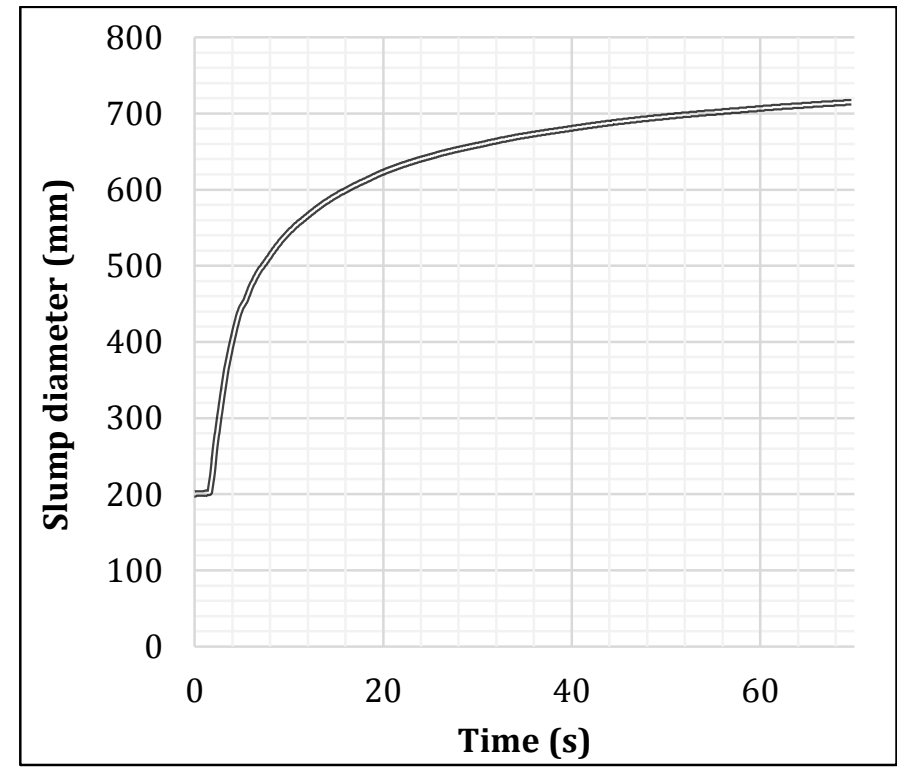

Figure 3.27: Flow curve provided by the rheometer afer a slump flow test

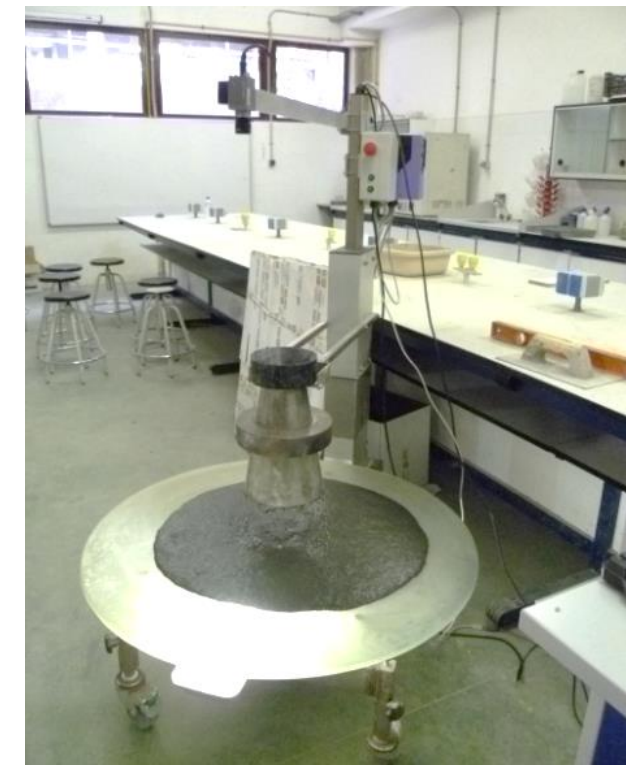

Figure 3.28: Rheometer developing a slump flow test 


\subsection{Casting PROCESS}

After mix the concrete it was poured in several buckets. After wait 4-5 minutes to let the air bubbles rise to the surface, each one was used to fill some of the prisms. The prisms were filled moving the bucket from side to side in order to align the fibers along the longest direction (figure 3.29). The prism surface was not treated after fill the element. The cubic elements were filled pouring two times over the mold with the bucket (see figure 3.30).

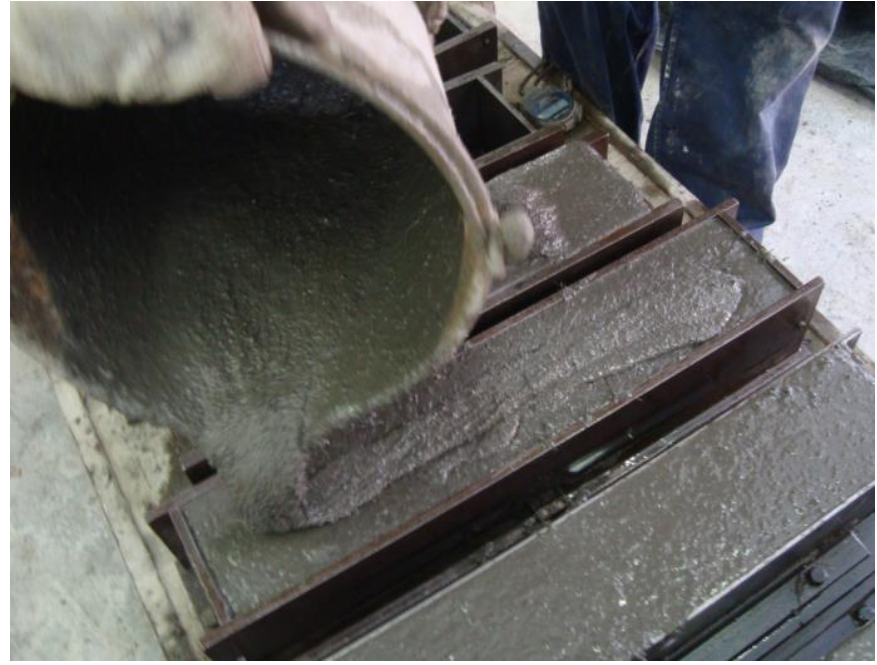

Figure 3.29: $100 \times 100 \times 400 \mathrm{~mm}$ prisms being filled

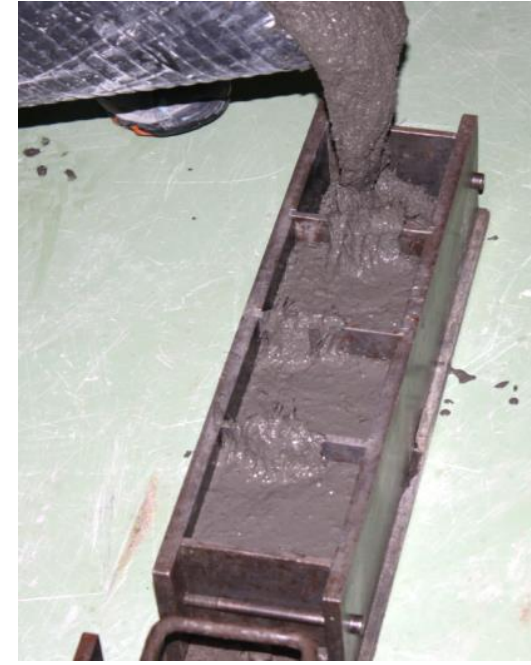

Figure 3.30: Prisms being filled

\subsection{CURING PROCESS}

After casting, the molds with the fresh UHPC-UHPFRC were stored in a humidity chamber for 24 hours at $20^{\circ} \pm 2^{\circ} \mathrm{C}$ and a relative humidity higher than $95 \%$ according with the norm UNEEN-12390-2 (figure 3.31). Then, the cubes or prisms were demoulded and stored again at $20^{0} \pm 2^{\circ} \mathrm{C}$ with relative humidity higher than $95 \%$ until the corresponding test. Thirty minutes before testing, the elements were extracted from the curing chamber. For the few cases where steam curing was applied, the cubes were put in a plastic box, with water and a three plastic bundles. The box was inserted in an oven at $100^{\circ} \mathrm{C}$ for $48 \mathrm{~h}$ (figure 3.32).

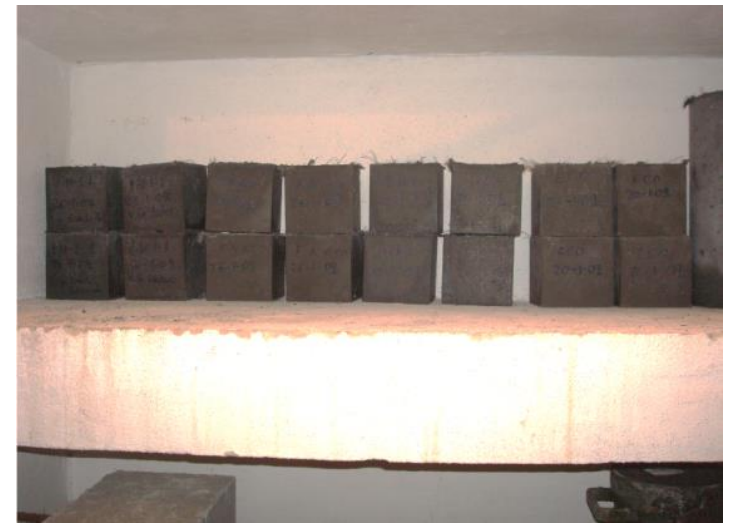

Figure 3.31: Cubes stored at $20^{\circ} \mathrm{C}$

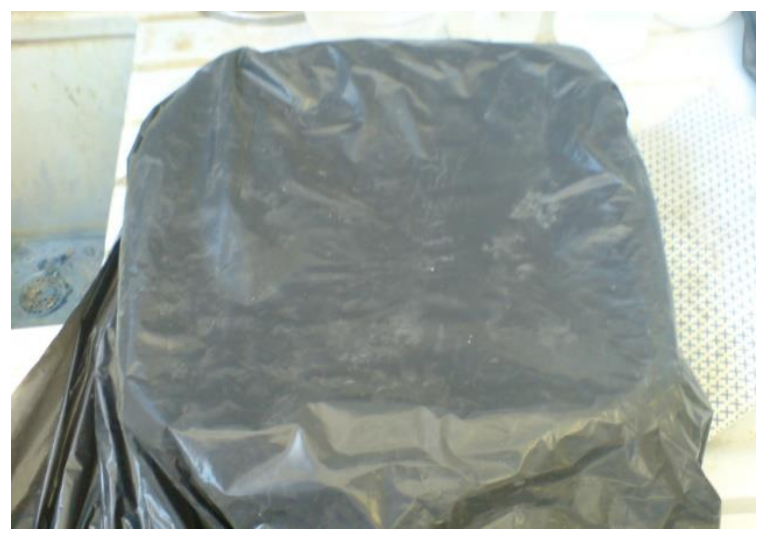

Figure 3.32: Cubes cured with steam 


\subsection{HARDENED STATE TESTS}

\subsubsection{COMPRESSIVE TESTS}

The use of the $150 \times 300 \mathrm{~mm}$ standard cylinders recommended in the Spanish code EHE2008 was avoided since the high sectional area could exceed the jack compression capacity. Also the sulfur capping might break over $100 \mathrm{MPa}$. For the UHPFRC developed in this Ph.D. cubes of L=100 mm were used (figure 3.33) to determine the compressive strength, according with the RILEM recommendations. The specimen size used was useful to compare results with other authors since it's the most used for UHPC-UHPFRC. In the case of testing UHPC (without fiber reinforcement), the space around the jack was surrounded with a gum covering that protected the machine from the debris of the explosive failure.

The very high strength of the material tested required the use of a jack able to apply high load. A $3000 \mathrm{kN}$ capacity IBERTEST equipment was used (figure 3.34). The control was performed with a computer, and the tests were applied with a constant load increase per unit of time $(8.5 \mathrm{kN} / \mathrm{s})$, applied up to a constant decrease of load carrying capacity.

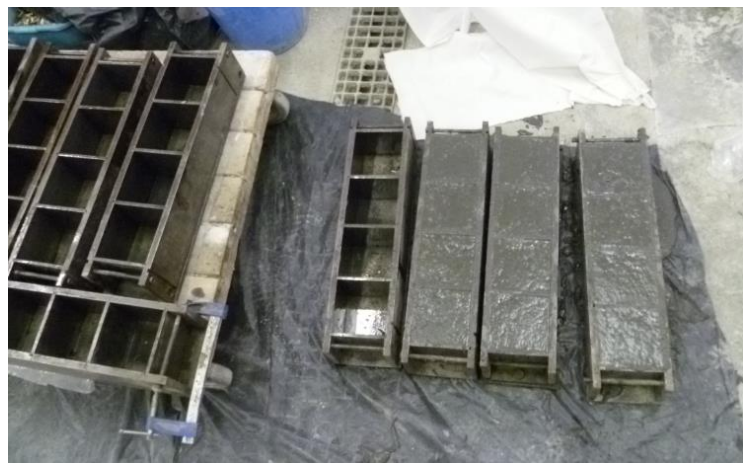

Figure 3.33: $L=100 \mathrm{~mm}$ moulds

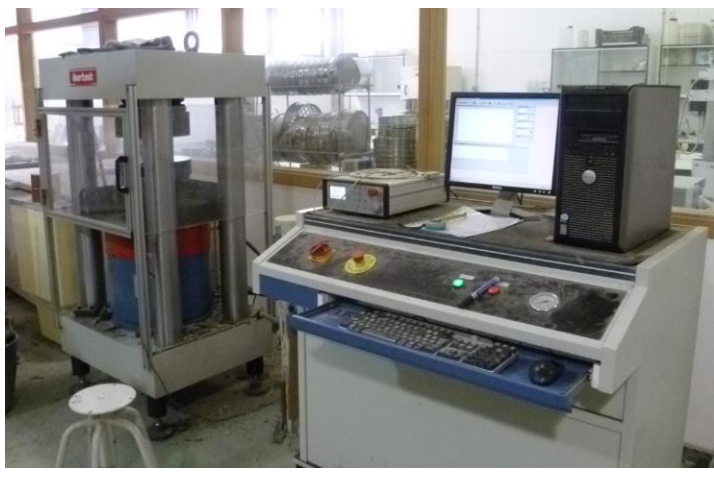

Figure 3.34: IBERTEST $3000 \mathrm{kN}$ equipment

The compressive strength was determined at 1, 2, 7 and 28 days. For each case, three cubes were tested and the average strength determined. For the subchapter 4.3 of the binder optimization, compressive tests were applied to prisms $40 \times 40 \times 160 \mathrm{~mm}$ in an IBERTEST 600 $\mathrm{kN}$ machine. The results overestimate the real UHPFRC strength but are useful to make relative comparisons. In this case only short fibers can be used, as longer sizes distort the real compressive strength.

\subsubsection{ELASTIC MODULUS}

Elastic modulus was determined at 1, 2, 7 or 28 days in the same equipment as compressive tests (IBERTEST $3000 \mathrm{kN}$ ). The process was developed according to the Spanish norm UNE83316:1996. Three concentrically LVDTs placed around the cylinder allowed a proper measurement of the Young modulus. For each determination, three cylinders from each batch were tested.

\subsubsection{FLEXURAL TESTS}

Flexural tests were developed in $100 \times 100 \times 500 \mathrm{~mm}$ prisms that were previously cast favoring a great alignment of the fibers with the material displacement. Initially three point flexural tests were developed to an un-notched prism with a span length of $450 \mathrm{~mm}$, with a 
center load application (figure 3.35). For the final material characterization, four point bending test were carried out with a support span length of $450 \mathrm{~mm}$ and a loading span of $150 \mathrm{~mm}$ (1/3) (figure 3.36). With the testing machine the displacement speed was controlled manually, ranging between 0.3 and $0.6 \mathrm{~mm} / \mathrm{min}$.

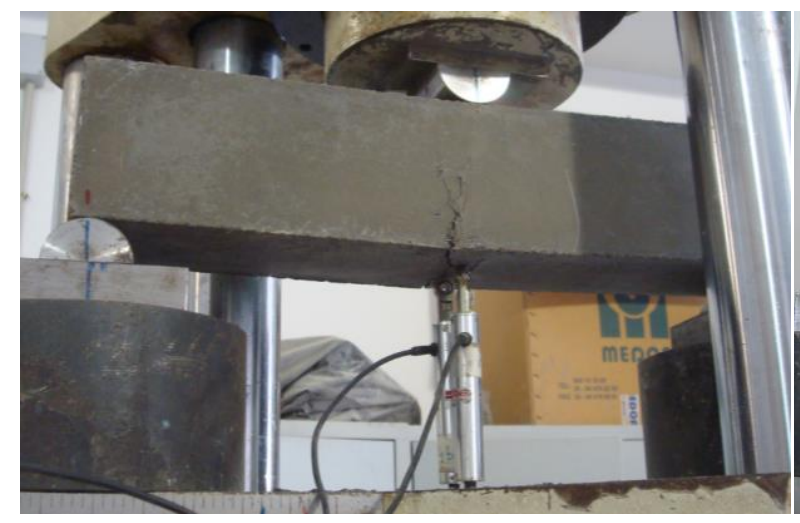

Figure 3.35: Three point bending test performed

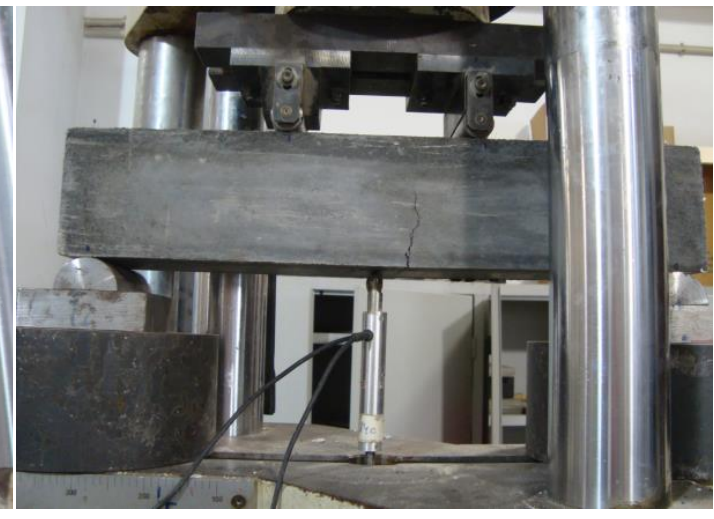

Figure 3.36: Four point bending test performed

In every case two Linear Variable Differential Transformers (LVDTs) were vertically disposed in the center of the span to measure the deflection. A program developed in the Universitat Politècnica de València was used to register the applied load-deflection chart during the test. Afterwards a back analysis was applied to obtain the tensile stress-strain law (see subchapter 3.8.1). For each batch, three prisms were cast, determining the average flexural strength and the dispersion. Figure 3.37 shows the curve bending moment-central span deflection obtained for six prisms from the same batch in a four point bending test in the context of this Ph.D. [141].

More specific tests were developed in the case of real size precast elements. Then, hydraulic jacks of 500 or $1000 \mathrm{kN}$ were used with different span lengths, measuring the middle span deflection with LVDTs. An example is shown in figures 3.38 and 3.39 .

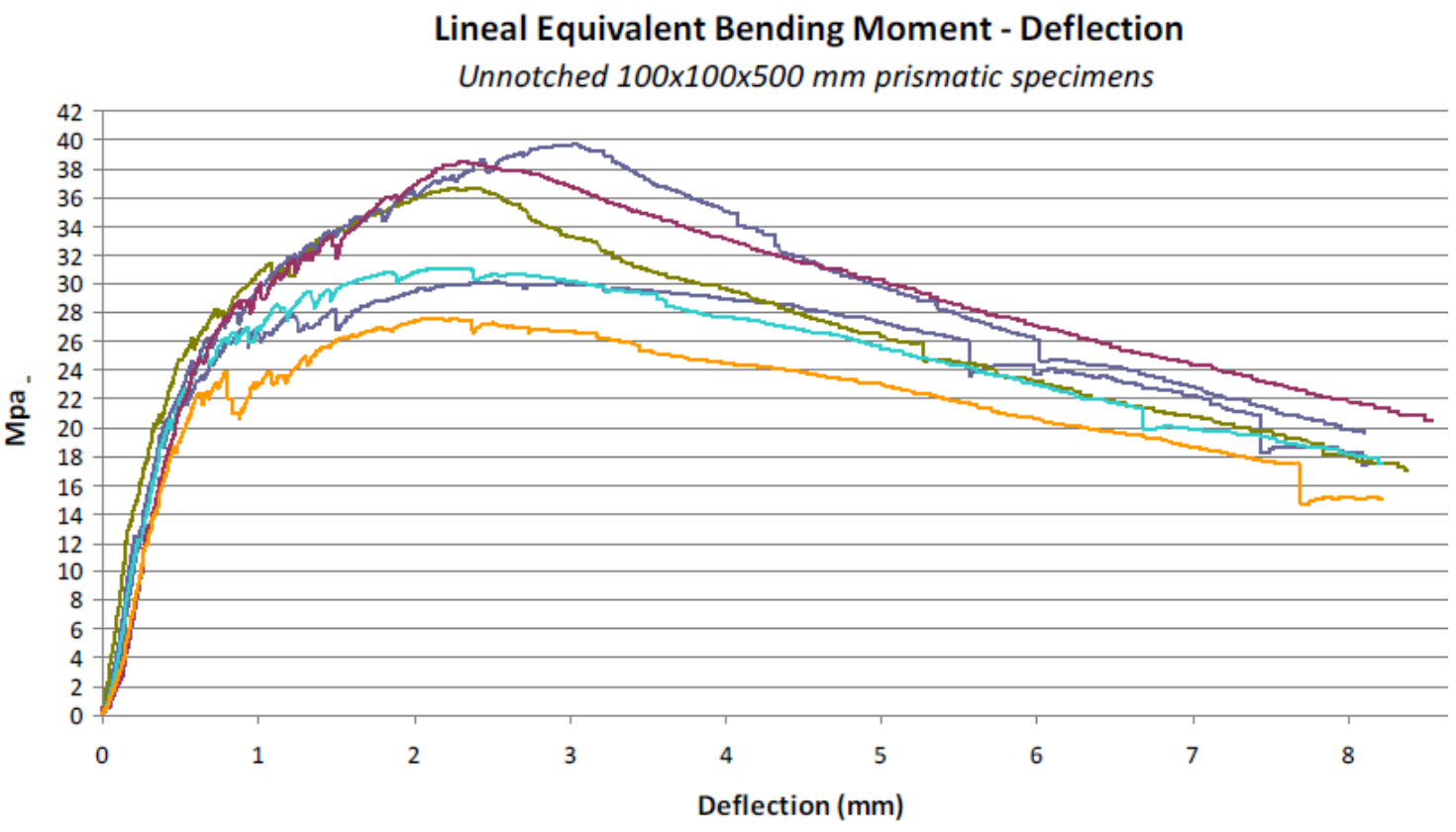

Figure 3.37: Curve bending strength-central span deflection of six prisms in four point test 


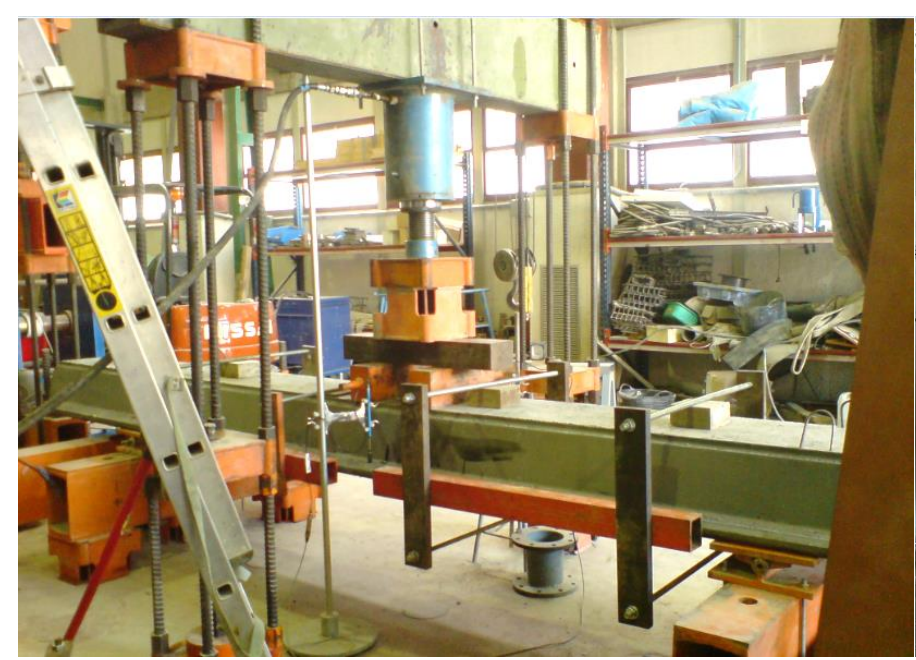

Figure 3.38: Bending test performed to a precast prestressed beam

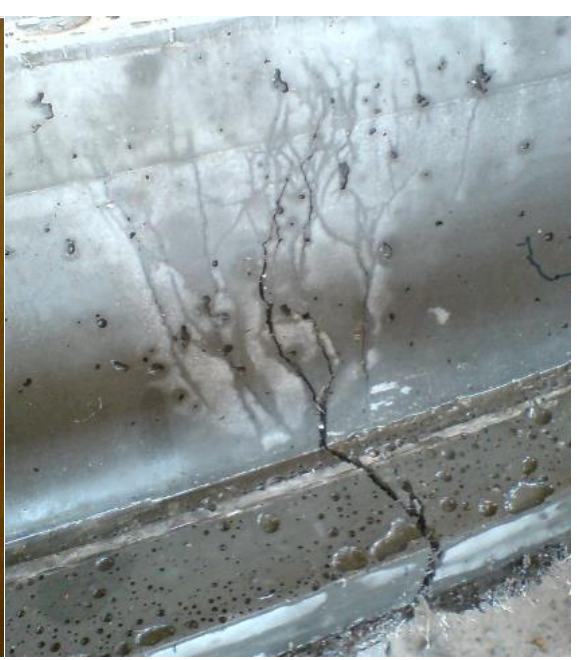

Figure 3.39: Crack in the center of the span of the prestressed beam

\subsubsection{MICROSCOPY}

In order to analyze the structure of UHPC in the binder proportion analysis (subchapter 4.3), a Scanning Electron Microscope (SEM) was used, capturing several microphotographs.

\subsection{COMPUTATIONAL PROCESSES}

\subsubsection{BACK ANALYSIS}

The tensile stress-strain laws obtained in this Ph.D. thesis have been deduced performing an inverse analysis to the experimental bending tests developed. Other authors and even the French Recommendations [235] [8] also resort to this method assuming different hypothesis, since direct tensile tests are more difficult to be successfully performed. In the following lines the back analysis method is explained.

The results and difficulty of the process depend on the hypothesis assumed for the tensile stress-strain law. Some authors approximate the tensile behavior of the UHPFRC with fiber content below 3\% as elasto-plastic [224]. Other proposals are more generic, assuming a trilinear tensile stress-strain law (elastic, strain hardening and after strain softening) [8].

Finally, some authors try to deduce progressively the real tensile stress-strain law in base of the bending tests, but this process is more complicated. In a bending test, the central span section will experiment a strain that can be considered linear along the depth. In a cracked section, each depth will have associated certain strain, and thus a value of strength associated, both related with the constitutive law of the material (figure 3.40), which is initially unknown.

Given a constitutive law for the material and an external bending moment applied to a section, it is possible deduce the top strain and the neutral axis depth that generate the section equilibrium. In a three point bending test, the moment $\mathrm{M}$ is generated by a central load $\mathrm{P}$ 
applied in the middle span with absence of direct tensile load. For a four point bending tests the process is similar but with two similar loads $\mathrm{P} / 2$ applied with certain loading span.

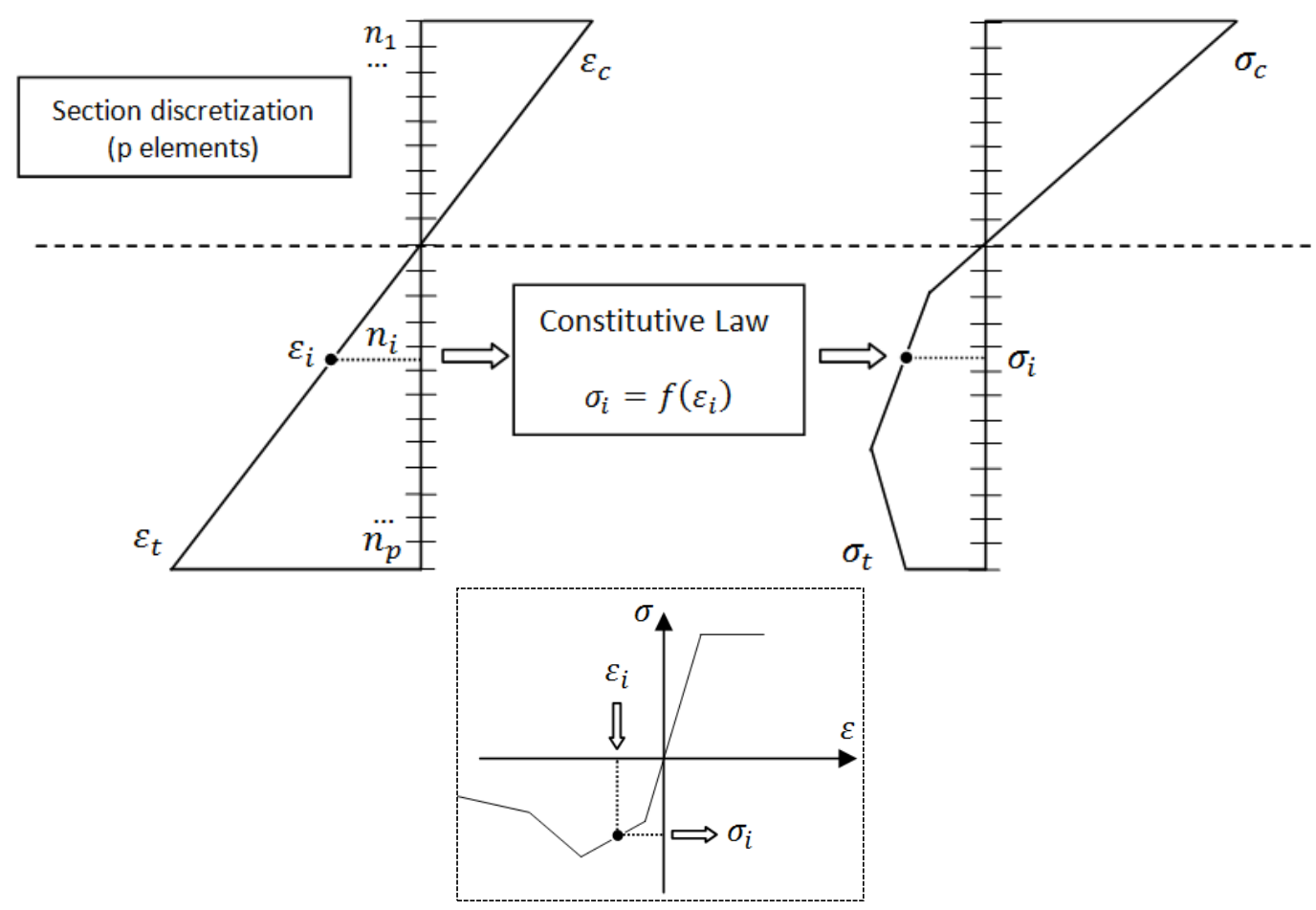

Figure 3.40: Scheme of the discretization made to the section analysed

In each section of the bended prism, and for the progressive increase of P load applied along the bending test, there is a top strain and crack depth that equilibrate the section for certain constitutive law. Discretizing the prism in t elements, and integrating the curvature of every partition, the slope can be deduced and then the increase of deflection between consecutive sections (figure 3.41).

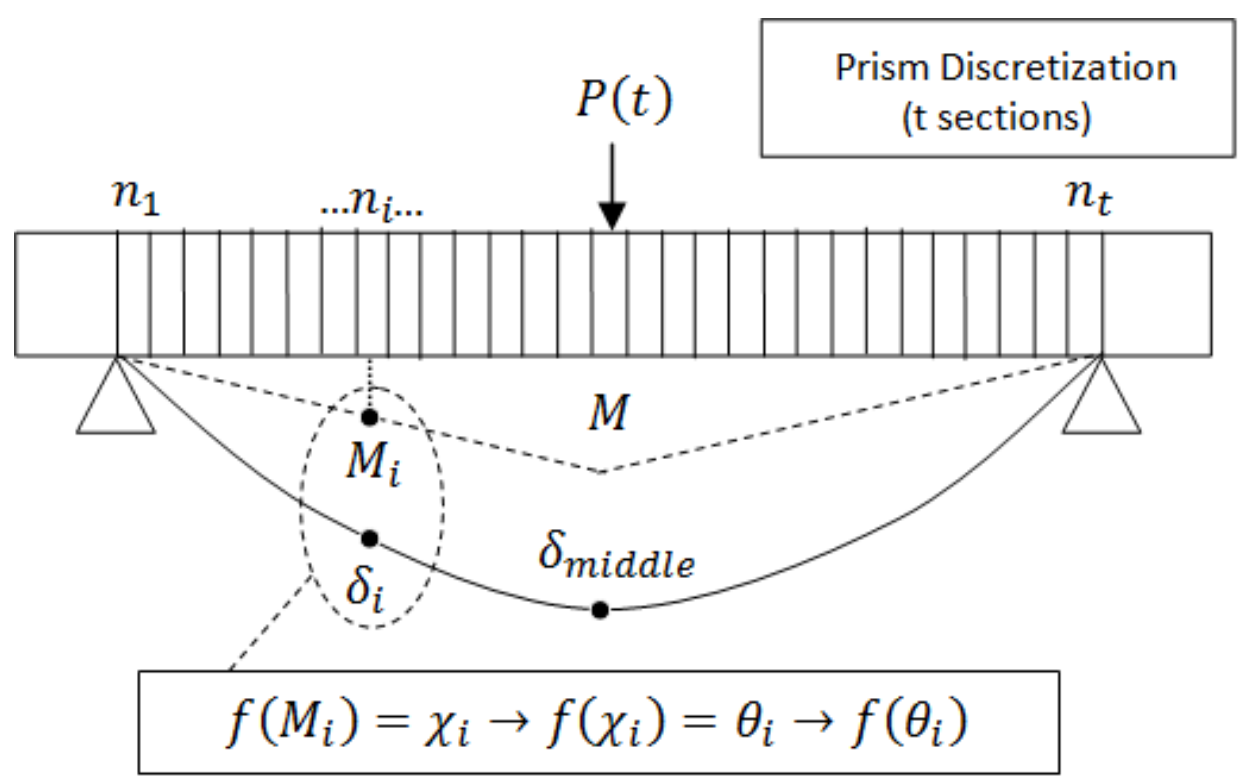

Figure 3.41: Scheme of the relation load applied and deflection in a three point bending test

Then, the middle span deflection associated to each value of the increasing P load can be deduced. Plotting in a graphic the middle span deflection associated to the $\mathrm{P}$ load the 
theoretical graphic load-deflection is found. It depends on the geometry of the prism (breadth and depth of the section, span length...) and the constitutive law of the material.

The back analysis process is based in finding by successive approximations the constitutive law that produces a theoretical load-deflection law similar than the experimental obtained during the bending test. Besides, when the constitutive law is already deduced for the UHPFRC, this process let predict the deflection of any beam with non-rectangular transversal section. In this Ph.D. thesis a bilinear tensile stress-strain law with strain hardening behavior was assumed up to the maximum tensile strength. The discretizations to perform the integrations were developed in an Excel file.

As an example, on figures 3.42 to 3.44 is shown the inverse analysis performed to the four point bending tests performed to a $100 \times 100 \times 400 \mathrm{~mm}$ element. The multilinear law deduced is the one that approximates better the theoretical curve to the experimentally obtained. As can be seen, the approximation is very accurate.

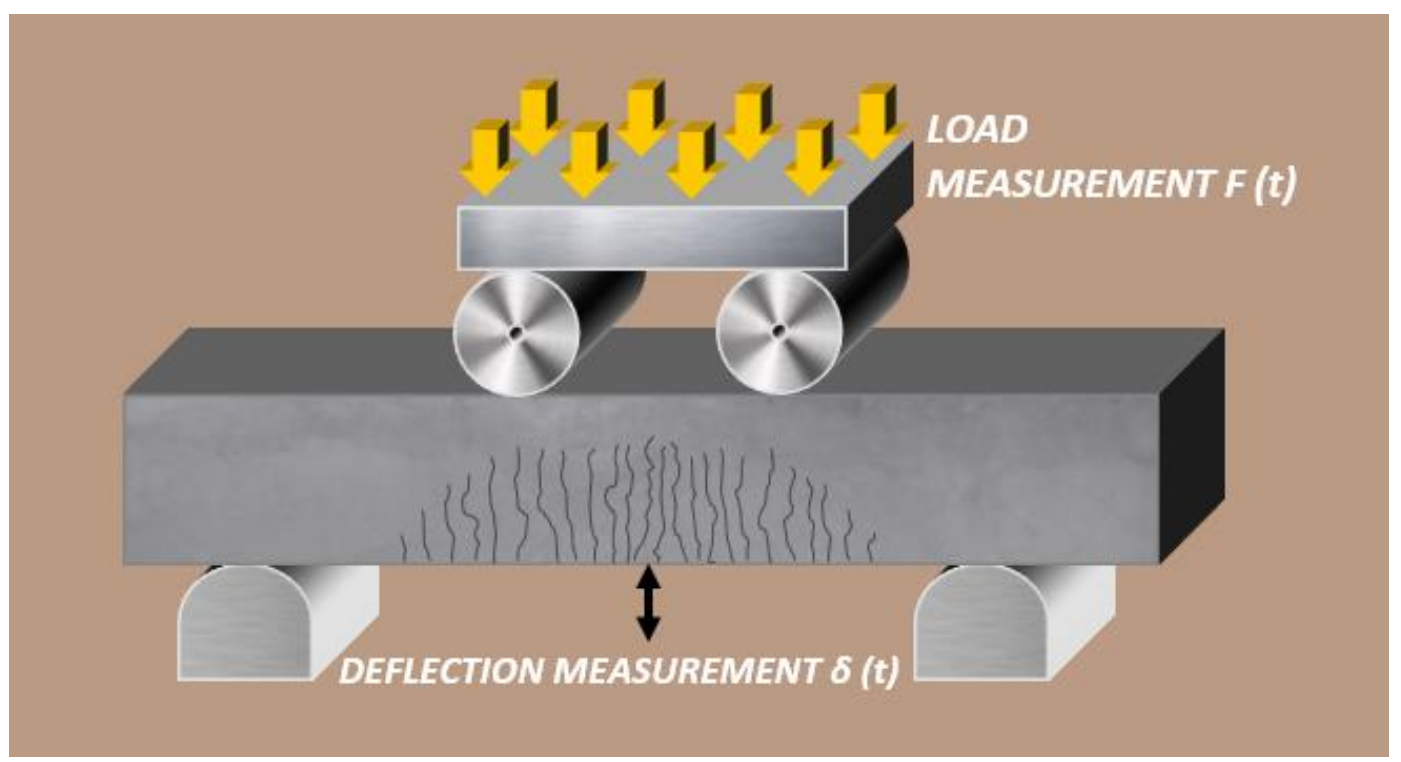

Figure 3.42: Schematic draw of a four point bending test

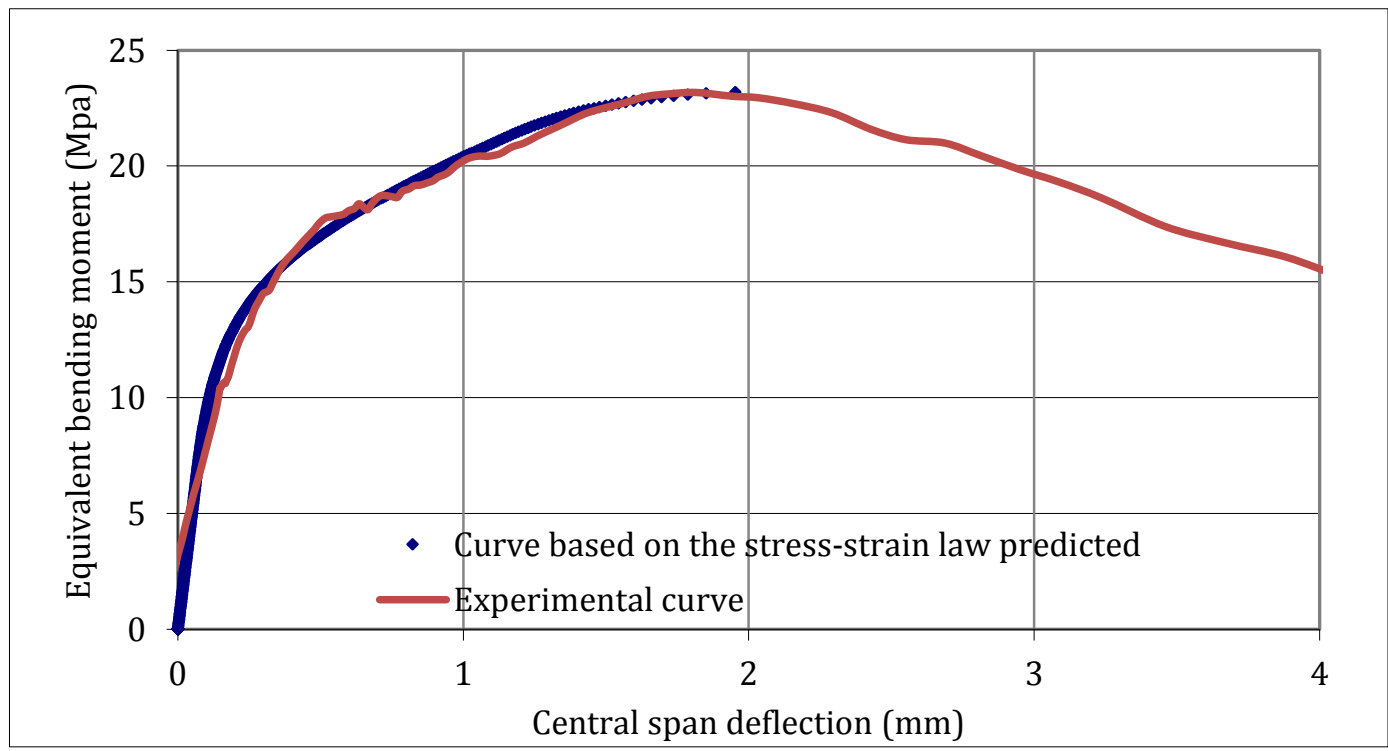

Figure 3.43: Experimental curve obtained from the four point bending test 


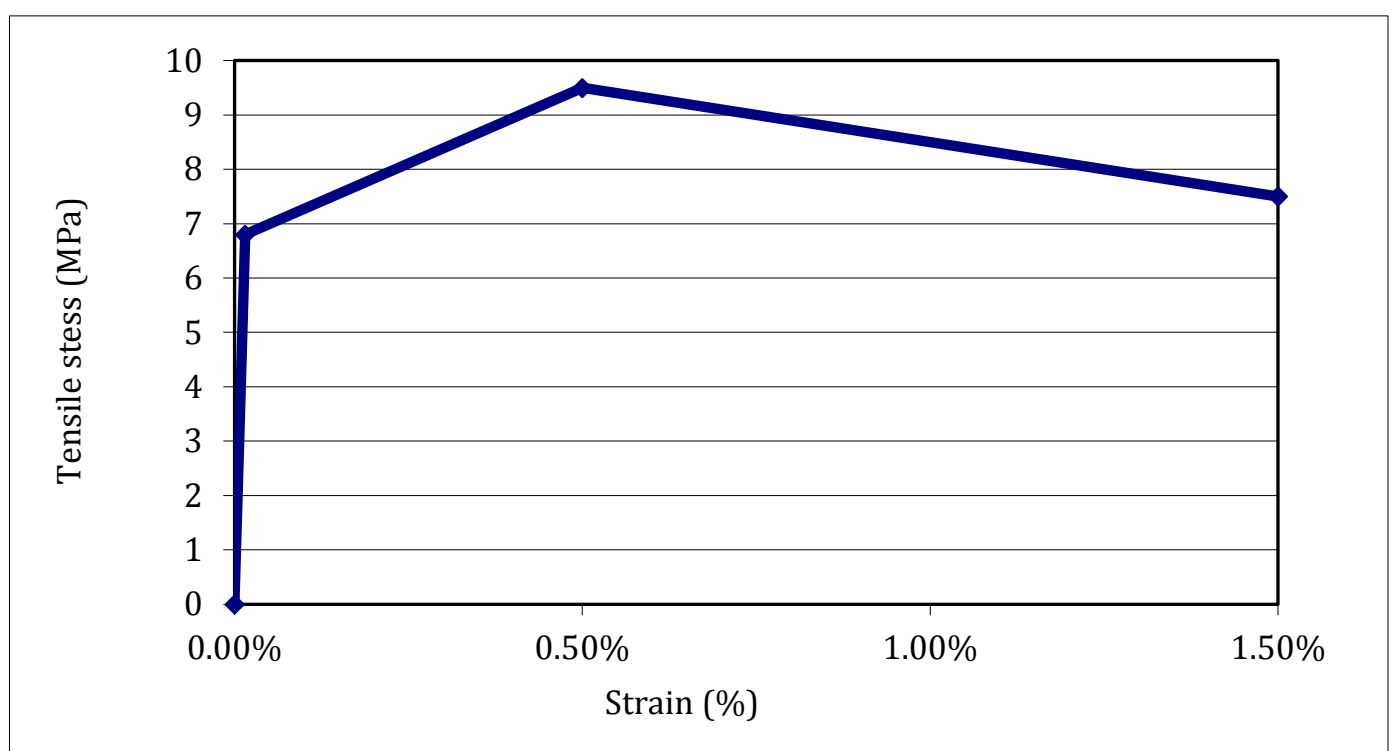

Figure 3.44: Tensile stress strain law deduced for aproximation to the experimental curve 
ON THE INFLUENCE OF SEVERAL VARIABLES IN THE UHPFRC DOSAGE

\section{ON THE INFLUENCE OF SEVERAL VARIABLES IN THE UHPFRC DOSAGE}





\subsection{INTRODUCTION AND MOTIVATIONS}

As was introduced in the Chapter 1, up to the present, the great majority of UHPFRC real applications have been performed with patented products. Most of these dosages are performed with exclusive materials, intensive mixers and steam curing. This leads to high range products with mechanical properties that in many cases exceed sharply the application requirements. Their high price and difficult availability hamper the use in daily applications.

Because of that there is an increasing tendency to design dosages using local available materials, and also choosing the mechanical and rheological properties according to the application exigencies.

The present chapter, developed from 2009, becomes the first wide experience with VHPFRC and UHPFRC at the Universitat Politècnica de València. A great spectrum of non-exclusive components and easier processes were analyzed in order to cover the main key points of hybrid VHPFRC-UHPFRC. The idea is to identify the possibilities of the dosing, mixing and pouring with the available components, tools and budget.

The analysis of the effect of each variable helps to understand how UHPFRC can be simplified. The success finding the right material for an application depends completely on this understanding.

After the studies and recommendations here provided, the designer should be able to control the dosing, mixing and pouring to develop a concrete with the following features:

- Reach a compatible combination of binder components, having also an acceptable content comparing with other mixtures from international experience in this field.

- Use available materials that can be easily got by a precast industry. This may decrease the price comparing with the patented UHPFRC mixtures.

- Be self-consolidating at fresh state along an acceptable setting time. This must ensure the movement of the entrapped air, a homogeneous fiber distribution and an easy casting.

- Have a fast strength development with no specific curing processes, being then more profitable for precast applications.

- Have strain-hardening in tension and bending. Because of that hybrid concretes are proposed and finally used, since they showed synergic effect in previous works from several authors [148] [37]. Also very high compressive strength and ductility are searched.

- Have a dense matrix to prevent the entrance of detrimental substances, increasing then the durability.

In fact, this work provided an accumulated knowledge to the UPV team that allowed the success building the first Spanish structural applications with non-patented UHPFRC: A footbridge over the Ovejas ravine, in Alicante. 


\subsection{OBJECTIVES AND STRUCTURE}

There are several variables affecting to the UHPFRC rheology and hardened state. Thus, the research is here divided in the study of several single variables in order to simplify the process of understand the material.

The chapter is structured in subchapters, where each one analyzes non-exclusive alternatives to the traditional high performance components and processes, showing thus the influence of this modifications in the material. The main goal of the chapter is understand the relation between the design (components, criteriums and mixing) and the final rheological and mechanical properties.

There is an optimum dosage, criterion process and mixing for each application: it is the cheapest that covers all the necessities. There are also some procedures and components that are essential for this type of concrete. This two ideas imply that we should use local available materials and simple processes in greater or lesser extent, depending on the application.

The specific goals of the analysis performed are:

* Study the effect of the binder components on UHPC (without fibers) using different cements and pozzolanic additions.

* Identify the effect of the binder content over the UHPFRC rheology and mechanical performance and deduce the optimum $\mathrm{W} / \mathrm{B}$ ratio for the dosages.

* Study the effect over the rheology and mechanical strength of the use of local active additions (FC3R and CSF) and compare it with low carbon content CSF.

* Study the viability of perform UHPFRC with limestone coarse aggregate, and obtain the differences with fine aggregate UHPFRC.

* Cast UHPFRC adopting different particle packing theories and deduce their suitability comparing rheology and compressive strength.

* Analyze the effect of the mixer type in the mixing process, the fresh and the hardened state.

* To give an overall view, carry out a statistical analysis including the most important variables studied before, deducing thus their influence on the compressive and flexural strength.

* Finally, provide useful and easy recommendations for designers of UHPFRC based on the previous state of art analysis and mostly on the findings done throughout this studies.

The Chapter is structured as follows: It is started at 4.3 with a compatibility study of 50 dosages, where the effect of the binder components of UHPC (without fibers) is studied. After it, the fibers were already added for all the studies. Sections 4.4 to 4.9 study the effect on the rheological and hardened state evolution of different variables modified one by one. At 4.4 is shown the influence of the cement content and W/B ratio. Subchapter 4.5 studies the effect of the addition type, while 4.6 analyze the impact of the crushed limestone coarse aggregate. At 4.7 is studied how adopt simpler packing criteria affect to the properties. Finally, at 4.8 the influence of the mixer type on the rheology and hardened properties is evaluated. To provide 
a better overview and give statistical rigor, at 4.9 the effect on the strength of all the variables together is analyzed, including also as a variable the fiber type used.

Some recommendations for VHPFRC-UHPFRC dosage and mixing processes are provided at 4.10 , as a result from the experience acquired during the research. It is a useful and simple summary for UHPFRC designers.

As a colophon, at subchapter 4.11 the experience is used to propose five examples of optimized VHPFRC-UHPFRC dosages, which could be used as the best solutions for different applications. They could belong to three different levels of performance, attending to the compressive strength. The output is the result of apply the knowledge gained throughout the chapter. Finally, at 4.12 are summarized the main ideas developed in this part.

It is important to remark some common aspects for all the tests here carried out unless otherwise stated in the experimental program:

- Steam curing are avoided, as the Ph.D. is focused in the simplification of the processes.

- The batch size in the EIRICH mixer is 50 liters, while in the tilting mixer is 20 liters, as these were identified as the optimum mixing volumes for each one.

- The compressive strength at $24 \mathrm{~h}, 48 \mathrm{~h}, 7$ and 28 days was obtained as the average of 3 cubes of length $100 \mathrm{~mm}$ for the intensive mixer and 2 cubes for the tilting drum mixer. The flexural strength, when studied, was obtained from three point bending tests performed to three prismatic beams of size $100 \times 100 \times 400 \mathrm{~mm}$. The scatter of the results does not require higher number of elements.

- The concretes performed are hybrid, containing a $1 \%$ of short fiber $13 / 0.16$ and $1 \%$ of long fiber. The reason is the better flexural performance identified in previous researches [40] [41], comparing with monofiber concretes with the same total fiber volume. This performance will cover the structural requirements of the bolted joints developed at Chapter 5.

- The pouring procedures are similar for all the batches, waiting 2 minutes between the mixing end and pour the concrete in the bucket used to fill the molds.

\subsection{UHPC BINDER PROPORTION ANALYSIS}

This work with UHPC without fibers is an adequate previous step for a VHPFRC-UHPFRC dosage design, as it is useful to identify incompatibilities and find out the best combinations of the available components. Here silica fume, fly ash and Fluid Catalytic Cracking Catalyst Residue have been added in different proportions to cement to study the rheology and hardened state of the mixtures. Once the effect of the binder proportions was understood, the development of the sections 4.4 to 4.8 was able to be performed.

\subsubsection{MOTIVATION AND OBJECTIVES}

The binder composition can strongly affect to the rheology and strength evolution. In this work, available active additions, all from Spanish suppliers, are proposed in order to perform 
simpler dosages. The materials used were Condensed Silica Fume (CSF), Fluid Catalytic Cracking Catalyst Residue (FC3R), and Fly Ash (FA).

Nowadays, the most used active addition for UHPC-UHPFRC is silica fume, being considered necessary. It provides stability in the fresh state, and higher compacity and compressive strength in hardened state. However, CSF composition and particle distribution can significantly vary depending on the supplier. Some CSF can strongly decrease the workability of the mixture, being sometimes impossible mix a dosage with low $\mathrm{W} / \mathrm{B}$ content and the typical content of CSF (15-30\%) in UHPC. In previous works with local CSF [38], the maximum content acceptable was found to be $10 \%$ over cement weight. The reason might be the high carbon content of the addition ( $>4 \%)$.

Fluid Catalytic Cracking Catalyst Residue (FC3R) is a pozzolanic residue from petrol refinery processes developed by the GIQUIMA group of UPV (see 3.2). It might be a useful alternative to CSF. FC3R has an activity index in the same range as CSF and can be produced in a not condensed state, what means that no intensive energy mixing is required to develop the potential efficiency of the addition. In this research is published the first experience of FC3R with UHPC-UHPFRC in any conditions.

On the other hand, fly Ash (FA) has been used few times in UHPC [225] [271] [159]. It is a pozzolan cheaper than cement with an Activity Index is near to 1 when the $\mathrm{W} / \mathrm{B}$ ratio is very low. In some cases its combination with higher activity additions (CSF or probably with FC3R) can develop a very interesting synergy to reach higher mechanical strengths.

Thus, the objectives of this step are:

* Determine the optimum binder components combination for non-fiber reinforced UHPC. The results will be a base for the UHPFRC dosage optimization.

* Determine the effect of the different active additions to the mixing process and the rheology of the mixture.

* Correlate the compressive strength evolution of the mixtures with the binder components.

* Evaluate the synergic effect of using FA as a second pozzolan for UHPC mixtures.

* Support some of the statements using SEM micro-photographs.

\subsubsection{EXPERIMENTAL PROGRAM}

To do that, a program of fifty different mortar dosages of three $40 \times 40 \times 160 \mathrm{~mm}$ prisms each one was composed modifying the cement type and the binder proportions. In the binder was considered the cement, the CSF, the FC3R and the FA. All mortars were prepared with 1:1 sand/binder weight ratio. The same $0-2 \mathrm{~mm}$ quartz sand provided by Caolines Lapiedra (see 3.2) was used as aggregate for the mortars. PCE admixture Glenium ACE 32 was used, keeping constant the content in $4.5 \%$ respect to the binder weight, so fluidity suffered logic variations due to the binder proportions. Variables of this phase were:

- Two type I sulphate resistant cements were used: $42.5 \mathrm{R} / \mathrm{SR}$ and $52.5 \mathrm{R} / \mathrm{SR}$ (described in 3.2), according with the Spanish standard UNE 80303-1. 
- As pozzolanic additions a Ferroatlántica CSF, a FA from Andorra Thermal Station and a FC3R were used (see 3.2 for the components properties).

It is worth to highlight that cement with the lower resistant class ( $42.5 \mathrm{R} / \mathrm{SR}$ ) is finer than the $52.5 \mathrm{R} / \mathrm{SR}$, but the water absorption can be smaller due to its higher content of inert particles. Besides, according with the data provided by the producers, the strength evolution is more progressive for the $42.5 \mathrm{R} / \mathrm{SR}$, what indicates the better suitability to distribute the heat of hydration.

On the other hand, it is noticeable that almost half of the FC3R chemical composition is $\mathrm{Al}_{2} \mathrm{O}_{3}$, being different than CSF, based on silicon dioxide. As can be seen in the granulometries shown at part 3.2, CSF sizes are coarser, and depending on the mixing efficiency they will disperse in greater or lesser extent. FC3R contains the greatest percentage of fine particles of all the pozzolanic additions.

25 dosages were cast with cement $42.5 \mathrm{R} / \mathrm{SR}$ (W/B ratio fixed in 0.18 ) and the other 25 with $52.5 \mathrm{R} / \mathrm{SR}$ (W/B ratio of 0.2 ), both with similar solid proportions. The difference in the waterbinder ratio was established due to the water demand noticed in previous tests for the 52.5 cement, reaching with this change comparable workability for the same binder combinations. The content of FC3R was varied between $0 \%$ and $20 \%$ over the cement weight. CSF ranged between 0 and $15 \%$ as higher contents were expected to decrease strongly the workability (see previous research, [37]). FA content over cement weight ranged between $0 \%$ and $30 \%$.

The table 4.1 shows the dosages (similar for both cement types) prepared with the percentage of each component over the total solid weight. As can be seen the binder sum equals $50 \%$, since this weight was fixed similar than the sand weight. In brackets are shown for the pozzolans the percentage of content over cement weight, which is a more extended way to express this value.

Table 4.1: Experimental program of the binder optimization. Proportions over solid weight. Notice that Cement, CSF, FC3R and FA sum 50

\begin{tabular}{|cccccc|}
\hline Dosage no & Cement & CSF & FC3R & FA & Sand \\
\hline \multicolumn{5}{c}{ \% over total weight of solids, [\% over cement weight] } \\
\hline 1 & 45 & $4.5[10]$ & 0 & 0 & 50 \\
2 & 41.7 & $4.2[10]$ & 0 & $4.2[10]$ & 50 \\
3 & 38.5 & $3.8[10]$ & 0 & $7.7[20]$ & 50 \\
4 & 35.7 & $3.6[10]$ & 0 & $10.7[30]$ & 50 \\
5 & 41.7 & $4.2[10]$ & $4.2[10]$ & 0 & 50 \\
6 & 43.5 & $6.5[15]$ & 0 & 0 & 50 \\
7 & 40 & $6[15]$ & 0 & $4[10]$ & 50 \\
8 & 37 & $5.6[15]$ & 0 & $7.4[20]$ & 50 \\
9 & 34.5 & $5.2[15]$ & 0 & $10.3[30]$ & 50 \\
10 & 40 & $6[15]$ & $4[10]$ & 0 & 50 \\
11 & 45.5 & 0 & $4.5[10]$ & 0 & 50 \\
12 & 41.7 & 0 & $4.2[10]$ & $4.2[10]$ & 50 \\
13 & 38.5 & 0 & $3.8[10]$ & $7.7[20]$ & 50 \\
14 & 35.7 & 0 & $3.6[10]$ & $10.7[30]$ & 50 \\
15 & 43.5 & 0 & $6.5[15]$ & 0 & 50 \\
\hline
\end{tabular}




\begin{tabular}{|cccccc|}
\hline 16 & 40 & 0 & $6[15]$ & $4[10]$ & 50 \\
17 & 37 & 0 & $5.6[15]$ & $7.4[20]$ & 50 \\
18 & 34.5 & 0 & $5.2[15]$ & $10.3[30]$ & 50 \\
19 & 41.7 & 0 & $8.3[20]$ & 0 & 50 \\
20 & 38.5 & 0 & $7.7[20]$ & $3.8[10]$ & 50 \\
21 & 35.7 & 0 & $7.1[20]$ & $7.1[20]$ & 50 \\
22 & 33.3 & 0 & $6.7[20]$ & $10[30]$ & 50 \\
23 & 45.5 & 0 & 0 & $4.5[10]$ & 50 \\
24 & 41.7 & 0 & 0 & $8.3[20]$ & 50 \\
25 & 38.5 & 0 & 0 & $11.5[30]$ & 50 \\
\hline
\end{tabular}

One liter of UHPC was cast for each dosage in the mortar mixer introduced at 3.3.1, where also the mixing process is detailed but without the fiber addition. In general, between the minute 5 and 8 the consistency changed from dry to plastic, and later to liquid. Only between the minute 8 and 9 high mixing speed was applied and the process finished at normal speed in the minute 10 .

Workability was measured with the mini-slump test (see 3.4.1), using a tronco-conical mold similar than the used in UNE-EN 1015-3 [7]. Three $40 \times 40 \times 160 \mathrm{~mm}$ specimens were cast without vibration for compressive strength tests. Curing process was at $20^{\circ} \mathrm{C}$ with $100 \%$ of relative humidity, as detailed in subchapter 3.6. Flexural and compressive strength were determined at 2, 7 and 28 days according to EN 196-1 [6], testing the two halfs of a prism at each age. Finally, a study with Scanning Electron Microscope (SEM) was performed 90 days after casting to mixtures 5, 8 and 24 with cement $52.5 \mathrm{R} / \mathrm{SR}$.

\subsubsection{RESULTS AND DISCUSSION}

Figures 4.1 and 4.2 show the mixtures rheology for both cements. The mini-slump flow decreases with the increasing content of FC3R or CSF as was expected. It can be appreciated that for dosages with CSF the decrease of flowability is much more marked than for similar contents of FC3R. This effect is more significant when cement type I-52.5 R/SR is used. It was noticed that the amount of FC3R over cement weight can reach $20 \%$ without mixing difficulties.

On the other hand, CSF reduced radically the workability for contents above $10 \%$. An addition of $20 \%$ of CSF was attempted in additional experiments, but it was impossible to reach a plastic-liquid mix even with very long mixing times.

It was also confirmed that increasing the FA content implies an increase of flowability. This effect is stronger with I-52.5 R/SR cement, because in this case FA substitutes cement that has greater water demand. 


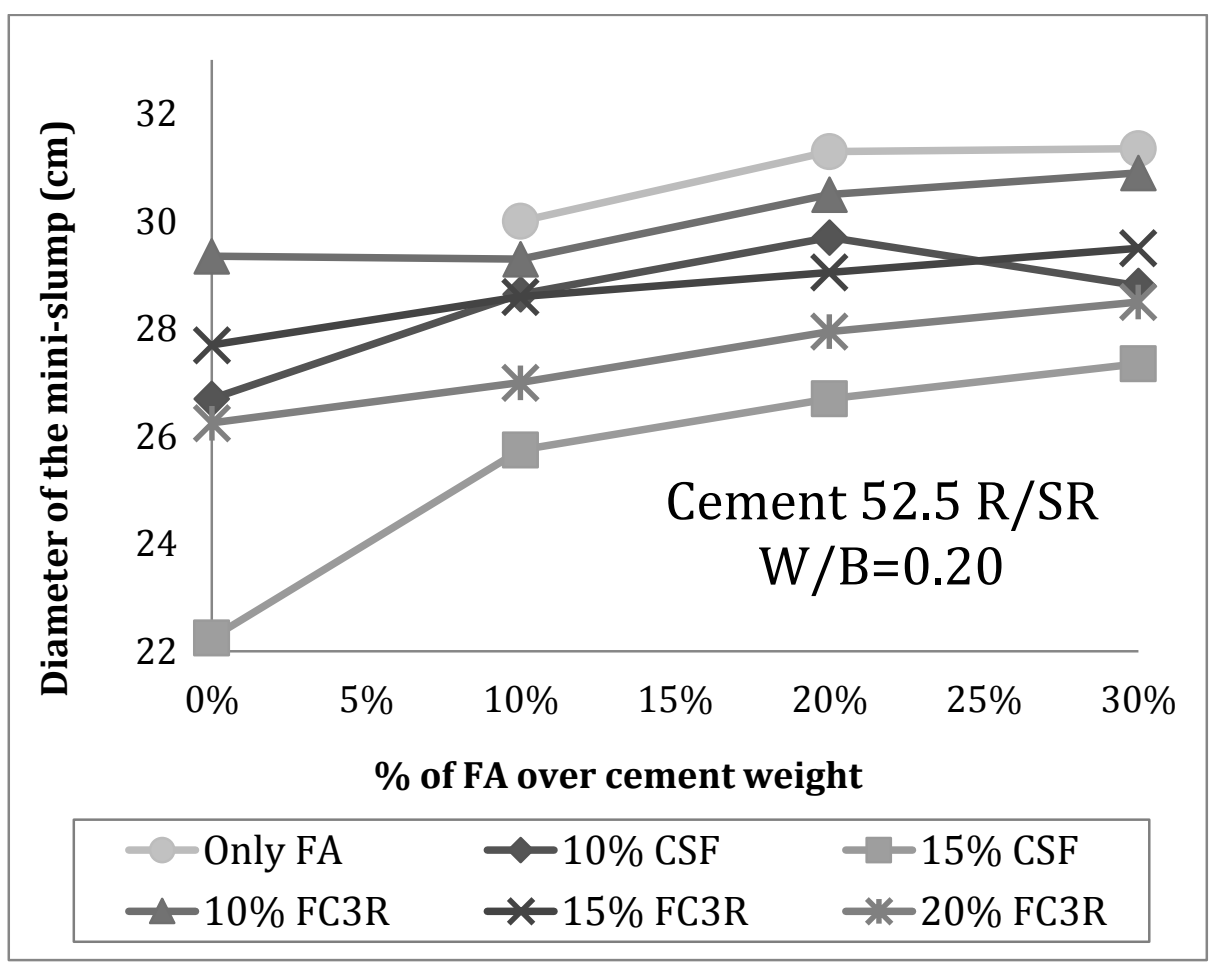

Figure 4.1: Mini-slump flow diameter for mixtures with cement I-52.5 R/SR

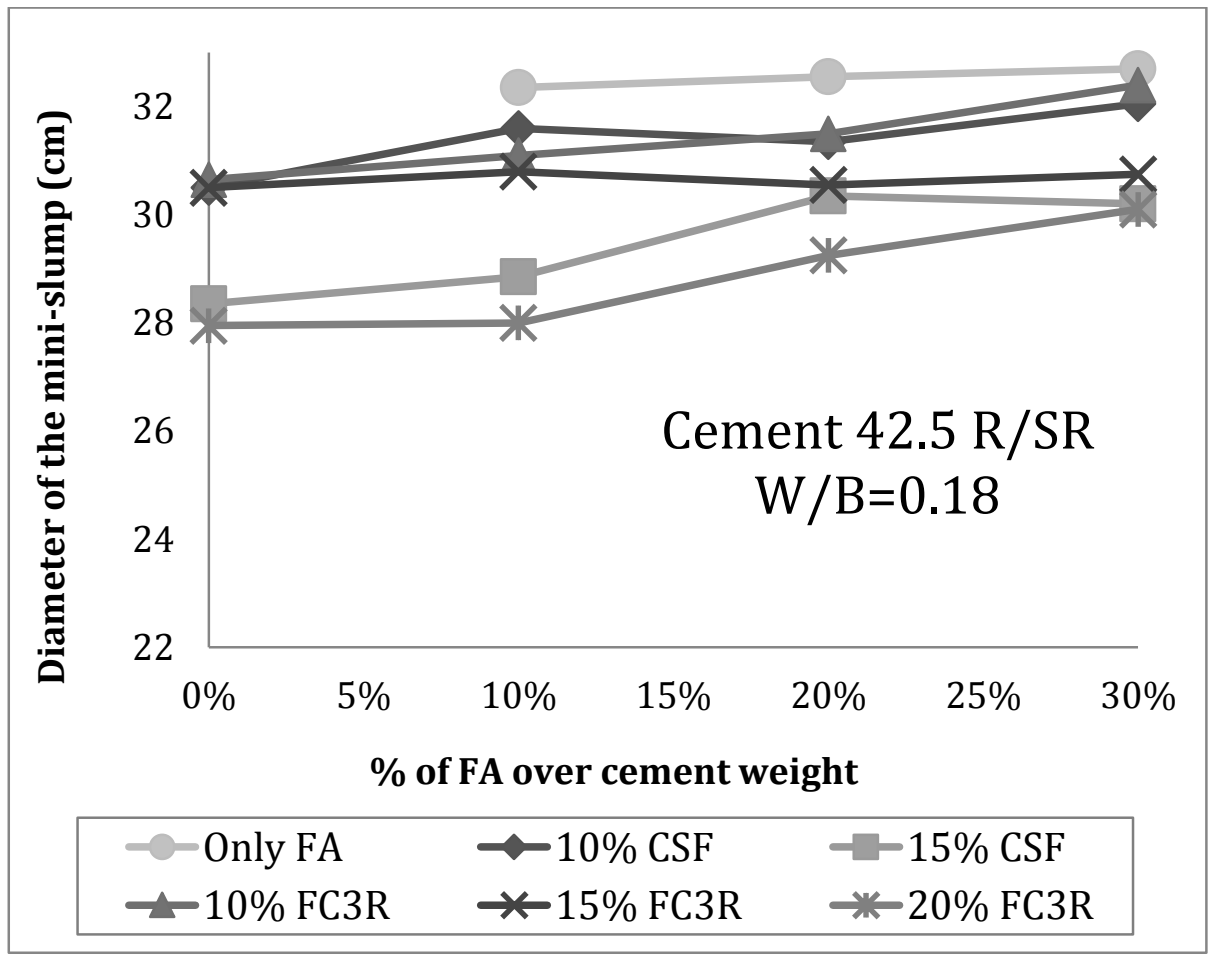

Figure 4.2: Mini-slump flow diameter for mixtures with cement I-42.5 R/SR

With regard to the hardened state, figures 4.3 to 4.8 show the 2, 7 and 28 days compressive strength depending on the mixture composition and cement type. The absence of fibers produced a brittle failure which provided higher scatter in the compressive strength results.

The 2 days compressive strength was $60 \%-70 \%$ of the 28 days strength, depending of the FA substitution but without noticeable differences between the FC3R and CSF mixtures. At 7 days CSF mixtures strength ranged in $80-85 \%$ of the 28 days strength, while the FC3R mixes 
had between $87 \%-94 \%$, depending on the FA content. This difference was attributed to the higher early age FC3R activity, while the CSF developed its most pozzolanic activity the following weeks. An increase in the content of FA produced, in general, noticeable lower strengths at 2 days and slightly lowers ones at 7 days.

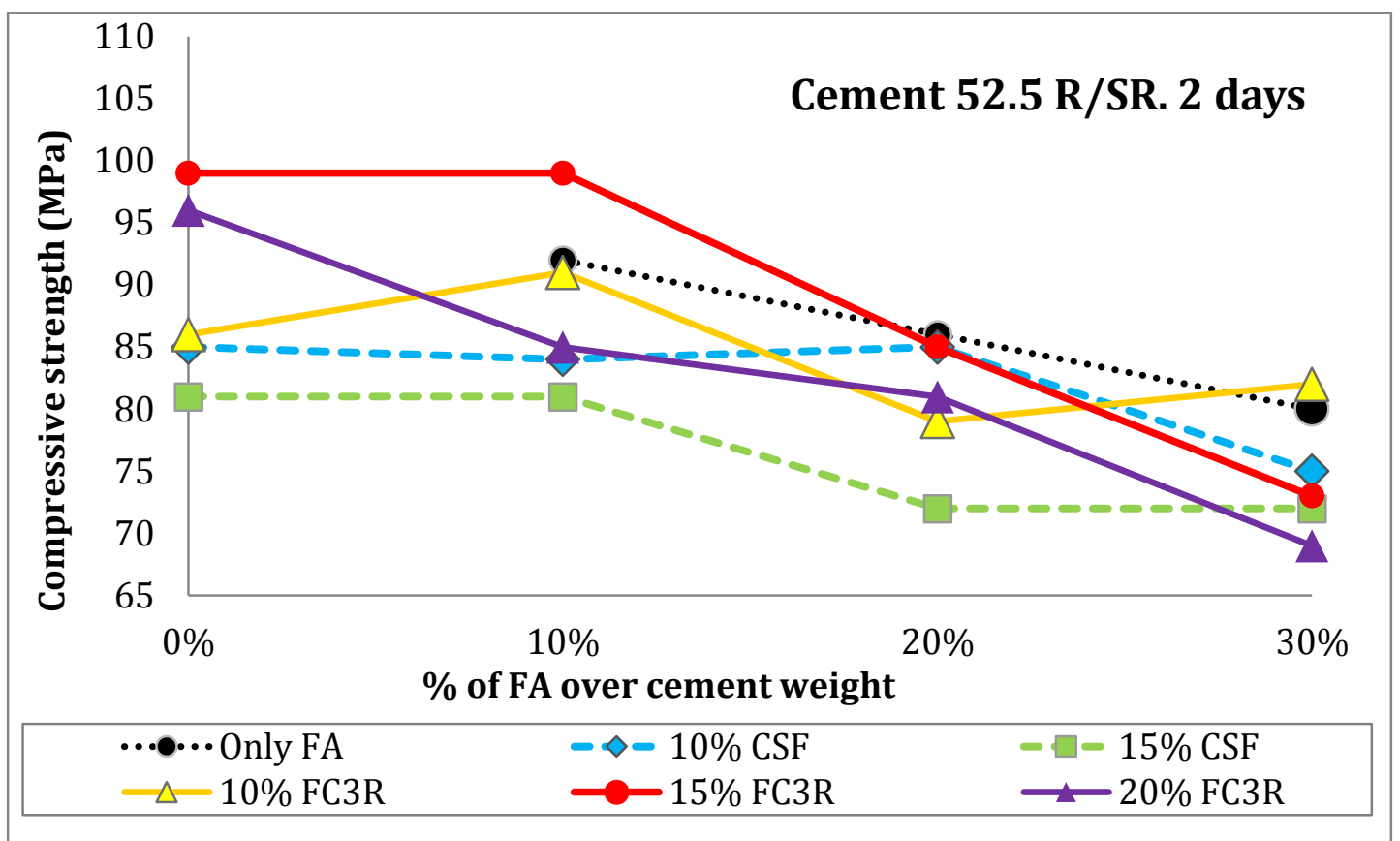

Figure 4.3: Two days compressive strength for cement $52.5 \mathrm{R} / \mathrm{SR}$

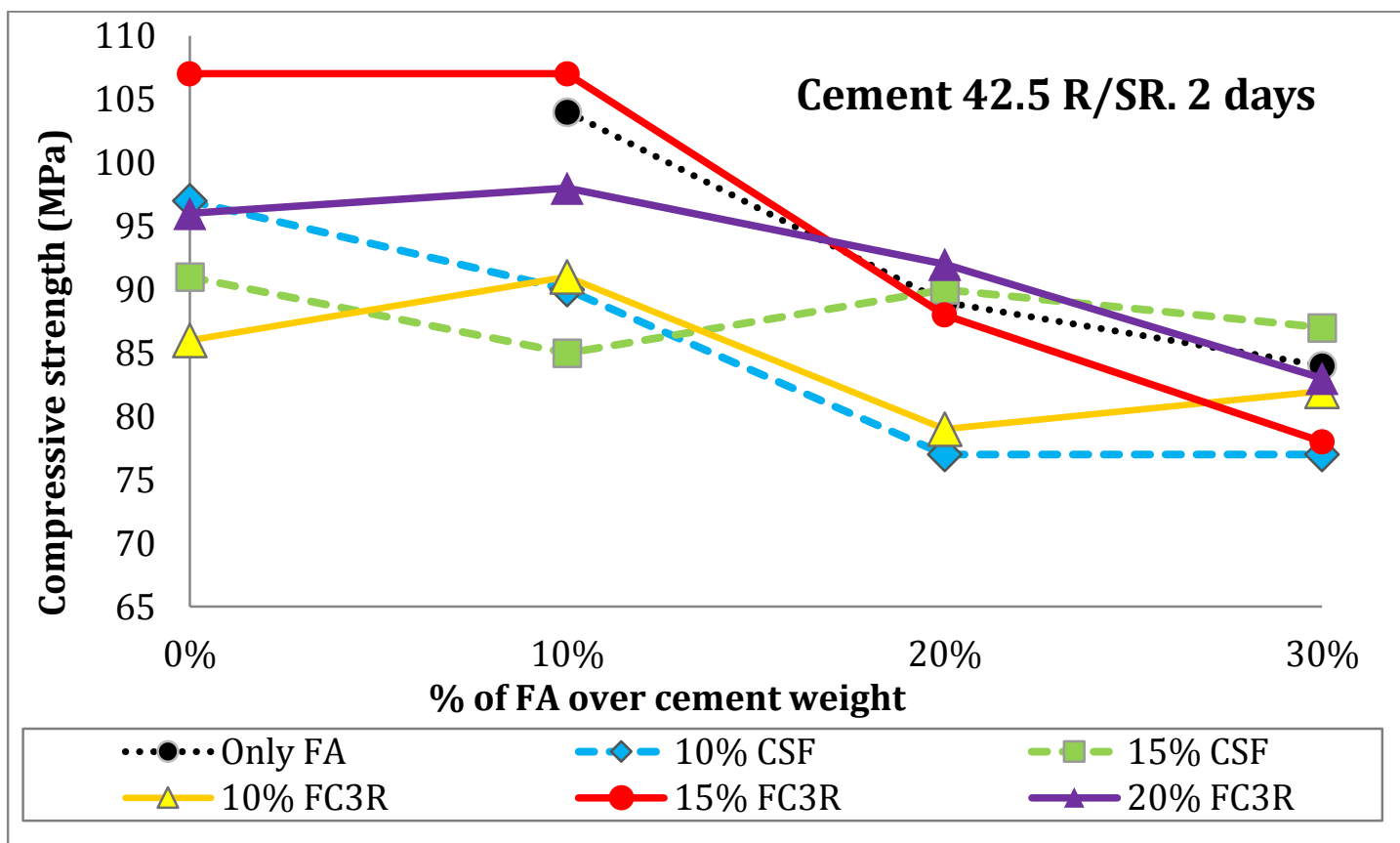

Figure 4.4: Two days compressive strength for cement $42.5 R / S R$

Whatever the cement type, the 28 days compressive strength for mixtures with $10 \%$ of FC3R was slightly higher $(\approx 5 \%)$ than the ones with $10 \%$ of CSF. For $15 \%$ of content over cement weight, this difference became more remarkable, being of $14 \%$ and $16 \%$ with I-52.5 R/SR and I-42.5 R/SR cements respectively. The difference can be attributed partly to the decrease of workability with $15 \%$ CSF content, which implies a more porous matrix since the air cannot rise to the surface. Moreover, it is possible that the condensed silica fume particles 
didn't reach a complete dispersion during the mixing, having then smaller efficiency than the FC3R. This will be checked with the SEM micro-photography.

Besides, it is noticeable that, thanks to the long term FA reactivity, the strength didn't decrease at 28 days, showing even increases for some cases. This can be explained by a high activity with low W/B ratio but also due to the better workability that provides to the mix, which let the air go out, creating then a more compact matrix. From other point of view, if the self-compactability of a mixture is adequate, FA can be added and the W/B ratio be reduced, increasing the strength and maintaining the flowability.

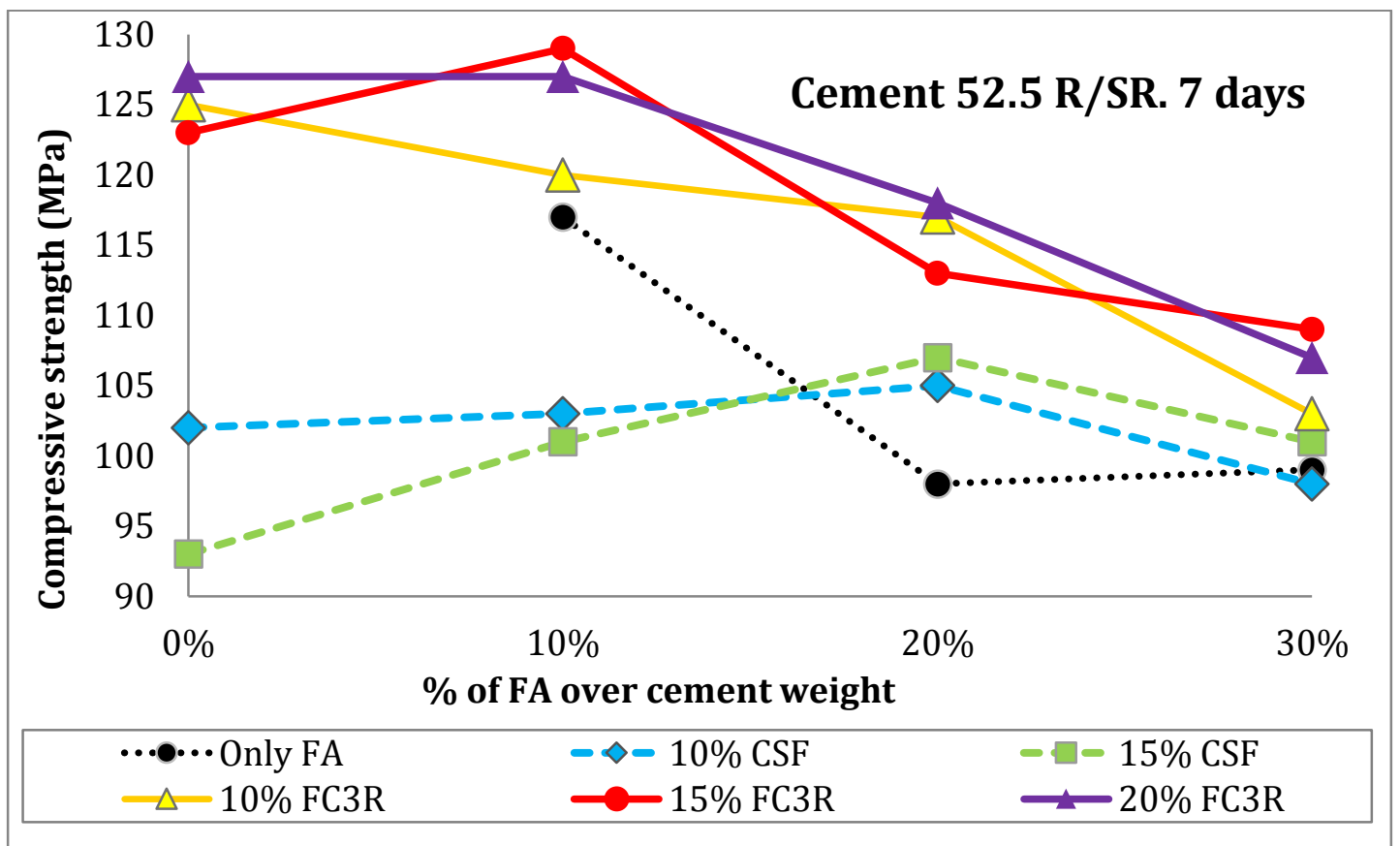

Figure 4.5: Seven days compressive strength for cement $52.5 \mathrm{R} / \mathrm{SR}$

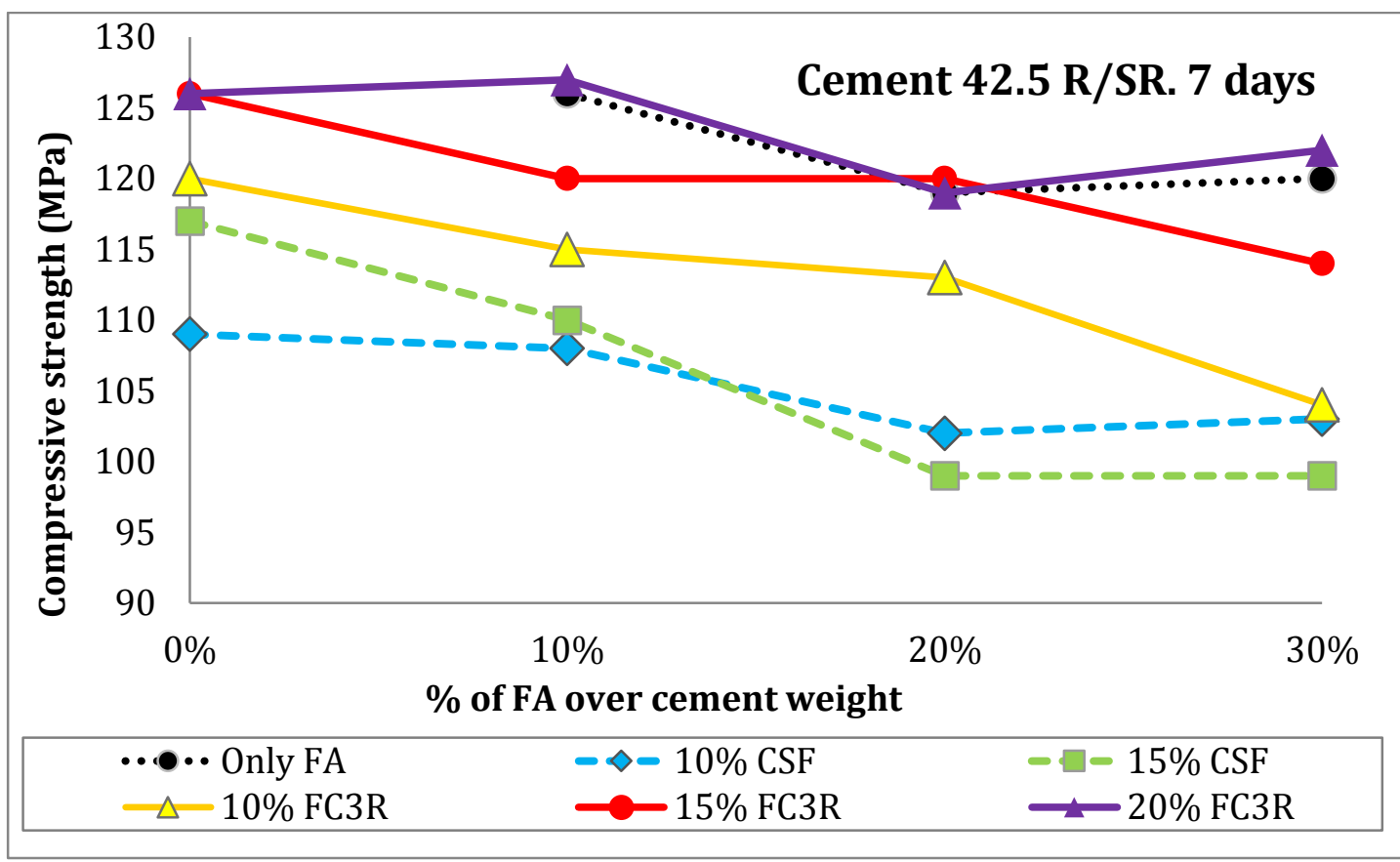

Figure 4.6: Seven days compressive strength for cement $42.5 \mathrm{R} / \mathrm{SR}$ 


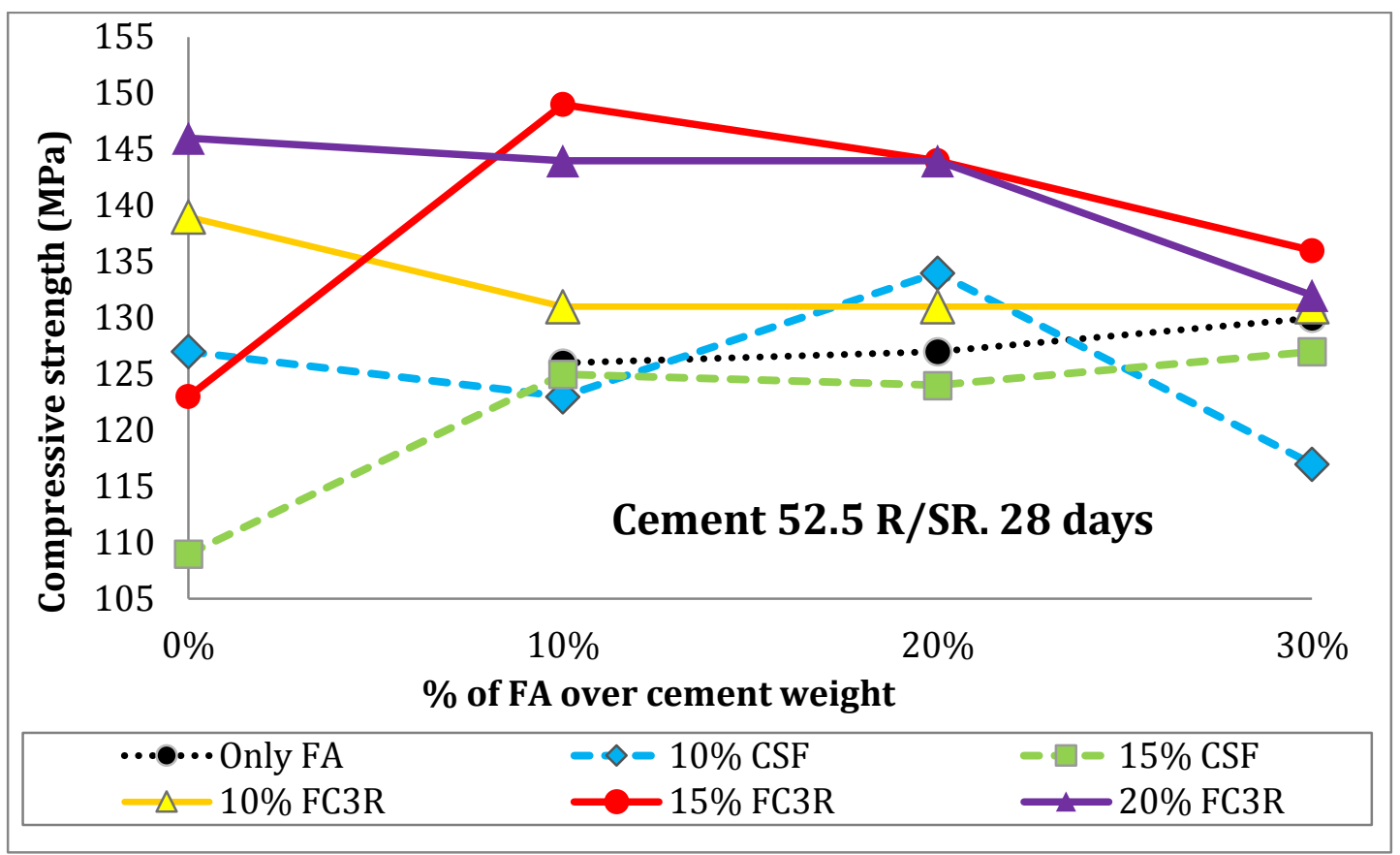

Figure 4.7: Twenty eight days compressive strength for cement $52.5 \mathrm{R} / \mathrm{SR}$

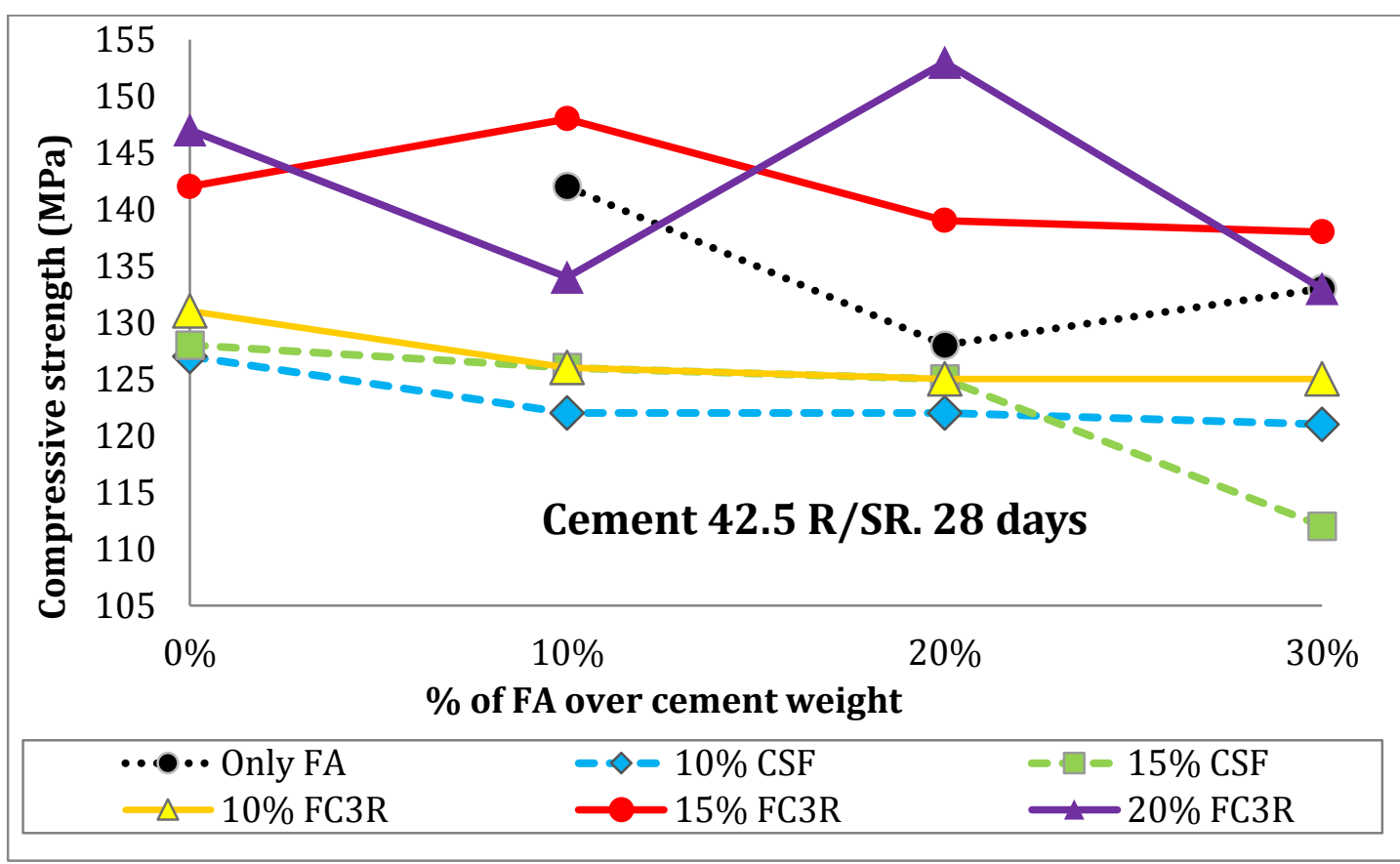

Figure 4.8: Twenty eight days compressive strength for cement $42.5 \mathrm{R} / \mathrm{SR}$

The combination of active additions with FA provided the best results: Mixture 22, with $20 \%$ of FC3R and $30 \%$ of FA over cement weight $\left(711 \mathrm{~kg} / \mathrm{m}^{3}\right)$ reached similar strengths than others with $10 \%$ of FC3R over cement weight $\left(1000 \mathrm{~kg} / \mathrm{m}^{3}\right)$, as mixture 11 , with the advantages of more flowability, less shrinkage expected, better compacity, lower costs and more sustainability. At 2 days the FA optimum content is between $0 \%$ and $10 \%$, with a decrease of strength for higher FA contents. At 7 days the higher strengths are found with a FA content of $10 \%$, and 28 days the most adequate content is between $10 \%$ and $20 \%$.

As can be deduced from the figures, the strength values with cement $42.5 \mathrm{R} / \mathrm{SR}$ and 52.5 $\mathrm{R} / \mathrm{SR}$ are very similar. The smaller strength of the $42.5 \mathrm{R} / \mathrm{SR}$ is compensated by the lower W/B 
ratio of its dosages. From a practical point of view, the use of one or other cement would depend of each situation (prices, compatibility of materials, availability of the components, etc.).

Finally, the mixtures where FC3R and CSF were combined without FA provided better performance at short term with cement $42.5 \mathrm{R} / \mathrm{SR}$, and similar than with $52.5 \mathrm{R} / \mathrm{SR}$ at 28 days (see figure 4.9). At this time the maximum strength was over $130 \mathrm{MPa}$, smaller than the reached for combinations with FA. Then, and considering also the worse flowability of these mixtures, the combination of CSF and FC3R didn't seem to be an interesting option.

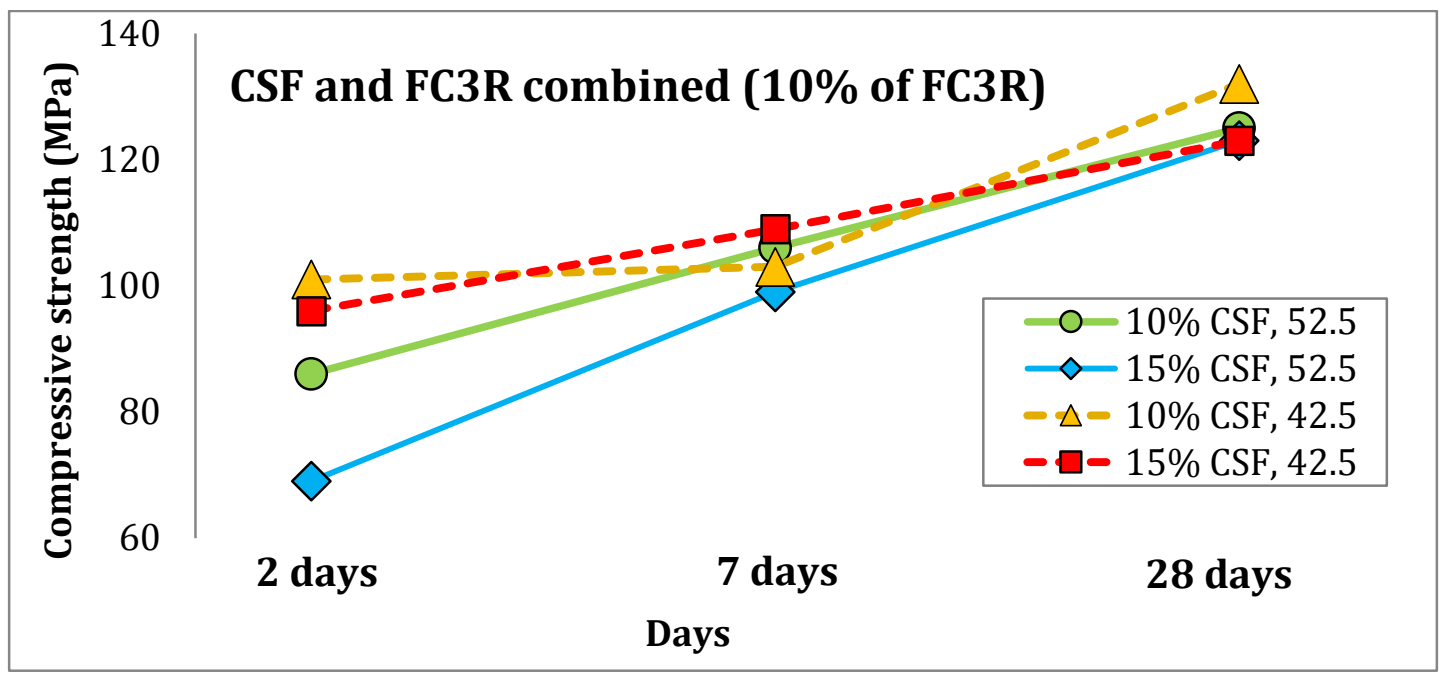

Figure 4.9: Strength evolution of the mixtures where FC3R and CSF are combined without FA

SEM microphotographs, shown at figures 4.10 to 4.13 , are worth to sustain some of the statements done before. They are made to mixtures number 5 ( $10 \%$ of CSF and $10 \%$ of FC3R), number 8 (15\% de CSF and $20 \%$ of FA) and 24 (only with $20 \%$ of FA).

At the first two pictures can be appreciated some CSF agglomerates with a diameter of 50 $60 \mu \mathrm{m}$. This is an evidence that CSF is not fully dispersed, so the potential of this active addition is only partially developed. Particles of FC3R were not found, as expected from an efficient dispersion. Figure 4.12 shows an Interfacial Transition Zone (ITZ) in dosage 5. Active additions improved the ITZ, so the cracked faces suffered due to the compressive failure broke the silica aggregates. At figure 4.13 is appreciated one FA particle developing the pozzolanic reaction. No conglomerates of FA particles were observed, so the dispersion reached was adequate.

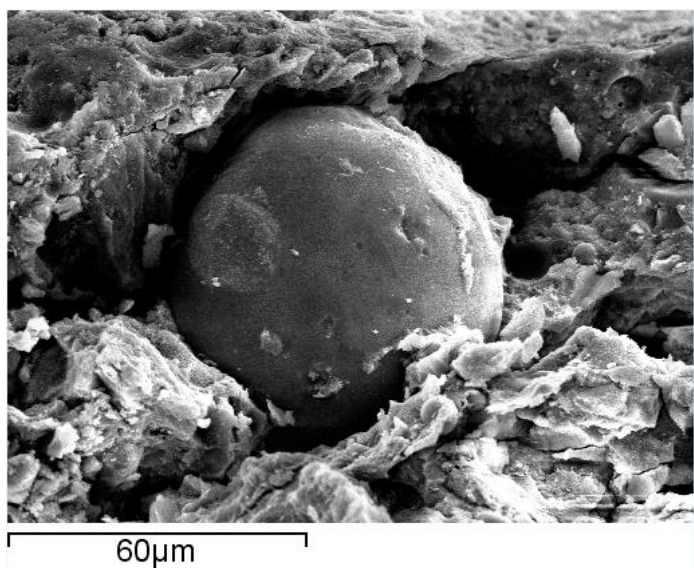

Figure 4.10: CSF particle, dosage 5

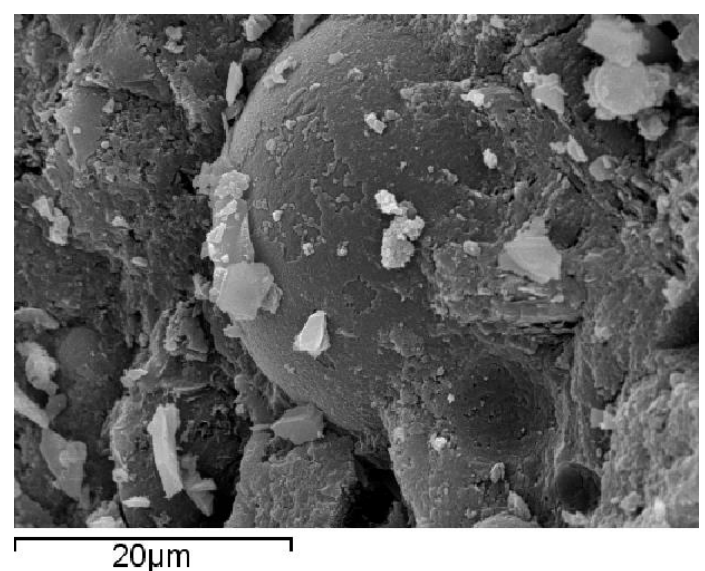

Figure 4.11: CSF particle, dosage 5 


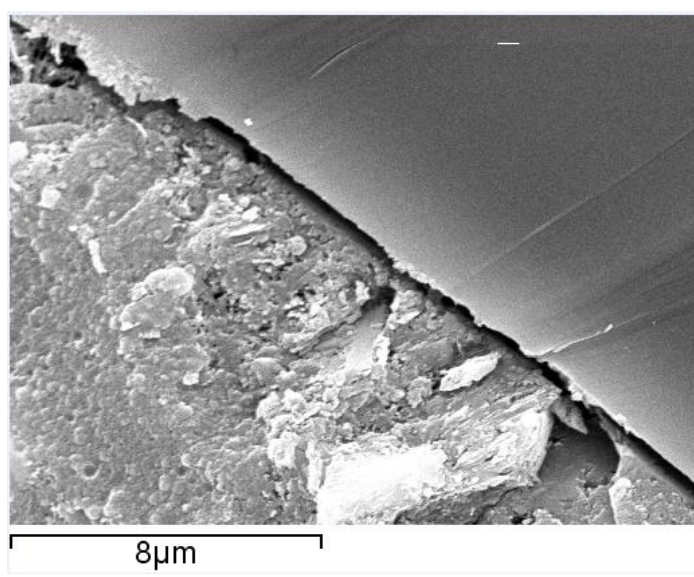

Figure 4.12: Interfacial Transition Zone (ITZ), dosage 5

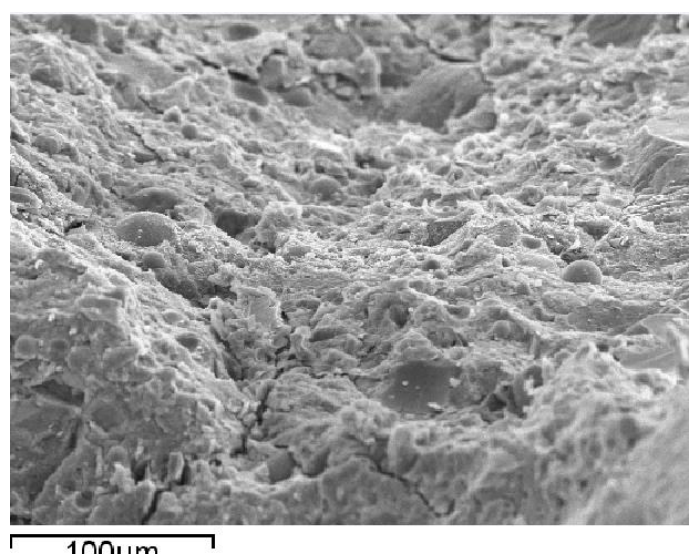

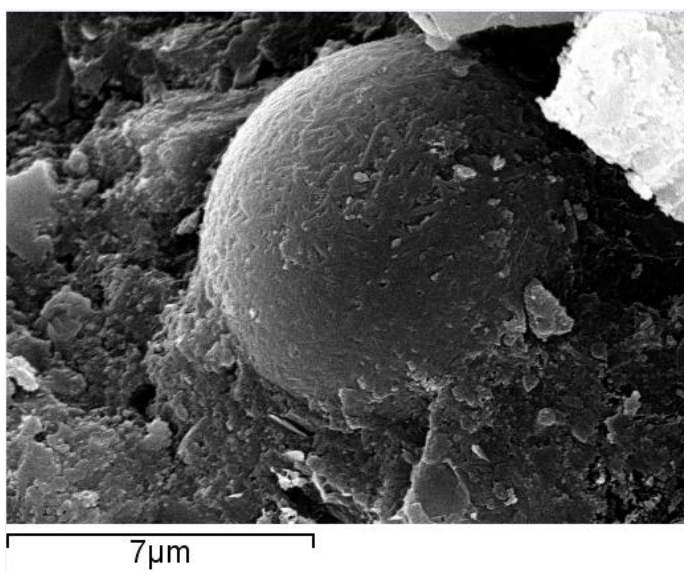

Figure 4.13: Fly Ash particle reacting with porlandite, dosage 24

Figure 4.14: CSF particles of the dosage 8. High content of CSF agglomerate can be distinguished perturbing the matrix spatial structure

\subsubsection{CONCLUSSIONS OF THE UHPC BINDER ANALYSIS}

Several aspects can be concluded:

* The same compressive strength and flowability can be reached with different binder proportions, having multiple options to choose. The most adequate depends mainly on the early compressive strength demand and the components suitability and prices.

* The CSF selected is can be added in a maximum content of $15 \%$, though $10 \%$ provides the best results. It is necessary change the type for higher contents. The most compatible cement here is $52.5 \mathrm{R} / \mathrm{SR}$.

* FC3R decreases workability less than CSF, and provides better results with cement 42.5 $\mathrm{R} / \mathrm{SR}$. Its reacts in shorter term than CSF, observing a pozzolanic reaction after 2 days.

* Fly ash is a very useful pozzolan combined with CSF or FC3R. It increases the workability when substitute cement. It reduces the cement content and only decreases the strength at short term. The use of this addition in UHPFRC is convenient if there is an available supply with constant properties and if it doesn't give to the mixture a too reduced compressive strength at early age.

* The last is the reason for not to continue using fly ash as a main addition at this research. Besides, as the CSF dispersion observed was inefficient, a new CSF type with lower carbon content was introduced. The FC3R was still used as an addition because of the results obtained. 


\subsection{INFLUENCE OF THE W/B RATIO ON THE RHEOLOGY AND HARDENED STATE}

$\mathrm{W} / \mathrm{B}$ ratio is the main parameter that controls the capillary porosity, and consequently the concrete performance. This parameter is controlled with the variation of both the water content and the binder content.

The cement content, thus, can increase to reduce the W/B ratio. Then, it can be a useful parameter to establish different levels of VHPFRC-UHPFRC performance. Cement content can vary between a range of values: A minimum quantity to guarantee high flowability with a sufficiently low W/B ratio. On the other side, very high cement content in a UHPFRC mixture becomes a waste as a big part of it is acting as an inert filler, and also a heat hydration problem. At this chapter the performance of different cement contents will be shown.

Also the W/B can be reduced using smaller amount of water, increasing the strength. But water content needs to vary between two values: The minimum that provides enough hydration and PVF to provide selfcompactability to the concrete, and a maximum that decreases the strength and produces the segregation of the fibers or the coarse aggregate. At this chapter, the effect reduce the water content will be studied, and also the maximum flowability acceptable for a UHPFRC mixture.

\subsubsection{EFFECT OF W/B ON THE HARDENED STATE: EXPERIMENTAL PROGRAM}

Here three cement contents $\left(700 \mathrm{~kg} / \mathrm{m}^{3}, 850 \mathrm{~kg} / \mathrm{m}^{3}\right.$ and $\left.1000 \mathrm{~kg} / \mathrm{m}^{3}\right)$ and different W/B ratios are proposed to study the variation produced in the rheology (one slum flow) and the compressive strength (12 prisms per each batch) of each of the 13 batches. Active additions will be added proportionally to the cement weight. The cement content of the three mixtures set along this subchapter will be also used in the following sections.

The same two cements than in 4.3 and two different CSF were used. One is the used in 4.3 from Ferroatlántica and the other is ELKEM 940D (properties at 4.3). Besides the PCE used in 4.3, two different PCE admixtures were used: Sika Viscocrete ${ }^{\circledR} 20$ HE and BASF GLENIUM ${ }^{\circledR}$ SKY 575 (properties at 3.2). Two quartz sands $(0-0.5 \mathrm{~mm}$ and $0-2 \mathrm{~mm}$ ) were combined for every dosage, adjusting the curve with the modified Andreasen \& Andersen method (A\&A $A_{\text {mod, }}$ subchapter 2.8.2). All mixtures were hybrid, containing $1 \%$ of short fibers Dramix ${ }^{\circledR}$ OL$13 / 0.16 \mathrm{~mm}$ and $1 \%$ of fibers Dramix® RC-80/30-BP. The mixing process is explained at 3.3.4. No vibration was carried out and neither steam curing.

The experimental mixtures, shown at table 4.2, were performed to evaluate:

- The effect of the binder content. Mixtures C-1, C-2, C-3 (with CSF); and also C-6, C-7, C-8 (with FC3R) have increasing binder content, and consequently smaller $\mathrm{W} / \mathrm{B}$ ratio required to reach the appropriate workability.

- The effect of the W/B ratio. The groups of dosages C-3 to C-5; C-9 to C-11, and C-12, C-13 contain all of them $1000 \mathrm{~kg} / \mathrm{m}^{3}$ of cement, differing only in the W/B ratio. With this the effect of this parameter over rheology and hardened state with constant binder content was studied. 
Table 4.2: Experimental dosages to evaluate the effect of $W / B$ ratio and cement content

\begin{tabular}{|c|c|c|c|c|c|c|c|}
\hline \multirow{2}{*}{$\begin{array}{c}\text { Mix } \\
\text { № } \\
\end{array}$} & \multicolumn{2}{|c|}{ Cement } & \multicolumn{2}{|c|}{ Active addition } & \multirow{2}{*}{$\begin{array}{c}\text { PCE } \\
\text { Type }\end{array}$} & \multirow{2}{*}{$\begin{array}{c}\% \\
\% \text { o.c.w. }\end{array}$} & \multirow{2}{*}{$\frac{\mathrm{W} / \mathrm{B}}{\text { Ratio }}$} \\
\hline & Type & $\mathrm{kg} / \mathrm{m}^{3}$ & Type* & \% o.c.w. & & & \\
\hline $\mathrm{C}-1$ & $42,5 \mathrm{R} / \mathrm{SR}$ & 700 & CSF 940D & $15 \%$ & Sika VSC 20HE & $3 \%$ & 0,245 \\
\hline $\mathrm{C}-2$ & $42,5 \mathrm{R} / \mathrm{SR}$ & 850 & CSF 940D & $15 \%$ & Sika VSC 20HE & $2,5 \%$ & 0,205 \\
\hline $\mathrm{C}-3$ & $42,5 \mathrm{R} / \mathrm{SR}$ & 1000 & CSF 940D & $15 \%$ & Sika VSC 20HE & $2,5 \%$ & 0,175 \\
\hline $\mathrm{C}-4$ & $42,5 \mathrm{R} / \mathrm{SR}$ & 1000 & CSF 940D & $15 \%$ & Sika VSC 20HE & $3 \%$ & 0,166 \\
\hline$C-5$ & $42,5 \mathrm{R} / \mathrm{SR}$ & 1000 & CSF 940D & $15 \%$ & Sika VSC 20HE & $3 \%$ & 0,162 \\
\hline $\mathrm{C}-6$ & $52,5 \mathrm{R} / \mathrm{SR}$ & 700 & FC3R & $10 \%$ & BASF SKY 575 & $3 \%$ & 0,27 \\
\hline $\mathrm{C}-7$ & $52,5 \mathrm{R} / \mathrm{SR}$ & 850 & FC3R & $10 \%$ & BASF SKY 575 & $3 \%$ & 0,21 \\
\hline $\mathrm{C}-8$ & $52,5 \mathrm{R} / \mathrm{SR}$ & 1000 & FC3R & $15 \%$ & BASF SKY 575 & $3 \%$ & 0,2 \\
\hline$C-9$ & $42,5 \mathrm{R} / \mathrm{SR}$ & 1000 & FC3R & $15 \%$ & BASF ACE 32 & $4,5 \%$ & 0,19 \\
\hline$C-10$ & $42,5 \mathrm{R} / \mathrm{SR}$ & 1000 & FC3R & $15 \%$ & BASF ACE 32 & $4,5 \%$ & 0,185 \\
\hline$C-11$ & $42,5 \mathrm{R} / \mathrm{SR}$ & 1000 & FC3R & $15 \%$ & BASF ACE 32 & $4,5 \%$ & 0,18 \\
\hline $\mathrm{C}-12$ & $42,5 \mathrm{R} / \mathrm{SR}$ & 1000 & CSF ferroat & $15 \%$ & BASF ACE 32 & $4,5 \%$ & 0,21 \\
\hline C-13 & $42,5 \mathrm{R} / \mathrm{SR}$ & 1000 & CSF ferroat & $15 \%$ & BASF ACE 32 & $4,5 \%$ & 0,195 \\
\hline
\end{tabular}

This will show if smaller binder contents affect strongly to the UHPFRC rheology and hardened state, and also the sensibility of both to a variation in the W/B ratio.

For the mixtures where the cement is changed ( $\mathrm{C}-1$ to $\mathrm{C}-3$ and $\mathrm{C}-6$ to $\mathrm{C}-8)$, the W/B ratio was chosen to be the expected to provide a fluid concrete 3 minutes after the water addition in the mixing. For mixtures where the effect of the W/B is evaluated, the ratio was reduced from the value adopted at $\mathrm{C}-3$ and C-8. Besides, additionally to the compressive tests done according with 4.2 , for C-1, C-2 and C-3 the evolution of this workability was measured with the rheometer.

Three different additions were used to amplify the validity of the study. As PCE has different solid content and also different effectiveness with each binder, the quantity added was the one that produced in previous tests adequate workability and compressive strength evolution for the same dosage.

\subsubsection{RESULTS OF THE EFFECT OF W/B ON THE HARDENED STATE}

The slump flow evolution of mixtures C-1, C-2 and C-3 is shown in figure 4.15. Even though $\mathrm{W} / \mathrm{B}$ ratio is higher for $\mathrm{C}-1$ than for $\mathrm{C}-3$ and total water content is very similar, $\mathrm{C}-1$ slump flow is much more reduced. The reason is that, even though the $\mathrm{C}-1$ paste has smaller yield stress, its aggregate volume fraction is higher and consequently the coarse particles friction, hampering the movement. With other words, dosages C-2 and C-3 are have enough paste volume fraction to behave as a semi-dilute regime, and the reduced PVF of C-1 makes it more similar to a random loose packing regime [150].

The C-1 mixture could enhance the slump flow increasing the PVF to reach the semi-dilute regime. This requires increase the paste content adding water, cement, quartz flour or pozzolanic additions. The water addition would imply reduce the UHPFRC properties. Increase the PCE normally would not imply a marked slump flow improvement, as it does not increase 
significantly the PVF. Another way to enhance the flowability is increase the maximum diameter of the aggregate, but then other problems might appear: Segregation, decrease of strength and specially interaction with fibers.

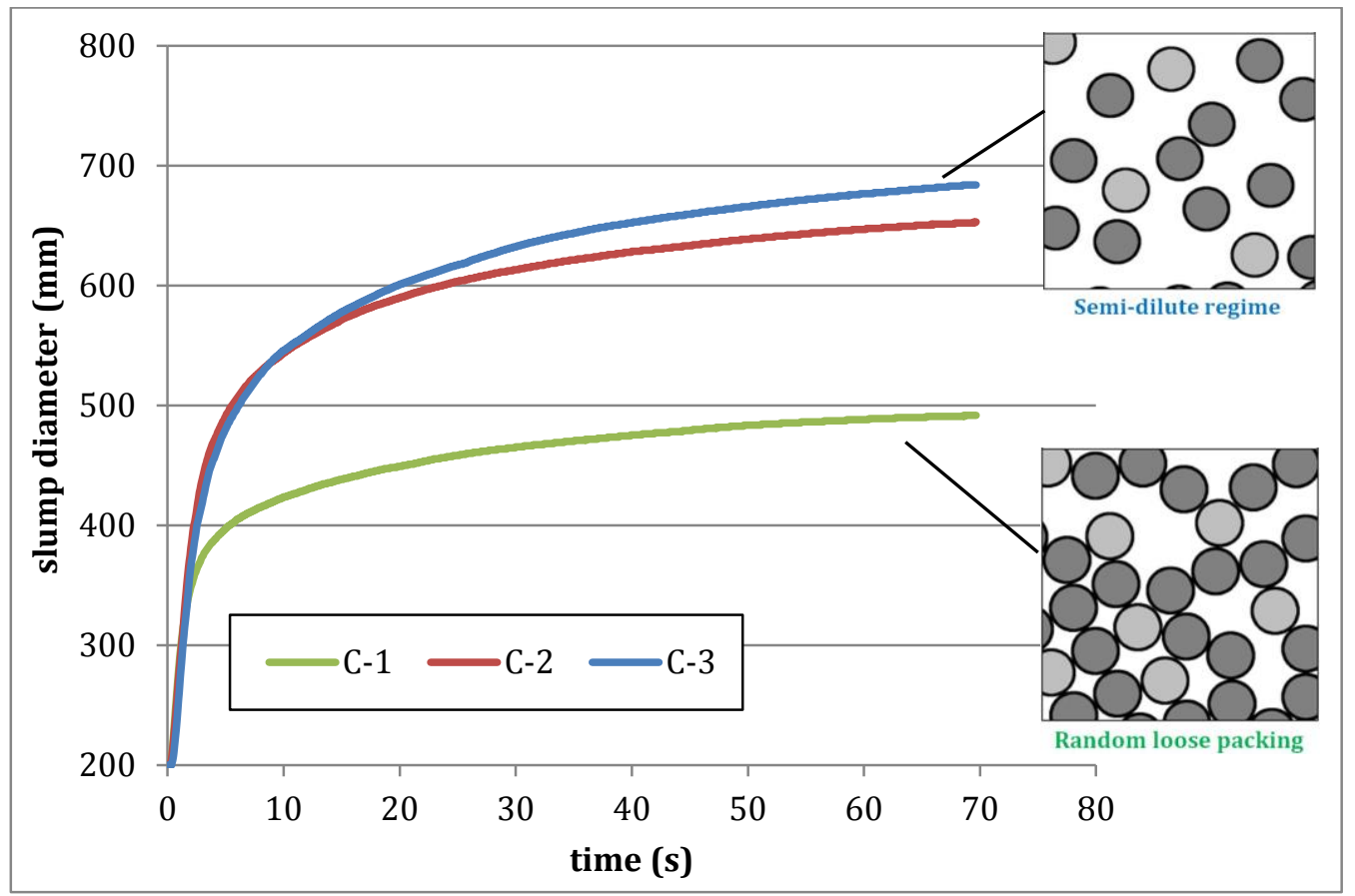

Figure 4.15: Slump-Flow evolution of mixtures $C-1, C-2$ and $C-3$, all with similar water content

As can be seen in figure 4.16, the compressive strength evolution obtained accorded with the expected performance, increasing with less W/B ratio. Even though C-1 was less workable the strength shows good performance without vibration. In the case of the dosages C-6, C-7 and C-8 (figure 4.17), the effect of the cement content is only visible for C- 6 , as the W/B ratio is much higher. As dosages C-7 and C-8 have comparable W/B ratio, the performances are similar.

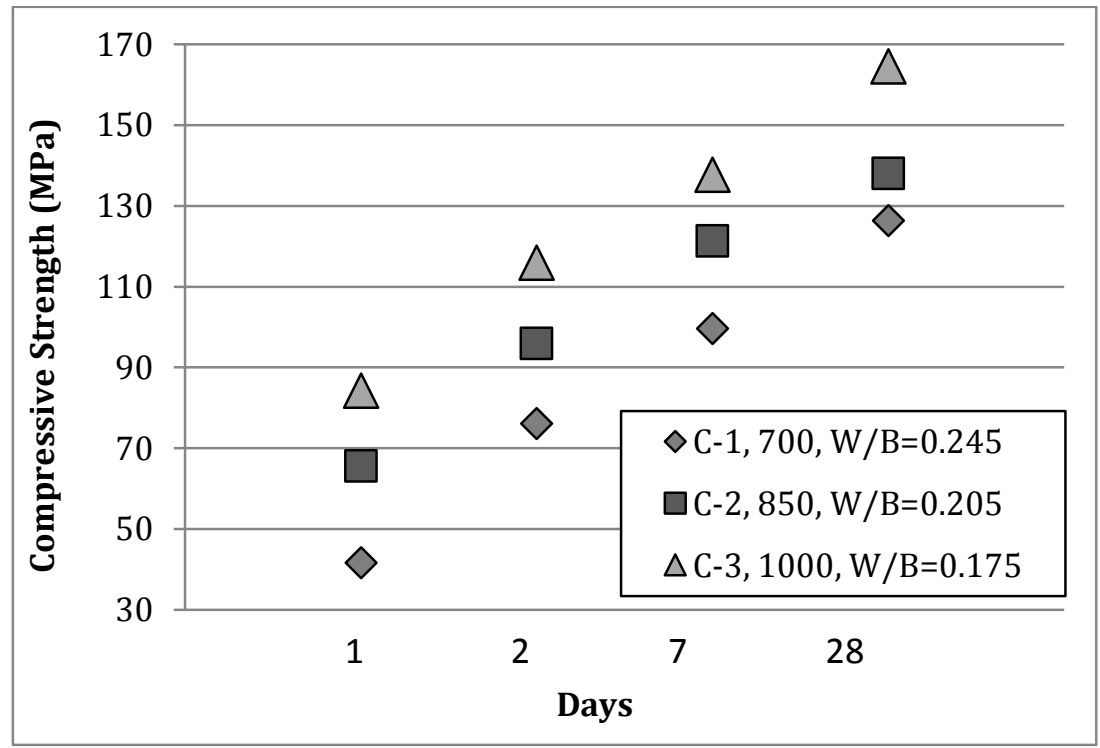

Figure 4.16: Compressive strength evolution for mixtures $C-1, C-2$ and $C-3$ 


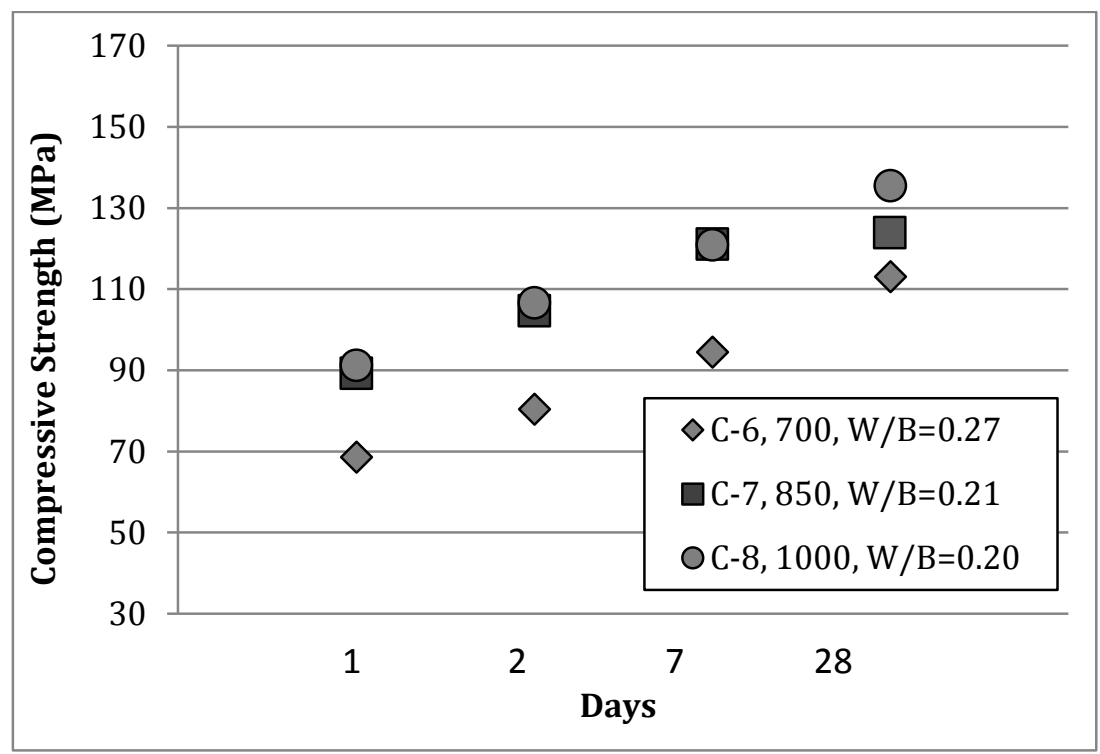

Figure 4.17: Compressive strength evolution for mixtures $C-6, C-7$ and $C-8$

The groups of mixtures in which only $\mathrm{W} / \mathrm{B}$ ratio was modified (cement content was fixed in $1000 \mathrm{~kg} / \mathrm{m}^{3}$ ) are presented in figure 4.18 .

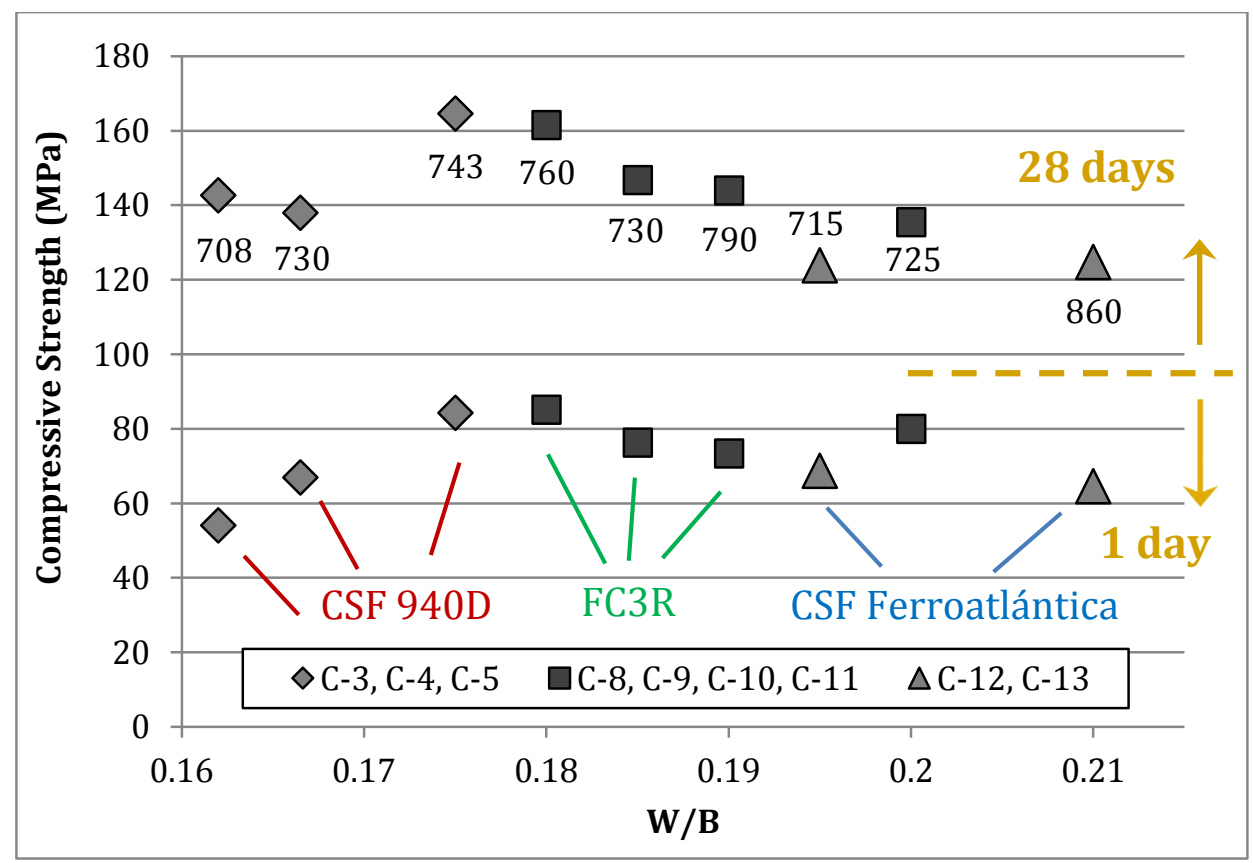

Figure 4.18: Compressive strength depending on the W/B ratio for the mixtures with $1000 \mathrm{~kg}$ of cement. Strength at 1 and 28 days. The slump flow is indicated in the figure

It shows the compressive strength at $24 \mathrm{~h}$ and 28 days related with the $\mathrm{W} / \mathrm{B}$ ratio. The slump flow is also presented for each dosage.

As can be observed, the optimum W/B ratio for the dosages here is between 0.175 and 0.18 . Smaller W/B values might provide smaller compressive strength because the percentage of hydrated cement is more reduced. Other reason could be the entrapped air of the less workable mixtures, but the slump flow data does not indicate a strong workability decrease. W/B ratios higher than 0.18 already reduce the strength as capillary pore's content are higher due to the free water increase. Mixtures $\mathrm{C}-12$ and $\mathrm{C}-13$ provided smaller strengths as were performed with a CSF with less reactivity than the others. 


\subsubsection{INFLUENCE ON THE RHEOLOGY: THE CRITICAL SLUMP FLOW}

It has been seen that the water content needs to be enough to provide an acceptable flowability and for not to decrease too much the cement hydration. But there is also an upper limit for the water content, being is the one that produces the segregation of the denser particles.

Fibers and aggregates sink in the paste when the pressure they produce exceeds the yield value of the concrete. This value can be related with the slump flow. Thus, here is indicated how to deduce the maximum slump flows acceptable for a certain mixture, and the designer has to control the water addition for not to exceed them.

At subchapter 2.10.1 self compacting concrete is defined as a Bingham fluid, which can be characterized with a yield stress value $\left(\tau_{0}\right.$, measured in Pa) and the plastic viscosity $(\eta$, measured in $\mathrm{Pa}^{*} \mathrm{~s}$ ). The greatest size components (fibers and coarse aggregates) of the material tend to sedimentation when the yield stress is too reduced.

The pressure that fibers are applying over the paste can be calculated as the pressure of the weight least the buoyancy. For acicular particles as fibers the area of the two circles at the bottom and head can be neglected. This is expressed at equation 1 . The same formula for a spherical aggregate is developed at equation 2 .

$$
\begin{gathered}
\mathrm{p}_{\text {fibers }}=\frac{\left(\rho_{\mathrm{f}}-\rho_{\mathrm{p}}\right) \cdot \mathrm{g} \cdot \mathrm{V}}{\mathrm{A}} \rightarrow \frac{\pi}{4} \cdot \mathrm{d}_{\mathrm{f}} \cdot\left(\rho_{\mathrm{f}}-\rho_{\mathrm{p}}\right) \\
\mathrm{p}_{\text {aggregates }}=\frac{2}{3} \cdot \mathrm{d}_{\mathrm{a}} \cdot\left(\rho_{\mathrm{a}}-\rho_{\mathrm{p}}\right)
\end{gathered}
$$

Where $\rho_{f}$ is the steel density, $\rho_{p}$ the UHPC paste density, and $d_{f}$ and $d_{a}$ the fiber and aggregate diameter respectively. The units used are Newton and meters. It can be appreciated that the pressure applied over the paste depends only on its density and on the fiber diameter. If the yield stress is smaller than this pressure the particles will settle at a speed that depends on the dynamic viscosity. Then, it is essential to design the concrete with a yield stress over the pressures obtained for fibers and maximum diameter aggregates that are going to be used.

At previous works [36] was deduced the correlation between the yield stress obtained by the rheometer (defined at 3.4.3) and the slump flow for several of the mixtures developed with this type of UHPFRC. It is shown at figure 4.19, and a logarithmic equation seems to predict this behavior with a high accuracy.

This equation correlates directly the Yield stress and the slump flow of the mixture. Then, using it, can be obtained the maximum slump flow admissible for not to have sediment of the greatest size components. Those values are shown at table 4.3, where appear the pressure applied over the paste by the most common fibers and aggregates used at this work (considering $\rho_{p}=2400 \mathrm{Kg} / \mathrm{m}^{3}, \rho_{a}=2750 \mathrm{Kg} / \mathrm{m}^{3}$ ). 


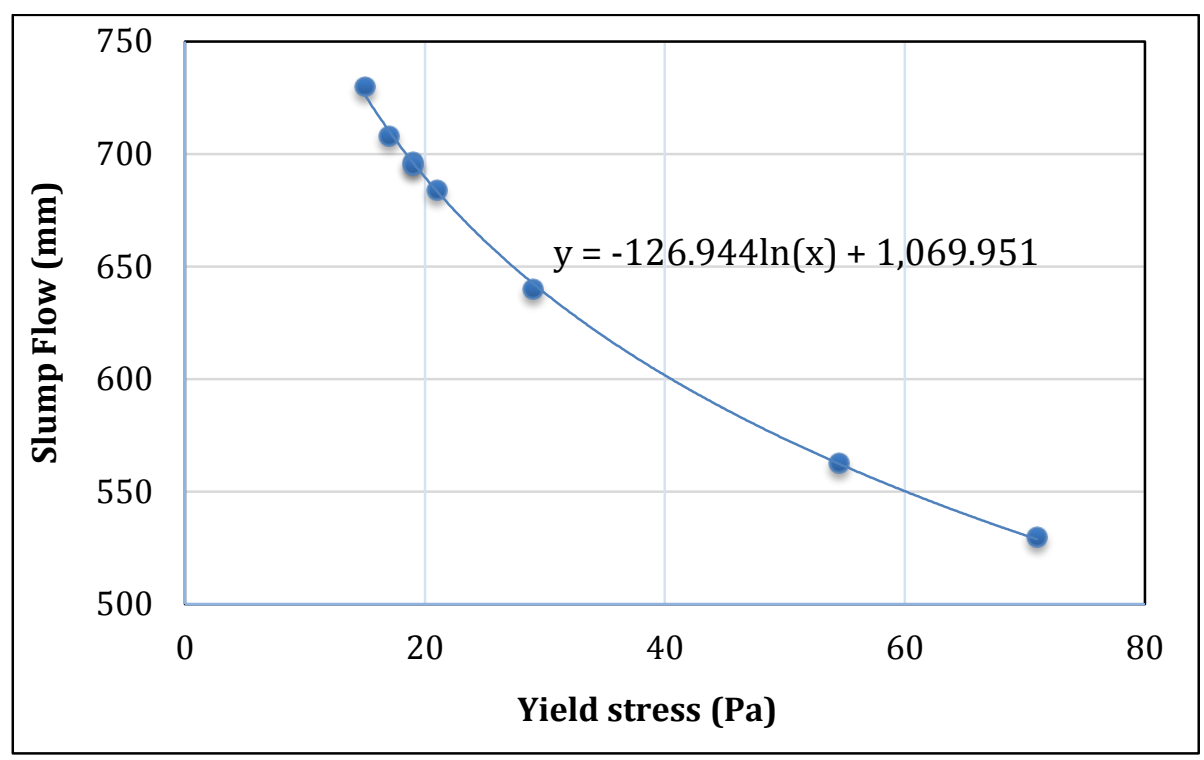

Figure 4.19: Yield stress vs. slump flow for several UHPFRC mixtures [36]

For the case of the hybrid concrete, it is supposed that the long fibers settle first, contacting with the small ones and applying an equivalent pressure both types together. The pressure of a long fiber is distributed in thirteen short fibers, as corresponds to their sizes and proportions in the hybrid concrete.

Table 4.3. Pressure of different particles in the UHPC paste, and critical value of slump flow, over which they suffer sedimentation

\begin{tabular}{|c|c|c|c|c|c|c|}
\hline & 1 & 2 & $1+2$ & 4 & 5 & 6 \\
\hline Name & Short fiber & Long fiber & Hybrid & Long fiber & \multicolumn{2}{|c|}{ Aggregate } \\
\hline Type & OL-13/0.16 & RC-80/30-BP & $1 \%+1 \%$ & RC-65/35-BN & $1.5 \mathrm{~mm}$ & $4 \mathrm{~mm}$ \\
\hline Pressure & $6.8 \mathrm{~Pa}$ & $15.6 \mathrm{~Pa}$ & $9.3 \mathrm{~Pa}$ & $22.4 \mathrm{~Pa}$ & $3.4 \mathrm{~Pa}$ & $9.2 \mathrm{~Pa}$ \\
\hline Critical slump & $827 \mathrm{~mm}$ & $718 \mathrm{~mm}$ & $786 \mathrm{~mm}$ & $673 \mathrm{~mm}$ & $880 \mathrm{~mm}$ & $755 \mathrm{~mm}$ \\
\hline \multicolumn{7}{|c|}{ Values obtained assuming an aggregate density of $28 \mathrm{kN} / \mathrm{m}^{3}$ and paste density of $23.5 \mathrm{kN} / \mathrm{m}^{3}$} \\
\hline
\end{tabular}

Substituting the pressure at the equation, simple formulations are obtained to predict the maximum slump flow acceptable for each type of fibers (1) and each type of aggregates (2).

$$
\begin{aligned}
& \text { Slump }_{\text {crit }}=-126.94 \cdot \ln \left(d_{f} \cdot\left(\rho_{\mathrm{f}}-\rho_{\mathrm{p}}\right)\right)+1100.6 \\
& \text { Slump }_{\text {crit }}=-126.94 \cdot \ln \left(d_{a} \cdot\left(\rho_{a}-\rho_{\mathrm{p}}\right)\right)+1121.4
\end{aligned}
$$

Being $d_{f}$ the fiber diameter, $d_{a}$ is the aggregate diameter and $\rho_{a}$ the coarse aggregate density. The sensibility of the critical slump to the value of the paste density in the case of the fibers equation is very reduced, so assume $2400 \mathrm{~kg} / \mathrm{m}^{3}$ provides enough approximation.

Then, as can be seen, ensuring stability, more flowable UHPFRC can be accepted for hybrid or short fiber UHPFRC than the one using long fiber or coarse aggregate. This theoretical explanation has been supported with the cumulated laboratory experience by the Ph.D. author. Figure 4.20 show some data of several mixtures performed with different fibers, showing the expected segregation when the flowability indicated by the previous prediction was exceeded. 


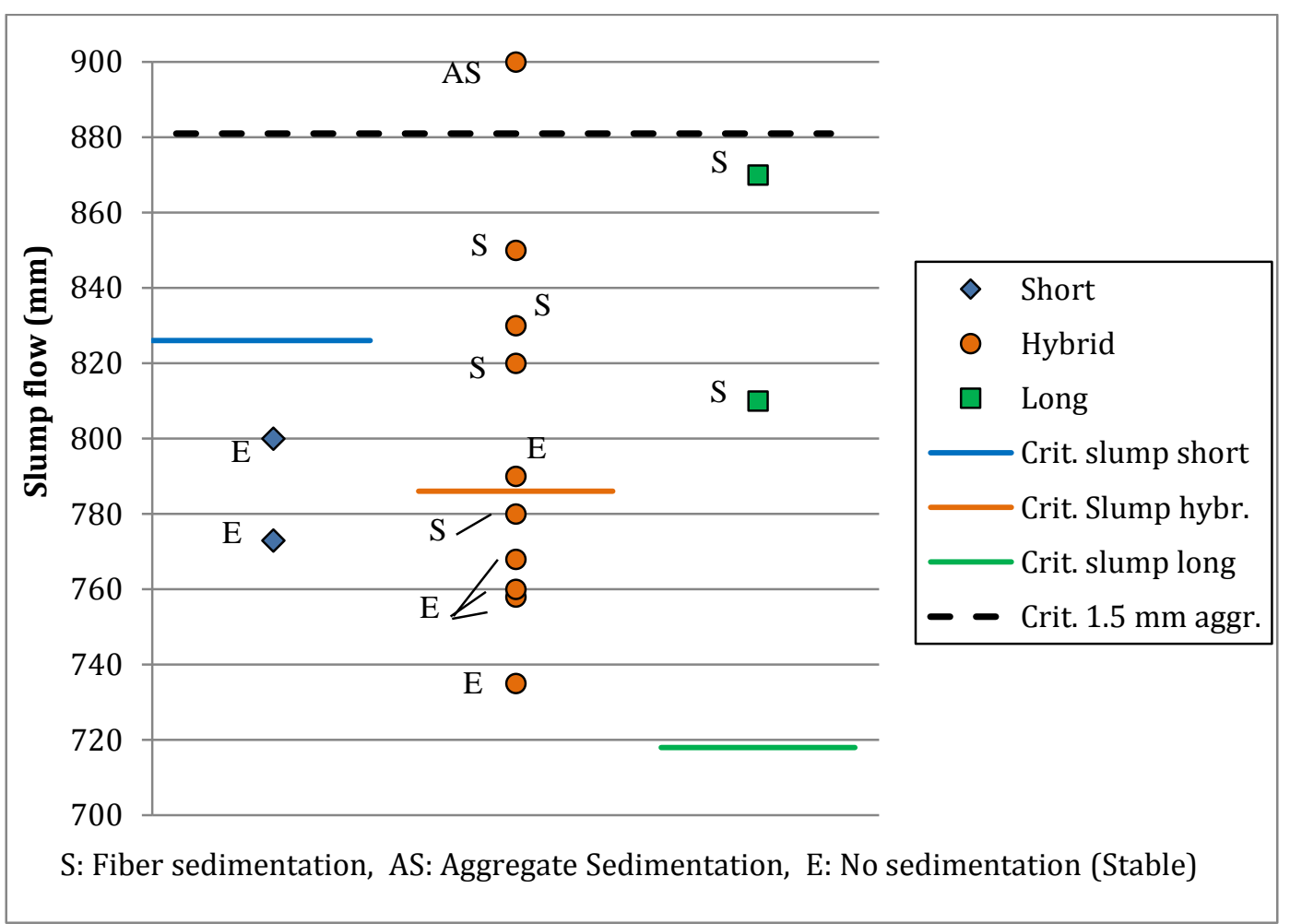

Figure 4.20: Stability of UHPFRC mixtures performed in this Ph.D. depending on their slump flow. The colored lines show the maximum acceptable cone to avoid sedimentation

\subsubsection{CONCLUSSIONS OF THE W/B RATIO EFFECT}

Based in the previous results, the following aspects can be highlighted and connected with the initial objectives:

- The cement content can be used to define the compressive performance of UHPFRC mixtures. However, the flowability strongly decrease proportionally with the cement content due to the low PVF. Reach a high the PVF with high strength and low cement content requires increase the quantity of other additions to the paste.

- In dosages with high cement content $\left(1000 \mathrm{~kg} / \mathrm{m}^{3}\right)$ the $\mathrm{W} / \mathrm{B}$ should not be decreased in excess, as the reduction of the hydrated cement affects to the strength. Adequate $\mathrm{W} / \mathrm{B}$ ratios for these mixtures are $0.175-0.18$, with slumps flow about $750 \mathrm{~mm}$.

- The water addition should be limited by a critical slump flow, which depends on the fibers and coarser aggregates used. Simple formulations to obtain this dependance have been provided, and the correlation has been experimentally proven.

\subsection{ACTIVE ADDITION EFFECT}

At this part the rheological and mechanical difference between different active additions types is studied for the UHPFRC. The objective is check the suitability of several alternatives to imported silica fume. The use of the Fluid Catalytic Cracking Residue (FC3R) addition is motivated by the same reasons detailed in 4.3. 
In this section fibers are added, and therefore the improvement of the mortar-fiber ITZ by active addition might create an effect over the flexural strength, which is studied. Compatibility between cement type, active additions and PCE admixtures is studied. The 75 liters intensive mixer introduced at 3.3.4 has been used, casting 50 liters.

\subsubsection{EXPERIMENTAL PROGRAM}

Variables modified in this phase were:

- The cement type, using the same as in previous steps (42.5 R/SR and $52.5 \mathrm{R} / \mathrm{SR}$ ) and the cement content, varied between $700-1000 \mathrm{Kg} / \mathrm{m}^{3}$ to define the performance.

- Active addition type: Three different are proposed. As local products were used CSF from Ferroatlántica and FC3R, and from international providers was chosen a Norwegian low carbon content CSF (ELKEM 940-D). It was used to compare the rheological and mechanical differences with the local CSF and the FC3R. All components are described at 3.2.

- The active additions (CSF and FC3R) content varied between $10 \%$ and $25 \%$. Besides, $15 \%$ of FA was used in mix no 13 as it was the optimum content in 4.3.

- The same three admixtures as used in 4.3 were chosen (BASF GLENIUM SKY 575, BASF GLENIUM ACE 32, SIKA VSC 20 HE). The PCE SKY 575 was selected for mixtures with cement I-52.5 R/SR, while the other two were used with I-42.5 R/SR cement mixtures, as deduced the most efficient combinations according with previous studies [40]. The concrete contained a fiber cocktail with a total content of $2 \%$ over volume, as at section 4.4 .

The UHPFRC mixtures were cast in the EIRICH intensive mixer, according with the process detailed at 3.3.4. The same mixtures are performed with both local active additions to analyze the effect. Table 4.4 shows the 16 different dosages (18 batches) performed in this study. Each one was characterized using twelve prismatic cubes and three $100 \times 100 \times 500 \mathrm{~mm}$ elements for the compressive and flexural performance.

Additionally, three and two batches respectively of the dosages F-11 and F-12 were cast with different mixing times than those indicated at section 3.3.4, in order to evaluate and compare the effect of the mixing times for each addition. For F-11, with FC3R, the mixing times of the 30 liters batch were 13, 16 and 19 minutes. For F-12, with CSF, it was 10 and 13 minutes. After that the flowability was studied with a rheometer.

The percentage of each PCE added was determined in a previous study, providing all them similar workability to the same dosage. It is clear that effectiveness depends on the admixture solid content, but also on its specifics properties and compatibility with the binders. With ELKEM CSF (mixtures 12 and 15), the dosage of SIKA VSC 20 HE was smaller as the low carbon content leads to a much more fluid concrete. W/B ratio was modified with the purpose of having similar workability.

The same sands as combined at section 4.4 were used, proportioning in accordance with the A\& $A_{\text {mod }}$ method. Sand was added for each dosage to complete a cubic meter of UHPFRC. Rheological and mechanical performances were determined with the process detailed in 3.4.2 and 3.7.1. 
Table 4.4: Experimental program to evaluate the differences between CSF and FC3R

\begin{tabular}{|c|c|c|c|c|c|c|c|}
\hline \multirow{2}{*}{$\begin{array}{c}\text { Mix } \\
\text { № }\end{array}$} & \multicolumn{2}{|c|}{ Cement } & \multicolumn{2}{|c|}{ Active addition } & \multirow{2}{*}{$\begin{array}{l}\text { PCE } \\
\text { Type } \\
\end{array}$} & \multirow{2}{*}{$\begin{array}{c}\% \\
\% \text { o.c.w. }\end{array}$} & \multirow{2}{*}{$\begin{array}{r}\text { W/B } \\
\text { Ratio } \\
\end{array}$} \\
\hline & Type & $\mathrm{kg} / \mathrm{m}^{3}$ & Type* & \% o.c.w. & & & \\
\hline $\mathrm{F}-1$ & $52.5 \mathrm{R} / \mathrm{SR}$ & 700 & CSF ferroat & $10 \%$ & BASF SKY 575 & $3 \%$ & 0.27 \\
\hline F-2 & $52.5 \mathrm{R} / \mathrm{SR}$ & 700 & FC3R & $10 \%$ & BASF SKY 575 & $3 \%$ & 0.27 \\
\hline F-3 & $52.5 \mathrm{R} / \mathrm{SR}$ & 850 & CSF ferroat & $10 \%$ & BASF SKY 575 & $3 \%$ & 0.21 \\
\hline F-4 & $52.5 \mathrm{R} / \mathrm{SR}$ & 850 & FC3R & $10 \%$ & BASF SKY 575 & $3 \%$ & 0.21 \\
\hline F-5 & $42.5 \mathrm{R} / \mathrm{SR}$ & 850 & CSF ferroat & $10 \%$ & BASF ACE 32 & $4.5 \%$ & 0.22 \\
\hline F-6 & $42.5 \mathrm{R} / \mathrm{SR}$ & 850 & FC3R & $10 \%$ & BASF ACE 32 & $4.5 \%$ & 0.21 \\
\hline F-7 & $42.5 \mathrm{R} / \mathrm{SR}$ & 1000 & CSF ferroat & $15 \%$ & Sika VSC $20 \mathrm{HE}$ & $3.5 \%$ & 0.21 \\
\hline F-8 & $42.5 \mathrm{R} / \mathrm{SR}$ & 1000 & FC3R & $15 \%$ & Sika VSC $20 \mathrm{HE}$ & $3.5 \%$ & 0.2 \\
\hline F-9 (x2) & $42.5 \mathrm{R} / \mathrm{SR}$ & 1000 & CSF ferroat & $15 \%$ & BASF ACE 32 & $4.5 \%$ & 0.195 \\
\hline $\mathrm{F}-10(\mathrm{x} 2)$ & $42.5 \mathrm{R} / \mathrm{SR}$ & 1000 & FC3R & $15 \%$ & BASF ACE 32 & $4.5 \%$ & 0.19 \\
\hline F-11* & $42.5 \mathrm{R} / \mathrm{SR}$ & 1000 & FC3R & $15 \%$ & Sika VSC 20HE & $3 \%$ & 0.175 \\
\hline $\mathrm{F}-12^{*}$ & $42.5 \mathrm{R} / \mathrm{SR}$ & 1000 & CSF 940D & $15 \%$ & Sika VSC $20 \mathrm{HE}$ & $2.5 \%$ & 0.175 \\
\hline $\mathrm{F}-13$ & $42.5 \mathrm{R} / \mathrm{SR}$ & 850 & $\mathrm{FC} 3 \mathrm{R}+\mathrm{FA}$ & $10 \%+15 \%$ & Sika VSC $20 \mathrm{HE}$ & $3 \%$ & 0.175 \\
\hline F-14 & $42.5 \mathrm{R} / \mathrm{SR}$ & 800 & CSF ferroat & $25 \%$ & BASF ACE 32 & $4.5 \%$ & 0.22 \\
\hline F-15 & $42.5 \mathrm{R} / \mathrm{SR}$ & 800 & CSF 940D & $25 \%$ & Sika VSC $20 \mathrm{HE}$ & $2.5 \%$ & 0.205 \\
\hline F-16 & $42.5 \mathrm{R} / \mathrm{SR}$ & 800 & FC3R & $25 \%$ & Sika VSC 20HE & $2.5 \%$ & 0.205 \\
\hline
\end{tabular}

\subsubsection{RESULTS}

During the mixing process, some differences were noticed between concretes made with FC3R and those made with both CSF types. The first needed longer times (9-11 minutes) to change from a mass of solids to a semi-dilute regime, with hydrodynamic particle interactions (to see more about these concepts, review [150]). At this moment the intensive mixer required the maximum power to keep the programmed rotational speed. After that, extra time was required to add and dilute the long fibers bundles. The stabilization time (time required until particles are homogeneously mixed) was then 2-3 minutes longer for dosages with FC3R than for those with CSF.

This phenomenon was observed with the dosages F-11 and F-12, cast for different mixing times. Table 4.5 show the rheological parameters deduced for the different minutes, and figure 4.21 represents their slump flow and $t_{500}$. It is deduced that for CSF dosages at least 13 min of mixing are required in order to reach great flowability. Longer mixing times didn't increase the flowability, but it remained stable.

Table 4.5: Rheological properties of batches $F-11$ and F-12 with different mixing times

\begin{tabular}{|cccccc|}
\hline Batch & Slump (mm) & $\mathbf{t}_{\mathbf{5 0 0}}(\mathbf{s})$ & $\boldsymbol{f}_{\boldsymbol{c 1 , 2 , 7 , 2 8} \boldsymbol{d}} \mathbf{( M P a )}$ & $\boldsymbol{\tau}_{\mathbf{0}}$ (Pa) & $\boldsymbol{\eta}$ (Pa*s) \\
\hline F-12, 10 min & 684 & 11.7 & $62-91-115-139$ & 21 & 288 \\
F-12, 13 min & 708 & 7.2 & $54-94-119-143$ & 17 & 268 \\
F-11, 13 min & 697 & 11 & $55-100-124-137$ & 19 & 449 \\
F-11, 16 min & 730 & 14.9 & $59-93-120-135$ & 15 & 209 \\
F-11, 19 min & 695 & 8.1 & $63-101-123-135$ & 19 & 299 \\
\hline
\end{tabular}




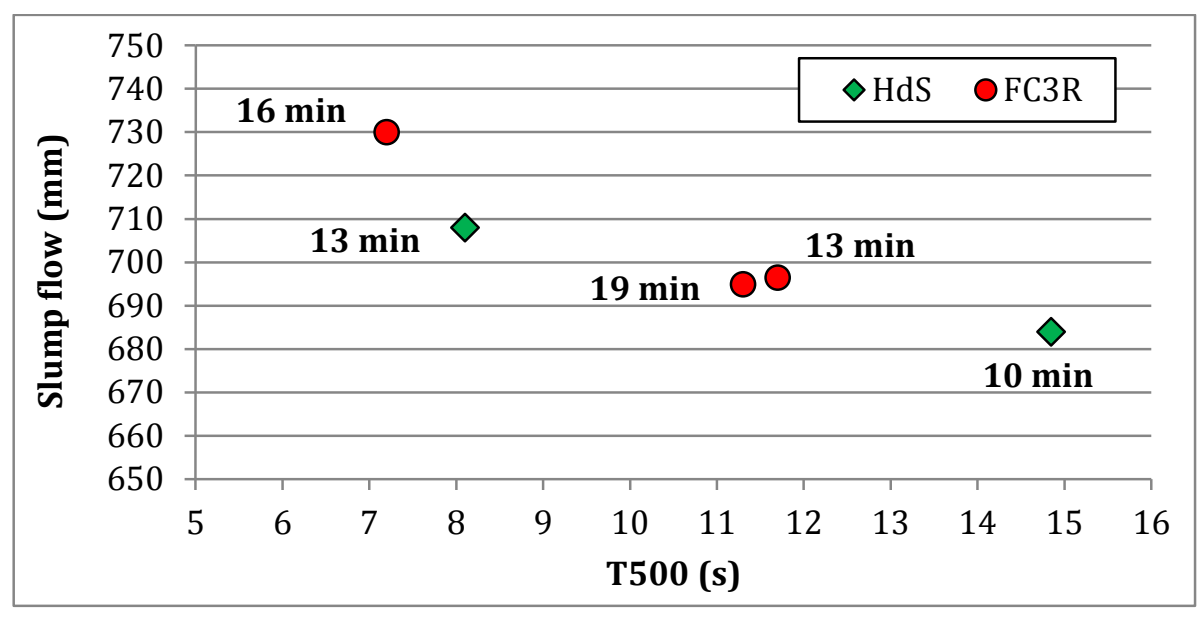

Figure 4.21: Slump flow for the different mixing times of dosages F-11 and F-12

For FC3R the best rheological properties were reached for 16 min of mixing. Two are the reasons for this increase respect to the CSF addition:

- FC3R is a non-dispersed addition, so the specific surface that water needs to cover is greater than for CSF, implying this increase of mixing time.

- The low $\mathrm{C}_{3} \mathrm{~A}$ content of the sulfate resistant cements limits the primary ettringite formation. In the UHPFRC made with FC3R the primary ettringite formation may increase due to its high $\mathrm{Al}_{2} \mathrm{O}_{3}$ content. In an alkaline medium the change to $\mathrm{AlO}_{2}^{-}$takes place, and forms ettringite crystals of sizes between 300 and $500 \mathrm{~nm}$ [210]. These are the first molecules of the rapid forming ettringite. The admixture particles, with sizes 20 or 30 times smaller, are overgrown by these crystals or are chemically incorporated to these new formed hydration products, losing their efficiency. To solve this problem part or all the PCE addition is delayed after rapid forming ettringite is formed, taking higher advantage of it but requiring therefore longer mixing times. Slight increase of water added could reduce this time, but when the mass becomes a suspension the fluidity increases radically showing a tendency to segregation.

Increase the mixing time up to 19 min produced a decrease of flowability. Then, FC3R seemed to be more sensitive to the mixing time and water addition than the CSF, which provided more stability and robustness. It is important to highlight that the mixing times have been optimized with this mixer just to check the relative differences between both admixtures, so the times might vary for any other mixer.

A qualitative measure of the segregation can be assigned to the mixtures by the Visual Stability Index (VSI) [10], based in a visual evaluation of the segregation of the UHPFRC during the slump flow test (0: high stable SCC, 3: Totally segregated SCC). VSI for mixtures with CSF was 0 , while for FC3R was 1 . From a practical point of view, this fact implies that the use of FC3R requires even more control of the humidity, water added and mixing process to reach the desired mix workability.

Related to the slump flow (table 4.6), most of the mixtures were SF3 according to the consistence classification of [60] -between 760 and $850 \mathrm{~mm}$ - having similar filling ability. Dosages with FC3R showed markedly higher values of $t_{500}$ even though slump flow was higher, which means higher viscosity than similar mixtures with CSF. Probably this is due to the lower PCE efficiency previously discussed for the mixtures with FC3R. 
Table 4.6: Slump flow diameters and $t_{500}$ of some of the mixtures

\begin{tabular}{|c|cc|cc|cc|c|ccc|}
\cline { 2 - 11 } \multicolumn{1}{c|}{} & \multicolumn{10}{c|}{ Mixtures } \\
\hline Test & 5 & 6 & 9 & 10 & 11 & 12 & 13 & 14 & 15 & 16 \\
\hline Slump (mm) & 830 & 763 & 744 & 790 & 770 & 743 & 820 & $<500$ & 675 & 830 \\
t500 (s) $_{50,7}$ & 4,7 & 12,2 & 6,8 & 8,9 & 10,6 & 6,1 & 9,6 & - & 3,5 & 6 \\
\hline
\end{tabular}

As the mixtures with the ELKEM CSF (12 and 15) had less PCE they provided lower value of slump than the equivalent mixtures made with other pozzolans. However, the $t_{500}$ is smaller than similar mixtures made with the Ferroatlántica CSF because the carbon content of the last decreased the free water amount. The lower water demand of the FC3R when compared with any type of CSF is clear from data obtained for the mixtures 9-10 and 15-16. Finally, dosage with FA (number 13) provided high workability but much slower evolution of the slump flow.

Relative to the hardened state, it is noticeable the different effect of the active additions depending on the cement type (figure 4.22). FC3R showed better compatibility with the cement type I-42.5 R/SR and CSF with the cement type I-52.5 R/SR. The PCE type used could also have affected to this compatibility.

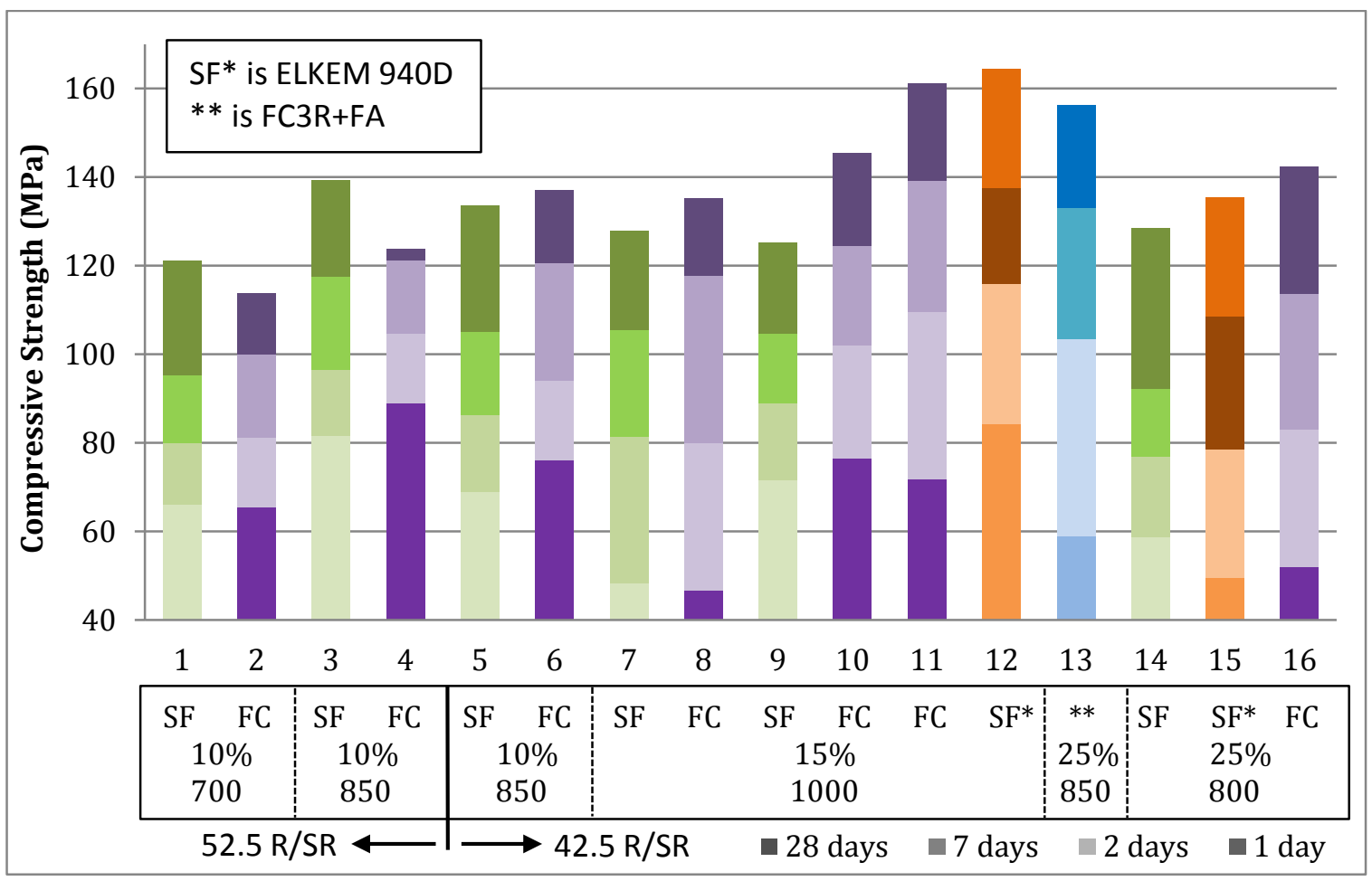

Figure 4.22: Compressive Strengh evolution of the mixtures. CSF is expressed as SF and FC3R as FC

It is noticeable the strength increase in comparison with the mortar step (Section 4.3) due to the addition of $2 \%$ of fiber in volume, which sews the microcracks appeared during the compressive test. It is observed that mixtures with FC3R develop greater strength at 2-7 days because of the higher short term reactivity, while CSF is more active from second week. This idea was already introduced in the mortar study. Dosage 13, with 15\% of FA, had, as expected, slightly lower strength at $24 \mathrm{~h}$, but the increase from this age is marked, reaching $157 \mathrm{MPa}$ at 28 days, 10 MPa more than the dosage 6, similar but without FA. 
Dosages with ELKEM CSF in the composition provided better performances than with the local CSF. Mixtures 7, 11 and 12 differed only in the active addition (Ferroatlántica CSF, FC3R and ELKEM CSF). Even though higher content of PCE (3.5\%) was used in mixture 7, the W/B ratio required for good workability was 0.21 , while for mixtures 11 and 12 was 0.175 . The only reason is the composition and microgranulometry of the CSF. For mixtures 11 and 12, the compressive strength is very similar. This proves the suitability of FC3R as an active addition for UHPC-UHPFRC, since it is comparable with a low carbon content CSF.

In the mixtures 14, 15 and 16 typical contents of CSF in UHPFRC were added (25\% over cement). Ferroatlántica CSF was not self-compacting even though the W/B ratio of 0.22 . It could be possible increase the W/B ratio to reach higher workability, but it is unacceptable since produces a strong decrease of the performance, being out of the UHPC range. ELKEM CSF provided workable mixture with $\mathrm{W} / \mathrm{B}$ of 0.19 , generating consequently better strength results. Mixture 16 proved that FC3R workability benefits increase with the replacement over cement weight. Higher compressive strength $(\approx 5 \%)$ was obtained comparing with similar mixture with ELKEM CSF. In general terms, it can be observed that, if the binder content is constant, the ratio cement-active addition of 1:0,15 provides better properties than the ration 1:0,25.

Relative to the flexural strength, it is worth to highlight that differences between the use of FC3R or Ferroatlántica CSF are not remarkable. Generally average values differ less than a 5\%. The ELKEM CSF does provide slightly better performances, but still deeper research has to be carried out. In any case no tensile failure of the fibers was observed. This details are explained subsequently. In the figures 4.23 and 4.24 are shown the prisms after the flexural test. The cut prism proves the homogeneous fiber distribution along all the section, the no segregation of the mixture, the adequate removal or air and the absence of fiber bundles.

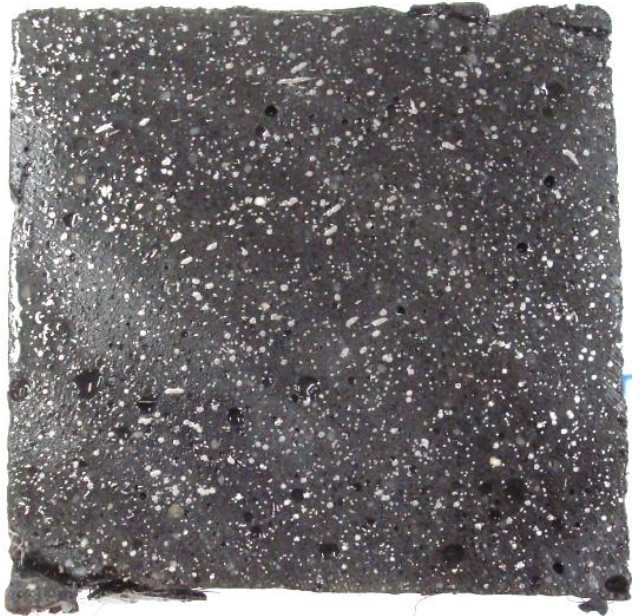

Figure 4.23: Cut prism of F-7

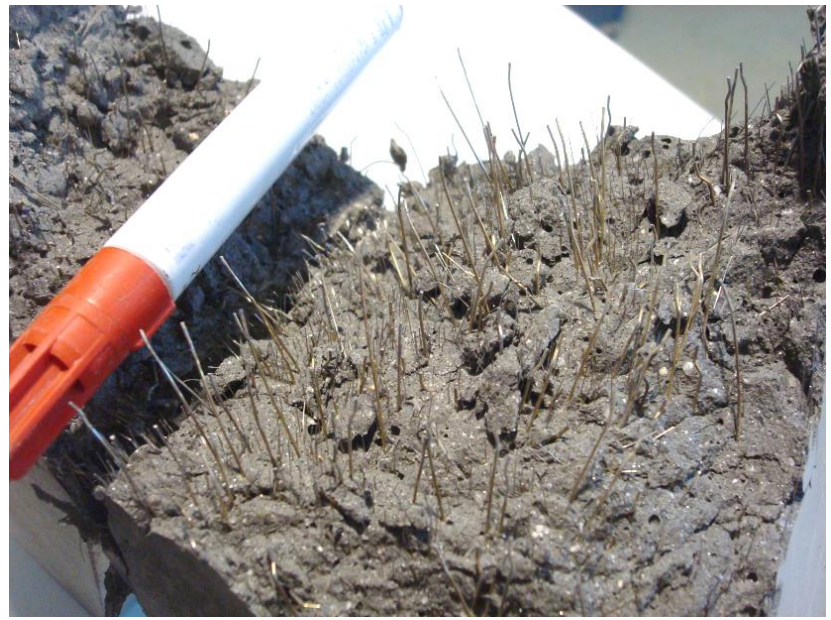

Figure 4.24: Flexural failure section opened, dosage F-6

In the figure 4.25 are shown the flexural strengths related with it. As all concretes contain the same cocktail and percentage of fibers they can be compared. It can be seen the exponential increase of this value when W/B ratio decreases. This improvement with the W/B decrease can be considered provided that the slump flow is high, ensuring a high fiber orientation during the casting. Even though some of the mixtures with W/B of 0.21 have different cement content, the flexural performance is comparable. As the water demand of FC3R dosages is more reduced than for Ferroatlántica CSF, slightly higher performance with it might be expected. 


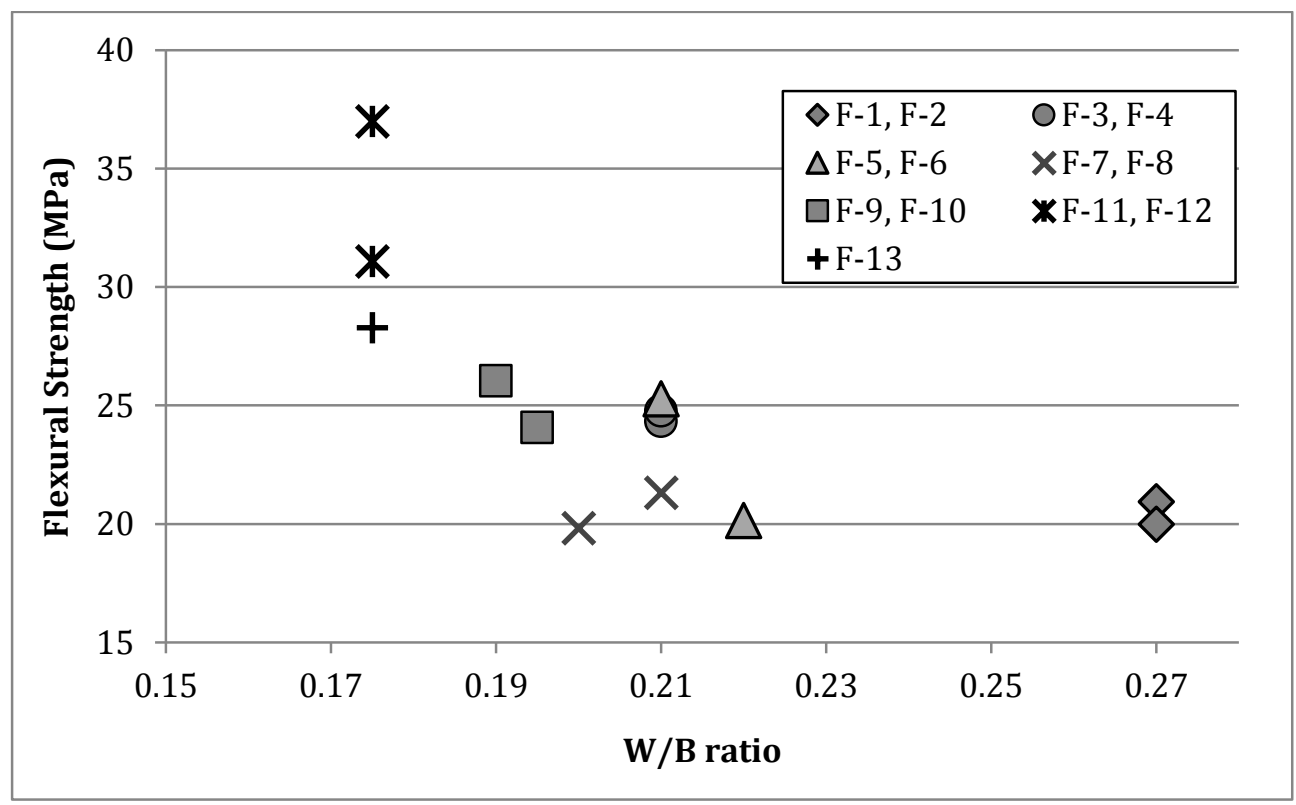

Figure 4.25: Flexural strength related with the $W / B$ ratio

In figure 4.26 the same flexural performances are related with the cement content. It can be seen that mixtures with the same cement content but higher $\mathrm{W} / \mathrm{B}$ ratio can reduce to almost half the flexural performance. It can be concluded that the $\mathrm{W} / \mathrm{B}$ ratio is the best parameter to explain the flexural performance of self-compacting UHPFRC.

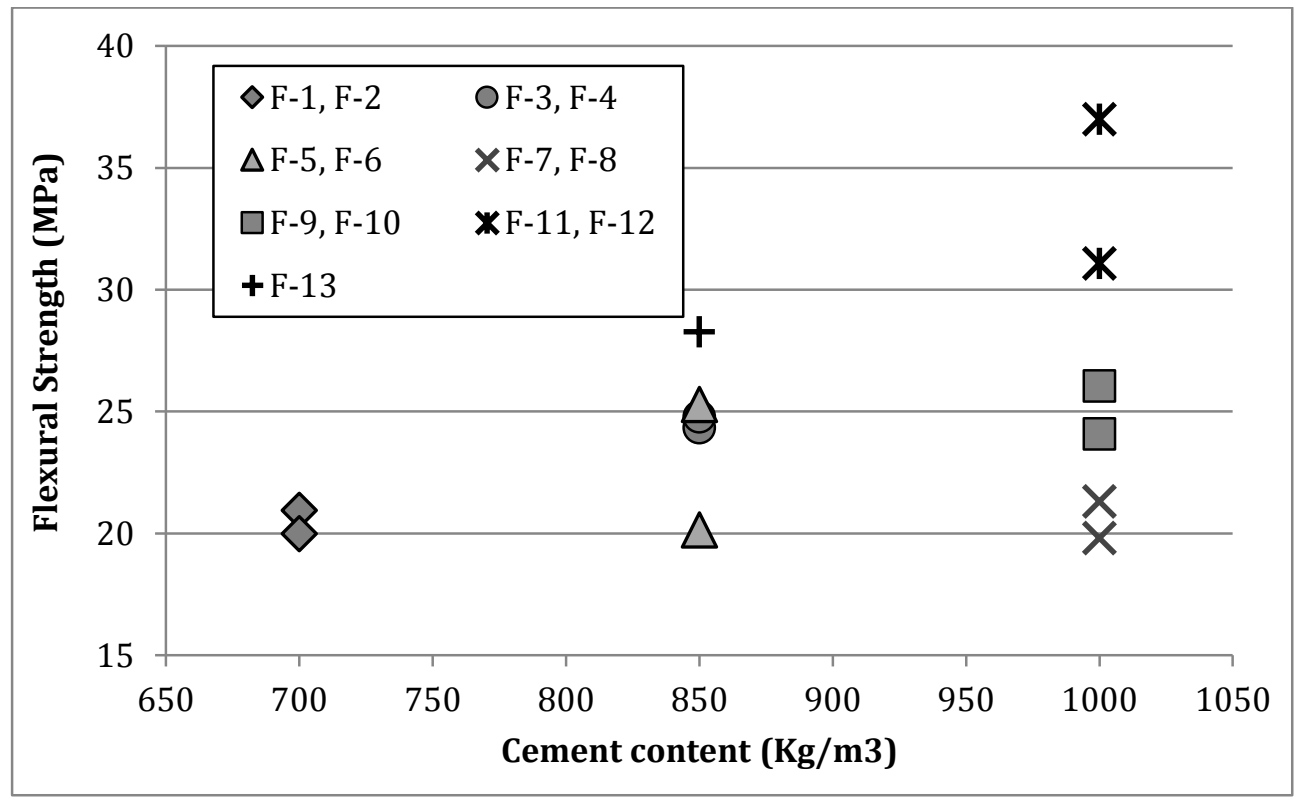

Figure 4.26: Flexural strength related with the cement content

FC3R and ELKEM CSF provided the highest flexural strengths. The great particles dispersion derived in an improved interfacial transition zone between the paste and the fibers, increasing the pull out energy required.

Variability between maximum flexural strengths of the same batch was in the range of $15 \%$. This low scatter and the great value of strength show that the casting process aligned constantly the fibers on the desired direction. The flexural strength-deflection laws of dosage F-12 are shown in figure 4.27. 


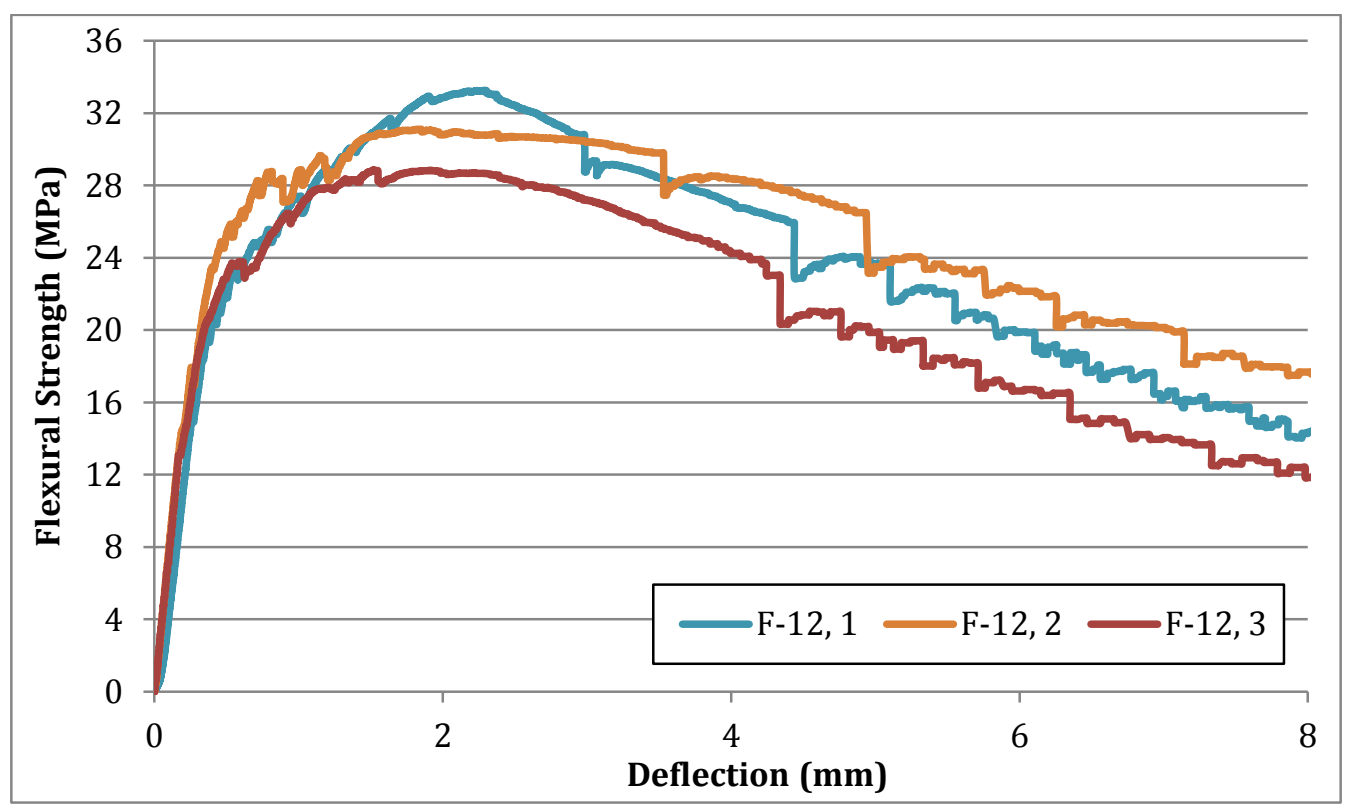

Figure 4.27: Flexural strength of the prisms of mixture F-12

The flexural strength ( $100 \times 100 \times 400 \mathrm{~mm}$, see 3.5.2) of mixtures F-1, F-3 and F-13 is shown in figure 4.28. These correspond to the three levels of performance in the Ph.D. Thesis, with 700,850 and $1000 \mathrm{~kg} / \mathrm{m}^{3}$ of cement respectively. It is worth to highlight that comparing with mixtures of other authors, the ratio flexural strength/compressive strength is high, since the fiber cocktail is the result of a previous optimization to maximize the flexural strength.

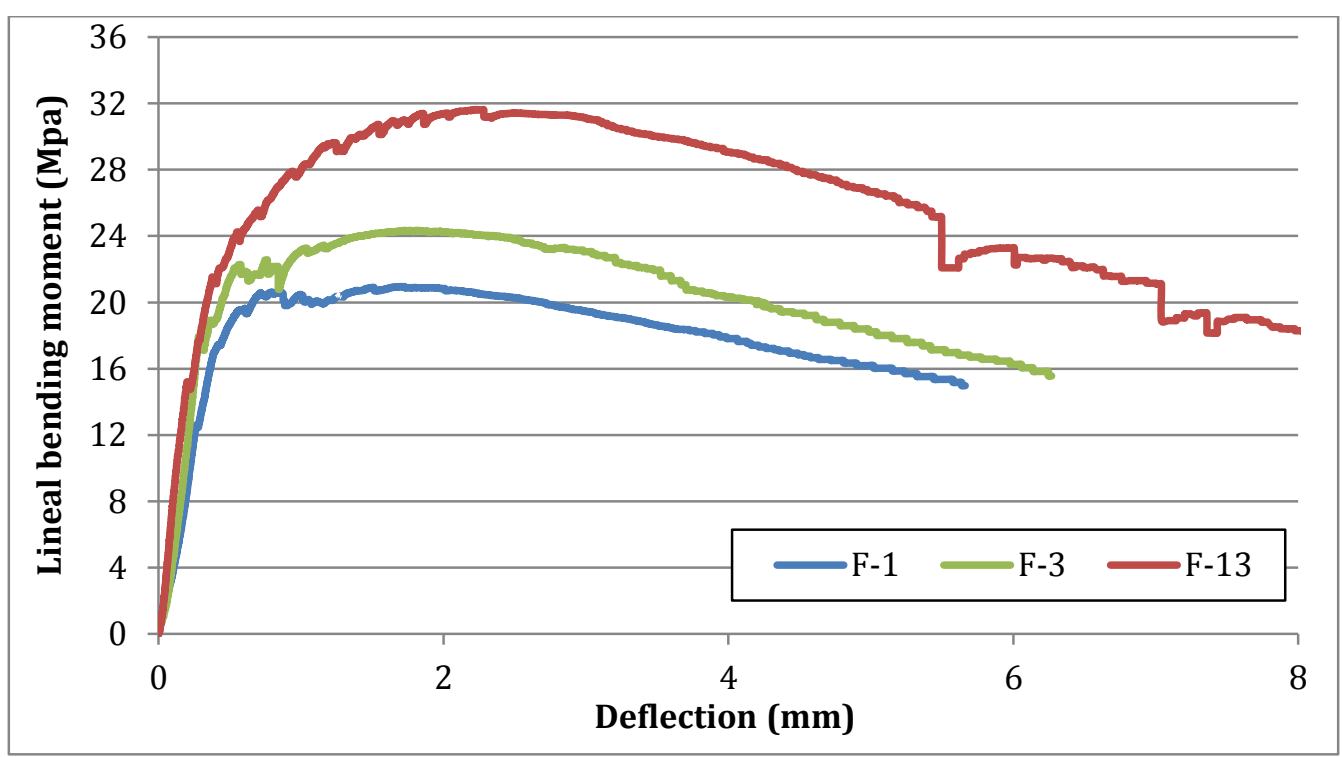

Figure 4.28: Flexural strength

Figure 4.29 shows the correlation between compressive and flexural strength of the dosages evaluated. Marked linear correlation is appreciated. As can be seen, there are not significant differences in the correlation for depending on the local addition used. 


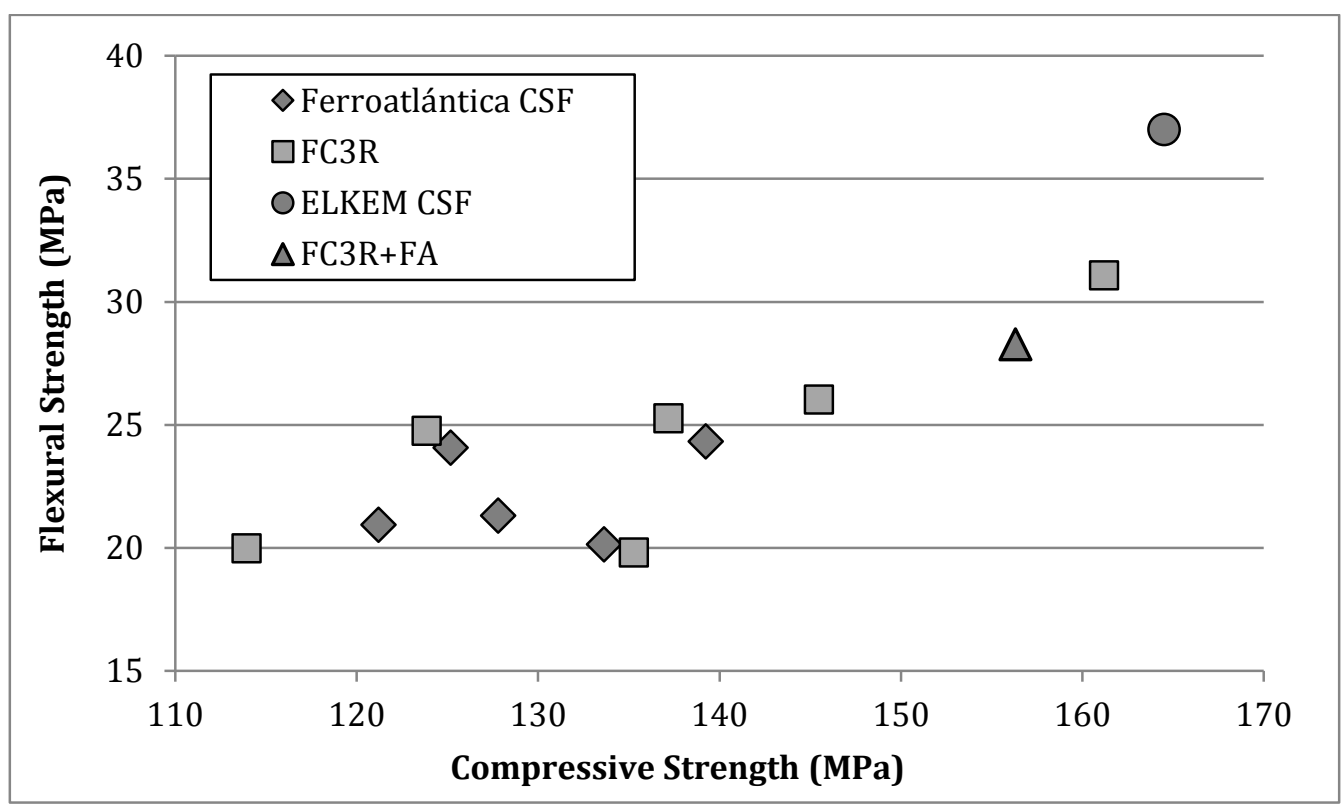

Figure 4.29: Flexural strength related with the compressive strength

\subsubsection{CONCLUSSIONS OF THE ACTIVE ADDITION EFFECT}

Concluding, ELKEM CSF and FC3R shown the best compressive performances, but with more stable and less sensible rheology for the CSF, and faster activity in the strength development for the FC3R. The flexural response didn't provide significant differences between the additions, and seemed to depend, besides the fibers, mainly on the W/B ratio.

Again the use of one or other addition depends on the conditions. The CSF is more available, has easier to control in the mixing and longer opened time, but FC3R could have provide higher strengths at short term and a lighter color that can be necessary for aesthetical applications. Also the available PCE admixture or cement can condition the election because the better compatibility.

\subsection{Limestone CoARSE Aggregate EFFECT}

The use of coarse aggregate in UHPFRC is scarce, especially for the case of limestone. Only in some cases basalt, bauxite or granite are used. The main reason is not only the necessity of a very high strength aggregate, but also the influence over the workability and the fiber orientation. Here crushed limestone coarse aggregate is proposed since it is the most common in eastern Spain, so the viability of cast with this material could decrease the costs and simplify dosages. Even though this aggregate is used to perform ordinary concrete, it's very attainable and its strength theoretically enough to be used in VHPFRC.

Three are the main effects have been studied in this section:

- The effect over the compressive strength evolution, since the limestone aggregate strength is much smaller than the one from aggregates used normally for UHPFRC (bauxite, basalt, diabase).

- The effect over the rheology, as strong interaction between the aggregate and the fiber cocktail might appear. 
- The effect over the flexural strength, since spacing between coarse aggregates may disturb the unidirectional fiber orientation, decreasing the performance.

\subsubsection{EXPERIMENTAL PROGRAM}

The experimental program consists in compare dosages of different levels of performance with and without coarse aggregate. Thirteen dosages were used, casting eight cubes and two $100 \times 100 \times 500 \mathrm{~mm}$ beams for the compressive and flexural strength respectively. A fixed quantity of $4 / 7 \mathrm{~mm}$ crushed limestone coarse aggregate $\left(600 \mathrm{~kg} / \mathrm{m}^{3}\right)$ was added to the basic, medium and high performance mixtures, implying a proportional reduction of cement $/ \mathrm{m}^{3}$ of concrete (in basic dosage from 700 to $522 \mathrm{~kg}$, in medium from 850 to $635 \mathrm{~kg}$, and in high from 1000 to $747 \mathrm{~kg}$ ). Volume cast for fine aggregate dosages was 40 liters, being 49.4 liters for the coarse aggregate addition. The increase is due to the limestone, the water and the proportional fiber increase.

In order to keep constant the workability after the coarse aggregate addition, it is added with the water demanded to cover the particles adsorption and absorption. This resulted a $4 \%$ of the coarse aggregate weight. The coarse mixtures $\mathrm{W} / \mathrm{B}$ ratio increase respect to the fine mixtures are produced by this $4 \%$ of water added. The process is represented in figure 4.30 for one of the basic dosages.

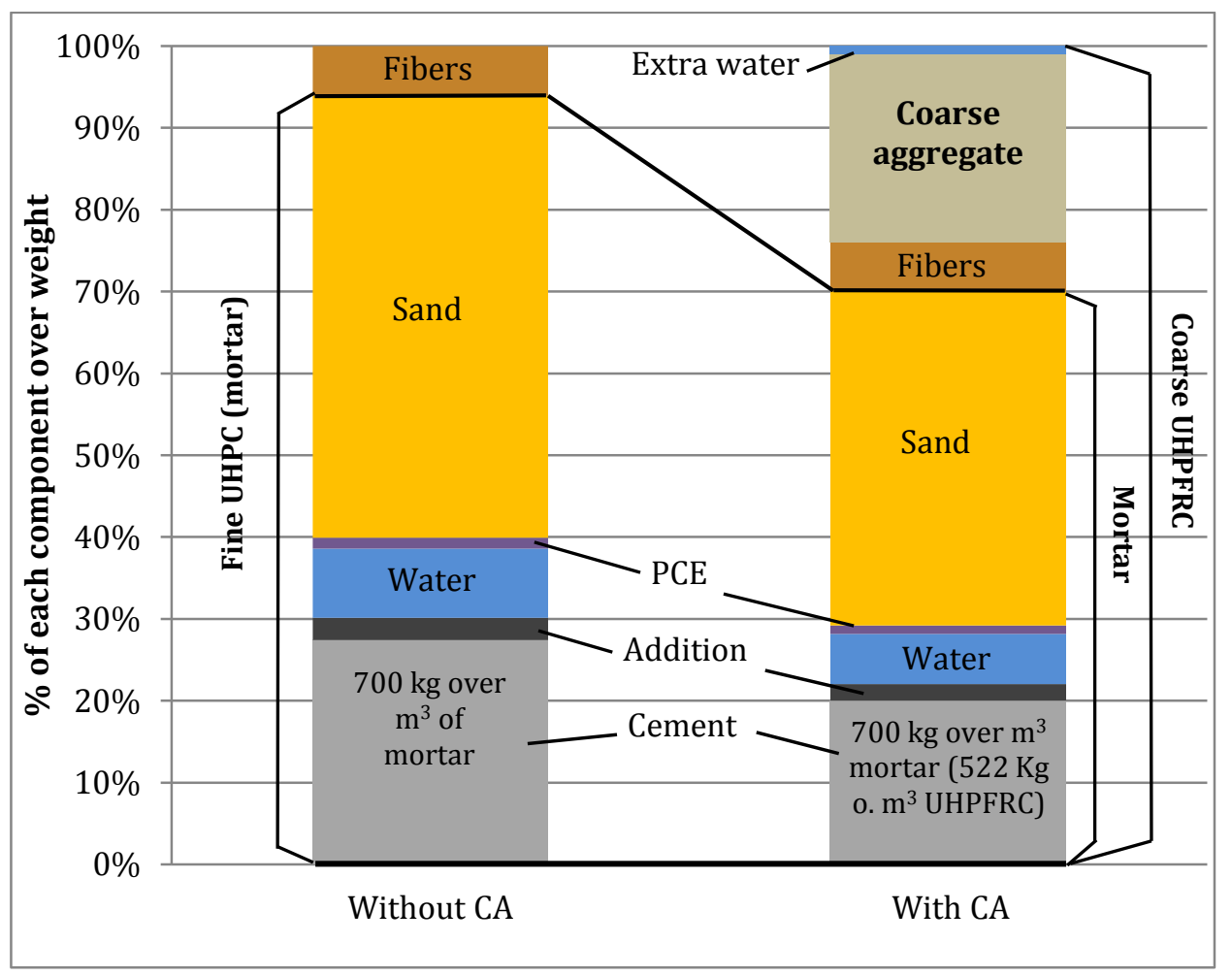

Figure 4.30: Example of the process to design a coarse UHPFRC from a fine UHPFRC

The dosages with $\mathrm{d}_{\max }$ of $2 \mathrm{~mm}$ were designed adopting a W/B ratio to have an adequate workability. To cast the coarse aggregate mixtures, the same fine aggregate dosages were mixed and, before incorporate the long fibers, the $4 / 7 \mathrm{~mm}$ limestone coarse aggregate with the extra water was added.

This mixing process minimizes the differences between the dosages with and without coarse aggregate. If it is added with the other dry materials, the intensive mixing of the initial 
minutes break partially the aggregates and increase the fines content, decreasing the workability. The longer and faster the mixing process, the higher the workability decrease. The additional water used to cover the specific surface and porosity of the coarse aggregate is not added at the beginning because it would increase abruptly the fluidity until the addition, so segregation might happen.

The 13 dosages proposed for the experimental program are shown in the table 4.7. The dosages have to be compared in pairs. The mixtures of UHPFRC were cast in a tilting mixer (TM in table 4.7) or in an intensive mixer EIRICH R08-W (IM in table 4.5) according with the processes detailed in 3.3.2 and 3.3.4.

Table 4.7: Experimental program to evaluate the effect of the coarse aggregate addition

\begin{tabular}{|ccccccccccc|}
\hline Mix & Cement & Coarse & \multicolumn{2}{c}{ Active addition } & & PCE & W/B & Mixer & Long Fib. \\
\hline No & Type & $\mathbf{~ k g} / \mathbf{m}^{3}$ & $\mathbf{k g} / \mathbf{m}^{3}$ & Type & \% o.c.w. & Type & \% o.c.w. & Ratio & Type & Type \\
\hline CA-1 & 42.5 & 700 & 0 & SF-940 & $10 \%$ & C & $4,5 \%$ & 0,28 & IM & $65 / 35$ \\
CA-2 & 42.5 & 522 & 600 & SF-940 & $10 \%$ & C & $4,5 \%$ & 0,33 & IM & $65 / 35$ \\
CA-3 & 42.5 & 522 & 600 & SF-940 & $10 \%$ & C & $3,0 \%$ & 0,36 & IM & $65 / 35$ \\
\hline CA-4 & 52.5 & 850 & 0 & FC3R & $10 \%$ & A & $3,0 \%$ & 0,23 & TM & $80 / 30$ \\
CA-5 & 52.5 & 635 & 600 & FC3R & $10 \%$ & A & $3,0 \%$ & 0,25 & TM & $80 / 30$ \\
\hline CA-6 & 52.5 & 850 & 0 & SF-940 & $10 \%$ & A & $3,0 \%$ & 0,23 & TM & $80 / 30$ \\
CA-7 & 52.5 & 635 & 600 & SF-940 & $10 \%$ & A & $3,0 \%$ & 0,25 & TM & $80 / 30$ \\
\hline CA-8 & 42.5 & 850 & 0 & FC3R & $10 \%$ & C & $4,5 \%$ & 0,24 & TM & $80 / 30$ \\
CA-9 & 42.5 & 635 & 600 & FC3R & $10 \%$ & C & $4,5 \%$ & 0,27 & TM & $80 / 30$ \\
\hline CA-10 & 42.5 & 850 & 0 & SF-940 & $10 \%$ & C & $4,5 \%$ & 0,22 & IM & $80 / 30$ \\
CA-11 & 42.5 & 635 & 600 & SF-940 & $10 \%$ & C & $4,5 \%$ & 0,26 & IM & $80 / 30$ \\
\hline CA-12 & 42.5 & 1000 & 0 & FC3R & $15 \%$ & C & $4,5 \%$ & 0,19 & IM & $80 / 30$ \\
CA-13 & 42.5 & 747 & 600 & FC3R & $15 \%$ & C & $4,5 \%$ & 0,22 & IM & - \\
\hline
\end{tabular}

All dosages except CA-13 contained a fiber cocktail with a total content of $2 \%$ over the total volume, where $1 \%$ of short fibers OL-13/0.16 were combined with $1 \%$ of the fiber shown in the table. Dosage CA-13 contained 2\% of short fibers. To keep the $2 \%$ after the addition of the coarse aggregate, during the mixing the initial fiber addition was higher than for the fine aggregate dosages. The process of curing and testing was described at 3.6 and 3.7.

The grading curve of the mortar was adjusted to the modified A\&A theory, as exposed in 2.3.4.3. However, the coarse aggregate added is not the result of adjust by an "ideal" grading curve. The paste volume fraction is high and the aggregates much larger than the sand, so they are not in contact, being lubricated by the paste. This discontinuity of the grading curve didn't produce segregation because of the high fines content and the similar density of mortar and aggregate.

The granulometric curve of the coarse aggregate, a fine (CA-8) and a coarse dosage (CA-9) are shown in the figure 4.31. Notice that the CA-9 curve is the sum of the blue and the red one in the adequate proportion. 


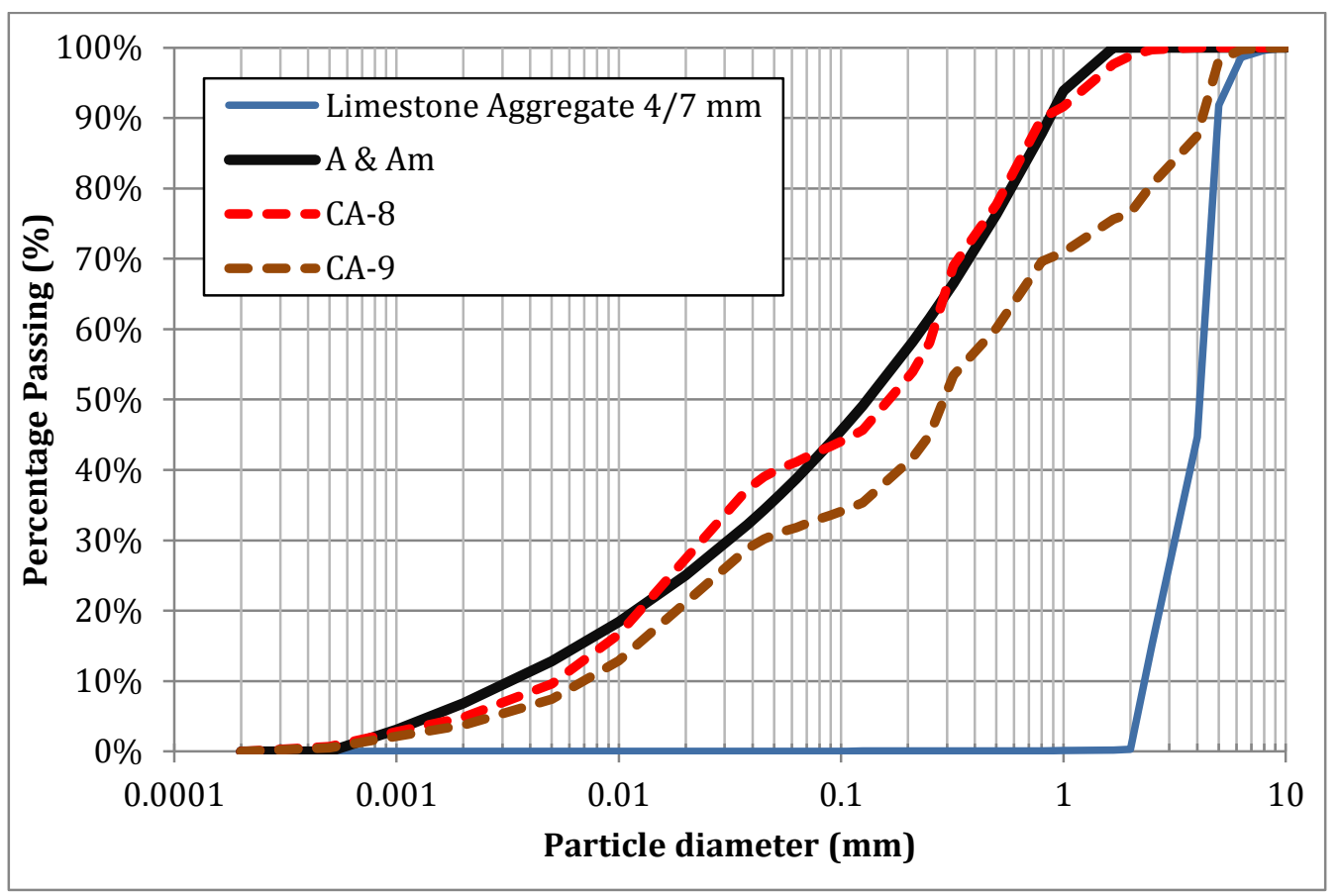

Figure 4.31: Difference in the granulometry of dosages with and without CA

\subsubsection{RESULTS}

Related to the rheology, the mixing process last the same time for fine and coarse aggregates UHPFRC, as the limestone particles were adequately mixed two minutes after the addition. Coarse aggregate dosages generated lower value of slump, because in absence of movement aggregates and fibers tend to form a mass in the center of the cone. This effect is less marked as much as higher is the binder content, since the Paste Volume Fraction increases and as a result the lubrication between fibers and coarse aggregates.

Some comparable values of slump flow can be seen in table 4.8. Dosages CA-1 and CA-2, with $700 \mathrm{~kg} / \mathrm{m}^{3}$ of cement per cubic meter of mortar, exhibit a great difference of slump diameter. This effect is smaller for medium and for high performance dosages (CA-10/CA-11 and CA12/CA-13 respectively). Dosage CA-13 showed also smaller interlocking between coarse aggregates and fibers because the last were all short. Figures 4.32 to 4.37 show the slump flow differences between both UHPFRC types.

The interlocking between CA and fibers can be avoided decreasing the content or size of the former or modifying the fiber cocktail added.

Table 4.8: Slump-flow of mixtures with and without $C A$

\begin{tabular}{|c|cc|cc|cc|}
\cline { 2 - 7 } \multicolumn{1}{c|}{} & \multicolumn{6}{c|}{ Mixtures } \\
\cline { 2 - 7 } \multicolumn{1}{c|}{} & CA-1 & CA-2 & CA-10 & CA-11 & CA-12 & CA-13 \\
\hline Slump (mm) & 850 & 505 & 830 & 588 & 730 & 598 \\
Aggregate & Fine & Coarse & Fine & Coarse & Fine & Coarse \\
\hline
\end{tabular}




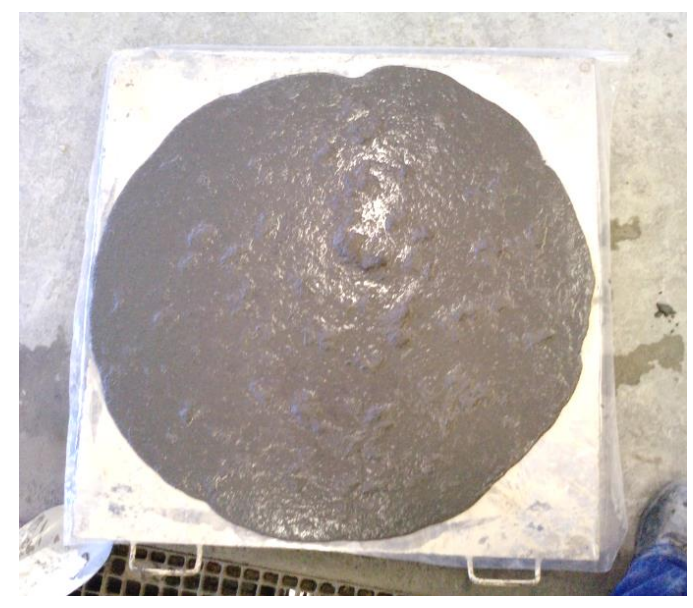

Figure 4.32: Slump-flow of CA-1

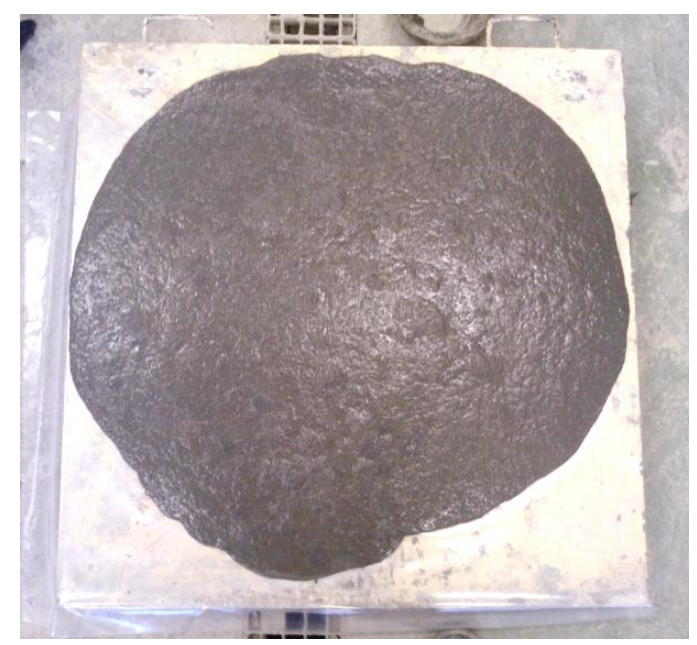

Figure 4.34: Slump-flow of CA-10

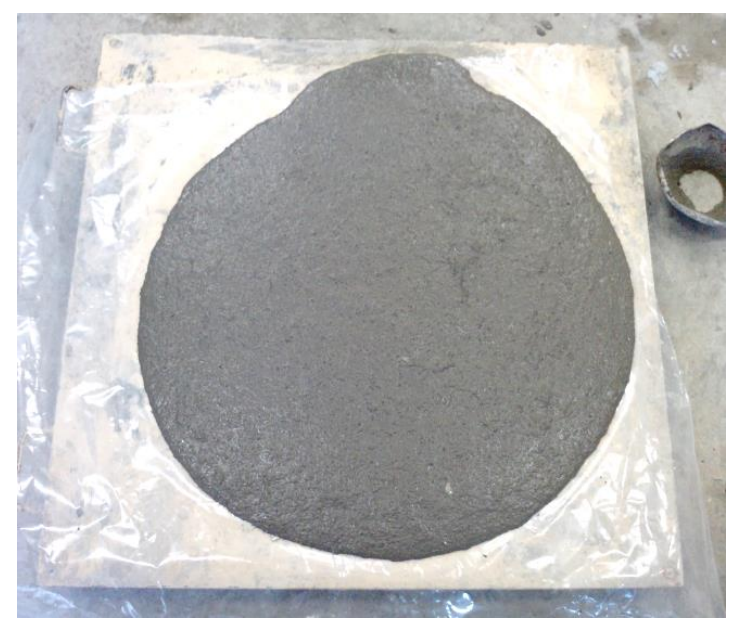

Figure 4.36: Slump-flow of CA-12

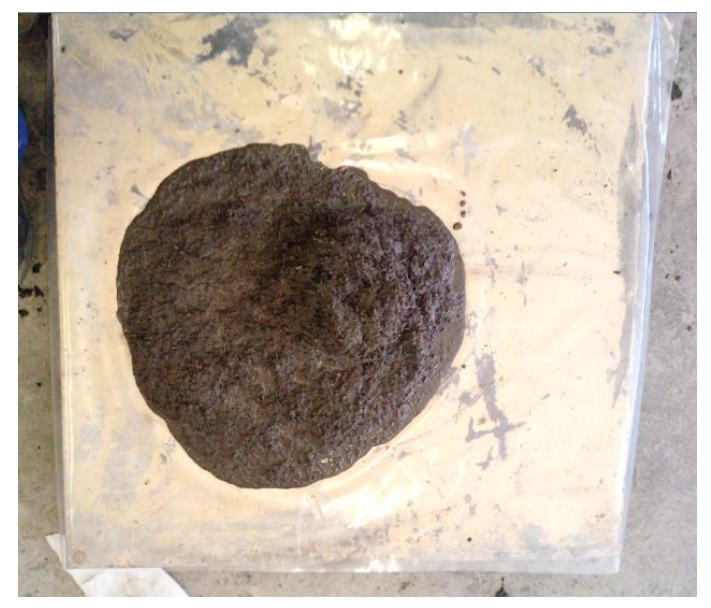

Figure 4.33: Slump-flow of CA-2

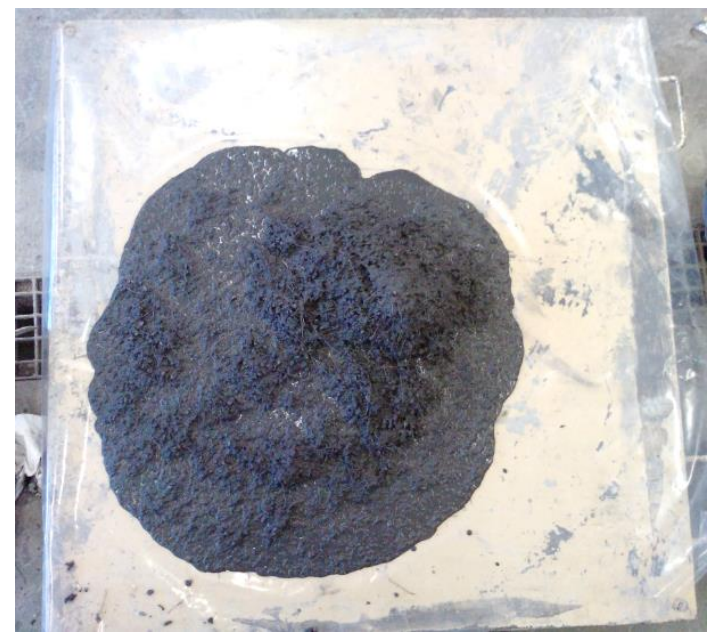

Figure 4.35: Slump-flow of CA-11

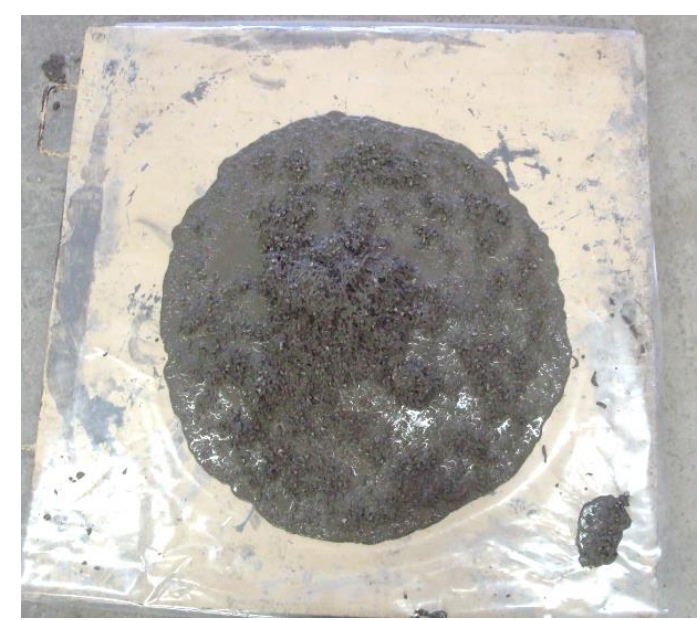

Figure 4.37: Slump-flow of CA-13

Despite of the aspect of the coarse aggregate dosages, the product flowed adequately in dynamic conditions and the no segregation of the products was checked cutting the flexural beams (figure 4.38). It can be appreciated the homogeneous spacing between coarse particles and the adequate fiber distribution and orientation between them (figure 4.39). 


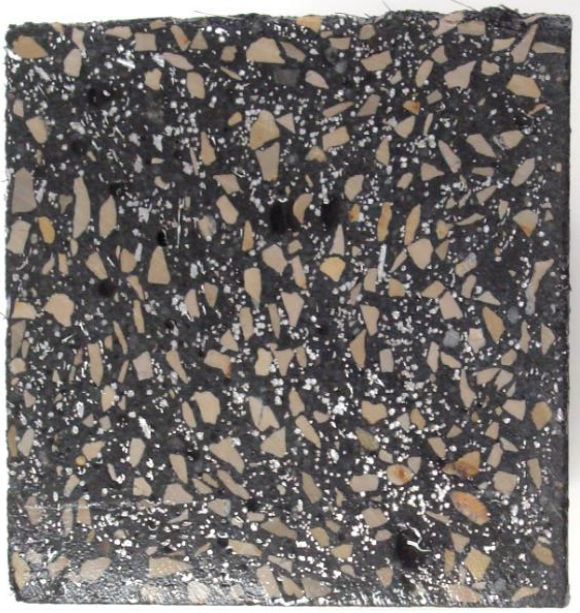

Figure 4.38: Cut section of a coarse aggregate prism

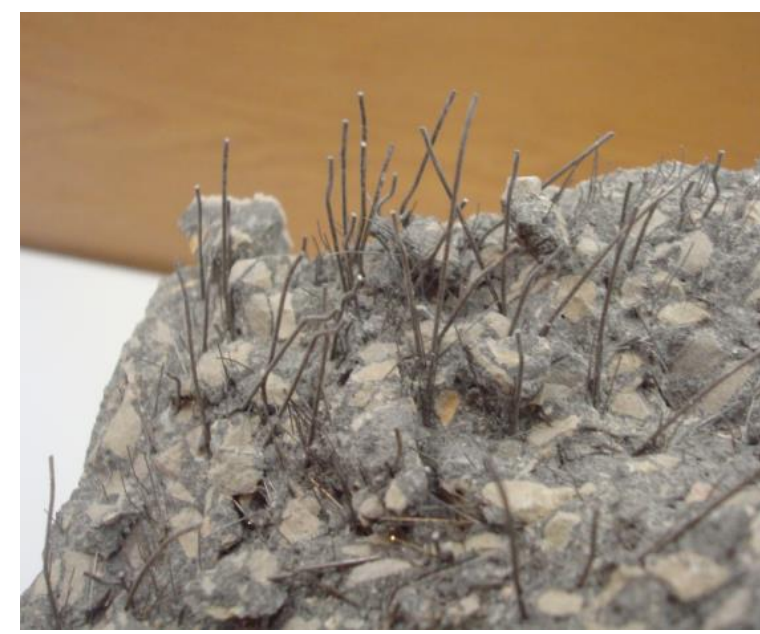

Figure 4.39: Fibers in the section of a tested prism (CA-9)

Figure 4.40 shows the compressive strength evolution of the different mixtures developed. The vertical straights comprise comparable dosages, since their difference is only the coarse aggregate addition with $4 \%$ of water over its weight.

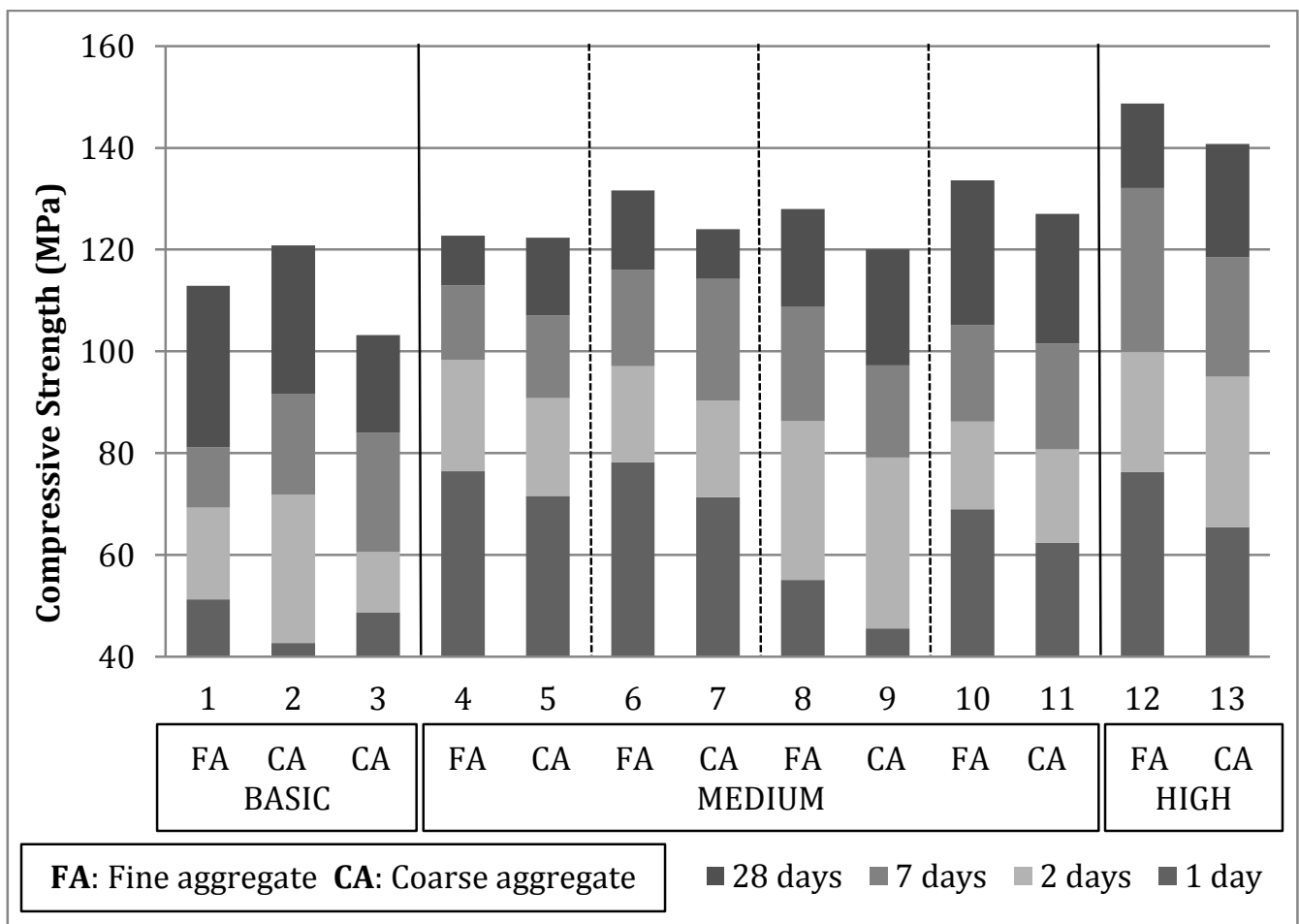

Figure 4.40: Evolution of the compressive strengths of mixtures with and without coarse aggregates

The general tendency is that for all mixtures the 28 days compressive strength is $5 \%$ smaller for coarse aggregate dosages than for the equivalent with fine aggregates. However, the binder content is $25.4 \%$ smaller, so the use of coarse aggregate increase the efficiency of the materials used. In the figure 4.41 is shown the ratio 28 days compressive strength/binder content for all the dosages, related with the binder content. The efficiency increases an average of $27 \%$ for high dosages, $28 \%$ for medium and $33 \%$ for basic dosages. Also, as logic, the efficiency increases with the lower binder content, since mixtures with high binder content have smaller degree of hydration due to the lower $\mathrm{W} / \mathrm{B}$ ratio. 


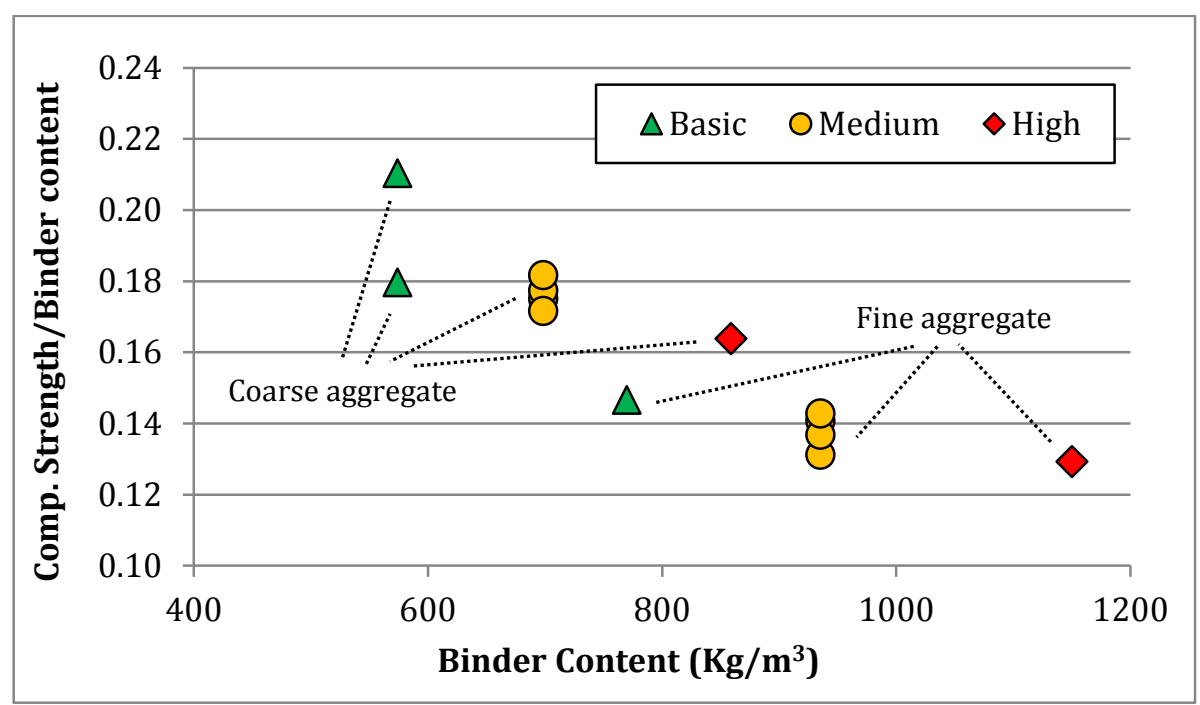

Figure 4.41: Relation between the binder content and the compresive strength/Binder content for different dosages

The compressive strength doesn't seem limited by the strength of the limestone aggregate. The maximum reached has been $141 \mathrm{MPa}$, but more tests are necessary to check if the value can be increased. Despite of the aggregate strength, two other reasons might have produced the slight decrease of the strength for the coarse dosages:

- The increase in the W/B ratio, that was necessary for reach comparable workability.

- The bond of matrix-coarse aggregate ITZ. This is the weakest region at early ages. The aggregate has a reduced mechanical interlock for the high volume it has. With the age evolution of the active addition's hydration, ITZ improves and the strength differences between coarse and fine aggregate UHPFRC became smaller. Figure 4.42 show the relative differences of compressive strength between coarse aggregate dosages and their comparable fine aggregate dosages at 1 and 28 days. The long term improvement for the former is clearly appreciated.

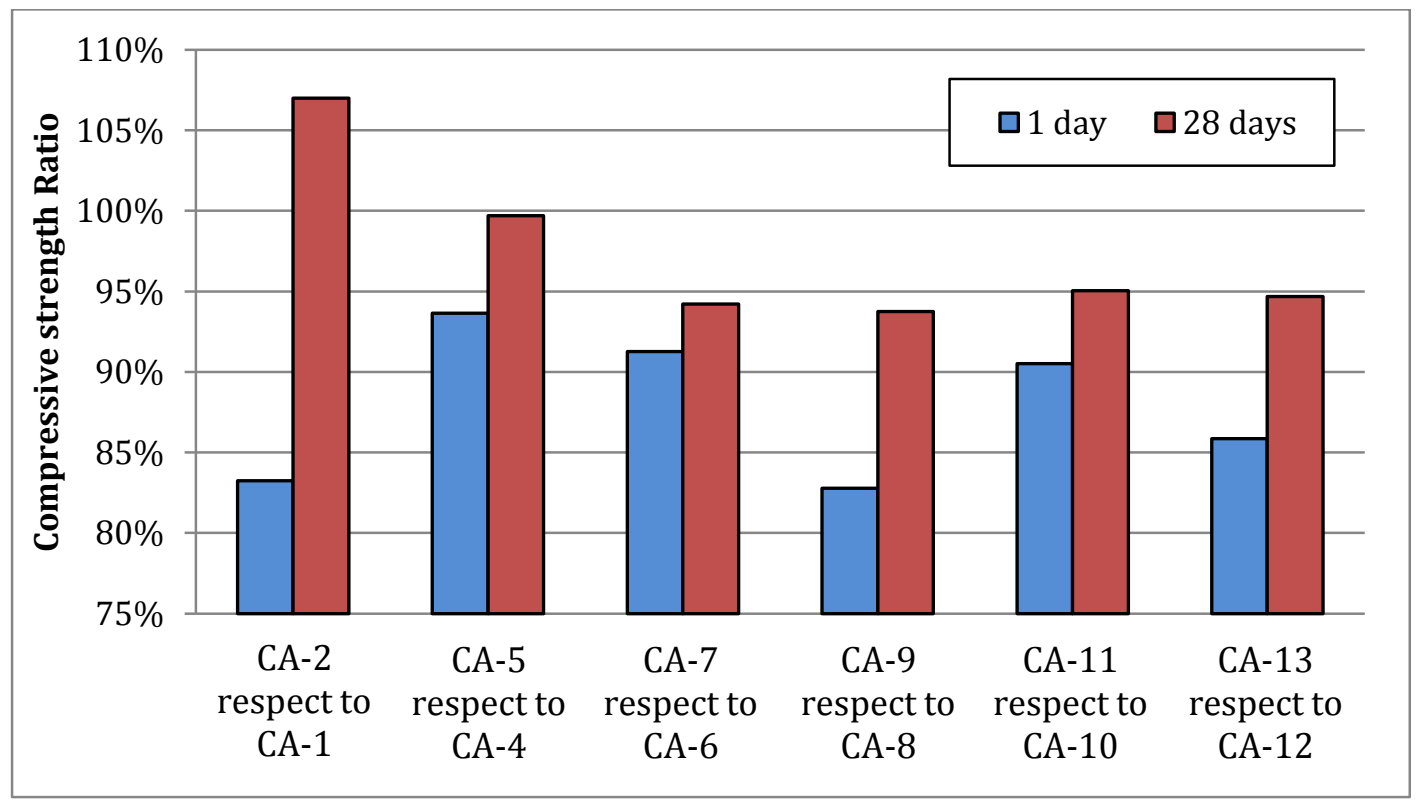

Figure 4.42: \% of compressive strength of dosages with coarse aggregate compared with dosages with similar mortar without coarse aggregate 
The flexural strength of the fine and coarse aggregate was similar for the comparable mixtures. This demonstrates that the fiber orientation factor of the mixtures with coarse aggregate doesn't seem to be significantly smaller than for the others. The ductility was evaluated obtaining the energy accumulated in the bending test up to a deflection of $3 \mathrm{~mm}$. This value was correlated with the maximum flexural strength, and is shown at figure 4.43. The high correlation shows the stability of the test due to the adequate fiber distribution. The coarse aggregate mixtures have comparable behaviors than those without.

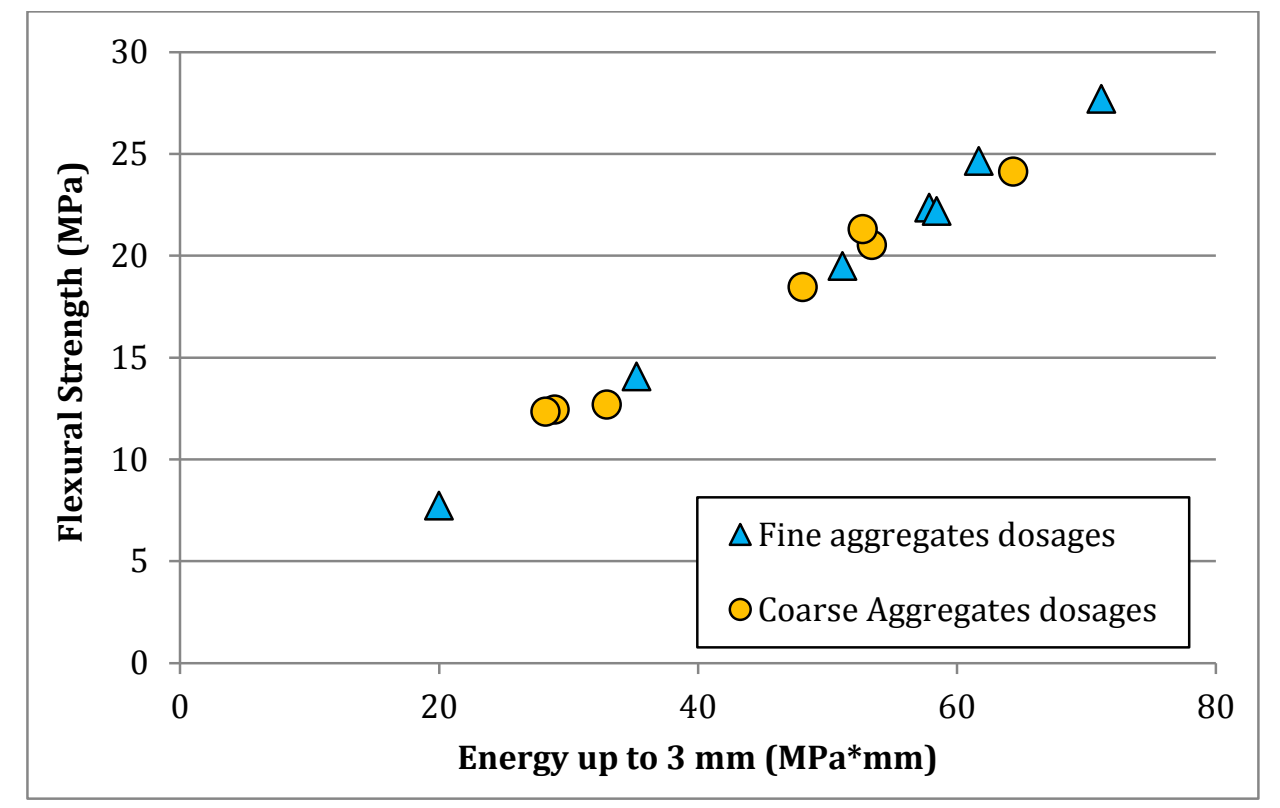

Figure 4.43: Maximum flexural strength related with the energy up to $3 \mathrm{~mm}$ of deflection

\subsubsection{CONCLUSSIONS OF THE LIMESTONE COARSE AGGREGATE EFFECT}

From the mechanical results is concluded that limestone can be a useful coarse aggregate to perform VHPFRC-UHPFRC, decreasing the price and the cement content required. This can be useful when less cement wants to be used or the price wants to be reduced. Long term compressive strength is comparable with the VHPFRC-UHPFRC without coarse aggregate, showing that the exclusive aggregates normally used for coarse UHPFRC are not a must for reach ultra high strength.

However, the rheological properties might be a limitation for real applications, since the mass has higher tendency to the aggregate-fiber interlock. Also the uses are limited to those elements with a thickness that allows the adequate advance of the flow.

\subsection{PARTICLE PACKING THEORY EFFECT}

One of the key points of UHPFRC mixture design is the packing density. Normally the higher this value the greater the slump flow and compressive strength reached [11]. Some methods have been developed to design an adequate micro-grading curve, searching the highest compacity and then decreasing the concrete water demand (De Larrard, Andreasen and Andersen (A\&A), Dinguer and Funk). However, reach a simple satisfactory method that suggests an adequate UHPFRC particle size distribution is still a challenge. 
Here couples of mixtures are dosed with two different simple methods: The modified A\&A method (A\&A $A_{M O D}$, see 2.3.4.3), which is semi-empirical and has been already used by some authors to design UHPFRC dosages, and the Ternary Packing Diagram (TPD), a simple empirical process to find the aggregate combination that provides the highest bulk density. The differences of rheological and mechanical properties between mixtures designed with both methods are compared.

\subsubsection{DEFINITION OF THE DOSAGE CRITERIA}

The experimental process is based in couples of similar UHPFRC dosages that have been cast with the only difference of the sand distribution. Three different quartz sands were proposed for this section. The first is the AFA- 60 shown at $4.3(0.6 \mathrm{~mm})$, and the others are two coarser with maximum diameters of 0.8 and $1.5 \mathrm{~mm}$. The granulometry of them is shown in figure 4.44 . The density is $2.65 \mathrm{~kg} / \mathrm{dm}^{3}$.

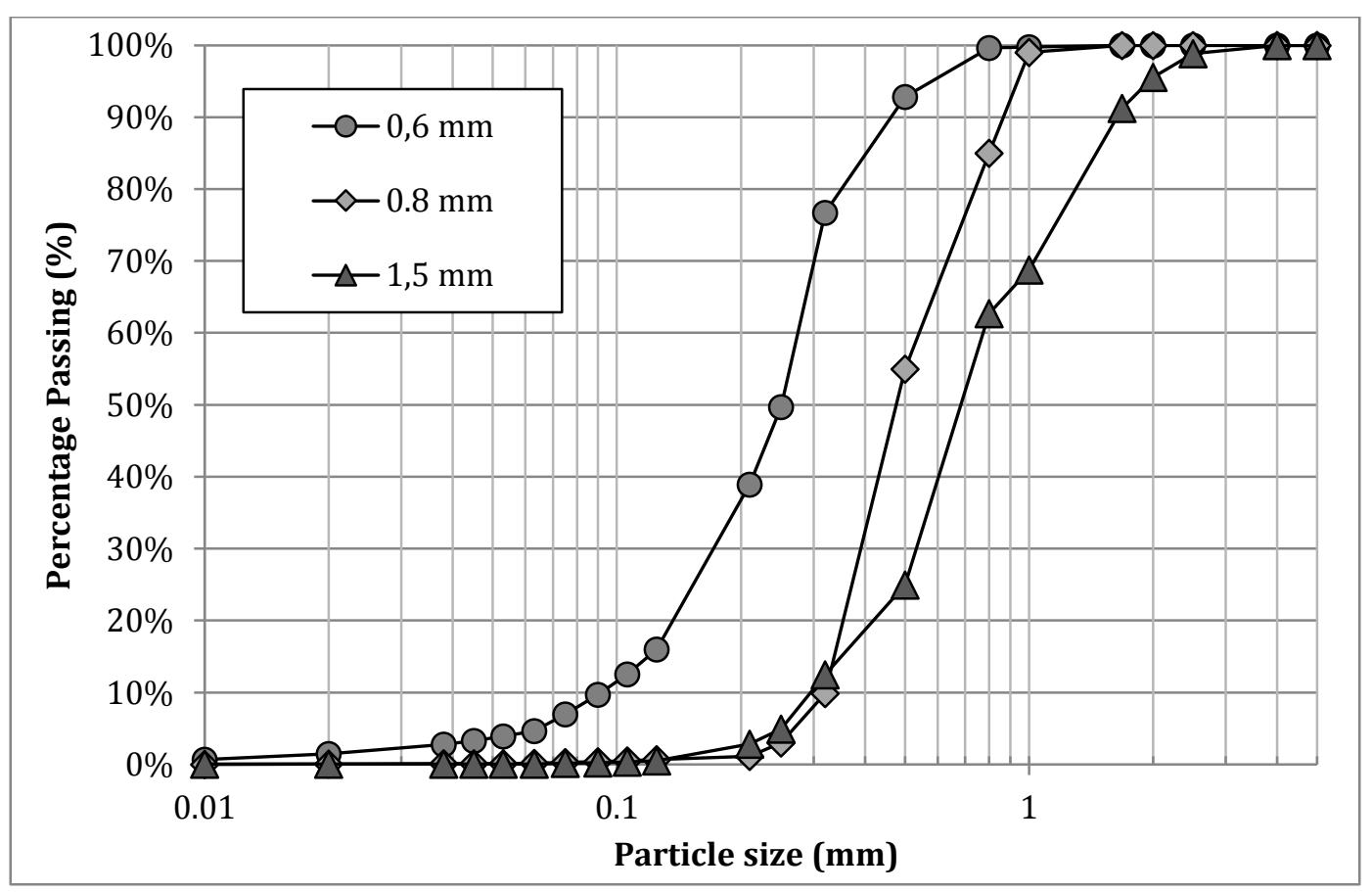

Figure 4.44: Granulometry of the sands used in this subsection

The two methods used to obtain the combination of the three sands available for the UHPFRC are explained in the following lines:

-The $\mathbf{A} \boldsymbol{\&} \mathbf{A}_{\text {MоD }}$ particle packing theory is semi-empirical method proposed by Dinger and Funk, and explained at 2.3.4.3. It is a simple way to deduce the grading curve that suggests high packing density. It requires introduce three parameters: The maximum particle size, the minimum particle size, and a $\mathrm{q}$ factor that ranges between 0.1 and 0.5 .

$$
\frac{C P F T}{100 \%}=\frac{D^{q}-D_{\text {Min }}^{q}}{D_{\text {Max }}^{q}-D_{\text {Min }}^{q}}
$$

For this work the minimum particle diameter $\left(D_{\text {Min }}\right)$ considered was $0.5 \mu m$, as this is the minimum particle size identified for the FC3R or for the silica fume when it's dispersed. The maximum particle size considered was $1.25 \mathrm{~mm}$ for the basic and medium performance 
mixtures, and $1 \mathrm{~mm}$ for the high performance. These values are slightly higher than the generally used by other authors for UHPC.

For the mixtures of this work where this theory was used has been adopted q=0.2, $0.25 \mathrm{y}$ 0.3 , depending if the level of performance of the concrete was high, medium or basic respectively. This is done according to the information from some researchers, which indicates that the higher the finer content, the smaller the $\mathrm{q}$ that provides the highest packing density. In figure 4.45 are shown the three curves obtained with these parameters for the $D_{\text {Min }}$ and $D_{\text {Max }}$ indicated before. The sand combination for basic, medium and high performance dosages will be adjusted to these curves with the method of the least squares.

The program Microsoft $\AA$ Office Excel was used to obtain the A\&AMoD curves with the different q parameters. With the Solver application, the sand combination that provided the least squares of difference with this optimum curve was chosen as the adequate one.

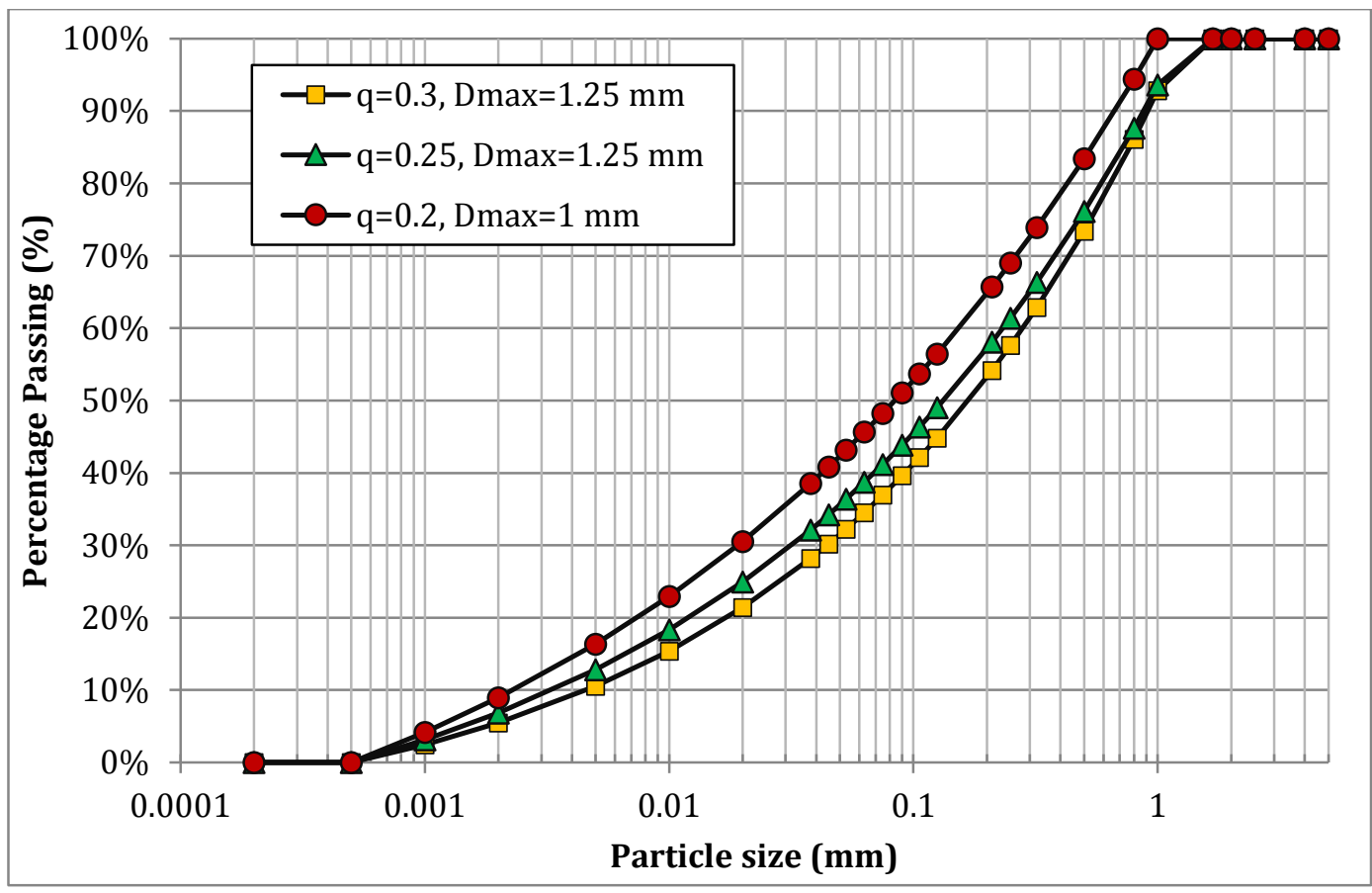

Figure 4.45: $A \& A_{\text {MоD }}$ curves to which the dosages were approached

-The Ternary Packing Diagram (TPD) is a simple empirical method that shows in a ternary system the packing density of different combinations of three aggregates. The one that provides the highest value will be used to dosage the concrete. This method is not used normally for UHPC. It is remarkable that, as cement is not considered in the granulometry, the sand proportions proposed are similar for any cement content.

In this research, three sands were combined in different percentages by volume. Each sand complemented the others with a $0,20,40,60,80$ or $100 \%$ of the total volume. To draw all the diagram 21 mixtures were generated. The process to obtain the bulk density was:

- Mix 1000 g. of sands, combined with the corresponding proportions and mixed manually.

- The mixed aggregates are poured into a container with constant volume without any compactation. The excess aggregates remaining above the top level of the cylinder are 
removed. Deducing the cylinder weight the sand weight was obtained, and consequently the bulk density.

- The bulk densities are represented in a ternary diagram, and the combination that provides the highest one was chosen as the best possible with these sands.

\subsubsection{EXPERIMENTAL PROGRAM}

The concrete dosages performed are shown in the table 4.9, being organized in couples that only differ in the packing theory method used. The $\mathrm{W} / \mathrm{B}$ ratio was added according with the water demand observed, while the PCE admixture used was kept constant. It was always slightly higher for the A\&A dosages as the granulometry is finer. To study the influence in different conditions, the three cement contents and two active additions were used, as both intensive and tiliting mixer.

$2 \%$ of fibers were added, being $1 \%$ of short and $1 \%$ of long as in previous subchapters. No coarse aggregate was used. Slump flow and compressive strength evolution were measured according to the process described at 3.4.2 and 3.7.1.

Table 4.9: Experimental program to evaluate the effect of the packing theory adopted

\begin{tabular}{|c|c|c|c|c|c|c|c|}
\hline \multirow{2}{*}{$\frac{\text { Mix }}{\text { № }}$} & \multicolumn{2}{|c|}{ Cement } & \multicolumn{2}{|c|}{ Active addition } & \multirow{2}{*}{$\begin{array}{c}\text { W/B } \\
\text { Ratio } \\
\end{array}$} & \multirow{2}{*}{$\begin{array}{c}\text { Mixer } \\
\text { Type } \\
\end{array}$} & \multirow{2}{*}{$\begin{array}{c}\text { Packing method } \\
\text { name }\end{array}$} \\
\hline & Type & $\mathrm{kg} / \mathrm{m}^{3}$ & Type & \% o.c.w. & & & \\
\hline COM-1 & 42,5 & 700 & SF A & $10 \%$ & 0,27 & IM & TPD \\
\hline COM-2 & 42.5 & 700 & SF A & $10 \%$ & 0,28 & IM & $A \& A$ \\
\hline COM-3 & 52.5 & 850 & FC3R & $10 \%$ & 0,22 & TM & TPD \\
\hline COM-4 & 52.5 & 850 & FC3R & $10 \%$ & 0,23 & $\mathrm{TM}$ & $A \& A$ \\
\hline COM-5 & 42,5 & 1000 & FC3R & $15 \%$ & 0,175 & IM & TPD \\
\hline COM-6 & 42,5 & 1000 & FC3R & $15 \%$ & 0,185 & IM & $A \& A$ \\
\hline
\end{tabular}

\subsubsection{RESULTS}

Figures 4.46 to 4.48 show the $A \& A_{\text {MOD }}$ curve for $\mathrm{q}=0.2, \mathrm{q}=0.25$ and $\mathrm{q}=0.3$, with the particle distribution of the basic, medium and high dosages. All the sand combinations obtained result in a content of fine sand higher than $50 \%$ and the rest of coarse sand. The least squares method showed that sand $0.8 \mathrm{~mm}$ was not necessary. The curve for the Ternary Packing Diagram adjust is also shown, being similar than the $\mathrm{A} \& \mathrm{~A}_{\mathrm{M} о \mathrm{D}}$ in the binder size region.

The convex part of the curve appears in all cases because the cement content is fixed and high. Introduce the cement content as a variable to be adjusted by least squares would lead in dosages with a lack of fines, requiring higher W/B ratio to keep high the Paste Volume Fraction and then reach acceptable workability. 


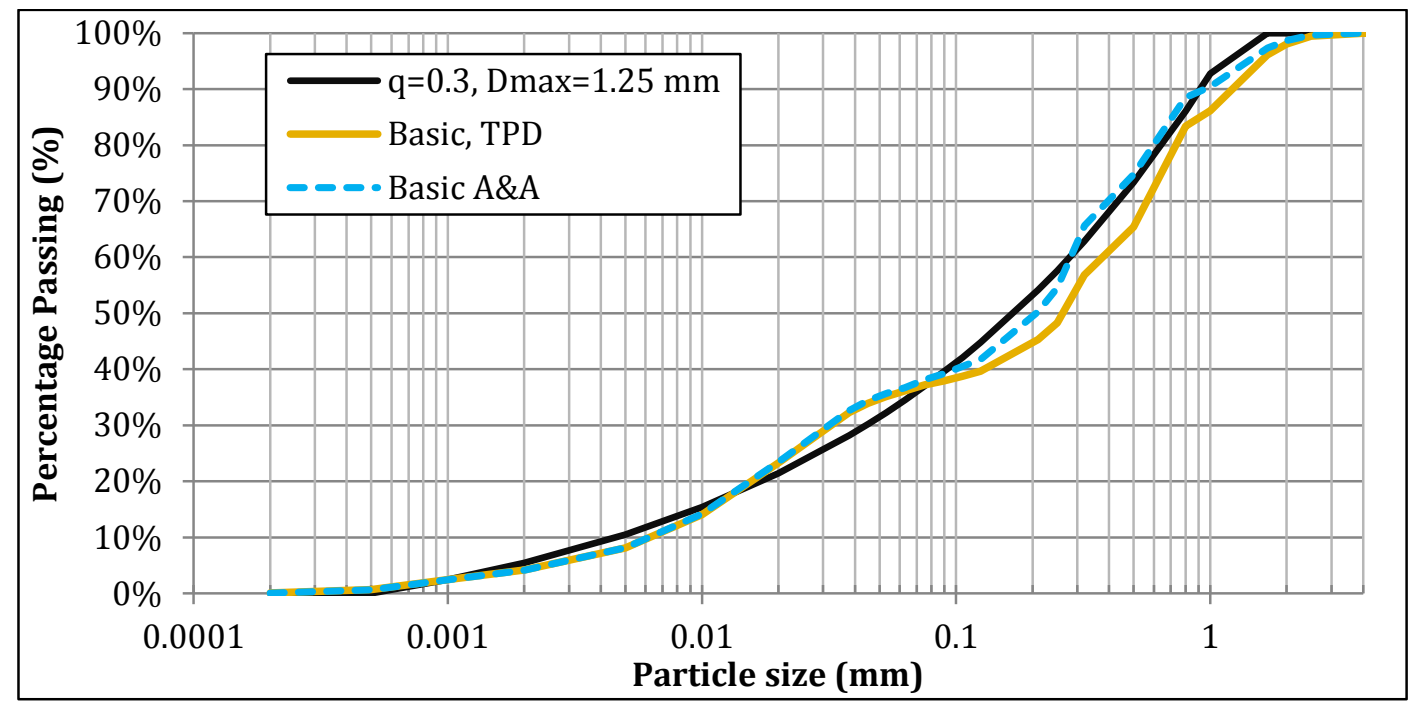

Figure 4.46: Particle size distribution suggested by the A\&AMOD $(q=0.3)$ and TPD method, adjusted for the VHPFRC

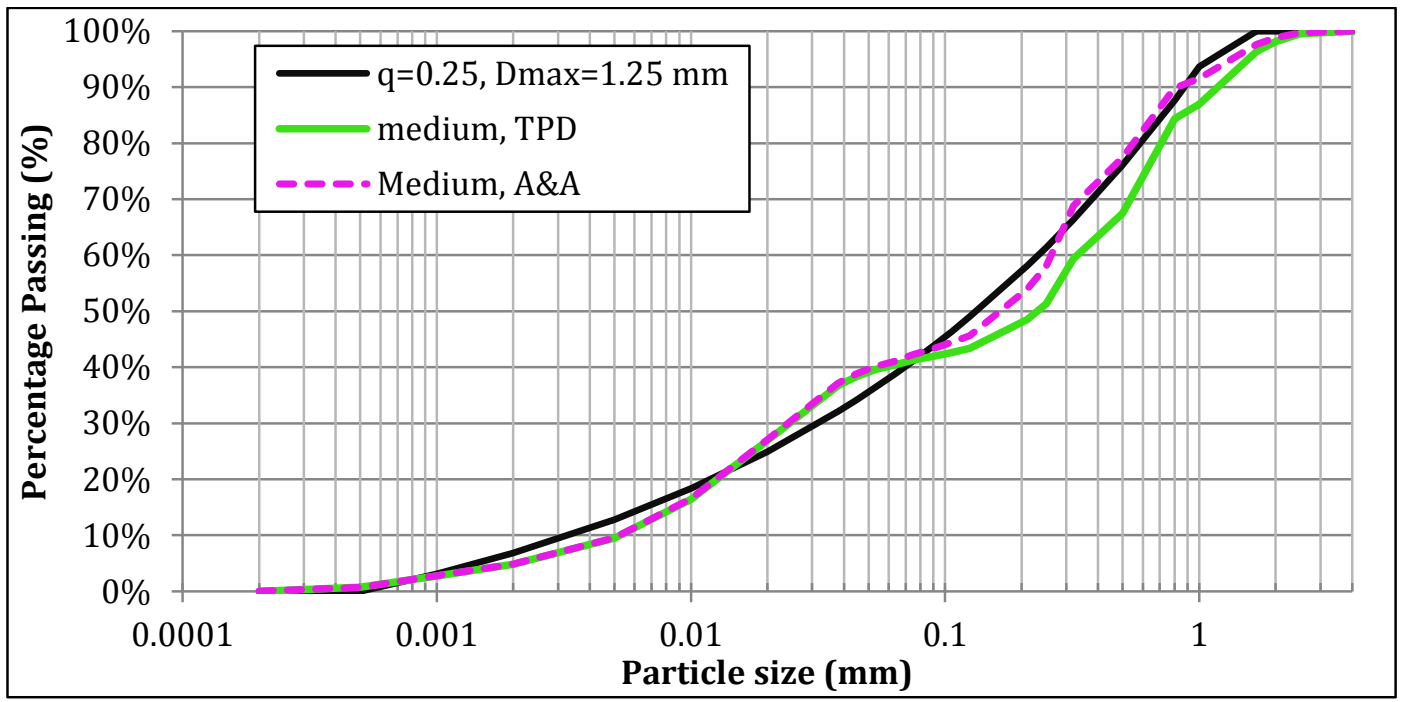

Figure 4.47: Particle size distribution suggested by the $A \& A_{\text {моD }}(q=0.25)$ and TPD method, adjusted for the medium performance UHPFRC

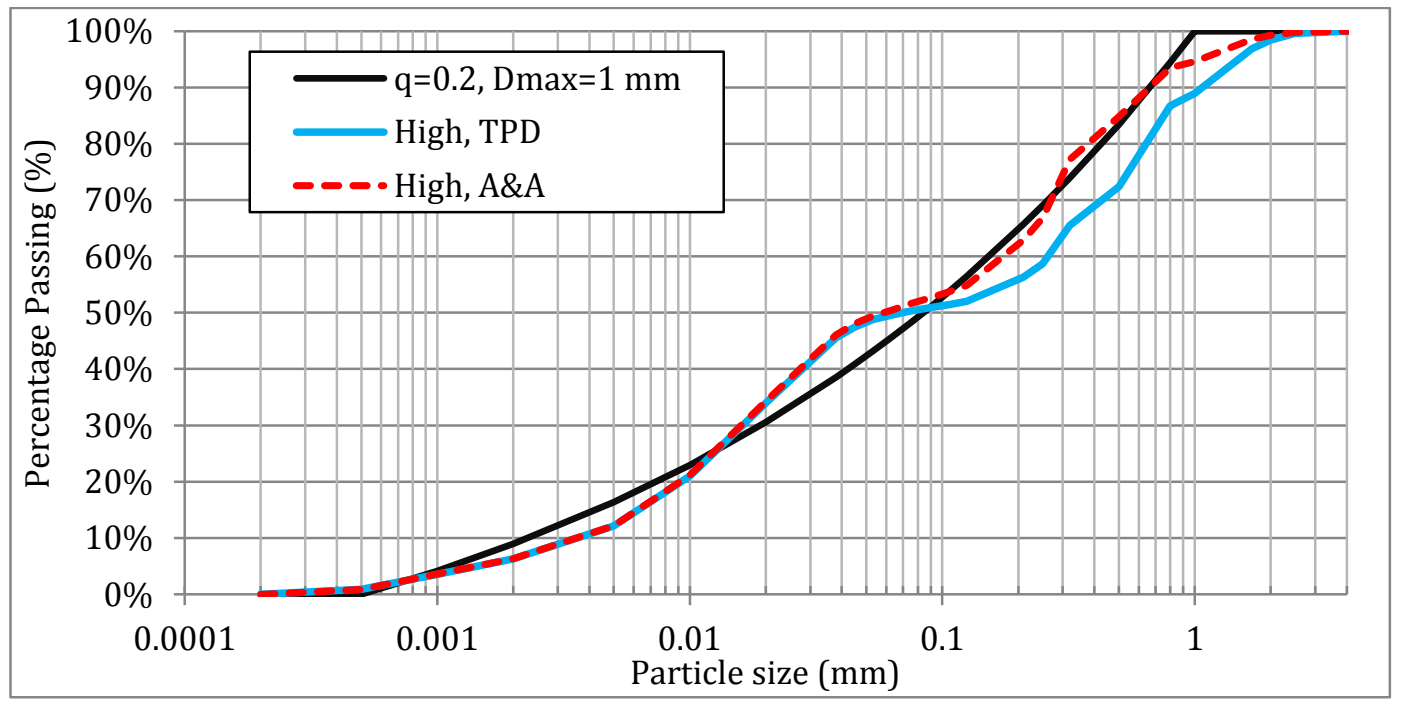

Figure 4.48: Particle size distribution suggested by the A\&AмоD (q=0.2) and TPD method, adjusted for the UHPFRC 
The TPD obtained for the three sands is shown at figure 4.49. The combination that provides the highest bulk density is with a content of $30 \%$ of fine sand $0-0.6 \mathrm{~mm}$ and $70 \%$ of thick sand $0-2 \mathrm{~mm}$. It is noticeable that the medium size sand is not required, as for the mixtures adjusted with the $A \& A_{M O D}$.

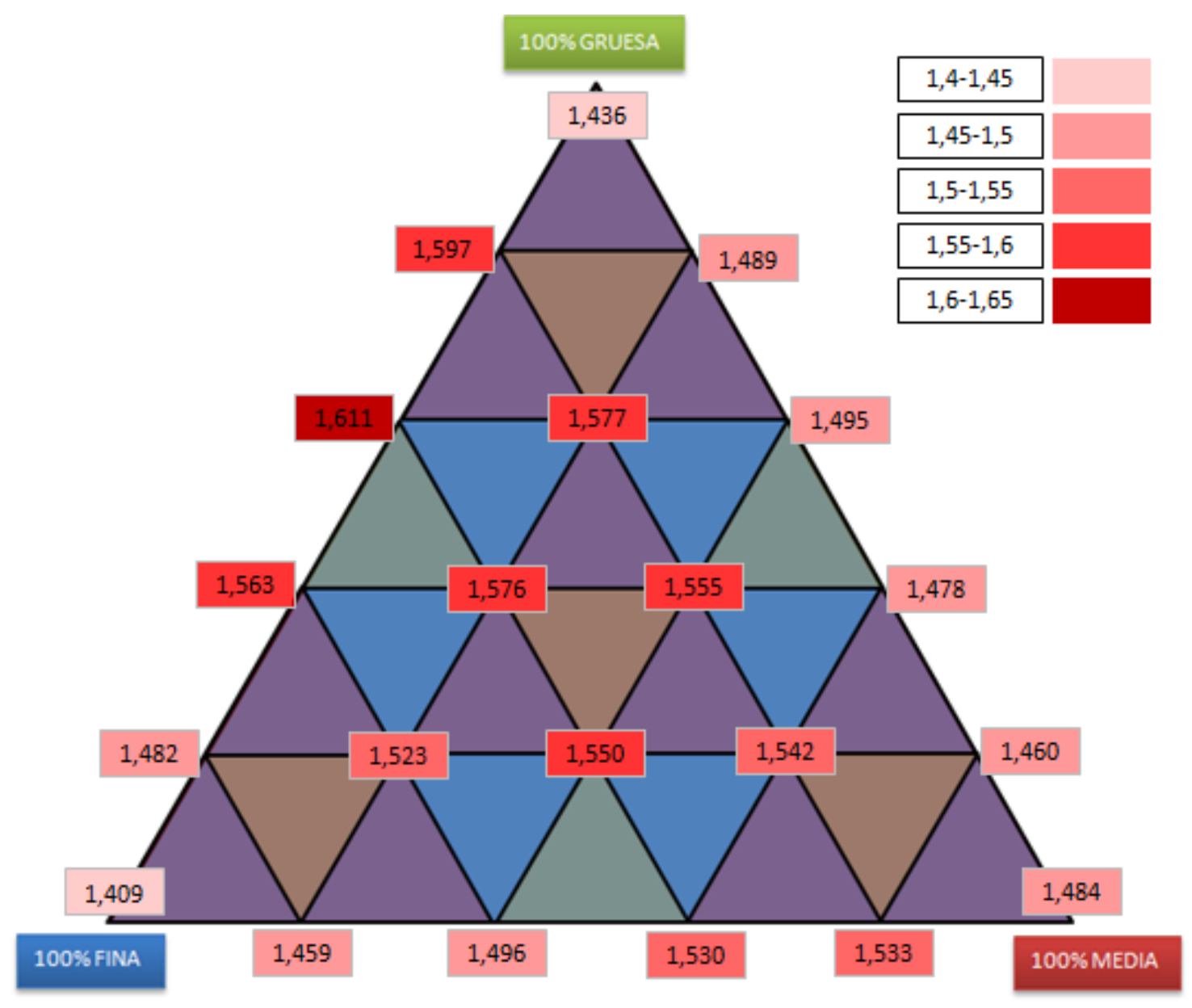

Figure 4.49: Ternary Packing Diagram for the three sands used

The percentages in volume of each sand resultant of adjusting to each method are shown in table 4.10. The TPD provided thicker granulometry than the A\& $A_{\text {MоD }}$ method. This could derive in more flowability, but also in higher segregation risks and in lower compressive strength due to the higher $D_{\text {Max }}$ of the aggregate, which increases the size of the micro-cracks that generate the compressive failure.

In order to reach similar workability the W/B ratio of the dosages adjusted with the TPD method were slightly reduced, as was shown in the table 4.9. On table 4.11 can also be observed the slump flows and 28 days compressive strength of each dosage. Figures 4.50 and 4.51 show the aspect of some of these slump flows.

Table 4.10: Percentage of each sand depending on the packing method adopted

\begin{tabular}{|c|ccc|}
\hline & $\mathbf{0 . 6} \mathbf{~} \mathbf{m}$ & $\mathbf{0 . 8} \mathbf{~ m m}$ & $\mathbf{1 . 5} \mathbf{~ m m}$ \\
\hline High (q=0.2) & $66,1 \%$ & $0 \%$ & $33,9 \%$ \\
Medium (q=0.25) & $54,8 \%$ & $0 \%$ & $45,2 \%$ \\
Basic (q=0.3) & $51,9 \%$ & $0 \%$ & $48,1 \%$ \\
TPD (basic, medium and high) & $30,0 \%$ & $0 \%$ & $70,0 \%$ \\
\hline
\end{tabular}


Table 4.11: Compressive strength and slump flow of the mixtures

\begin{tabular}{|cccc|}
\hline Mix & Compressive strength & Slump flow & Packing method \\
\hline No & $\mathbf{2 8} \mathbf{d}$. & $\mathbf{m m}$ & name \\
\hline COM-1 & 121,2 & $<500$ & TPD \\
COM-2 & 112,9 & 800 & A\&A \\
\hline COM-3 & 125,2 & 720 & TPD \\
COM-4 & 122,7 & 850 & A\&A \\
\hline COM-5 & 161,2 & 770 & TPD \\
COM-6 & 148,7 & 760 & A\&A \\
\hline
\end{tabular}

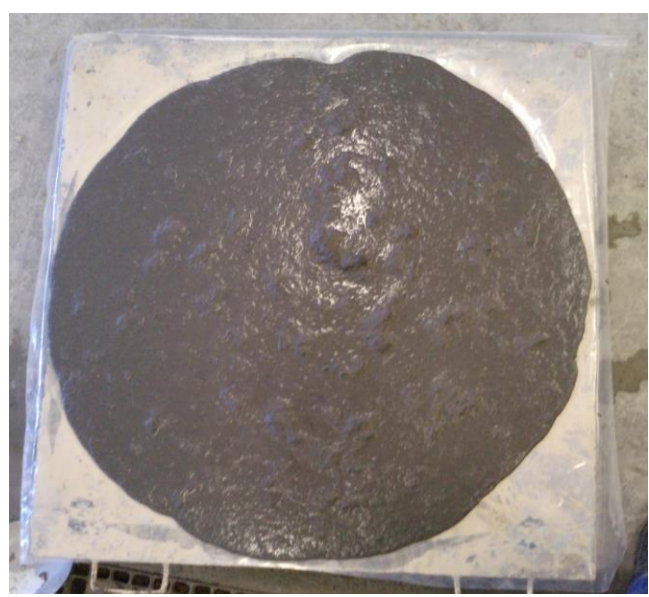

Figure 4.50: Slump-flow of dosage COM-2

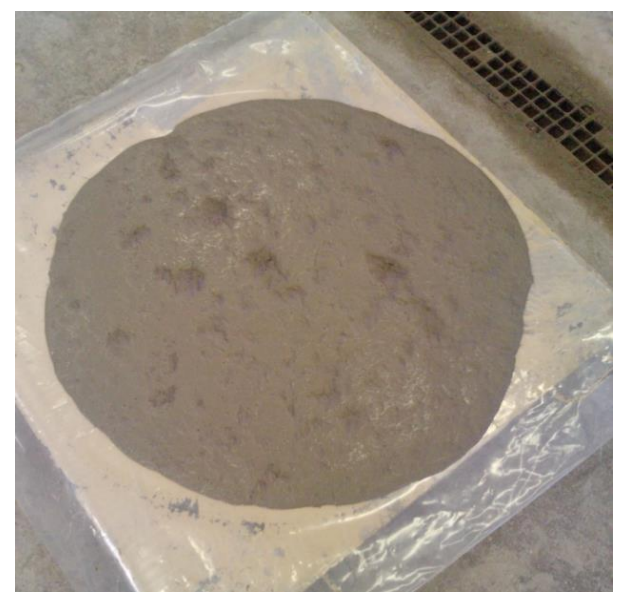

Figure 4.51: Slump-flow of dosage COM-3

The results evidence the difference of workability for the dosages with 700 and $850 \mathrm{~kg} / \mathrm{m}^{3}$ of cement depending on the packing method chosen. This showed the different suitability of the TPD method depending on the Paste Volume Fraction.

For high dosage the use of the TPD method provided stability and no segregation, with a compressive strength $8.3 \%$ higher than with the $A \& A_{\text {MOD }}$ method. Medium dosage provided similar compressive strengths with slightly smaller slump flow for the TPD method, since the $\mathrm{W} / \mathrm{B}$ was more reduced.

Basic performance dosage with the A\&A method was self-compacting. The use of TPD theory increase the coarse sand volume fraction, which is higher for the basic dosages. This resulted in two effects:

- A higher interaction with the long fibers, as can be explained with the theory developed by Martinie et al. [150].

- The interaction between coarse particles is high, so the system can't be considered semidiluted.

\subsubsection{CONCLUSSIONS OF THE PARTICLE PACKING THEORY EFFECT}

As a conclusion, the simple experimental process named here TPD provides a discontinuous granulometry that implies better rheology and compressive strength when the regime is semidiluted. This happens when the Paste Volume Fraction is much higher than the empty space between coarser aggregates ( $36 \%$ for spherical one size particles). Normally this is the case for 
UHPFRC, so TPD can be used as a useful criteria, not being necessary appeal to more complicated packing theories. A\& $A_{\text {MоD }}$ packing theory is more convenient for dosages with lower binder content, as many HPFRC or VHPFRC.

\subsection{MIXER EFFECTS}

Intensive mixers are the most convenient for UHPFRC casting to be more powerful and efficient, improving the dispersion of the active additions and the PCE admixture. Part of the problem for the UHPFRC market development is the absence of this mixer type in most of precast companies and the impossibility to use them on in-situ applications.

The use of ordinary mixers for UHPFRC mixing is scarcely reported. Therefore, here is analyzed the suitability to cast UHPFRC in six different concrete mixers. Special emphasis is put in three of them: The intensive mixer, as is the most recommended to cast this concrete, the tilting mixer, because it is the one with the most reduced relative power, and finally a planetary industrial mixer, as the concrete for precast applications has to be cast in it. The results of all mixtures are compared to evaluate their suitability to cast UHPFRC mixtures.

\subsubsection{EXPERIMENTAL PROGRAM}

The experimental program is based in 43 batches and separated in three parts:

Part 1: The first is focused in demonstrate the efficiency of the intensive mixer to disperse the CSF particles. This is made casting several UHPC mixtures in the same mixer with CSF, and also with the same CSF after a sonication process. Sonication is a process to disperse the condensed SF agglomerations by means of applying sound energy, and it is performed to a slurry of water and CSF before the addition to the concrete.

This research block was developed together with the Chemical group of the UPV [197]. It was used to cast UHPC with CSF and with SSF (Sonicated Silica Fume), and compare the pozzolan activity by means of the 28 days compressive strength. Similar values would mean that the intensive mixing produces an effective dispersion of the CSF particles.

Part 2: The second part is a single UHPFRC dosage cast at seven different mixers. Slight W/B ratio change can be introduced in order to reach the adequate flowability. This is performed to evaluate the suitability of different mixer types to cast this product. The mixers used have been: A 1 liter mortar mixer (defined at 3.3.1), a 30 liters tilting mixer (defined in 3.3.2, named TM), a 50 liters rotating pan mixer (defined at 3.3.3), a 110 liters planetary mixer (defined at 3.3.5), a 75 liters EIRICH Intensive Mixer (defined in 3.3.4, and called IM from now on), a 1000 liters industrial mixer (defined in 3.3.6 and called IndM from now on), and a 2000 liters industrial mixer (defined at 3.3.7). All the mixing processes are explained in the subsections referenced above.

Part 3: The third is based in five couples of dosages, where each couple has been cast both in the intensive and the tilting mixer. The last, with the highest binder content, was cast at the industrial mixer instead of the tilting. The only difference between the dosages of each couple is the $\mathrm{W} / \mathrm{B}$ ratio, modified to cast the UHPFRC in an acceptable mixing time. Generally the lower the power, the higher the $\mathrm{W} / \mathrm{B}$ ratio required to mix the concrete in a viable time. The tilting 
mixer has been chosen to represent low energy mixing, since it works without any paddles relative movement. Drum mixing takes place by lifting part of the material and then letting it fall.

On the other hand, the intensive mixer has a rotor that was used in a speed range between 50 and 300 r.p.m. The industrial mixer has a fixed pan and mixes the material with the movement of seven concentric paddles, providing a relative mixing energy between the machines mentioned above.

Dosages of part 1 are shown at table 4.12. The admixture type used was SIKA@ VSC 20-HE and the active additions content a $10 \%$ over the cement weight.

Table 4.12: Dosages to check the dispersion efficiency of the intensive mixer

\begin{tabular}{|c|c|c|c|c|c|c|c|}
\hline Mix & \multicolumn{2}{|c|}{ Cement } & Addition & PCE & W/B & Short Fibers & Coarse ag, \\
\hline № & Type & $\mathrm{kg} / \mathrm{m}^{3}$ & Type & \% o.c.w. & Ratio & $\%$ & $\mathrm{~kg} / \mathrm{m}^{3}$ \\
\hline M1-1 (x2) & 42.5 & 850 & CSF & $2 \%$ & 0.195 & - & - \\
\hline M1-2 (x2) & 42.5 & 850 & SSF & $2 \%$ & 0.195 & - & - \\
\hline M1-3 & 42.5 & 700 & CSF & $2.5 \%$ & 0.22 & - & - \\
\hline M1-4 & 42.5 & 700 & SSF & $2.5 \%$ & 0.22 & - & - \\
\hline M1-5 & 42.5 & 700 & CSF & $2.5 \%$ & 0.22 & - & 568 \\
\hline M1-6 & 42.5 & 700 & SSF & $2.5 \%$ & 0.22 & - & 568 \\
\hline M1-7 & 42.5 & 700 & CSF & $2.5 \%$ & 0.22 & $2 \%$ & - \\
\hline M1-8 & 42.5 & 700 & SSF & $2.5 \%$ & 0.22 & $2 \%$ & - \\
\hline
\end{tabular}

Dosages from parts 2 and 3 contained a fiber cocktail with a total content of $2 \%$ over the total volume, as in the previous subsections. For the part 2 the dosage used was the called C- 3 at table 4.2 of the subsection 4.4. Just for the tilting mixer the W/B ratio was increased from 0.175 to 0.195 as required to break the slumps along the mixing time.

At part 3 the same three different active additions introduced in previous subchapters were used (Ferroatlántica CSF, ELKEM CSF and FC3R). The reason to modify the active addition was study if the use of a non-condensed active addition (FC3R) minimizes the difference of mixing efficiency between the intensive and the tilting mixers, as the dispersion of the agglomerated particles is not necessary for that component.

The processes of curing and testing was described at 3.6 and 3.7.1. For the third part, the grading curve of the mixtures $\mathrm{M}-1$ to $\mathrm{M}-8$ was adjusted to the $\mathrm{A} \& \mathrm{~A}_{\mathrm{MOD}}$ theory, as exposed in 2.3.4.3. For M-9 and M-10 a proportion 60-40 of fine-coarse sand was used. Table 4.13 shows the dosages performed, which can be compared in couples.

Table 4.13: Experimental program of part 3, to evaluate the effect of the mixer

\begin{tabular}{|ccccccccc|}
\hline Mix & \multicolumn{2}{c}{ Cement } & \multicolumn{2}{c}{ Active addition } & \multicolumn{2}{c|}{ PCE } & W/B & Mixer \\
\hline No & Type & $\mathbf{k g} / \mathbf{m}^{3}$ & Type & \% o.c.w. & Type & \% o.c.w. & Ratio & Type \\
\hline M3-1 & 42.5 & 700 & SF A & $10 \%$ & C & $4,5 \%$ & 0,28 & IM \\
M3-2 & 42.5 & 700 & SF A & $10 \%$ & C & $4 \%$ & 0,31 & TM \\
\hline M3-3 & 52.5 & 850 & FC3R & $10 \%$ & A & $3 \%$ & 0,21 & IM
\end{tabular}




\begin{tabular}{|ccccccccc|} 
M3-4 & 52.5 & 850 & FC3R & $10 \%$ & A & $3 \%$ & 0,23 & TM \\
\hline M3-5 & 52.5 & 850 & SF A & $10 \%$ & A & $3 \%$ & 0,21 & IM \\
M3-6 & 52.5 & 850 & SF A & $10 \%$ & A & $3 \%$ & 0,23 & TM \\
\hline M3-7 & 42.5 & 850 & FC3R & $10 \%$ & C & $4,5 \%$ & 0,21 & IM \\
M3-8 & 42.5 & 850 & FC3R & $10 \%$ & C & $4,5 \%$ & 0,24 & TM \\
\hline M3-9 & 52.5 & 1000 & SF B & $15 \%$ & B & $2,5 \%$ & 0,185 & IM \\
M3-10 & 52.5 & 1000 & SF B & $15 \%$ & B & $2,5 \%$ & 0,175 & Ind.M \\
\hline
\end{tabular}

\subsubsection{RESULTS}

At table 4.14 are shown the rheological and mechanical results obtained for the CSF and SSF mixed at the intensive mixer.

Table 4.14: Results of the dosages cast at the intensive mixers with both SF types

\begin{tabular}{|ccccc|}
\hline Mix & SF & Mixing time & Slump flow & Compr. Strength \\
\hline No & Type & Min. & mm & 28 days (MPa) \\
\hline M1-1 (x2) & CSF & 14 & 780 & 117.8 \\
M1-2 (x2) & SSF & 12 & 795 & 117.9 \\
\hline M1-3 & CSF & 14 & 520 & 111 \\
M1-4 & SSF & 12 & 520 & 111.9 \\
\hline M1-5 & CSF & 14 & 700 & 118 \\
M1-6 & SSF & 12 & 730 & 119.1 \\
\hline M1-7 & CSF & 15 & $<500$ & 130.7 \\
M1-8 & SSF & 13 & $<500$ & 132.5 \\
\hline
\end{tabular}

The mixing time is slightly reduced when SSF is used instead of CSF. That is logic because the dispersion happened before, along the sonication process. No marked differences are observed related to the slump flow. The 28 days compressive strength is very similar for each compared couple. This shows that pozzolan activity of the CSF and the SSF is very similar, demonstrating that the mixing process can disperse the SF agglomerates as good as a sonication process. In ordinary concretes cast at conventional mixers the strength was over a $10 \%$ higher for dosages with SSF. It brings to the conclusion that intensive mixer is efficient in the CSF dispersion.

At the step 2 the same dosage was cast in seven different mixers. An idea of the mixing energy applied to the concrete can be quantified with the ratio between the power of the mixture and the material volume cast, obtaining a number that can be named relative mixing power. Attending to this the 1 liter mortar mixer, the intensive mixer (50 liters cast) and the industrial mixer have the greater values, while the tilting mixer has a ratio of $12 \mathrm{~W} / \mathrm{liter}$, in a smaller order of magnitude than the formers. That's the reason why the dosage requires higher $\mathrm{W} / \mathrm{B}$ ratio, to be able to destroy the slumps in the mixing. The values are shown with the rheological and mechanical parameters obtained (table 4.15).

The main differences appreciated are in the mixing time, as is appreciated at figure 4.52. If it is correlated with the Power/liter a logarithmic relation is found (figure 4.53). The 
compressive strength values are all near $150 \mathrm{MPa}$, showing that mix an adequate UHPFRC is possible with every several mixer types, but the mixing process needs to be modified, stabilization time will differ and also the tendency to segregation, which is higher as smaller is the relative mixing power.

Table 4.15: Rheological and mechanical results of the mixtures developed at the second step

\begin{tabular}{|cccccccc|}
\hline Mixer & Volume & Power/litre & Mixing time & W/B & Slump & t500 & com. strength \\
\hline Type & Mixed & W/l & min. & ratio & mm & sec. & 28 d. (MPa) \\
\hline Mortar & 1 & 370 & 12 & 0.175 & - & - & 156.8 \\
Tilting & 16 & 15 & 26 & 0.195 & 570 & 17 & 142.0 \\
Rotating pan & 25 & 90 & 18 & 0.175 & 650 & 3.7 & 148.5 \\
Planetary & 70 & 58 & 20 & 0.175 & 640 & 3.6 & 145.5 \\
Intensive & 45 & 244 & 13 & 0.175 & 665 & 2.4 & 151.4 \\
$\mathbf{1 ~ m}^{3}$ industr. & 300 & 123 & 15 & 0.175 & 730 & 2.0 & 147.2 \\
$\mathbf{2}$ m $^{3}$ industr. & 900 & 82 & 17 & 0.175 & 688 & 5.1 & $146.8^{*}$ \\
& *Average from 64 cubes obtained from 17 different batches & \\
\hline
\end{tabular}

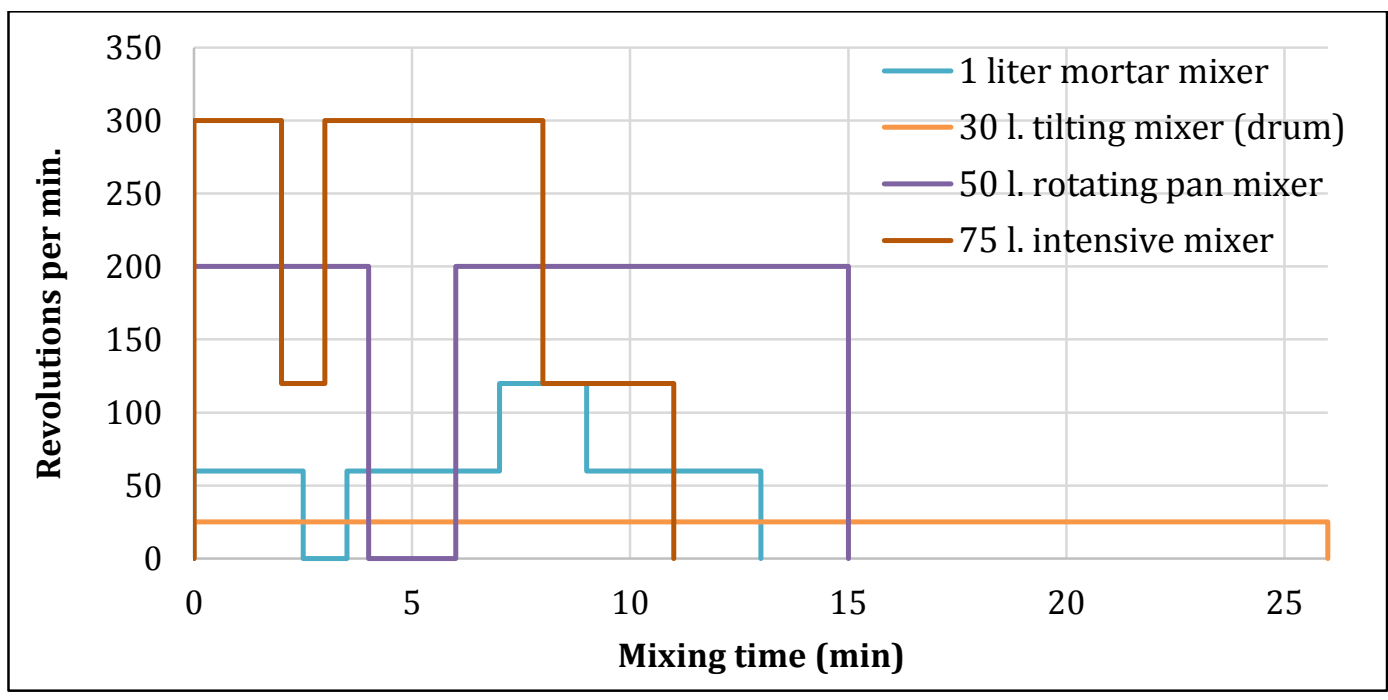

Figure 4.52: Mixing speed of the rotor or paddle for the different mixers during the mixing steps

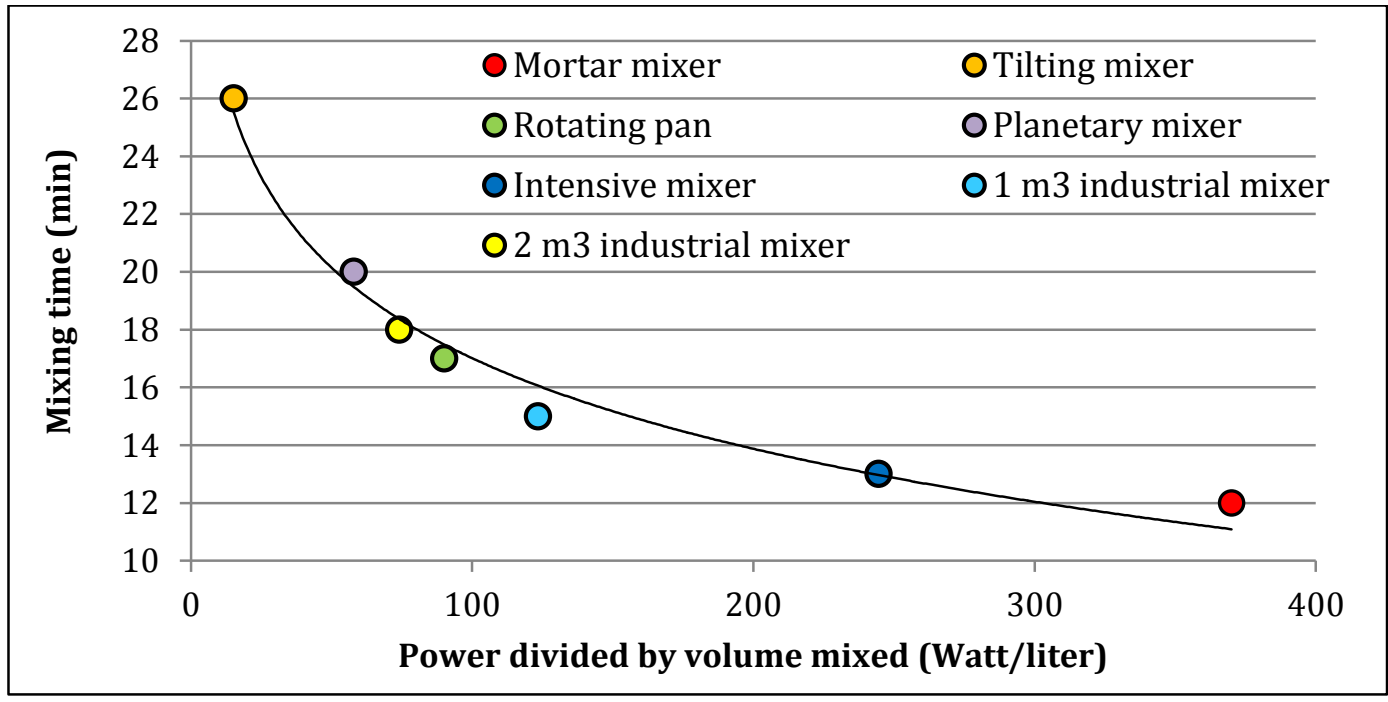

Figure 4.53: Correlation between the relative power of the mixers and the mixing time 
Finally, related to the third part, first the differences observed along the mixing process will be explained. When mixing in the tilting mixer, it was clearly observed that mixtures with the same W/B than those cast in the intensive mixer remained dry even with long mixing times. This is because after the water addition, agglomerates are formed and the water particles stay entrapped inside. The friction of the low energy mixing is not enough to break them. A slight increase of the $\mathrm{W} / \mathrm{B}$ was found the way to destroy the agglomerates, passing from dry to plastic and from plastic to fluid state during the mixing time.

In the tilting mixer, the higher the $\mathrm{W} / \mathrm{B}$ increase, the shorter the mixing time required to reach fluid state. However it was found necessary keep the value as low as possible to avoid segregation when fluid state is reached, and to reach UHPFRC mechanical properties. Then, in the tilting mixer choose an adequate $\mathrm{W} / \mathrm{B}$ ratio is a compromise between establish an acceptable mixing time and the stability of the concrete obtained. As can be seen in the planning at table 4.16 , the adequate W/B ratios for the dosages cast in the tilting mixer were $10-15 \%$ higher than for the intensive. With this ratio the mixing time in the former was double than for the latter. Mixing in the intensive mixer is much faster, and spherical agglomerates are not formed since the knock of the rotational tool destroy them all along.

Table 4.16: Rheological and mechanical results of the mixtures developed

\begin{tabular}{|ccccccc|}
\hline Mix & Mixing time & W/B & Slump flow & t500 & Compr. Strength & S. Deviation \\
\hline No & Min. & ratio & mm & seconds & 28 days (MPa) & \% \\
\hline M3-1 (IM) & 17 & 0,28 & 850 & 8,4 & 112,9 & $2,3 \%$ \\
M3-2 (TM) & 35 & 0,31 & 712,5 & - & 101,0 & $2,6 \%$ \\
\hline M3-3 (IM) & 16 & 0,21 & $>500$ & - & 123,8 & $5,0 \%$ \\
M3-4 (TM) & 28 & 0,23 & 850 & - & 122,7 & $0,8 \%$ \\
\hline M3-5 (IM) & 15 & 0,21 & $>500$ & - & 139,2 & $1,3 \%$ \\
M3-6 (TM) & 29 & 0,23 & 758 & 3,6 & 131,6 & $4,4 \%$ \\
\hline M3-7 (IM) & 17 & 0,21 & 763 & 12,2 & 137,2 & $2,9 \%$ \\
M3-8 (TM) & 30 & 0,24 & 840 & 7,3 & 128,0 & $0,8 \%$ \\
\hline M3-9 (IM) & 11 & 0,185 & 762 & 3,9 & 141,7 & $3,2 \%$ \\
M3-10 (Ind.M) & 17 & 0,175 & 730 & 4,7 & 147,2 & $4,6 \%$ \\
\hline
\end{tabular}

The additional water required for mix in the tilting mixer with acceptable times induced, when the fluid state was reached, greater slump flows. This effect can be appreciated in table 4.16. The $\mathrm{W} / \mathrm{B}$ ratio added for the dosage at the industrial mixer was slightly smaller than for the intensive mixer, since the higher diameter of the pan and the fast turning of the seven paddles induced more kinetic energy to the mixed particles. However, the W/B ratio of 0.175 for M-10 is just a reference, since the humidity and water adding system in the industrial plant doesn't provide an accurate control of the total water really added, especially because the volume cast was almost 300 liters, three times smaller than the typically performed.

Even though CSF (used for the couples M1-M2, M5-M6 and M9-M10) is condensed and FC3R (used for the couples M3-M4 and M7-M8) not, the differences observed for the mixing process of the intensive and tilting mixers were similar for dosages with both components. This shows that the smaller performance of a low energy mixer compared with an intensive is not due to 
the better dispersion or the addition in the latter, but due to the higher efficiency destroying the slumps and dispersing the PCE admixture.

On the pictures pertaining to figure 4.54 are shown the steps of the mixing process for a dosage cast in the tilting mixer (M-8). After the water addition, agglomerates were formed along 8-10 minutes. The addition of the remaining PCE admixture helped to destroy the agglomerates, which joined to form two plastic consistence masses.
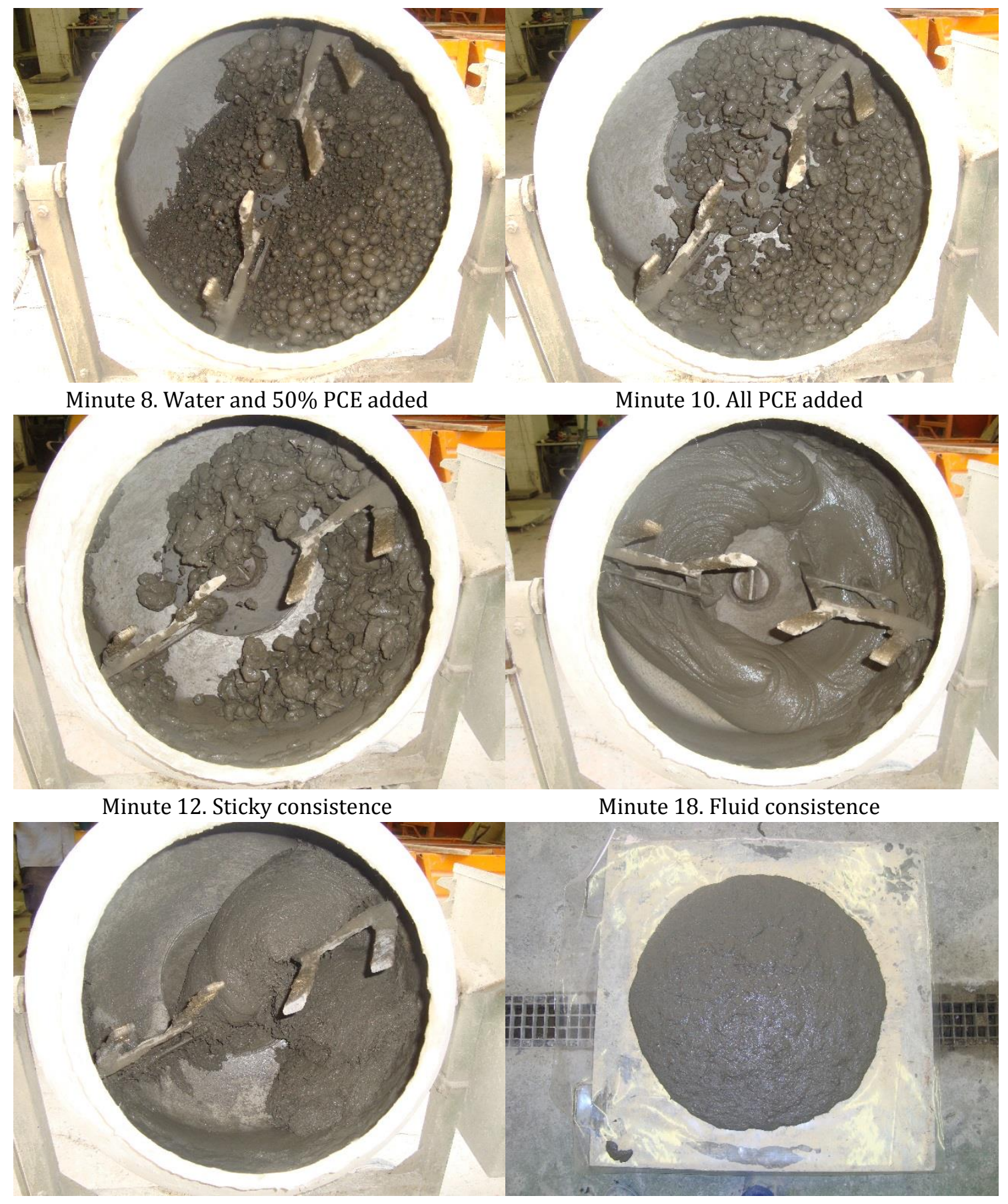

Minute 22, after fiber addition.

Slump flow of the mixture

Figure 4.54: Progressive aspects of the UHPFRC mixed in the tilting mixer 
Long mixing time changed their consistency to fluid. In the last step the workability decreased slightly due to the fibers addition. The time required to separate the fiber bundles was longer than for the intensive mixer, since the glue dissolving was slower.

Additional dosages not shown at table 4.16 were cast with coarse aggregates in the tilting mixer. The mixing required slightly shorter time, because the coarse aggregate broke up faster the solid slumps with the knocking.

Figure 4.55 shows the compressive strength evolution of the mixtures. The differences found at all ages can be explained due to the higher W/B ratio, which is indicated on the top of each column. The decrease of compressive strength suffered by the use of a low energy mixing was never higher than $11 \%$. It is also remarkable that the dispersion of the compressive strength of the prisms dosages was obtained (values are shown at table 4.16), being for both mixers comparable and smaller than $5 \%$. This shows the homogeneity of the product mixed in any of the cases.

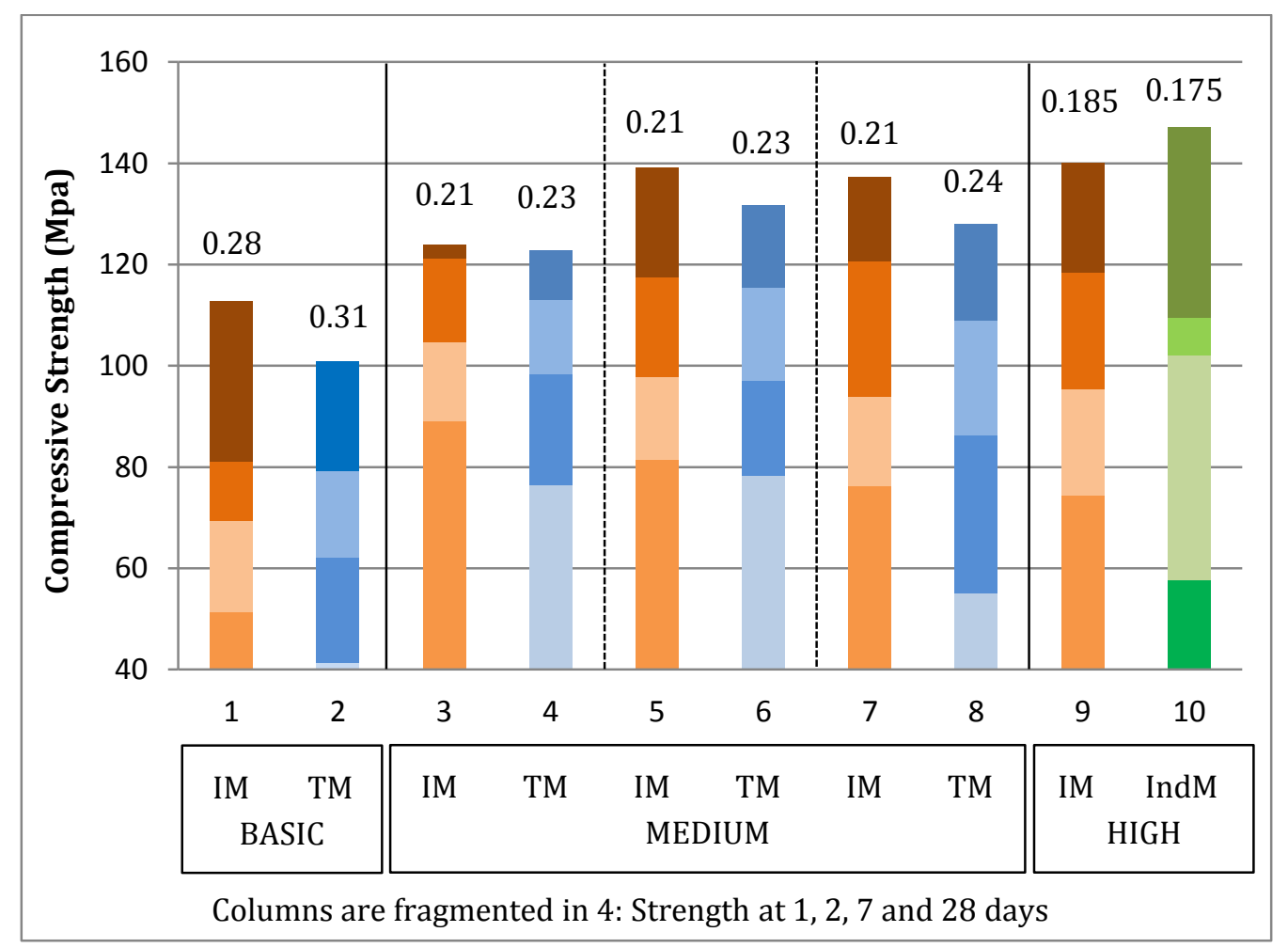

Figure 4.55: Compressive strength evolution of the mixtures developed

Respect to the industrial mixer, the mixing efficiency was adequate, being able to cast a dosage in 17 minutes with a W/B ratio comparable to the used for the intensive mixer. This fits with the ratio mixing power/volume cast, since it was in the same magnitude order for both mixer types. The transition from dry to plastic and from plastic to fluid happened fast, but longer mixing time was necessary due to the manual process of the fibers addition.

For the dosage cast in the precast company (number 10), the compressive strength values at 1, 2 and 7 days were smaller than expected because until the seventh day the storage was done at the precast company, where the average temperature was 12 degrees. 


\subsubsection{CONCLUSSIONS OF THE MIXER EFFECT}

It can be concluded after the study that UHPFRC can be cast successfully in mixer types with very different power, but is necessary take in account that mixing time might increase noticeably. The dosage should be readjusted for low energy mixers, increasing slightly the W/B ratio to mix in a reasonable time.

An intensive mixers allows an efficient dispersion of the CSF. However, a conventional industrial mixer should not be discarded for UHPFRC mixing, as the power can be enough to reach the desired properties. This opens the way to the cast of UHPFRC at ordinary prefabrication companies. Cast the maximum pan volume in this mixer type was not checked, being a point to study in future research.

\subsection{STATISTICAL ANALYSIS OF THE INFLUENCE OF THE PARAMETERS}

In this subchapter are proposed a wide group of dosages, of which many have been used in previous parts of Chapter 4. The objective is to determine with a statistical study the significance of the variables modified, which are those changed singly in the last steps. This may confirm, with statistical rigor, the results and conclusions obtained before.

The dependent variables are the compressive strengths at different ages, the flexural strength and the energy up to a deflection of $3 \mathrm{~mm}$ in the three point bending test. A univariate ANOVA was performed for each one of these dependent variables.

\subsubsection{EXPERIMENTAL PROGRAM}

A group of 37 different dosages (a total of 44 batches) is proposed. The variables modified have been:

- The cement per cubic meter of mortar $\left(700,850\right.$ and $1000 \mathrm{~kg} / \mathrm{m}^{3}$ defined as basic, medium and high performance dosages), as in 4.4 .

- Sulphate Resistant Cements 42.5 and 52.5 were used, and the PCE chosen for each cement was the most compatible according with previous tests. Both cement and PCE type are considered together in the same variable.

- The active addition content is $10 \%$ for those with 700 and $850 \mathrm{~kg} / \mathrm{m}^{3}$, and $15 \%$ for the dosage with $1000 \mathrm{~kg} / \mathrm{m}^{3}$. Active additions used are Ferroatlántica CSF and FC3R, as in 4.5.

- Crushed limestone coarse aggregate. Some dosages contain $600 \mathrm{~kg}$ per cubic meter of concrete, and some others don't, as in 4.6. In the dosages with coarse aggregate the cement content will became smaller per cubic meter of concrete. Then, the binder content ranges between $575 \mathrm{~kg} / \mathrm{m}^{3}$ for basic dosages with coarse aggregate, and the double value $(1150$ $\mathrm{kg} / \mathrm{m}^{3}$ ) for the high dosages without coarse aggregates.

- Three fiber types were used. At all mixtures short straight fiber Dramix® OL 13/0.16 was added. In monofiber concretes, the content over volume was $2 \%\left(156 \mathrm{~kg} / \mathrm{m}^{3}\right)$. Hybrid concretes contained $1 \%$ of this type, and the other $1 \%$ was high strength fiber Dramix ${ }^{\circledR}$ 
RC-80/40-BP (tensile strength of at least $2000 \mathrm{MPa}$ ) or $1 \%$ of normal strength fiber Dramix® RC-65/35-BN (tensile strength of at least $1200 \mathrm{MPa}$ ).

- The mixers proposed are a 75 liters EIRICH Intensive Mixer and a 30 liters tilting mixer, as in 4.6.

The W/B ratio was not a factor considered, as it's a variable that mainly depends on other factors studied: Cement content, coarse aggregate content, mixer used, and active addition type mainly. The W/B ratio was adjusted for every dosage to produce a slump flow between 700 and $850 \mathrm{~mm}$, with an acceptable mixing time. On the table 4.17 are shown the 37 dosages used for the statistical study. The mechanical results obtained are the 1, 2, 7 and 28 days compressive strength, the 28 days flexural strength and, as a parameter to evaluate the ductility of the bending tests, the energy of the graphic flexural strength-deflection up to $3 \mathrm{~mm}$. The test process was described at subsection 3.7.3.

Table 4.17: Experimental program of the dosages submitted to statistical analysis

\begin{tabular}{|c|c|c|c|c|c|c|c|c|c|}
\hline \multirow{2}{*}{$\frac{\text { Mix }}{\text { № }}$} & \multicolumn{2}{|c|}{ Cement } & \multicolumn{2}{|c|}{ Active addition } & \multicolumn{2}{|c|}{ PCE } & \multirow{2}{*}{$\frac{\text { W/B }}{\text { Ratio }}$} & \multirow{2}{*}{$\frac{\text { Mixer }}{\text { Type }}$} & \multirow{2}{*}{$\frac{\text { Long fibers }}{\text { type }}$} \\
\hline & Type & $\mathrm{Kg} / \mathrm{m}^{3}$ & Type & \% o.c.w. & Type & \% o.c.w. & & & \\
\hline E-1 & 52.5 & \multirow{10}{*}{700} & FC3R & $10 \%$ & A & $3,0 \%$ & 0,27 & EI & $80 / 40$ \\
\hline E-2 & 52.5 & & CSF ferr. & $10 \%$ & A & $3,0 \%$ & 0,27 & EI & $80 / 40$ \\
\hline E-3 & 52.5 & & FC3R & $10 \%$ & $\mathrm{~A}$ & $3,0 \%$ & 0,27 & EI & $80 / 40$ \\
\hline E-4 & 42.5 & & CSF ferr. & $10 \%$ & A & $3,0 \%$ & 0,367 & EI & $65 / 35$ \\
\hline E-5 & 42.5 & & CSF ferr. & $10 \%$ & $\mathrm{C}$ & $3,0 \%$ & 0,3 & EI & $65 / 35$ \\
\hline E-6 & 42.5 & & CSF ferr. & $10 \%$ & $\mathrm{C}$ & $3,0 \%$ & 0,357 & EI & $65 / 35$ \\
\hline E-7 & 42.5 & & CSF ferr. & $10 \%$ & $\mathrm{C}$ & $4,0 \%$ & 0,31 & TM & $65 / 35$ \\
\hline E-8 & 42.5 & & CSF ferr. & $10 \%$ & $\mathrm{C}$ & $4,5 \%$ & 0,28 & EI & $65 / 35$ \\
\hline E-9 & 42.5 & & CSF ferr. & $10 \%$ & $\mathrm{C}$ & $4,5 \%$ & 0,327 & EI & $65 / 35$ \\
\hline E-10 & 42.5 & & FC3R & $10 \%$ & $\mathrm{C}$ & $4,5 \%$ & 0,31 & $\mathrm{TM}$ & $80 / 40$ \\
\hline $\mathrm{E}-11(\mathrm{x} 2)$ & 52.5 & \multirow{12}{*}{850} & FC3R & $10 \%$ & A & $3,0 \%$ & 0,23 & TM & $80 / 40$ \\
\hline $\mathrm{E}-12(\mathrm{x} 2)$ & 52.5 & & CSF ferr. & $10 \%$ & A & $3,0 \%$ & 0,23 & $\mathrm{TM}$ & $80 / 40$ \\
\hline E-13 & 52.5 & & CSF ferr. & $10 \%$ & A & $3,0 \%$ & 0,25 & $\mathrm{TM}$ & $80 / 40$ \\
\hline E-14 & 52.5 & & FC3R & $10 \%$ & A & $3,0 \%$ & 0,21 & EI & $80 / 40$ \\
\hline E-15 & 52.5 & & FC3R & $10 \%$ & A & $3,0 \%$ & 0,25 & TM & $80 / 40$ \\
\hline E-16 & 52.5 & & CSF ferr. & $10 \%$ & A & $3,0 \%$ & 0,21 & EI & $80 / 40$ \\
\hline E-17 & 42.5 & & CSF ferr. & $10 \%$ & B & $3,0 \%$ & 0,259 & EI & $80 / 40$ \\
\hline E-18 & 42.5 & & CSF ferr. & $10 \%$ & $\mathrm{C}$ & $4,5 \%$ & 0,22 & EI & $80 / 40$ \\
\hline E-19 & 42.5 & & FC3R & $10 \%$ & $\mathrm{C}$ & $4,5 \%$ & 0,21 & EI & $80 / 40$ \\
\hline E-20 & 42.5 & & CSF ferr. & $10 \%$ & $\mathrm{C}$ & $4,5 \%$ & 0,259 & EI & $80 / 40$ \\
\hline E-21 & 42.5 & & FC3R & $10 \%$ & $\mathrm{C}$ & $4,5 \%$ & 0,24 & $\mathrm{TM}$ & $80 / 40$ \\
\hline E-22 & 42.5 & & FC3R & $10 \%$ & $\mathrm{C}$ & $4,5 \%$ & 0,269 & TM & $80 / 40$ \\
\hline E-23 & 52.5 & \multirow{6}{*}{1000} & FC3R & $15 \%$ & A & $3,0 \%$ & 0,2 & EI & $80 / 40$ \\
\hline E-24 & 42.5 & & CSF ferr. & $15 \%$ & B & $3,5 \%$ & 0,21 & EI & $80 / 40$ \\
\hline E-25 & 42.5 & & FC3R & $15 \%$ & B & $3,5 \%$ & 0,2 & EI & $80 / 40$ \\
\hline E-26 & 42.5 & & CSF ferr. & $15 \%$ & $\mathrm{C}$ & $4,5 \%$ & 0,21 & EI & $2 \%$ short \\
\hline E-27 & 42.5 & & FC3R & $15 \%$ & $\mathrm{C}$ & $4,5 \%$ & 0,19 & EI & $2 \%$ short \\
\hline E-28 & 42.5 & & CSF ferr. & $15 \%$ & $\mathrm{C}$ & $4,5 \%$ & 0,195 & EI & $2 \%$ short \\
\hline
\end{tabular}




\begin{tabular}{|ccccccccc|} 
E-29 & 42.5 & FC3R & $15 \%$ & C & $4,5 \%$ & 0,19 & EI & $2 \%$ short \\
E-30 & 42.5 & CSF ferr. & $15 \%$ & C & $4,5 \%$ & 0,195 & EI & $80 / 40$ \\
E-31 & 42.5 & FC3R & $15 \%$ & C & $4,5 \%$ & 0,19 & EI & $80 / 40$ \\
E-32 & 42.5 & FC3R & $15 \%$ & C & $4,5 \%$ & 0,221 & EI & $2 \%$ short \\
E-33 & 42.5 & FC3R & $15 \%$ & C & $4,5 \%$ & 0,221 & EI & $2 \%$ short \\
E-34 & 42.5 & FC3R & $15 \%$ & C & $4,5 \%$ & 0,18 & EI & $80 / 40$ \\
E-35 (x5) & 42.5 & FC3R & $15 \%$ & C & $4,5 \%$ & 0,185 & EI & $80 / 40$ \\
E-36 & 42.5 & FC3R & $15 \%$ & B & $3,0 \%$ & 0,175 & EI & $80 / 40$ \\
E-37 (x2) & 42.5 & FC3R & $15 \%$ & B & $3,0 \%$ & 0,18 & EI & $80 / 40$ \\
\hline
\end{tabular}

The statistical process used to analyze the possible influence of the factors is the univariate ANOVA (Analysis of Variance). Each one of the six mechanical results obtained from compressive and bending tests were the dependent variables considered for the univariate ANOVAs. Even though the experimental program doesn't correspond to a balanced design, this might be a useful tool to support the ideas previously carried on.

The factors considered for each ANOVA are shown in the table 4.18. For each dependent variable analyzed two ANOVAs were performed. The possible hypothesis proposed were:

- The null hypothesis, $\mathrm{H}_{0}$, is that certain factor doesn't affect to the mechanical property analyzed with the ANOVA.

- The alternative hypothesis, $\mathrm{H}_{1}$, is that certain factor affects the mechanical property analyzed.

The analysis was performed in two stages: The first ANOVA analysis was performed to evaluate initially which variables are significant, considering a significance level of 0.1 of refuse the null hypothesis when it is the right one. Only the factors that showed significant $p<0.1$ were considered as factors for the second ANOVA, and the others, as no-significant, were included in the residue. Finally the factors with a p-value similar or smaller than 0.05 were considered significant, accepting the alternative hypothesis.

The effect of the cement type and PCE admixture was considered together in the same factor (C), as the cement type 52.5 was used always with PCE A, and the 42.5 with PCE B and PCE C.

The first univariate ANOVA was performed including as simple effects the main independent variables that affect to the compressive strength (cement content, active addition type, type of cement/PCE admixture, mixer used and coarse aggregate) and the interaction between the active addition type and the cement/PCE type. The interaction was considered as there are some evidences that the compatibility between cement type, active addition type and PCE is of great importance for the performance of the concrete. Table 4.18 schematizes the ANOVAs performed for each dependent variable and the factors considered.

Monofiber concretes were cast only with high performance dosages $\left(1000 \mathrm{~kg} / \mathrm{m}^{3}\right.$ of cement and long fibers 80/40), so the ANOVA made to study the effect of fiber combination on flexural performance was done just for high performance mixtures. Then at table 4.19 the p-value results of cement content and long fiber type are marked as " $\mathrm{Ct}$ " (Constant). For the same reason only hybrid concretes were considered for the analysis of the cement content and fiber 
type on the flexural strength, because the modified fiber was the long. Then in the table 4.19 the fiber combination is marked as " $\mathrm{Ct}$ " (Constant) for the flexural strength results.

Table 4.18: Scheme of the ANOVAs performed

\begin{tabular}{|c|c|c|c|}
\hline Test & Dependent Variable & 10 ANOVA & 2o ANOVA \\
\hline \multirow{4}{*}{$\begin{array}{l}\text { Compressive } \\
\text { strength }\end{array}$} & 1 day & \multirow{4}{*}{$\begin{array}{c}\text { Cement content (A) } \\
\text { Active addition type (B) } \\
\text { Cement type/PCE (C) } \\
\text { Coarse aggregate (D) } \\
\text { Mixer type (E) } \\
\text { Interaction: (B) x (C) }\end{array}$} & $(A),(C),(D),(E)$ \\
\hline & 2 days & & $(\mathrm{A}),(\mathrm{B}),(\mathrm{C}),(\mathrm{D}),(\mathrm{E}),(\mathrm{B}) \times(\mathrm{C})$ \\
\hline & 7 days & & $(A),(B),(C),(E),(B) \times(C)$ \\
\hline & 28 days & & $(A),(B),(E),(B) \times(C)$ \\
\hline \multirow{2}{*}{$\begin{array}{l}\text { Flexural } \\
\text { strength }\end{array}$} & Max. value & \multirow{2}{*}{$\begin{array}{c}\text { Cement content }(\mathrm{A}) \\
\text { Active addition type }(\mathrm{B}) \\
\text { Coarse aggregate }(\mathrm{D}) \\
\text { Fiber type }(\mathrm{F}) \\
\text { Fiber combination (G) }\end{array}$} & $(A),(F),(G)$ \\
\hline & Energy $3 \mathrm{~mm}$ & & $(A),(F),(G)$ \\
\hline
\end{tabular}

\subsubsection{RESULTS}

Table 4.19 shows the p-values of the second six ANOVAs developed for the dependent variables. In red bold are shown the variables with p-value smaller than 0.05 . The change of the $p$-value shows the increasing or decreasing influence of each factor over the compressive strength with the age evolution. The first ANOVA showed the no influence of the long fiber type and the fiber combination (cocktail or monofiber) in the compressive strength, so they were not considered as factors for the second ANOVAs.

Table 4.19: P-Value of each variable for the different ANOVAs performed

\begin{tabular}{|c|c|c|c|c|c|c|}
\cline { 2 - 7 } \multicolumn{1}{c|}{} & \multicolumn{5}{c|}{ Significance Level of each dependent variable } \\
\hline Factors & \multicolumn{4}{c|}{ Compressive strength } & \multicolumn{2}{c|}{ Flexural strength } \\
\hline & 1 day & 2 days & 7 days & 28 days & fct,fl & E. $\delta=3$ mm \\
\hline Cement (A) & $\mathbf{0 . 0 0 0}$ & $\mathbf{0 . 0 0 0}$ & $\mathbf{0 . 0 0 0}$ & $\mathbf{0 . 0 0 0}$ & Ct-0.004 & Ct-0.097 \\
\hline Active Addition (B) & 0.231 & $\mathbf{0 . 0 0 0}$ & $\mathbf{0 . 0 0 0}$ & $\mathbf{0 . 0 0 2}$ & - & - \\
\hline Cement type/PCE (C) & $\mathbf{0 . 0 0 0}$ & $\mathbf{0 . 0 0 0}$ & $\mathbf{0 . 0 4 1}$ & 0.086 & - & - \\
\hline Coarse aggregate (D) & $\mathbf{0 . 0 0 0}$ & $\mathbf{0 . 0 4 5}$ & 0.275 & 0.364 & - & - \\
\hline Active ad. x Cem.type/PCE (B) x (C) & 0.756 & $\mathbf{0 . 0 4 9}$ & $\mathbf{0 . 0 0 0}$ & $\mathbf{0 . 0 0 0}$ & - & - \\
\hline Mixer type (E) & $\mathbf{0 . 0 0 0}$ & $\mathbf{0 . 0 4 7}$ & $\mathbf{0 . 0 0 9}$ & $\mathbf{0 . 0 0 3}$ & - & - \\
\hline Long fiber type (F) & - & - & - & - & Ct-0.014 & Ct-0.005 \\
\hline Fiber combination (G) & - & - & - & - & $\mathbf{0 . 0 0 5}-\mathrm{Ct}$ & $\mathbf{0 . 0 0 3 - C t}$ \\
\hline
\end{tabular}

Cement content per cubic meter of mortar was clearly significant to all the compressive and flexural parameters measured, as is evident considering that the increase of this value let reduce the W/B ratio. Active addition type was not significant at 24 hours, since they require 
longer times to react. At 2 and 7 days the active addition type become relevant since FC3R has higher short term reactivity than the CSF. At 28 days the difference is still significant, but slightly smaller because the CSF develops its pozzolanic properties at longer ages. The difference is supposed to be less and less remarkable with the time. This confirm the results of the study made at 4.5 .

The factor cement type/PCE is significant at short term ( 1 and 2 days), but the p-value increases to not to be significant at 28 days. This is explained because the main difference between admixtures is mainly the capacity to provide short term compressive strength. To observe this effect, in the figure 4.56 is shown for all the mixtures the ratio compressive strength at 1, 2 and 7 days over the 28 days compressive strength. It is appreciated the marked different short term evolution of the mixtures with different PCEs. Cement $52.5 \mathrm{R} / \mathrm{SR}$ with the PCE admixture BASF SKY® 575 produces high early strength, providing at $48 \mathrm{~h}$ an average of $75 \%$ of the 28 days compressive strength. On the other hand, the slower reaction happends with the cement $42.5 \mathrm{R} / \mathrm{SR}$ with the PCE SIKA Viscocrete ${ }^{\circledR} 20 \mathrm{HE}$, providing over $60 \%$ of the 28 days compressive strength after $48 \mathrm{~h}$. If, according with the application, the long $24 \mathrm{~h}$. strength is acceptable, then the slow progression of the strength is more interesting, since the heat of hydration is less concentrated and the matrix structure might be better ordered.

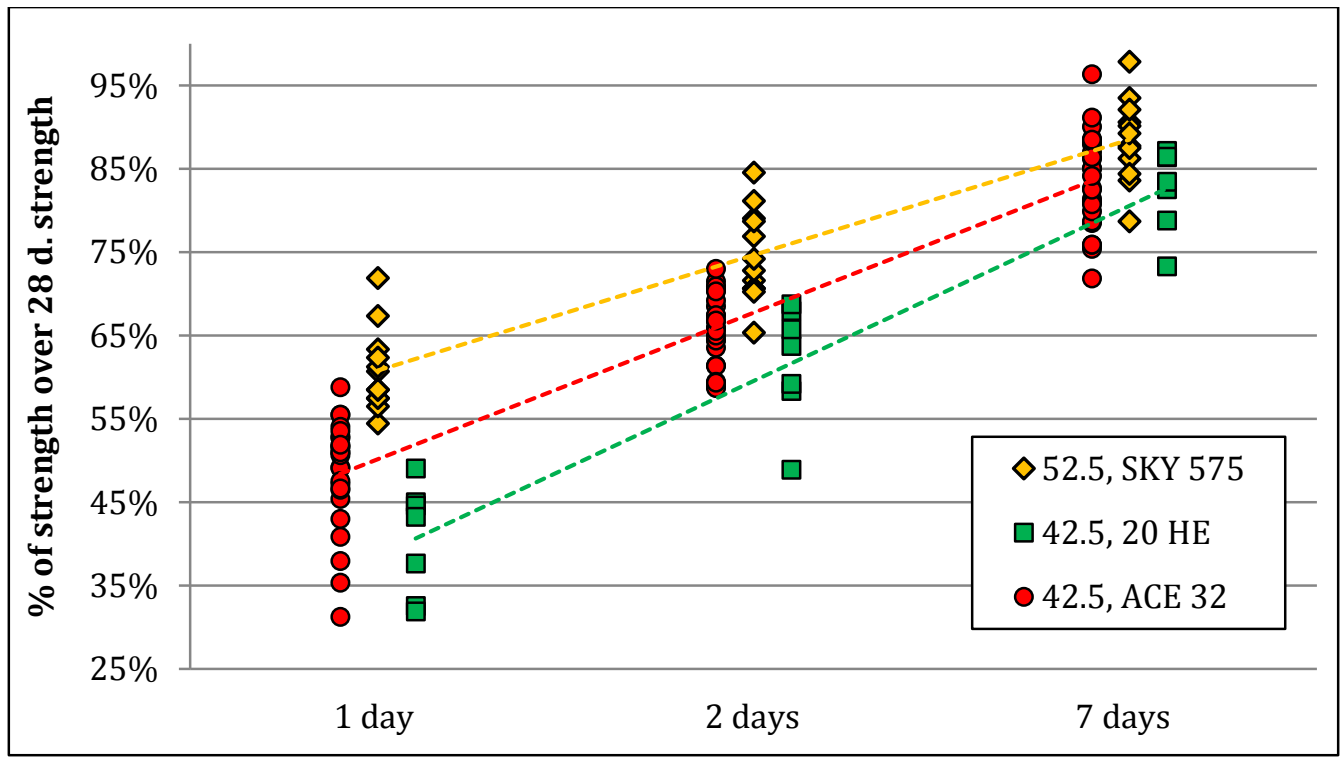

Figure 4.56: Percentage of the strength at 1, 2 and 7 days respect to the 28 days

Interaction between the active addition and the cement type/PCE become significant from the second day, since then the cement is markedly hydrated and the active additions react. From this age the interacting appears as significant. Cement $42.5 \mathrm{R} / \mathrm{SR}$ is more compatible with FC3R and PCE type A (BASF GLENIUM $®$ ACE 32) or B (SIKA Viscocrete ${ }^{\circledR} 20 \mathrm{HE}$ ), while cement $52.5 \mathrm{R} / \mathrm{SR}$ combines better with CSF and PCE type C (BASF SKY® 575). This supports the results obtained at 4.5 .

Coarse aggregate is not a significant factor for 7 and 28 days compressive strength, but it is at short term ( 1 and 2 days), providing smaller value. This results explain the phenomenon commented already at 4.6. The Interfacial Transition Zone paste-coarse aggregate is weak at short ages, improving as soon as active additions develop the reactions. This confirms the possibility of add considerable contents of limestone coarse aggregate to a dosage and obtain similar compressive strength at medium-long term than with fine aggregate mixtures. 
The mixer type, as is expected from the deductions made at 4.8, is a significant factor to the compressive strength results at all ages. The reason is the higher $\mathrm{W} / \mathrm{B}$ ratio necessary to cast the concrete in the low energy tilting mixer.

It was proven that the normal strength fibers affected both to the maximum flexural strength as to the energy movilized up to $3 \mathrm{~mm}$ of deflection. Besides, monofiber UHPFRC reached smaller flexural strengths than hybrid concretes, as was expected from previous researches [37][40] and results from other authors [148]. The active addition type was not a significant factor affecting the flexural strength, showing that the adhesion of the fiber to the matrix doesn't change significantly with the addition type. Coarse aggregate was not significant neither as was deduced at 4.6, discarding that coarse aggregate geometry affected markedly to the fiber orientation.

\subsection{GENERAL RECOMMENDATIONS FOR VHPFRC- UHPFRC: DOSAGE, MIXING AND POURING}

UHPFRC is the result of a dosage design, a mixing process, a pouring method and a type of curing. Those processes that provide the optimum properties are different depending on the components and available tools, which differ greatly conditioned by the provider and the country.

In this Ph.D. more than one hundred dosages from different authors were analyzed together at Chapter 2. This provided a comprehension of how authors from all over the world design and work with VHPFRC-UHPFRC. Later, more than 80 different dosages with several components and proportions were cast by the author of this Ph.D., accumulating considerable personal experiences. As a result of both processes, here some recommendations and keypoints related with the dosage design, mixing and casting process are provided. The goal is that any operator who wants to use this material finds in these general recommendations a practical tool to have success.

\subsubsection{DOSAGE COMPONENTS}

Some tips related to the dosage components are described as follows:

1. Previous tests: Perform a compatibility test with different cements, silica fume and admixtures is of great importance. The PCE admixtures should come from different chemical companies and the cement be Sulfate Resistant if possible. After, with them has to be organized a scheme of dosages combining the components to cast a small volume of UHPC-UHPFRC, where fibers are not necessary and coarse aggregate should not be used. As the volume is reduced, a mortar mixer is recommended. The dosages should have a constant sand volume fraction. A mini-slump flow and prisms 40 x 40 x $160 \mathrm{~mm}$ can be an easy way to perform these tests. A mixture can be considered compatible if provides a mini-slump flow between 25 and $30 \mathrm{~cm}$, acceptable opened time (at least 45 minutes before a strong workability decrease) and a 24 hours compressive strength higher than $30 \%$ of the 28 days compressive strength. It is important to highlight that the combination of products from the same company or the use of high-quality components does not ensure the best compatibility. 
2. UHPFRC precast elements that have to be extracted at early age require a PCE admixture that provide high early age compressive/tensile strength. In the other cases, is better resort to those that develop the strength slower, since the long term strength evolution is generally higher.

3. The proportions of the components of the paste should be a compromise solution between cost and performance, depending on the objectives. Normally the designer can start with the most typical proportions: Cement:SF:QF=1:0.25:0.25. The compressive results and water demand of other proportions will recommend the optimum. The ratio W/B chosen will also depend on the materials, but normally the adequate is the one that induces plasticity in the mixture after 3-5 minutes of the water addition in an ordinary mortar mixer. A typical W/B ratio to start is 0.18 .

4. For the dosage the cement fineness may be more important than its nominal strength, as it conditions the workability. The same happens with the additions, so they should be chosen according with the capacity of the mixer to perform an effective dispersion. Consider the use of fly ash as a secondary pozzolan might improve many properties and reduce the costs. The size and spherical morphology of the particles can imply lower particle friction and also an increase of the packing density. Slightly lower early age strengths can be suffered, but at long term are comparable with the dosages with cement instead of fly ash. Before choose the FA is important to check if it will be possible guarantee a continuous supply of this component.

5. Once the most adequate components combination is found at the compatibility tests, it is necessary to develop the mixture, with fibers, and the mixer that will be used for cast the final product. The changes in the dosage, different mixing energy, volume cast or environmental conditions will modify the rheology and affect to the hardened properties. The necessary readjustments will be identified at this step.

6. The components size should be chosen according with the structural application and pouring limitations. If the elements that will be cast are thin or with high density of conventional steel reinforcement, coarse aggregate has to be avoided. In very thin elements with difficult pouring process also long fibers can't be used since they can block the flow advance. Table 4.20 abstract other applications with examples and suggestion of dosage.

Table 4.20: Fiber and aggregate type reccomended for several applications

\begin{tabular}{|c|c|c|}
\hline Application & Fiber types & Aggregate \\
\hline $\begin{array}{c}\text { Thin applications with few steel reinforcement } \\
\text { (Thin shells, elements for façades, etc.) }\end{array}$ & Hybrid & Fine $(<2 \mathrm{~mm})$ \\
\hline $\begin{array}{c}\text { Applications submitted mainly to tensile strength } \\
\text { (ties without prestressing steel) }\end{array}$ & Hybrid & Fine $(<2 \mathrm{~mm})$ \\
\hline $\begin{array}{c}\text { Applications with pouring difficulties or high density of steel bars } \\
\text { (prestressed pipes) }\end{array}$ & Short fibers & Fine $(<2 \mathrm{~mm})$ \\
\hline UHPFRC layer submitted to high abrasion (dam spillways) & Short fibers & Coarse $(2-5 \mathrm{~mm})$ \\
\hline Elements in to flexo-compressive strength* (pier columns) & Short fibers & Coarse $(2-5 \mathrm{~mm})$ \\
\hline $\begin{array}{c}\text { Thick high prestressed elements* } \\
\text { (precast beams for bridges) }\end{array}$ & Short fibers & Coarse $(2-5 \mathrm{~mm})$ \\
\hline *: Ductility at high deformation ranges is guaranteed combining UHPFRC with ordinary steel \\
\hline
\end{tabular}


7. It is important to find the sand combination that decreases the water demand as much as possible without segregation. Adopt the A\&A compacity model, which consider all the solid particles, provide good results, especially for reduced PVF. With high PVF it is better to take the experimental way proposed here and called Ternary Packing Diagram, which identify the sand combination that provides the higher packing density. An increase of the fine fraction increases the viscosity and the stability of the mixture but also the water demand.

8. Related to the dosage proportions, it is recommended define first the maximum aggregate diameter, the fiber type and the fiber content, as they all depend completely on the application. The last is conditioned by the $D_{\max }$, as it should be smaller than the average fiber spacing, which can be calculated simply by the Krenchel formula (see 2.3.3.8). Besides, the experience from many authors dosages recommend increase the paste volume fraction when $\mathrm{D}_{\max }$ is reduced. From the database analysis done at Chapter 2 the following linear relation was deduced at this Ph.D. (see 2.3.3.5):

$$
P V F=-0,0177 \cdot D_{\max }+0,6331
$$

The PVF should be the resulting from this formulation or higher in order to get selfcompactability. Generally a UHPFRC with adequate rheological properties has a PVF ranging between $55 \%$ and $65 \%$ without coarse aggregates and between $40 \%$ and $45 \%$ with coarse aggregates. To increase the PVF, the water or the fines content has to be increased.

\subsubsection{DOSAGE RHEOLOGY}

The water added is, with the admixture, the main parameter that modifies the flowability. An increase in the water content provides higher slump flow, but might also produce the segregation due to the sinking of the denser particles.

At section 4.4 was obtained a formulation to predict the maximum slump flow acceptable without sinking. Here these formulas are transformed in a simpler diagram (figure 4.57), which could be an easier way for UHPFRC designers to know, introducing the steel fiber diameter and the maximum aggregate diameter, the maximum slump flow they can accept for their material (the most limiting of both is the so-called here Critical slump flow). As the curve used for the aggregate depends on its density, several curves are plotted. The paste density assumed is 24 $\mathrm{kN} / \mathrm{m}^{3}$.

As can be seen, to avoid the segregation much more flowable UHPFRC can be accepted for hybrid or short fiber concrete than for long fiber or coarse aggregate concrete. This has to be considered by the designer as some important restriction to cast concretes these type of concretes, and might explain in part why many of the commercial UHPFRC dosages around the world use short fibers and avoid coarse aggregates.

It has to be considered that is possible have a very high initial slump flow with high viscosity (the particles would settle very slowly), with a fast yield stress increase that can stop this process in few minutes. This situation might happen with those PCE with reduced workability time, or also with FC3R (see 3.2), which reacts faster than CSF. 


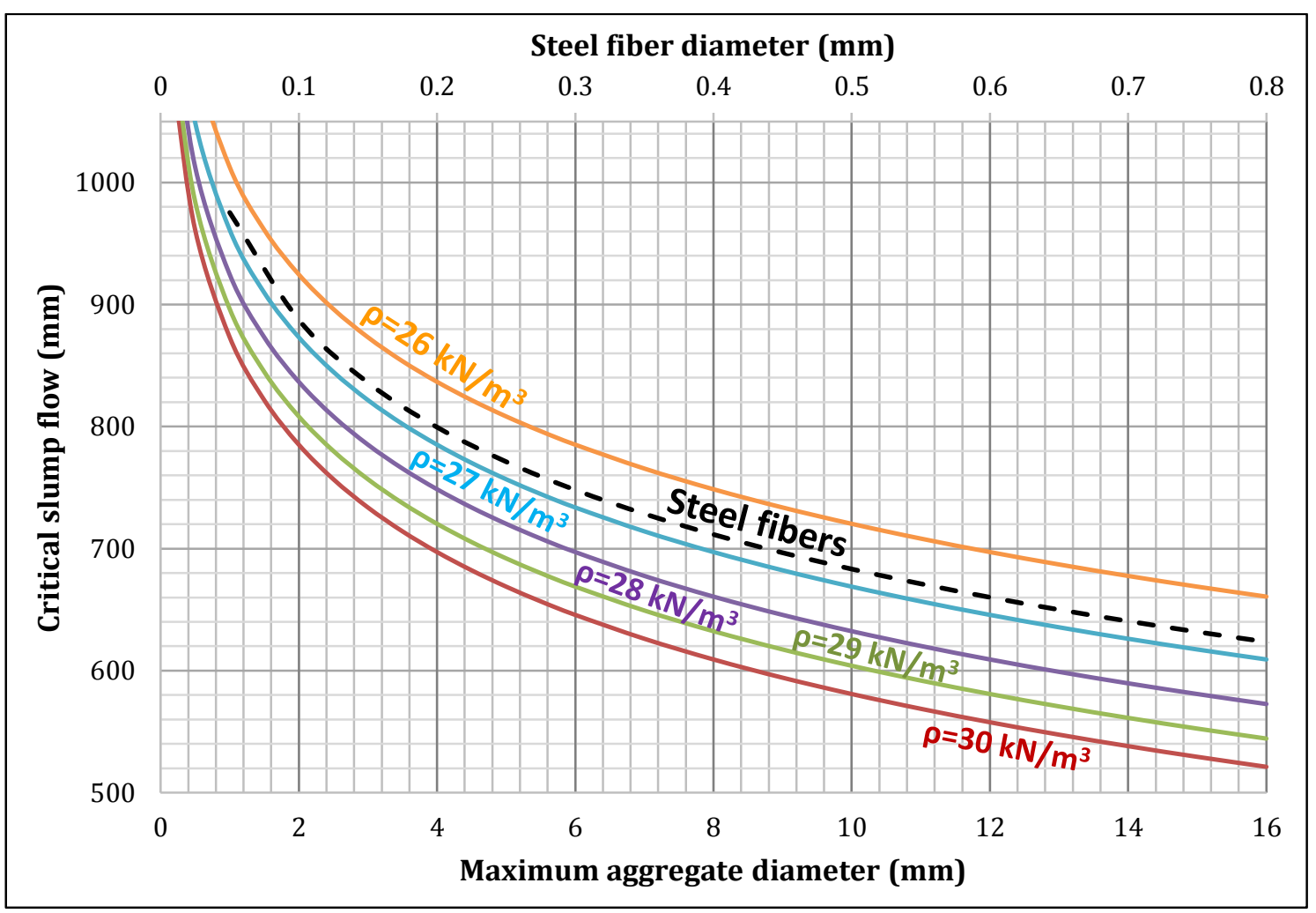

Figure 4.57: Diagram of the maximum slump flow acceptable in a UHPFRC dosage depending on the fiber and aggregate sizes that will be used

\subsubsection{MIXING PROCESS}

Recommendations about the mixing process are abstracted in the following points:

1. Short fiber addition at the end of the mixing process can be slow and tricky. If it is added all at once in large amounts the risk of fiber balls formation is high. Introduce the short fibers with the dry components at the beginning normally avoid these problems. High rotor speed separates the fibers adequately. While the short fiber content is smaller than $2 \%$, the mixing process does not differ greatly compared with the mixing without fibers.

2. The addition of short fibers in industrial mixers can be problematic, as the addition all at once increases dramatically the risk of fiber balls. One solution is a little by little addition, but it can imply the use of too much manpower and a high increase of the mixing time. Other solution is install a vibration system that separates fast the fibers in the addition. Finally, another option is increase slightly the diameter of the fiber used. At this Ph.D. was seen that fibers $13 / 0.16$ create more balls than fibers $13 / 20$. Of course, this can have an effect in the tensile performance.

3. The intensive mixing is very aggressive, smashing specially the weakest particles. Then, in the case of use limestone coarse aggregate in the dosage, late addition is recommendable, since the knocks of the rotor destroy progressively the particles, increasing the fine content and then reducing the workability. For the same reason after the coarse aggregate addition slow rotor speed is recommended.

4. As was mentioned by other researchers (see 2.4.2), the addition of PCE admixture in two parts is more efficient than a single addition. This is because after the water is added the 
first germs of primary ettringite are formed. PCE might become covered by these composes. If all PCE is added immediately after the water, a lot of its particles became entrapped and lose their efficiency. If the entire admixture is added late, the material remains dry for longer time. Then the optimum solution is the two steps addition [247].

5. The workability of the UHPFRC increases along all the process up to the stabilization time is reached. This is the situation when the power consumption of the mixer has become constant, and it is the most recommended moment to finish the mixing process.

6. Each mixer has an optimum volume, for which the power provides the best benefit to the mixed mass. Cast the optimum volume of concrete provides higher workability with the same components, so it is useful proceed this way when possible.

Table 4.21 abstract several of the ways already mentioned to increase the workability of a mixture keeping constant the $\mathrm{W} / \mathrm{B}$ ratio and the cement content. These are also ways to decrease the $\mathrm{W} / \mathrm{B}$ ratio maintaining the workability. These options are interesting to maximize the material performance with fixed cement content.

Table 4.21: Measures to increase the workability of an UHPFRC

\begin{tabular}{|c|}
\hline Compatibility between cement, active addition and PCE admixture \\
\hline Substitute cement for fly ash \\
\hline Combine the sands to reach high packing density \\
\hline Add the PCE in two steps \\
\hline Stop the mixing process when the stabilization time is reached \\
\hline Cast the optimum volume of the mixer \\
\hline In the case of Coarse Aggregate Content, late addition of the material \\
\hline
\end{tabular}

\subsubsection{POURING OF THE CONCRETE}

The pouring of the concrete is important especially when the fibers will play an important role in the performance of the application. From the experience acquired the following tips can be deduced:

1. The slump flow test is necessary to evaluate the workability. The most recommended value is between 720 and $780 \mathrm{~mm}$, providing high flowability without segregation. The latter is not happening if in the perimeter of the slump short and long fibers are appreciated homogeneously concentrated.

2. If the concrete is poured from a high between 50 and $100 \mathrm{~cm}$, the concrete trickle should not separate into several parts. If the mass elongates but not divides the concrete proves high stability, high surface contact and no segregation.

3. Even though UHPFRC is selfcompacting, the pouring of the material should be done moving the container or hose along the desired direction for the fibers alignment. The effect is similar than add a layer immediately over preceding one (figure 4.58). This method provides a $\mathrm{K}$ factor near to 1 , being higher than set the hose in a place and let the flow advance.

4. The concrete should be poured on the existing fresh concrete, not dividing the volume in two different masses. If two advancing material tongues join is possible that a cold joint is formed, with the absence of fibers along a section. 
5. The ordinary reinforcement in the formwork disturbs considerably the fiber orientation, so its presence should not be neglected.

6. After pour the concrete in a container, some visual checking can be done to evaluate the suitability of the mixture done:

- In the top of the volume a continuous ascent of air bubbles must be observed along some minutes. This is a sign that the workability is adequate, as no vibration is required to remove the entrapped air.

- After pour the container content in the desired element, short and long fibers have to be searched in the bottom of the empty container. If a high content is found is because workability is too high and fiber segregation is taking place. An adequate UHPFRC never creates a fiber layer in the bottom of the recipient. In the case of use coarse aggregate, the absence of it in the bottom has also to be checked.

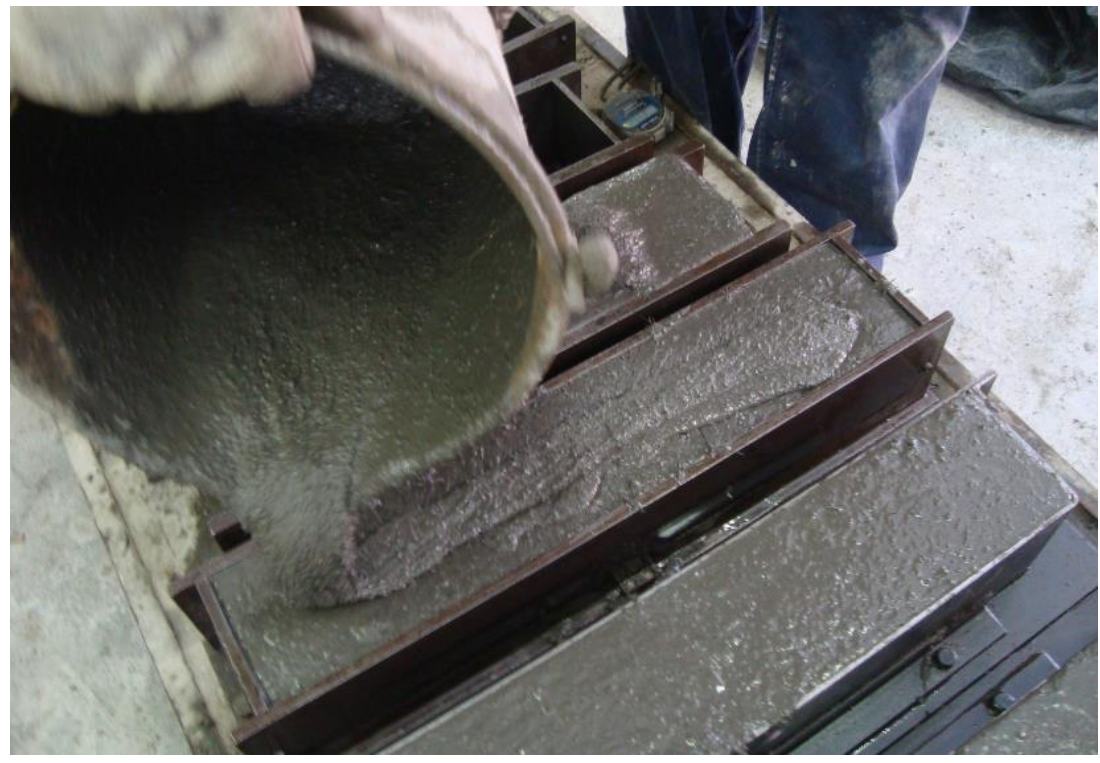

Figure 4.58: Pouring of UHPFRC (Q3-HY) to fill $100 \times 100 \times 500 \mathrm{~mm}$ prisms

\subsection{IMPLEMENTATION OF THE PREVIOUS CONCEPTS: DOSAGES ADAPTED FOR DIFFERENT REQUIREMENTS}

\subsubsection{OBJECTIVES}

The purpose of this subchapter is, according with the results and conclusions of the previous research, define and characterize five dosages with three different levels of performance, which will be suitable for applications with different requirements. It is important highlight that the suggested dosages are just adequate examples for specific applications.

Surely with different components, equipment and structural requirements, another proposition would fit better. For instance, if the available mixer has low mixing energy, the addition has to be already dispersed and the $\mathrm{W} / \mathrm{B}$ ratio required is higher. If the element to be precast is a washbasin, the fibers used have to be synthetic, affecting this also to the aggregate size. 


\subsubsection{DEFINITION OF THE DOSAGES}

The five dosages characterized here are showing different properties because of the change in the components. The suitability of each one depend on the structural requirements. Four of the proposed mixtures are hybrid and without coarse aggregates. These should be used for those elements where the UHPFRC has to provide a remarkable part of the tensile strength or the ductility required. Also D-regions without ordinary reinforcement, where the performance of the long fibers avoid the macrocrack. The bolted connections suggested in the next chapter might be an example. Hybrid dosages are appropriated also for those elements where in Service Limit State the concrete is in tension, and the macro-crack opening has to be avoided. Normally these elements have not conventional reinforcement or have a low prestressing steel content, being the fibers the most responsible of providing the element's structural capacity.

On the other hand, monofiber dosages with coarse aggregates are suitable for thicker structures where the prestressing steel provide the greatest part of the tensile strength required. In these cases UHPFRC is used mainly to avoid the use of secondary reinforcement and for durability applications. Long fibers are not required as concrete is compressed along all the depth. Other situation where the short fiber UHPFRC should be used, but without coarse aggregate, is when at the element cannot be ensured an adequate pouring with long fibers UHPFRC. This happens especially at slender elements with ordinary reinforcement.

The designed dosages are described briefly as follows, being followed by five files that provide the main rheological and mechanical parameters. A single batch of 50 liters in the intensive mixer was required as all of them are very similar than the concretes developed along all the Chapter 4 . The $\mathrm{W} / \mathrm{B}$ ratios were those found as the most suitable before, as the combinations between cement and active additions and the 3\% of PCE admixture over binder weight used for all dosages.

Here the nomenclature proposed with letters and numbers for the dosages depended on their properties:

- Type of aggregate: $\mathrm{F}$ if it only contains fine aggregate, $\mathrm{Q}$ if it contains also quartz flour, and $\mathrm{C}$ if it contains also limestone coarse aggregate.

- Level of performance: The number increases with the performance; 1 for high compressive strength, 2 for very high, and 3 for ultra high compressive strength.

- Type of fibers: $\mathrm{M}$ in the case of a monofiber concrete (short fibers) and HY in the case of hybrid concrete. All concretes contain $2 \%$ of total fiber volume content.

Then, the mixtures characterized are:

F1-HY: Fine aggregate dosage, high performance and fiber cocktail. The dosage is proposed with normal strength long fibers to reduce the price, being useful for applications where the flexural performance required is between FRC and UHPFRC. It is useful also for applications where a high abrasion or corrosion resistant concrete is required. The short fibers used are Dramix ${ }^{\circledR} \mathrm{L}-13 / 0.16$, as for all the others.

F2-HY: Fine aggregate dosage, very high performance and fiber cocktail. It contains higher binder content than the F1-HY. High tensile strength fibers are used in order to reach higher flexural performance than for the F1-HY. It could be used in applications that require a very 
high flexural strength, abrasion or corrosion resistance is required. Also for applications where high flowability is required.

F3-HY: Fine aggregate dosage, ultra high performance and fiber cocktail. This dosage contains higher binder content to be able to reduce notably the $\mathrm{W} / \mathrm{B}$ ratio. The cement type used is $42.5 \mathrm{R} / \mathrm{SR}$ to distribute more the exothermic reaction along the time. Then the active addition used is FC3R, as was found the most compatible with this cement type. Low carbon CSF can be used instead without marked variations in the dosage. This material is would be suitable for any application where very high performance from the concrete is expected: Very slender elements, thin slabs, structures with high strains expected, or any element where the cost of the material doesn't mean a high percentage of the final budget.

Q3-HY: Fine aggregate dosage with quartz flour in the binder, ultra performance and fiber cocktail. This dosage is an option only in the case that an adequate quartz flour provider can be easily found, as is the case of eastern Spain. It has the advantage of reduce the cement content and increase the packing density of the materials. It is interesting also when a lighter color is searched for the concrete, as the quartz flour is white. A suitable fly ash could be an alternative to the use of the quartz flour in this mixture.

C3-M: Coarse limestone aggregate, ultra high performance and monofiber. This dosage proposes UHPFRC for applications where mainly compressive strength and durability are required. Also when the volume used is high, as the price is more reduced, or when high abrasion or corrosion resistance is required, as in those cases long fibers are not necessary. This dosage corresponds to similar paste than dosage F3-HY, but with coarse aggregates added and the water demanded by them.

Table 4.22 abstract the desired initial properties for each of the dosage performed.

Table 4.22: Expected rheological and mechanical properties of each mixture

\begin{tabular}{|cccc|}
\hline Mix & Slump flow & Compressive Strength & Flexural Strength \\
\hline Name & mm & MPa & Equivalent MPa \\
\hline F1-HY & $>600$ & $110-120$ & $16-22$ \\
F2-HY & $>700$ & $135-145$ & $22-28$ \\
Q3-HY & $>720$ & $>150$ & $>30$ \\
F3-HY & $>720$ & $>145$ & $25-30$ \\
C3-M & $>550$ & $>150$ & $>15$ \\
\hline
\end{tabular}

The rheological parameters ( $t_{500}$ and slump flow) were obtained according to 3.4 .2 , and the compressive and flexural strength tests according with 3.7.1 and 3.7.3 respectively. Also young modulus was obtained at 2,7 and 28 days following the process defined in 3.7.2. The tensile strength was deduced by inverse analysis, as defined in 3.8.1.

For each batch one slump flow was done, two cylindrical $150 \times 300 \mathrm{~mm}$ elements, 12 cubes of $100 \times 100 \times 100 \mathrm{~mm}$ and three prismatic $100 \times 100 \times 500 \mathrm{~mm}$ elements to perform the flexural tests, according with the specifications detailed in Chapter 3.

In the following files are presented the dosages and properties of the characterized composites. The prize indicated corresponds to the Spanish market in July of 2013. At the beginning a preliminary file is describing the meaning of each file cell. 


\begin{tabular}{|l|l|}
\hline \multicolumn{2}{|l|}{ Code of the concrete described } \\
\hline Concrete Family & Family to which concrete belongs \\
\hline Technological features & Short description of the rheological and mechanical parameters \\
\hline Price Spanish Market 2012 & Price of $1 \mathrm{~m}^{3}$ of material in Spain, at July 2013 \\
\hline
\end{tabular}

\begin{tabular}{|c|c|c|}
\hline \multicolumn{3}{|c|}{ Dosage } \\
\hline Components & Type & Content \\
\hline Cement & Resistant class, provider and content & \\
\hline Active addition & Type, provider and content & ontents in kg per cubic \\
\hline Sand 1; Sand 2 & Range of sizes and content & ercentages over \\
\hline PCE admixture & Provider, type of product and liquid content & welght (o.c.W.) or \\
\hline Total water & Type and content & entages over Dina \\
\hline Fiber 1; Fiber 2 & Provider, aspect ratios and content & \\
\hline
\end{tabular}

\begin{tabular}{|c|c|c|}
\hline \multicolumn{2}{|c|}{ Additional information } \\
W/B ratio & $\begin{array}{c}\text { Total water/Binder ratio (quartz flour } \\
\text { considered if used) }\end{array}$ & \multirow{3}{*}{$\begin{array}{c}\text { Gading curve of all the } \\
\text { concrete dry components }\end{array}$} \\
\hline$W / C$ ratio & Total water/cement ratio & \\
\hline$P V F$ & Paste Volume Fraction in percentage & \\
\hline$D_{10}$ & Size below which is the $10 \%$ of the particles & \\
\hline$D_{90}$ & Size below which is the $90 \%$ of the particles & \\
\hline Dry Density & Dry density obtained after 28 days & \\
\hline Vol. of fine particles & Volume of particles smaller than $0.063 \mathrm{~mm}$ & \\
\hline
\end{tabular}

\begin{tabular}{|c|c|c|}
\hline & \multicolumn{2}{|c|}{ Rheological properties } \\
\hline Properties & Norm & Value \\
\hline Mixing time- Workability time & $\begin{array}{c}\text { Mixing time required to reach the maximum flowability and } \\
\text { period of time before strong decrease of workability }\end{array}$ \\
\hline Slump flow-t500 & $\begin{array}{c}\text { Diameter of the slump after } 60 \text { seconds and time required from } \\
\text { the rising of the cone to reach } 500 \mathrm{~mm} \text { of slump flow }\end{array}$ \\
\hline
\end{tabular}

\begin{tabular}{|c|c|c|c|c|c|}
\hline \multicolumn{6}{|c|}{ Mechanical properties (Air curing, $2^{\circ}$ ) } \\
\hline Parameter & Element tested & Norm & Days & Value & S.Desv. (\%) \\
\hline $\begin{array}{l}\text { Compressive } \\
\text { Strength }\end{array}$ & Cube $L=100 \mathrm{~mm}$ & \multicolumn{4}{|c|}{$\begin{array}{c}\text { Compressive strength at } 1,2,7 \text { and } 28 \text { days for } 3 \text { cubes in } \\
\text { each case, and standard deviation obtained }\end{array}$} \\
\hline Young modulus & Cyl. $150 \times 300 \mathrm{~mm}$ & \multicolumn{4}{|c|}{ Young modulus of cylinders at 2,7 and 28 days } \\
\hline Flexural strength & \multirow{2}{*}{$\begin{array}{c}\text { Prism } \\
100 \times 100 \times 500 \mathrm{~mm}\end{array}$} & \multirow{2}{*}{\multicolumn{4}{|c|}{$\begin{array}{l}\text { Maximum flexural equivalent strength reached in a } 4 \text { point } \\
\text { un-notched bending test performed to } 3 \text { prisms, and } \\
\text { energy developed up to a deflection of } 3.5 \mathrm{~mm} \text { in the } \\
\text { center. The energy is expressed in Newton*meter }\end{array}$}} \\
\hline $\operatorname{Energy}\left(N^{*} m\right)$ & & & & & \\
\hline $\begin{array}{l}\text { Tensile stress } \\
\text { strain law }\end{array}$ & $\begin{array}{l}\text { Obtained by } \\
\text { Inverse analysis }\end{array}$ & \multicolumn{4}{|c|}{$\begin{array}{l}\text { Average tensile stress-strain law deduced by inverse } \\
\text { analysis from the flexural tests. The graphic is representing } \\
\text { the elastic and strain-hardening behaviour }\end{array}$} \\
\hline
\end{tabular}




\begin{tabular}{|l|l|}
\hline \multicolumn{2}{|c|}{ F1-HY } \\
\hline Concrete Family & VHPFRC \\
\hline Technological features & Self-compacting, hybrid fiber reinforced, very high strength \\
\hline Price Spanish Market 2012 & $638 € / \mathrm{m}^{3}$ \\
\hline
\end{tabular}

\begin{tabular}{|l|l|l|}
\hline \multicolumn{2}{|c|}{ Dosage } \\
\hline \multicolumn{1}{|c|}{ Components } & \multicolumn{1}{c|}{ Content } \\
\hline Cement & 52.5 R/SR, Lafarge Sagunto & $700 \mathrm{~kg} / \mathrm{m}^{3}$ \\
\hline Active addition & Elkem $® 940-$ Densified & $70 \mathrm{~kg} / \mathrm{m}^{3}(10 \%$ o.c.w) \\
\hline Sand 1; Sand 2 & $0-0.8 \mathrm{~mm} ; 0.8-2 \mathrm{~mm}$ & $825.8 \mathrm{~kg} / \mathrm{m}^{3} ; 50.5 \mathrm{~kg} / \mathrm{m}^{3}$ \\
\hline PCE admixture & Sika Viscocrete@ $20 \mathrm{HE}$ & $23.1 \mathrm{~kg} / \mathrm{m}^{3}(3 \%$ o.b.w) \\
\hline Total water & Tap water & $204.1 \mathrm{liters}$ \\
\hline Fiber 1; Fiber 2 & OL-13/0.16; RC-80/35-BN (Dramix@) & $78.1 \mathrm{~kg} / \mathrm{m}^{3} ; 78.1 \mathrm{~kg} / \mathrm{m}^{3}$ \\
\hline
\end{tabular}

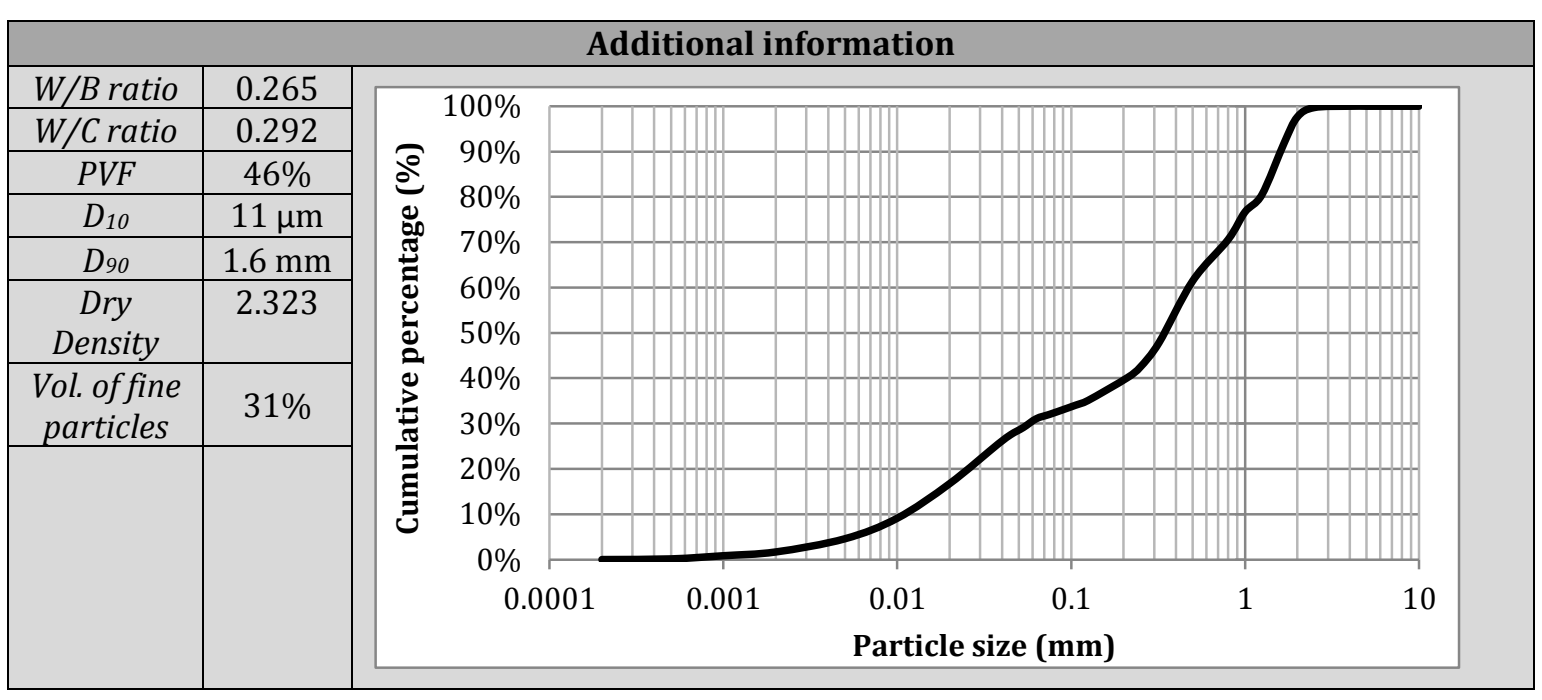

\begin{tabular}{|c|c|c|}
\hline \multicolumn{3}{|c|}{ Rheological properties } \\
\hline Properties & Norm & Value \\
\hline Mixing time- Workability time & - & $12 \mathrm{~min}-60 \mathrm{~min}$ aprox. \\
\hline Slump flow- $t_{500}$ & UNE-EN-12350-8 & $683 \mathrm{~mm} .-4.4$ seconds \\
\hline
\end{tabular}

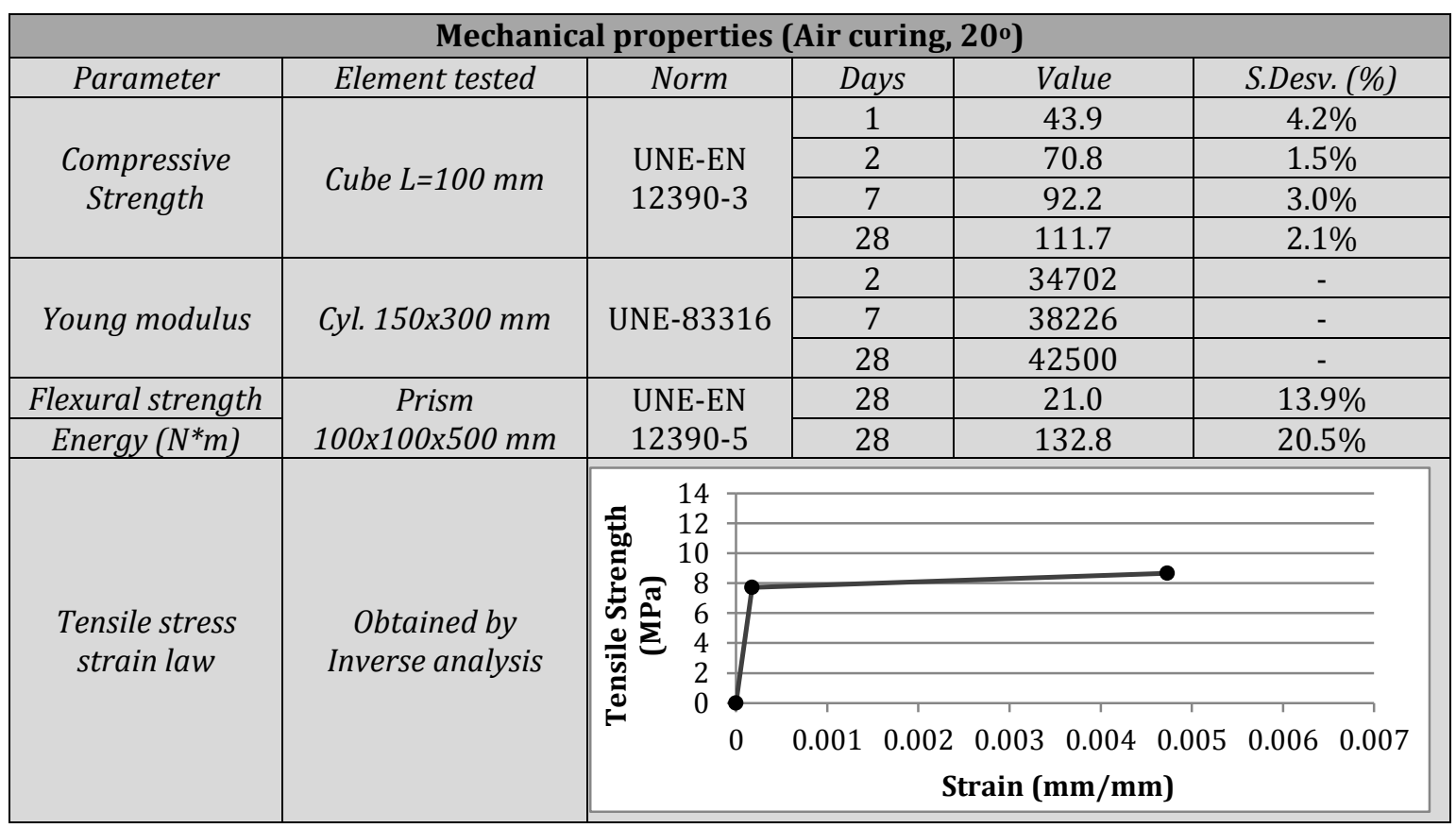




\begin{tabular}{|l|l|}
\hline \multicolumn{2}{|c|}{ F2-HY } \\
\hline Concrete Family & VHPFRC \\
\hline Technological features & Self-compacting, hybrid fiber reinforced, very high strength \\
\hline Price Spanish Market 2012 & $799 € / \mathrm{m}^{3}$ \\
\hline
\end{tabular}

\begin{tabular}{|l|l|l|}
\hline \multicolumn{2}{|c|}{ Dosage } \\
\hline \multicolumn{1}{|c|}{ Components } & \multicolumn{1}{c|}{ Content } \\
\hline Cement & 52.5 R/SR, Lafarge Sagunto & $850 \mathrm{~kg} / \mathrm{m}^{3}$ \\
\hline Active addition & Elkem $\AA 940-$ Densified & $127.5 \mathrm{~kg} / \mathrm{m}^{3}(15 \%$ o.c.w) \\
\hline Sand 1; Sand 2 & $0-0.8 \mathrm{~mm} ; 0.8-2 \mathrm{~mm}$ & $703.5 \mathrm{~kg} / \mathrm{m}^{3} ; 469 \mathrm{~kg} / \mathrm{m}^{3}$ \\
\hline PCE admixture & Sika Viscocrete@ $20 \mathrm{HE}$ & $29.3 \mathrm{~kg} / \mathrm{m}^{3}(3 \%$ o.b.w) \\
\hline Total water & Tap water & $205.3 \mathrm{liters}$ \\
\hline Fiber 1; Fiber 2 & OL-13/0.16; RC-80/30-BP (Dramix $囚)$ & $78.1 \mathrm{~kg} / \mathrm{m}^{3} ; 78.1 \mathrm{~kg} / \mathrm{m}^{3}$ \\
\hline
\end{tabular}

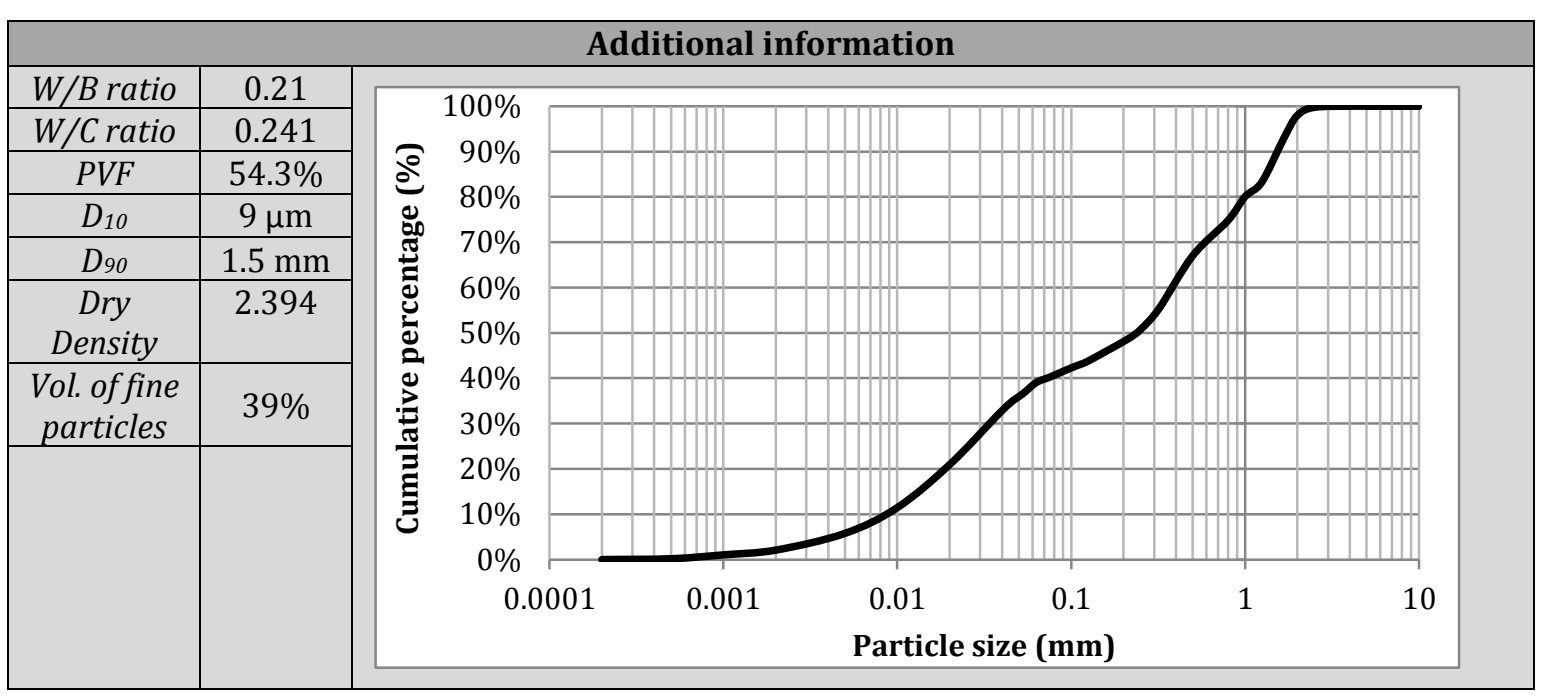

\begin{tabular}{|c|c|c|}
\hline & Rheological properties & \\
\hline Properties & Norm & Value \\
\hline Mixing time- Workability time & & $12 \mathrm{~min}-60 \mathrm{~min}$ aprox. \\
\hline Slump flow- $t_{500}$ & UNE-EN-12350-8 & $749 \mathrm{~mm} .-2.9$ seconds \\
\hline
\end{tabular}

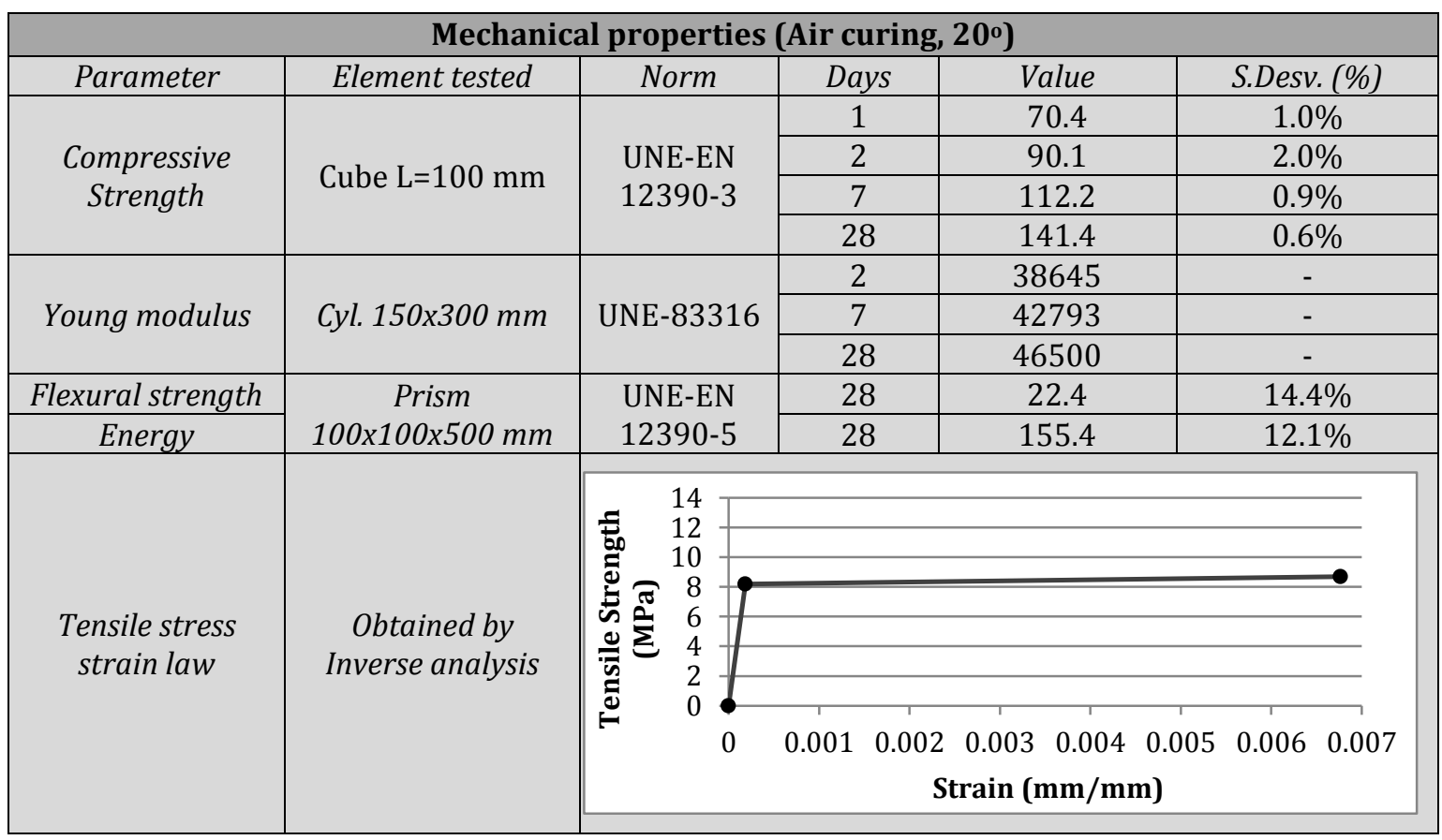




\begin{tabular}{|l|l|}
\hline \multicolumn{2}{|c|}{ F3-HY } \\
\hline Concrete Family & UHPFRC \\
\hline Technological features & Self-compacting, hybrid fiber reinforced, ultra high strength \\
\hline Price Spanish Market 2012 & $840 € / \mathrm{m}^{3}$ \\
\hline
\end{tabular}

\begin{tabular}{|l|l|l|}
\hline \multicolumn{2}{|c|}{ Dosage } \\
\hline \multicolumn{1}{|c|}{ Components } & \multicolumn{1}{c|}{ Content } \\
\hline Cement & 42.5 R/SR, Lafarge Sagunto & $1000 \mathrm{~kg} / \mathrm{m}^{3}$ \\
\hline Active addition & FC3R Omya Clariana & $150 \mathrm{~kg} / \mathrm{m}^{3}(15 \%$ o.c.w) \\
\hline Sand 1; Sand 2 & $0-0.8 \mathrm{~mm}$ 0.8-2 mm & $610.1 \mathrm{~kg} / \mathrm{m}^{3} ; 406.8 \mathrm{~kg} / \mathrm{m}^{3}$ \\
\hline PCE admixture & Sika Viscocrete@ $20 \mathrm{HE}$ & $34.5 \mathrm{~kg} / \mathrm{m}^{3}(3 \%$ o.b.w) \\
\hline Total water & Tap water & $201.2 \mathrm{liters}$ \\
\hline Fiber 1; Fiber 2 & OL-13/0.16; RC-80/30-BP (Dramix $囚)$ & $78.1 \mathrm{~kg} / \mathrm{m}^{3} ; 78.1 \mathrm{~kg} / \mathrm{m}^{3}$ \\
\hline
\end{tabular}

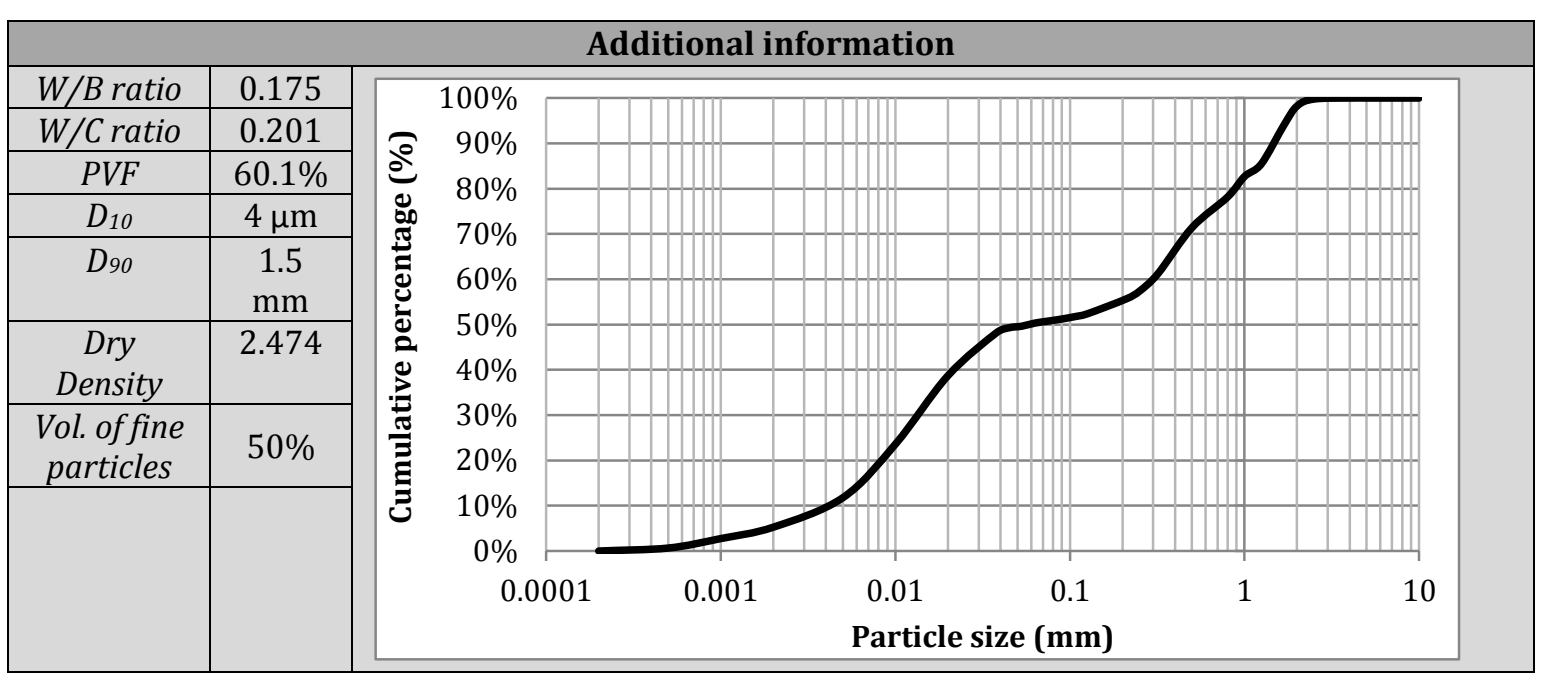

\begin{tabular}{|c|c|c|}
\hline & Rheological properties & \\
\hline Properties & Norm & Value \\
\hline Mixing time- Workability time & - & $15 \mathrm{~min}-40 \mathrm{~min}$ aprox. \\
\hline Slump flow- $t_{500}$ & UNE-EN-12350-8 & $713 \mathrm{~mm} .-4.0$ seconds \\
\hline
\end{tabular}

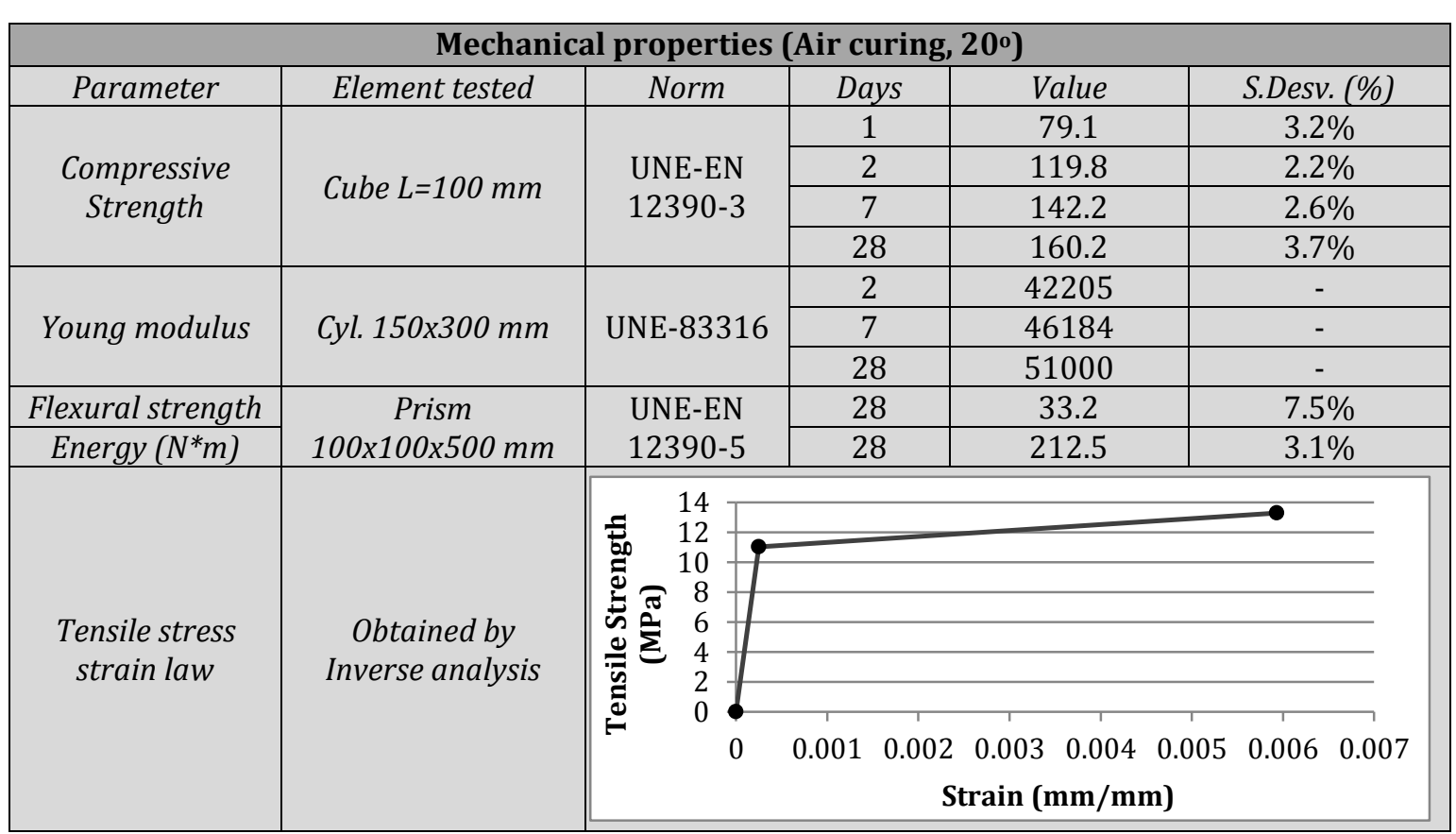




\begin{tabular}{|l|l|}
\hline \multicolumn{2}{|c|}{ Q3-HY } \\
\hline Concrete Family & UHPFRC \\
\hline Technological features & Self-compacting, hybrid fiber reinforced, ultra high strength \\
\hline Price Spanish Market 2012 & $842 € / \mathrm{m}^{3}$ \\
\hline
\end{tabular}

\begin{tabular}{|c|c|c|}
\hline \multicolumn{3}{|c|}{ Dosage } \\
\hline Components & Type & Content \\
\hline Cement & 42.5 R/SR, Lafarge Sagunto & $850 \mathrm{~kg} / \mathrm{m}^{3}$ \\
\hline Active addition & Elkem $₫ 940$-Densified & $127.5 \mathrm{~kg} / \mathrm{m}^{3}(15 \%$ o.c.w $)$ \\
\hline Quartz flour & Sikron U-S500, Sibelco® & $170 \mathrm{~kg} / \mathrm{m}^{3}$ (20\% o.c.w.) \\
\hline Sand 1; Sand 2 & $0-0.8 \mathrm{~mm} ; 0.8-2 \mathrm{~mm}$ & $601.1 \mathrm{~kg} / \mathrm{m}^{3} ; 400.7 \mathrm{~kg} / \mathrm{m}^{3}$ \\
\hline PCE admixture & Sika Viscocrete® $20 \mathrm{HE}$ & $34.4 \mathrm{~kg} / \mathrm{m}^{3}(3 \%$ o.b.w $)$ \\
\hline Total water & Tap water & 200.8 liters \\
\hline Fiber 1; Fiber 2 & OL-13/0.16; RC-80/30-BP (Dramix®) & $78.1 \mathrm{~kg} / \mathrm{m}^{3} ; 78.1 \mathrm{~kg} / \mathrm{m}^{3}$ \\
\hline
\end{tabular}

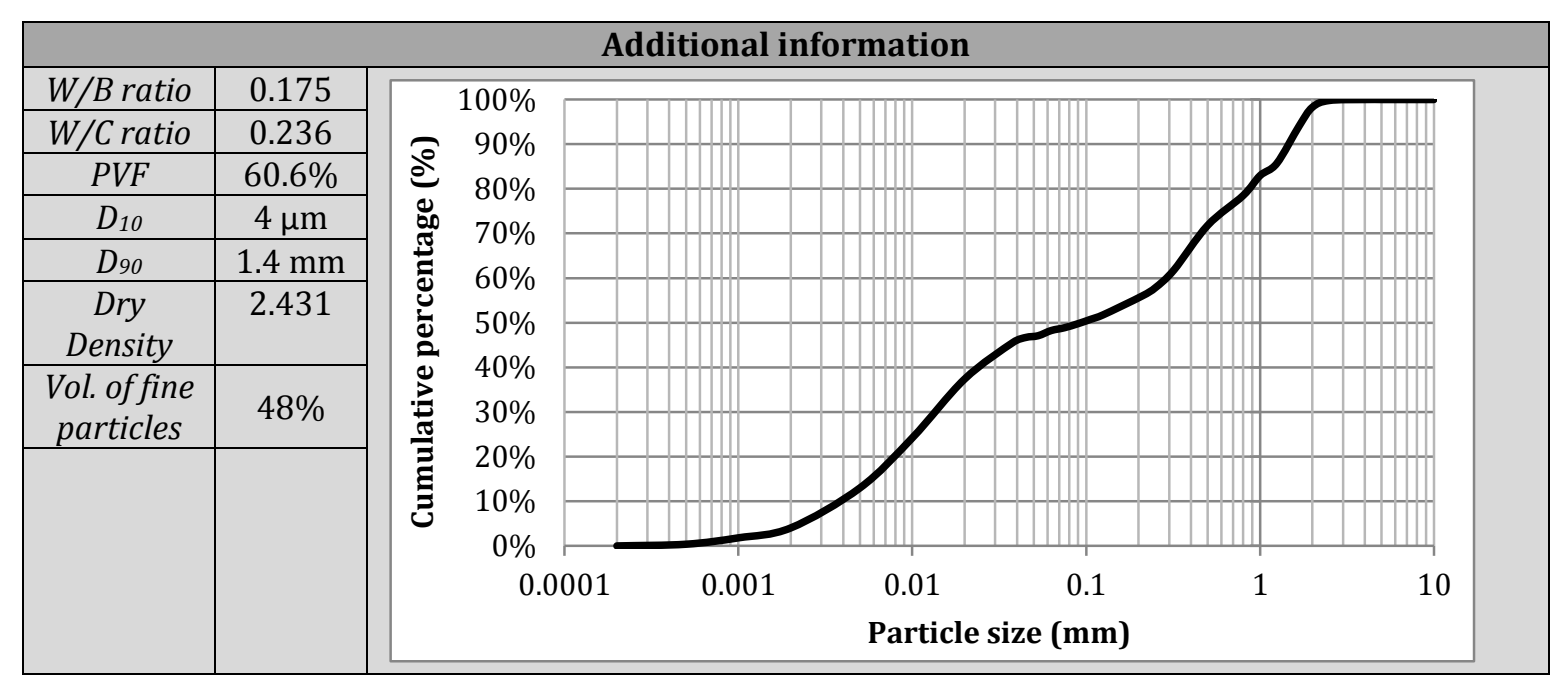

\begin{tabular}{|c|c|c|}
\hline \multicolumn{3}{|c|}{ Rheological properties } \\
\hline Properties & Norm & Value \\
\hline Mixing time- Workability time & - & $12 \mathrm{~min}-60 \mathrm{~min}$ aprox. \\
\hline Slump flow- $t_{500}$ & UNE-EN-12350-8 & $723 \mathrm{~mm}-3.8$ seconds \\
\hline
\end{tabular}

\begin{tabular}{|c|c|c|c|c|c|}
\hline \multicolumn{6}{|c|}{ Mechanical properties (Air curing, $2^{\circ}$ ) } \\
\hline Parameter & Element tested & Norm & Days & Value & S.Desv. (\%) \\
\hline \multirow{4}{*}{$\begin{array}{l}\text { Compressive } \\
\text { Strength }\end{array}$} & \multirow{4}{*}{ Cube $L=100 \mathrm{~mm}$} & \multirow{4}{*}{$\begin{array}{l}\text { UNE-EN } \\
12390-3\end{array}$} & 1 & 75.4 & $4.0 \%$ \\
\hline & & & 2 & 100.2 & $2.2 \%$ \\
\hline & & & 7 & 129.1 & $1.8 \%$ \\
\hline & & & 28 & 159.4 & $2.0 \%$ \\
\hline \multirow{3}{*}{ Young modulus } & \multirow{3}{*}{ Cyl. $150 \times 300 \mathrm{~mm}$} & \multirow{3}{*}{ UNE-83316 } & 2 & 39596 & - \\
\hline & & & 7 & 43327 & - \\
\hline & & & 28 & 47670 & - \\
\hline \multirow{2}{*}{$\frac{\text { Flexural strength }}{\text { Energy }\left(N^{*} m\right)}$} & \multirow{2}{*}{$\begin{array}{c}\text { Prism } \\
100 \times 100 \times 500 \mathrm{~mm}\end{array}$} & \multirow{2}{*}{$\begin{array}{l}\text { UNE-EN } \\
12390-5 \\
\end{array}$} & 28 & 28.4 & $10.8 \%$ \\
\hline & & & 28 & 190.3 & $8.8 \%$ \\
\hline $\begin{array}{l}\text { Tensile stress } \\
\text { strain law }\end{array}$ & $\begin{array}{l}\text { Obtained by } \\
\text { Inverse analysis }\end{array}$ & 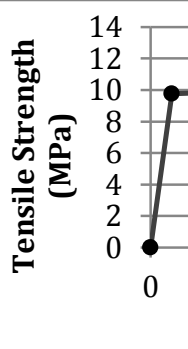 & $001 \quad 0.00$ & $\begin{array}{l}030.004 \\
(\mathrm{~mm} / \mathrm{m}\end{array}$ & \begin{tabular}{ll}
\multicolumn{1}{c}{} \\
$\overline{1}$ \\
$0.006 \quad 0.007$
\end{tabular} \\
\hline
\end{tabular}




\begin{tabular}{|l|l|}
\hline \multicolumn{2}{|c|}{ C3-M } \\
\hline Concrete Family & UHPFRC \\
\hline Technological features & Self-compacting, monofiber, ultra high strength \\
\hline Price Spanish Market 2012 & $697 € / \mathrm{m}^{3}$ \\
\hline
\end{tabular}

\begin{tabular}{|c|c|c|}
\hline \multicolumn{3}{|c|}{ Dosage } \\
\hline Components & Type & Content \\
\hline Cement & 42.5 R/SR, Lafarge Sagunto & $789 \mathrm{~kg} / \mathrm{m}^{3}$ \\
\hline Active addition & FC3R Omya Clariana & $118 \mathrm{~kg} / \mathrm{m}^{3}(15 \%$ o.c.w) \\
\hline Silica sand & $0-0.6 \mathrm{~mm}$ & $790 \mathrm{~kg} / \mathrm{m}^{3}$ \\
\hline Coarse aggregate & Limestone crushed aggregate $4-7 \mathrm{~mm}$ & $500 \mathrm{~kg} / \mathrm{m}^{3}$ \\
\hline PCE admixture & Sika Viscocrete® $20 \mathrm{HE}$ & $27.2 \mathrm{~kg} / \mathrm{m}^{3}(3 \%$ o.b.w) \\
\hline Total water & Tap water & 190.3 liters \\
\hline Fiber & Dramix® OL-13/0.16 mm & $123 \mathrm{~kg} / \mathrm{m}^{3}(1.58 \%)$ \\
\hline
\end{tabular}

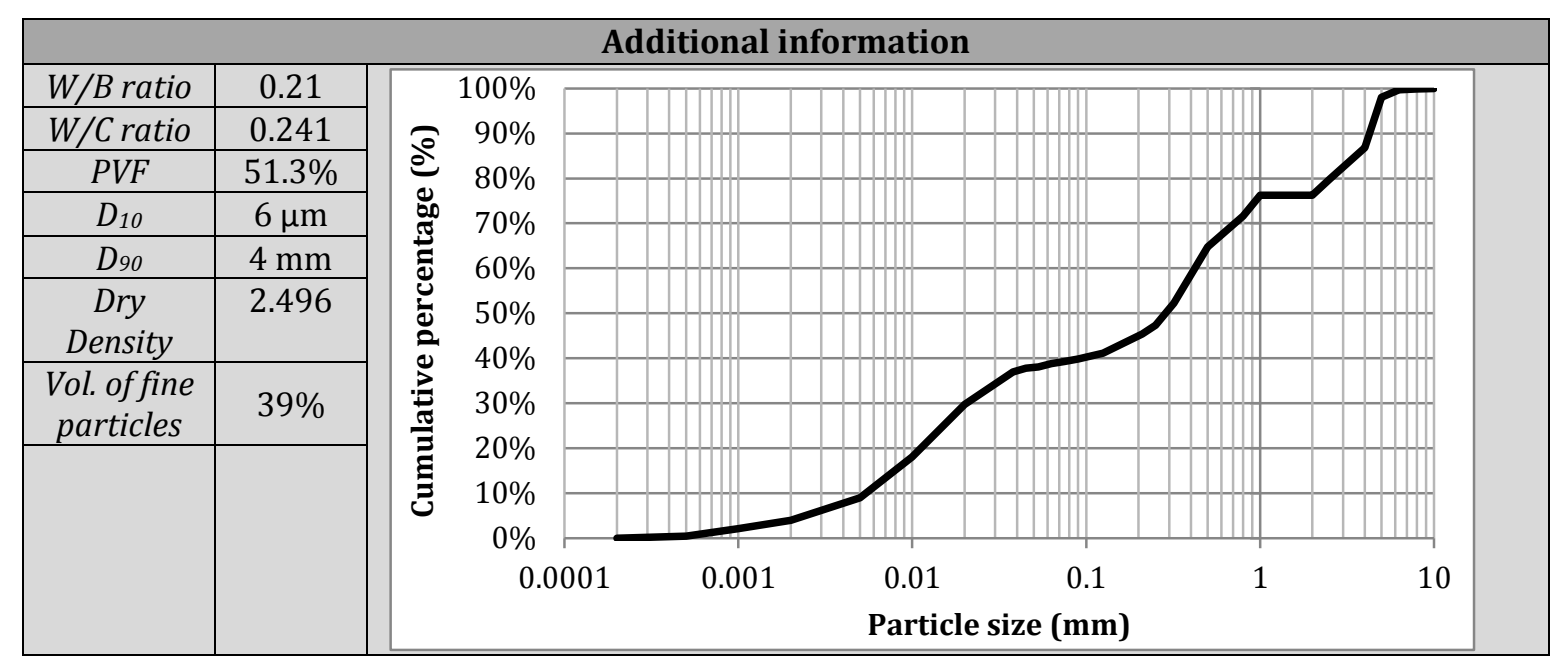

\begin{tabular}{|c|c|c|}
\hline \multicolumn{3}{|c|}{ Rheological properties } \\
\hline Properties & Norm & Value \\
\hline Mixing time- Workability time & - & $14 \mathrm{~min}-40$ min aprox. \\
\hline Slump flow $-t_{500}$ & UNE-EN-12350-8 & $515 \mathrm{~mm}$ - $\mathrm{t}_{500}>10$ seconds \\
\hline
\end{tabular}

\begin{tabular}{|c|c|c|c|c|c|}
\hline \multicolumn{6}{|c|}{ Mechanical properties (Air curing, 20) } \\
\hline Parameter & Element tested & Norm & Days & Value & S.Desv. (\%) \\
\hline \multirow{4}{*}{$\begin{array}{l}\text { Compressive } \\
\text { Strength }\end{array}$} & \multirow{4}{*}{ Cube $\mathrm{L}=100 \mathrm{~mm}$} & \multirow{4}{*}{$\begin{array}{l}\text { UNE-EN } \\
12390-3\end{array}$} & 1 & 70.4 & $1.9 \%$ \\
\hline & & & 2 & 116.0 & $0.4 \%$ \\
\hline & & & 7 & 142.2 & $1.9 \%$ \\
\hline & & & 28 & 162.8 & $3.8 \%$ \\
\hline \multirow{3}{*}{ Young modulus } & \multirow{3}{*}{ Cyl. 150x300 mm } & \multirow{3}{*}{ UNE-83316 } & 2 & 38349 & - \\
\hline & & & 7 & 45668 & - \\
\hline & & & 28 & 47500 & - \\
\hline \multirow{2}{*}{$\begin{array}{c}\text { Flexural strength } \\
\text { Energy }\end{array}$} & \multirow{2}{*}{$\begin{array}{c}\text { Prism } \\
100 \times 100 \times 500 \mathrm{~mm}\end{array}$} & \multirow{2}{*}{$\begin{array}{l}\text { UNE-EN } \\
12390-5 \\
\end{array}$} & 28 & 21.5 & $4.2 \%$ \\
\hline & & & 28 & 130.1 & $3.1 \%$ \\
\hline $\begin{array}{l}\text { Tensile stress } \\
\text { strain law }\end{array}$ & $\begin{array}{c}\text { Obtained by } \\
\text { Inverse analysis }\end{array}$ & 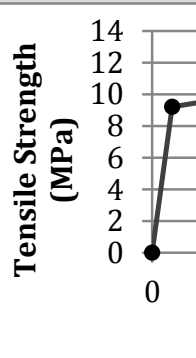 & 0.0010 .00 & $\begin{array}{l}03 \quad 0.0040 .005 \\
\mathbf{n}(\mathbf{m m} / \mathbf{m m})\end{array}$ & \begin{tabular}{ll}
\multicolumn{1}{c}{} \\
$0.006 \quad 0.007$
\end{tabular} \\
\hline
\end{tabular}


The mixtures show an evidence: The price per cubic meter does not suffer strong variations. In this case the best benefit from the material spending is obtained when mixtures from the highest performance are chosen (F3-HY, Q3-HY and C3-M) (see figure 4.59). However, the figure is an example that the most efficient material depends on the most required property.

Thus, it does not became the main decision factor when it is already decided the use of a VHPFRC-UHPFRC. The decision is mainly token depending mainly on which concrete has the properties that fit better with the requirements and restrictions.

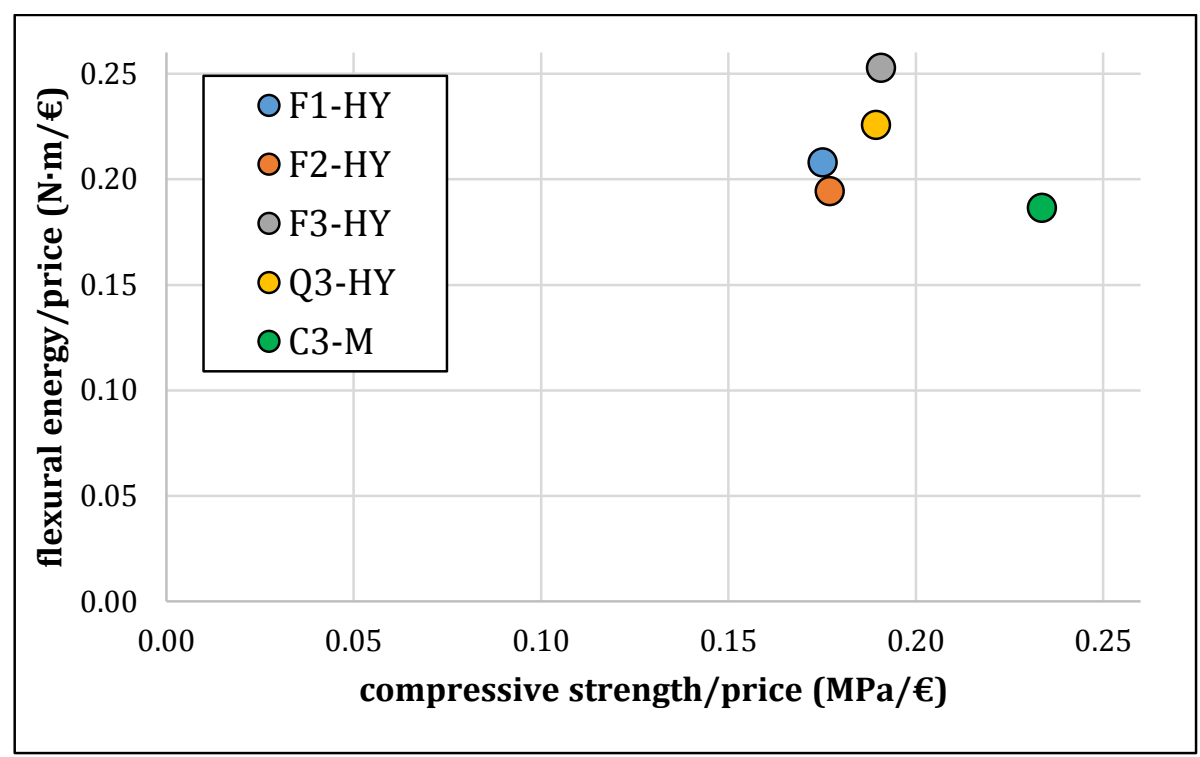

Figure 4.59: Ratios of flexural energy $/ \mathrm{m}^{3}$ price and compressive strength $/ \mathrm{m}^{3}$ price for the dosages proposed

\subsection{SUMMARY AND FINAL REMARKS}

In this section new materials and processes have been introduced in order to simplify VHPFRC and UHPFRC. The influence of using local active additions, suitable cements, commercial PCE admixtures, limestone coarse aggregate and different mixers was evaluated, supporting finally the deductions with a statistical analysis.

Once the effect of each variable was known, five different optimized dosages have been proposed as the most suitable for different applications, characterizing the rheological and mechanical properties. After it, some recommendations relative to the UHPFRC dosage composition, mixing and pouring process have been provided.

On the basis of the performed optimization and the results obtained can be concluded:

- The substitution of cement for fly ash up to contents of $20 \%$ increases the workability keeping similar long term compressive strength.

- The cement content can be used to modify the performance of UHPFRC mixtures. The W/B should not be decreased in excess even though slump flows are acceptable. For dosages with $1000 \mathrm{~kg} / \mathrm{m}^{3}$ of cement, adequate W/B ratios are $0.175-0.18$, with slumps flow about $750 \mathrm{~mm}$. 
- FC3R requires even more control of the humidity and water added to reach the desired mix workability. This material showed better compatibility with the cement type I-42.5 R/SR, while CSF with the I-52.5 R/SR.

- FC3R can be added in contents higher than 15\% o.c.w., while local CSF decreases markedly the workability due to the high carbon content. FC3R also provides higher early age activity, while the CSF developed its most pozzolanic activity the following weeks. Relative to the flexural strength, the differences between the use of FC3R or Ferroatlántica CSF are not remarkable.

- In general terms, it can be observed that $15 \%$ with respect to cement of any addition provides better properties than $25 \%$.

- Limestone coarse aggregate addition reduces notably the workability of hybrid concretes, as the long fibers tangle with the aggregates. However, it reduces greatly the cement content keeping almost similar the long term compressive strength. The early age strength is more affected as the aggregate-paste ITZ requires the pozzolanic reaction to get improved.

- The TPD, a simple method to deduce empirically the adequate sand proportion for UHPFRC, provides more acceptable results than the $A \& A_{M O D}$ theory.

- Cast VHPFRC-UHPFRC in a low energy tilting mixer requires $10-15 \%$ more of $\mathrm{W} / \mathrm{B}$ ratio and much longer mixing times. The segregation tendency is higher, but properties obtained are in the range of the VHPFRC. A conventional industrial mixer can be sufficiently power to mix UHPFRC adequately.

- The statistical analysis performed in section 4.9 supports many of the conclusions previously commented.

- Optimum dosages defined in this Ph.D. (F1-HY, F2-HY, F3-HY, Q3-HY and C3-M) optimized targeted properties suitable for different applications. More than $160 \mathrm{MPa}$ at compressive strength and $30 \mathrm{MPa}$ at equivalent flexural strength are reached without any steam curing system and using accessible components from local providers. 
UHPFRC BOLTED CONNECTIONS

\section{UHPFRC BOLTED CONNECTIONS}


UHPFRC BOLTED CONNECTIONS 


\subsection{INTRODUCTION}

UHPFRC precast solutions are increasing their market share and still have a big potential for growing [155]. Unidirectional flat roofs, Double T girders, shells, retaining walls, truss structures are some of the applications [1] [236] [255].

The design of these applications is more and more similar to the steel precast elements and structures. However, one of the least studied fields to design with this material is the possibility of use a simpler connection method between UHPFRC elements, similar to the used at metallic structures. This development would provide to the precast UHPFRC structures higher industrialization, a reduction of the assembly works, faster and more cost-efficient construction and less interference at the work place. It could be especially useful for industrial structures, trusses, temporal solutions or applications that require immediacy, as emergency bridges.

At Chapter 2, the table 2.1 showed the intermedium mechanical properties of UHPFRC, halfway between steel and ordinary concrete. Thus, the high UHPFRC tensile and compressive strength, ductility and durability, allow systems with resemblance to the common practice in steel structures or composite materials, as the design of direct bolted connections.

This subject is treated at this chapter, where the bolted connections are conceived as a wide structural proposal, as the connections shall be designed to withstand the loads providing a ductile response.

In this chapter the work has been structured in both an experimental and analytical program, covering:

- Proposal of testing methods to evaluate the bolted joints capacity. This is not documented yet by any author for UHPFRC. After a preliminary proposal, a testing process with low scatter has been obtained. The proceeding can be modified or improved in the future.

- Bolted connections analysis: Study of the possible failure modes for different geometries and steel reinforcement. The experimental results are supported with a finite elements linear analysis.

- Verification of the proposed connections viability in a full size application, proving that the bolted region is working as expected and identifying possible drawbacks.

Based on the results of such approaches, simple strength prediction equations are developed for design in ultimate limit state (ELU), using as input the geometrical parameters and UHPFRC mechanical strength.

Obviously, the transmission of secondary stresses is viable and are implicitly incorporated as a specific and simpler case-study, easier to manage. For the less exigent connections could be possible even the use of a UHPFRC bolt, dosed with higher fiber content than normally to cover the high stress concentration. This is a research line for the future, viable if the researcher is open minded reconsidering the hole diameter, bolt design and concrete dosage. 


\subsection{UHPFRC BOLTED JOINTS. FAILURE MODES}

The study proposed requires the development of an accurate procedure to evaluate the bolted joints capacity. The objective is cover the single bolted connections submitted to tension (shown at figure 5.1), to compression (as element of the figure 5.2), or simply to ensure that the use of bolts to guarantee the position of a piece will be effective.

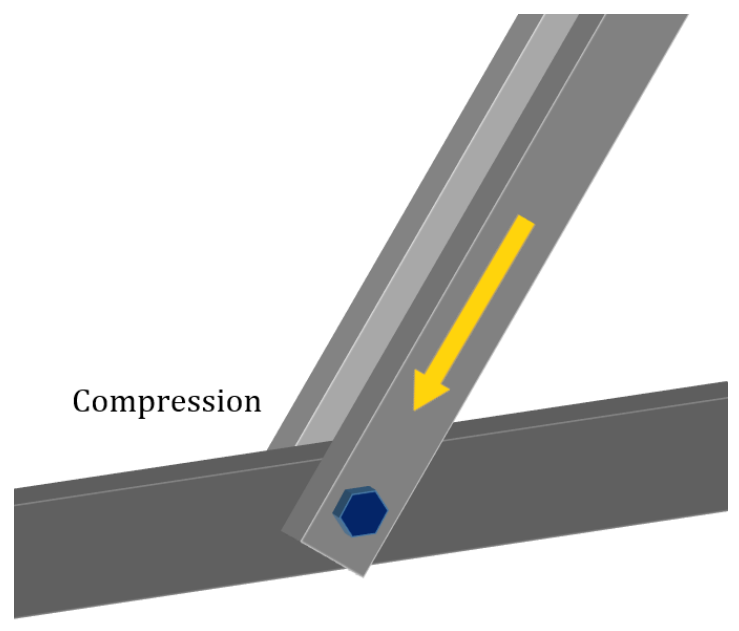

Figure 5.1: Single joint submitted to tension

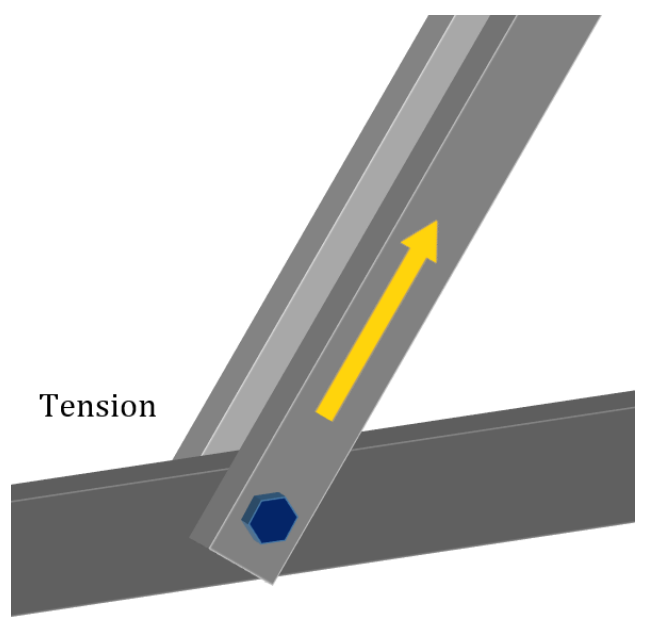

Figure 5.2: Single joint submitted to compression

The basic concept of test studied here is opened be modified in the future to cover more specific cases: The prestressing of the screw, more number of holes in the element, or the introduction of a bending moment.

Bolted joints can be performed in structure nodes with different type of materials. Some of them are isotropic, as the steel [199], the ferrocement [101], the resin-based composites, the aluminum or the plastic. Others are anisotropic, as the laminated composites [177], the fiber reinforced materials or the timber composites [168], which strength depends on the grain direction. The UHPFRC, as a fiber reinforced composite, has also anisotropic properties, providing better tensile response when the fibers are aligned on the direction of the tensile efforts.

At the time of this study experiences with UHPFRC bolted connections have not been found. Thus, the testing method was designed on the bases of the experiences of many researchers with other materials [101] [278] [279] [177] [199].

A bolted joint is susceptible to failure in different ways whatever the material it is made. The damages that can be suffered in the element are shown at figure 5.3. The bearing failure (a), is related with the compressive strength, shear out is related with the shear strength (c), and the last two with the material tensile strength (b and d). An example of the tensile stress distribution of a shell with two bolts is shown on the figure 5.4. For a similar geometry, the failure mode suffered depend mainly on the ratio between compressive, tensile and shear strength of each material. The following lines describe with detail the pattern of these four modes. 


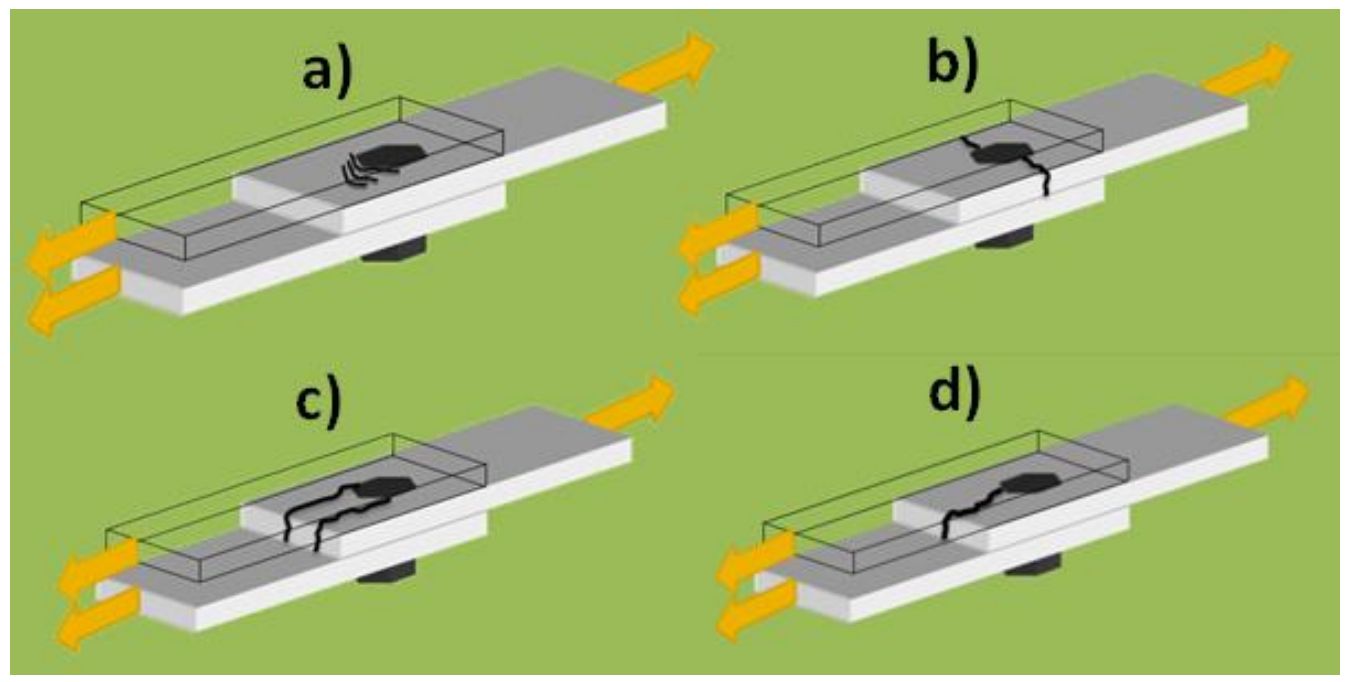

Figure 5.3: Possible UHPFRC failure modes of a bolted piece submitted to tensile load

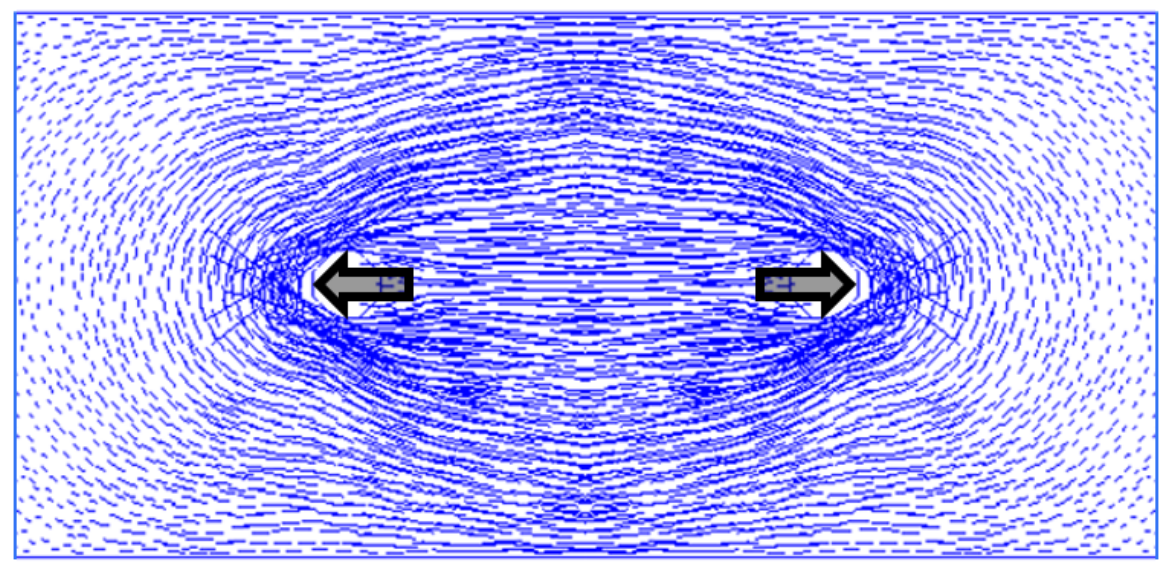

Figure 5.4: Bidimensional tensile stress distribution of an example of shell tested

a) Bearing failure. The material suffers a compressive failure due to the high stress concentration in the contact with the steel bolt, which is inducing a biaxial compressive stress. Initially this is the desirable failure, being the most ductile for most of the materials [119] [165], while the other three failures are considered premature. Figure 5.5 shows a bearing failure in a steel plate [199]. Bearing failure tests made in previous research at the UPV by the author of this Ph.D. [38] reached high compressive strength values with ductile behavior (shown at figure 5.6).

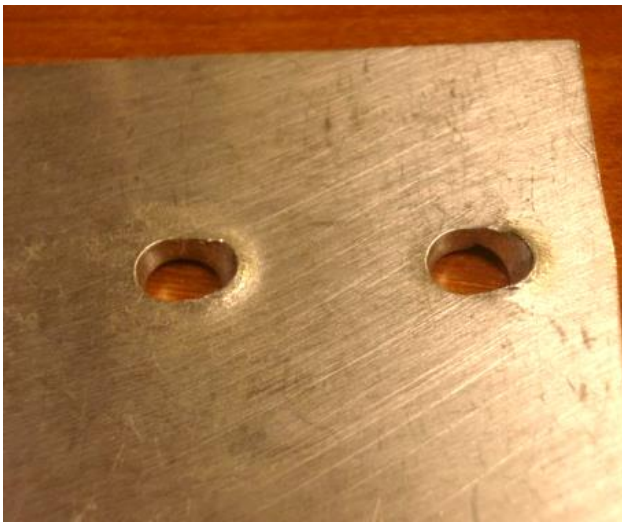

Figure 5.5: Bearing failure in a double bolt steel plate

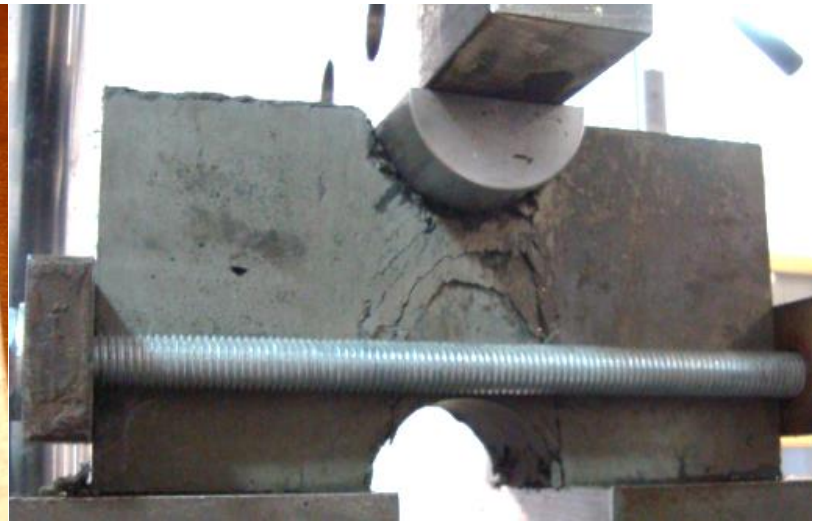

Figure 5.6: Bearing failure of a UHPFRC element 
b) Net tension failure. It is a tensile failure of the element suffered with a crack development orthogonal to the tensile effort. Normally it crosses the hole, as its section is the one with the most reduced area. In tests performed to materials as wood or laminated composites load drops to zero at maximum load [168], showing a brittle failure. At figures 5.7 and 5.8 this failure is exposed for shells made of different materials.

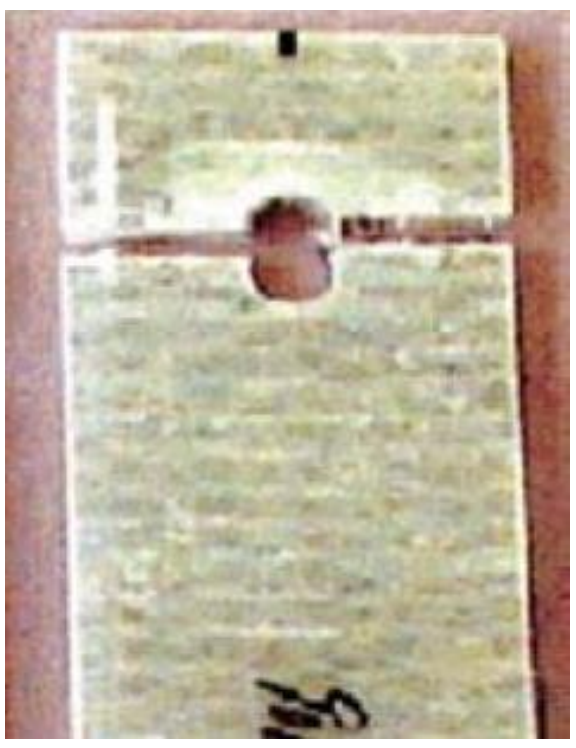

Figure 5.7: Net tension failure

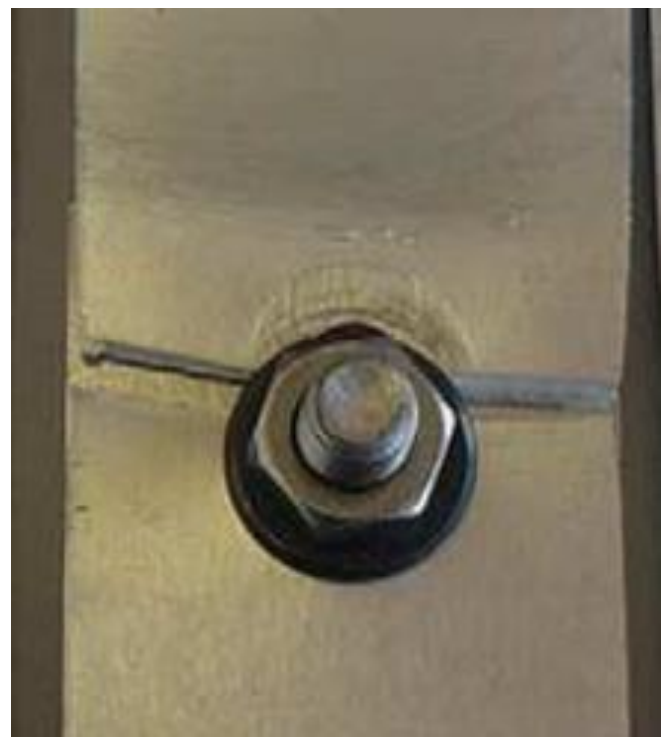

Figure 5.8: Failure on steel plate

c) Shear out failure. This mode shows the cracking development pattern in two sections placed at the cover behind the joint region. In materials as wood or laminated composites causes a brittle or semi-brittle failure [168] [217]. Figures 5.9 and 5.10 shows the shear out failure in shells of different materials. Shear test made to UHPFRC elements in previous research by the author of this Ph.D. [38] showed high ductility because of the $2 \%$ fiber content.

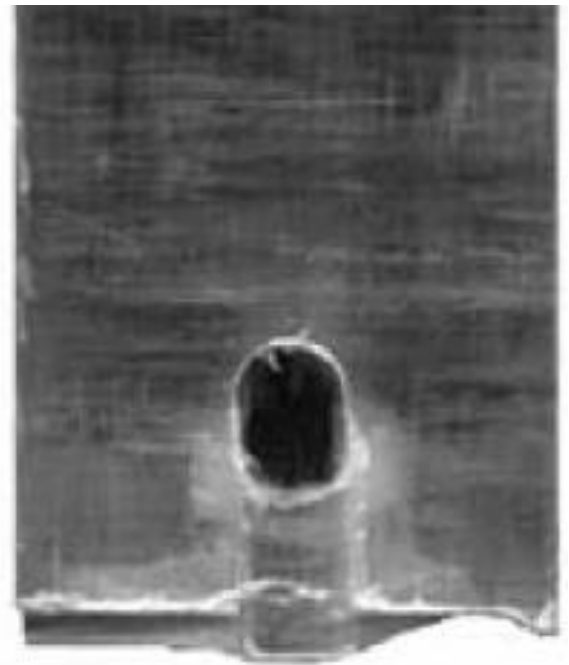

Figure 5.9: Shear out failure of a laminated composite plate [168]

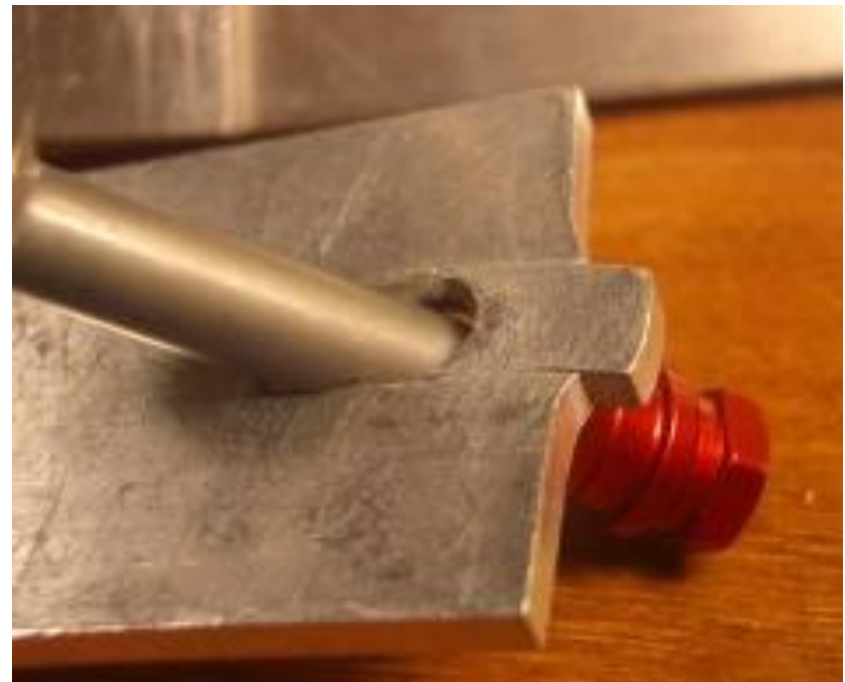

Figure 5.10: Shear out ductile failure

d) Cleavage failure. Bending failure suffered in cover at the end of the joint region due to the tensile stress induced by a flexion induced. In steel to timber dowel joints [217] this 
failure happens propagating a crack from the hole to the final part of the element, being brittle for multiple dowel joints.

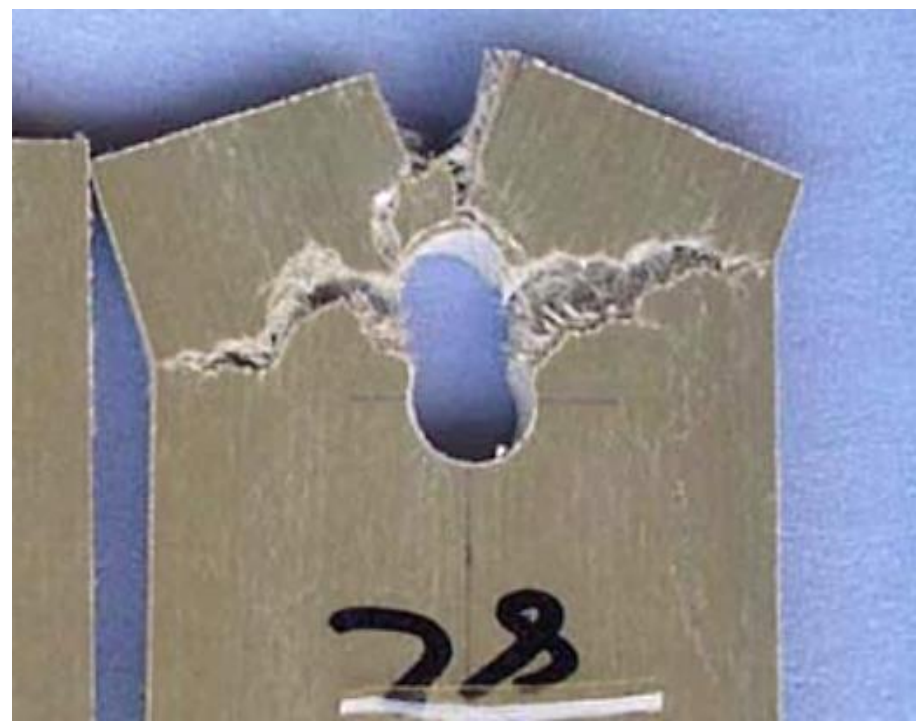

Figure 5.11: Cleavage failure of a pultruded GRP plate

Normally in steel pieces bearing failure is limiting, as the tensile strength of the material is as high as the compressive. In tests performed by other researchers to cementitious materials [101] the most common failures observed were cleavage failure and net tension, suffering also few bearing failure for the most reinforced elements. This agrees with the less order of magnitude of the tensile strength respect to the compressive for cementitious composites.

Other limiting situations than the element damage are possible: The bolt can fail due to shear or flexural effort, being necessary in many applications the use of a High Strength Steel Bolt.

Generally the most recommended is to perform the bolted connection conceiving it as the so-called total union, what means that all the possible failures are designed to resist more than the weakest element joined. All the geometrical and mechanical parameters that influence each one of these failure modes are shown at table 5.1. A function that predicts the maximum load that a connection can reach would depend on these parameters. The width of the element is expressed with the letter $\mathrm{W}$, and the distance to the free edge of the element, with $\mathrm{E}$.

Table 5.1: Failure modes and affecting variables

\begin{tabular}{|c|c|c|}
\hline Failure mode & Geometrical parameters & Mechanical parameters \\
\hline Bearing & $\begin{array}{l}\text { Screw-hole diameters }\left(D_{\text {screw }} \text {; Dhole }\right) \\
\text { Specimen Thickness }(t)\end{array}$ & UHPFRC Compr. strength \\
\hline Net Tension & $\begin{array}{c}\text { Specimen Width }(\mathrm{W}) \\
\text { Specimen Thickness }(\mathrm{t})\end{array}$ & UHPFRC Tensile strength \\
\hline Shear out & $\begin{array}{l}\text { Cover behind bolt }(\mathrm{E}) \\
\left.\text { Hole diameter ( } \mathrm{D}_{\text {hole }}\right) \\
\text { Specimen Thickness }(\mathrm{t})\end{array}$ & UHPFRC Shear strength \\
\hline Cleavage & $\begin{array}{l}\text { Cover behind bolt }(\mathrm{E}) \\
\text { Specimen Thickness }(\mathrm{t})\end{array}$ & UHPFRC Tensile strength \\
\hline Screw Shear & Screw diameter $\mathrm{D}_{\text {screw }}$ & Steel bolt Shear strength \\
\hline
\end{tabular}


In a connection with UHPFRC the weakest failures expected according with figure 5.3 are b) and d), which depends of the UHPFRC tensile strength.

The success in the connection design is based in understand and take profit of the mechanical material properties (table 5.1 column of the right) to select the adequate geometrical variables (table 5.1 central column): Diameter, thickness of the element, cover behind the hole, etc. Thus all can be optimized to reduce to costs and dimensions.

For instance, when a bolted joint is used for wood, an anisotropic material, the key point is to have the wood fibers oriented parallel to the load, as tensile and compressive strength are several times higher in this direction than in the orthogonal. However, cleavage strength is acting $90^{\circ}$ respect to the fibers, so this might be the conditioning failure and some reinforcement might be necessary.

As other example: if the high strength steel bolt of a connection wants to be replaced for a UHPFRC bolt, the design should be restated: now the most limiting stress would be the concrete shear strength, so this could require provide to bolt of a higher diameter. Also the flexural strength is more limiting, so the clearance between bolt and hole should be smaller, or maybe the bolt covered with a steel sleeve.

\subsection{PRELIMINARY TESTS FOR BOLTED CONNECTIONS}

\subsubsection{TEST SET UP}

As introduced before, the testing method was designed on the bases of the experiences of many researchers with other materials [101] [278] [279] [177] [199], studying the effect of a single pure bolted connection submitted to tension. Thus, one of the two main goals here is to check the suitability of this first type of test proposed and identify drawbacks for improve the design in the next step.

The other objective is identify the relation between geometry, material characteristics and failure modes. This knowledge will allow in the future to guarantee a safety bolted connection in real structures. With this goal was designed the experimental program, where the variables modified were similar than other author's scheme:

- Element thickness $(20,30,40 \mathrm{~mm})$ : To study if the variable has a remarkable influence on the fiber alignment, as the wall effect is higher for thinner elements. Also the ductility might increase with the thickness. The values were chosen because the thickness of a UHPFRC shell varies normally in this range.

- Bolt diameter $(20,24$ and $27 \mathrm{~mm}$ ): To evaluate the sensibility of the possible bearing failures to the bolt diameter, as the stress concentration is higher for smaller diameters.

- Width/Hole diameter (4 or 8): To evaluate the effect of the width to the failure mode and their ductility. This will modify mainly the net tension carrying capacity. The values are in the same range as the experiments done for different materials by other authors.

- Cover E/Hole diameter (2 or 4): To evaluate the effect of the cover behind the bolt to the failure mode and their ductility. This variable will increase mainly the cleavage capacity. 
The values were thought to failure with loads in the same magnitude order than the net tension.

The bearing failure was expected to happen at much higher load than the net tension or cleavage failure.

The bolt used was oversized as its possible failure modes are out of this scope. For that reason it was always used a High Strength Bolt, through a hole directly produced in the piece when casting with the formwork.

The test design simulated a tie, testing a UHPFRC specimen with two holes (figure 5.12) submitted to direct tension by means of an anchoring system (shown at figure 5.13). The jack used had a maximum capacity of $600 \mathrm{kN}$. The dimensions of the specimen shown in figure 5.12 with letters varied according with the experimental program performed.

The test set up (schematized in figure 5.13, where the elements are numbered, and presented in figure 5.14) was designed to localize a failure area in the top connection (1) of the specimen (2). High strength steel plates connect the specimen to the loading system. To avoid the failure of the other UHPFRC hole, which is just auxiliary, a steel reinforcement was set when casting the specimen, and also the bolt, with a $25 \mathrm{~mm}$ diameter, was prestressed. No preload moment or prestressing to the top bolt (3) was introduced. To control the relative displacement between the specimen and the steel shells four LVDTs were placed (4).

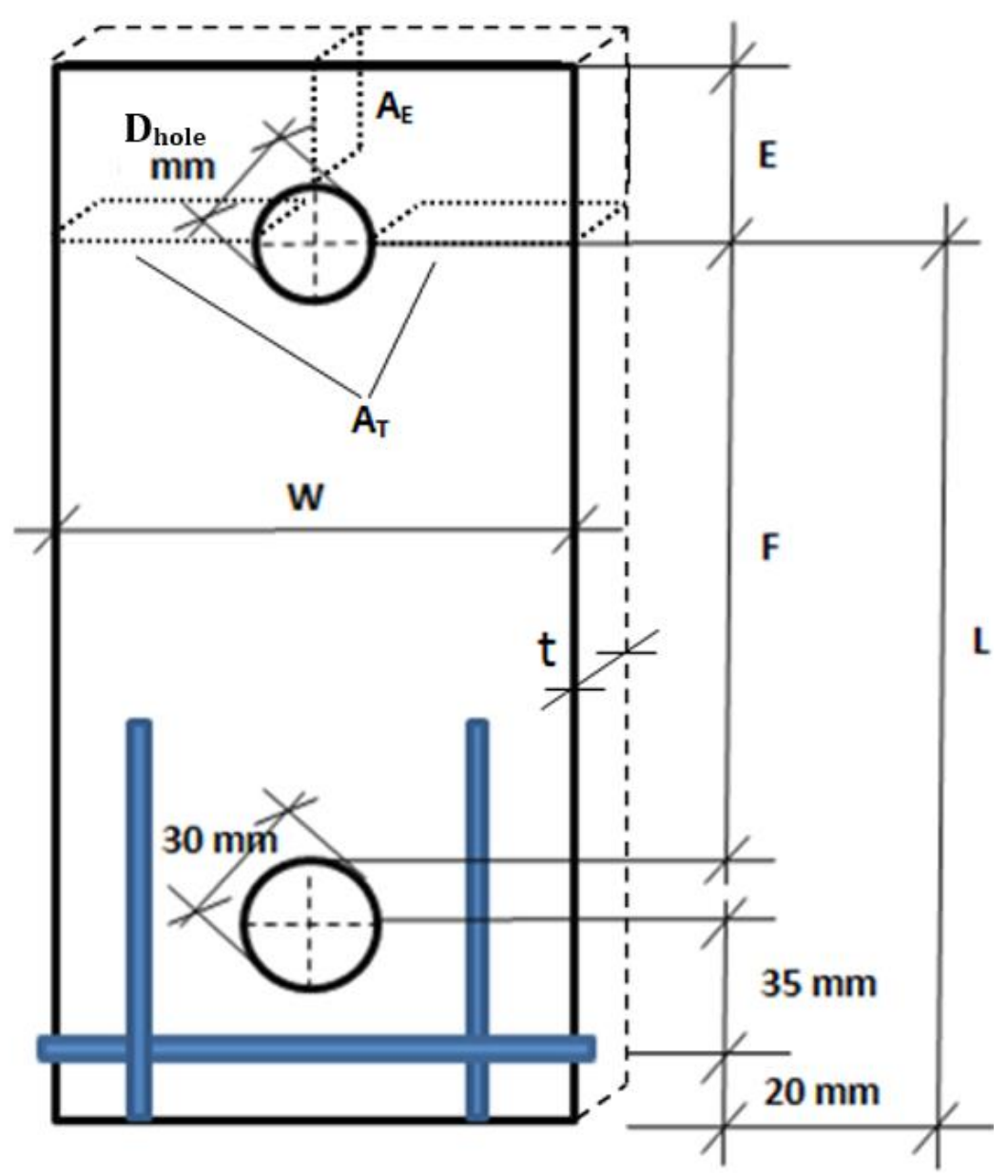

Figure 5.12: UHPFRC element tested 
To cast the specimens, steel moulds were used, and steel pins were placed and fixed with a screw to the molds in the holes locations (figure 5.15). The steel reinforcement, in each case, was placed inside the mold carefully to fit in the proper positions.

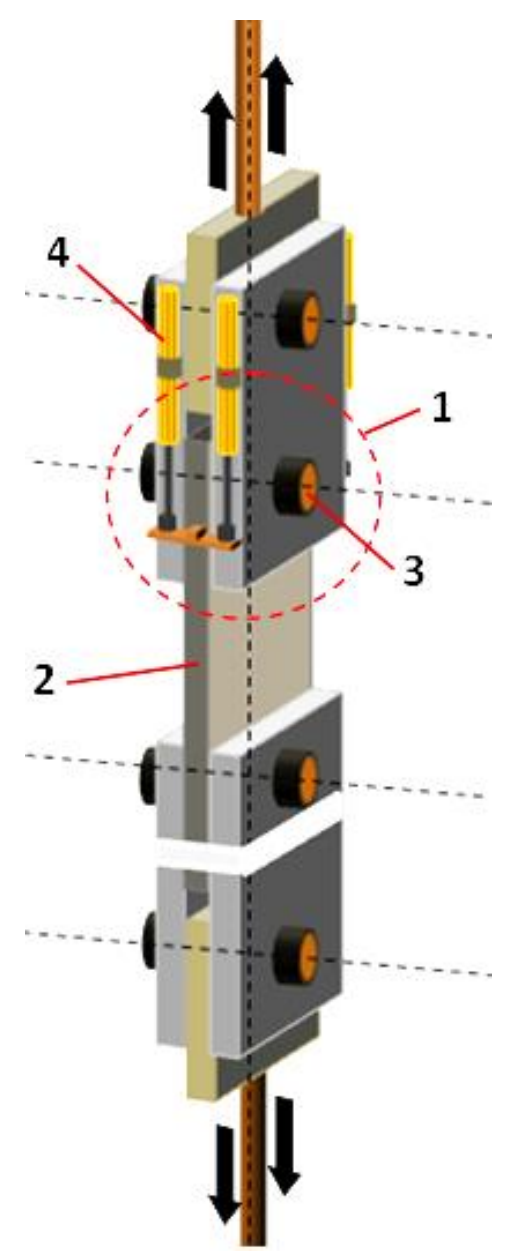

Figure 5.13: Test set up scheme

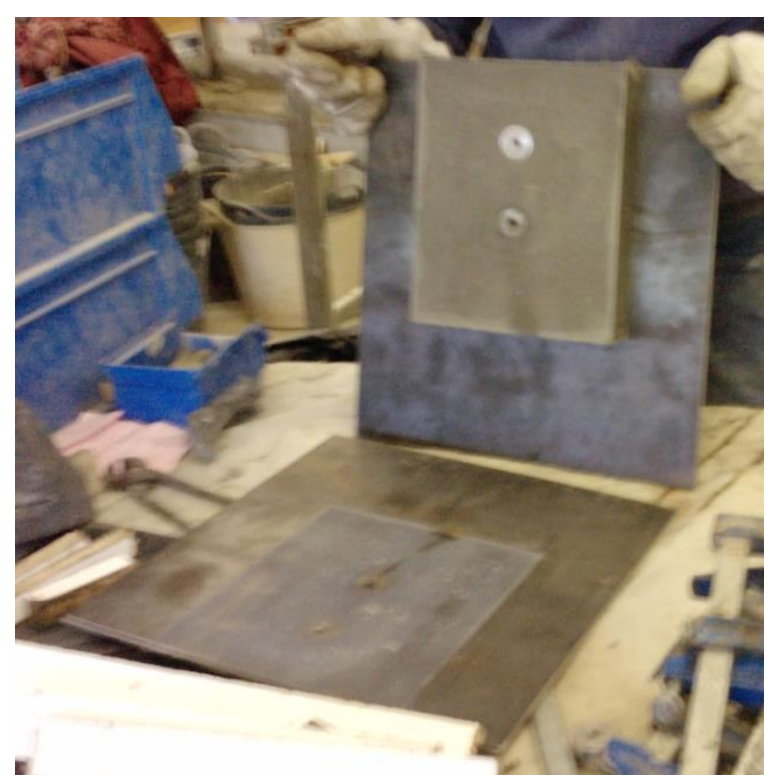

Figure 5.15: Element in the demoulding process. The pouring was made in the vertical position

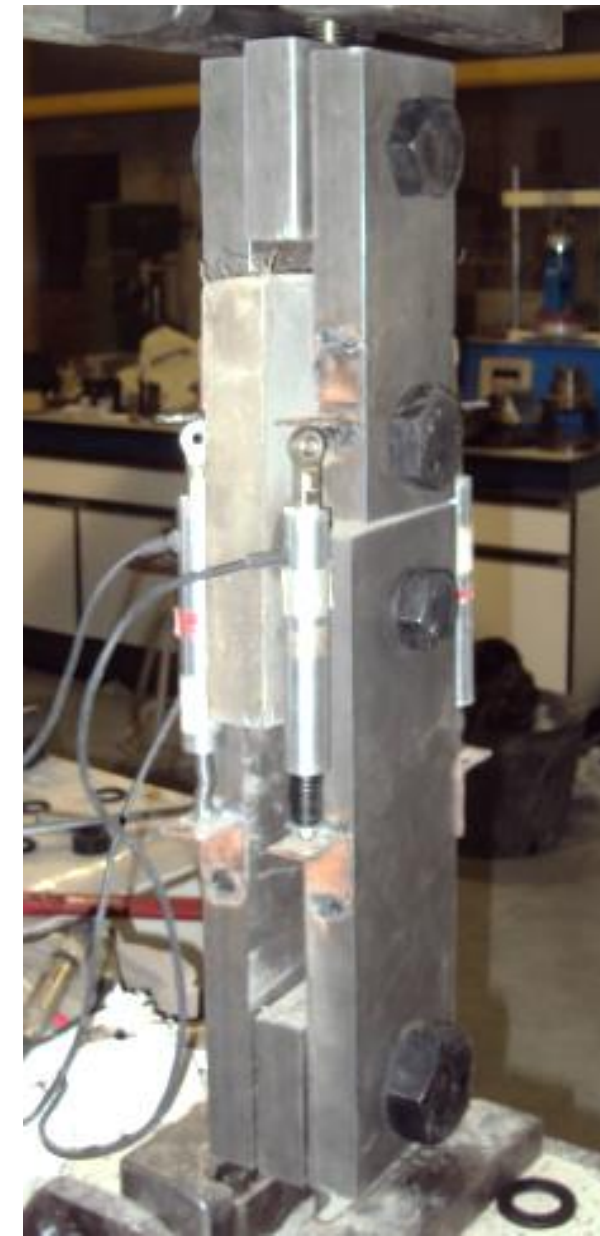

Figure 5.14: Test performed

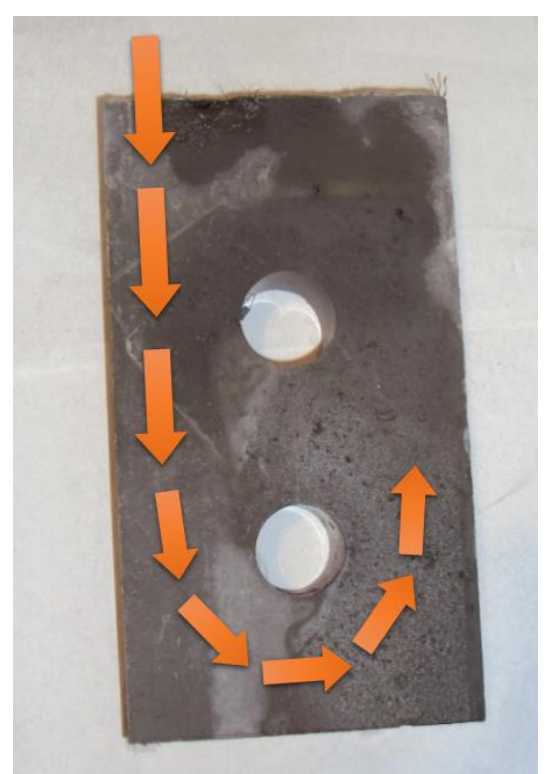

Figure 5.16: Element before testing, where the material path pretended is shown 
As was shown at figure 5.4, the tensile principal direction is parallel to the hole perimeter. Thus, the most appropriate fiber alignment would be in these directions, being parallel to the perimeter of the hole where the load is applied. The casting process is then a key point to reach the best performance of the connection designed, not only for this test but also for any bolted connection in FRC or UHPFRC. This was favoured here with a casting from the top part of the figures 5.15 and 5.16, the closer face to the secondary hole.

\subsubsection{EXPERIMENTAL PROGRAM}

The exterpimental program was composed of 27 shells with different geometry, shown at table 5.2. The UHPFRC mix design used to cast the specimens and characterize the mechanical/rheological properties was developed at UPV, and is the one defined as F3-HY at section 4.11 .2 (Slump of $713 \mathrm{~mm}, \mathrm{t}_{500}$ of 4 seconds, $\mathrm{f}_{\mathrm{ct}}$ by inverse analysis of $13 \mathrm{MPa}$ and $\mathrm{f}_{\mathrm{cm} 28 \mathrm{~d}}$ of $160 \mathrm{MPa}$ ). Three batches were cast, casting 9 elements with each one. $24 \mathrm{~h}$ after pouring, the specimens were removed from the forms. At this point, the steel pins were removed from the pieces (figures 5.515 and 5.16).

Table 5.2: Experimental program of the shells tested

\begin{tabular}{|c|ccccc|}
\hline No test & Code & Thickness t & Bolt diameter d & W/D & E/D \\
\hline $\mathbf{1}$ & $20-20-4-2$ & 20 & 20 & 4 & 2 \\
$\mathbf{2}$ & $20-20-8-2$ & 20 & 20 & 8 & 2 \\
$\mathbf{3}$ & $20-20-8-4$ & 20 & 20 & 8 & 4 \\
\hline $\mathbf{4}$ & $20-24-4-2$ & 20 & 24 & 4 & 2 \\
$\mathbf{5}$ & $20-24-8-2$ & 20 & 24 & 8 & 2 \\
$\mathbf{6}$ & $20-24-8-4$ & 20 & 24 & 8 & 4 \\
$\mathbf{7}$ & $20-27-4-2$ & 20 & 27 & 4 & 2 \\
$\mathbf{8}$ & $20-27-8-2$ & 20 & 27 & 8 & 2 \\
\hline $\mathbf{9}$ & $30-20-4-4$ & 30 & 20 & 4 & 4 \\
$\mathbf{1 0}$ & $30-20-8-2$ & 30 & 20 & 8 & 2 \\
$\mathbf{1 1}$ & $30-20-8-4$ & 30 & 20 & 8 & 4 \\
\hline $\mathbf{1 2}$ & $30-24-4-2$ & 30 & 24 & 4 & 2 \\
$\mathbf{1 3}$ & $30-24-8-2(1)$ & 30 & 24 & 8 & 2 \\
$\mathbf{1 4}$ & $30-24-8-2(2)$ & 30 & 24 & 8 & 2 \\
\hline $\mathbf{1 5}$ & $30-27-8-2$ & 30 & 27 & 8 & 2 \\
$\mathbf{1 6}$ & $30-27-8-4$ & 30 & 27 & 8 & 4 \\
\hline $\mathbf{1 7}$ & $40-20-4-2$ & 40 & 20 & 4 & 2 \\
$\mathbf{1 8}$ & $40-20-8-2$ & 40 & 20 & 8 & 2 \\
\hline $\mathbf{1 9}$ & $40-24-4-2(1)$ & 40 & 24 & 4 & 2 \\
$\mathbf{2 0}$ & $40-24-4-2(2)$ & 40 & 24 & 4 & 2 \\
$\mathbf{2 1}$ & $40-24-8-2$ & 40 & 24 & 8 & 2 \\
$\mathbf{2 2}$ & $40-24-8-4(1)$ & 40 & 24 & 8 & 4 \\
$\mathbf{2 3}$ & $40-24-8-4(2)$ & 40 & 24 & 8 & 4 \\
\hline $\mathbf{2 4}$ & $40-27-4-2$ & 40 & 27 & 4 & 2 \\
$\mathbf{2 5}$ & $40-27-8-2$ & 40 & 27 & 8 & 2 \\
$\mathbf{2 6}$ & $40-27-8-4(1)$ & 40 & 27 & 8 & 4 \\
$\mathbf{2 7}$ & $40-27-8-4(2)$ & 40 & 27 & 8 & 4 \\
\hline
\end{tabular}

After the bolted connection test, 12 holes from non-damaged pieces were tested as shown at figure 5.17 in order to determine the bearing strength. The distance from the center hole to 
the loading section was $200 \mathrm{~mm}$. The analyzed diameters were similar both for the hole and the screw, being 20,24, 27 and $30 \mathrm{~mm}$ (three pieces for each one). No screw prestressing was induced.

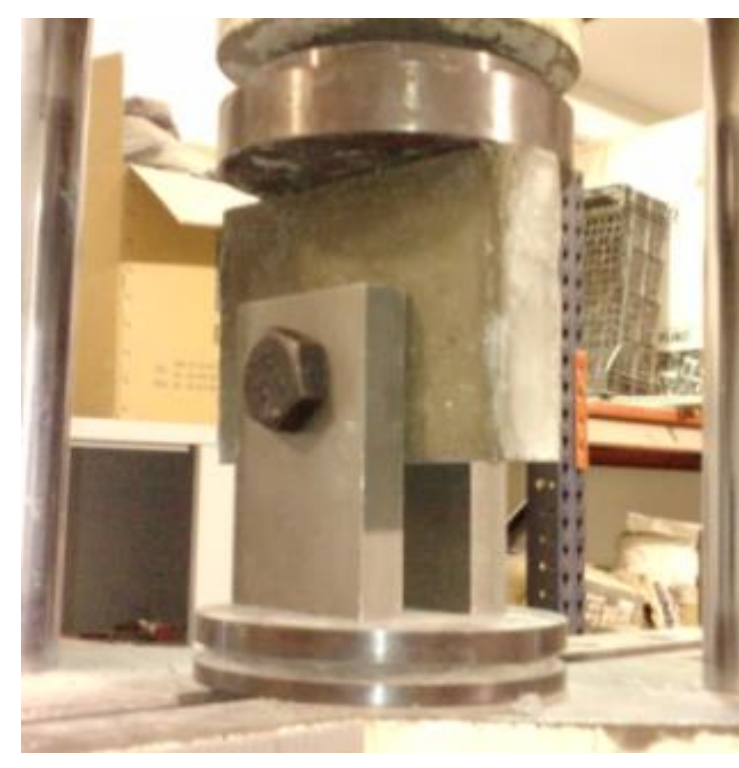

Figure 5.17: Bearing strength test set up

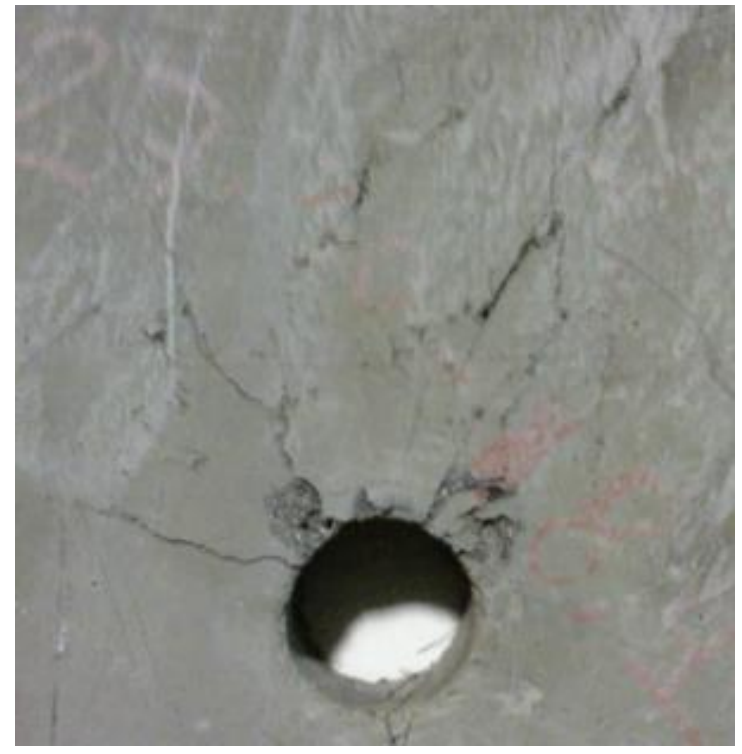

Figure 5.18: Bearing failure mode

\subsubsection{ANALYSIS OF THE PRELIMINARY TEST RESULTS}

In order to have a representative magnitude, the level of strength for the cleavage failure is evaluated as the load applied divided by the area behind the bolt $\left(\mathrm{E}-\mathrm{D}_{\text {hole }} / 2\right)^{*} \mathrm{t}$, named $\mathrm{F} / \mathrm{A}_{\mathrm{E}}$. This magnitude can be understood as an equivalent tension in Megapascals. For the tensile failure, the strength is measured as the load applied divided by the transversal area in the section crossing the hole, (W-D)*t. This will be named $F / A_{t}$, also as an equivalent tension in Megapascals.

A ductility parameter was measured as an objective criterion to evaluate the redistribution capacity ef each element. This dimensionless variable is obtained as the ratio between the displacement associated to the post peak load of $80 \%$ of the maximum load, and the displacement associated to the linear slope reaching the maximum load. Figure 5.19 abstracts the procedure. It is relevant that this ratio depends strongly on the distance measured by the LVDTs and the geometry of the element, being only comparable between comparable pieces of the same test.

Respect to the qualitative observations, generally no considerable damage was observed before reaching the maximum load. Unlike other composites used for connection tests, in which load drops to zero at maximum load, UHPFRC shells showed a relative ductile behavior. Table 5.3 shows the obtained results in equivalent MPa and the ductility ratio. As can be appreciated, the connection tests produced mainly two different failure modes, the net tension and the cleavage. In four of the tests the failure suffered was in the secondary bolt, being considered in the analysis. 


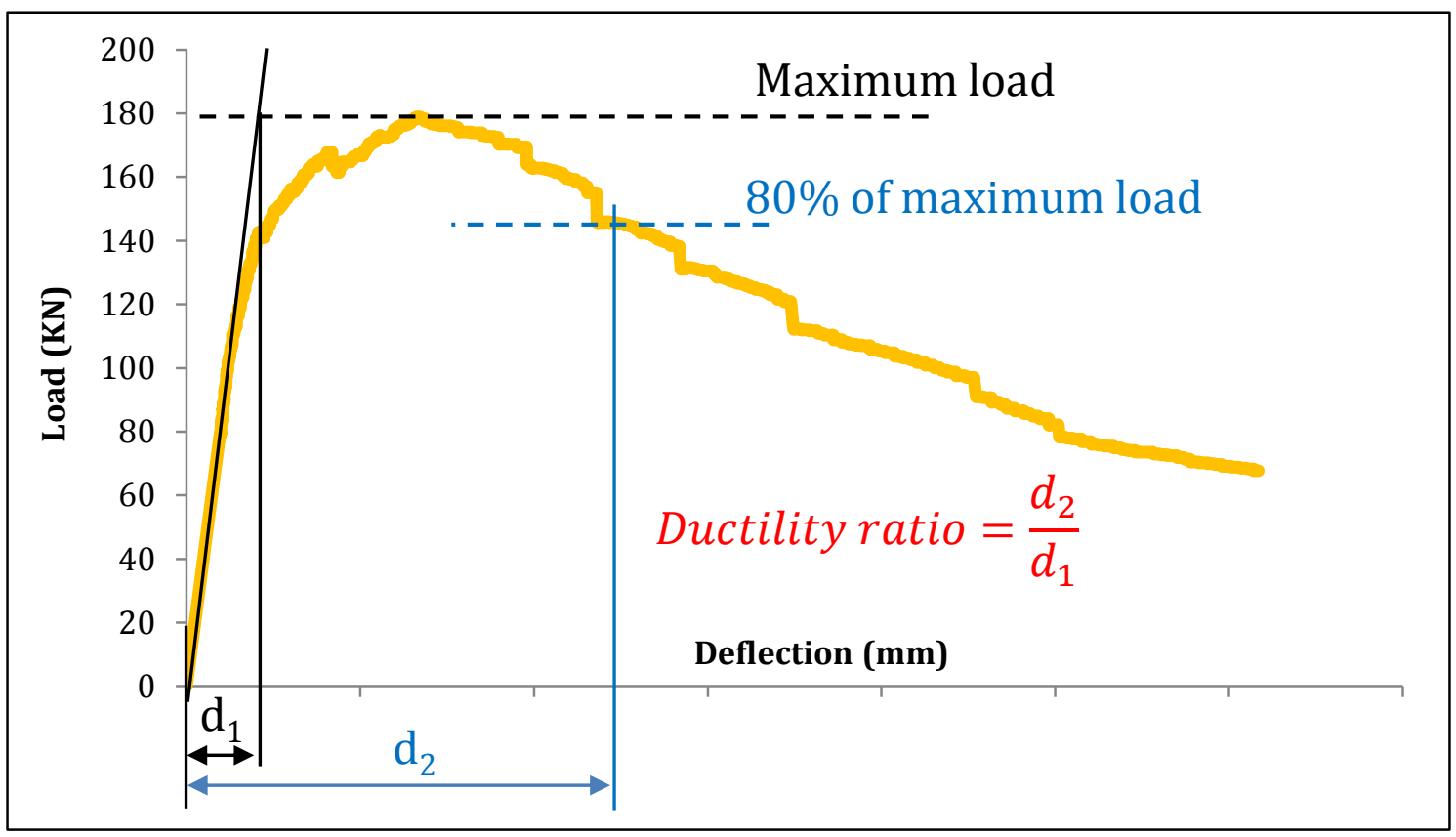

Figure 5.19: Procedure to obtain the ductility ratio for the tested elements

Table 5.3: Specimens geometry, failure modes and connection strength. Red colour shows the load of the failure mode

\begin{tabular}{|c|c|c|c|c|c|c|c|c|}
\hline $\begin{array}{c}\text { № } \\
\text { test }\end{array}$ & $\mathbf{t}$ & Dscrew & W/D & E/D & Failure & F/Ae (equiv. MPa) & F/At (MPa) & Ductility ratio \\
\hline 1 & 20 & 20 & 4 & 2 & Cleavage & 13,04 & $>6,47$ & 3.9 \\
\hline 2 & 20 & 20 & 8 & 2 & Cleavage & 15,72 & $>3,50$ & 5.7 \\
\hline 3 & 20 & 20 & 8 & 4 & Net tension & $>12,94$ & 6,35 & 6.6 \\
\hline 4 & 20 & 24 & 4 & 2 & Cleavage & 11,18 & $>5,24$ & 1.5 \\
\hline 5 & 20 & 24 & 8 & 2 & Cleavage & 10,30 & $>2,12$ & 8.4 \\
\hline 6 & 20 & 24 & 8 & 4 & Net tension & $>8,87$ & 4,39 & 2.3 \\
\hline 7 & 20 & 27 & 4 & 2 & Net tension & $>7,76$ & 4,33 & 6.2 \\
\hline 8 & 20 & 27 & 8 & 2 & Cleavage & 16,72 & $>3,64$ & 4.9 \\
\hline 9 & 30 & 20 & 4 & 4 & Net tension & $>6,64$ & 9,30 & 5.2 \\
\hline 10 & 30 & 20 & 8 & 2 & Cleavage & 12,99 & $>2,78$ & 7.1 \\
\hline 11 & 30 & 20 & 8 & 4 & Net tension & $>10,30$ & 5,09 & 2.1 \\
\hline 12 & 30 & 24 & 4 & 2 & Cleavage & 10,38 & $>4,50$ & 8.9 \\
\hline 13 & 30 & 24 & 8 & 2 & Cleavage & 10,57 & $>2,28$ & 3.4 \\
\hline 14 & 30 & 24 & 8 & 2 & Cleavage & 13,05 & $>3,41$ & 2.8 \\
\hline 15 & 30 & 27 & 8 & 2 & Cleavage & 18,15 & $>3,83$ & 4.8 \\
\hline 16 & 30 & 27 & 8 & 4 & 2o hole & $>13,08$ & $>6,41$ & 10.8 \\
\hline 17 & 40 & 20 & 4 & 2 & Cleavage & 14,68 & $>6,61$ & 5.1 \\
\hline 18 & 40 & 20 & 8 & 2 & Cleavage & 21,66 & $>4,77$ & 5.4 \\
\hline 19 & 40 & 24 & 4 & 2 & Cleavage & 11,42 & $>5,56$ & 1.7 \\
\hline 20 & 40 & 24 & 4 & 2 & Net tension & $>8,62$ & 4,28 & 4.1 \\
\hline 21 & 40 & 24 & 8 & 2 & Cleavage & 19,90 & $>4,43$ & 4.4 \\
\hline 22 & 40 & 24 & 8 & 4 & $2^{\text {o }}$ hole & $>14,02$ & $>7,18$ & 7.3 \\
\hline 23 & 40 & 24 & 8 & 4 & Net tension & $>11,64$ & 5,95 & 2.0 \\
\hline 24 & 40 & 27 & 4 & 2 & Net tension & $>9,94$ & 5,06 & 2.1 \\
\hline 25 & 40 & 27 & 8 & 2 & Cleavage & 11,60 & $>2,53$ & 4.5 \\
\hline 26 & 40 & 27 & 8 & 4 & $2^{\text {o }}$ hole & $>12,18$ & $>6,09$ & 5.1 \\
\hline 27 & 40 & 27 & 8 & 4 & $2^{\circ}$ hole & $>13,98$ & $>6,97$ & 4.7 \\
\hline
\end{tabular}


The two main cracking patterns observed, cleavage and net tension, are shown at figures 5.20 and 5.21, where the equivalent strengths are related with the displacements for the failures. As was expected from previous tests [38], no shear out failure was observed due to the high UHPFRC shear strength. Neither any bearing failure, was expected from the predimensioning.

The cleavage failure seemed to be more stable than the net tension one. In it, one crack starts from the centre of the specimen's bottom, and after that two cracks from the hole are developed along the horizontal section, providing an additional ductility (see figure 5.22). Considering those mechanisms can be understood the importance of the fiber orientation around the full hole, most significant in the cleavage mode due to the three cracks developed.

The net tension failure mode showed no uniform crack opening along all the section, developing the crack from a local damage in one of the external sides to the hole, with a center of rotation in the other external side (figure 5.23). As a consequence, the total section couldn't collaborate and the obtained values for net tension strength were in the magnitude order of half of the deduced direct tensile strength of the UHPFRC ( 4 to 7 equivalent MPa).

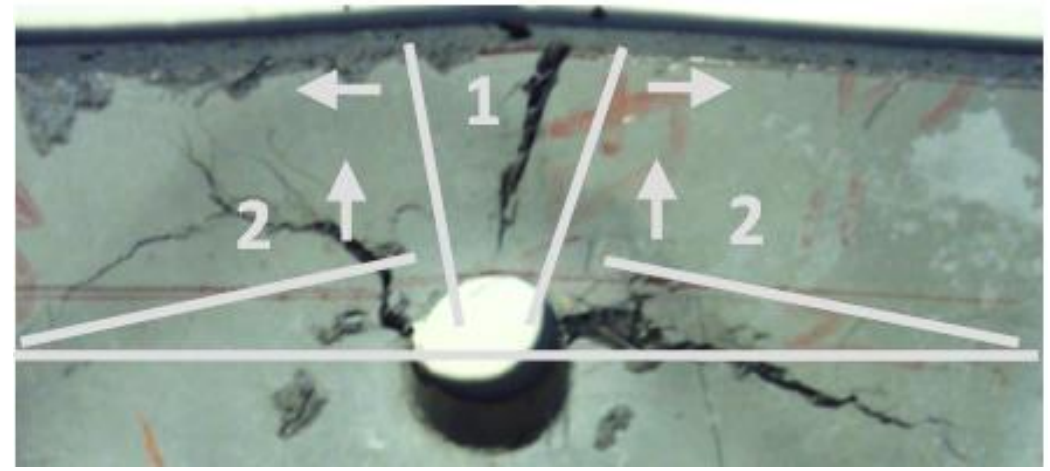

Figure 5.20: Crack pattern for the cleavage failure of the shell 20-27-8-2

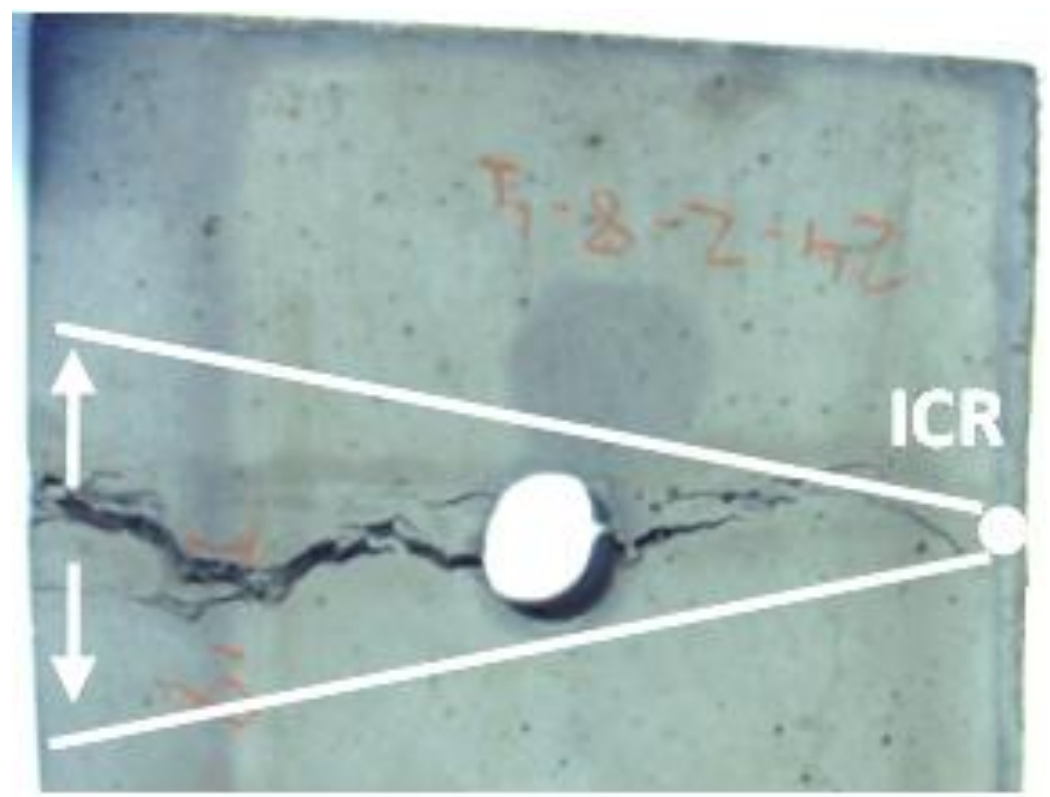

Figure 5.21: Crack pattern of the net tension failure for the shell 20-24-8-4 


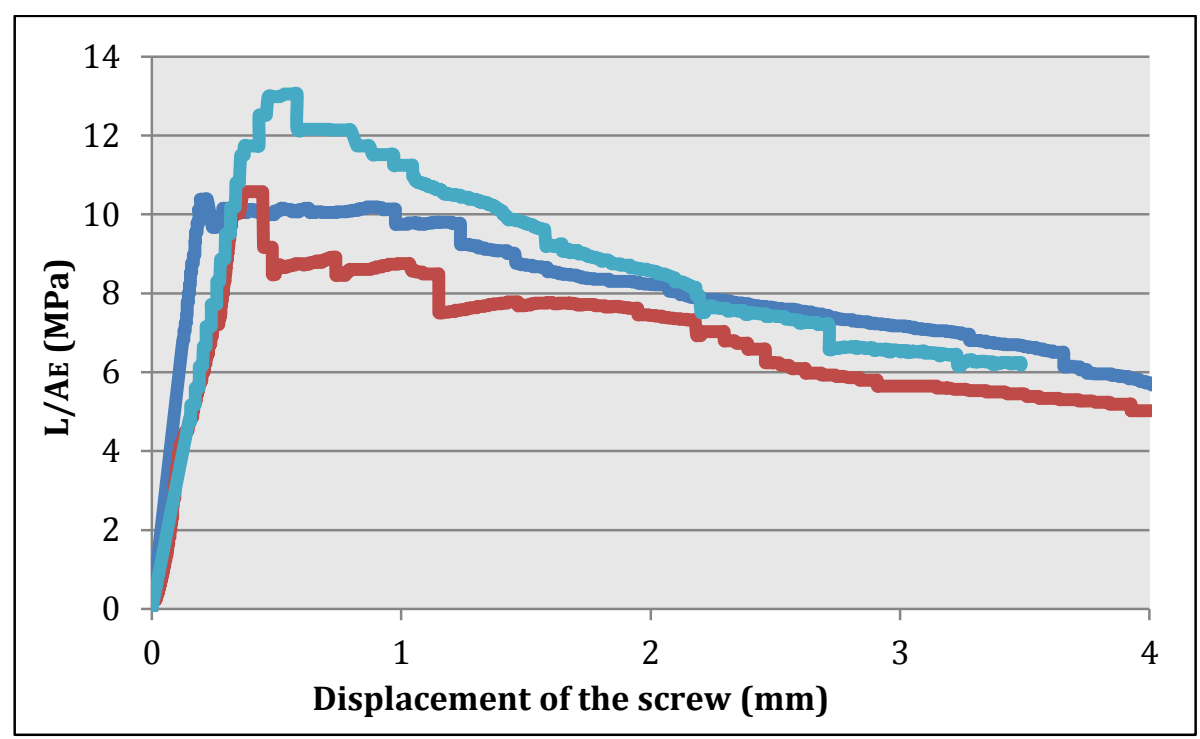

Figure 5.22: Equivalent strength related with the displacement of the screw for cleavage failures

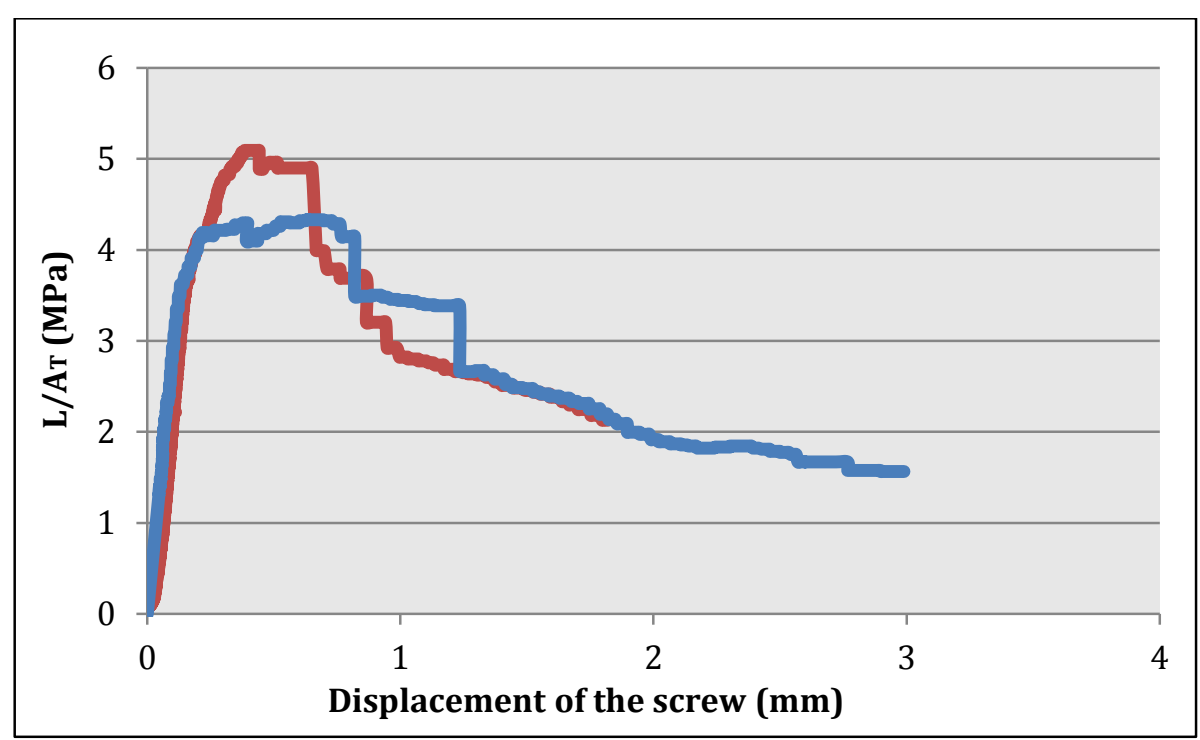

Figure 5.23: Equivalent strength related with the displacement of the screw for net-tension failures

Cleavage failure mode was associated to all the larger specimens $\left(\mathrm{W} / \mathrm{D}_{\text {hole }}=8\right)$ and with low cover $\left(E / D_{\text {hole }}=2\right)$. In specimens with longer cover $\left(E / D_{\text {hole }}=4\right)$ only net tension were observed even with cleavage stresses higher than in elements with $\mathrm{E} / \mathrm{D}_{\text {hole }}=2$ cracking by cleavage. For intermediate cases $\left(\mathrm{W} / \mathrm{D}_{\text {hole }}=4\right.$ and $\left.\mathrm{E} / \mathrm{D}_{\text {hole }}=2\right)$ both cleavage and net tension failures may occurs. The thickness of the specimen or screw diameter didn't seem to be relevant in the failure mode, as can be seen on figures 5.25 and 5.26 .

There is a slight tendence that, for similar $E$, higher value of $F / A_{E}$ is produced for specimens with $\mathrm{W} / \mathrm{D}_{\text {hole }}=8$ than for $\mathrm{W} / \mathrm{D}=4$ due to the higher length for develop these two secondary horizontal cracks (Figure 5.25). It is also noticed a size effect in specimens failing by cleavage with $\mathrm{W} / \mathrm{D}_{\text {hole }}=4$ and $\mathrm{E} / \mathrm{D}_{\text {hole }}=2$, where the cleavage strength is higher as much as reduced is the diameter. The effect is distinguished in figure 5.25. With higher ratios of $W / D_{\text {hole }}$ and $E / D_{\text {hole }}$ the redistribution capacity is higher, and the size effect is not evident anymore. No clear size effect is found for the elements that suffer net tension failure (Figure 5.26). 


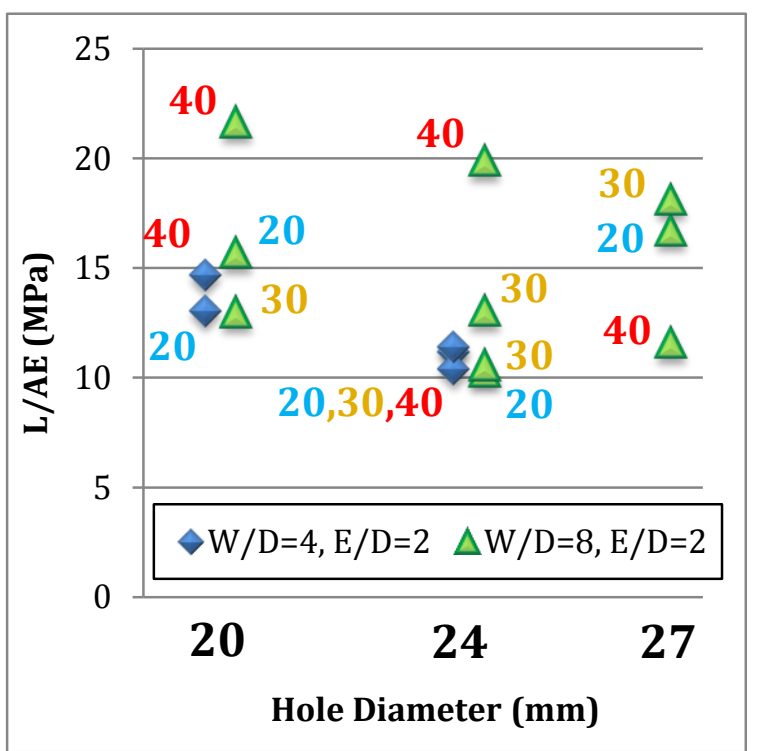

Figure 5.25: Equivalent strength vs hole diameter for cleavage failure mode

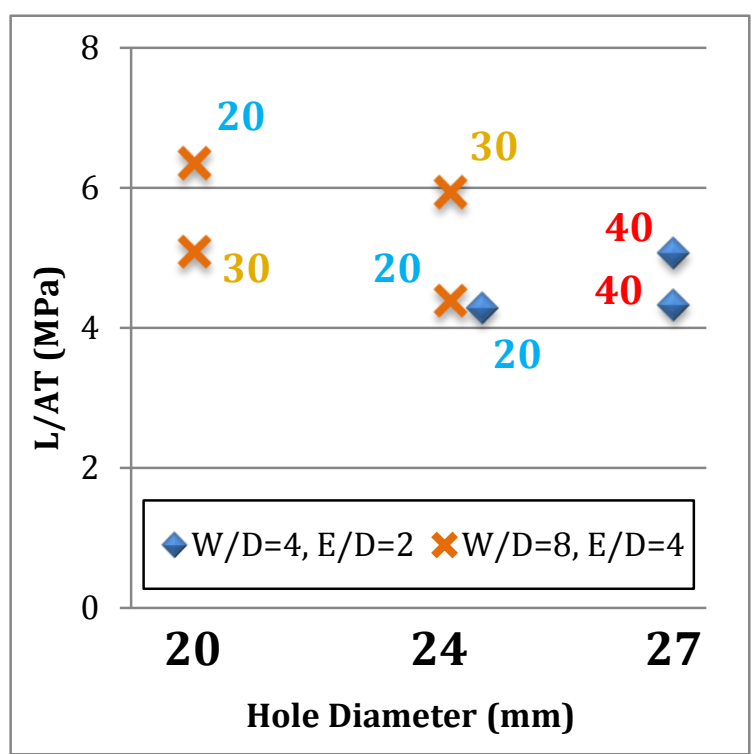

Figure 5.26: Equivalent strength vs hole diameter for net-tension failure mode

It was clearly observed on figures 5.22 and 5.23 the higher ductility of the cleavage failure modes, where the post peak behavior slope is less steep. Figure 5.24 quantify this phenomena for all the tests performed, and shows that the ductility ratio is higher for cleavage (average of 5) than for net tension (average of 3.8), specially for the elements with higher width (W=8), as they develop two longer macrocracks to be compatible with the hole displacement. Net tension doesn't seem to experience a change in the ductility ratio when the element increase the $\mathrm{W}$ value. It is finally observed that the ductility ratios have a considerable scatter for the same type of W/D and E/D chosen. This will be one of the reasons to suggest an improved test procedure.

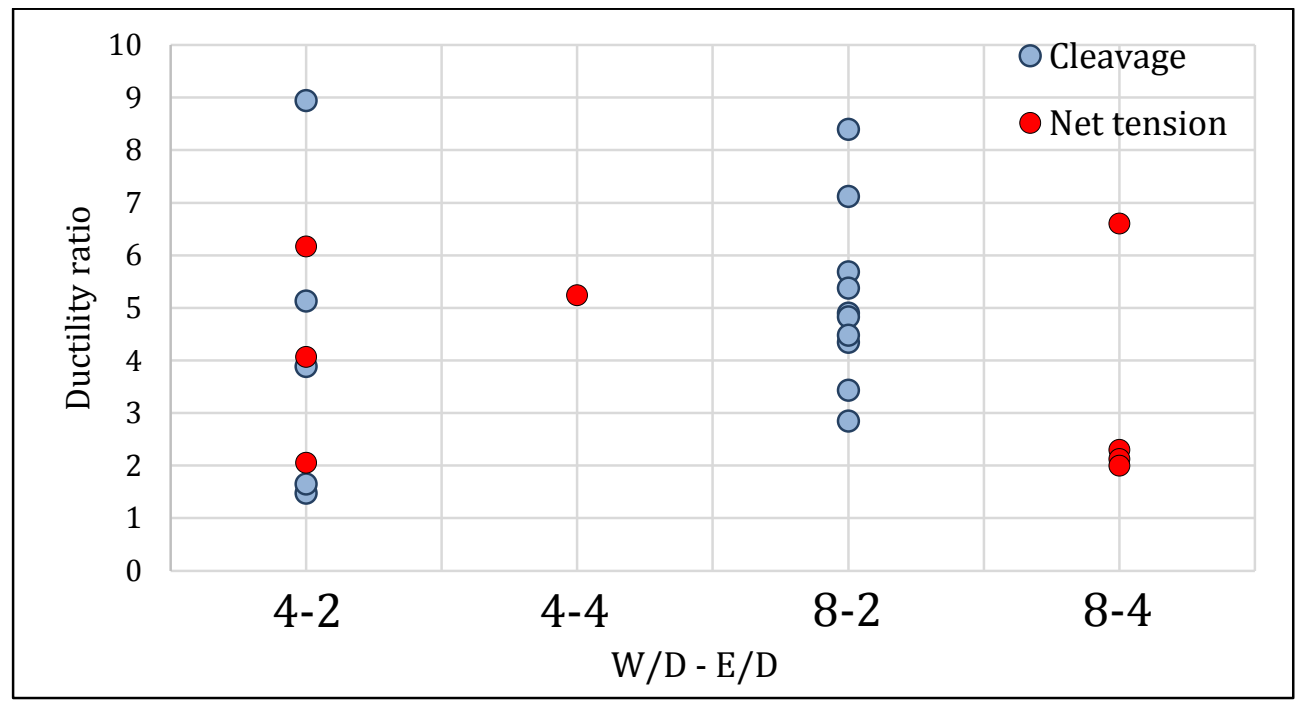

Figure 5.24: Ductility ratio for the different failure modes

Relative to the bearing capacity, it was determined for 12 holes, observing a ductile behavior. The equivalent compressive strength was measured as the load divided by the vertical area of contact $F /\left(D_{\text {bolt }} * t\right)$. It is clearly observed that, the smaller the bolt, the higher the strength, due to the intensity of biaxial compressive state. The effect is represented at figure 5.27. More test are necessary in the future to study the effect of the free length over the bolt, 
which in these tests is $200 \mathrm{~mm}$. Longer distance might imply a reduction of the bearing strength.

An increase of the bolt diameter may increase linearly the bearing load resisted, but in quadratic proportion the shear strength of the bolt. This explains the increase of the safety factor of the shear bolt failure when the bolt diameter is increased, as is shown in figure 5.28.

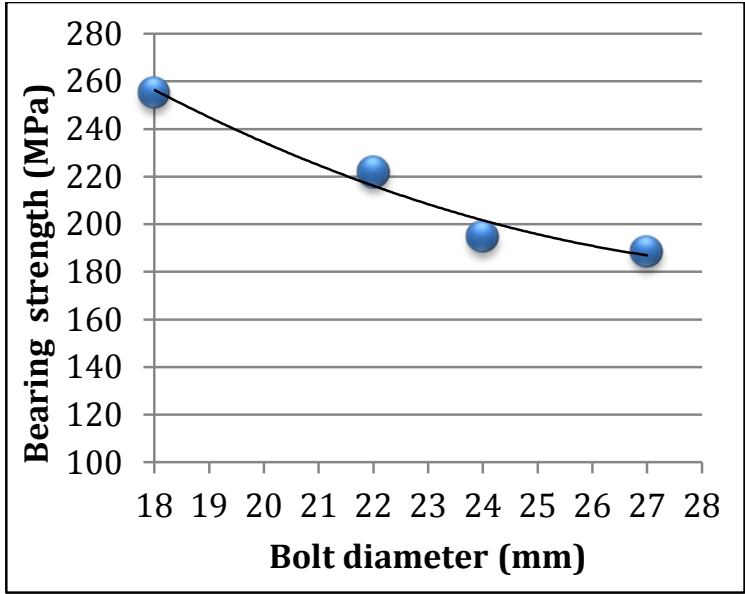

Figure 5.27: Bearing strength depending on the bolt diameter

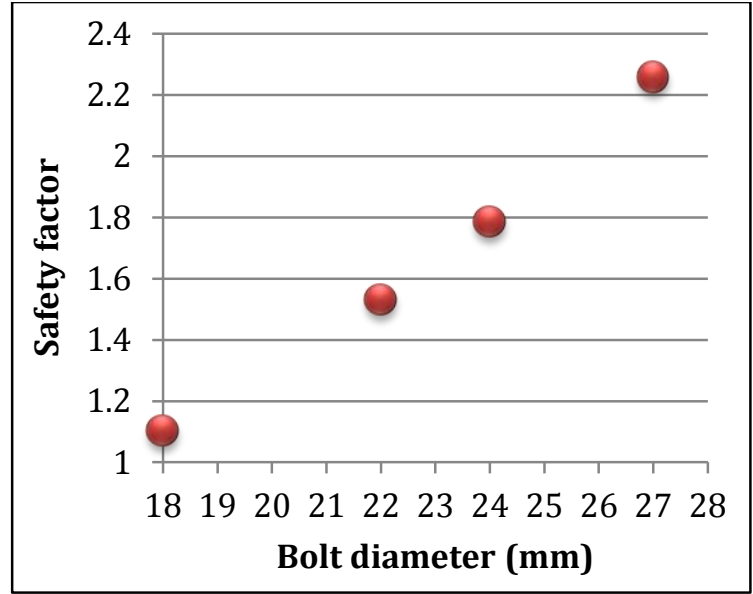

Figure 5.28: Safety factor for the shear failure of the bolt depending on its diameter

The efficiency of the pouring method was evaluated. As commented before, the pouring was the focused to take profit of the wall effect, gravity and concrete fluidity (figure 5.29). The efficiency was verified by means of an X-Ray analysis done to four of the specimens (figure 5.30). The orientations observed in the cleavage sections were satisfactory, while in the net tension sections fibers were worse aligned, probably due to the secondary flows generated.

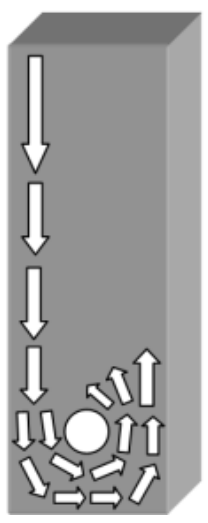

Figure 5.29: Casting process, desired/expected orientation

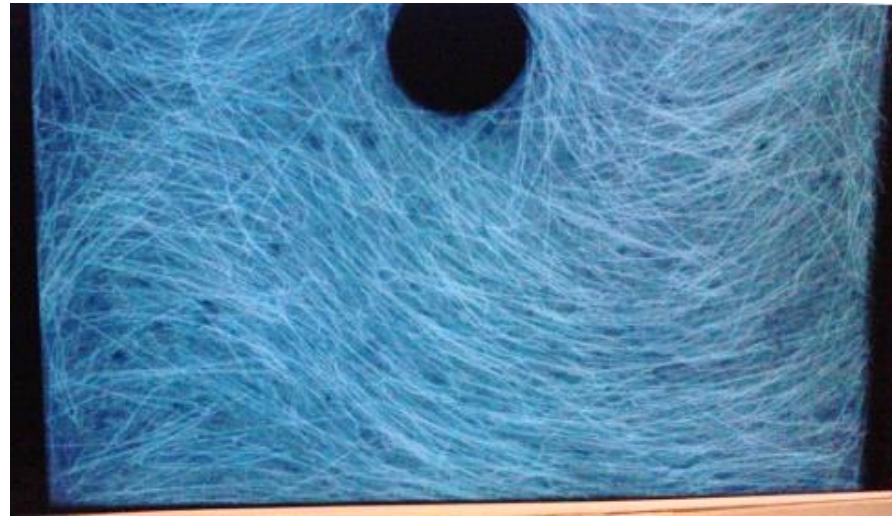

Figure 5.30: X-Ray fotography around the hole for one of the specimens

\subsubsection{CONCLUSIONS OF THE PRELIMINARY TESTS}

Some conclusions of this test process can be highlighted:

- The only failures modes detected in the test have been cleavage and net tension. Cleavage depends directly on the cover distance (E) and increases its ductility with the width W. Net tension suffers more brittle post peak behavior, which could be improved introducing ordinary reinforcement. 
- Net tension failure can't be directly estimated with the maximum tensile strength, due to the propagation of a crack through the section from one of the sides. Normally the equivalent strength obtained is half of the tensile strength of the concrete, which is approximately $12 \mathrm{MPa}$.

- The bearing failure was ductile and the equivalent compressive strength resulted higher than the expected from the uniaxial compressive tests performed to $100 \mathrm{~mm}$ cubes. Additional tests are required with longer distances over the hole to evaluate the bearing failure in more realistic conditions.

- The influence of the elements thickness is negligible, while the influence of the bolt diameter has a limited relevance.

- Some inconvenients were identified relative to the testing procedure:

- In $15 \%$ of the tests the failure was suffered in the auxiliary hole, which is supposed to be only part of the testing procedure. Unexpected failure modes as this should be avoided. The conception of a new test procedure should have a stronger reinforced secondary hole, or modify the piece to have only one.

- Distance between holes was sometimes too reduced, as the distance between the testing machine anchors limited markedly the length of the test performed. Then, a possible change of testing machine would increase the possibilities of the new connection tests.

- Even though was possible to obtain conclusions, results provided significant dispersion, especially in the ductility ratios. This makes sense to design an alternative testing method, and places particular emphasis in the necessity of cast more number of specimens with similar geometry to evaluate the dispersion of identical pieces.

- More geometrical variations of the pieces are required, in order to identify better the tendencies. Also reinforced or presstresed specimens must be evaluated.

\subsection{IMPROVED PROPOSAL: SINGLE BOLTED TEST (T)}

\subsubsection{TEST SET UP}

At the preliminary bolted tests, were obtained the failure modes, ultimate load and ductility ratio. However, and despite of the marked dispersion obtained, it was worth to identify problems that could be solved in a second test version: The one presented here.

The testing machine was changed so it does not pull the elements as before, avoiding the risk of the testing auxiliary bars slipping between the jaws. This change allowed also to introduce longer elements, and then introduce the ordinary bars in the UHPFRC to improve the net tension strength and ductility. The secondary hole was removed, reaching better stress distribution around the studied region.

The element designed to develop this single bolted test proposal has $\mathrm{T}$ geometry (figure 5.31), where the thin longer part has a section of $200 \times 50 \mathrm{~mm}$ (similar to the designed tie shown on Annex I around the joint region). The upper part, with two wings, was used to carry the load transmitted by the joint to both supports placed at the sides. In a first concept test was proven that premature failure could be suffered in the wings, so the thickness of this region 
was increased up to $80 \mathrm{~mm}$ and was reinforced with $10 \mathrm{~mm}$ diameter steel bars. The dimension represented by letter $\mathrm{E}$ on figure 5.31 is variable depending on the specimen according to the experimental program designed.

The variables modified were less than before, as the element thickness and bolt diameter seemed to have in the previous tests a limited relevance. Thus, adopt a constant value for them (50 $\mathrm{mm}$ and $20 \mathrm{~mm}$ ) let focus the problem in the modified variables.

The width $\mathrm{W}$ also remained constant $(\mathrm{W} / \mathrm{D}=9$ for all elements), as the previous results suggested that, to increase the net tension load and ductility, is more efficient introduce ordinary steel than increase $\mathrm{W}$. This was the reason to include the use of ordinary bars and wires as variables. The cover $E$ was also a variable as it affects directly to the cleavage strength ( $E$ varied between 70 and $250 \mathrm{~mm}$, reaching values of $E / D_{\text {hole }}$ between 3.2 and 11.4).

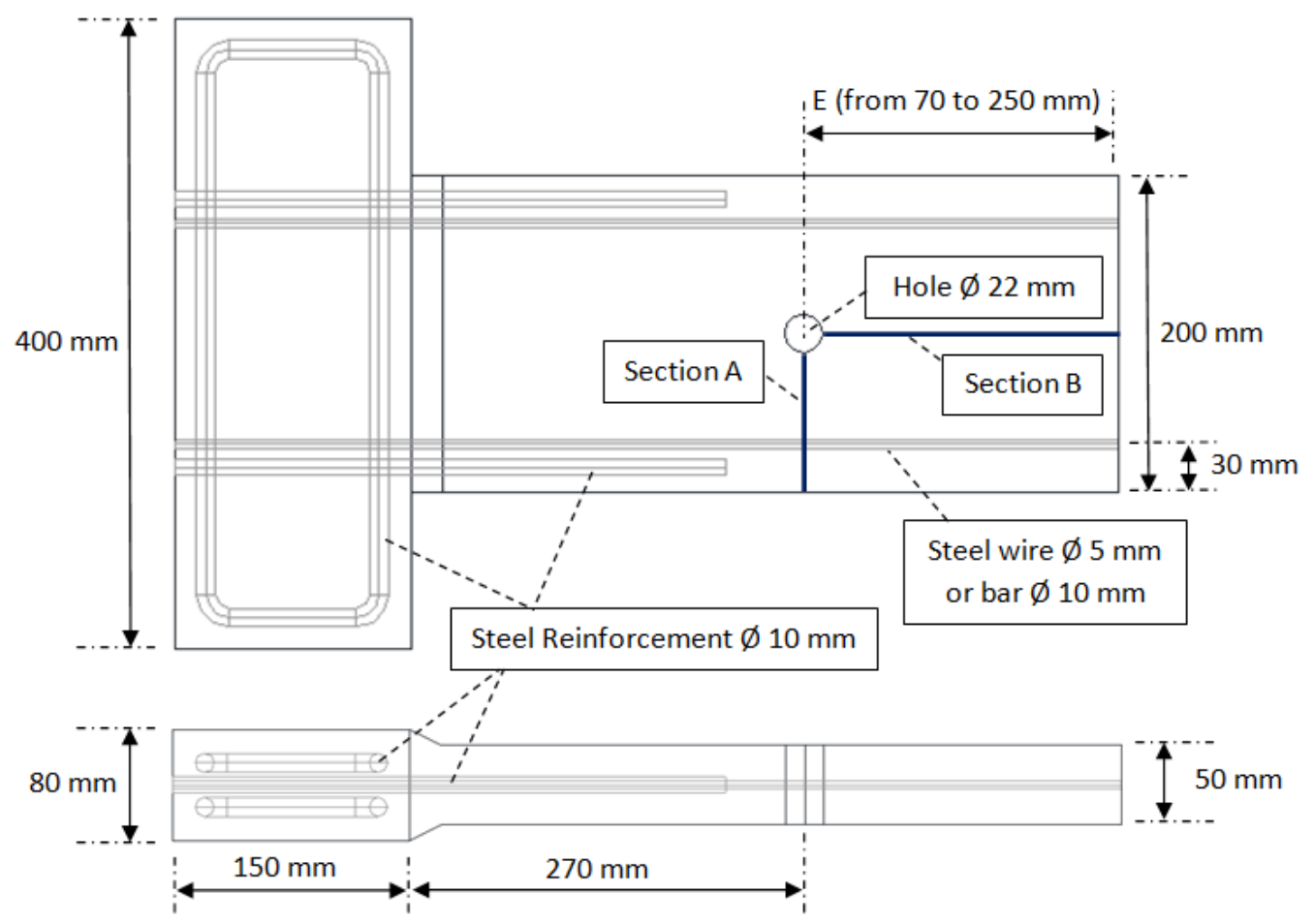

Figure 5.31: Geometry of the elements submitted to the single hole connection test

The hole in the piece was introduced with the formwork, in order to obtain softer surface than drilling (figures 5.32 and 5.33). The UHPFRC was poured through one of the lateral sides of the formwork (upper part at figure 5.31), producing an advance of the flow in the longitudinal direction in order to favour the alignment of the fibers in this plane.

The High Strength Bolt used for the joint had a diameter of $22 \mathrm{~mm}$ and was type 10.9 according with the classes defined in the Eurocode 3, part 1-8. No pretension was induced to the bolt, which was screwed manually.

The test was performed applying an increasing centred force with a $500 \mathrm{kN}$ hydraulic jack (figures 5.34 and 5.35). This force was transmitted from the jack to the UHPFRC element bolt zone symmetrically by means of two steel shells placed at both sides as shown in figures 5.36 to 5.38. The steel shells used to apply the force might rotate around the hole with the load application, producing a slight instability during the testing. Then, four LVDTs were placed in the four sides of the element to control the possible rotation during the test. 


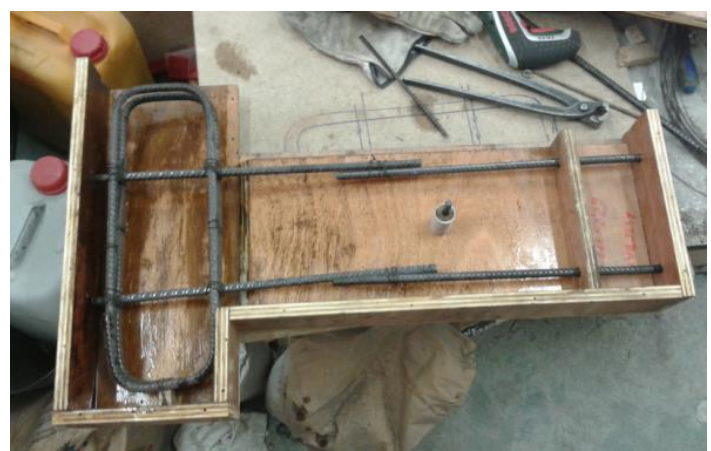

Figure 5.32: Formwork of the elements

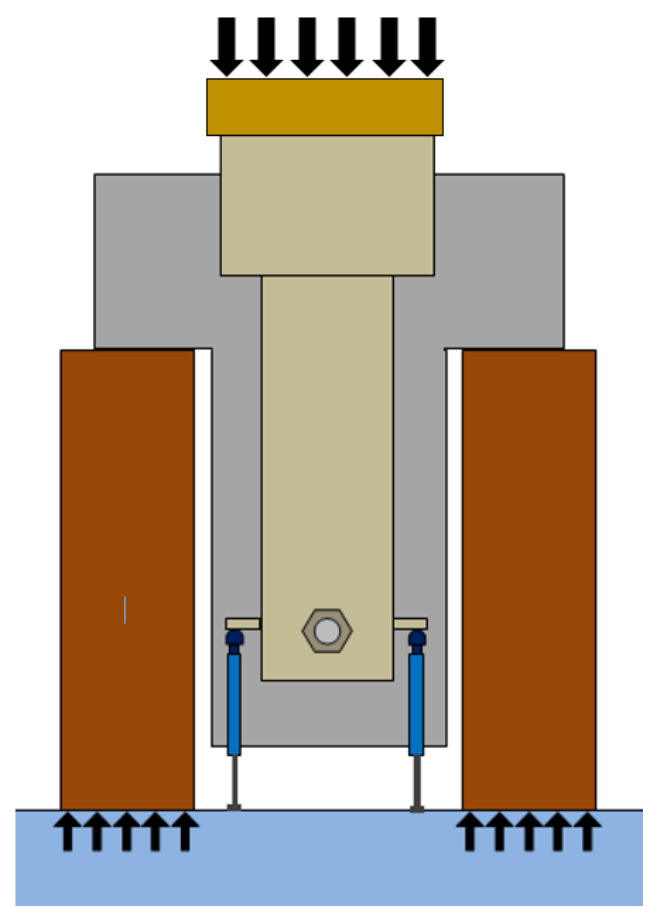

Figure 5.34: Test set up scheme. Front view. The upper green steel piece is shown at figure 5.36

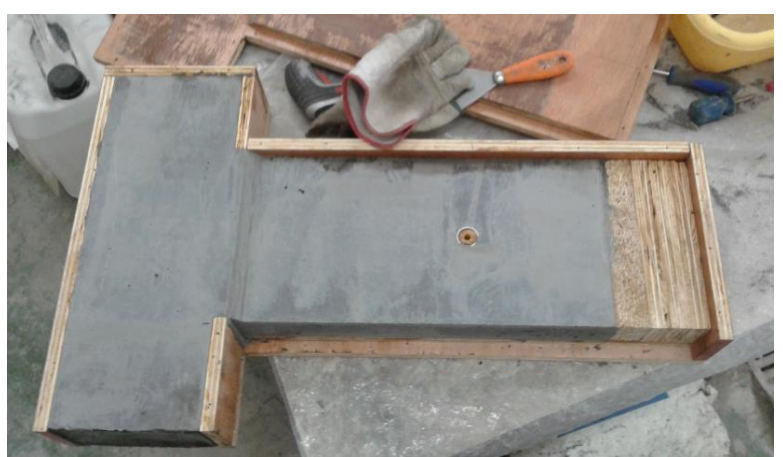

Figure 5.33: Element in the demoulding process

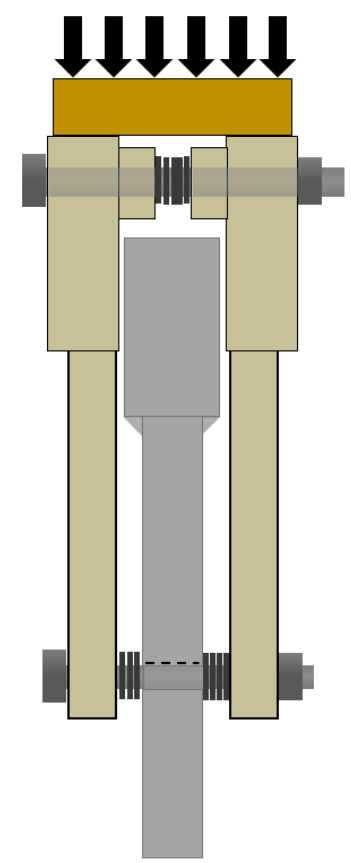

Figure 5.35: Test set up. Lateral view. The upper green piece is shown at fig.5.36

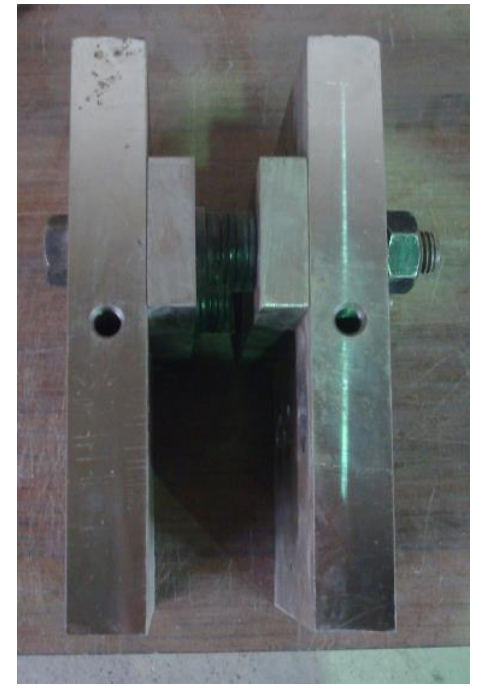

Figure 5.36: Steel pieces, placed in the upper part to apply the symmetrical load

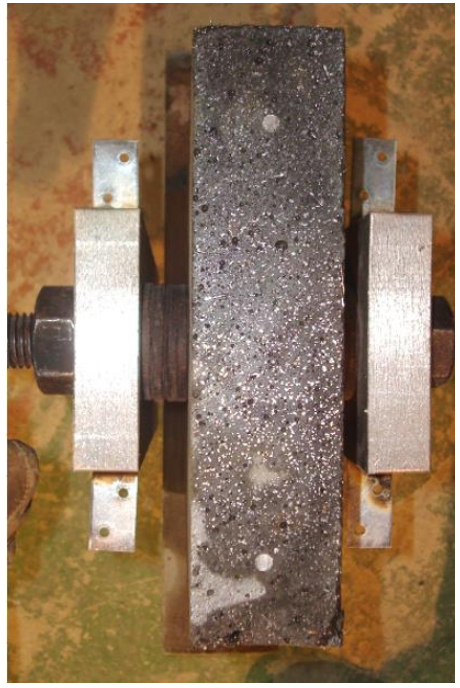

Figure 5.37: piece with the steel shells and bolt, before place it. View from bottom part

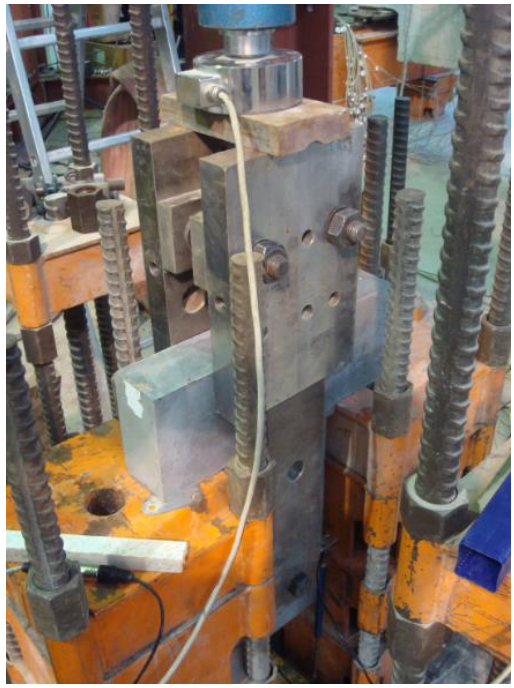

Figure 5.38: Test set up 


\subsubsection{EXPERIMENTAL PROGRAM}

The UHPFRC mix design used to cast the specimens and characterize the mechanical/rheological properties was developed in UPV, and is the one defined as F3-HY in the section 4.11.2. Two pieces of each type were performed in order to study the variability of the results. The experimental test program included two variables:

- The length of the concrete between the centre of the hole and the bottom of the element (E) (figure 5.31), with values of 70,100, 150, 200 and $250 \mathrm{~mm}$.

- The specimen longitudinal reinforcement. In some of them no reinforcement was placed. Other were made with two $\emptyset 10 \mathrm{~mm}$ reinforcing bars with nominal yield strength of 500 $\mathrm{N} / \mathrm{mm}^{2}$. This passive reinforcement could be plastified without a visible macrocrack, being thus very adequate for work with UHPFRC. The last reinforcement proposed contained two wires of $\emptyset 5 \mathrm{~mm}$ with a nominal ultimate strength of $1860 \mathrm{MPa}$. No prestress was provided because of the limiting conditions at the laboratory, but it was suggested because the prestress of this elements in a prefabricated company would have sense.

Testing program consist of 22 elements. The geometry and reinforcement of the 22 pieces tested are shown in the table 5.4.

Table 5.4: Variables of the elements tested

\begin{tabular}{|c|cc|}
\hline $\mathbf{E}$ (mm) & Passive steel & № pieces \\
\hline $\mathbf{7 0}$ & No & 2 \\
$\mathbf{1 0 0}$ & No & 2 \\
$\mathbf{1 5 0}$ & No & 2 \\
$\mathbf{2 0 0}$ & No & 2 \\
$\mathbf{1 0 0}$ & 2wires, Ø5 & 2 \\
$\mathbf{1 5 0}$ & 2wires, Ø5 & 3 \\
$\mathbf{2 0 0}$ & 2wires, Ø5 & 2 \\
$\mathbf{2 5 0}$ & 2wires, Ø5 \\
$\mathbf{1 5 0}$ & 2bars, Ø10 \\
$\mathbf{2 0 0}$ & 2bars, Ø10 \\
$\mathbf{2 5 0}$ & 2bars, Ø10 & 2 \\
\end{tabular}

\subsubsection{SINGLE BOLTED TEST RESULTS AND ANALYSIS}

The connection test proposed was developed successfully without instabilities and reaching the failures in the region of study. The maximum load, dispersion and failure modes of the 22 pieces tested are shown in the table 5.5. The ductility ratio is shown afterwards, at figures 5.46, 5.50 and 5.51. In bold red format is marked the failure suffered by the pieces. Generally, no considerable crack opening occurred before reach the maximum load.

The magnitude used to evaluate the capacity to cleavage failure was quantified, as before, by the equivalent strength Load/ $A_{E}$, being $A_{E}$ the area behind the hole in longitudinal direction (section $B$ in figure 5.31). Equivalent tensile strength in the section crossing the hole quantifies the capacity to net tension failure, and it is evaluated by the load over the homogenised sectional area Load $/\left(2 * A_{T}\right)$, being $A_{T}$ the sectional area shown before at figure 5.31 . 
Only two failure modes were suffered in the elements, and the typical cracking patterns are shown in figures from 5.40 to 5.43. Cleavage failure in elements without ordinary steel reached maximum load when the main crack behind the bolt (along section $B$, parallel to the tension) was measuring 0.7-1.5 mm (observed during the test). The development of this crack seemed to induce the growth of two orthogonal cracks in section B, as was observed in the first test type proposed (section 5.3). The same cracking pattern was observed by Hammoud and Naaman [101] for the cleavage failure of ferrocement bolted shear joints.

Table 5.5: Average maximum load, average equivalent strength, deviation from the average (dev.) and failure modes of the pieces tested

\begin{tabular}{|c|c|c|c|c|c|c|c|c|}
\hline $\begin{array}{c}\mathbf{E} \\
(\mathrm{mm})\end{array}$ & $\begin{array}{c}\text { E/Dhole } \\
(\mathrm{mm} / \mathbf{m m})\end{array}$ & $\begin{array}{c}\text { Passive } \\
\text { steel }\end{array}$ & $\begin{array}{c}\text { № } \\
\text { elem. }\end{array}$ & $\begin{array}{c}\text { Max load } \\
(\mathrm{kN})\end{array}$ & $\begin{array}{l}\text { Dev. } \\
(\%)\end{array}$ & Failure modes & $\begin{array}{l}\text { F/AE } \\
\text { (MPa) }\end{array}$ & $\begin{array}{l}\text { F/2At } \\
\text { (MPa) }\end{array}$ \\
\hline 70 & 3.2 & No & 2 & 37,3 & $1,0 \%$ & Cleavage. Ductile. & 12,7 & 4,2 \\
\hline 100 & 4.5 & No & 2 & 50,1 & $1,3 \%$ & Cleavage. Ductile. & 11,3 & 5,6 \\
\hline 150 & 6.8 & No & 2 & 53,7 & $1,2 \%$ & Net tens. Brittle & 7,7 & 6,0 \\
\hline 200 & 9.1 & No & 2 & 61,3 & $0,9 \%$ & Net tens. Ductile. & 6,5 & 6,9 \\
\hline 100 & 4.5 & 2wires, Ø5 & 2 & 43,1 & $16,9 \%$ & Cleavage. Ductile. & 9,7 & 4,8 \\
\hline 150 & 6.8 & 2wires, Ø5 & 3 & 74,3 & $10,2 \%$ & Both. Brittle. & 10,7 & 8,2 \\
\hline 200 & 9.1 & 2wires, Ø5 & 2 & 96,4 & $1,3 \%$ & Net tens. Ductile. & 10,2 & 10,7 \\
\hline 250 & 11.4 & 2wires, $\varnothing 5$ & 1 & 81,0 & - & Net tens. Ductile. & 6,8 & 9,0 \\
\hline 150 & 6.8 & 2bars, $\emptyset 10$ & 2 & 67,4 & $3,3 \%$ & Cleavage. Ductile. & 9,7 & 7,1 \\
\hline 200 & 9.1 & 2bars, $\emptyset 10$ & 2 & 98,8 & $8,4 \%$ & Cleavage. Ductile. & 10,5 & 10,4 \\
\hline 250 & 11.4 & 2bars, $\emptyset 10$ & 2 & 111,4 & $4,5 \%$ & Both. Ductile. & 9,3 & 11,7 \\
\hline
\end{tabular}

Net tension failure in the elements without conventional reinforcement happens with a maximum equivalent stress in section A of 6-7 MPa, lower value than the maximum tensile strength of $12 \mathrm{MPa}$ deduced from inverse analysis for the UHPFRC. This is an evidence of the no homogeneous stress distribution along the section, as could be expected for a D-Region. In the case of reinforced elements, strength reached is higher as the area is homogenized with the steel.

In the case of the net tension failure (figure 5.43), generally crack emanates from a hole border, opening gradually towards one of the sides of the element. The net section failure doesn't have similar crack thickness along all the section due to the material anisotropy.

Element with two wires and $\mathrm{E}=150 \mathrm{~mm}$ provided lower value of equivalent tensile strength than those with two bars. One of the reasons is that $5 \mathrm{~mm}$ prestressing wires used have almost smooth surface. This increases the transmission length comparing with the bars, requiring an E longer than $150 \mathrm{~mm}$ to reach a total transmission. Visual checking to pieces with $\mathrm{E}=150 \mathrm{~mm}$ showed how in the bottom of the element the wire experienced a relative movement respect to the concrete of approximately $1 \mathrm{~mm}$. According to the results of the tests, at least $200 \mathrm{~mm}$ of $\mathrm{E}$ are necessary to reach an adequate transmission of the load.

It can be deduced from table 5.5 that all specimens with $\mathrm{E}$ below $150 \mathrm{~mm}$ develop cleavage failure, obtaining an equivalent strength in section B between 9,7 and 12,7 MPa. As can be seen in figure 5.39, the maximum load reached seems to increase linearly with the increasing length E, which means that this value, in the range studied, does not affect significantly to the 
equivalent strength $\mathrm{F} / \mathrm{A}_{\mathrm{E}}$. In other words, if the figure 5.39 is represented with the equivalent strength $F / A_{E}$ instead of the load, all values would be very similar. However, the $E$ value does affect to the ductility, as will be later commented.

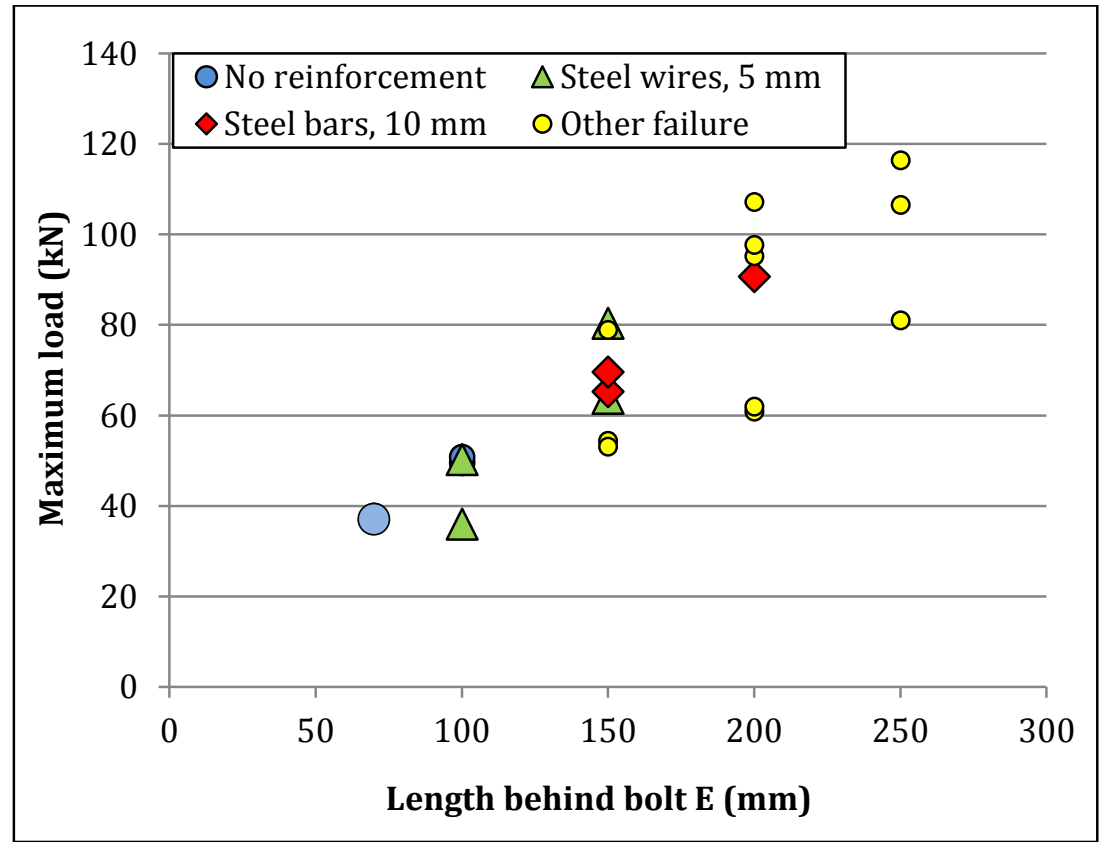

Figure 5.39: Maximum load reached related with the distance E in the elements that suffered cleavage failure

Some doubts were raised if the longitudinal reinforcement might help to avoid the crack development in this section due to the bending stiffness, but here didn't seem to increase significantly this load value. However, if a specimen would be prestressed the active steel could increase the strength as the direction of the prestressing load tends to avoid more effectively the crack opening.

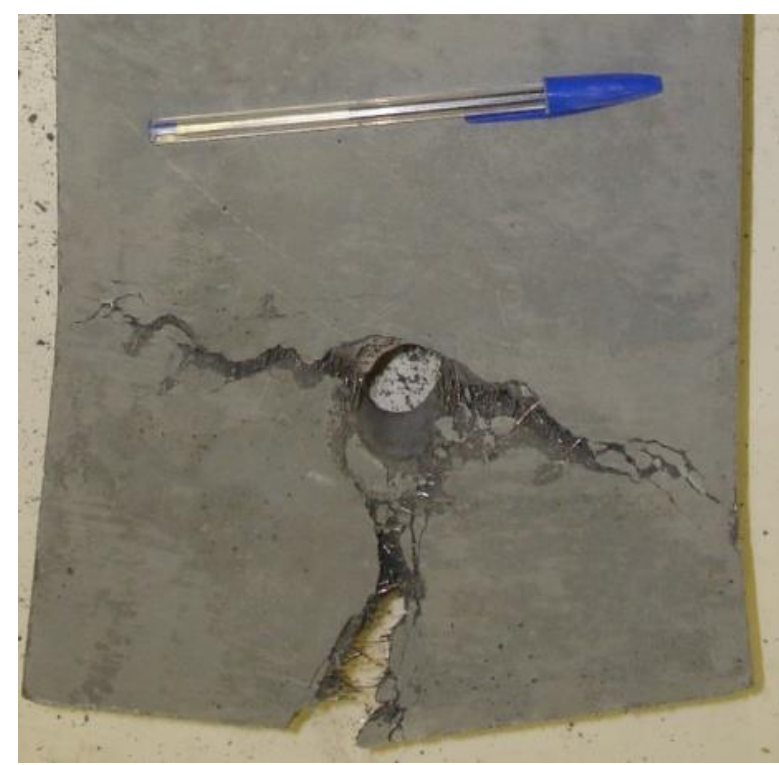

Figure 5.40: Cleavage failure of an element without reinforcement and $E=100 \mathrm{~mm}$

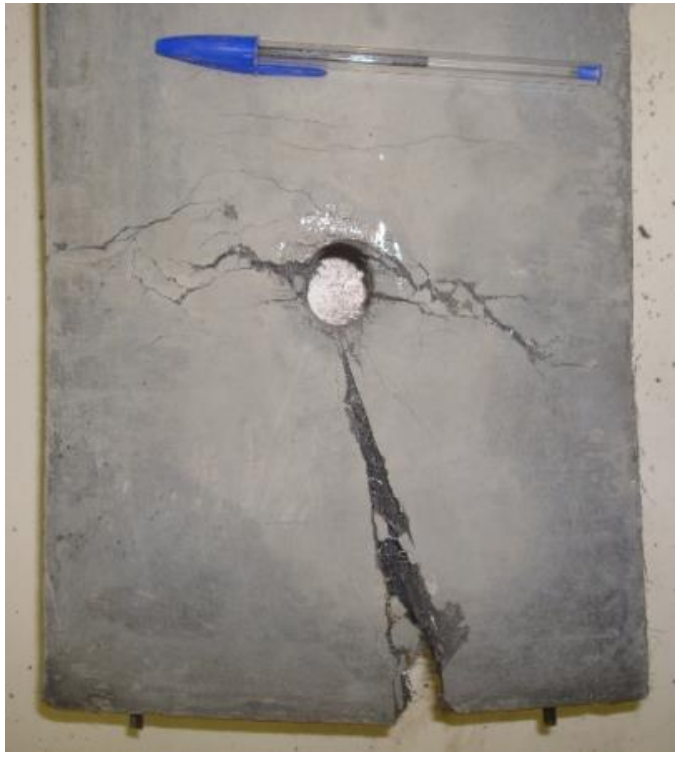

Figure 5.41: Cleavage failure of element with wire reinforcement and $E=150 \mathrm{~mm}$ 


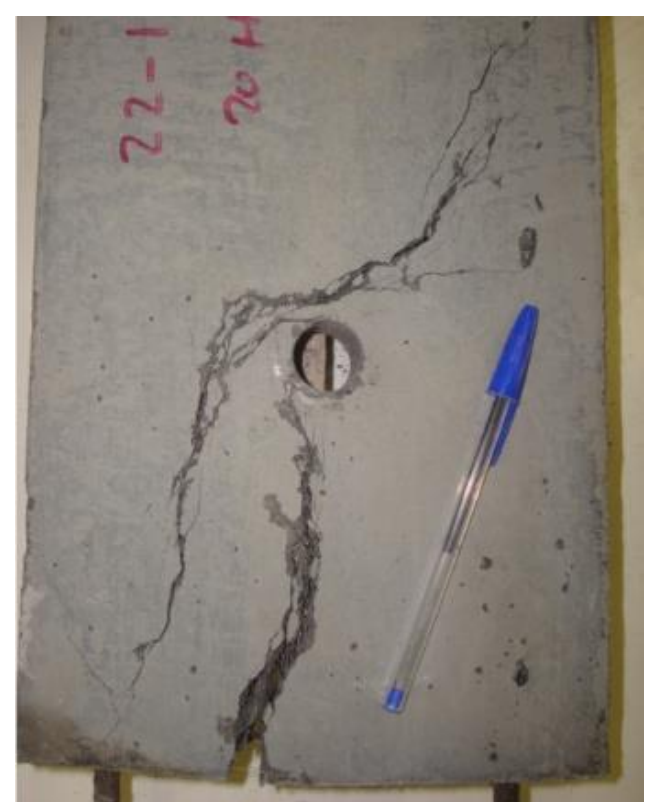

Figure 5.42: Cleavage failure of an element with bar reinforcement and $E=150 \mathrm{~mm}$

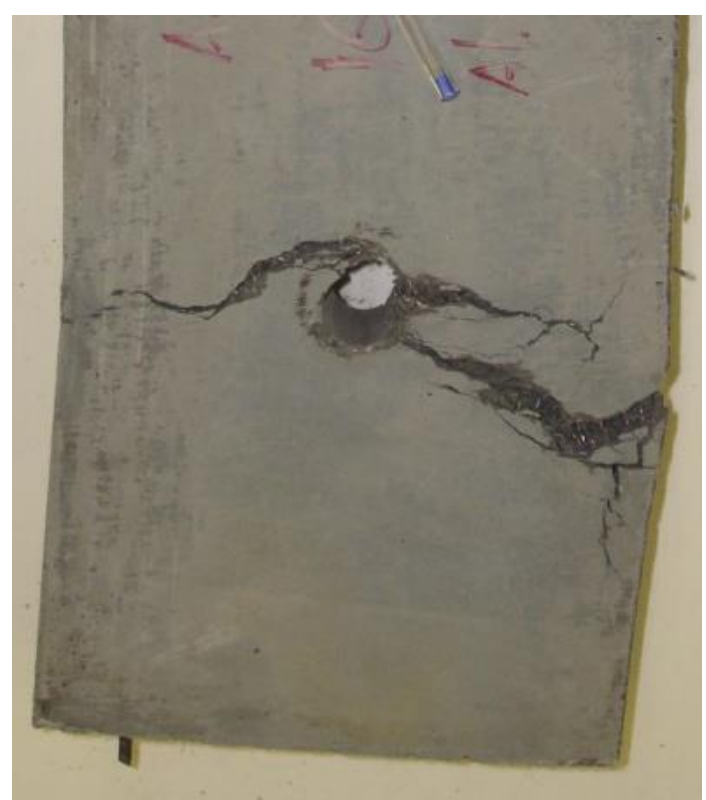

Figure 5.43: Net tension failure mode of element with wire reinforcement and $E=150$

$\mathrm{mm}$

The load-displacement behavior of all the elements is shown at the figures 5.44, 5.45, 5.47, 5.48 and 4.49 , separated by the reinforcement type and indicating the failure modes. As was shown in the table 5.5 and now in the curves, the dispersion observed for both the maximum load and ductility ratio was low, especially for elements where there was no steel reinforcement. This is an evidence of the adequate fibre orientation and stability in their behaviour and also of the test suitability.

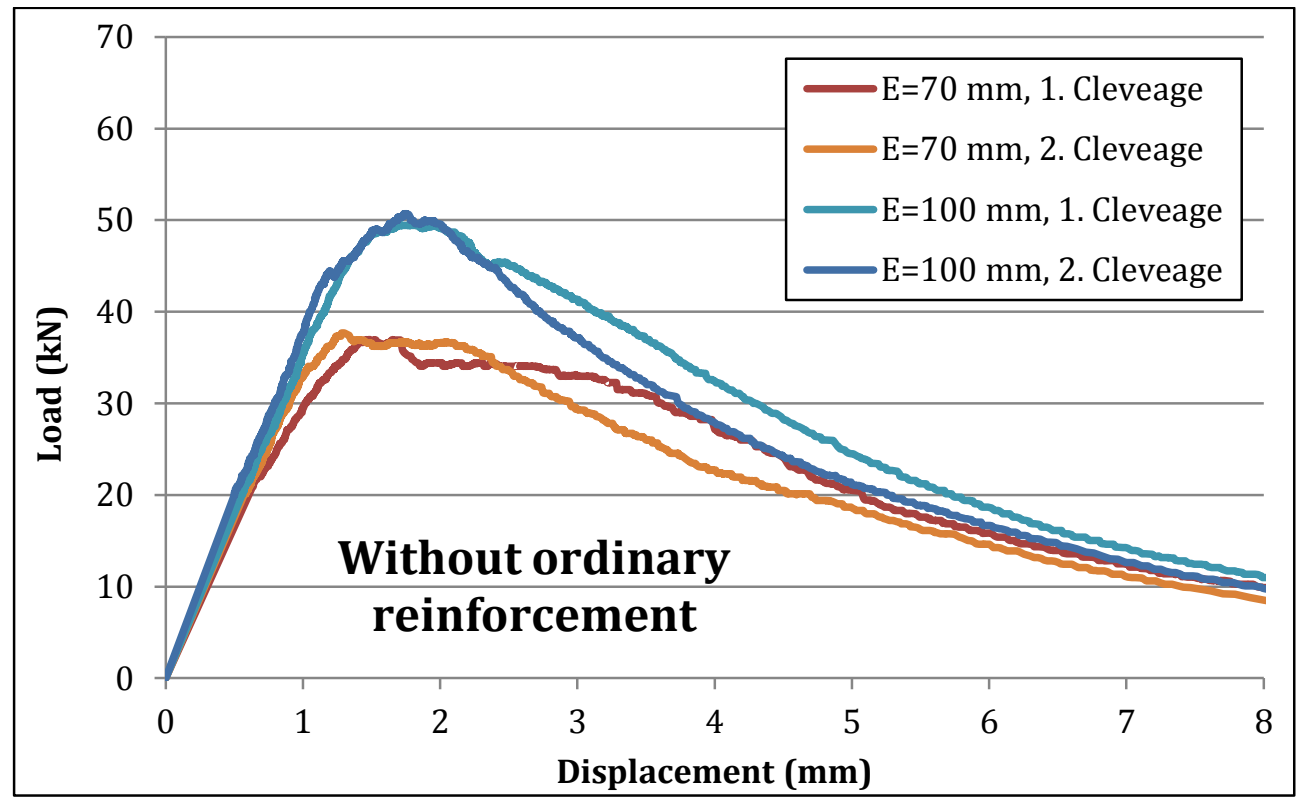

Figure 5.44: Load-Hole displacement law of elements without ordinary steel and cleavage failure mode

Observing the curves for the non-reinforced elements, it is noticed that less sharp slope of the softening branch can be distinguished for the cleavage failure when compared with the net tension. This is explained by the higher ductility that provides de development of two 
additional secondary macro-cracks, compared with the single opened for the net tension failure. Measuring the ductility ratios with the same process described at the figure 5.19, the figure 5.46 is obtained. It is important to remark that this values can not be compared with those from the preliminary test, as the elements and LVDTs length are different.

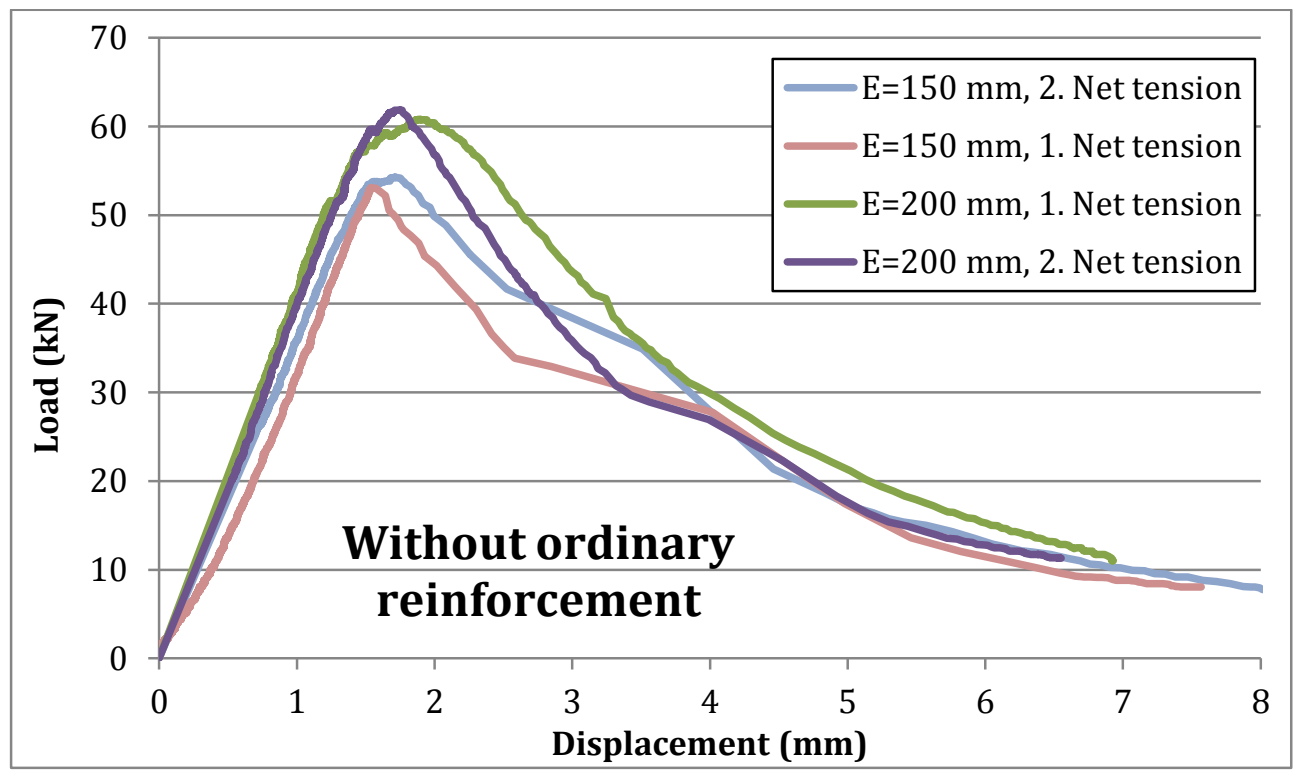

Figure 5.45: Load applied vs hole displacement law of elements without ordinary steel and net tension failure mode

It is very relevant that the cleavage failure has, in elements with low cover, almost double of the ductility of the net tension failures. It becomes more brittle with an increasing cover $\mathrm{E}$. This happens because of the failure mechanism. When the UHPFRC in the most external part exceeds the maximum tensile capacity, the non-damaged section decrease more and more with the stress concentration. The evolution of this crack is more dramatic as longer is the E cover. The ductility of the net tension failure is reduced and stable with the cover E, as it doesn't affect to the cracking pattern. The increase of this ductility was planned with the use of ordinary reinforcement.

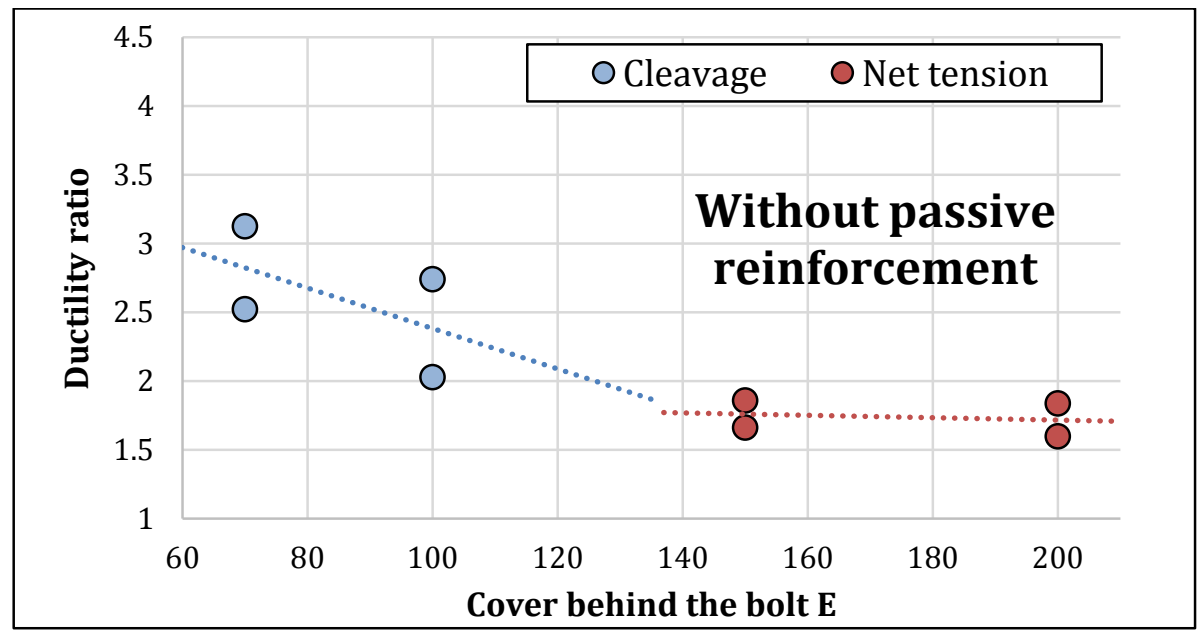

Figure 5.46: Ductility ratio of the pieces without passive reinforcement and different cover lengths

Figures 5.47 and 5.48 show the load-hole displacement law for the elements reinforced with wires. At the first are shown the cleavage failures suffered. For them, the use of the wire avoided the possible net tension failure, being the cleavage strength more limiting. It is 
observed, as for the non-reinforced elements, that increase the E increases the load carrying capacity but reduces the ductility. After reach the peak, the testing machine couldn't control properly the hole displacement. This phenomena is represented with the discontinuous lines.

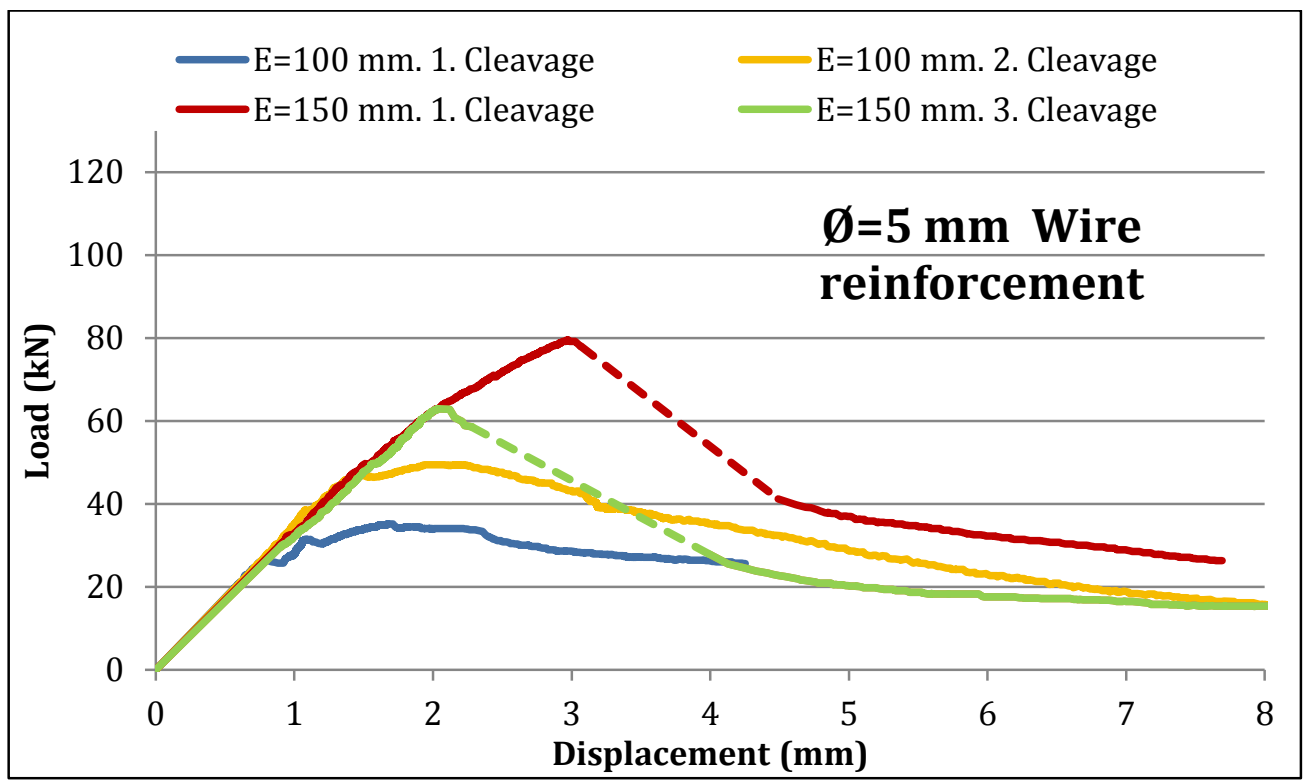

Figure 5.47: Load-Hole displacement law for elements with wire reinforcement. Cleavage failures

Figure 5.48 shows the elements with wires that suffered net tension failure. It is appreciated a marked increase of ductility respect to the elements without reinforcement. The damages are suffered for elements with cover E>150 mm, as the cleavage strength is enough for not to induce cleavage failure. Apparently the results show comparable load carrying capacity for any value of $E$, so the level of transmission of the wires is comparable for all the elements.

Finally, at the figure 5.49 are presented the curves for all the elements with bar reinforcement. The shorters suffered cleavage failure, and also one with $E=200 \mathrm{~mm}$, suffering an absolutely brittle failure as could be predicted from the last experiences. This element without steel bars would have suffered a net tension failure.

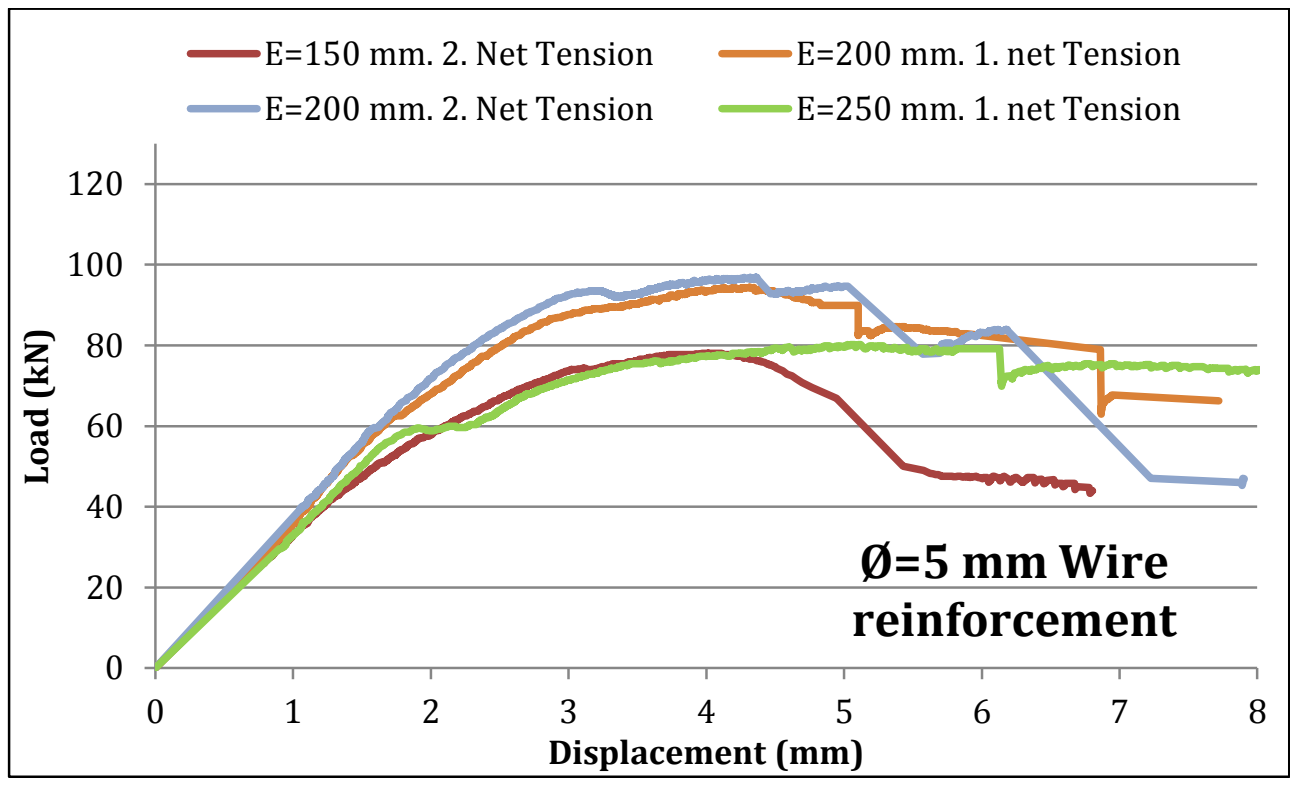

Figure 5.48: Load-Hole displacement law for elements with wire reinforcement. Net tension failures 


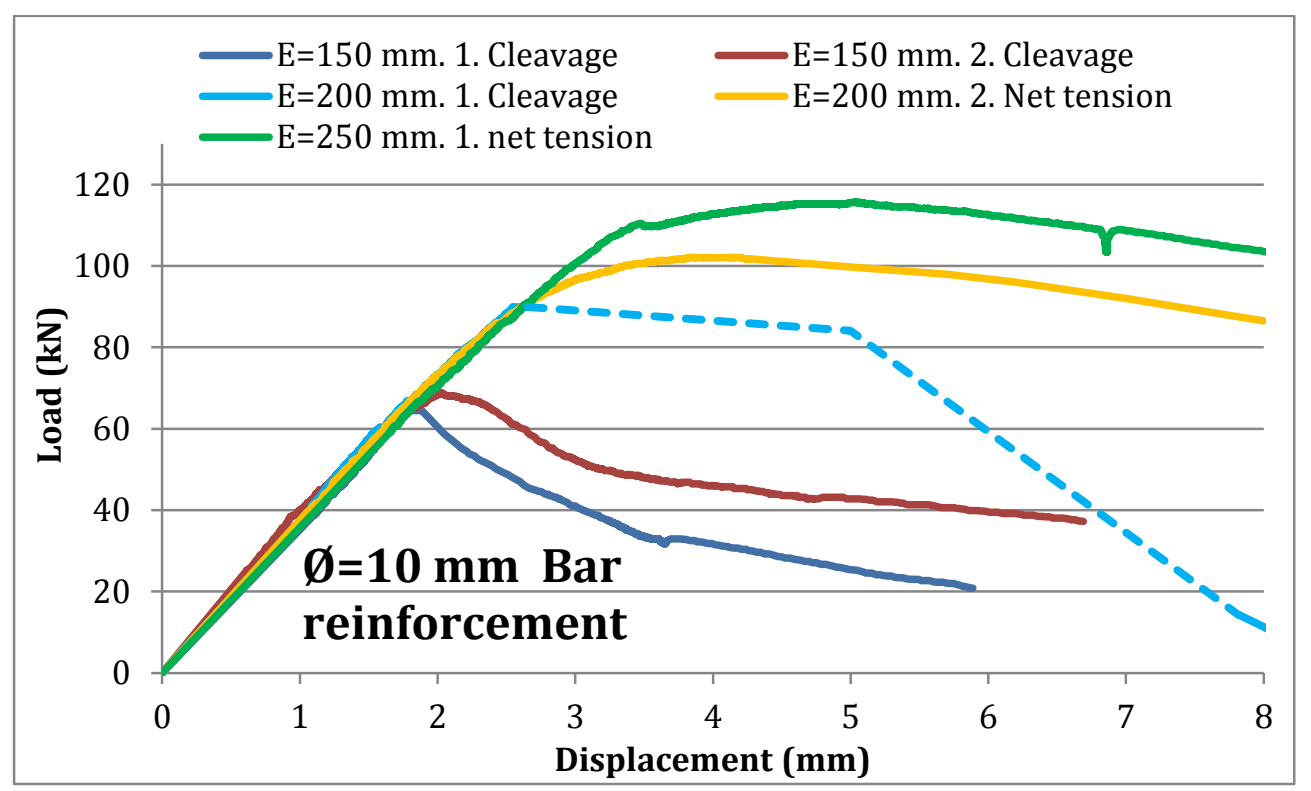

Figure 5.49: Load-Displacement law for reinforcement elements. Both failure modes are presented

The two longer elements suffered net tension failure. It is relevant to remind that the load carrying capacity of both bars is similar than for the previous wires. However, the maximum load reached for this pieces is nearly $20 \%$ higher. The reason is the stress-strain law of the passive bar, which reaches the material plasticity with the same strain as the UHPFRC. Thus, both materials reach their maximum capacity when the maximum load is applied. This property allows the steel to start plastify without any macrocrack in the UHPFRC.

Besides, the transmission of the load seemed to be more effective than for the wire proposal, as logic due to the ribs of the corrugated bars. The ductility is quantified on figures 5.50 and 5.51 for the reinforced elements. It was observed the same pattern for the cleavage failure than for the non-reinforced elements. As commented before, the ductility of the net tension failure increased markedly with the passive steel.

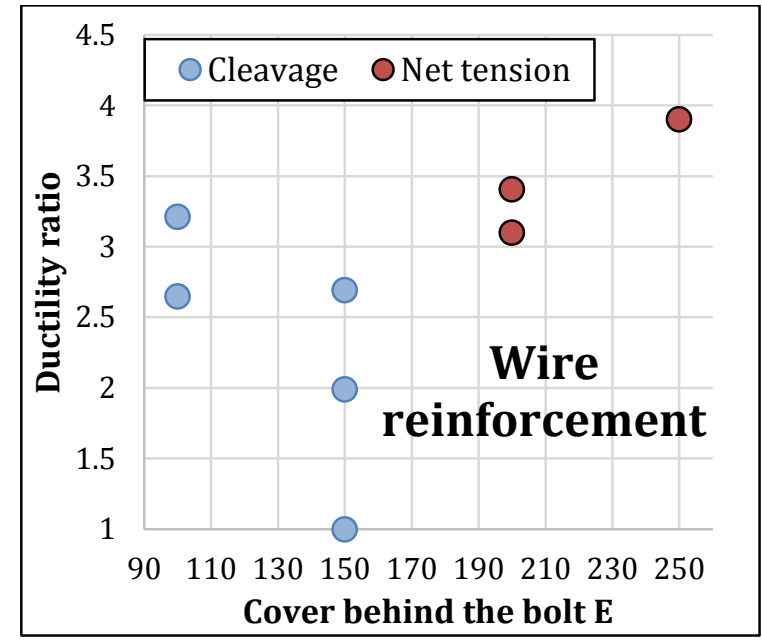

Figure 5.50: Ductility ratio of the wire reinforced pieces and different cover lengths

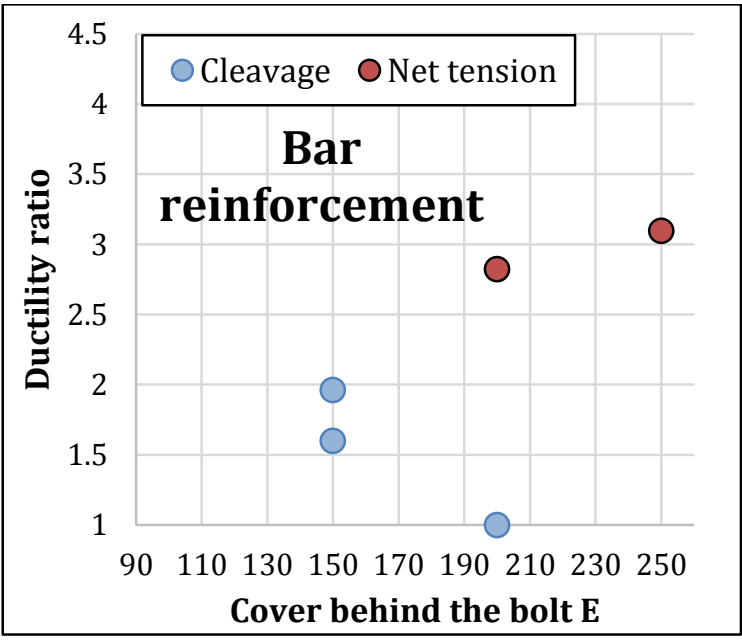

Figure 5.51: Ductility ratio of the bar reinforced pieces and different cover lengths

It is concluded that, attending to this results, the passive steel seems to be the best option to improve the net tension response for a structural connection. The tests revealed that with high $\mathrm{E}$ covers the possible cleavage failure is more and more brittle. Thus, for applications 
where high load is required, the steel reinforcement across the cleavage section is proposed. One of the options would be put it together with the longitudinal steel, using thus a stirrup.

However, this is only a proposal for a certain application. The framework of each application would determine the elements dimensions and if the reinforcement is required.

Besides, the single bolted test seemed adequate, as:

- It provided comparable elastic slope for all the elements.

- All the damages happened in the studied region

- The curves, patterns and maximum loads were showed reproducibility for similar pieces.

- However, it is complicated to develop due to the element geometry and reinforcement. An improvement should be done in this direction.

\subsubsection{SINGLE BOLTED TEST MODELIZATION}

\subsubsection{MODELLING}

For the study of the single bolted connection tests, a 2-D finite element model was performed in SAP-2000. This program assumes an elastic behavior for the elements, being possible only to change the young modulus of the material.

The purpose was:

- Explain the results obtained, deducing the initial stress distribution around the hole before macro-cracks appears.

- Deduce when and where the conventional steel can be placed in the section to increase the maximum load.

- Relate the results with a simple strut and tie model that justifies the initiation of the cracking.

The model was used to deduce which were initially the most tensioned regions and analyze the theoretical cracking pattern of the element up to the maximum load carrying capacity.

The "T" element tested was modeled as a group of thin shells. The level of detail was deeper in the region surrounding the hole and near the contact with the supports. The circular hole was modeled as an octagon where the load is applied in three vertexes (50\% of the load in the central and $25 \%$ in the adjacent). The geometry assigned to the piece was the real one measured from the cast elements.

Different Young modulus were assigned to the material depending on the stress it previously experimented. If never exceeded the matrix cracking strength the Young modulus is the elastic of the UHPFRC, measured before from $150 \times 300 \mathrm{~mm}$ cylinders. If it exceeded this value but not the maximum tensile UHPFRC strength $\sigma_{b t}$, then the elasticity assigned to represent the strain hardening is $E_{1}$ (see figure 5.52). If the material already reached the maximum strength, then the strain softening is modeled providing a value $E_{2}$. 
The process of analysis starts assigning the UHPFRC Young modulus to every finite element and applying at the hole certain load. The program is run and the user has to check if the principal tensile stresses are in any element higher than the matrix tensile strength. In this case, the Young modulus will be modified to $E_{1}$ or to $E_{2}$, depending if the stress exceeded or no the maximum concrete tensile strength. Then the program is run again, studying the new stress distribution.

This cyclic process tends to stabilize, providing at the end an idea of what is the crack pattern for certain load applied. Increasing this load the crack evolution can be deduced. In the case that load applied is too high for the element capacity, the stress level will be too high even after modify the Young modulus along all the element. The process is based on the steps shown in the figure 5.53.

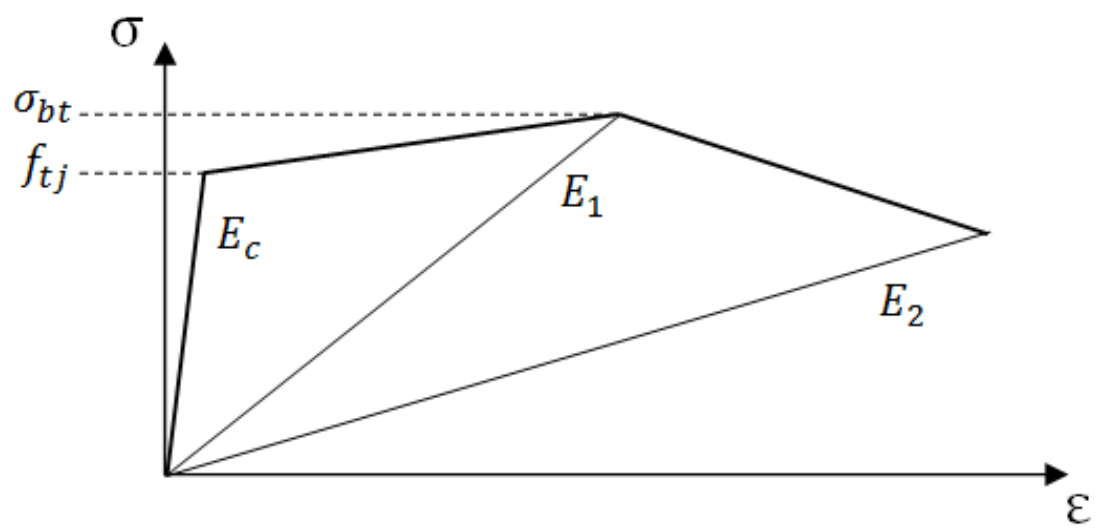

Figure 3.52: Elastic modulus given to the UHPFRC in the model

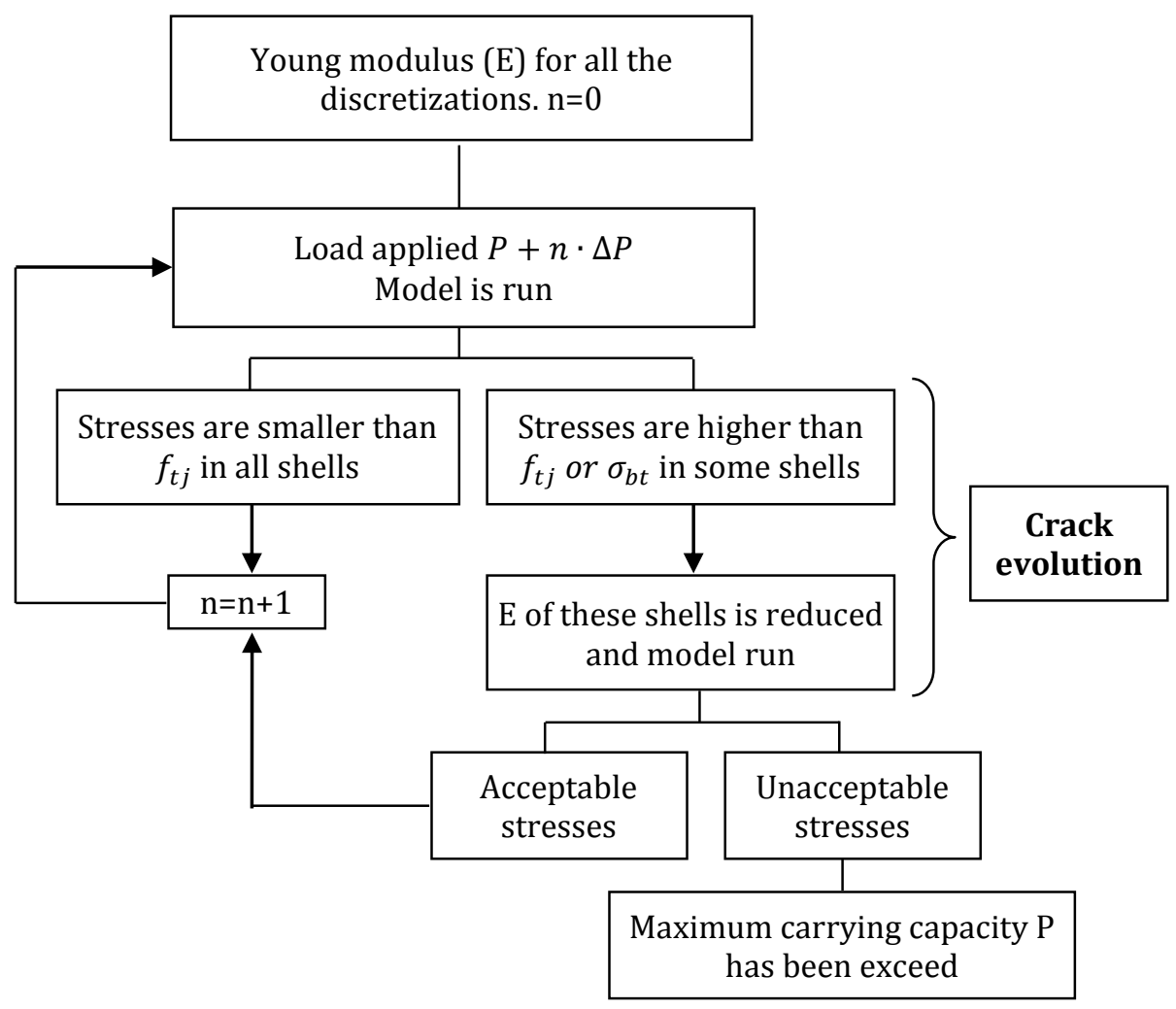

Figure 5.53: Scheme of the process followed to deduce the cracking pattern of the pieces 


\subsubsection{FINITE ELEMENT MODEL RESULTS}

First of all, the cleavage failure mode suffered in pieces without conventional reinforcement tried to be understood. The model for pieces with $\mathrm{E}=70 \mathrm{~mm}$ was developed, applying the average maximum load reached in the test (shown at table 5.5). First an elastic model with $\mathrm{E}=44000 \mathrm{MPa}$ for all piece was studied. The stresses obtained showed that very high tensile stresses concentrates in section A near the hole (figure 5.54, negative values represent tension stresses), being this the first cracks opened. Tensile efforts orthogonal to the load in section $B$ were increasing from the hole towards the end of the piece (figure 5.55), but didn't exceed the UHPFRC tensile strength, showed at both figures with a discontinuous line. This shows how the best ordinary reinforcement location would be the most near possible to the free edge, positioned as far below hole as possible.

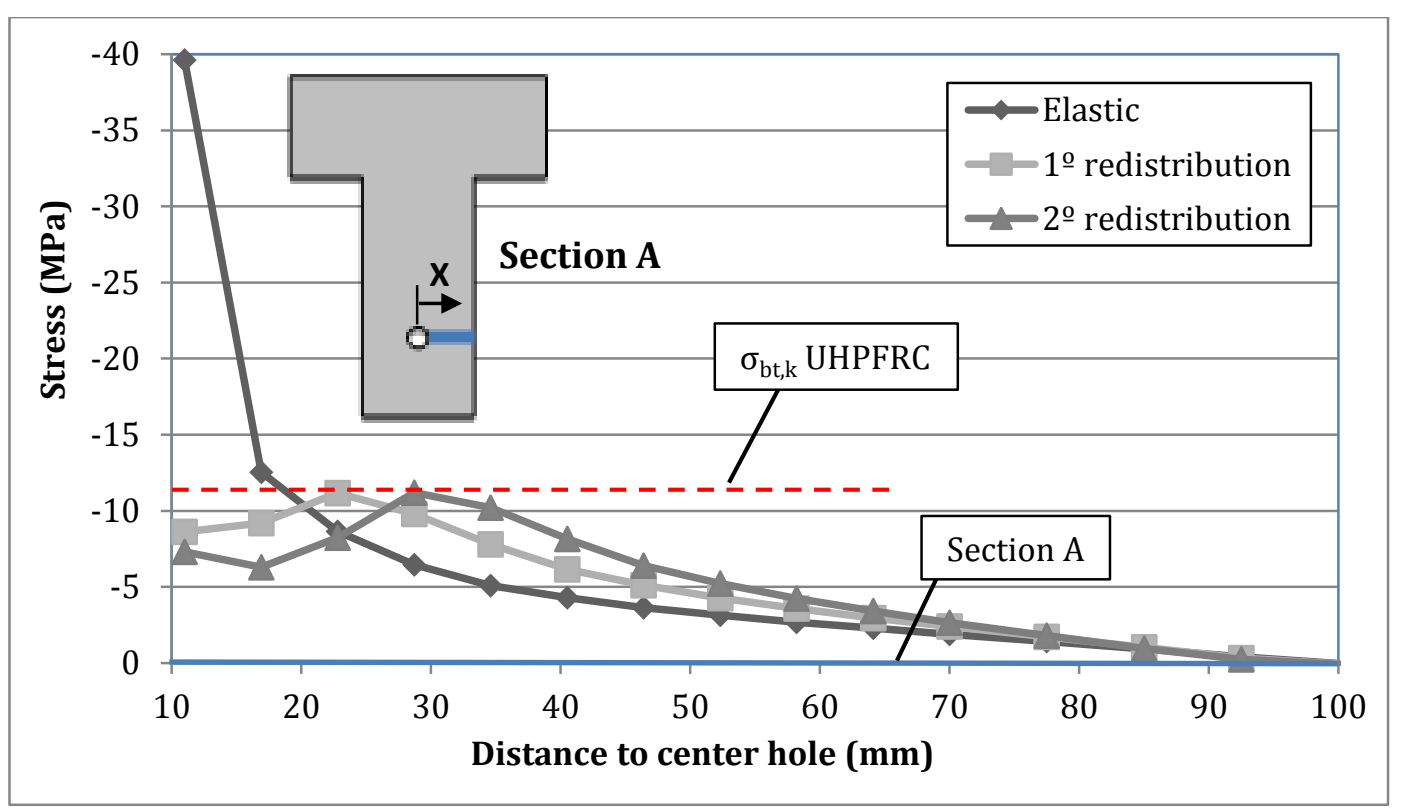

Figure 5.54: Maximum tensile stresses in section A (in the hole side) for the three models performed

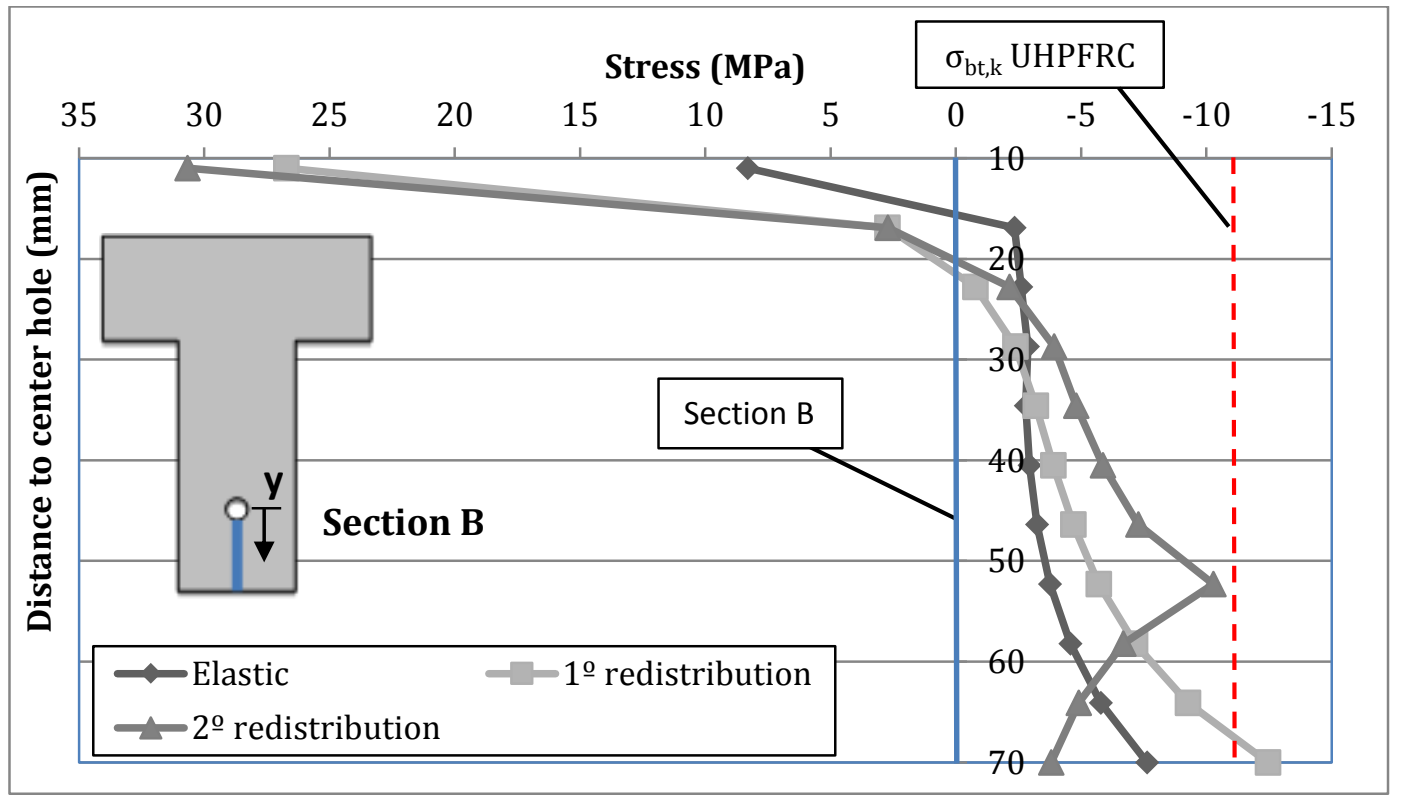

Figure 5.55: Maximum tensile stresses in section B (behind the hole) for the three models performed 
Redistribution was introduced in the model assuming that UHPFRC damages in region near the hole. The most damaged region was supposed to be in strain softening branch (simulated with $\mathrm{E}=2000 \mathrm{MPa}$ ) and the subsequent was considered in the top of the strain hardening branch $(E=5000 \mathrm{MPa}$, being this the slope between origin of the stress-strain law and the value $(0.002,11.6)$. This methodology is wider explained at 5.4.4.1. The stresses obtained after running this model are shown at figures 5.54 and 5.55.

After the first redistribution, tensile stress distribution in section A became more homogeneous, with top values near the maximum UHPFRC capacity. Tensile stresses in section B increased significantly, reaching the maximum UHPFRC tensile strength in the bottom part. The second redistribution assumed that the bottom part of section $\mathrm{B}$ redistributes efforts to the upper part, evolving the crack to the hole. This model provided in the three cracks tension between 10 and $12 \mathrm{MPa}$, so it can be accepted as the state of the piece when its submitted to the maximum load. Besides, both redistributed models showed also compressive stresses next to the hole distributed in wider region. Then, the crack opening for the cleavage failure starts with two cracks evolving from the hole, followed by a crack at the bottom of the piece and the evolution of all them.

Strut and tie models of these three situations (linear elastic, $1^{\circ}$ and $2^{\circ}$ redistribution) are shown in figure 5.56, explaining how the equivalent ties that represent the UHPFRC fiber capacity change with the development of the cracks. As can be understood in the second redistribution, the tie in section $B$ has reduced so much the thickness that load carrying capacity of the element decreases progressively. As the regions next to the hole in section A can't carry tensile stresses, struts from the hole increase their angle and horizontal tensile stress in section B increases dramatically. This pattern is in accordance with the observed in the experimental results of subsection 5.4.3, the increasing brittle behavior of the element when the cover $\mathrm{E}$ is increased.
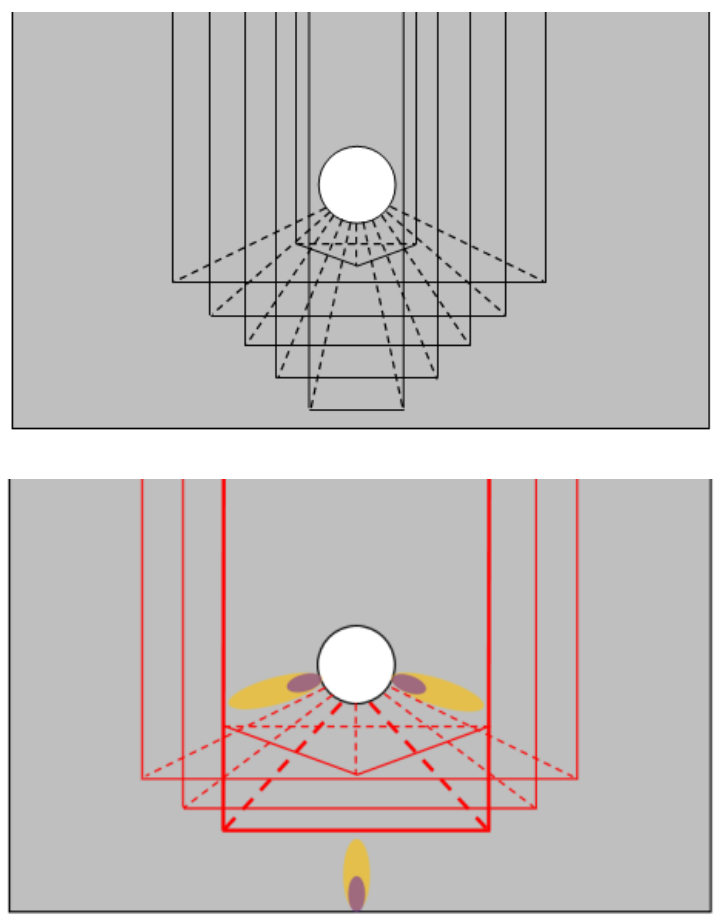

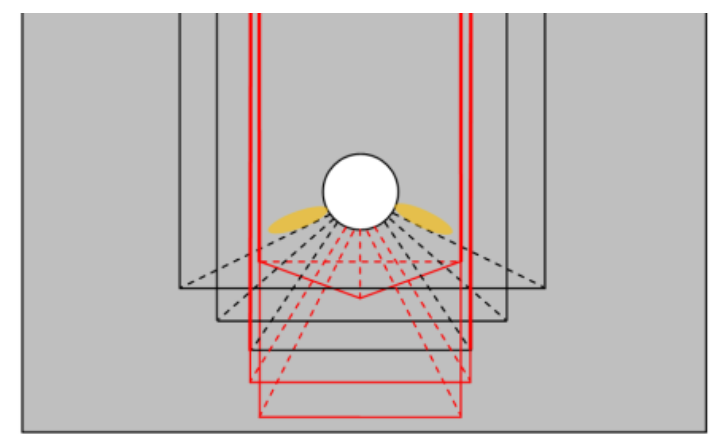

Figure 5.56: Strut and tie models for elastic situation (top left), $1^{\circ}$ and $2^{\circ}$ redistribution (top right and bottom left). Red colour shows the strut and ties that suffer a position variation, forced by the crack opening. Semidamaged regions ( $E=5000 \mathrm{MPa}$ ) are shown in yellow, and strongly damaged regions in purple $(E=2000 \mathrm{MPa})$. 
This process corroborates that failure mode experimented starts in the section A. When cracks allow a load redistribution, a new crack opens in the bottom part of the section B, growing towards the hole. Maximum load is reached with the three cracks opened, and their development leads finally in a decrease of the element capacity.

Model developed at SAP2000 for specimen with E=100 mm with no reinforcement showed exactly the same progression of the failure. In pieces with $E=150 \mathrm{~mm}$ or higher, the failure mode provided by the model was net tension. These results coincide completely with the experimental results obtained in the tests.

For $\mathrm{E}=150 \mathrm{~mm}$ It showed how, despite of the crack opening in section $\mathrm{A}$ at both sides of the hole, tensile stress in section B reaches maximum tensile values of $3.9 \mathrm{MPa}$ in the bottom part. The high fiber content of UHPFRC is essential in this region, as the tensile efforts transmission is guaranteed by them. Piece composed with OC could suffer a brittle failure produced by anisotropy.

The $\Phi=10 \mathrm{~mm}$ steel bar was included later in the model. For $E=150 \mathrm{~mm}$ and less the maximum load in the test didn't submit the bars to their yield stress, avoiding efficiently then the net tension failure and producing the cleavage one. These data coincides with the experimental failures produced. Loads achieved in the tests for $\mathrm{E}=200$ and $250 \mathrm{~mm}$ makes the bars exceed the elastic limit, suffering normally net tension failure. It has to be considered that the marked ridges of the rebar and the high compacity of the UHPFRC lead in a short anchorage length, what means that rebars showed an efficient behavior with E higher than $150 \mathrm{~mm}$.

It's remarkable to remind that, although both bars and wires with the dimensions used here have almost similar carrying capacity, their tensile stress-strain laws are very different. In the case of the wires, their maximum tensile strength is obtained with a strain four times higher than for the bars. For this strain the UHPFRC tensile capacity is already much reduced, and then the structural capacity of both materials can't be exploited together. In the case of prestressed elements this problematic disappears.

According to the results obtained in the tests, reinforcing steel has to be placed closer to the hole. Then it will contribute to sew the first cracks and work together with the strain hardening branch of the UHPFRC. In the case of prestressed elements, position of the steel would be less important as the concrete macro-cracking will appear with the steel wires already plasticized, so the tensile capacity of both materials would be considered together.

Finally it can be said that for no prestressed elements the value of E can be of $200 \mathrm{~mm}$, and in the case of prestressed it has to be tested to check if anchorage length increase, and also to check the failure modes and maximum loads that can be reached.

\subsection{REAL SIZE TRUSS STRUCTURE}

\subsubsection{INTRODUCTION}

At 5.1 was proposed the idea of develop UHPFRC truss structures with bolted connections. At 5.2 and 5.3, these connections were studied separatedly to analyze the failure modes and 
the viability of this innovative system. The study allowed to understand the mechanism of the bolted connections. However, some aspects should be ascertained:

- The previous section concluded that the use of a stirrup could be a useful way to increase the capacity and ductility of both net tension and cleavage damages.

- To be useful, the bolted connection elements must be able to be precast. To assemble the structure is necessary that the holes of the elements fit perfectly, and this has not been proven yet.

- The elements performance in the tests might not be similar than in a structure, where the boundary conditions are different. The elements are larger and structural redistribution capacity is possible. A full scale test could underline or refute the statements done in the previous sections.

To answer all these facts, a full scale truss structure was designed and built. It will face up all the previous issues and probably other that were not thought. The viability of this simple connection system in a structural scale opens the door to several applications, especially those which require fast construction or are temporary, being possible to re-use the disassembled elements for other standard uses.

The structure will also be useful to show if the assembling and disassembling process of the single elements is viable and fast. After the test, the diagonals will be extracted to perform bearing tests to each one, obtaining better knowledge of this failure mode.

\subsubsection{DESIGNED ELEMENT}

The element designed is a Warren type flat truss with three isosceles triangles and double diagonal elements. The angle between the down chord and the diagonals is $63^{\circ}$, as is appreciated at the figure 5.64. It is composed by seven nodes and 11 bars, being considered isosatic. The span length is $3000 \mathrm{~mm}$, and the depth of the assembled element is $1070 \mathrm{~mm}$. The high strength steel bolts used to connect have $120 \mathrm{~mm}$ of nominal length and $27 \mathrm{~mm}$ of thread diameter, being class 10.9 for structural steel joints according with the ASTM A490. Their minimum tensile strength is $1040 \mathrm{MPa}$. The truss is divided in four different type of UHPFRC pieces: The bottom chord, the upper chords, the compressive and the tensile diagonals. All transversal sections are shown at figures 5.57 to 5.63. Their characteristics are written afterwards:

- Compressive upper chord: The section has $120 \mathrm{~mm}$ of width and $70 \mathrm{~mm}$ of thickness without any conventional reinforcement. The length is $2480 \mathrm{~mm}$, and it is casted with three $27 \mathrm{~mm}$ thickness steel perforated steel shells separated $1000 \mathrm{~mm}$ each other. Considering a compressive strength of $150 \mathrm{MPa}$, the expected compressive failure for this element is in the range of $1200-1300 \mathrm{kN}$.

- Tensile bottom chord: The section has $150 \mathrm{~mm}$ of width and $70 \mathrm{~mm}$ of thickness with two reinforcement corrugated steel bars of $20 \mathrm{~mm}$ diameter. The length is $3960 \mathrm{~mm}$, and it is casted with four $27 \mathrm{~mm}$ thickness steel perforated steel shells separated $1000 \mathrm{~mm}$ each other. The bars recover to the bottom of the piece $(20 \mathrm{~mm})$ was kept welding them to the steel shells. The mold before pouring the concrete is shown at figure 5.65. Considering the typical UHPFRC tensile strength, the expected failure for this element is ranges between 400 and $550 \mathrm{kN}$. 
- Compressive diagonal: The section of these elements is $110 \mathrm{~mm}$ wide and $40 \mathrm{~mm}$ depth and without any reinforcement, not even around the joint. It has the same holes as the tensile diagonals, and also one additional in the center to connect with the other compressive diagonal and avoid the buckling. The corners, as for the tensile diagonals, are slightly rounded. The maximum compressive load capacity in the middle section varies between $600-700 \mathrm{kN}$, but the bearing failure would happened in the range of 320-340 kN.

- Tensile diagonal: The section of these elements is $110 \mathrm{~mm}$ wide and $40 \mathrm{~mm}$ depth, being reinforced with a longitudinal corrugated steel stirrup of $10 \mathrm{~mm}$ diameter (shown at figure 5.57). The stirrup is bended behind the hole with an internal radio of $50 \mathrm{~mm}$. The length of these diagonals is $950 \mathrm{~mm}$. It has two holes near the ends, with a separation of $785 \mathrm{~mm}$. The corner of the diagonals are slightly rounded to avoid the contact with the compressive diagonals during the assembling. This element would fail in a middle section at tension between 140 and $180 \mathrm{kN}$, but failure at the bolt region is more critical. Thus, this element is the most critical expected for the three point test.

The holes in the diagonals are included in the formwork using a PVC cylindrical element with an internal diameter of $27 \mathrm{~mm}$ and a thickness of $2 \mathrm{~mm}$ (external diameter is $31 \mathrm{~mm}$ ). Initially, this element is supposed to remain after the demoulding to protect the holes from the bolt, but if during the assembly process the elements don't fit some can be removed to increase the tolerance $4 \mathrm{~mm}$. The bolts connect the UHPFRC diagonals to steel perforated shells cast together with the compressive and tensile chords.

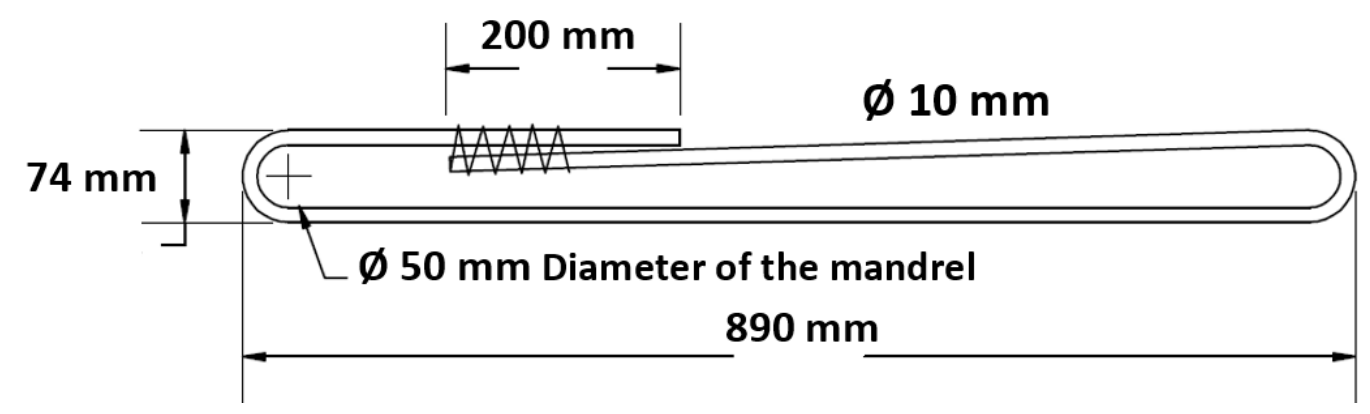

Figure 5.57: Stirrup used for reinforce the tensile diagonals

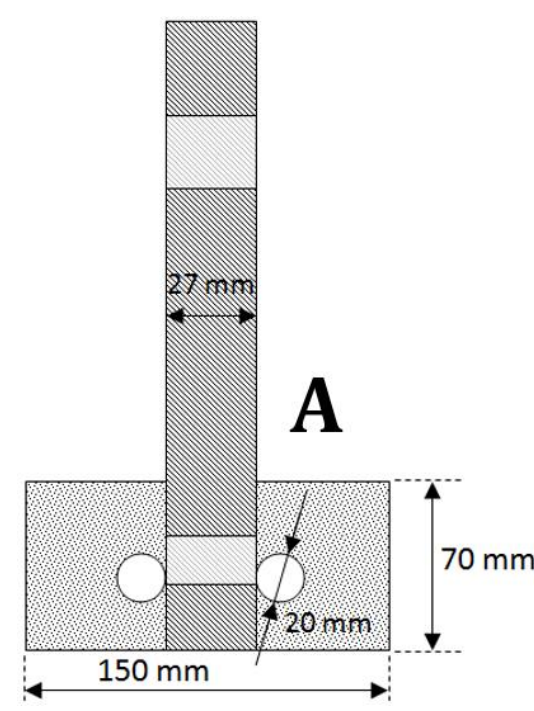

Figure 5.58: Transversal section of the bottom chord

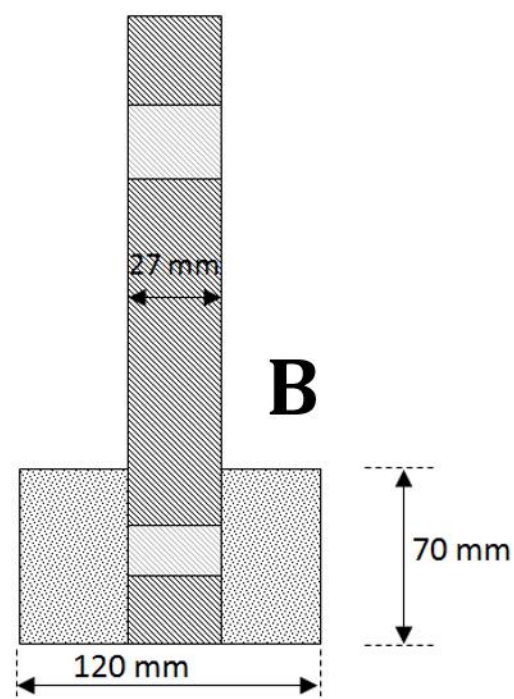

Figure 5.59: Transversal section of the upper chord 


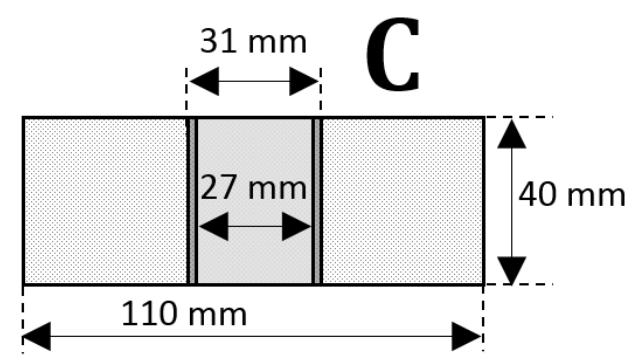

Figure 5.60: Transversal section of the compressive diagonal

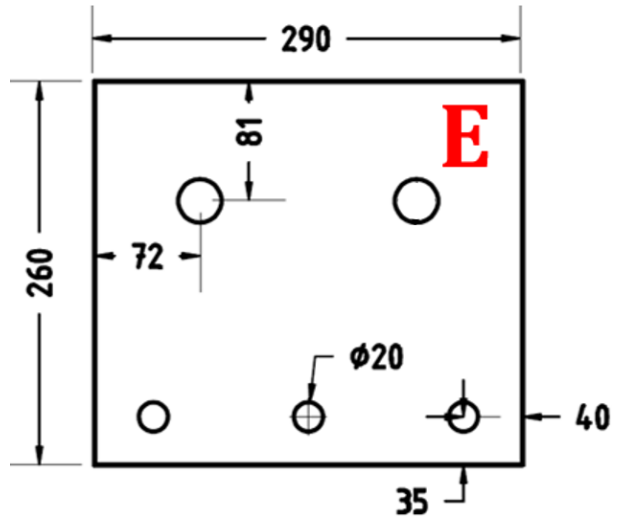

Figure 5.62: Steel shell used for the bottom chord

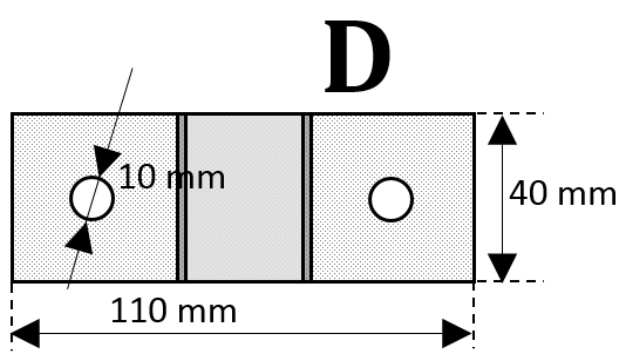

Figure 5.61: Transversal section of the tensile diagonal

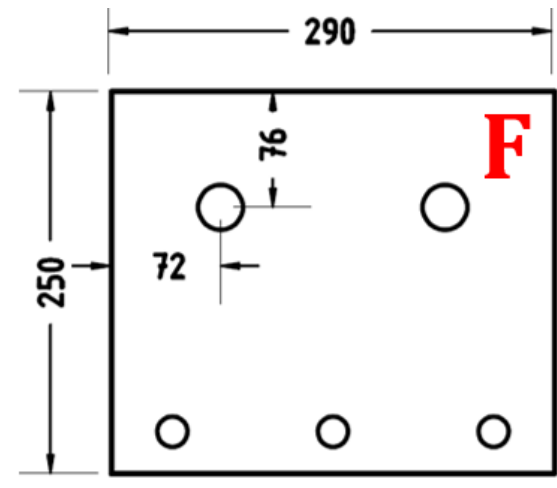

Figure 5.63: Steel shell used for the upper chord

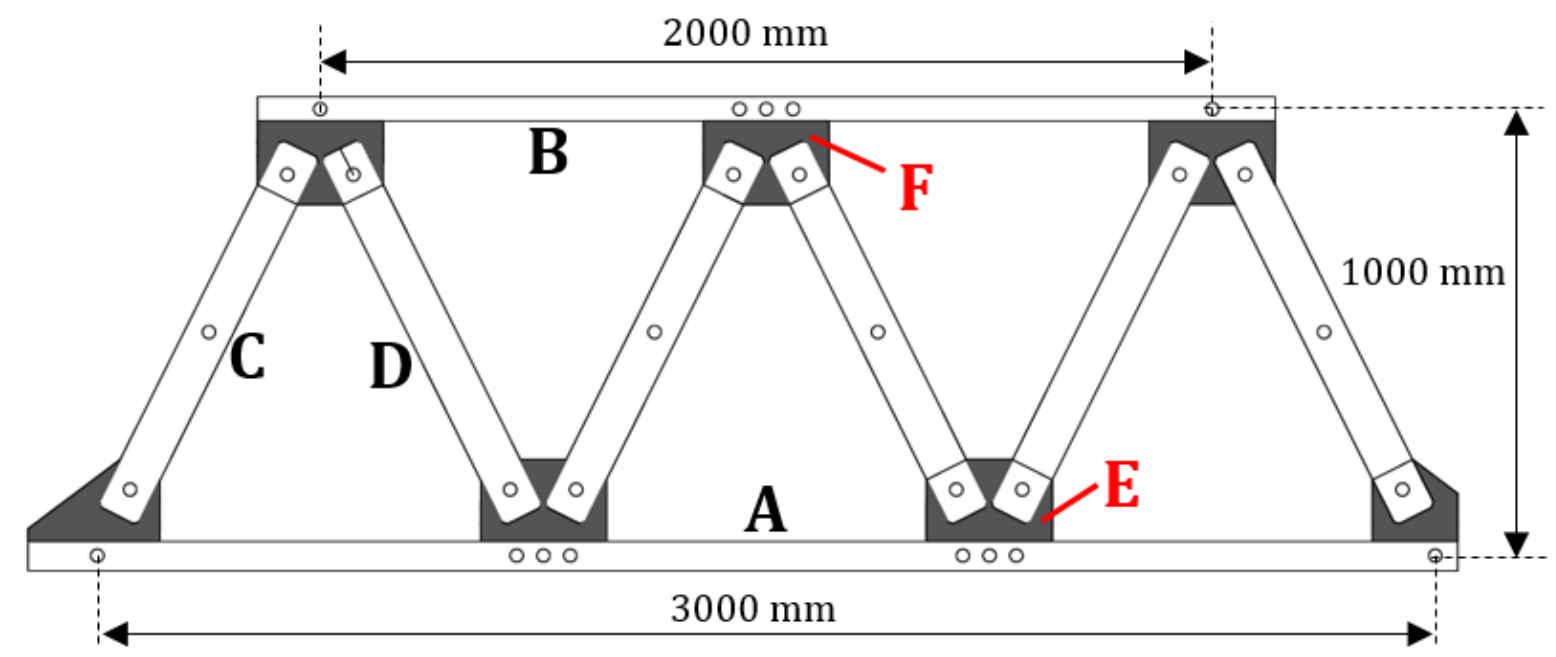

Figure 5.64: Front view of the truss structure already assembled

\subsubsection{EXPERIMENTAL PROGRAM}

The dosage used was the named F3-HY at section 4.11 .2 with the mixing process indicated for the EIRICH Mixer at section 3.3.4. The elements where cast following the recommendations indicated at chapter 4.10.4 even for the compressive elements. This means that fiber alignment is in these cases the most unfavorable, as the tensile stresses are orthogonal to the preferential orientation.

Three 45 liters similar batches were cast the same day, characterizing the compressive performance with eight $100 \mathrm{~mm}$ length cubes and the flexural strength with three $100 \mathrm{x} 100 \mathrm{x}$ $400 \mathrm{~mm}$. Both the truss structure and the samples were tested after 14 days. 
The assembly of the truss structure was made in 90 minutes with the only help of two workers and the High Strength Steel Bolts. Any crane was used, as the elements were able to be carried by two persons. Some of the diagonals didn't fit with the holes of the steel shells. Thus, one or both of the PVC hole covers were extracted, obtaining an additional clearance of $2 \mathrm{~mm}$ for each one. This implied that some diagonals were placed with the two PVC tubes in the holes, with one, or without any.

The bolts were not prestressed. The process of assembling is shown at figure 5.66 and the full assembled element at figure 5.67, with details at figures 5.68 and 5.69.

The truss structure was submitted to a three point bending test with a span length of 3000 $\mathrm{mm}$ and the central load applied in at the upper central node.

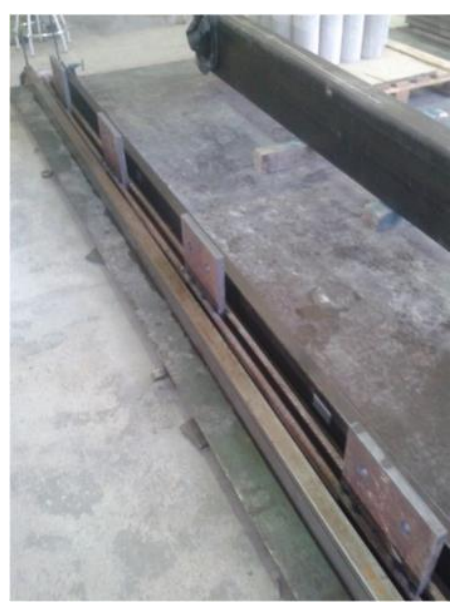

Figure 5.65: Mould of the bottom chord before pour the concrete

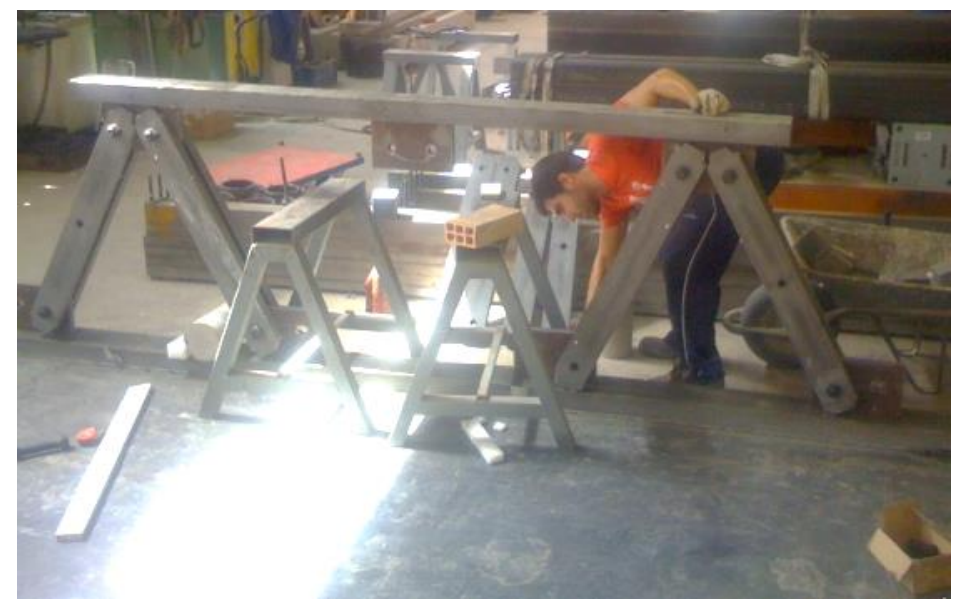

Figure 5.66: Truss during the assembly process

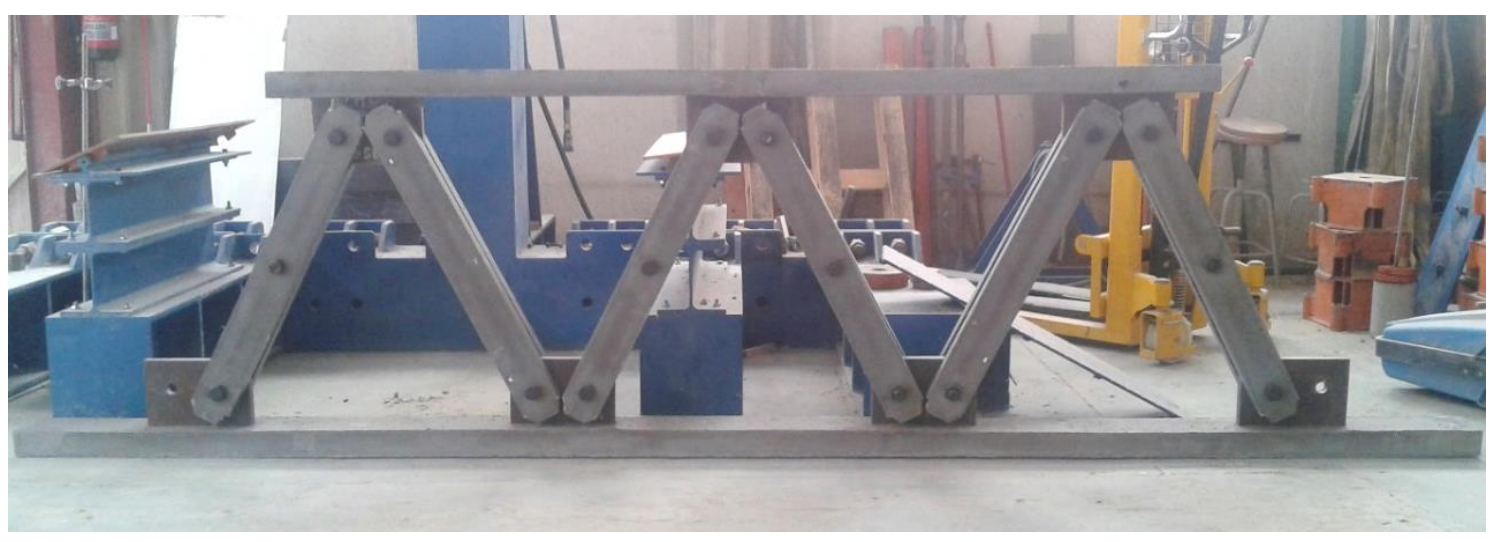

Figure 5.67: Truss element after assemblement and before test it 


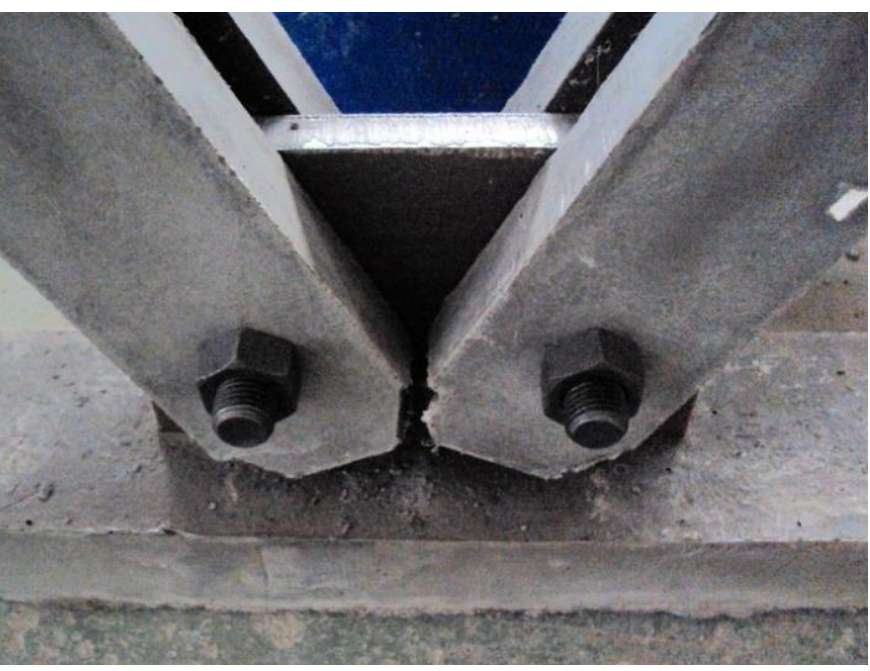

Figure 5.68: Detail of the bottom chord connection

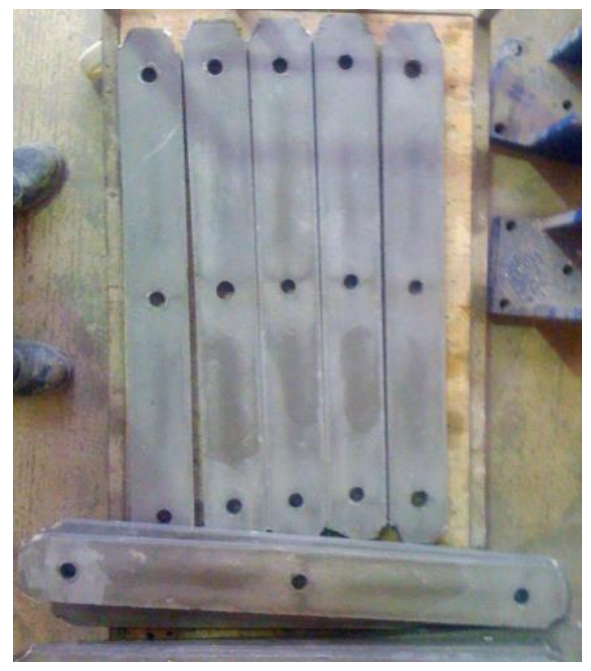

Figure 5.69: Diagonals after the demoulding process

In the test, four $125 \mathrm{~mm}$ LVDT's were used to measure the strain of the tensile diagonals (T1, T2, T3 and T4, in green color on figure 5.70), and a fifth to measure the central span deflection. Other four $50 \mathrm{~mm}$ LVDT's for the strain of the compressive central diagonals (C1, C2, C3 and C4, in yellow color on figure 5.71). This measures will help to verify the strain of the compressive and tensile elements and study the stability of the test. Figure 5.70 show the element before start the three point test. There can be seen the names used for each diagonal.

Four steel shells were placed at both sides of the central upper part to avoid a possible lateral displacement of the full structure during the test. The shells didn't contact with the truss and their only objective was provide more security. During the test a significant lateral movement was not observed.

Two parameters were limited, being the controller the most restrictive: The load applied in the time $(200 \mathrm{kN} / \mathrm{s})$ and the displacement of the jack in the time $(0.02 \mathrm{~mm} / \mathrm{s})$.

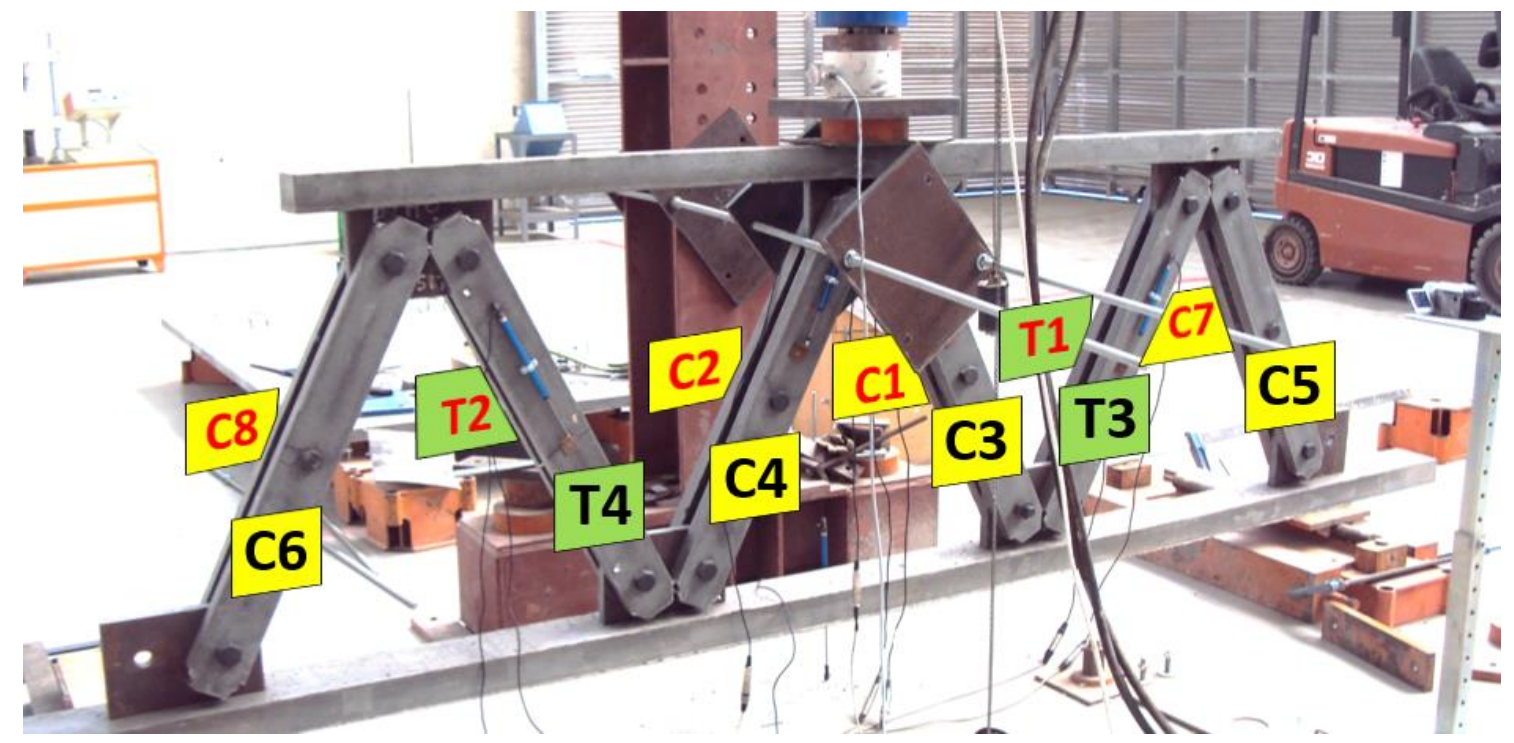

Figure 5.70: Name of each one of the diagonals 


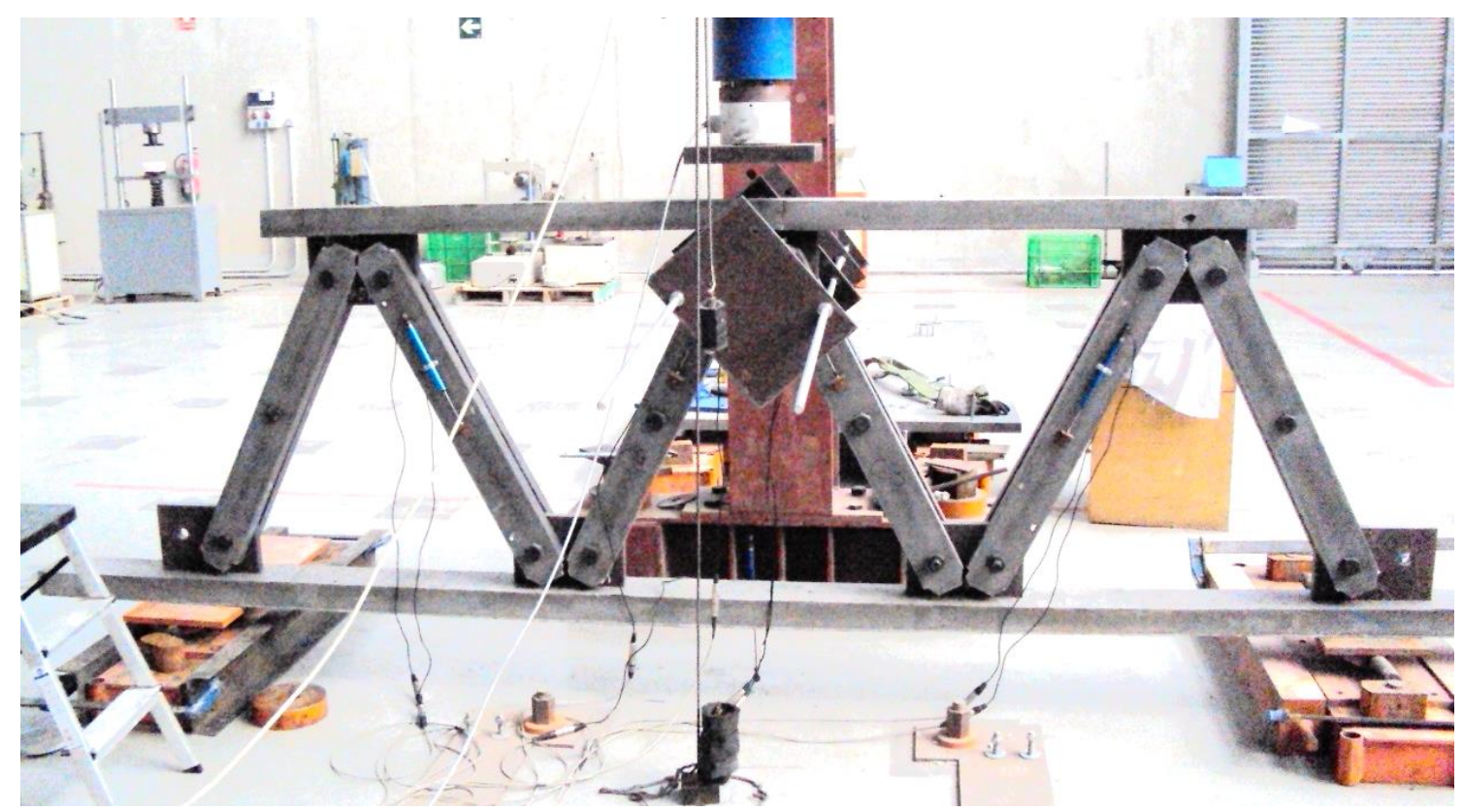

Figure 5.71: Three point test performed for the truss element. The horizontal shells to restrict a possible horizontal displement can be appreciated

\subsubsection{RESULTS}

\subsubsection{FULL SIZE TRUSS ELEMENT}

The element was tested after 14 days of mix the UHPFRC, when the average compressive strength of the air cured material was $166.5 \mathrm{MPa}$, and the flexural strength was comparable with the defined for F3-HY at 4.11.2. The figure 5.72 shows the central span deflection of the element related with the central span load. As can be seen, there is an increasing stiffness for the element, which is explained mainly by the clearance between the holes and the bolts for some of the diagonals. With the progressive contact of all the screws with the holes the flexural stiffness tended to a constant value.

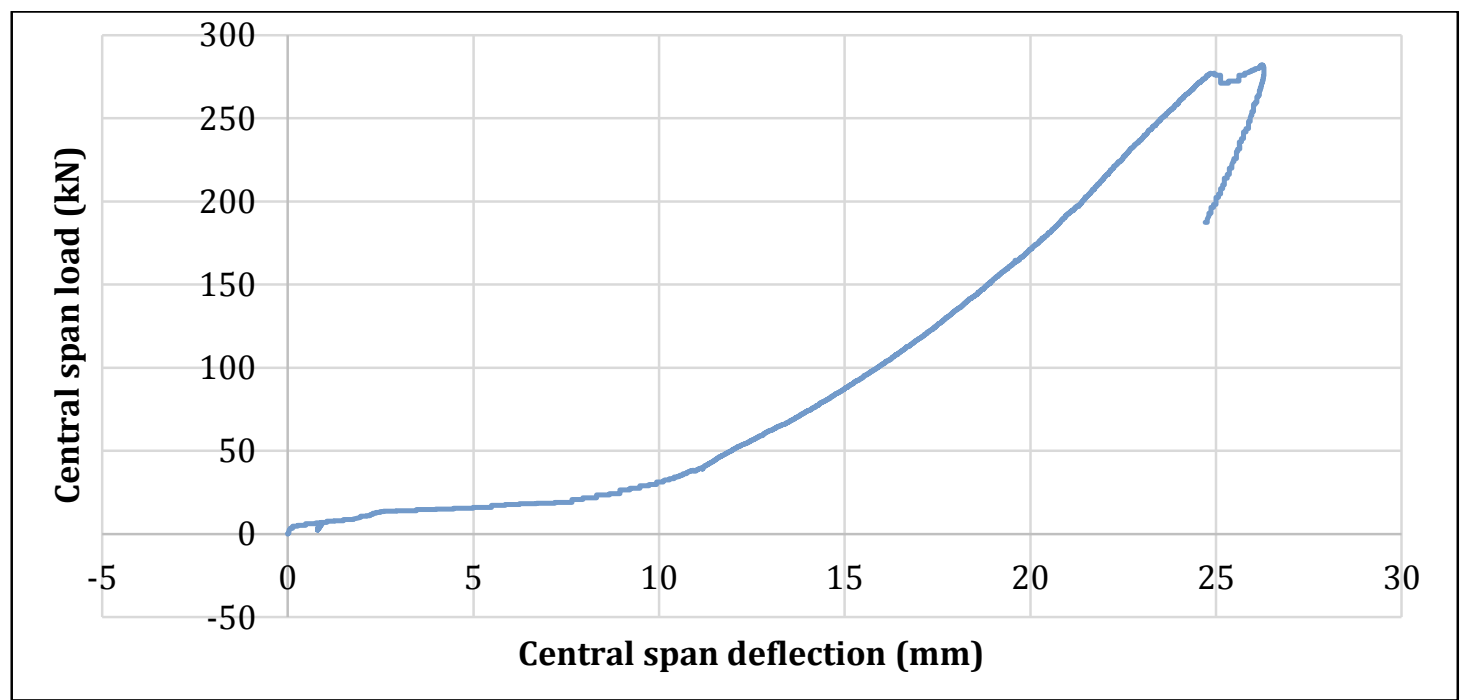

Figure 5.72: Central span load-central span deflection 
The maximum load reached was of $282.1 \mathrm{kN}$, being then stopped because of the joint of the compression diagonal C5 suffered a bearing failure (figure 5.73). However, the failure mode expected was net-tension at 400-450 kN of central load applied.

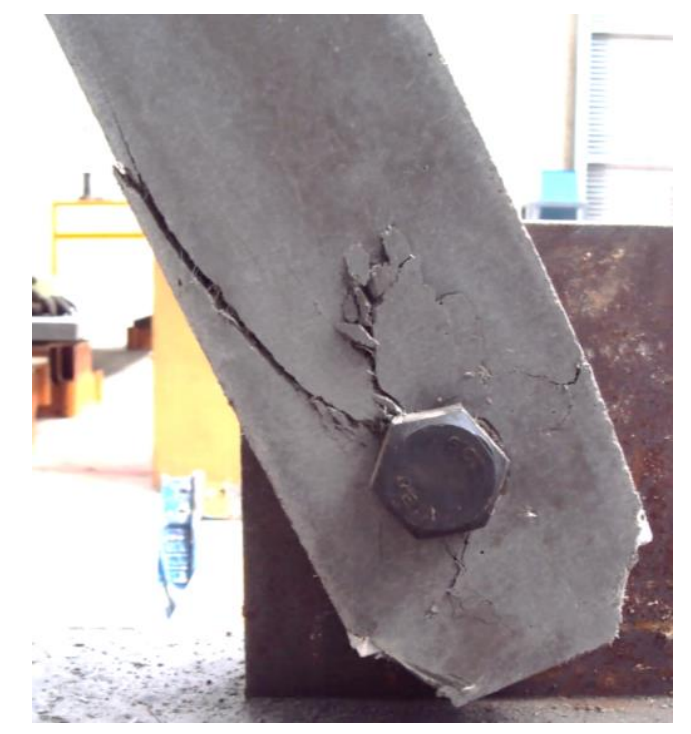

Figure 5.73: Joint of the compressive diagonal C5 after the bearing failure

It was observed that the compressive diagonal C5 had both PVC protections, having a clearance at each hole of $0.5 \mathrm{~mm}$. The diagonal C7, placed simetrically on the other side of the shell for work together, hadn't any PVC tube, so the clearance was $4 \mathrm{~mm}$ at each hole. This made that along all the test the diagonal $\mathrm{C} 7$ was almost without load. The diagonal C5, however, was carrying the compression that was designed for both. Theoretically, the load of $282.1 \mathrm{kN}$ generated an equivalent compression at $\mathrm{C} 5$ and $\mathrm{C} 7 \mathrm{of} 73 \mathrm{MPa}$, but on reality produced a failure on $\mathrm{C} 5$ at $146 \mathrm{MPa}$.

This premature failure showed the relevance of the clearance in elements with bolts. On the future the clearance should be similar for all elements, or a system of steel annulus or injected mortar could be placed in the holes to reduce or remove this space.

Other considerations can be done for some parts of the element. The upper chord didn't suffer any macrocrack, but several vertical microcracks were appreciated after the test when the region was wet. The bending of the continuous upper chord conditioned to a tensile strain in the bottom part of this strut. The bottom chord, submitted to tension and reinforced with steel bars, also suffered microcracking that was only appreciable after wet the concrete surface.

The tensile diagonals showed a great performance, with net tension microcracking along the element and macrocracks on the bolted region but without tensile failure. As the net tension failure, the cleavage failure was avoided thanks to the stirrup efficiency behind the bolt. At figures 5.74 to 5.75 can be seen some of these crackings. The stirrup worked properly, sewing after the macrocrack development, as was proven with the displacement observed by the LVDTs (figure 5.76). Also the tensile stress-strain law of the UHPFRC is well appreciated, with a change in the slope of the curve when the matrix cracks develop over 9-10 MPa. 


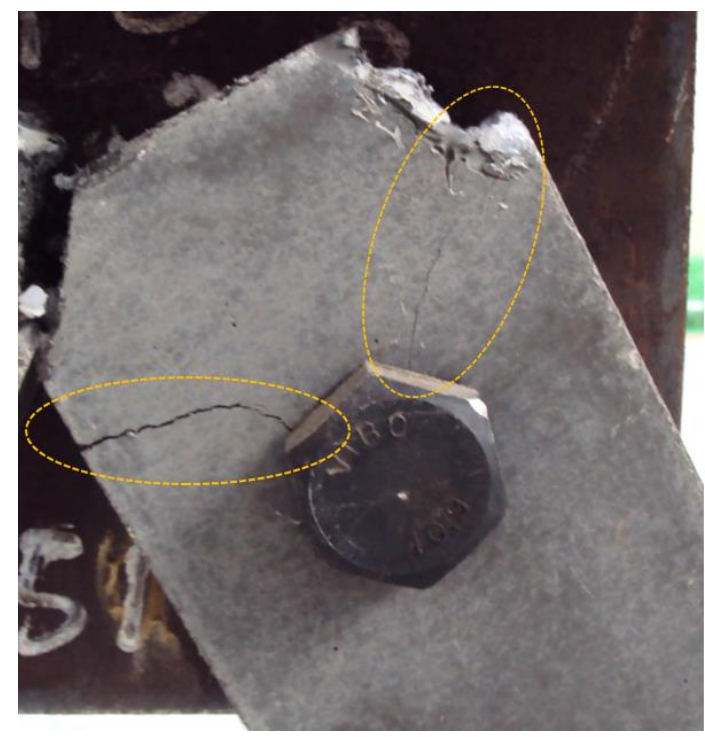

Figure 5.74: Net tension cracking at the diagonal T4

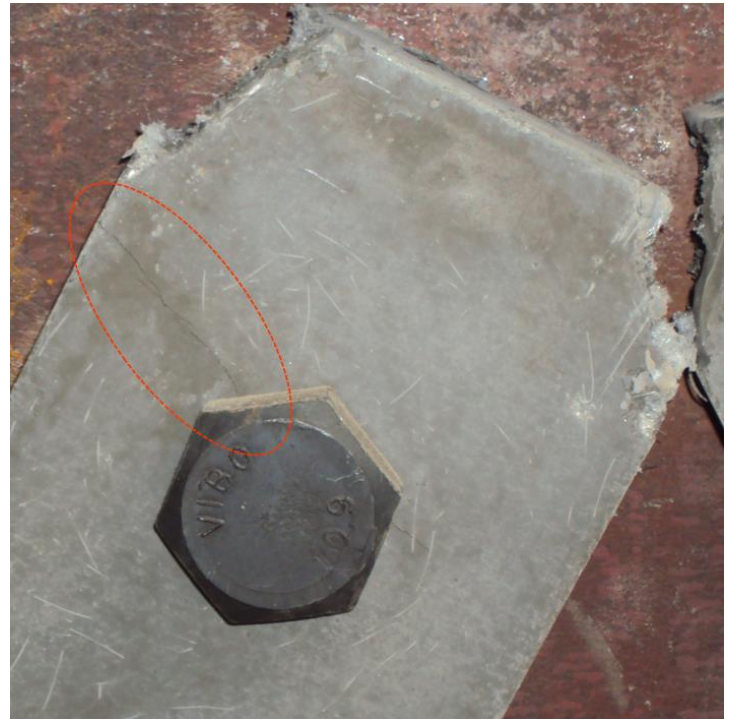

Figure 5.75: net tensión cracking at the upper joint of the diagonal T3

Some of the compressive diagonals, without ordinary reinforcement, showed tensile cracks over the bolt in the same direction of the compressive efforts at the last part of the test. These are the result of the ties orthogonal to the compressive force over the bolt. Those tensile macrocracks precede the bearing failure, but normally are not the reason of it, as will be explained at subsection 5.5.4.3 with a linear finite elements model. Figures 5.77 to 5.78 show several of these cracks appreciated at diagonal C5, which finally suffered the bearing failure and conditioned the structure.

It should be highlighted that the ties are orthogonal to the compressive load, so the fiber material should be poured in a different way than the tensile diagonals in order to reduce this cracking and increase the ductility. The most adequate pouring is the one that favor the fiber alignment orthogonally to the diagonal axis.

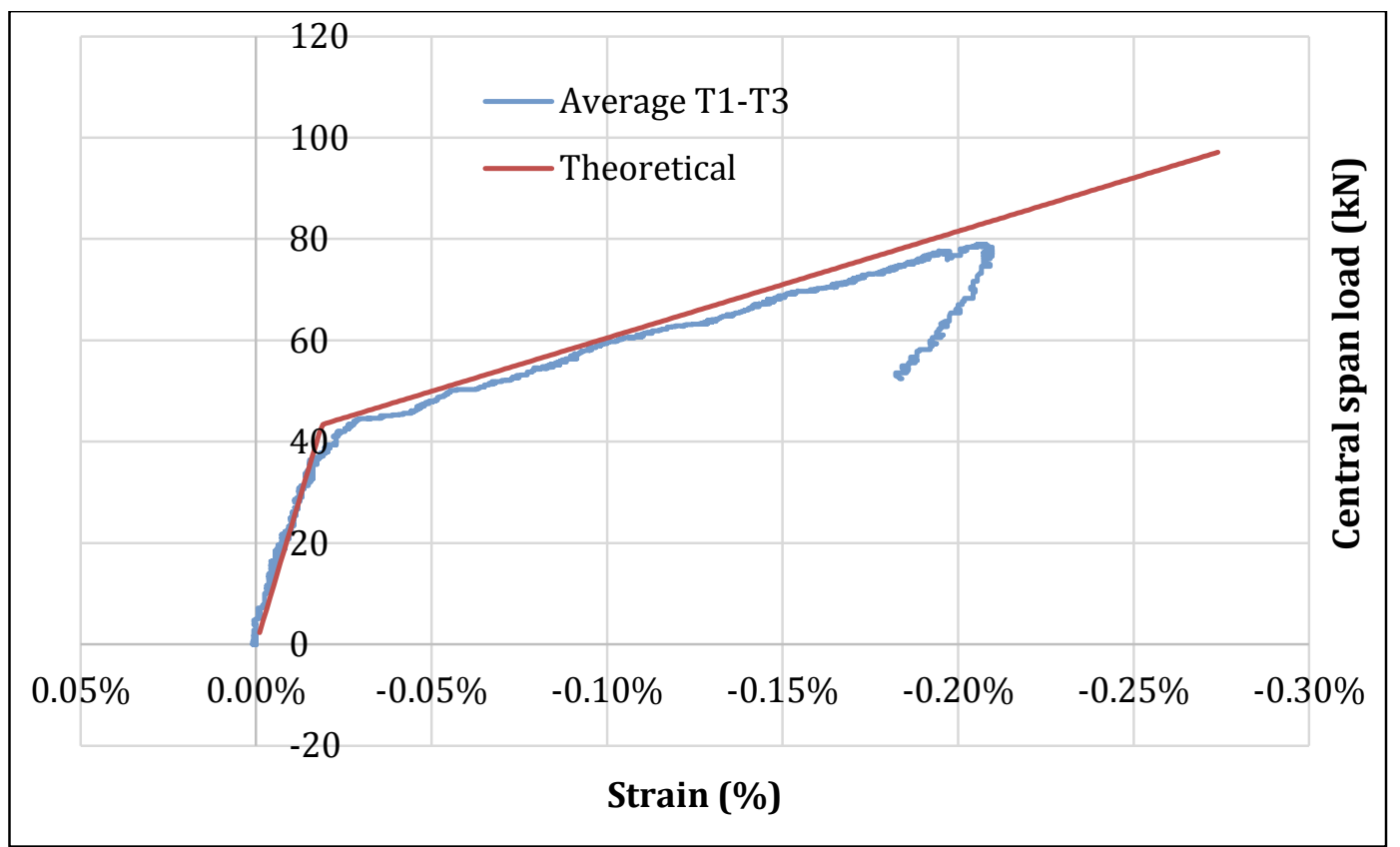

Figure 5.76: Tensile behaviour of the diagonals T1-T3, compared with the theorical tensile law of the diagonal 


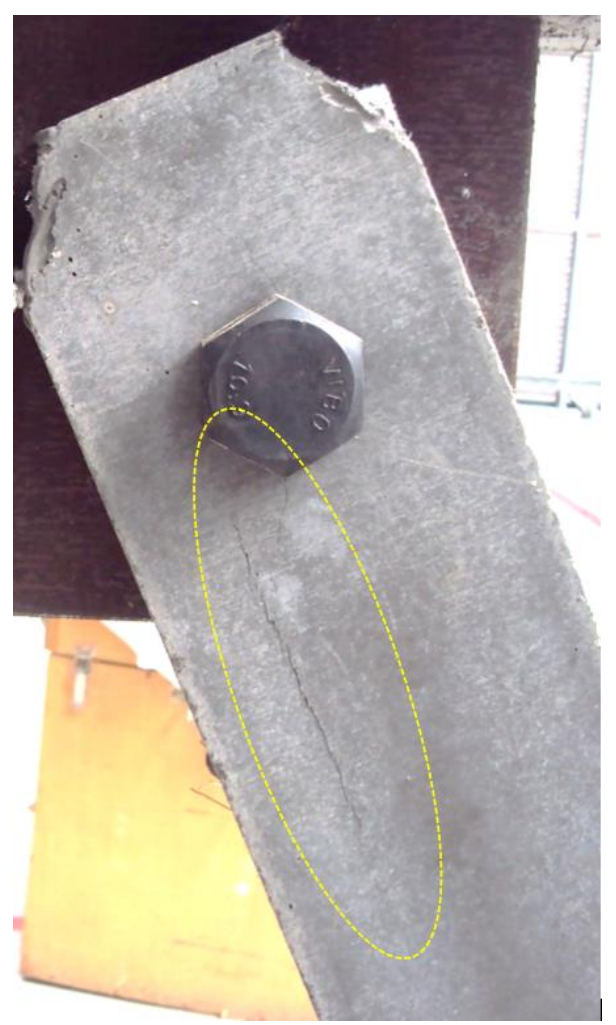

Figure 5.77: Upper joint of the compressive diagonal C5

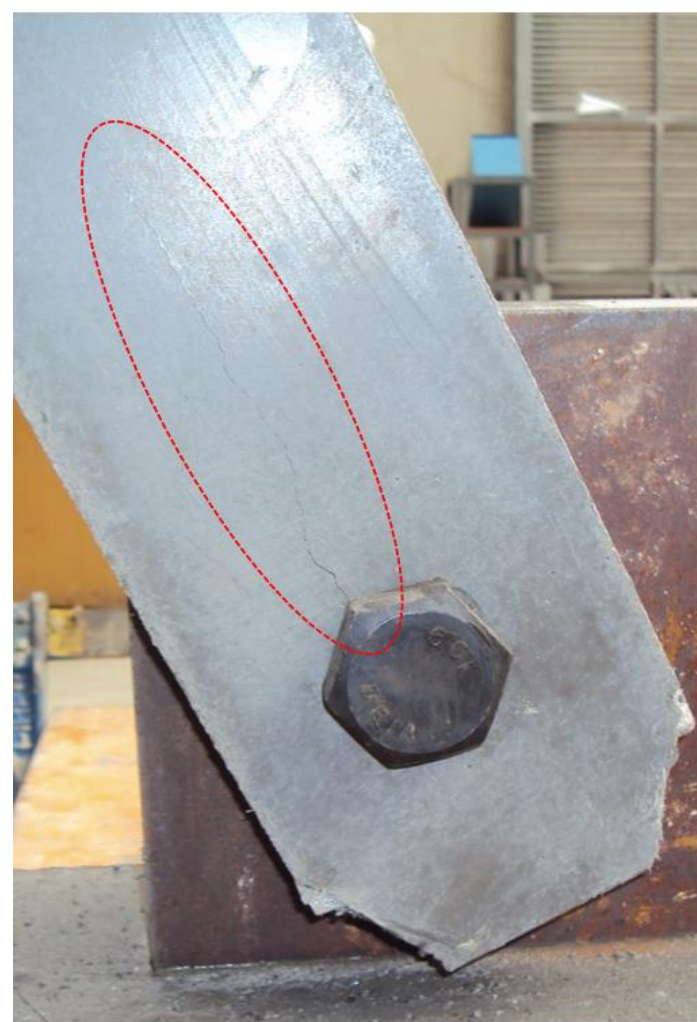

Figure 5.78: Bottom joint of the compressive diagonal $C 5$

\subsubsection{SUBSEQUENT TEST OF THE COMPRESSIVE DIAGONALS}

Finally, after the test was finished, the 15 non-damaged connections of the compressive diagonals were tested to obtain conclusions from the bearing failure behavior.

As the truss can be disassembled, the compressive diagonals were extracted for perform bearing tests and study better the failure mode that was suffered. The elements were cut and tested to check their bearing strength. The process was simple:

- The elements were sewed at $280 \mathrm{~mm}$ from the center of the hole (2.5 times the depth of the truss, $110 \mathrm{~mm}$ ) (figure 5.79).

- Two steel-made perforated pieces were placed at both sides of the hole and a $27 \mathrm{~mm}$ bolt was placed. No one of the 15 bolts was prestressed.

- The element was submitted to compression in a $250 \mathrm{~T}$ jack up to failure. This bearing test is shown at figure 5.80. The maximum load was registered.

- Three type specimens were tested: Five from the fifteen with the PVC cover remaining form the formwork, having a clearance of $0.5 \mathrm{~mm}$, five without the cover, having a clearance of $4 \mathrm{~mm}$ with the bolt, and the last five without PVC but with a flat washer (28 $\mathrm{mm}$ of internal diameter, $49 \mathrm{~mm}$ of external diameter) that was constraining the strain in the third axis. The washer was screwed manually, contacting the UHPFRC but not prestressing it.

The cracking pattern exteperimentally obtained will be explained by an elastic finite element model developed at SAP2000. 


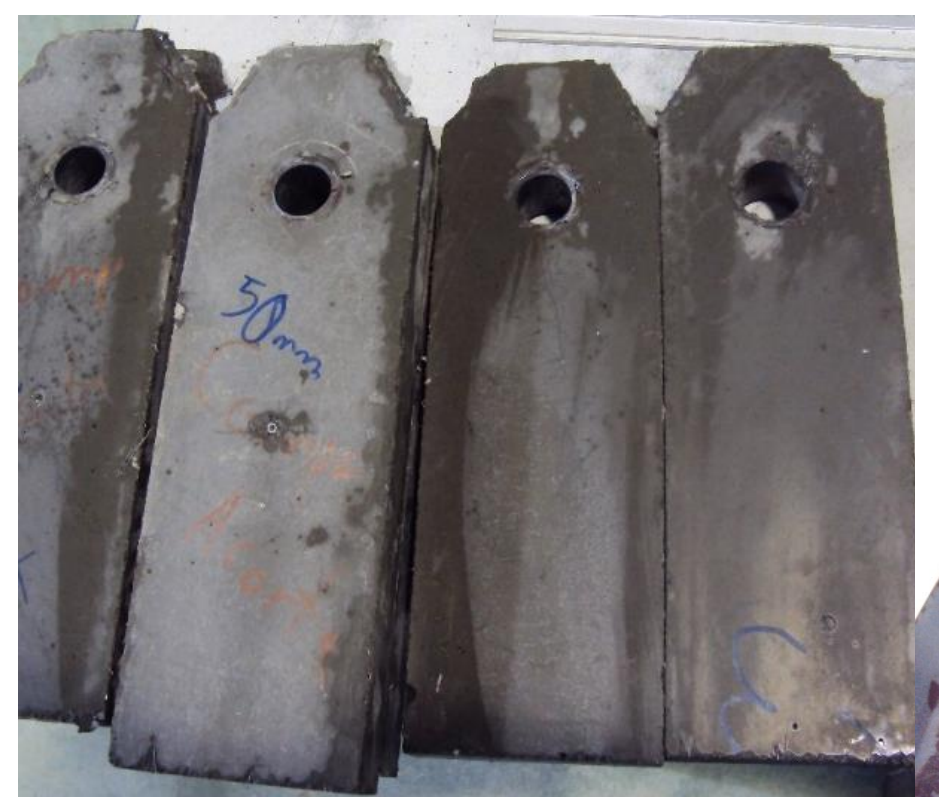

Figure 5.79: Compressive diagonals after sewing

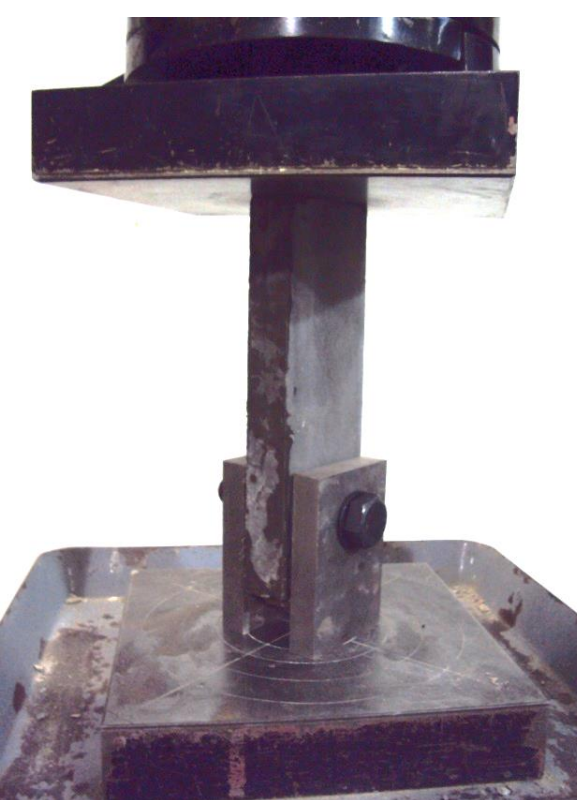

Figure 5.80: Bearing test

The results of the bearing tests are shown at figure 5.81, where the equivalent compressive strength is the load reached divided by the bolt diameter and the shell thickness. As can be seen, there is not a significant difference between have a clearance of $0.5 \mathrm{~mm}$ or $4 \mathrm{~mm}$. This supports that redistribution provided by the fibers is enough, so UHPFRC has a great capacity to carry very concentrated loads. However, the use of a flat washer increases the maximum load carrying capacity an average of $28.5 \%$, becoming a significant difference. This is explained by the triaxial compressive state of the concrete in the region where the washer is in contact.

The observed failure is a crushing in the region that sorrounds the washer, growing from it. The use of elements that constrain the strain in wider regions could increase more the equivalent compressive strength. This fact should be experimentally proven in the future.

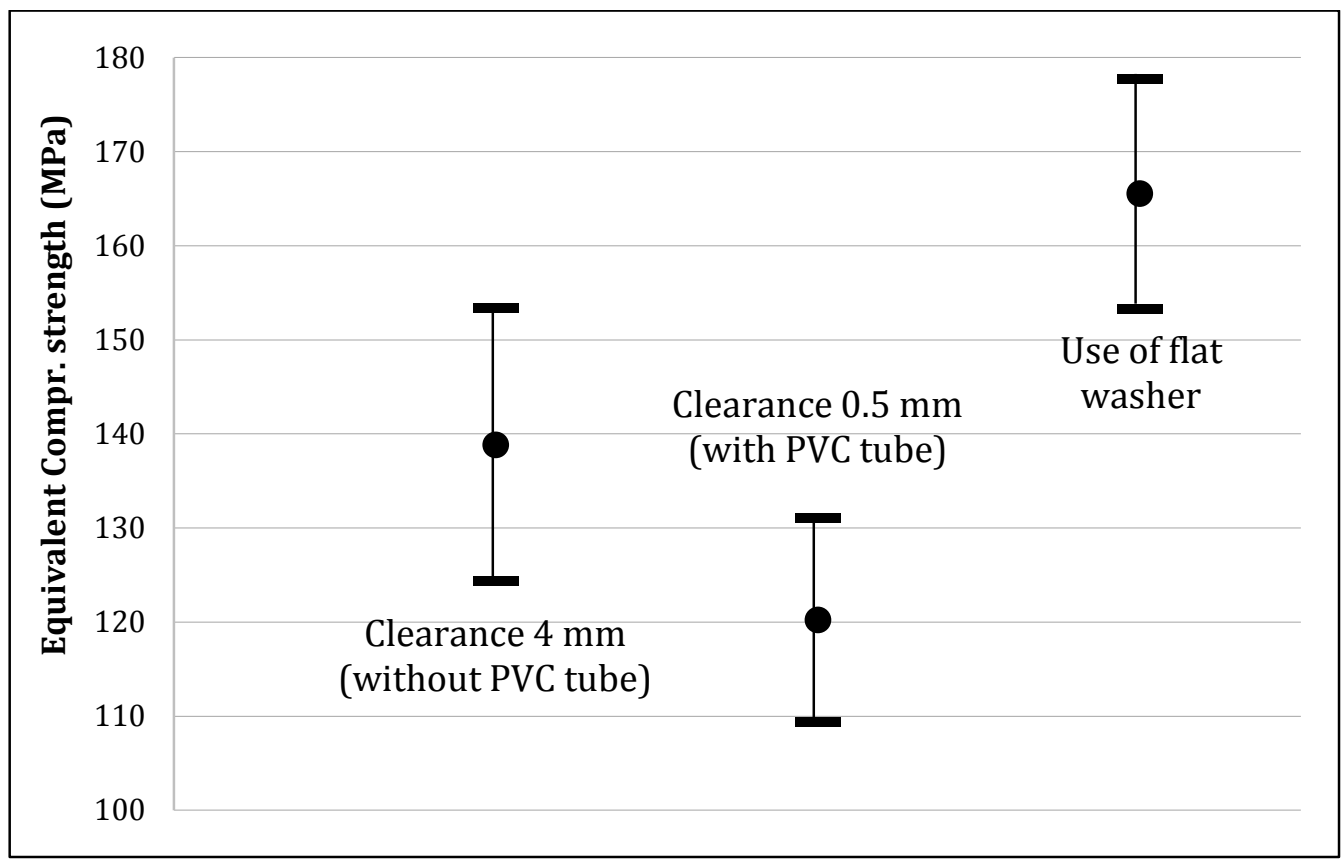

Figure 5.81: Average and starndard deviation of bearing tests results 
The cracking patterns observed for the bearing failure can be divided in three phenomena:

- First, a tensile crack that appears diagonally from both sides with an angle of approximately $30^{\circ}$ respect to the load applied. The reason is the distortion of the hole (figure 5.82).

- A tensile macrocracking over the hole parallel to the compressive load. It appear in many of the cases, but not always. Generally it is not the cracking that produces the final failure. It is relevant to say that the cracking starts in the perimeter of the hole, connecting in many cases with the diagonal cracks commented before.

- A crushing pattern in the biaxial compressed region immediately over the bolt. The progressive crush of the material involves in most of the cases the ductile failure.

The only difference appreciated was that at the elements with washer the material in contact with it didn't suffer a strain orthogonal to the shell. At figure 5.82 these issues can be appreciated. The material was wet as it facilitates the visualization of the cracks.
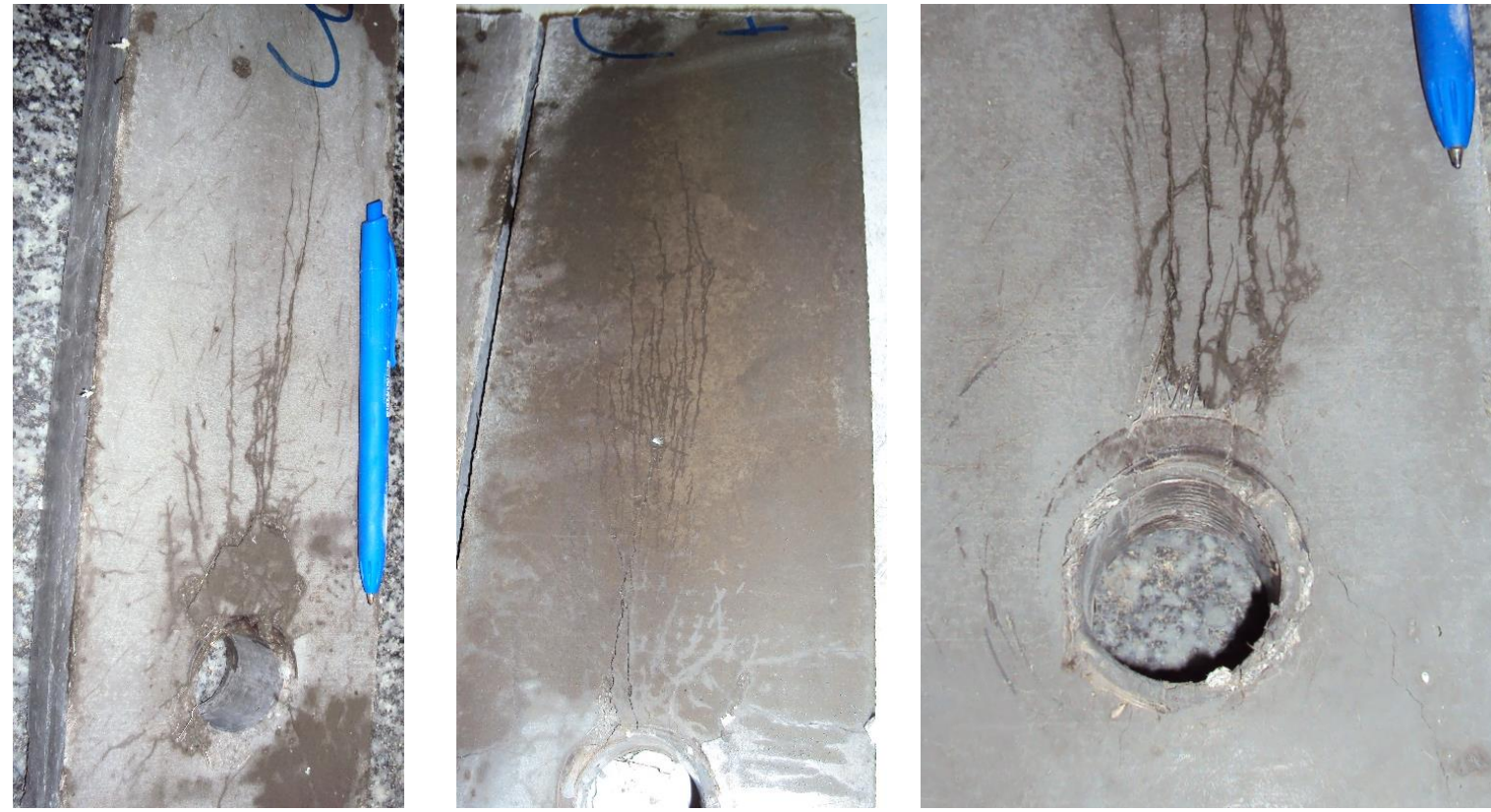

Figure 5.82: Cracking patterns of the bolts after the bearing tests. The right photo was an element tested with flat washer

\subsubsection{FINITE ELEMENT MODELLING OF THE BEARING FAILURE}

A linear finite element model was done in order to understand the bearing failure mechanism. It was performed with SAP2000 version 11 . The element was designed as a thin shell with the same dimensions as the tested piece $(380 \mathrm{~mm}$ high, $110 \mathrm{~mm}$ width and $40 \mathrm{~mm}$ of thickness). The shell was divided in 2006 elements, being a denser mesh in the region surrounding the hole, which was modeled as a 36 side polygon (see figure 5.83). The Young Modulus of the material is $48000 \mathrm{MPa}$, but when it reaches the maximum matrix tensile strength, the strain hardening and softening are modeled decreasing this value, as was done to model the cleavage failure. This process was explained at 3.8.1. 


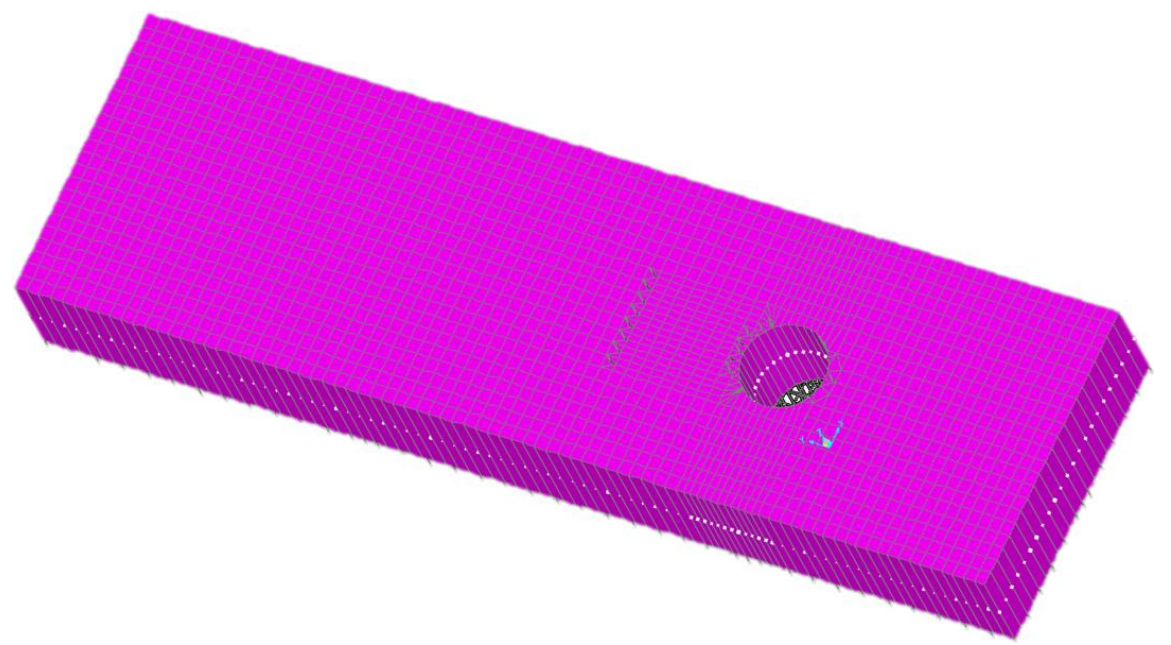

Figure 5.83: Image of the element modeled

One of the key points of the model is how to distribute this load in the hole. It depends on the stiffness of the elements and the clearance between the hole and the bolt. The assumptions made to distribute the load were:

- The force is orthogonal to the perimeter of the hole, being maximum in the upper part.

- The reduction of the distributed load is quadratic and symmetric until 0 at both sides.

- The models are performed with an increasing vertical load, as a percentage of the maximum average load obtained from the bearing tests $(50 \%, 85 \%$ or $100 \%$ of $130 \mathrm{kN})$.

In the model, the friction coefficient was made equal zero and the bolt was assumed to transmit only normal pressure (orthogonal to the hole perimeter), dividing it as punctual loads. Several models were tried to allocate the loads. The main difference is the consideration of the perimeter of contact between the UHPFRC and the bolt. This can be controlled with an angle $\alpha$, as can be seen on figure 5.84. The hypothesis tested at the model are shown at table 5.6. Also the same hypothesis were introduced with only vertical load, instead of being radial, but it provided a worse approximation to the results of the experimental tests.

\begin{tabular}{|c|c|c|c|c|c|c|c|}
\hline Hypothesis & A & B & C & D & E & F & G \\
\hline Points of load & 3 & 5 & 7 & 9 & 11 & 13 & 15 \\
\hline Angle of contact & 10 & 20 & 30 & 40 & 50 & 60 & 70 \\
\hline Vertical load & \multicolumn{7}{|c|}{$130000 \mathrm{~N}$} \\
\hline $\begin{array}{c}\text { One side horizontal } \\
\text { resultant load (N) }\end{array}$ & 5731 & 8002 & 16755 & 19344 & 23998 & 33169 & 38198 \\
Unolt
\end{tabular}

Table 5.6: Different hypothesis of distribution of the load

The vertical load is considered distributed in quadratic proportion. It can be seen for some of the load distribution hypothesis at figure 5.84. According with the stresses observed at the model, the most accurate assumption is distribute the load at 7 points (hypothesis $\mathrm{C}$ ), assuming that the circular sector of contact between bolt and UHPFRC is of $60^{\circ}\left(\alpha=30^{\circ}\right)$. 


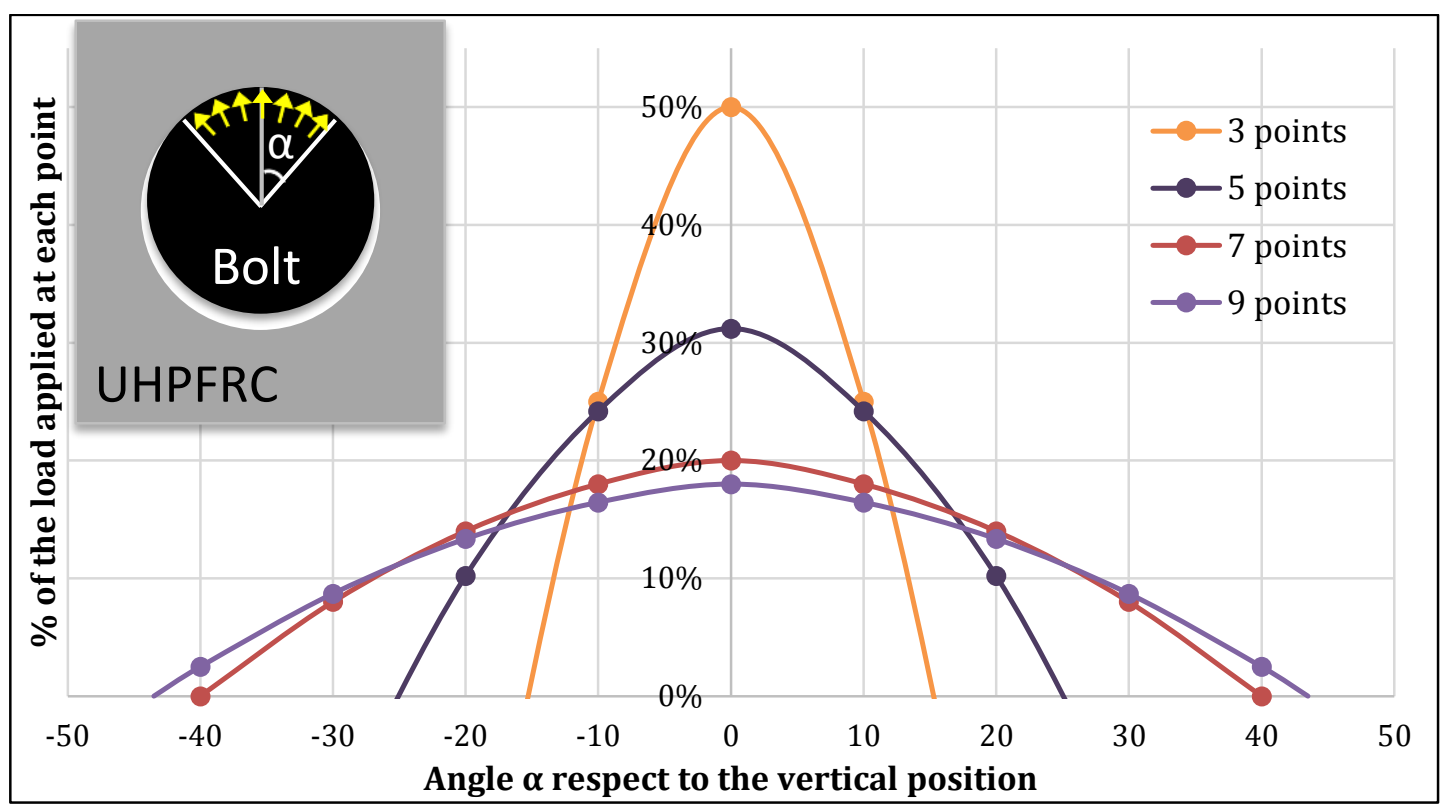

Figure 5.84: Distribution of the vertical load for different proposals

The hypothesis $C$ provided a tensional level that explains the cracking patterns obtained and the maximum loads. The load has to be progressively increased to explain the cracking patterns observed in the tests in the strain hardening and softening regions. Here the loads applied were:

- $50 \%$ of the average maximum load $\rightarrow$ Study the overloaded regions and plastify them

- $85 \%$ of the average maximum load $\rightarrow$ Study the overloaded regions and plastify them

- $100 \%$ of the average maximum load $\rightarrow$ Colapse

The stress distribution that will be studied is at the section shown on the figure 5.85 :

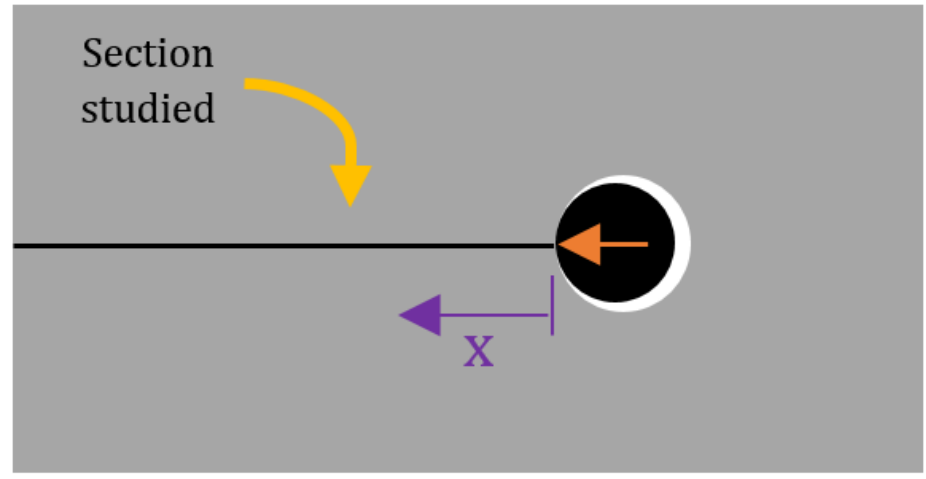

Figure 5.85: Section where stresses are studied

First load level: $65 \mathrm{kN}$ ( $50 \%$ of the average maximum load): The compressive strength over the bolt reaches a maximum of $96 \mathrm{MPa}$ (figure 5.86), and the tensile stress over the bolt on the $\mathrm{X}$ direction -8.3 MPa. The tensile stress concentration on the perimeter (blue region on figure 5.87) reaches $-44 \mathrm{MPa}$, so the UHPFRC plastifies before in that area. This means that, for the next model, the Young modulus of this region will be decreased, as the effort carrying capacity is more reduced. The cracking of this region will be therefore modeled decreasing the young modulus to $5000 \mathrm{MPa}$ in this regions, and to 10000 and 15000 in the adjacents. 


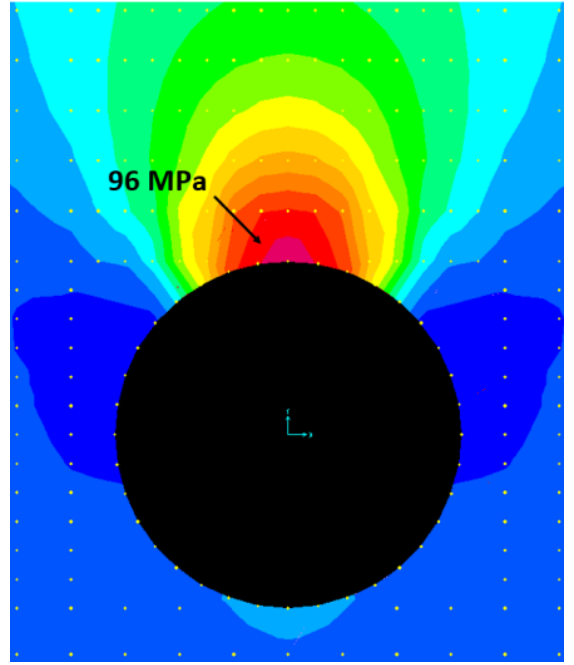

Figure 5.86: Maximum stresses around the hole

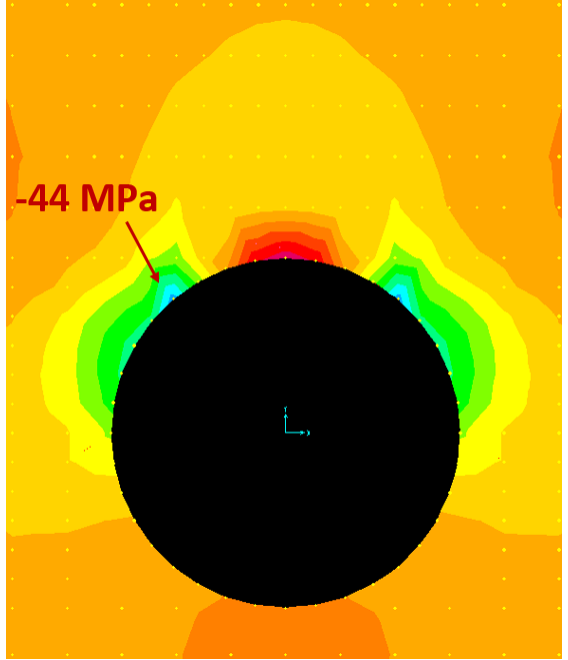

Figure 5.87: Minimum stresses around the hole

Second load level: $85 \%$ of the maximum load carrying capacity $(110.5 \mathrm{kN})$. To obtain the stresses, the previous model with the plastified regions near the bolt will be assumed. The young modulus modified can be seen at figure 5.88.

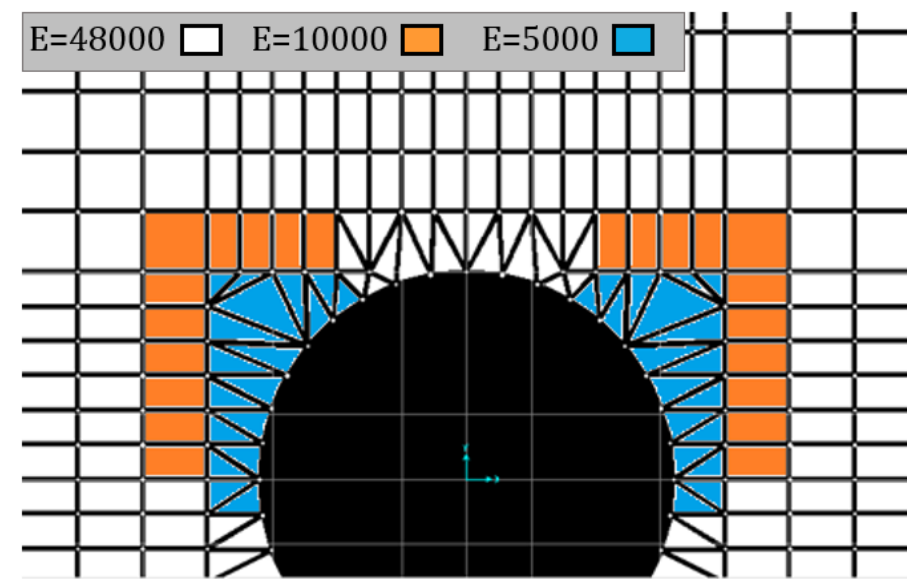

Figure 5.88: Plastified sections in the element

As can be observed on figure 5.90, regions plastified are at a stress level of $12 \mathrm{MPa}$, and the tension over the bolt reaches 10.4 MPa, so the material is in the limit of start the microcracking typical of the strain hardening behavior. Finally, the compression regime over the bolt is biaxial, as both the minimum and maximum stresses are in compression. The maximum one is $167 \mathrm{MPa}$ (figure 5.89), while $165 \mathrm{MPa}$ is the uniaxial compressive strength of the material for prisms $100 \times 100 \times 100 \mathrm{~mm}$. however, the biaxial state and the localization of the stress in a small region allows an increase of the capacity. 


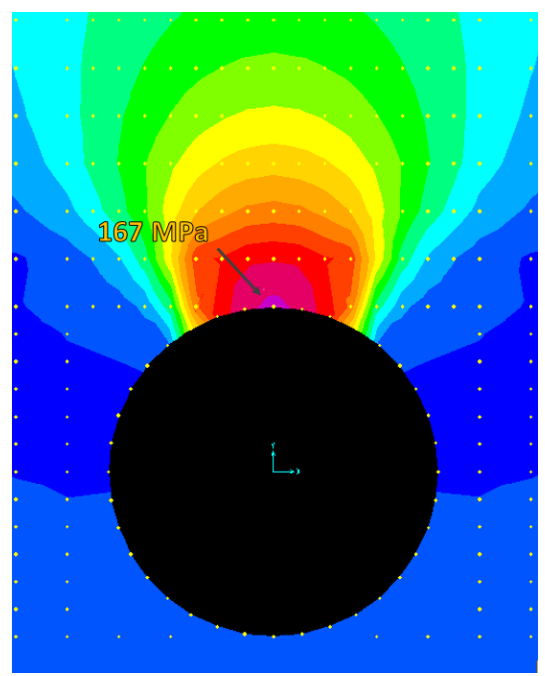

Figure 5.89: Maximum stresses around the hole

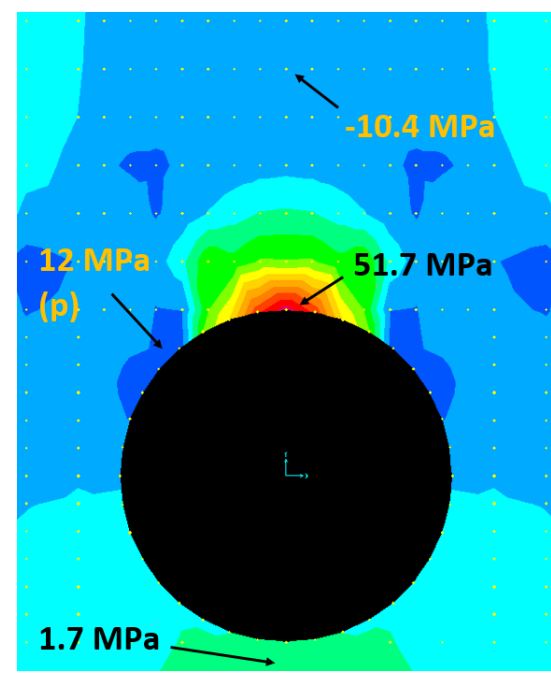

Figure 5.90: Minimum stresses around the hole

The maximum (axis $\mathrm{Y}$ ) and minimum (axis X) stress distribution in the section indicated at figure 5.85 is shown in figures 5.91 and 5.92 .

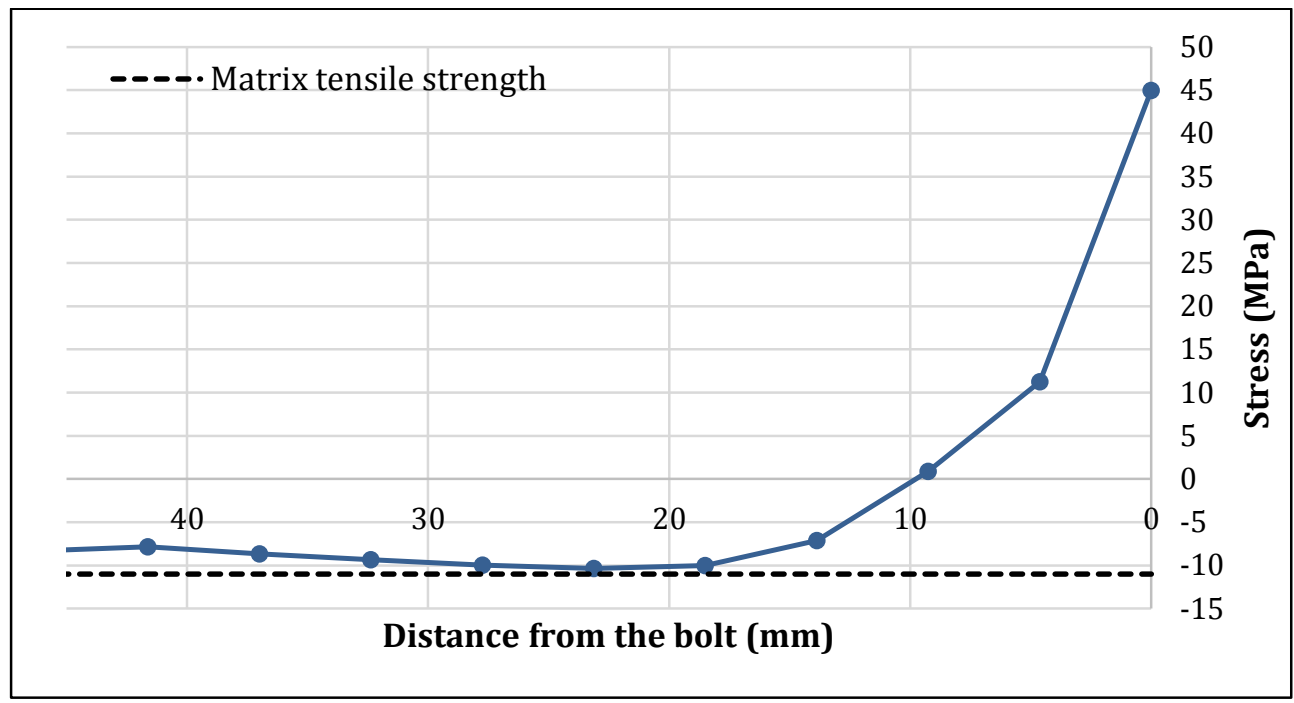

Figure 5.91: Minimum stress in the vertical section over the hole (axis X)

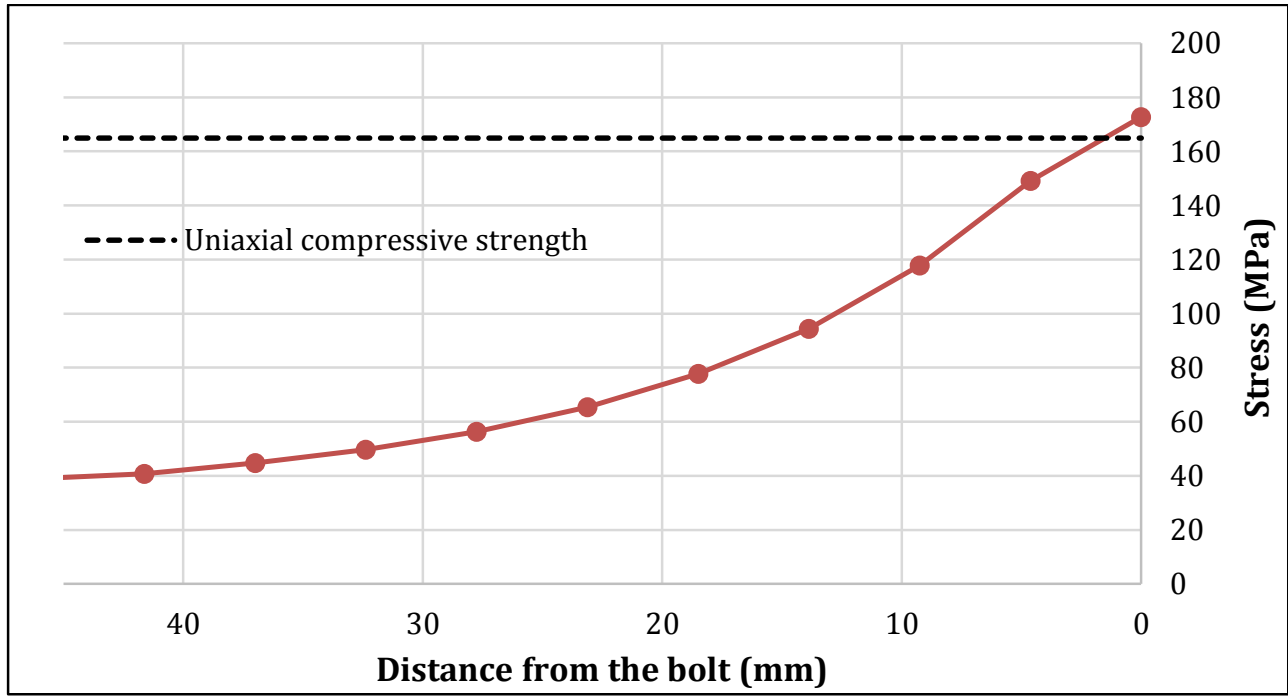

Figure 5.92: Maximum stress in the vertical section over the hole (axis Y) 
Third load level: $100 \%$ of the maximum load carrying capacity $(130 \mathrm{kN})$. With the increase of the load, the most deformed regions might be modeled with a stronger decrease of the Young modulus, as is shown at figure 5.93 .

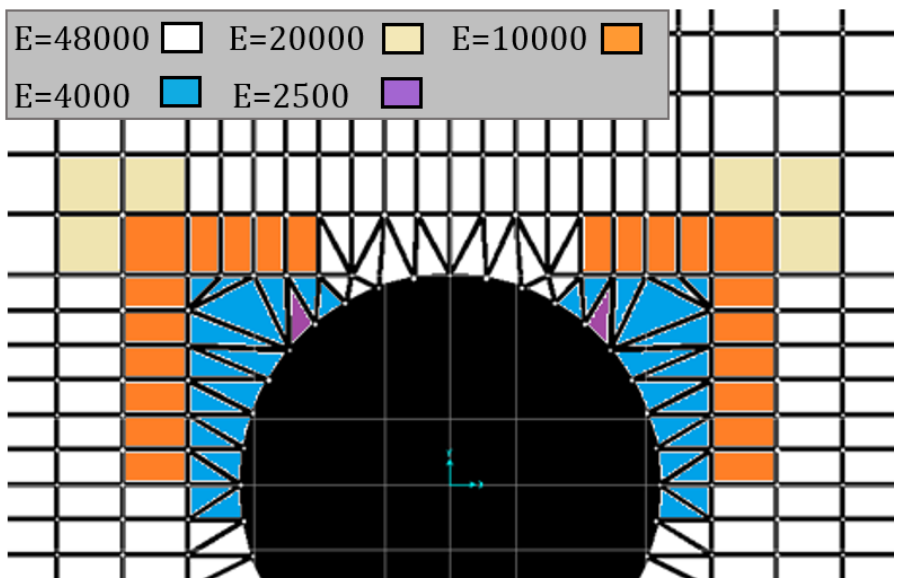

Figure 5.93: Plastified sections in the element

The model has shown that the region over the bolt reaches tensile stresses between -10 MPa and $-12 \mathrm{MPa}$, so microcracking and one macrocrack might appear, but the failure is not expected through this section.

The results obtained are showing that the final failure is in biaxial compression, explaining properly the failure mode observed when the experimental results reach an average maximum load of $130 \mathrm{kN}$. The clear blue region (plastified and the most tensile tensioned) of figure 5.95 coincides with the cracked section over the bolt visible on figure 5.96.

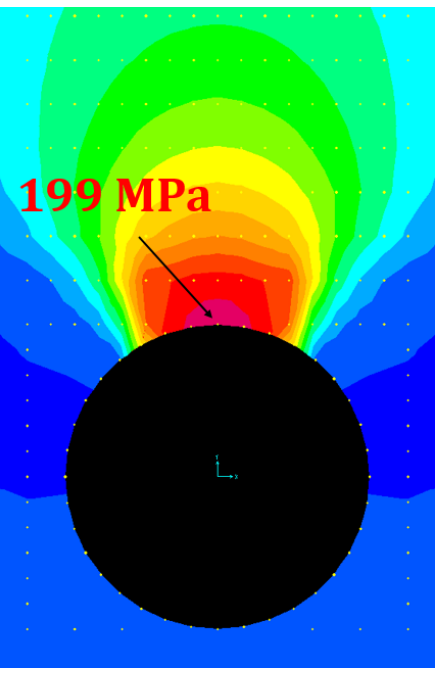

Figure 5.94: Maximum stress around the hole

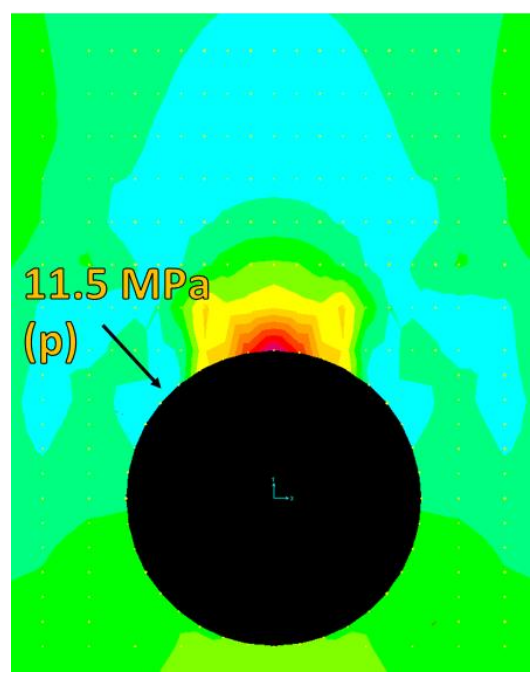

Figure 5.95: Minimum stress around the hole

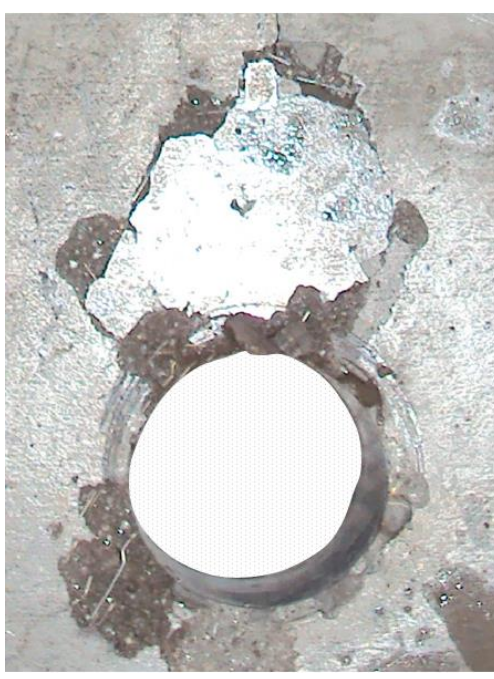

Figure 5.96: Example of bearing failure

The evolution of the maximum and minimum stresses behind the bolt (in the section of figure 5.85) is shown at figures 5.97 and 5.98. It can be noticed that the tensile strength does not exceeded the maximum tensile strength capacity. This means that the redistribution is possible over the bolt. However, the compressive stress reaches exactly over the bolt a maximum of $199 \mathrm{MPa}$ (with $45 \mathrm{MPa}$ in the normal direction). This seems to be the maximum in biaxial compression, as the final failure is suffered in this region with this load. 


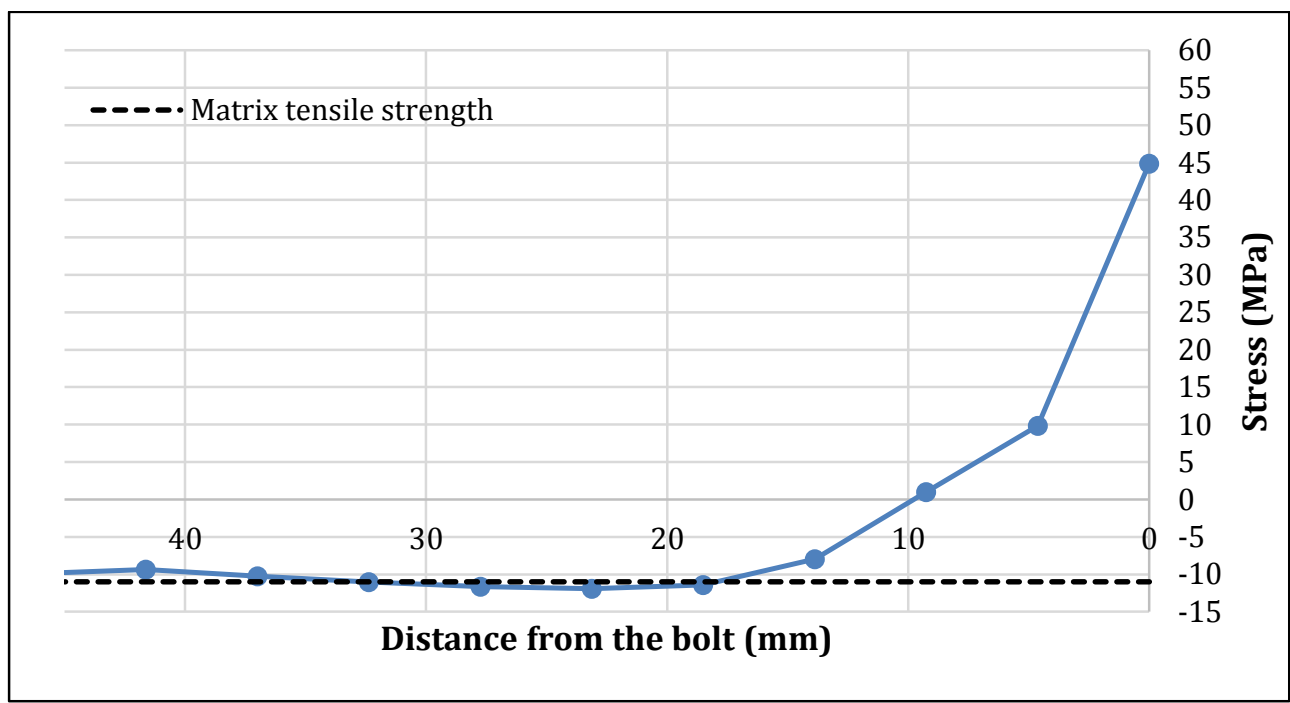

Figure 5.97: Minimum stress in the vertical section over the hole (Axis X)

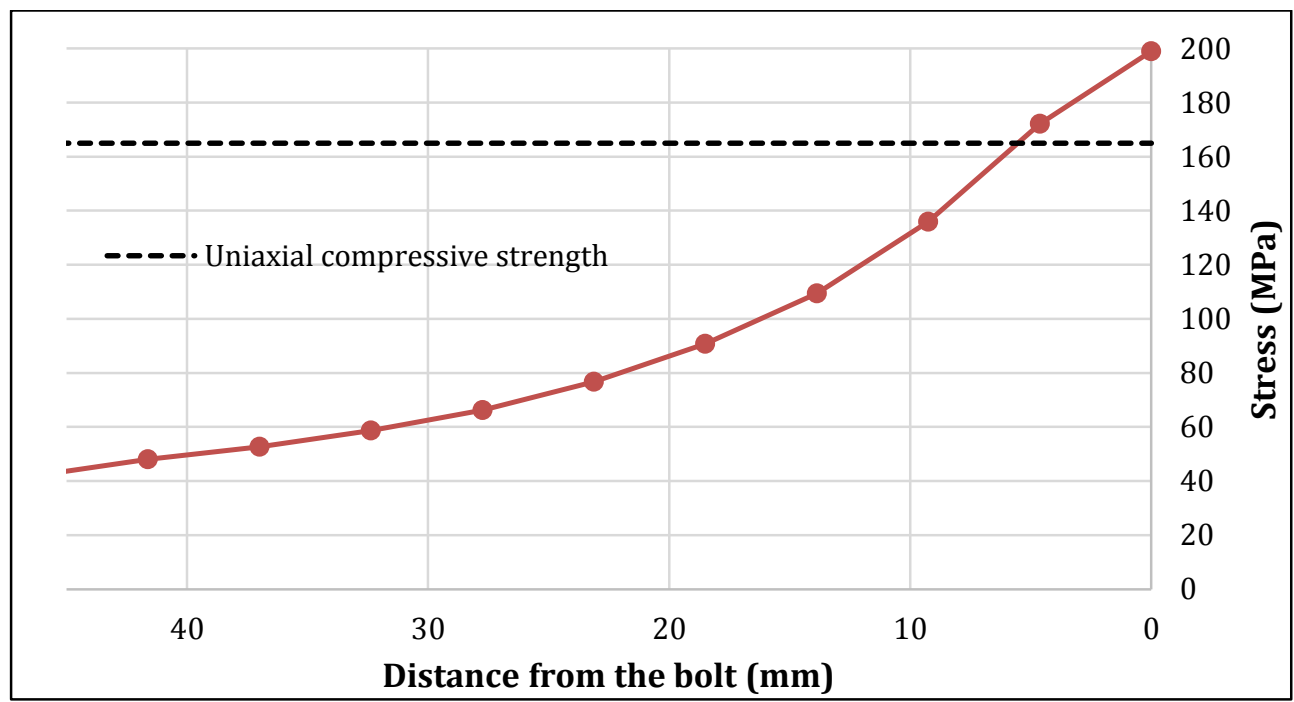

Figure 5.98: Maximum stress in the vertical section over the hole (Axis Y)

\subsubsection{CONCLUSIONS OF THE REAL SIZE STRUCTURE TEST}

Some of the most relevant observations have been:

- The results shown that stirrup is efficient avoiding the net tension and cleavage failure in the tensile diagonals. A steel corrugated stirrup of $10 \mathrm{~mm}$ of diameter was enough for the application.

- When the net tension and cleavage failures are avoided with steel reinforcement, bearing failure might appear. It was proven that increase the bearing strength is possible adding an external piece between the hole and the bolt that let the UHPFRC reach triaxial state.

- The elements fit adequately, with the only requirement of extract some PVC tubes from the holes to $2 \mathrm{~mm}$ of clearance for some diagonals.

- The first bolt failure was suffered at lower load than expected. It was found that the difference of clearance in a pair of diagonals overloaded one of them, while the other was almost without load. This emphasize the idea of give to all the bolts the same clearance to have the load distribution desired. 
Then, considering these options restrictions, bolted connections could be used for several real full-scale applications, particularly for truss structures.

\subsection{FORMULATION TO PREDICT FAILURE MODES}

Here are suggested formulations to predict the Ultimate Limit State for the joints proposed. They are based on the experimental results obtained previously.

\section{Cleavage failure:}

$$
F_{\text {cleavage }, R d}=\left(\frac{W}{25 D}+0.64\right) \cdot \frac{t \cdot E \cdot \sigma\left(w_{0.3}\right)}{\gamma_{b f} \cdot K}
$$

The factor $\left(\frac{W}{25 D}+0.64\right)$ takes in account the effect of the reduction of the element width, as a smaller secondary cracks reduce the cleveage strength. The factor has been obtained from the results of the first test proposal.

Where $\sigma\left(w_{0.3}\right)$ is the tensile strength associated to a crack opening of $0.3 \mathrm{~mm}$, which is normally the highest reached in a tensile test. The factor $\mathrm{K}$ is 1 or higher, being 1 if the alignment of the fibers is parallel to the perimeter of the hole, or more as worse is the fiber alignment. As the failure mode was ductile the safety factor $\gamma_{b f}$ chosen here was 1.3.

This formulation requires deeper study for values of $W / D<3$ and $W / D>10$.

\section{Net tension failure mode:}

First of all, this formulation varies depending on the type of ordinary reinforcement, if used. When the only reinforcement used are steel fibers, the formulation that predict the U.L.S. is:

$$
F_{\text {net tension }, R d}=0.55 \cdot \frac{(W-D) \cdot t \cdot \sigma\left(w_{0.3}\right)}{\gamma_{b f} \cdot K}
$$

The factor $\mathrm{K}$ is 1 if the fiber alignment is parallel to the tensile strength, or higher when fibers are oriented in several directions. The safety factor $\gamma_{b f}$ is again 1.3. This formulation requires deeper study for values of $W / D<3$ and $W / D>10$.

If the tie is reinforced with ordinary elements, they have to be token in account for the calculation. If the reinforcement are two corrugated steel bars, the maximum tensile strength of the UHPFRC is reached when the bar is already plastified. Thus, the capacity of both materials can be added to calculate the maximum load:

$$
F_{\text {net tension }, R d}=0.55 \cdot \frac{(W-D) \cdot t \cdot \sigma\left(w_{0.3}\right)}{\gamma_{b f} \cdot K}+1.3 \cdot \frac{f_{y} \cdot \pi \cdot D^{2}}{4 \cdot \gamma_{s}}
$$

Where the factor $\gamma_{s}=1.15$ is the material safety coefficient for the steel.

The second type of tests proposed shown that non-prestressed wires are not the most adequate type of reinforced. The reason is that their strain capacity is much higher than the strain of the UHPFRC when the maximum tensile strength is reached. Then, both materials 
cannot work together on their maximum capacities. This would be solved if the wire is prestressed. Besides, the wire is smooth and then the development length is much higher than for a corrugated steel bar. This could be solved if it is used as a stirrup.

\section{Bearing failure:}

The results are deduced from the bearing tests performed in the preliminary proposal (section 5.3) and also to the compressive diagonals tested from the full size truss structure (chapter 5.5.4). Two situations are modeled. For both a more reduced diameter implies higher equivalent compressive strength. The formulations proposed for U.L.S. are:

- When the deformation in the axis normal to the plate is constrained. Then, the UHPFRC of the region over the bolt can work in triaxial compression. The connection can carry higher load than what expected from uniaxial compressive capacity of the concrete. This capacity is reached when the element is in contact by both sides with other fixed elements. Also the use of washers with enough diameter produces this triaxial state. The formula proposed is:

$$
F_{\text {bearing }}=\left(15.3 \cdot D_{b}^{-0.778}\right) \cdot t \cdot \sigma_{c} / \gamma_{b f}
$$

Where $D_{b}$ is the diameter of the bolt and $\gamma_{b f}$ a safety factor that here is 1.3 , as the failure was ductile. Prestression is not considered.

- If the displacement on the third axes is free, the concrete in the damaged region over the bolt is not in triaxial condition, and the load carrying capacity is more reduced.

$$
F_{\text {bearing }}=\left(39 \cdot D_{b}^{-1.23}\right) \cdot t \cdot \sigma_{c} / \gamma_{b f}
$$

The experimental data that verified the effect of the confinement was supported mainly in the bolts of $D_{b}=27 \mathrm{~mm}$, and assumes that the relative reduction of capacity between confined and non-confined elements is similar for any diameter.

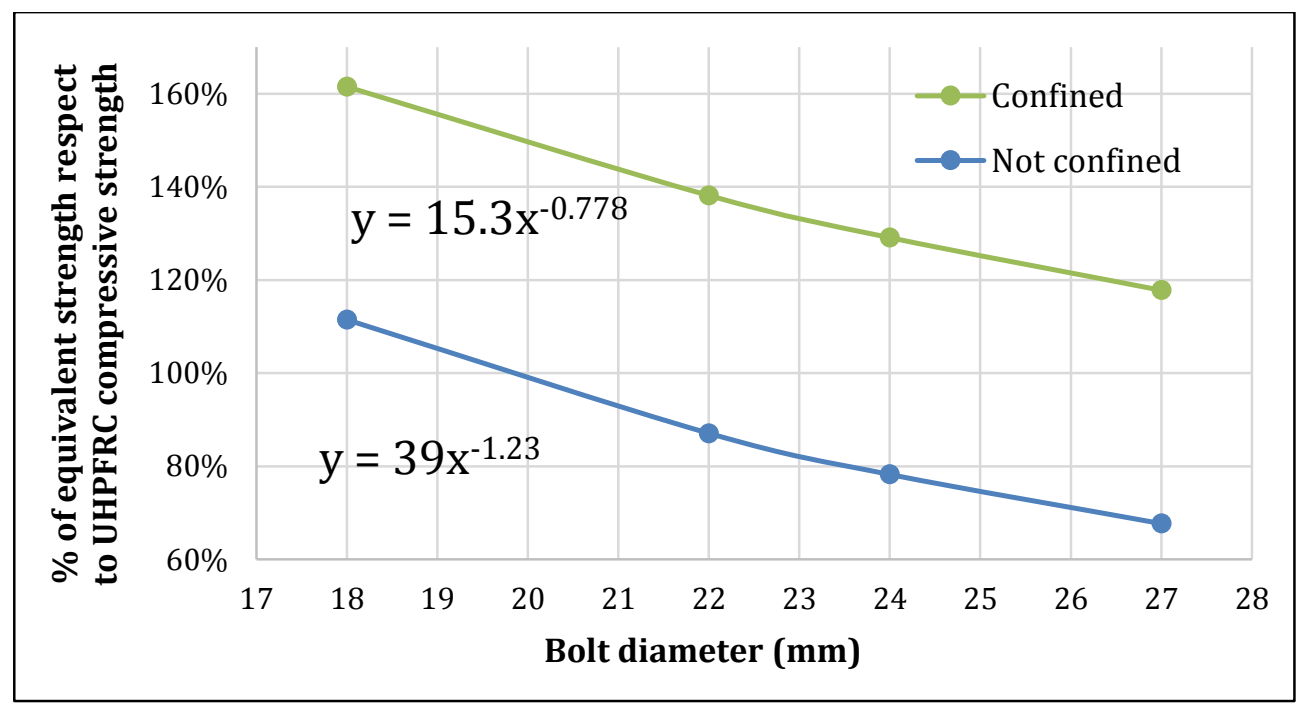

Figure 5.99: Relative increase of equivalent compressive strength respect to the uniaxial compressive strength depending on the bolt diameter

The figure 5.99 represents these formulations. For reduced diameters, the equivalent compressive strength is between 1.1 and 1.6 times the compressive strength of the UHPFRC, depending on the degree of confinement. 


\subsection{RECOMMENDATION FOR THE DESIGN OF BOLTED JOINTS}

After the tests and the design of a real size element, some general comments can be made relative to the design of bolted joints:

- In UHPFRC without ordinary reinforcement the main failure modes are cleavage and net tension. The capacity can be efficiently increased avoiding the premature failure of both with ordinary steel stirrups.

- If ordinary reinforcement is used, the development of the adherence has to be guaranteed with enough length behind the bolt or the use of stirrups.

- When net tension and cleavage are avoided, bearing failure can be limiting. For those cases, constrain of the deformation in the third axes increases significantly the strength. Also the reinforcement over the bolt region might avoid the opening of the tensile macrocracking along the ties formed.

- Clearance between elements is of great importance, as it can affect not only to the assembling process, but also to the structural global load distribution. Thus the control of the measurements at the prefabricated company should be high. 
6. ConClusions 
ConClusions 
The research project presented within this Ph.D. thesis develops a wide study of VHPFRCUHPFRC dosages and its application for bolted connections, an innovative system unusual with cementitious materials. Two have been the main aims of these studies:

* Develop dosages with different levels of performance introducing simplifications and seeking efficiency. This work became the implementation of the UHPFRC technology at Universitat Politècnica de València.

* In reference to the UHPFRC bolted connection systems, the research focused in design a useful testing process, use it to study the failure modes and check the viability and restraints for this solution.

In a reference to the first part, several simplifications in components and processes were introduced, obtaining a material with adequate properties for many applications and reasonable costs. The main conclusions obtained have been:

1. UHPFRCs can strongly differ on the dosages of different researchers. However, the most typical contain over $1200 \mathrm{~kg} / \mathrm{m}^{3}$ of binder, and with this content compressive strength can differ up to a $40 \%$ due to the components compatibility. The composition of the binder is not as important as its high content to reach the UHPFRC properties.

2. Quartz flour is added in the dosages of mostly of the authors. It should be considered as binder even though is inert as then the correlation W/B vs. compressive strength is higher. The use of 42.5 cement may increase the workability, but the strengths are similar than for higher class cement.

3. The dosage studied from different authors show that the Paste Volume Fraction and the maximum aggregate diameter follow a linear negative relation.

4. The dosages developed by the author shown that W/B ratio should not be decreased in excess even though slump flows are acceptable. For dosages with $1000 \mathrm{~kg} / \mathrm{m}^{3}$ of cement, adequate W/B ratios are 0.175-0.18, with slumps flow about $750 \mathrm{~mm}$. Higher slumps may produce fiber segregation.

5. FC3R requires higher water control than CSF to reach the desired workability. It showed better compatibility with the cement I-42.5 R/SR, while CSF with I-52.5 R/SR. FC3R can be added in contents higher than $15 \%$ o.c.w., while local CSF decreases markedly the workability due to the high carbon content. FC3R also provides higher early age activity.

6. Limestone coarse aggregate addition reduces notably the workability of hybrid concretes, as the long fibers tangle with them. However, it reduces greatly the cement content keeping similar long term compressive strength. The early age strength is more affected due to the weaker aggregate-paste ITZ.

7. Intensive mixer reaches a great dispersion of the CSF. However, any mixer can be used to cast UHPFRC. In a low energy tilting mixer the dosage requires $10-15 \%$ more of W/B ratio and much longer mixing times. Compressive strength is acceptable but segregation may be higher. 
8. The UHPFRC with excess of paste can be designed with the so-called here TPD method, a simple process to obtain empirically the sand combination with higher packing density.

9. Simple reccomendations related to the dosage, pouring and mixing process have been extracted as a useful guide for companies or engineers that want to develop UHPFRC.

10. Different requirements imply different suitable dosages. At this Ph.D. five dosages with targeted properties were defined as the most adequate for different conditions. Their properties varied between FRC $(<120 \mathrm{MPa}$ of compressive strength and $<20 \mathrm{MPa}$ of flexural strength) and UHPFRC ( $>150 \mathrm{MPa}$ of compressive strength and $>30 \mathrm{MPa}$ of flexural strength), and the cost study shown that the dosage with lower performance was about $20 \%$ cheaper than the one with medium performance. Enhance more the performance than the medium dosage increases $5 \%$ the costs but also requires much higher control and components not available in the local market. This has to be evaluated with the structure requirements to decide which the most interesting material is.

In regard to the second part, it was shown that bolted connections are possible with UHPFRC, and passive steel can provide the required capacity for structural applications, as both work efficienty together. Secondary connections can be performed without ordinary reinforcement as the failure mode is ductile. The most remarkable conclusions are:

11. The single bolted connection test studied is adequate for bolted joint analysis, providing low scatter in the results and failure modes in the studied section.

12. The most predominant failure modes are cleavage and net tension. The net tension failure mode is less ductile than the cleavage, which provides lower ductility as higher is the cover E behind the bolt. Without ordinary reinforcement bearing failure is not suffered at the pieces. The loads and cracking patterns obtained are consistent with the linear elastic models performed.

13. Passive bar reinforcement increases the net tension load carrying capacity and the ductility. Thus, the brittle cleavage failure can be suffered for high E distances. This suggest the use of passive reinforcement for the cleavage section.

14. The use bolted connections is viable in truss structures. The use of stirrups is very effective to avoid the cleavage and net tension failure. However, special attention should be put on the clearance between pieces.

15. Bearing failures are ductile and with biaxial compressive stresses in the region over the bolt. The use of an element that constrains the displacement in the orthogonal edge let the concrete reach triaxial stress and increases the capacity. 
POSSIBLE IMPROVEMENTS AND POTENTIAL OF DEVELOPMENT

7. POSSIBLE IMPROVEMENTS AND POTENTIAL OF DEVELOPMENT 
POSSIBLE IMPROVEMENTS AND POTENTIAL OF DEVELOPMENT 
UHPFRC is a relatively new material, so still lot of research lines should be developed for a better understanding. On one hand, the mixture dosing knowledge assist in the rational use of the components in the material. On the other, structural knowledge provides a rational use of the material in the designs. At this Ph.D. both the two strands have been treated.

The analysis of the dosages up to the moment by different researchers is done in the period 2004-2013. The updating and refinement of the database will provide more power to the study. This research line might provide new deductions and corroborate trends.

Though the UHPFRC dosing is the most developed subject present in the state of art, the research lines opened at this Ph.D. are innovating, all them focused in develop more economic and easier UHPFRC:

- The use of limestone coarse aggregate is almost unknown, and the success gives the opportunity to develop wider studies. A research line could study the interaction of this aggregate type with the fibers both for the rheological and hardened state. Other line should compare this aggregate with the typical used for coarse UHPFRC, observing the differences.

- The analysis of the effect of different mixers in a mixture is not referenced until this moment. This line could be completed with other a wider type of dosages and trying to adapt the procedure for the cast in place concrete.

- Finally, the method to obtain the sand proportions must be studied with more detail. A wider program with more types of sands and dosages should be used to check the validity of the procedure in different cases.

The tips and advertences made at the end of Chapter 4 could be a useful guide for potential users without experience. The enrichment of this section with the experience cumulated in the future and the comments from other authors would be very useful.

Chapter 5 proposes bolted connection for UHPFRC. This is the most innovative proposition of the Ph.D., as the research line is born in it. Thus, it has a great potential of development:

- The test finally proposed is successful, but future scope should open it to introduce new variables as the prestression, additional bolts or the application of a constant bending moment.

- The formulation proposed at the end of Chapter 5 is initial, as is based in the results of the tests performed. It is valid for the range of variation done in the elements. A future line of research should modify the parameters $\left(\mathrm{W}, \mathrm{E}, \mathrm{D}_{\mathrm{hole}}\right)$ in wider range for adjust the formulations and expand their use to a further spectrum of geometries. This may lead to a tipification of the bolted connections for structural and non-structural applications.

- The truss structure built has been a first element to check the viability, but many others in the future should be worth to strengthen and expand the idea. Thus, another area of investigation should focus in identify types of structure that could use bolted connections, and the changes that should be introduced.

Figure 7.1 shows a conceptual idea of the research lines related with UHPFRC and their potential of development in the following years. The group of this Ph.D. author, which started to study this concrete at UPV in 2008, continues with the growth of the current lines, which 
covers the components, the material, the design, the modelling and the connection of the material. As was mentioned, some of the future researches should be focused in the structures where the connection developed can be used.

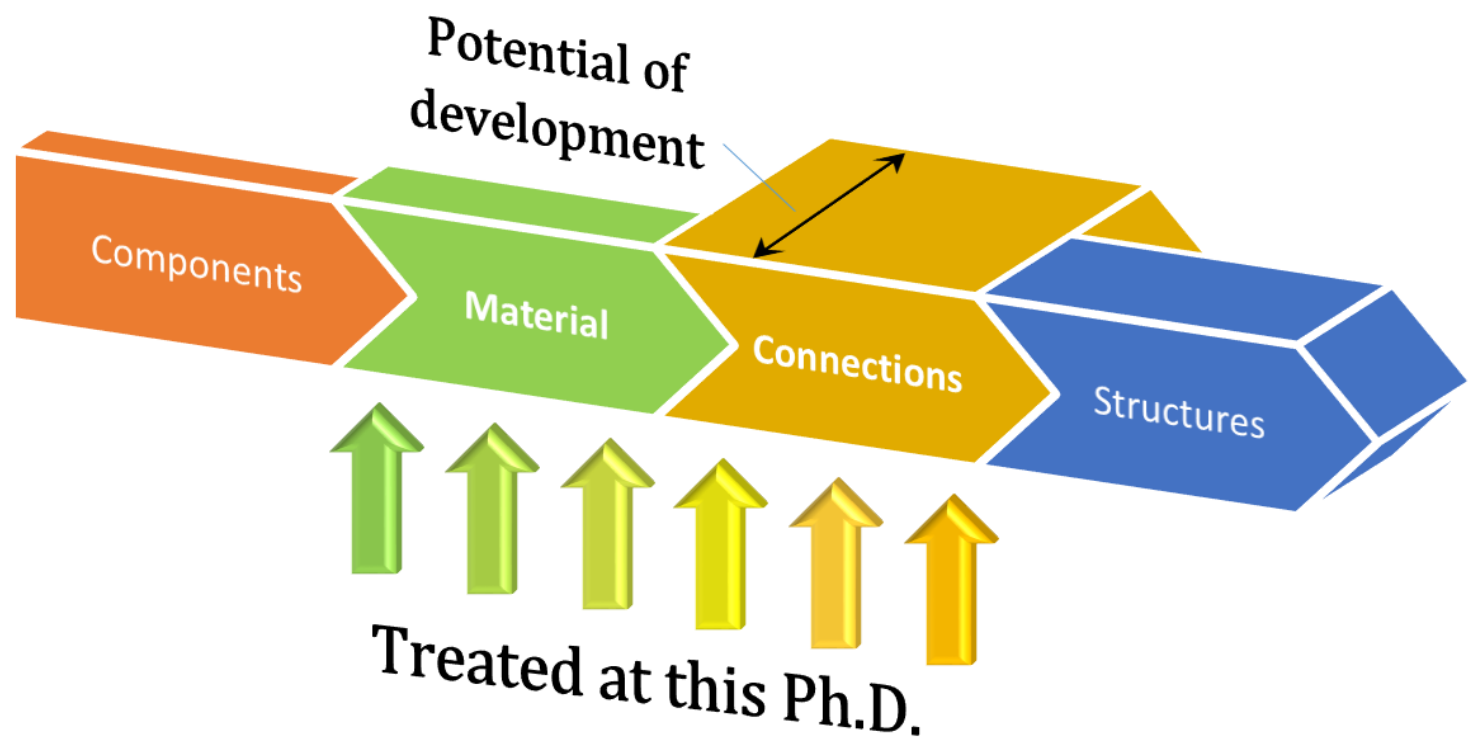

Figure 7.1: Conceptual diagram of the fields treated at this Ph.D 
REFERENCES 
[1] AARUP B.: CRC-Applications of Fiber Reinforced High Performance Concrete. Digital format document.

[2] AARUP B., JENSEN L.R., ALLEGAARD P.: Slender CRC columns. Digital format document.

[3] AARUP B.: CRC-Precast applications of Fibre Reinforced Ultra High Performance Concrete. International Workshop on UHPFRC. Marseille (France), November 17-18, 2009

[4] ACI COMITTEE 238: Report on Measurements of Workability and Rheology of Fresh Concrete. ACI Bookstore 238.1R-08. 70 pages, 2008

[5] ACKER P., BEHLOUL M.: Ductal Tecnology: A large spectrum of properties, a wide range of applications. $1^{\circ}$ International Symposium on UHPC. pp. 11-24, Kassel (Germany), September 13-15, 2004

[6] AENOR: Método de ensayo de cementos. Parte 1: Determinación de resistencias mecánicas. Norma Española UNE-EN 196-1. 2005

[7] AENOR: Método de ensayo de morteros para albañilería. Parte 3: Determinación de la consistencia del mortero fresco. Norma Española UNE-EN 1015-3. 2000

[8] AFGC-SETRA: Ultra High Performance Fiber Reinforced Concretes. Interim Reccomendations. France, January 2002

[9] ALMANSOUR H., LOUNIS Z.: Structural Performance of Precast Prestressed Bridge Girders Build with UHPC. 2을 International Symposium on UHPC. pp. 823-830, Kassel (Germany), March 05-07, 2008

[10] AMERICAN ASSOCIATION OF STATE AND HIGHWAY TRANSPORTATION OFFICIALS: Standard Method of Test for VSI of Self-Consolidating Concrete (SCC). AASHTO TP 80-10. 2010

[11] ANDERSEN P.J.: Control and Monitoring of concrete production. PhD Thesis, Academy of Technical Sciences, The Technical University of Denmark. Denmark, 1990

[12] ANDREASEN A.H.M., ANDERSEN J.: Über die Beziehung zwischen Kornabstufung und Zwischenraum in Producten aus losen Körnern (mit einigen Experimenten). 1930

[13] AY L.: Curing tests on Ultra High Strength plain and steel fibrous cement based composites. 1은 International Symposium on UHPC. pp. 695-702, Kassel (Germany), September 13-15, 2004

[14] BA/CRC TECHNOLOGY: Compact Reinforced Concrete. CRC Presentation. An Overview. www.crctech.com .

[15] BABY F., GRAYBEAL B., MARCHAND P., TOUTLEMONDE F.: Flexural tension test methods for determination of the tensile stress-strain response of UHPFRC. VIII International Conference on Fracture Mechanics of Concrete and Concrete Structures, FraMCoS-8.

[16] BANTHIA N.: A study of some factors affecting the fiber-matrix bond in steel fiber reinforced concrete. Canadian Journal Civil Engineering 17, no 4. pp. 610-620, 1990

[17] BASEL B.: The art of precast concrete. Collection Architecture and design. 2005

[18] BEHLOUL M., BATOZ J.F.: Ductal applications over the last Olympiad. $2^{\circ}$ International Symposium on UHPC. pp. 855-862, Kassel (Germany), March 05-07, 2008

[19] BERTRAM G., HEGGER J.: Shear Behavior of Pretensioned UHPC Beams-Tests and Design. 3rd International Symposium on UHPC, HIPERMAT. pp. 493-500, Kassel (Germany), March 07-09, 2012 
[20] BLAIS P.Y., COUTURE M.: Precast, prestressed pedestrian bridge - World's first Reactive Powder Concrete Structure. PCI Journal. pp. 60-71, September-October 1999

[21] BRETSCHNEIDER N., VILLMANN B., SLOWIK V.: On the characterization of strain hardening cement-based materials by inverse analysis of bending tests. VIII International Conference on Fracture Mechanics of Concrete and Concrete Structures, FraMCoS-8.

[22] BRISARD S.: Overview of the UHPC design french practice. Seminar der VSVI Hessen. France, April 5, 2006

[23] BRISARD S.: Conception et calcul de structures en BFUP. SETRA, Digital format document. June 14,2005

[24] BROWERS H.J.H., RADIX H.J.: Self-Compacting Concrete: Theoretical and experimental study. Cement and Concrete Research 35. pp. 2116-2136, 2005

[25] BROWERS H.J.H., RADIX H.J.: Self-Compacting concrete: The role of the particle size distribution. $1^{\circ}$ International Symposium on Design, Performance and Use of SCC. Changsha, Hunan, (China), May 26-28, 2005

[26] BRÜHWILER E., DENARIÉ E.: Rehabilitation of concrete structures using UHPFRC. 2은 International Symposium on UHPC. pp. 895-902, Kassel (Germany), March 05-07, 2008

[27] BUDELMANN H., EWERT J.: Mechanical Properties of UHPC at Early Age. 3rd International Symposium on UHPC, HIPERMAT. pp. 301-308, Kassel (Germany), March 07-09, 2012

[28] BUITELAAR P., BRAAM R., KAPTIJN N.: Reinforced High Performance Concrete Overlay System for Rehabilitation and Strenghening of Orthotropic Steel bridge decks. 2004 Orthotropic Bridge Conference. Sacramento, California (USA), August 25-27, 2004

[29] BUITELAAR P.: Ultra High Performance Concrete: Developments and applications during 25 years. $1^{\circ}$ International Symposium on UHPC. Plenary Session, Kassel (Germany), September 13-15, 2004

[30] BUITELAAR P.: Heavy Reinforced Ultra High Performance Concrete. $1^{\circ}$ International Symposium on UHPC. pp. 25-35, Kassel (Germany), September 13-15, 2004

[31] CAMACHO E., LÓPEZ J.A., SERNA P.: Definition of three levels of performance for UHPFRCVHPFRC with available materials. 3rd International Symposium on UHPC, HIPERMAT. Kassel (Germany), March 07-09, 2012

[32] CAMACHO E., LÓPEZ J.A.: Optimización de dosificaciones de Hormigón Autocompactante de Muy Alto Rendimiento Reforzado con Fibras Híbrido. bac2010 - 2 Congresso Ibérico sobre betão autocompactável. Guimaraes (Portugal), Julio 1-2, 2010

[33] CAMACHO E., SERNA P., LÓPEZ J.A.: Caracterización de dosificaciones de HMAR con diferentes niveles de exigencia mecánica. V Congreso de ACHE. Barcelona (Spain), October 25-27, 2011

[34] CAMACHO E., SERNA P., LÓPEZ J.A.: Fluid Catalytic Cracking Residue additions such an alternative to Silica Fume in UHPFRC. 3rd International Symposium on UHPC, HIPERMAT. Kassel (Germany), March 07-09, 2012

[35] CAMACHO E., SERNA P., LÓPEZ J.A.: Hormigón de muy alto rendimiento reforzado con fibras (UHPFRC): innovaciones para la transimisión unidireccional de cargas. Hormigón y Acero 63, no 264. pp. 81-92, April-June 2012 
[36] CAMACHO E., SERNA P., LÓPEZ J.A.: UHPFRC bolted joints: Failure modes of a new simple connection system. High Performance Fiber Reinforced Cement Composites 6. pp. 421-428, RILEM State of the art reports, 2012

[37] CAMACHO E., SERNA P.: Hybrid UHPFRC thin walled " $\pi$ " beams for flat roofing applications. Proceedings of the International Association for Shell and Spatial Structures (IASS) Symposium. Valencia (Spain), 2009

[38] CAMACHO E., SERNA P.: Design and analysis of UHP-Hybrid-FRC ties for truss structures. 8th fib PhD Symposium in Civil Engineering. Copenhague (Denmark), 2010

[39] CAMACHO E., SERNA P.: Design and experimental verification of selfcompacting Ultra High Performance Hybrid Fiber Reinforced Concrete ties. 6th International RILEM Symposium on SelfCompacting Concrete. Montreal (Canada), September 26-29, 2010

[40] CAMACHO E.: Caracterización de hormigones de Muy Alta Resistencia con fibras: Estudio de las propiedades reológicas y mecánicas para dosificaciones de distintos niveles de rendimiento. Master Thesis. Valencia (Spain), February 2011

[41] CAMACHO E.: Diseño de Hormigón Autocompactante de Muy Alta Resistencia con Fibras para su aplicación en la cubierta del nuevo centro comercial situado en el término municipal de Burjassot (Valencia). Final Degree Project. 380 pages, Valencia (Spain), 2009

[42] CAZACLIU B., LOUKILI A., LE ROY R.: Mixing of an ultra high-performance fiber-reinforced concrete. Note technique, BLPC no 261-262.

[43] CHANSVILLARD G., RIGAUD S.: Complete Characterisation of Tensile Properties of Ductal UHPFRC according to the french recommendations. International Workshop High Performance Fiber Reinforced Cement Composites, e-ISBN: 2912143799. pp. 21-34, 2003

[44] CHARRON J.P., NIAMBA E., MASSICOTTE B.: Precast bridge parapets in ultra-high performance fibre reinforced concrete. International Workshop on UHPFRC. Marseille (France), November 17-18, 2009

[45] CHIOCCHIO G., MANGIALARDI T., PAOLINI A.E.: Effects of Addition Time of Superplasticizers on Workability of PCP with different Mineralogical Composition. Il Cemento. Italy, 1986

[46] COUSINS T., WOLLMANN C.R., SOTELINO E.: UHPC Deck Panels for Rapid Bridge Construction and Long Term Durability. 2o International Symposium on UHPC. pp. 699-706, Kassel (Germany), March 05-07, 2008

[47] CWIRZEN A., CWIRZEN K.H., PENTTALA V.: The effect of heat treatment on the salt freeze-thaw durability of UHSC. $2^{\circ}$ International Symposium on UHPC. pp. 221-230, Kassel (Germany), March 05-07, 2008

[48] CWIRZEN A., PENTTALA V., VORNANEN C.: Reactive Powder based concretes: Mechanical Properties, durability, and hybrid use with OPC. Cement and Concrete Research 38. pp. 1217-1226, 2008

[49] DANISH TECHNOLOGICAL INSTITUTE: 4c-Rheometer: Determination of the rheological properties of Self-Compacting Concrete. www.danishtechnology.dk/building.

[50] DE LARRARD F.: The High-Performance Cementitious Material (HPCM), a Cousin of UHPFRC for Long-Life pavement. International Workshop on UHPFRC. Marseille (France), November 17-18, 2009 
[51] DELAUZUN O., ROGAT D., BOUTILLON L., LINGER L., CLERGUE C.: Construction du pont de la Chabotte en BFUP sur l'Autoroute A51. International Workshop on UHPFRC. Marseille (France), November 17-18, 2009

[52] DENARIÉ E.: Report on preliminary studies for the use of HPFRCC for the rehabilitation of road infrastructure components. SAMARIS: Sustainable and Advanced Materials for Road Infrastructure. August 31, 2004

[53] DI PRISCO M., COLOMBO M.: FRC and HPFRC composites: From constitutive behaviour to structural applications. Measuring, Monitoring and Modeling Concrete Properties, M.S. KonstaGdoutos (ed.),(C) Springer. pp. 59-68, 2006

[54] DI PRISCO M., LAMPERTI M., LAPOLLA S., KHURANA R.: HPFRCC thin plates for precast roofing. $2^{\circ}$ International Symposium on UHPC. pp. 675-682, Kassel (Germany), March 05-07, 2008

[55] DILS J., DE SCHUTTER G., BOEL V.: Influence of mixing procedure and mixer type on fresh and hardened properties of concrete: A review. Materials and structures. Vol 45. pp. 1673-1683, 10 of May of 2012

[56] DILS J., DE SCHUTTER G.D., BOEL V., BRAEM E.: Influence of vacuum mixing on the mechanical properties of UHPC. 3rd International Symposium on UHPC, HIPERMAT. pp. 241-248, Kassel (Germany), March 07-09, 2012

[57] DROLL K.: Influence of additions on ultra high performance concrete-grain size optimisation. 1은 International Symposium on UHPC. pp. 285-302, Kassel (Germany), September 13-15, 2004

[58] DUDZIAK L., MECHTCHERINE V.: Mitigation of volume changes of UHPC by using Super Absorbent Polymers. 2 International Symposium on UHPC. pp. 425-432, Kassel (Germany), March 05-07, 2008

[59] EDWARDS H.H.: First Use of UHPFRC in Thin Precast Concrete Roof Shell for Canadian LRT Station. PIC Journal. Alberta (Canada), 2005

[60] EFNARC: The Self-Compacting Concrete European Project Group. The European Guidelines for SCC: Specification, Production and Use. www.efnarc.org/pdf/SCCGuidelinesMay2005.pdf. 2005

[61] EMPELMAN M., TEUTSCH M., STEVEN G.: Improvement of the post-fracture behaviour of UHPC by fibres. $2^{\circ}$ International Symposium on UHPC. pp. 177-184, Kassel (Germany), March 05-07, 2008

[62] EPPERS S., MÜLLER C.: Autogeneous Shrinkage Strain of UHPC. $2^{\circ}$ International Symposium on UHPC. pp. 433-442, Kassel (Germany), March 05-07, 2008

[63] EUROPEAN STANDARD: EN 206-1. Concrete - Part 1: Specification, performance, production and conformity. 2000

[64] EWERT J., BUDELMANN H., KRAUSS M.: Heat of hydration and Hardening of UHPC. 2은 International Symposium on UHPC. pp. 409-416, Kassel (Germany), March 05-07, 2008

[65] FAIRBAIRN E.M.R., TOLEDO R.D., BATTISTA R.C., BRANDAO J.H., ROSA J.I.: Experimental and numerical analysis of UHPFRC plates and shells. Measuring, Monitoring and Modeling Concrete Properties, M.S. Konsta-Gdoutos (ed.),(C) Springer.. pp. 49-58, 2006

[66] FARROKHI F., SULTANY A.: Properties of High Performance Self Compacting Concrete in Fresh and hardened State. The 4ํㅡㄴ National conference on Civil Engineering, University of Tehran. Tehran (Iran), May 2008 
[67] FEHLING E., BUNJE K., SCHMIDT M., SCHREIBER W.: The "Gärtnerplatzbrücke" Design of First Hybrid UHPC-Steel Bridge across the River Fulda in Kassel. 2을 International Symposium on UHPC. pp. 581-588, Kassel (Germany), March 05-07, 2008

[68] FEHLING E., BUNJE K., SCHMIDT M.: Gärtnerplatz-Bridge over River Fulda in kassel-Multispan Hybrid UHPC-Steel Bridge. International Workshop on UHPFRC. Marseille (France), November 17 18,2009

[69] FEHLING E., SCHMIDT M., BUNJE K., SCHREIBER W.: Ultra High Performance Composite Bridge across the River Fulda in Kassel. 1ํInternational Symposium on UHPC. pp. 69-76, Kassel (Germany), September 13-15, 2004

[70] FEHLING E., SCHMIDT M., TEICHMANN T., BUNGE K., BORNEMANN R., MIDDENDORF B.: Entwicklung, Dauerhaftigkeit und Berechnung Ultrahochfester Betone (UHPC). Forschungsbericht DFG FE 497/1-1. Kassel (Germany), 2005

[71] FERRARA L., FAIFER M., MUHAXHERI M., TOSCANI S., OTTOBONI R.: Connecting NonDestructive Fiber Dispersion Measurements with Tensile HPFRCC Behavior. High Performance Fiber Reinforced Cement Composites 6. RILEM Bookseries. Springer. ISBN: 978-94-007-2435-8. pp. 4350,2011

[72] FERRARA L.: Chapter 6. Self-Consolidating Fiber Reinforced Concrete. January 2011

[73] FERRARIS C.F.: Concrete mixing methods and concrete mixers: State of Art. National Institute of Standards and Technology. Gaithersburg (USA), March/April 2001

[74] FIDJESTOL P., THORSTEINSEN R.T., SVENNEVIG P.: Making UHPC with Local Materials-The Way Forward. 3rd International Symposium on UHPC, HIPERMAT. pp. 207-214, Kassel (Germany), March 07-09, 2012

[75] FORMAGINI S.: Dosagem cientifica e caraterizacao mecanica de concretos de altissimo desempenho. Ph.D. Thesis, Universidade Federal do Rio de Janeiro. Rio do Janeiro (Brasil), February 2005

[76] FRÖLICH S., SCHMIDT M.: Influence of Repeatability and Reproducibility of Testing Methods for Fresh UHPC. 3rd International Symposium on UHPC, HIPERMAT. pp. 225-232, Kassel (Germany), March 07-09, 2012

[77] GERLICHER T., HEINZ D., URBONAS L.: Effect of Finely Ground Blast Furnace Slag on the Properties of Fresh and Hardened UHPC. $2^{\circ}$ International Symposium on UHPC. pp. 367-374, Kassel (Germany), March 05-07, 2008

[78] GERMAN FOUNDATION DFG: Nachhaltiges Bauen mit UHPC, German Research Foundation. Priority Program SPP 1182. Germany, 2007

[79] GERMAN SOCIETY FOR CONCRETE AND CONSTRUCTION TECHNOLOGY: Sachstandbericht Ultrahochfester Beton, Betontechnik und Bemessung. Deutscher Ausschuss für Stahlbeton. Germany, March 2005

[80] GOBIERNO DE ESPAÑA: Código Técnico de la Edificación (CTE). Spain, March 2006

[81] GOBIERNO DE ESPAÑA: Instrucción de Hormigón Estructural (EHE-08). Spain, July 2008

[82] GOLDBACH U., STEHLING S.: Precasting of UHPC Elements. 2o International Symposium on UHPC. pp. 589-596, Kassel (Germany), March 05-07, 2008 
[83] GOWRIPALAN N., GILBERT I.R.: Design Guidelines for Ductal Prestressed Concrete Beams. School of Civil and Environmental Engineering, University of New South Wales. South Wales (Wales), May 2000

[84] GRACE CONSTRUCTION: Test methods for Self-Consolidating Concrete (SCC). www.graceconstruction.com, Technical Bulletin TB-1506.

[85] GRAYBEAL B., DAVIS M.: Cylinder or Cube: Strength Testing of 80 to $200 \mathrm{MPa}$ (11.6 to $29 \mathrm{ksi}$ ) Ultra-High-Performance Fiber-Reinforced Concrete. ACI Materials Journal. pp. 603-609, NovemberDecember 2008

[86] GRAYBEAL B., HARTMANN J., PERRY V.: Ultra-High Performance Concrete for Highway Bridges. Concrete Structures: The Challenge of Creativity, Symposioum. Avignon (France), April 26-28, 2004

[87] GRAYBEAL B.: Characterization of the behavior of Ultra-High Performance Concrete. Ph.D. Thesis, University of Maryland. Maryland (USA), 2005

[88] GRAYBEAL B.: UHPC in the U.S. Highway Infrastructure. International Workshop on UHPFRC. Marseille (France), November 17-18, 2009

[89] GRAYBEAL B.: Material property characterization of UHPC. U.S. Department of Transportation. Publication № FHWA-HRT-06-103. 188 pages, August 2006

[90] GRÖGER J., VIET TUE N., WILLE K.: Bending Behaviour in Variation of flexural Parameters of UHPFRC. 3rd International Symposium on UHPC, HIPERMAT. pp. 419-426, Kassel (Germany), March 07-09, 2012

[91] GRÜNEWALD S., FERRARA L., DEHN F.: fib-Recommendation: Structural design with flowable concrete. 3rd fib international Congress. Washington D.C. (USA), May 29-June 2, 2010

[92] GRÜNEWALD S., WEYNS R., DEKKERS J.: Experience with prefabricated UHPFRC in the Netherlands. International Workshop on UHPFRC. Marseille (France), November 17-18, 2009

[93] GRÜNEWALD S.: Performance based design of self-compacting fiber reinforced concrete. Ph-D Thesis. Section of Structural and Building Engineering. Delft University of Technology. Delft (The Netherlands), 2004

[94] GÜVENSOY G., BAYRAMOV F., ILKI A., SENGÜL C., TASDEMIR M.A.: Mechanical behavior of High Performance Steel Diber Reinforced Cementitious Composites under Cycling Loading Condition. $1^{\mathrm{O}}$ International Symposium on UHPC. pp. 649-660, Kassel (Germany), September 13-15, 2004

[95] HA L.T., SIEWERT K., LUDWIG H.M.: Synergistic Effect of Rice Husk and Fly Ash on properties of Self-Compacting High Performance Concrete. 3rd International Symposium on UHPC, HIPERMAT. pp. 187-196, Kassel (Germany), March 07-09, 2012

[96] HABEL K., CHARRON J.F., BRAIKE S., HOOTON D., GAUVREAU P., MASSICOTTE B.: Ultra High Performance Fiber Reinforced Concrete mix design in central Canada. Canadian Journal of Civil Engineering 35. pp. 217-224, 2008

[97] HABEL K., VIVIANI M., DENAIRÉ E., BRÜHWILER E.: Development of the mechanical properties of an Ultra-High Performance Fiber Reinforced Concrete (UHPFRC). Cement and Concrete Research 36. pp. $1362-1370,2006$

[98] HAJAR Z., NOVARIN M., SIMON A., THIBAUX T., CHANUT S., SALE R.: La poutre ITE®, une alternative economique et durable aux poutrelles enrobees. International Workshop on UHPFRC. Marseille (France), November 17-18, 2009 
[99] HAJAR Z., SIMON A., LECOINTRE D., PETITJEAN J.: Construction of the fist road bridges made of Ultra-High-Performance Concrete. ISHPC. 2003

[100] HAJEK P., KYNCLOVA M., FIALA C.: Timber-UHPC composite floor structures-environmental study. 3rd International Symposium on UHPC, HIPERMAT. pp. 679-684, Kassel (Germany), March 07-09, 2012

[101] HAMMOUD H., NAAMAN A.E.: Ferrocement Bolted Shear Joints: Failure Modes and Strength Prediction. Cement and Concrete Composites 20. pp. 13-29, 1998

[102] HECHT M.: Practical use of fibre-reinforced UHPC in construction-production of precast elements for Wild-Brücke in Völkermarkt. 3rd International Symposium on UHPC, HIPERMAT. pp. 889-896, Kassel (Germany), March 07-09, 2012

[103] HEGGER J., BERTRAM G.: Shear capacity of steel fiber reinforced UHPC. 2o International Symposium on UHPC. pp. 513-520, Kassel (Germany), March 05-07, 2008

[104] HEGGER J., GALLWOSZUS J., RAUSCHER S.: Load-Carrying Behaviour of Connectors under Shear, Tension and Compression in Ultra High Performance Concrete. NSCC. 2009

[105] HEGGER J., RAUSCHER S.: UHPC in Composite Construction. $2^{\circ}$ International Symposium on UHPC. pp. 545-552, Kassel (Germany), March 05-07, 2008

[106] HEINZ D., LUDWIG H.M.: Heat Treatment and the Risk of DEF Delayed Ettringinte Formation in UHPC. $1^{\circ}$ International Symposium on UHPC. pp. 717-730, Kassel (Germany), September 13-15, 2004

[107] HEINZ D., URBONAS L., GERLICHER T.: Effect of Heat Treatment Method on the properties of UHPC. 3rd International Symposium on UHPC, HIPERMAT. pp. 283-290, Kassel (Germany), March 07-09, 2012

[108] HEROLD G., MÜLLER H.S.: Measurement of porosity of Ultra High Strength Fibre Reinforced Concrete. $1^{\circ}$ International Symposium on UHPC. pp. 685-694, Kassel (Germany), September 13-15, 2004

[109] HIRSCHI T., WOMBACHER F.: Influence of different superplasticizers on UHPC. $2^{\circ}$ International Symposium on UHPC. pp. 77-84, Kassel (Germany), March 05-07, 2008

[110] HOLSCHEMACHER K., WEISSE D., KLOTZ S.: Bond of Reinforcement in Ultra High Strengh Concrete. $1^{\circ}$ International Symposium on UHPC. pp. 375-388, Kassel (Germany), September 13-15, 2004

[111] HONG K.N., KANG S.T., KIM S.W., PARK J.J., HAN S.H.: Material properties of air-cured ultrahigh-performance steel-fiber-reinforced concrete at early ages. International Journal of the Physical Sciences 5, no 17. pp. 2622-2634, December 2010

[112] JAYAKUMAR K.: Role of Silica fume concrete in Concrete Tecnology. 1을 $^{\circ}$ International Symposium on UHPC. Kassel (Germany), September 13-15, 2004

[113] JSCE: Guidelines for the Design and Construction of Ultra High Strength Fibre Reinforced Concrete. Draft. Japan, September 2006

[114] JSCE: Reccomendations for Design and Construction of High Performance Fiber Reinforced Cement Composites with Multiple Fine Cracks (HPFRCC). March 2008 
[115] JUHART J., FREYTAG B., SANTNER G., BAUMGARTNER E.: Adhesion of fine-grained HPC and UHPC to Steel and Glass. 3rd International Symposium on UHPC, HIPERMAT. pp. 717-724, Kassel (Germany), March 07-09, 2012

[116] JUNGWIRTH J., MUTTONI A.: Structural behavior of Tension Members in UHPC. 1 International Symposium on UHPC. pp. 533-546, Kassel (Germany), September 13-15, 2004

[117] KAMEN A., DENAIRÉ E., SADOUKI H., BRÜHWILER E.: Thermo-mechanical response of UHPFRC at early age-Experimental study and numerical simulation. Cement and Concrete Research 38. pp. 822-831, 2008

[118] KAMEN A., DENAIRÉ E., SADOUKI H., BRÜHWILER E.: Evaluation of UHPFRC activation energy using empirical models. Materials and Structures 42. pp. 527-537, 2009

[119] KANTRO D.L.: Influence of water-reducing admixtures on properties of cement paste-a miniature slump test. Cement, Concrete and Aggregates 2, Issue 2. pp. 95-102, 1980

[120] KARIHALOO B.L.: CARDIFRC-From Concept to Industrial Application. High Performance Fiber Reinforced Cement Composites 6. RILEM Bookseries. Springer. ISBN: 978-94-007-2435-8. pp. 397404 ,

[121] KENNAN C.: Particle Packing Models and Their Use in the Design of Ultra High Performance Concretes. PhD Candidate. Digital format document.

[122] KIM B.S., KIM S., KIM Y.J., PARK S.Y., KOH K.T., JOH C.: R\&D Activities and Application of UHPC to Cable Stayed Bridges. 3rd International Symposium on UHPC, HIPERMAT. pp. 865-872, Kassel (Germany), March 07-09, 2012

[123] KIM D.J., NAAMAN A.E., EL-TAWIL S.: High Tensile Strength Strain-Hardening FRC Composites with less than 2\% Fiber Content. 2을 International Symposium on UHPC. pp. 169-176, Kassel (Germany), March 05-07, 2008

[124] KIM S., PARK J., YOO D., YOON Y.: Shrinkage Behavior of Ultra High Performance Concrete at the Manufacturing Stage. 3rd International Symposium on UHPC, HIPERMAT. pp. 317-324, Kassel (Germany), March 07-09, 2012

[125] KOEHLER E. P., FOWLER D.W.: Summary of Concrete Workability Tests Methods. Aggregates Foundation for Technology, Research and Education. Texas (USA), 2003

[126] KOHOUTKOVÁ A.: Expansion of Fiber Reinforced Concretes and their application in structures. Czech Technical University in Prague, Faculty of Civil Engineering. Prague (Czech Republic),

[127] KOROLUK K.: Ultra High-Performance Concrete extends materials limit's. Daily Commercial News \& Construction Record. June 20, 2008

[128] LAPPA E.S., RENÉ BRAAM C., WALRAVEN J.C.: Static and fatigue bending tests of UHPC. 1은 International Symposium on UHPC. pp. 449-460, Kassel (Germany), September 13-15, 2004

[129] LAPPA E.S.: High Strength Fiber Reinforcement Concrete. Static and fatigue behaviour in bending. Doctoral Thesis, Delft University. Delft (The Netherlands), 2007

[130] LAPPA E.S.: Fatigue of high strength steel fibre reinforced concrete. Technology Foundation. The Netherlands, 2007 
[131] LATASTE J.F., BARNETT J., PARRY T., SOUTSOS M.: Determination of fibres orientation in UHPFRC and evaluation of their effect on mechanical properties. NDTCE'09, Non-Destructive Testing in Civil Engineering. Nantes (France), June 30-July 3, 2009

[132] LEE C.H., KIM Y.J., CHIN W.J., CHOI E.S.: Shear Strength of UHPFRC Precast Bridge Joint. High Performance Fiber Reinforced Cement Composites 6. RILEM Bookseries. Springer. ISBN: 978-94007-2435-8. pp. 413-420,

[133] LEHMANN C., FONTANA P., MÜLlER U.: Evolution of phases and Micro Structure in Hydrotermally Cured Ultra-High Performance Concrete (UHPC). Federal Institute for Materials Research and Testing (BAM). Berlin (Germany),

[134] LEONHARDT S., LOWKE D., GEHLEN C.: Effect of fibres on Impact Resistance of UHPC. 3rd International Symposium on UHPC, HIPERMAT. pp. 811-818, Kassel (Germany), March 07-09, 2012

[135] LI V.: Engineered Cementitious Composites (ECC)-Material, Structural, and Durability Performance. Concrete Construction. August 2007

[136] LOHAUS L., ELSMEIER K.: Fatigue Behaviour of plain and fibre reinforced UHPC. 3rd International Symposium on UHPC, HIPERMAT. pp. 631-638, Kassel (Germany), March 07-09, 2012

[137] LOHAUS L., RAMGE P.: Robustness of UHPC-A new Approach for Mixture Proportining. 2oㅡ International Symposium on UHPC. pp. 113-120, Kassel (Germany), March 05-07, 2008

[138] LÓPEZ J.A., CAMACHO E., SERNA P., NAVARRO J.: Preliminary calculations and casting stages of a UHPFRC truss footbridge. 8th RILEM International Symposium on Fiber Reinforced Concrete: Challenges and Opportunities. Guimaraes (Portugal), September 19-21, 2012

[139] LÓPEZ J.A., CAMACHO E., SERNA P., NAVARRo J.: Structural Design and Preliminary Calculations of a UHPFRC Truss Footbridge. 3rd International Symposium on UHPC, HIPERMAT. pp. 897-904, Kassel (Germany), March 07-09, 2012

[140] LÓPEZ J.A., SERNA P., NAVARRO J., CAMACHO E.: Construction of the U-Shaped truss footbridge over the Ovejas ravine in Alicante. $2^{\circ}$ International Symposium on UHPFRC. Designing and Building with UHPFRC.. Marseille (France), 1-3 october 2013

[141] LÓPEZ J.A.: Diseño estructural de un muro de contención de tierras para la defensa de taludes en el puerto de Jávea (Alicante) con la utilización de HMAR. Final Degree Project. Valencia (Spain), January 2011

[142] LÓPEZ J.A.: Adaptación del Modelo de Comportamiento del Ultra High Performance Concrete (UHPC) para el Estudio de la Respuesta Estructural y Análisis Numérico de una Celosía. Master Thesis, Ingeniería de la Construcción y Proyectos de Ingeniería Civil. 179 pages, Valencia (Spain), 41091

[143] LOWKE D., STENGEL T., SCHIESSL P., GEHLEN C.: Control of Rheology, Strength and Fiber Bond of UHPC with Additions-Effect of Packing Density and Addition Type. 3rd International Symposium on UHPC, HIPERMAT. pp. 215-224, Kassel (Germany), March 07-09, 2012

[144] MA J., ORGASS M., DEHN F., SCHMIDT M., TUE N.V.: Comparative investigations on Ultra High performance Concrete with and withour coarsse aggregates. $1^{\circ}$ International Symposium on UHPC. pp. 205-212, Kassel (Germany), September 13-15, 2004

[145] MAEDER U., LALLEMANT-GAMBOA I., CHAIGNON J., LOMBARD J.P.: Ceracem, a new high performance concrete: Charactersations and applications. International Symposioum on UHPC. pp. 59-68, 13-15 September, 2004 
[146] MALHOTRA V.M.: Role offly ash in reducing greenhouse gas emissions during the manufacturing of portland cement clinker. Jean Péra Symposium on Specialty Cements and Sustainability Issues. pp. 175-182, Warsaw (Poland) , 24 of May 2007

[147] MARKOVIĆ I., VAN MIER J.G.M., WALRAVEN J.C.: Single fiber pull out from hybrid fiber reinforced concrete. HERON 46, no 3. ISSN 0046-7316. 2001

[148] MARKOVIĆ I.: High-Performance Hybrid-Fiber Concrete. Development and utilisation. Doctoral Thesis, Delft University. Delft (The Netherlands), 2006

[149] MARTínEZ D.A.: Caracterización y reactividad de materiales puzolánicos. Ph.D. Thesis, Universitat Politècnica de València. Valencia (Spain), 2006

[150] MARTINIE L., ROSSI P., ROUSSEL N.: Rheology of fiber reinforced cementitious materials: Classification and Preddiction. International Workshop on UHPFRC. Marseille (France), November 17-18, 2009

[151] MATSUBARA N., OHNO T., SAKAI G., WATANABE Y., ISHI S.: Application of a New Type of UHSFRC to a Prestressed Concrete Bridge. $2^{\circ}$ International Symposium on UHPC. pp. 787-794, Kassel (Germany), March 05-07, 2008

[152] MATTEIS D., NOVARIN M., MARCHAND P., FABRY N., PETEL A.: A fifth French bridge including UHPFRC components, the widening of the Pinel bridge, in Rouen (France). $2^{\circ}$ International Symposium on UHPC. pp. 795-802, Kassel (Germany), March 05-07, 2008

[153] MAZANEC O., LOWKE D., SCHIE $\beta$ L P.: Mixing of high performance concrete: effect of concrete composition and mixing intensity on mixing time. Materials and Structures 43. pp. 357-365, 2010

[154] MAZANEC 0., SCHIE $\beta$ L P.: Mixing time optimisation for UHPC. $2^{\circ}$ International Symposium on UHPC. pp. 401-408, Kassel (Germany), March 05-07, 2008

[155] Mc. CRAVEN S. : Ultra High Performance Fiber Reinforced Precast Concrete proves market potential. PCI Journal. November-December 2007

[156] MILLON O., RIEDEL W., MAYRHOFER C., THOMA K.: Failure Mechanisms of UHPC Components under Explosive Loading. 3rd International Symposium on UHPC, HIPERMAT. pp. 583-592, Kassel (Germany), March 07-09, 2012

[157] MONAI B., SCHNABL H.: Practice of UHPC in Austria. $2^{\circ}$ International Symposium on UHPC. pp. 839-846, Kassel (Germany), March 05-07, 2008

[158] MÜLLER H.S., HAIST M., SCHEIDT J., BURKART I.: Neuartige Konstruktionsbetone-Eine Chance fü Innovationen im Massivbau. Dresden Baustatik Seminar-innovative Materialien und Tragwerke. Technische Universität Dresden. Dresden (Germany), 2007

[159] MÜLLER U., MENG B., KÜHNE H.C., NEMECEK J.: Micro texture and mechanical properties of heat treated and autoclaved UHPC. $2^{\circ}$ International Symposium on UHPC. pp. 213-220, Kassel (Germany), March 05-07, 2008

[160] NAAMAN A.E., REINHARDT H.W.: Proposed classification of HPFRC composites based on their tensile response. Materials and Structures 39. pp. 547-555, 2006

[161] NAAMAN A.E., WILLE K.: Some correlation between high packing density, ultra-high performance, flow hability, and fiber reinforcement of a concrete matrix. bac2010, Congresso Ibérico sobre betao auto-compactavel. Guimaraes (Portugal), July 1-2, 2010 
[162] NAAMAN A.E., WILLE K.: The path to UHPFRC: Five Decades of Progress. 3rd International Symposium on UHPC, HIPERMAT. pp. 3-16, Kassel (Germany), March 07-09, 2012

[163] NAAMAN A.E.: Engineered Steel Fibers with optimal properties for Reinforcement of Cement Composites. Journal of Advanced Concrete Technology 1. Japan, 2003

[164] NAAMAN A.E.: Looking Ahead. Fibre Reinforced Concretes (FRC), BEFIB, RILEM. 2000

[165] NGUYEN V.T., KÜCHLER M., HENZE S.: Modulare truss construction made of Ultra High Performance Concrete. The 3th ACF International Conference-ACF/VCA. 2008

[166] OESTERLEE C., DENARIÉ E., BRÜHWILER E.: UHPFRC protection layer on the crash barrier walls of a bridge. pp. 203-210,

[167] OKUMA H., NISHIKAWA K., IWASAKI I., MORITA T.: The first highway bridge applying UHSFRC in Japan. Advanced Materials in Bridges. $7^{\circ}$ International Conference on Short and Medium span bridges. Montreal (Canada), 2006

[168] OKUTAN B.: Behavior of Pin-loaded Laminated Composites. Expermiental mechanics 46. pp. 589-600, 2006

[169] ORGASS M., KLUG Y.: Fibre Reinforced Ultra-High Strength Concretes. 1은 International Symposium on UHPC. pp. 637-648, Kassel (Germany), September 13-15, 2004

[170] ORGASS M., KLUG Y.: Steel Fiber Reinforced UHSC. LACER no 9. 2004

[171] ØSTERGAARD L., WALTER R., OLESEN J.F.: Method for determination of tensile properties of ECC II: Inverse analysis and experimental results. Department of Civil Engineering, Technical University of Denmark.

[172] PALECKI S., SETZER M.J.: UHPC under frost and de-icing salt attack. 2o International Symposium on UHPC. pp. 443-452, Kassel (Germany), March 05-07, 2008

[173] PARK J.J., KANG S.T., KOH K.T., KIM S.W.: Influence of the ingredients on the Compressive Strength of UHPC as a Fundamental Study to Optimize the Mixing Proportion. 2ㅇ International Symposium on UHPC. pp. 105-112, Kassel (Germany), March 05-07, 2008

[174] PAYA J., MONZÓ J., BORRACHERO M.V., SERNA P., VELÁZQUEZ S., ORDOÑEZ L.M.: El factor de eficacia cementante de puzolanas silíceas y silicoaluminosas muy reactivas. VIII Congreso Nacional de Propiedades Mecánicas de Sólidos. Gandía (Spain), 2002

[175] PAYÁ J., MONZÓ J., BORRACHERO M.V.: Physical, chemical and mechanical properties of fluid catalytic cracking catalyst residue (FC3R) blended cements. Cement and concrete research 31. pp. 57 61,2001

[176] PAYÁ J., MONZÓ J., BORRACHERO M.V.: Fluid catalytic cracking catalyst residue (FC3R), an excellent mineral by-product for improving early strength development of cement mixtures. Cement and Concrete Research 29. pp. 1773-1779, 1999

[177] PEKBEY Y.: The bearing strength and failure behavior of bolted E-glass/epoxy joints. Mechanics of Composite Materials 44. 2008

[178] PERRY V., ROYCE M.: Innovative field-cast UHPC joints for precast brige decks (full-depth precast deck panels) Oneonta, NY: Design, prototype, testing and construction. CBC. 2010 
[179] PERRY V., WEISS G.: Innovative Field Cast UHPC Joints for Precast Bridge Decks - Design, Prototype Testing and Projects. International Workshop on UHPFRC. Marseille (France), November 17-18, 2009

[180] PERRY V.H., SEIBERT P.J.: The use of UHPFRC (Ductal) for bridges in North America: The technology, applications and challenges facing comercialization. $2^{\circ}$ International Symposium on UHPC. pp. 815-822, Kassel (Germany), March 05-07, 2008

[181] PETERS H., BÄNZIGER H., POLTERA M.: Durable adhesive bonding with epoxy resins in civil engineering construction. $2^{\circ}$ International Symposium on UHPC. pp. 267-274, Kassel (Germany), March 05-07, 2008

[182] PIÉRARD J., DOOMS B., CAUBERG N.: Evaluation of Durability parameters of UHPC using Accelerated Lab Tests. 3rd International Symposium on UHPC, HIPERMAT. pp. 371-376, Kassel (Germany), March 07-09, 2012

[183] PIMIENTA P., CHANVILLARD G.: Durability of UHPFRC specimens kept in various aggressive environments. International Conference On Durability of Building Materials and Components. Lyon (France), 17-20 April 2005

[184] QUIAN S., LI V.C.: Simplified Inverse Method for Determining the Thensile Properties of Strain Hardening Cementitious Composites (SHCC). Journal of Advanced Concrete Technology, Vol 6, № 2. pp. 353-363, June 2008

[185] REBENTROST M., WIGHT G.: Experience and Applications of UHPC in Asia. 2으ternational Symposium on UHPC. pp. 19-30, Kassel (Germany), March 05-07, 2008

[186] REBENTROST M., WIGHT G.: UHPC perspective from a Specialist Construction Company. International Workshop on UHPFRC. Marseille (France), November 17-18, 2009

[187] REDA M.M., SHRIVE N.G., GILLOTT G.E.: Microstructural Investigation of Innovative UHPC. Cement and Concrete Research 29. pp. 323-329, 1999

[188] REICHEL M., FREYTAG B., SPAROWITZ L., ZIMMERMANN W.: Road Bridge WILD - UHPFRC for a segmental arch structure. International Workshop on UHPFRC. Marseille (France), November 17-18, 2009

[189] REICHEL M., FREYTAG B., SPAROWITZ L.: UHPC-Segmental Bridges Material-based design principles and adapted construction methods. 2을 International Symposium on UHPC. pp. 779-786, Kassel (Germany), March 05-07, 2008

[190] REINECK K.H., GREINER S.: Scale effect and combined loading of thin UHPFRC members. Digital format document.

[191] REINECK K.H., GREINER S.: Tests on ultra-high performance fibre reinforced concrete designing hot-water tanks and UHPFRC-shells. 1ํInternational Symposium on UHPC. pp. 361-374, Kassel (Germany), September 13-15, 2004

[192] REMY O., WASTIELS J., CAUBERG N., PIÉRARD J.: Flexural behaviour of FRUHPC and the Application in Cladding Panels. $2^{\text {o }}$ International Symposium on UHPC. pp. 691-698, Kassel (Germany), March 05-07, 2008

[193] RESPLENDINO J., PETITJEAN J.: Ultra-High-Performance Concrete: First Recommendations and Examples of Application. ISHPC. 2003 
[194] RESPLENDINO J.: First recommendations for Ultra-High-Performance Concretes and examples of application. $1^{\circ}$ International Symposium on UHPC. pp. 79-90, Kassel (Germany), September 1315,2004

[195] RESPLENDINO J.: UHPC-Recent realizations and research programs on UHPFRC bridges in France. $2^{\circ}$ International Symposium on UHPC. pp. 31-43, Kassel (Germany), March 05-07, 2008

[196] REVENTROST M., CAVILL B.: Reactive Powder Concrete Bridges. AustRoads Conference. 2006

[197] RODRIGUEZ E.D., SORIANO L., PAYÁ J., BORRACHERO M.V., MONZÓ J.M.: Increase of the reactivity of densified silica fume by sonication treatment. Ultrasonics Sonochemistry 19, issue 5. pp. 1099-1107, February 2012

[198] ROGEAU P., BORYS B.: Ultra High Performance Concrete with ultrafine particles other than silica fume. $1^{\mathrm{O}}$ International Symposium on UHPC. pp. 213-225, Kassel (Germany), September 1315,2004

[199] ROGERS C.A., HANCOCK G.J.: Failure Modes of Bolted Sheet Steel Connections Loaded in Shear. Research Report No R772, Department of Civil Engineering Sydney NSW. Sydney (Australia), 2006

[200] ROSSI P.: Steel Fiber reinforced Concrete (SFRC): An example of French Research. ACI Materials Journal (Thecnical Paper). 1994

[201] ROSSI P.: Mechanical behaviour of metal fibre reinforced concretes. Cement and Concrete Composites 14, no 1 . pp. 3-16, 1992

[202] ROSSI P.: High Performance Multimodal Fiber Reinforced Cement Composites (HPMFRCC): The LCPC Experience. ACI Materials Journal, Technical paper. 94-M54. pp. 478-483, NovemberDecember 1997

[203] ROUSSEL N., STEFANI C., LEROY R.: From mini-cone test to Abrams cone test: measurement of cement-based materials yield stress using slump tests. Cement and Concrete Research 35. pp. 817822, 2005

[204] SAKAI E., AIZAWA K., NAKAMURA A., KATO H., DAIMON M.: Influence of superplasticizers on the fluidity of cements with different amount of aluminate phase. 20 International Symposium on UHPC. pp. 85-92, Kassel (Germany), March 05-07, 2008

[205] SCHACHINGER I., HILBIG H., STENGEL T.: Effect of Curing Temperature at an Early Age on the Long Term Strength Development of UHPC. $2^{\circ}$ International Symposium on UHPC. pp. 205-212, Kassel (Germany), March 05-07, 2008

[206] SCHACHINGER I., SCHUBERT J., MAZANEC O.: Effect of Mixing and Placement Methods on Fresh and Hardened UHPC. 1 - International Symposium on UHPC. pp. 575-586, Kassel (Germany), September 13-15, 2004

[207] SCHENCK G., KÜCHLER M.: Application of UHPC filled tubes in Buildings and Briges. LACER no 9. 2004

[208] SCHEYDT J., HEROLD G., MÜLLER H., KUHNT M.: Development and Application of UHPC Convenience Blends. 2을 International Symposium on UHPC. pp. 69-76, Kassel (Germany), March 0507,2008

[209] SCHIE ROSSIGNOLO J.A: Effect of Silica Fume and SBR Latex on the Paste-aggregate Interfacial Transition Zone. Materials Research 10, no 1. pp. 83-86, 2007 
[210] SCHIEßL P., MAZANEC O., LOWKE D., PLANK J., SCHRÖFL C.: Rheology of UHPC-Effect of superplasticicer and silica fume on mixing and workability of UHPC. 3rd fib international Congress. Washington D.C. (USA), May 29-June 2, 2010

[211] SCHIE $\boldsymbol{\beta L}$ P., MAZANEC 0., LOWKE D.: Effect of Mixing Technology on Fresh Concrete Properties. Digital format document. pp. 514-522,

[212] SCHINDLER A.: Effect of temperature on the hydration of cementitious materials. ACI Mater 101 (1). pp. 72-81, 2004

[213] SCHMIDT C., RIEDL S., GEISENHANSLÜKE C., SCHMIDT M.: Strengthening and Rehabilitation of Pavements Applying Thin Layers of Reinforced UHPC (UHPC-White topping). $2^{\circ}$ International Symposium on UHPC. pp. 655-662, Kassel (Germany), March 05-07, 2008

[214] SCHMIDT M., BRAUN T., MÖLLER H.: Sewer pipes and UHPC-Development of an UHPC with earth-moist consistency. 3rd International Symposium on UHPC, HIPERMAT. pp. 833-840, Kassel (Germany), March 07-09, 2012

[215] SCHMIDT M., FEHLING E.: Ultra-High-Performance Concrete: Research, Development and Application in Europe. Digital format document.

[216] SHAKHMENKO G., KORJAKINS A., KARA P., JUSTS J., JUHNEVICA I.: UHPC containing Nanoparticles Synthesized by Sol-gel method. 3rd International Symposium on UHPC, HIPERMAT. pp. 79-86, Kassel (Germany), March 07-09, 2012

[217] SJÖDIN J., SERRANO E., ENQUIST B.: Contact-free measurements and numerical analyses of the strain distribution in the joint area of steel-to-timber dowel joints. Holz als Roh-und Werkstoff 64. pp. 497-506, 2006

[218] SKAZLIĆ M., BJEGOVIĆ D., JAMBRESIĆ M.: Development in High Performance Concrete Technology. Digital format document.

[219] SKAZLIĆ M., BJEGOVIĆ D.: Toughness testing of ultra high performance fibre reinforced concrete. Materials and Structures 42. pp. 1025-1038, 2009

[220] SKAZLIĆ M., SERDAR M., BJEGOVIĆ D.: Influence of test specimens geometry on compressive strengh of UHPC. $2^{\circ}$ International Symposium on UHPC. pp. 295-302, Kassel (Germany), March 0507, 2008

[221] SORELLI L.G., CONSTANTINIDES G., ULM F.J., TOUTLEMONDE F.: The nano-mechanical signature of Ultra High Performance Concrete by statistical nanoindentation techniques. Cement and Concrete Research 38. pp. 1447-1456, 2008

[222] SORELLI L.G., FANNING P., TOUTLEMONDE F.: Innovative bridge system of UHPFRC: Experiments, modeling and design. 7th International Conference on short and medium span bridges. 2006

[223] SPASOJEVIĆ A., REDAELLI D., FERNÁNDEZ M., MUTTONI A.: Influence of tensile properties of UHPFRC on Size Effect in Bending. $2^{\circ}$ International Symposium on UHPC. pp. 303-310, Kassel (Germany), March 05-07, 2008

[224] SPASOJEVIĆ A., REDAELLI D., MUTTONI A.: Think UHPFRC spabs without conventional reinforcement as light-weight structural elements. Digital format document.

[225] STÄLHI P.: Ultra-Fluid, oriented Hybrid Fibre Concrete. Doctoral Thesis, ETH Zurich. Zurich (Switzerland), 2008 
[226] STARK U., MUELLER A.: Optimization of packing density of aggregates. 2ㅇ International Symposium on UHPC. pp. 121-128, Kassel (Germany), March 05-07, 2008

[227] STENGEL T., LIN X., SCHIESSL P., GEHLEN C.: Tailor-Made Steel Fiber Reinforced ultra High Performance Concrete-Single Fiber pull-Out bending Capacity and Fracture Toughness. High Performance Fiber Reinforced Cement Composites 6. RILEM Bookseries. Springer. ISBN: 978-94007-2435-8. pp. 127-135,

[228] STENGEL T.: Sustainability aspects of traffic bridges made from UHPFRC - State of the art and challenges for concrete technology. International Workshop on UHPFRC. Marseille (France), November 17-18, 2009

[229] STEPHAN D., KRELAUS R., SCHMIDT M.: Direct measurement of particle-particle interactions of fines for UHPC using AFM technology. $2^{\circ}$ International Symposium on UHPC. pp. 375-382, Kassel (Germany), March 05-07, 2008

[230] STIEL T., KARIHALOO B., FEHLING E.: Effect of Casting Direction on the Mechanical Properties of CARDIFRC. $1^{\circ}$ International Symposium on UHPC. pp. 481-494, Kassel (Germany), September 1315,2004

[231] STÜRWALD S., FEHLING E.: Design of Reinforced UHPFRC in Flexure. 3rd International Symposium on UHPC, HIPERMAT. pp. 443-450, Kassel (Germany), March 07-09, 2012

[232] SUTER R., MOREILLON L., CLERGUE C., BRUSA R.: Élements de façade complexes en béton fibré à ultra-hautes performances. International Workshop on UHPFRC. Marseille (France), November $17-18,2009$

[233] TACKETT A., ROYCE W., RUIZ E.D., HALE W.M.: Effect of mixer type on the performance of Ultra-High Performance Concrete. Digital format document.

[234] TALEBINEJAD I., BASSAM S.A., IRANMANESH A., SHEKARCHIZADEH M.: Optimizing mix proportions of Normal Weight Reactive Powder Concrete with Strengths of 200-350 MPa. 10 International Symposium on UHPC. pp. 133-142, Kassel (Germany), September 13-15, 2004

[235] TANAKA Y., ISHIDO M., KOBAYASHI T., OHKAWA M.: Technical developement of a long span monorail girder applying UHSFRC. 20 International Symposium on UHPC. pp. 803-811, Kassel (Germany), March 05-07, 2008

[236] TANAKA Y., MAEKAWA K., KAMEYAMA Y., OHTAKE A., MUSHA H.: Innovation and application of UHPFRC bridges in Japan. International Workshop on UHPFRC. Marseille (France), November 17-18, 2009

[237] TANAKA Y., MUSHA H., FUKUURA N., OOSHIMA K.: Design of Perfobond Strip Applied for Reactive Powder Concrete Bridge. http://www.pwri.go.jp/eng/ujnr/tc/g/pdf/23/23-93watanabe.pdf.

[238] TANAKA Y., MUSYA H., SHIMOYAMA Y., KOBAYASHI T.: Application technology of UHSFRC for a $50 \mathrm{~m}$ span "Sakata Mirai footbridge". 28th Conference on Our World in Concrete \& Structures. Singapore, August 28-29, 2003

[239] TANG M.C.: High Performance Concrete- Past, present and future. $1^{o}$ International Symposium on UHPC. pp. 3-10, Kassel (Germany), September 13-15, 2004

[240] TAZAWA E.: Autogenous Shrinkage of Concrete. Proceedings of the International Workshop organized by JCE. Hiroshima (Japan), June 13-14, 1998 
[241] TEICHMANN T., SCHMIDT M.: Influence of the packing density of fine particles on structure, strength and durability of UHPC. 1을 International Symposium on UHPC. pp. 313-324, Kassel (Germany), September 13-15, 2004

[242] TERZIJSKI I.: Compatibility of Components of High and Ultra High Performance Concrete. 1ำ International Symposium on UHPC. pp. 175-186, Kassel (Germany), September 13-15, 2004

[243] TERZIJSKI I.: Optimization of UHPC for the Model of a Pedestrian Bridge. 20 International Symposium on UHPC. pp. 707-716, Kassel (Germany), March 05-07, 2008

[244] THOMAS M., GREEN B., O'NEAL E., PERRY V., HAYMAN S., HOSSACK A.: Marine Performance of UHPC at Treat Island. 3rd International Symposium on UHPC, HIPERMAT. pp. 365-370, Kassel (Germany), March 07-09, 2012

[245] TOUTLEMONDE F., SCHAUMANN E., KELLER T.: New material properties and modelling rules. NR2C: New Road Construction Concepts. 18/11/2005

[246] TRAYNER D.: Bridge construction methods. Post-tensioned Institute of Australia Limited. 2004

[247] TUE N.V., MA J., ORGASS M.: Influence of addition method of superplasticizer on the properties of fresh UHPC. $2^{\circ}$ International Symposium on UHPC. pp. 93-102, Kassel (Germany), March 05-07, 2008

[248] VAN GYSEL A.: Study of the pullout behavior of steel fibers inbedded in cement-bonded matrix with application on the FRC in bending. Ph.D. Thesis, Gent University. Gent (Belgium), 2000

[249] VANDE VOORT T., SULEIMAN M., SRITHARAN S.: Design and Performance Verification of Ultra-High Performance Concrete Piles for Deep Foundations. Final Report, Iowa State University. Iowa (USA), November 2008

[250] VICAT ${ }^{\circledR}:$ BCV-Béton Composite Vicat-Vicat's Composite Concrete. F2F continuum: From file to factory. http://f2f-continuum.eu/downloads/educationalMaterial/notes_vicat.pdf.

[251] VICENZINO E., CULHAM G., PERRY V.H., ZAKARIASEN D., CHOW T. S.: First Use of UHPFRC in the Thin Precast Concrete Roof Shell for Canadian LRT Station. PCI Journal. pp. 50-67, SeptemberOctober 2005

[252] VOGT C., LAGERBLAD B., HUGO-PERSSON T.: Optimization of UHPC for selective stabilization of deep boreholes. $1^{\circ}$ International Symposium on UHPC. pp. 769-782, Kassel (Germany), September $13-15,2004$

[253] VOO Y.L., NEMATOLLAHI B., SAID A.B.B.M., GOPAL B.A., YEE T.S.: Application of UHPFRCThe Malaysia perspective. International Journal of Sustainable Construction Engineering \& Technology. Vol 3. Issue 1. 2012

[254] VOO Y.L., FOSTER S.J.: Characteristics of ultra-high performance 'ductile' concrete and its impact on sustainable construction. The IES Journal Part A: Civil \& Structural Engineering. Online publication day. pp. 168-187, July 20, 2010

[255] VOO Y.L., POON W.K.: The world first portal frame builiding (Wilson Hall) constructed using Ultra-High performance Concrete. 33th concerence on Our World in Concrete \& Structures. pp. 493 500, Republic of Singapore, August 25-27, 2008

[256] VOO Y.L., POON W.K.: Malaysia first UHPC prestressed motorway bridge: Experimental verification. 5th Int'l Specialty Conference on Fibre Reinforced Materials. pp. 169-176, Republic of Singapore, August 28-29, 2008 
[257] VOO Y.L., POON W.K.: Experimental study on structural behaviour of steel fiber reinforced DURA® T875 prestressed bridge girders. Technical Report, no TR-0004. Dura Technology SDN BH. ISBN: 978-983-43785-3-0. Perak (Malaysia), March 2008

[258] WALKER W.J.: Persistence of Granular Structure during Compaction Processes. KONA no 21. 2003

[259] WALRAVEN J.C., SERNA P., DI PRISCO M.: Aplicaciones estructurales del hormigón con fibras. Technical conference. Barcelona, 2007

[260] WALRAVEN J.C.: On the way to design recommendations for UHSFRC. 2 International Symposium on UHPC. pp. 45-58, Kassel (Germany), March 05-07, 2008

[261] WALRAVEN J.C.: Designing with UHSC: Basics, potential and perspectives. 1 International Symposium on UHPC. pp. 853-864, Kassel (Germany), September 13-15, 2004

[262] WALRAVEN J.C.: High performance fiber reinforced concrete: Progresss in knowledge and design codes. Materials and Structures 42. pp. 1247-1260, 2009

[263] WILLE K., KIM D.J., NAAMAN A.E.: Strain-hardening UHP-FRC with low fiber contents. Materials and Structures 44. pp. 583-598, 2011

[264] WILlE K., NAAMAN A.E., PARRA G.: Ultra High Performance concrete with compressive strength exceeding 150 Mpa. A simpler way. ACI Journal. January 6, 2010

[265] YAMAN I.O., HEARN N., AKTAN H.M.: Active and Non-Active Porosity in Concrete. Part I: Experimental Evidence. Materials and Structures 35, no 2. pp. $102-109,2002$

[266] YAN H., SUN W., CHEN H.: The effect of silica fume and steel fiber on the dynamic mechanical performance of high-strength concrete. Cement and Concrete Research 29, no 3. pp. 423-426, 1999

[267] YAN P.Y., FENG J.W.: Mechanical Behavior of UHPC and UHPC Filled Steel Tubular Stub Columns. 2을 International Symposium on UHPC. pp. 355-362, Kassel (Germany), March 05-07, 2008

[268] YANG I.H., JOH C., KIM B.S.: Structural behavior of ultra high performance concrete beams subjected to bending. Engineering Structures 32. pp. 3478-3487, 2010

[269] YANG J., PENG G.F., GAO Y.X., ZHANG H.: Characteristics of Mechanical properties and durability of UHPC incorporating coarse aggregate. 3rd International Symposium on UHPC, HIPERMAT. pp. 257-264, Kassel (Germany), March 07-09, 2012

[270] YANG S.L., MILLARD S.G., SOUTSOS M.N., BARNETT S.J., LE T.T.: Influence of aggregate and curing time on the mechanical properties of ultra-high performance fibre reinforced concrete (UHPFRC). Construction and Building Materials 23. pp. 2291-2298, 2009

[271] YAZICI H.: The effect of curing conditions on compressive strength of Ultra High Strength Concrete with high wolume mineral admixtures. Building and Environment 42. 2083-2089, 2007 


\section{AnNeXes}




\section{ANNEX I: ELEMENTS DESIGNED AT UPV}

\section{INTRODUCTION}

The previous research endorses the utilization of local components and conventional processes to perform UHPFRC. The dosage used has to be chosen considering not only the requirements of each application, but also the casting processes. This was explained at 4.7, where concretes with different types of fibers and aggregates were suggested as the most adequate for certain precast elements and pouring conditions.

At Universitat Politècnica de València, along the last 3 years several structural and nonstructural applications have been designed and tested. The UHPFRC used were always one of the developed by the research group, being cast at laboratory or at the precast industry. Here the design, the elements casting and the benefits of each solution are exposed. Also the results of some full scale elements are presented.

The designs here exposed suggest new shapes, much more slender than the common practice to ordinary concretes, trying to find the structural systems that take the full advantage of this material.

\section{STRUCTURAL APPLICATIONS}

The role of UHPFRC in precast elements depends on their geometry and application. In the case of thin elements without any ordinary steel reinforcement, the strength depends completely on the fiber orientation and distribution. In the case of the prestressed beams, its flexural capacity depends mainly on the prestressing steel. In those cases, fibers normally provide only $10-20 \%$ of the total flexural capacity, but only adding them the design can be so slender, with small covers and in absence of shear reinforcement. Both for structures with and without ordinary steel, the conceptual design wouldn't be possible without the fiber addition.

The following applications, developed at the UPV, are elements with structural requirements that reduce significantly the volume of concrete used respect to the traditional solutions.

\section{$\pi$ GIRDER FOR UNIDIRECTIONAL LOAD TRANSMISSIONS}

This consists in a one-way spanning system made of precast prestressed thin walled "pi" beams and thin flat slabs (figure A.1). The thickness of the elements varies between 20 and 40 $\mathrm{mm}$. The main structural element is prestressed with two strands of seven wires with an equivalent diameter of $13 \mathrm{~mm}$. The secondary element is a slab without conventional reinforcement and with the goal of cover the span between the primary beams to complete the flat roof. 


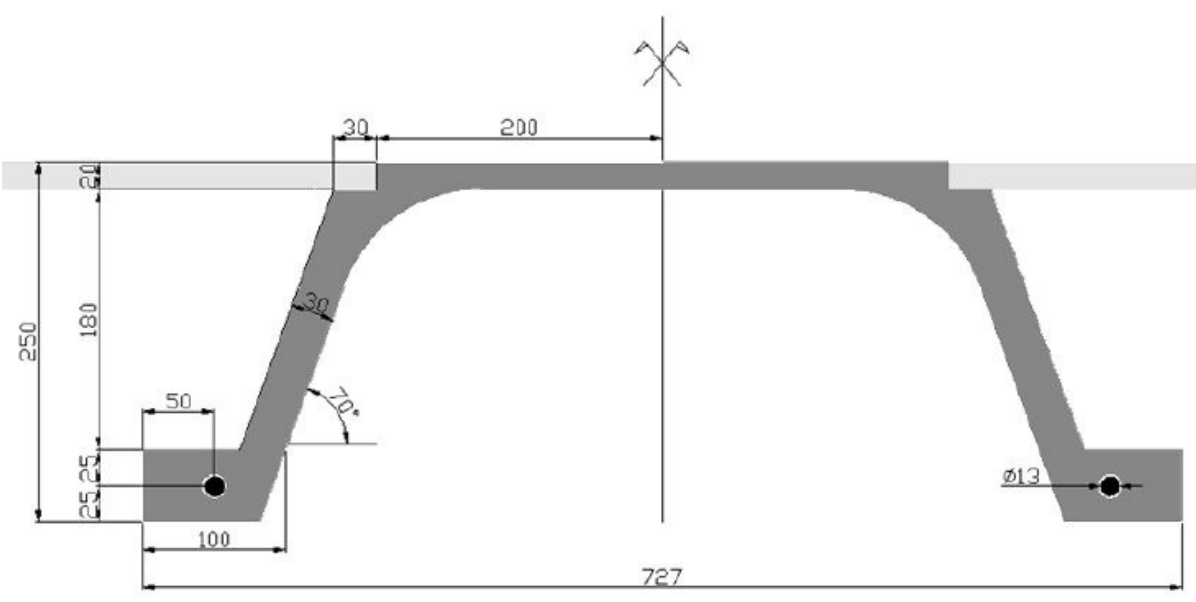

Figure A.1: Geometry of the structural element for the unidirectional load transmissions

This system can be used for spans of $12 \mathrm{~m}$ with loads of $5 \mathrm{kN} / \mathrm{m}^{2}$, or spans of $9 \mathrm{~m}$ with loads of $10 \mathrm{kN} / \mathrm{m}^{2}$. The depth is only of $250 \mathrm{~mm}$ and the weight of $1.25 \mathrm{kN} / \mathrm{m}^{2}$, being $30 \%$ of the weight of ordinary solutions for these range of spans and loads. The key-point of this beam is that the reduced self-weight implies a small increase of the dead weight in long spans, which increases dramatically in other ordinary concrete solutions.

This system minimizes the materials consumption. It doesn't require in-situ concrete for any compression layer or for the connections, which implies also a high level of industrialization. The reduced weight facilitates the transport and placing and the geometry is specially designed for allow an efficient storage (figure A.3). The secondary slab can be extracted to canalize installations or pipes.

Full scale beams were casted in laboratory without prestressed steel and, by means of flexural tests the stress-strain tensile law of the material was deduced. Prestressed beams were cast in a precast company (see figures A.2 and A.4) and tested for check the real behavior of the element. The elements suffered ductile failure reaching the expected strength, and the strands transmitted adequately the tension with a cover smaller than $15 \mathrm{~mm}$. More information can be found at [37].

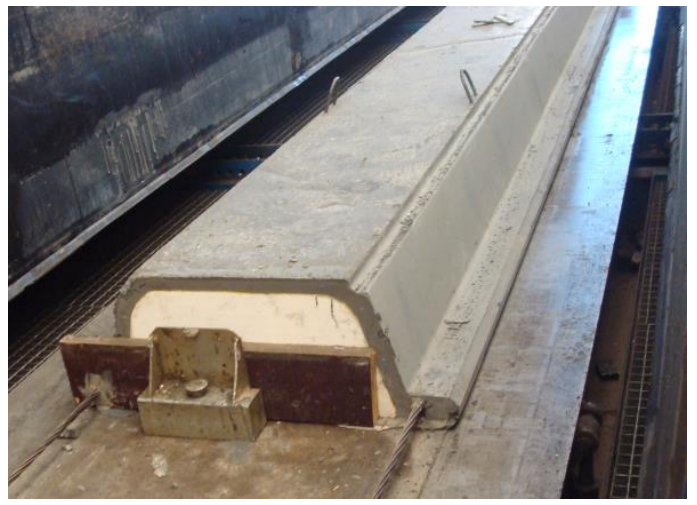

Figure A.2: Element prestressed in the precast industry

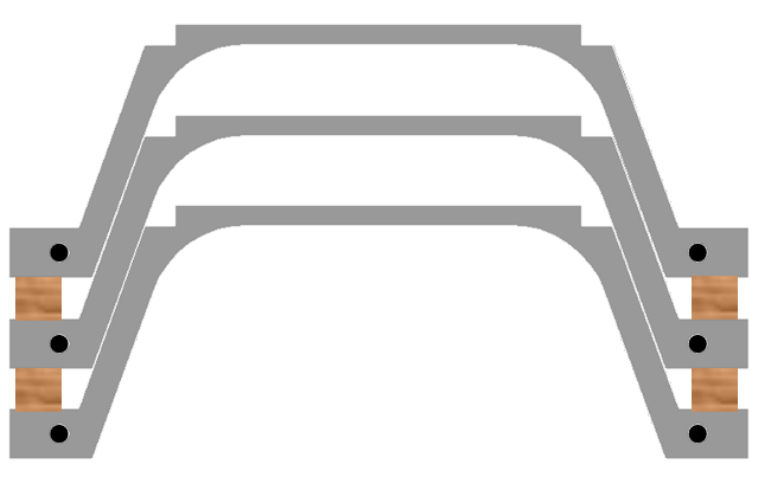

Figure A.3: Picture of the efficient storage system proposed for the elements 


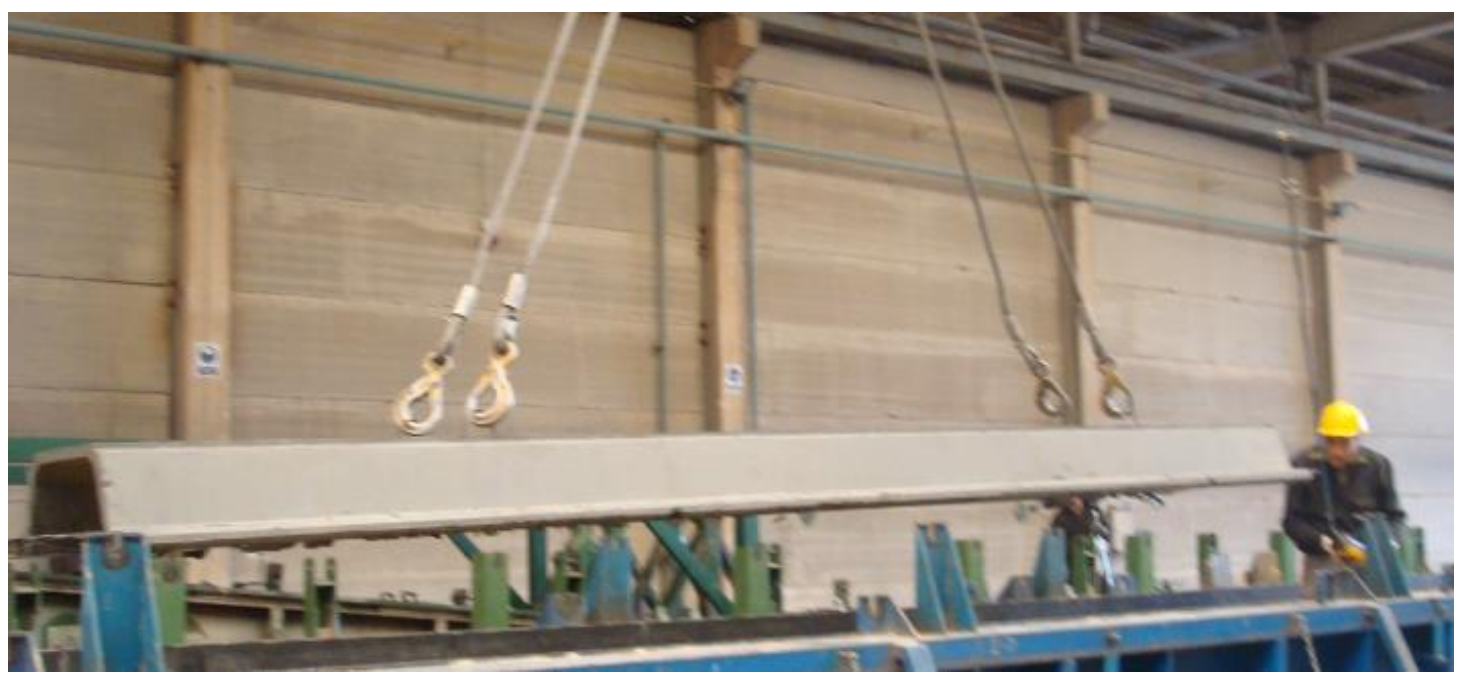

Figure A.4: Removal of a 5 meters length precast prestressed element 24 hours after casting

\section{TRUSSES FOR TEMPORAL STRUCTURES}

The application of precast prestressed UHPFRC truss system can be worth when a light, durable and fast assembly structure is required. The group work at UPV has worked in the development of light elements that can compose a truss by means of bolted connections (tested here at Section 5). Figures A.5 and A.6 show one of the precast pieces, cast at a precasting company with the UHPFRC denoted as F3-HY at the section 4.6.2 of this Ph.D. Thanks to the use of both fiber types, the tie can remain very stiff after the micro-cracking, and the reduced crack width should make it also very durable.

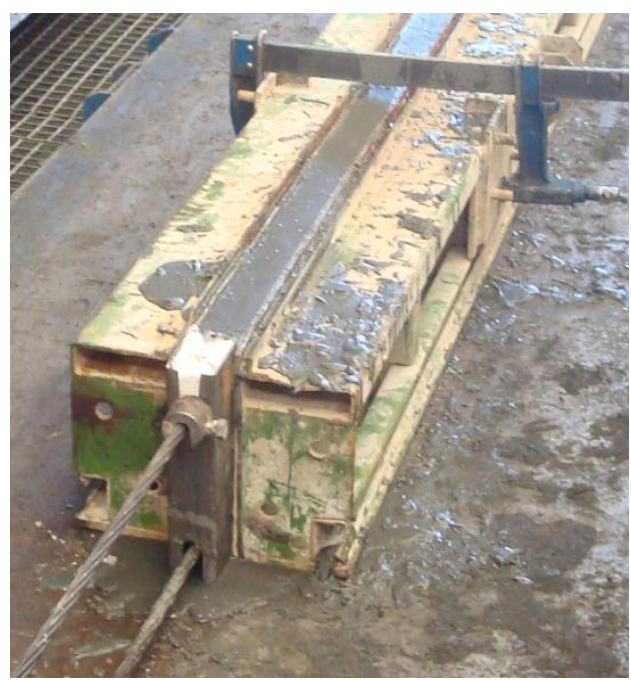

Figure A.5: Tie being cast at the precast company

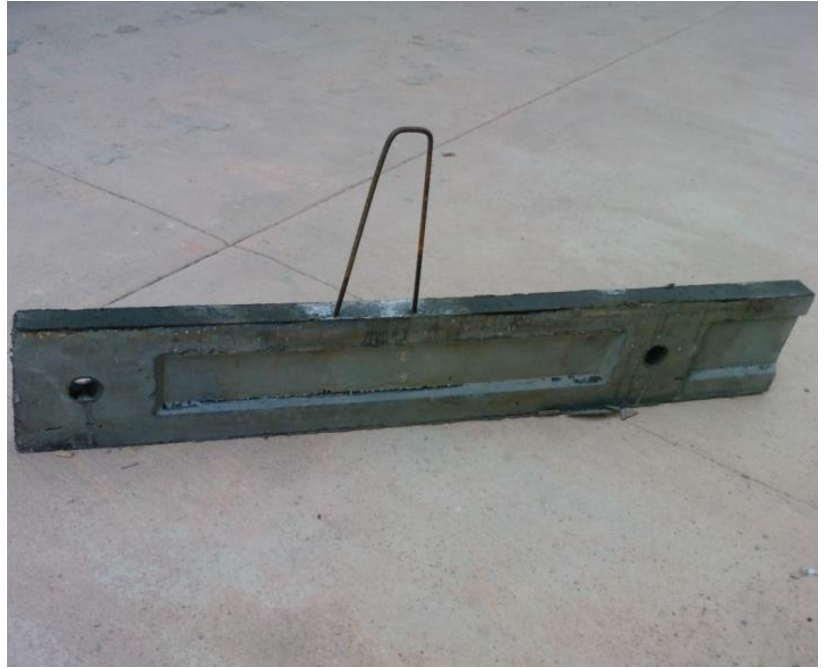

Figure A.6: Tie element $24 \mathrm{~h}$ after release (sectional area of $200 \times 50 \mathrm{~mm}$ at the bolted region)

The tie can be much thinner than with OC by several reasons: High shear strength and ductility provided by the fibers avoid the use of secondary ordinary reinforcement, and penetration of the carbonation is not conceived as the oxygen permeability of UHPFRC is 1000 times lower than for OC. The element small thickness implies a marked wall effect and then a suitable fiber orientation taking full structural advantage of them. Efficient pouring process 
and desired orientation are obtained with a high self-compactability. The minimum thickness is only limited by the pouring viability. Also a much reduced thickness will decrease the inertia in one axis, appearing a noticeable bending of the pieces if the strands are not perfectly placed. More information about this system can be found at [38][39].

The success of this simple connection system in a structural scale opens the door to several applications, especially those which require fast construction or are temporary, being possible to re-use the disassembled elements for other standard uses. Natural disasters, as floods, hurricanes, landslides, earthquakes can collapse primary infrastructures, wreaking havoc and isolating populations for months, until another is built. Also wars produce the same effects. Urgent priorities such as care for the injured, housing the homeless, providing food and preventing disease can become desperate if relief workers and supplies cannot get through to the stricken area. It's in these cases where an emergency structure is especially useful. Some of the advantages of a bolted connection truss structure are abstracted as follows:

\section{At the prefabricate company}

- Simplification of the molds used to cast the pieces, becoming all of them linear

- Better control of the fiber orientation

- The reinforcement of the nodal region is substituted for a simple steel piece

- Easier steam curing application thanks to the simpler elements

- Easier manipulation of the elements

- Simpler storage at a warehouse, being possible to store the pieces in a reduced area and assemble them in few hours if necessary

\section{During the manipulation}

- Better storage for the transport: Higher ratio weight/volume. Smaller truck can be used

- The transport to difficult emplacements is easier thanks to the elements dimensions

- Less hand work might be needed for the assembling process than for a full truss placement

\section{After the construction}

- Smaller crane might be used for the final placement

- The damaged elements can be substituted

- If the structure is removed, the elements can be reutilized for other

On the other side, there are some possible difficulties to be considered compared with the one piece truss structure:

\section{At the prefabricate company}

- More number of elements to manipulate

- Higher control is required in the joint regions

\section{During the manipulation}

- Human errors are possible during the assembling process

- Special tools might be required 


\section{$\underline{\text { After the construction }}$}

- Possible unscrew of the bolts because of the structure vibrations

- Higher maintenance than for a one piece concrete element

- Less stiffness

\section{Precast Retaining WALL}

This system consists in a new solution for retaining walls based in two types of precast UHPFRC elements. It consists on vertical precast prestressed beams designed with a lightened section and fastened to the soil with anchors. The wall is completed by slender curved shells elements between the beams and supported on them.

The prestressed beam is $300 \mathrm{~mm}$ depth and includes in total six prestressed strands of 15.2 $\mathrm{mm}$ of equivalent diameter $\left(1860 \mathrm{~N} / \mathrm{mm}^{2}\right)$. The beam is lightened thanks to a $200 \mathrm{~mm}$ diameter hole except at the anchored area. The curve shell is $30 \mathrm{~mm}$ thick with a rise/span ratio of $1 / 7$. The piece is shown in the upper part of figure A.7, where it is compared with similar carrying capacity traditional solution.

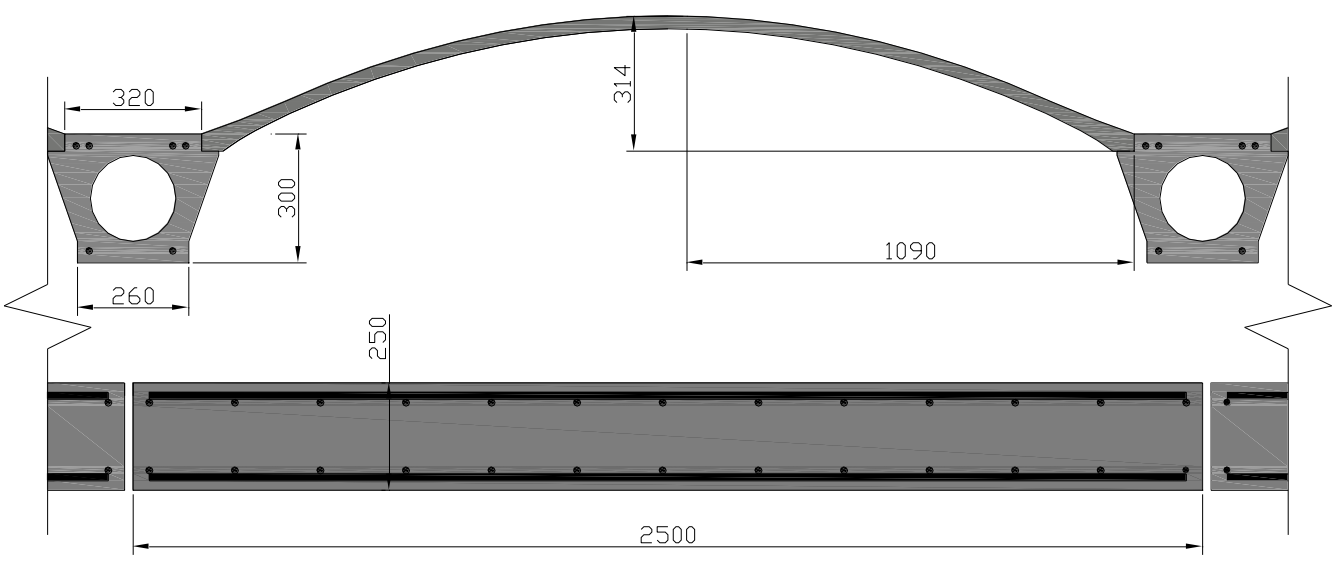

Figure A.7: Comparison between UHPFRC design (up) and a conventional reinforced concrete one (down)

This system is especially adequate for aggressive environments (with contact of sulphate waters, or near the sea), because the absence of macro-cracks and the low porosity of the concrete ensures a long service life. The high level of industrialization allows the fast replacement of possible damaged precast elements.

The solution takes the full advantage of the UHPFRC compressive strength and ductility. The design let to reduce approximately four times the total concrete volume used with respect to a traditional proposal, having the same structural capacity and improving the concrete durability. This implies a decrease in the material consumption, in the transport and in the placing methods.

The release of the prestressed strands was considered two days after casting. Ultimate Limit State (ULS) and Service Limit State (SLS) were checked using French recommendations. With the purpose to check the design criteria, a reinforced UHPFRC three metres length beam with the designed cross-section was cast in laboratory (figure A.9). A four-point-flexural test of the 
beam was performed, and the load-middle span deflection diagram is shown at figure A.8. The beam failed, as expected, by tensile ductile failure, showing a reliable mechanical behaviour. Photos of the aspect of the middle span at 80 and $100 \%$ of the maximum load are shown, with the corresponding micro-cracks and macro-crack associated. The curved shell was also tested (figure A.10) obtaining the expected results.

The absence of rebar jobs and the reduction of $84 \%$ of the weight compared with the traditional solution leads in a cost reduction of a $25 \%$. More information about this system can be found in [141].

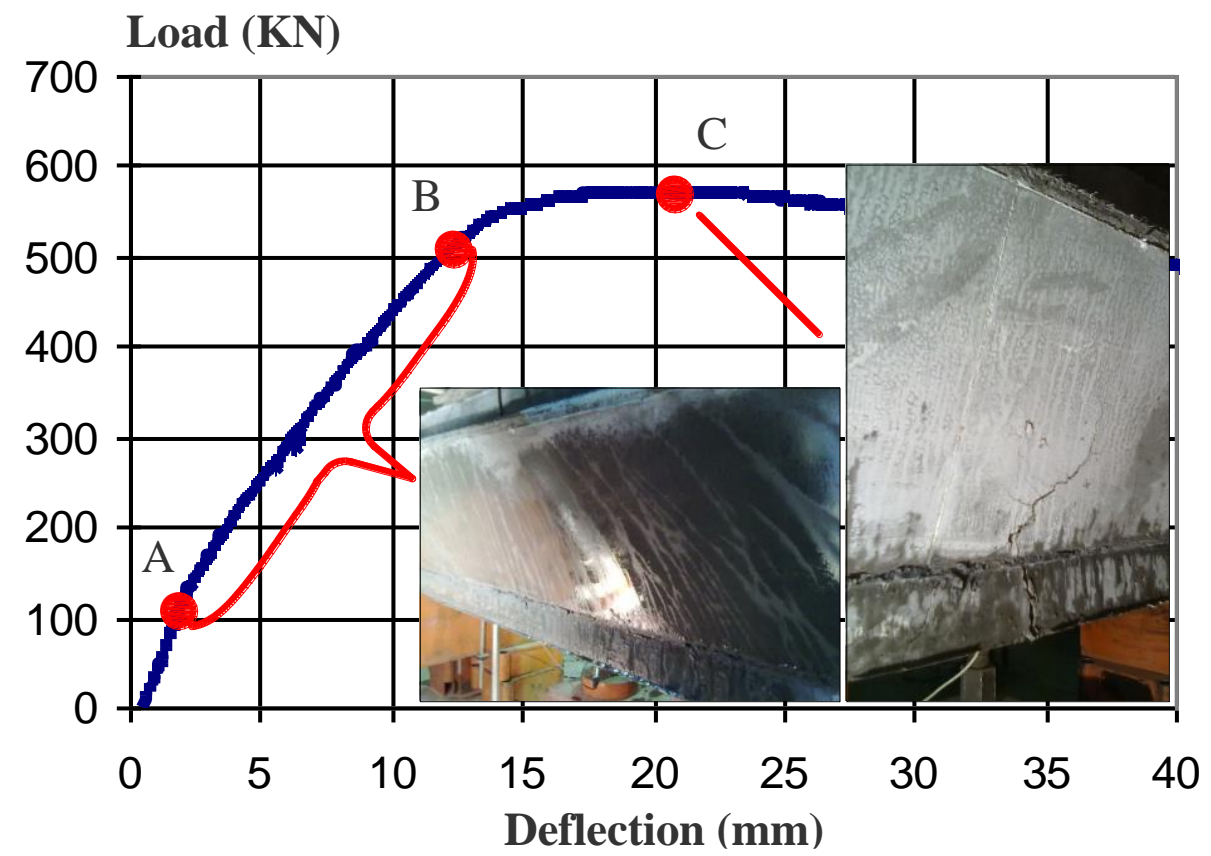

Figure A.8: Load-center span deflection diagram for the reinforced beam cast

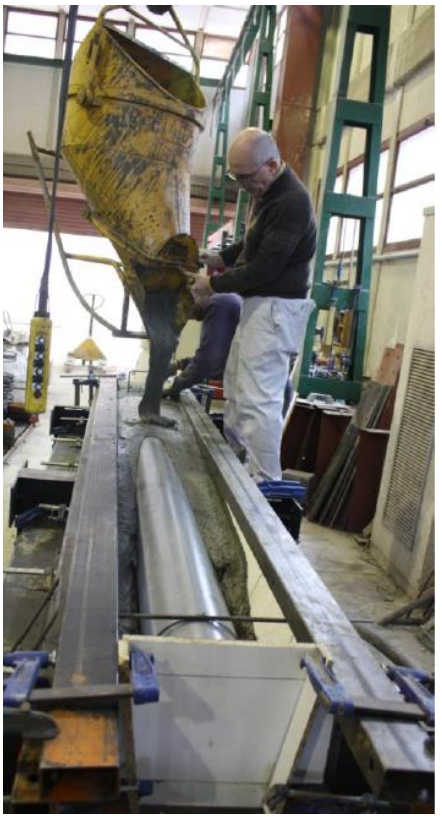

Figure A.9: Three meters length beam being cast

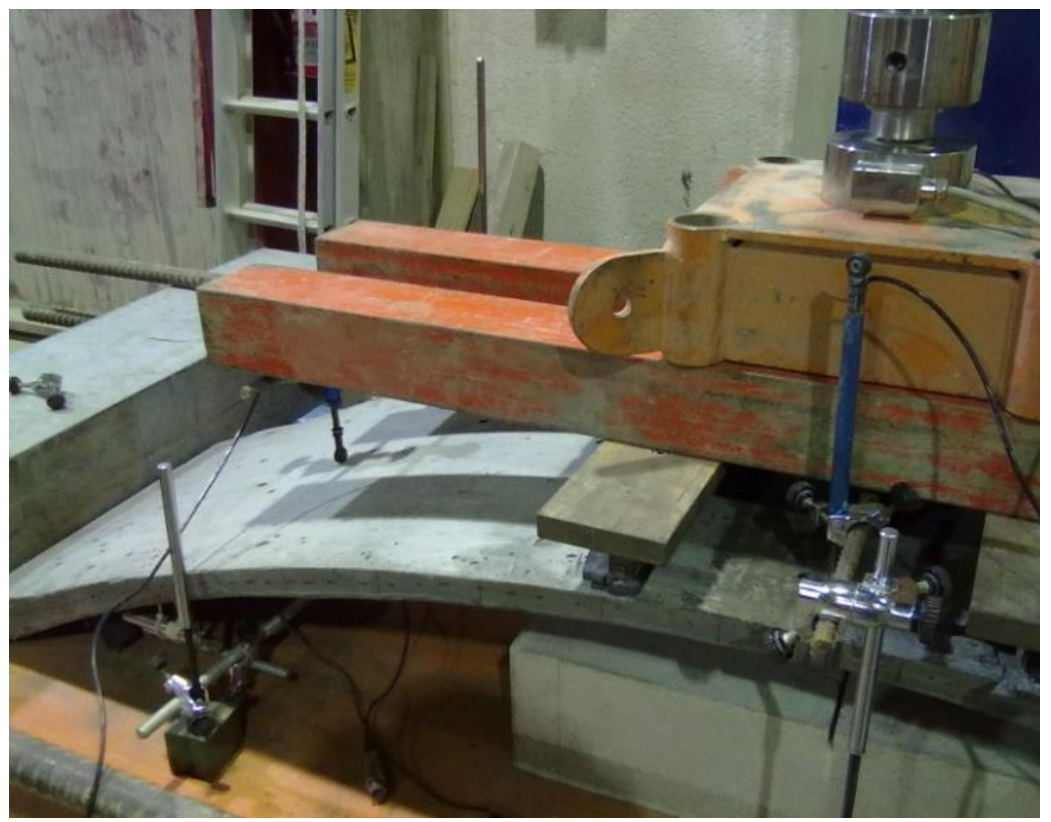

Figure A.10: Four point compressive test applied to the $30 \mathrm{~mm}$ thickness curved shell in laboratory 


\section{PRECAST TRUSS FOOTBRIDGE}

Here is presented the first footbridge built with UHPFRC in Spain and, as far as we know, the first truss pedestrian bridge made only of UHPFRC in the world. It will be placed very close to the sea in Alicante at autumn of 2012. The use of this material allows very aesthetic, innovative and slender design to communicate two districts historically isolated by the Ovejas ravine. The design required has to save 45 meters of span with a minimal visual impact. Moreover, the final solution should be easy to manufacture in an ordinary precast factory.

The structural system chosen consisted on two modified Warren trusses of variable depth (from $1.34 \mathrm{~m}$ to $2.02 \mathrm{~m}$ at mid-span, see figure A.11 and cross-section at figure A.12), in which the compressed chord was also used as a railing. The design of the truss follows a wave shape that provides an adequate transmission of the shear loads along the footbridge. The truss bottom chord depth is $0.15 \mathrm{~m}$ and contains a total of 180.6 " seven-wire prestressing strands. The truss diagonal members have a cross-section of $150 \times 120 \mathrm{~mm}$ and have a reinforcement of four $20 \mathrm{~mm}$ steel bars. An intermediate curved ribbed slab connected both trusses and worked as the bridge deck, as well as a third truss connected the bottom chords (figure A.12).

The structural design was carried out according to the Recommendations of AFGC [8] for both ultimate (ULS) and serviceability limit states (SLS). Special attention was given to the buckling of the struts and to the shear reinforcement requirement at the construction joints.

The concrete used was the defined as F3-HY at the subchapter 4.6 of this Ph.D. Hybrid UHPFRC was chosen to guarantee the control of the macro-crack opening in the ties when the steel is exceed the elastic stage.

The solution weights the same as the initially designed with steel, but with much better durability against the aggressive sea environment, with costs savings and an innovative design (figure A.14). More information can be found at [138][139].

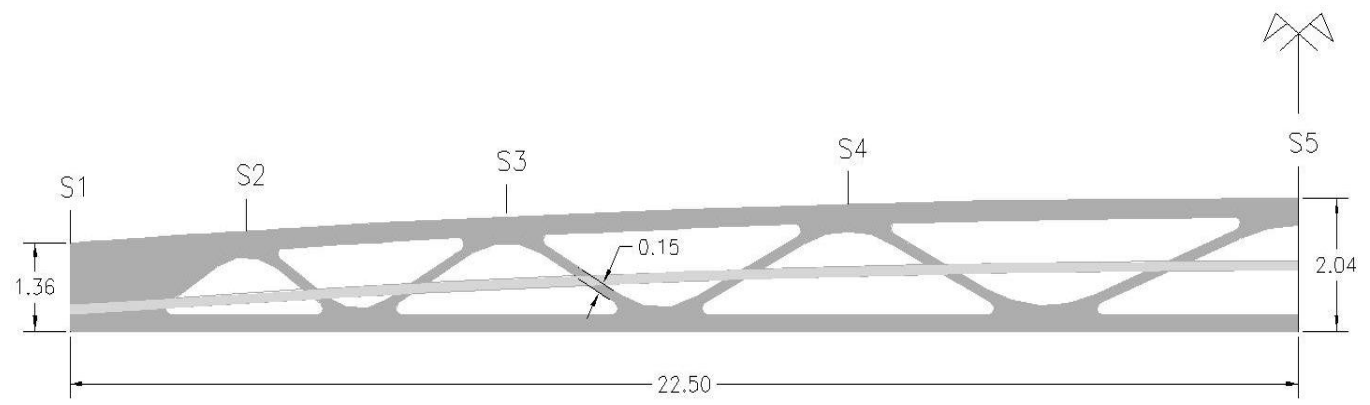

Figure A.11: Longitudinal elevation of the footbridge

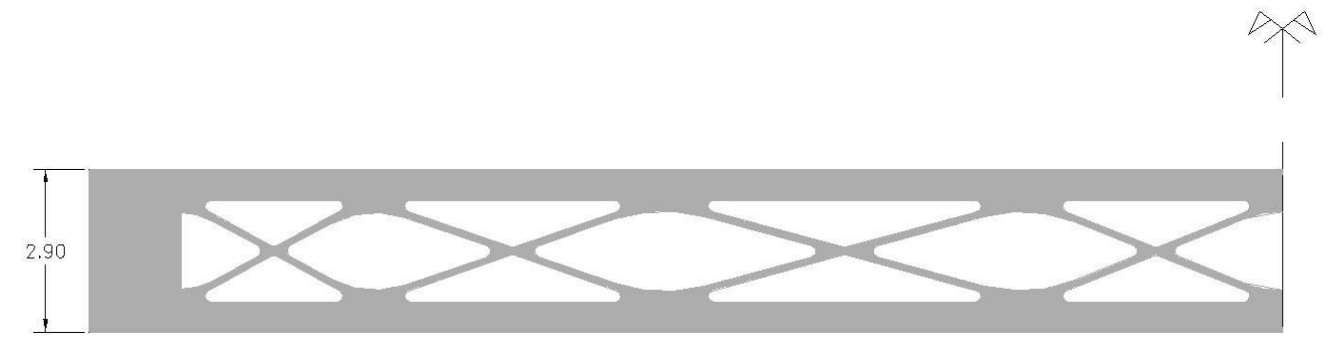

Figure A.12: The X-shaped truss at the bottom chord 


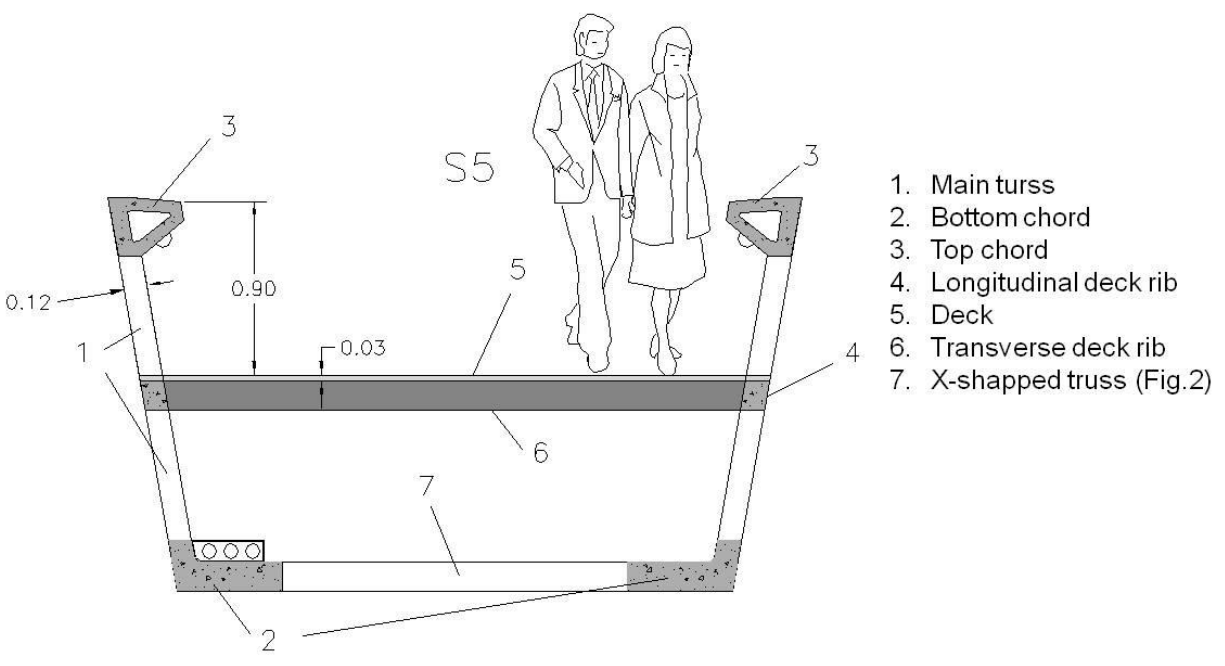

Figure A.13: Cross-section at S5.
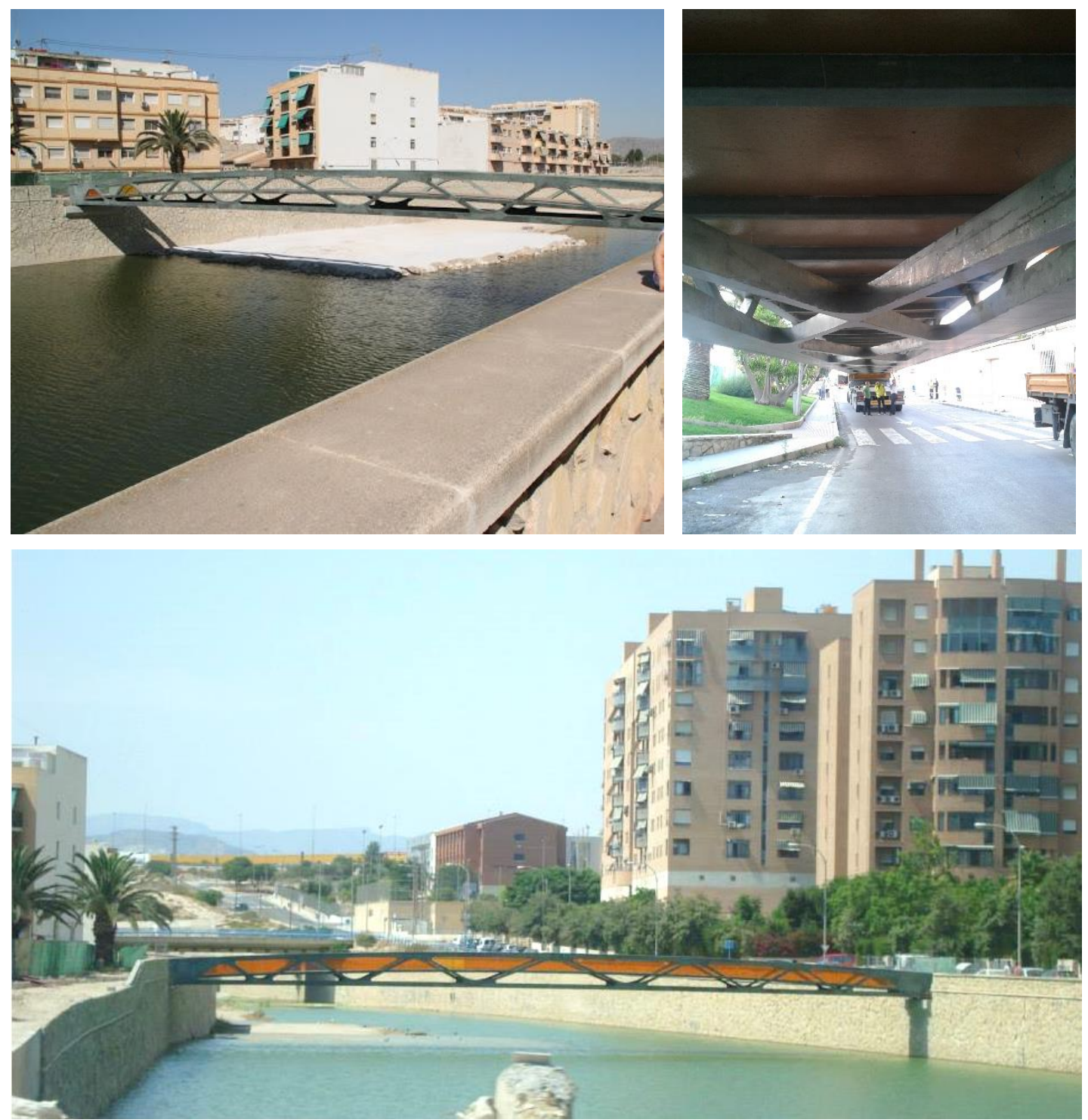

Figure A.14: Bottom view of the footbridge during the placing and final view 


\section{NON-STRUCTURAL APPLICATIONS}

UHPFRC can be also a worth material for applications that has very little to do with civil engineering, as urban furniture or jewelry. The most appreciated properties in these cases are the surface aspect, the wide design possibilities, the high impact strength and the great long term durability.

The suitability of UHPFRC for urban or garden furniture is supported by several reasons. Compared with other materials it doesn't require maintenance, it can be cast with different colours (not requiring a coat of paint) and a great variety of surface aspects. It is fireproof, resitant to the pets urine, resistant to ultraviolet rays and to the ice thaw cycles. The high strength and ductility makes it proof to vandalism. Setting the elements to the pavement can be fast thanks to the possibility of screwed connections. Finally, these applications consume much less material than the conventional concrete and can be used for the fixation of heavy metals, cooperating with the environment.

At UPV, several different urban furniture were designed, calculated and cast. No ordinary reinforcement was used, and the thickness of the elements was limited by strength required and the viability of the pouring method. At figure A.15 is appreciated a $20 \mathrm{~mm}$ thickness chair cast in white color. The surface got a plastic texture since the mold was covered with lining paper. The radial geometry of the chair allowed a casting process from the central upper part, as is shown at figure A.16, orienting the fibers in the efforts direction. The UHPFRC developed contained white binders and only the short fiber type as required for such a reduced mold thickness.

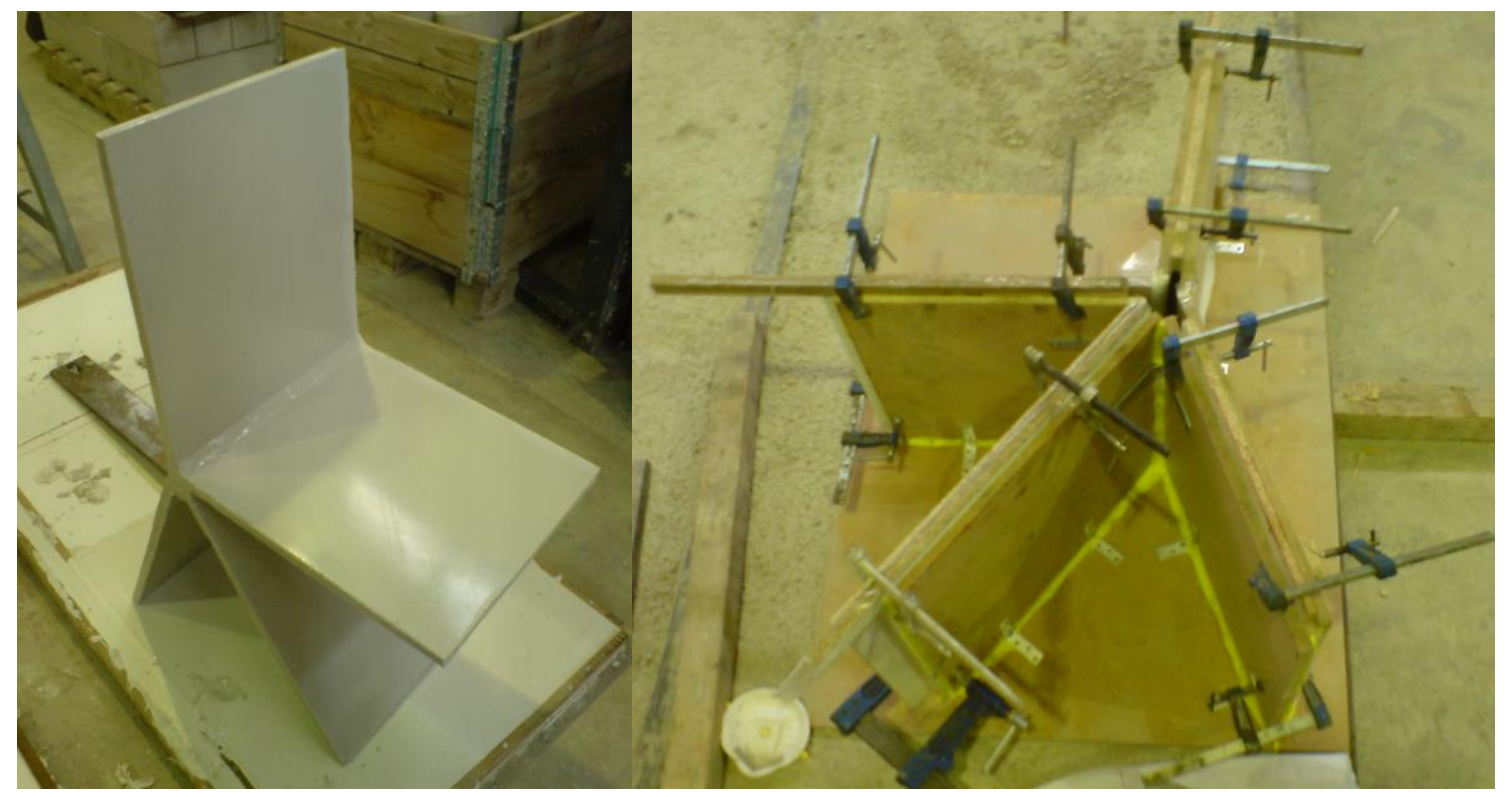

Figure A.15: White chair

Figure A.16: Mould of the white chair 


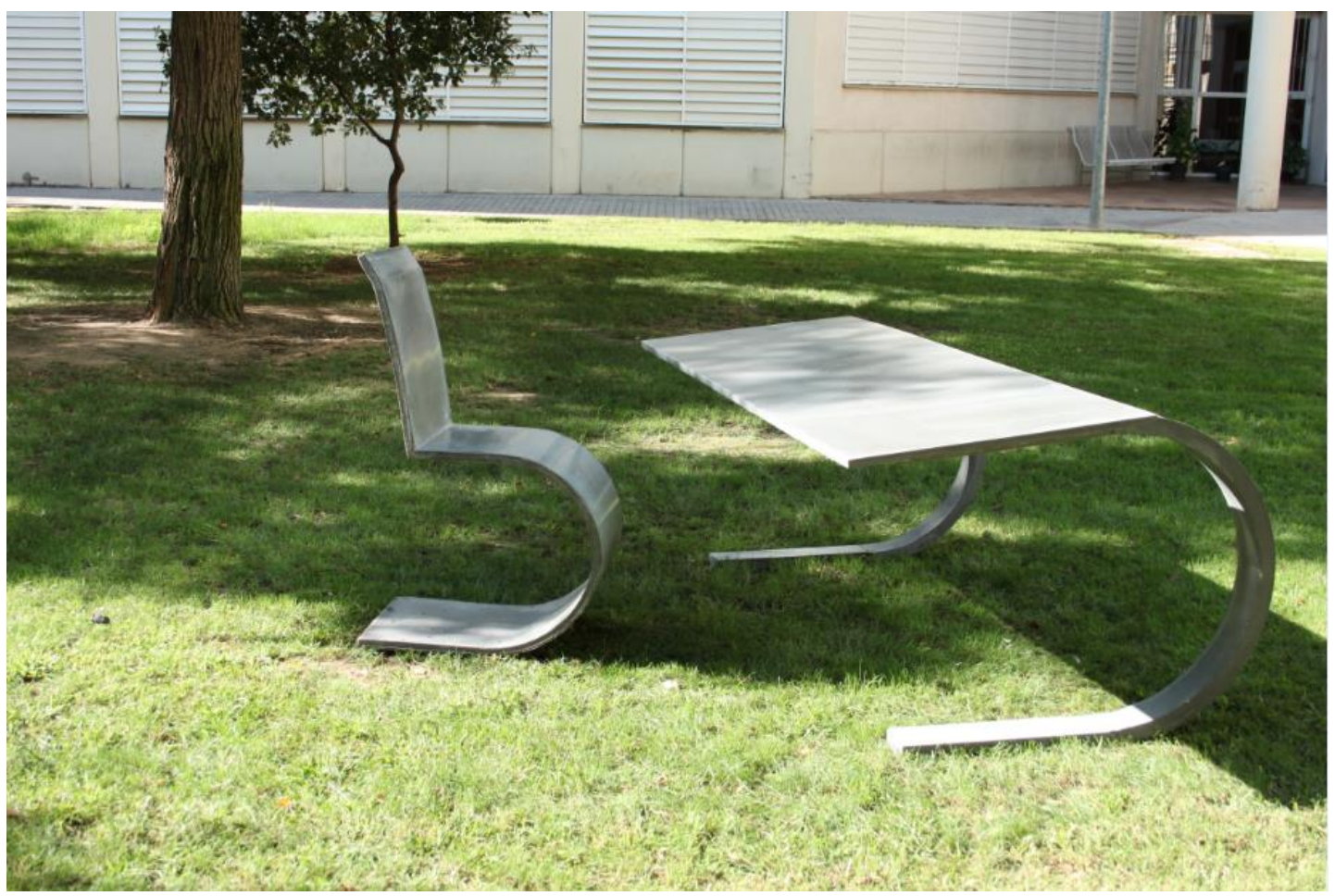

Figure A.17: Chair and table urban furniture developed at UPV

On the figure A.17 are shown a chair and a table designed for urban furniture collection at the UPV. The chair is a single element that was cast through the upper part with the dosage named F3-HY at chapter 4.6.2, but substituting the content of long fibers for short ones. The high flowability and casting process allowed an adequate fiber orientation in the curved region, the most tensioned. The table was composed of three pieces: Two legs and the top, being all cast with the hybrid dosage since the mould geometry didn't impede the long fiber's advance.

The high capacity of UHPC-UHPFRC to imitate the contacted surface and the high impact strength makes it interesting also for develop jewelry pieces. At figures A.18 and A.19 is shown a ring (design of Menis Arquitectos) cast at UPV with UHPC that combines the concrete with rhinestones in a non-closed circumference. The glasses are crimped in a small wire inserted along the entire perimeter. The thin design is only possible thanks to the high compacity of the material, which dosage was specially designed for this application. The high content of unhidrated binder allows the progressive enclosure of any microcrack that might be suffered.

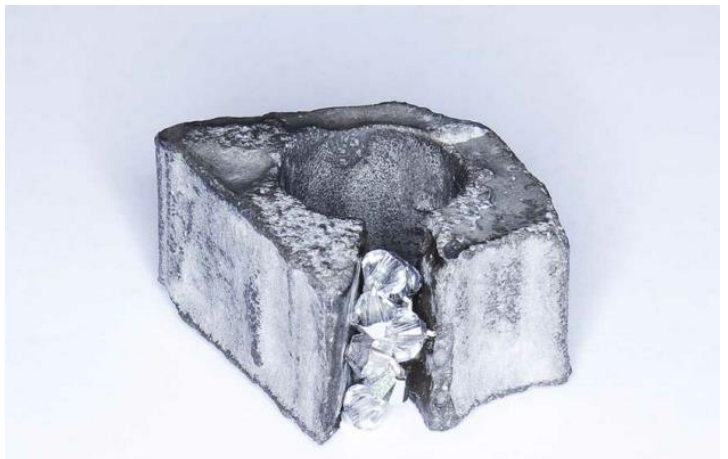

Figure A.18: Jewlery

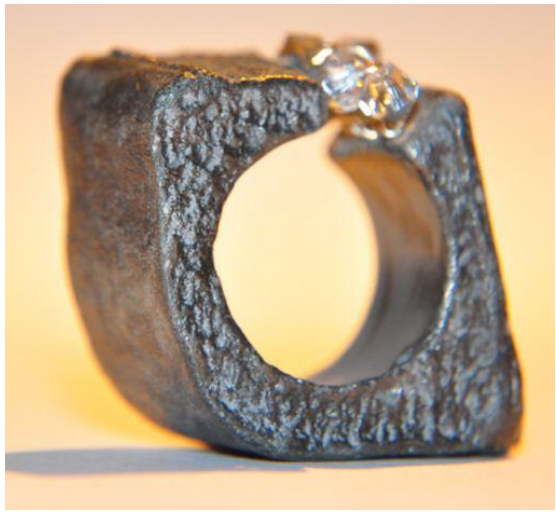

Figure A.19: Jewlery 
10. OTHERS 


\section{European Curriculum Vitae}

\section{Personal information}

$\begin{array}{ll}\text { First name(s) / Surname(s) } & \text { Camacho Torregrosa, Esteban Efraím } \\ \text { Address(es) } & \begin{array}{l}\text { Albalat dels Tarongers, 34, } 9 . \\ \text { CP: } 46021, \text { Valencia. Spain. } \\ \end{array} \\ \text { Telephone(s) } & \text { estebancamacho@msn.com } \\ \text { E-mail } & \text { Spanish } \\ \text { Nationality } & 07-12-1985 \\ \text { Date of birth } & \text { Male } \\ \text { Gender } & \end{array}$

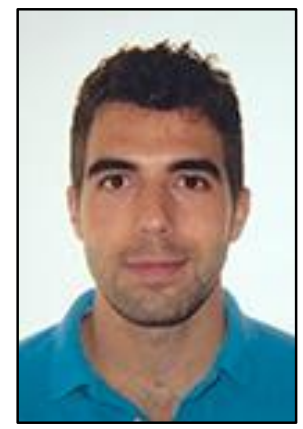

\section{Work experience}

Dates

Occupation or position held

Main responsibilities

Name of employer

Dates

Occupation or position held

Main responsibilities

Name of employer

Dates

Occupation or position held

Main responsibilities

Name of employer

\section{Education and training}

Dates

Title qualification awarded

Principal occupational skills covered

Organisation providing education and training

Dates

Title qualification awarded

Principal occupational skills covered
06/2009-09/2011

$2^{\text {nd }}$ Cicle specialization scholarship holder

Development of UHPC and UHPFRC dosages

Universitat Politècnica de València

1-10-2011 - 15-10-2012

Senior Laboratory Technician

Design, cast and test of UHPFRC dosages. Design and development of UHPFRC precast elements. Expert in casting and mixing technology.

Universitat Politècnica de València

From 9-01-2014

COMEX Scholar at the Spanish Chamber of Commerce in Serbia

Realization of market studies, support for the Spanish exports in the region, cooperation for the promotion of the Spanish companies, organization of outbound and inbound trade missions, etc..

Ministerio de Economía y Competitividad

2003-2009

Civil Engineer

Speciality developed in structural engineering and construction engineering

Universitat Politècnica de València

2009-2011

Master on Concrete Engineering

Concrete technology, admixtures and additions, experimental analysis and special concretes. 
Organisation providing

education and training

Dates

Title qualification awarded

Principal occupational skills covered

Organisation providing

education and training
Universitat Politècnica de València

2012-2013

Master Universitario en Gestión Internacional de la Empresa

Business administration, specially related to the internacionalization of the company (exports, international marketing, logistics and finances).

Universitat Internacional Menéndez Pelayo

\section{Personal skills and competences}

Mother tongue(s)

Other language(s)

Social skills and

competences

Organizational skills and competences

Technical skills and competences

Computer skills and competences

Artistic skills and competences

Other skills and competences

Driving license

\section{Additional information}

\section{Spanish}

English (C1), French (A1), Valencian (C1), Russian (A2),
Serbian (A2)

Entrepreneur and open attitude. Hard-worker and fast learning

I pertain to two Spanish research groups: "El hormigón con Fibras de Acero como superación del Hormigón Tradicional y sus Perspectivas de Futuro (FIBAC)". Ref: BYA2009-12722, and "Desarrollo de Nuevas Tecnologías en Soluciones Estructurales con Hormigones de Muy Alto Rendimiento (SOLESHMAR)". № Exp.: IPT2011-1242-380000; working closely with other researchers in the field of self-compacting concrete and fiber reinforced concrete.

High level of concrete knowledge, especially in the field of Ultra High Performance Fiber Reinforced Concretes. Publication of research documents in 12 International and 3 national congresses; being the speaker in many of them. Also 2 publications in technical journals.

Experience with SAP, AutoCAD 2D, AutoCAD 3D and Autodesk Civil. Also high knowledge of Microsoft Office 2007, Derive, Mathematica, and programming with Matlab and Visual Basic.

Design of urban furniture and casting of jewelry with Ultra High Performance Fiber Reinforced Concrete.

Replace this text by a description of these competences and indicate where they were acquired. (Remove if not relevant, see instructions).

Driving lesson type B. Own vehicle.

Number 6 of the 2009 Promotion.

Winner of the contest "Aspectos tecnológicos en Ingeniería Civil y Arquitectura", organized because of the V ACHE Congress (October 2011).

Winner of the contest "Expresividad del Hormigón y sus Elementos", organized because of the V ACHE Congress (October 2011).

Winner of the first prize of the National Sika Contest (XIV Edition, year 2008). 


\section{Published documents}

1. CAMACHO E., "El dique Yazirí: una estructura integrada, un espacio urbano". Publicación en la revista "Arte y Cemento". Número 2098, Año 2009.

2. CAMACHO E., SERNA P. "Hybrid UHPFRC thin walled " $\pi$ " beams for flat roofing applications", Proceedings of the International Association for Shell and Spatial Structures (IASS) Symposium, Valencia. 28 Sept-2 Oct. 2009.

3. CAMACHO E., SERNA P., "Optimización de dosificaciones de Hormigón Autocompactante de Muy Alto Rendimiento Reforzado con Fibras Híbrido". 2o Congresso Ibérico sobre HAC, Guimaraes, Portugal, 1-2 Julio 2010.

4. CAMACHO E., SERNA P., "Design and analysis of Ultra High Performance Hybrid Fiber Reinforced Concrete ties for truss structures". $8^{\text {th }}$ fib International PhD Symposium in Civil Engineering, Copenhagen, Dinamarca, 20-23 Junio 2010.

5. CAMACHO E., PÉREZ M.L., "Mathematical Model for shape voids optimization in precast breakwater structures", Congreso de Matemática Multidisciplinar, Valencia, 8-10 Septiembre, 2010

6. CAMACHO E., SERNA P., "Design and experimental verification of selfcompacting Ultra High Performance Hybrid Fiber Reinforced Concrete ties", 60 International RILEM symposium on SCC, Montreal, Canada. 26-29 Septiembre 2010.

7. CAMACHO E., SERNA P., LÓPEZ J.A., "UHPFRC bolted joints: Failure modes of a new simple connection system". International Workshop on HPFRCC-6, Michigan, Junio 2011.

8. LÓPEZ, J.A., CAMACHO. E., SERNA P., "Structural design and previous tests for a retaining wall made with precast elements of UHPFRC" International Workshop on HPFRCC-6, Michigan, Junio 2011.

9. CAMACHO E., SERNA P., LÓPEZ J.A., “Caracterización de dosificaciones de Hormigón de Muy Alta Resistencia Reforzado con Fibras (HMAR) con diferentes niveles de exigencia mecánica", V Congreso ACHE, Barcelona, Octubre 2011.

10. LÓPEZ, J.A., SERNA P., CAMACHO. E., "Uso del hormigón de muy alto rendimiento como alternativa viable al diseño de un muro de contención de tierras", V Congreso ACHE, Barcelona, Octubre 2011.

11. CAMACHO E., LÓPEZ J.A., SERNA P., "Fluid Catalytic Cracking Residue additions such an alternative to Silica Fume in UHPFRC". 30 International Symposium on Ultra High Performance Concrete. Kassel, 07-09 March 2012.

12. CAMACHO E., LÓPEZ J.A., SERNA P., "Caracterization of UHPFRC with three different levels of performance". $3^{\circ}$ International Symposium on Ultra High Performance Concrete. Kassel, 07-09 March 2012.

13. LÓPEZ, J.A., SERNA P., CAMACHO. E., "Structural design and previous calculations of a triangulated footbridge made of UHPFRC". 3을 International Symposium on Ultra High Performance Concrete. Kassel, 07-09 March 2012.

14. SERNA P., LÓPEZ, J.A., CAMACHO. E., "UHPFRC: De los componentes a la estructura". I SILAMCAA, I Simpósio Latino Americano sobre Concreto Autodensavel. 08-10 October 2012. Maceió, Brasil.

15. CAMACHO E., LÓPEZ J.A., SERNA P., "Bolted joints for UHPFRC precast prestressed elements". BEFIB, Fiber Reinforced Concrete, 19-21 September 2012, Guimaraes, Portugal. 
16. LÓPEZ, J.A., SERNA P., CAMACHO. E., NAVARRO J. "structural design and preliminary calculations of a UHPFRC truss footbridge". BEFIB, Fiber Reinforced Concrete, 19-21 September 2012, Guimaraes, Portugal.

17. CAMACHO E., LÓPEZ J.A., SERNA P., ORDOÑEZ L.M. "Reología de mezclas de UHPFRC: Viabilidad en empresa de prefabricados". 3ำ Congreso Iberoamericano sobre Hormigón Autocompactante. Avances y Oportunidades. 3-4 December 2012. Madrid, Spain.

18. LÓPEZ, J.A., SERNA P., CAMACHO. E., NAVARRO J. "Análisis experimental de una celosía plana para la verificación del diseño de la pasarela sobre el Barranco de las Ovejas (Alicante)". 3ํㅡㄴ Congreso Iberoamericano sobre Hormigón Autocompactante. Avances y Oportunidades. 34 December 2012. Madrid, Spain.

19. CAMACHO E., SERNA P., LÓPEZ J.A. "Hormigón de muy alto rendimiento reforzado con fibras (UHPFRC): innovaciones para la transmisión unidireccional de cargas". Journal "Hormigón y Acero". 63 (264). Pages 81-92. 2012.

20. LÓPEZ J.A., SERNA P., NAVARRO J., CAMACHO E. "Construction of the U-Shaped truss footbridge over the Ovejas ravine in Alicante". $2^{\text {nd }}$ international Symposioum on UHPFRC. Designing and Building with UHPFRC. Marseille, France. 1-3 October 2013. 